\title{
Strategic Business Model Development in Ecosystems
}

\author{
BY DOMINIK MANN \\ A thesis submitted to the Victoria University of Wellington in fulfilment \\ of the requirements for the degree of Doctor of Philosophy.
}

Victoria University of Wellington

2020 



\begin{abstract}
Designing and strategically developing viable business models is vital for value creation and capture and in turn for the survival and performance of entrepreneurial ventures. However, the widely held firm-centric and static business model perspective appears inadequate to reflect the realities of increasingly blurred industry boundaries, interconnected economies, and the resulting collapse of incumbent value chains. This PhD thesis adds understanding of the dynamic business model development process from an ecosystem perspective. The evolution of ten entrepreneurial ventures' business models was documented and investigated through longitudinal in-depth case studies over twelve months. Analysing and comparing the cases revealed strategies that resulted in the development of effective interactive structures and robust value co-creation and capture mechanisms. The development of interactive structures, i.e. firm-ecosystem fits, was either supported by a focused or diversified ecosystem integration approach underpinned by heterogeneous interdependencies of value proposition and business model components across ecosystems. The obtained insights allowed the derivation of sets of capabilities that supported the business model development process and enhanced entrepreneurial ventures' chances of survival. The findings have several implications for advancements of the business model theory. In particular they indicate what integration strategies can inform entrepreneurs' and managers' business model design and execution strategies for operating in increasingly complex ecosystems.
\end{abstract}

Keywords: Business Model, Business Model Development, Value Creation, Value Capture, Customer Value Proposition, Stakeholder Value Proposition, Ecosystem, Configurations 


\section{Acknowledgements}

My PhD has been a journey of interesting and puzzling insights, pleasant and intriguing conversations, and difficult but motivating challenges. I would like to thank all people that accompanied me along the way.

Having Sally Davenport and Urs Daellenbach, 'the dream team of supervisors', as guides on my journey was more than fortunate. Their encouragement, dedication, and endless patience in numerous conversations eased the walk uphill. Sally's drive and Urs' precision represented the two poles of the compass needle that provided direction and helped me to find my way.

Moreover, I am grateful for The Victoria School of Management as a home for a PhD student and its staffs' efforts to make the administration of the process less stressful. I would also like to thank my PhD colleagues for various coffee breaks and workshops where we assured and encouraged each other. A special thanks to Ruth Weatherall who I had the fortunate pleasure to share an office with and several insightful conversations about our PhDs and beyond.

I would also like to thank all entrepreneurs and participants who dedicated their precious time for interviews, patiently described and explained the inner and outer working of their ventures and provided insights without this project would have been impossible.

Finally, I would like to thank my partner Maggie. Her continuous encouragement and support always helped me up when I stumbled, annihilated roadblocks, and was vital from the first step onwards. Additionally, special thanks to my parents that supported and believed in me. 


\section{Table of Content}

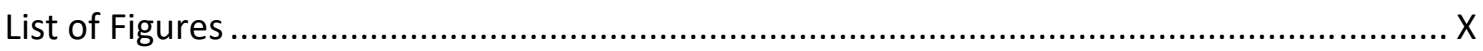

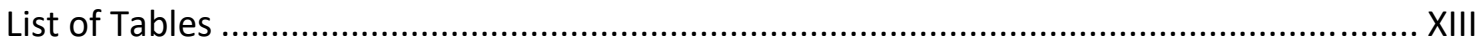

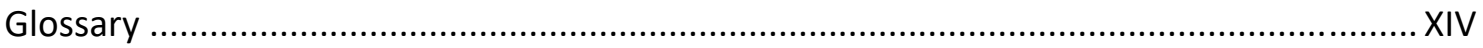

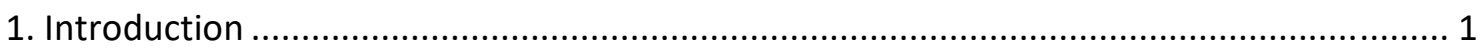

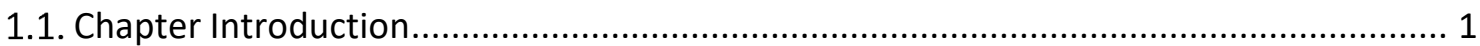

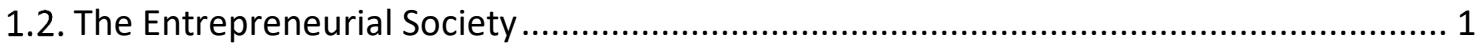

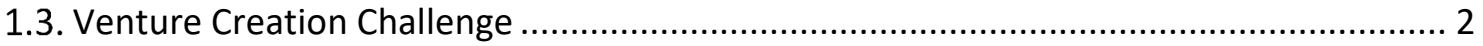

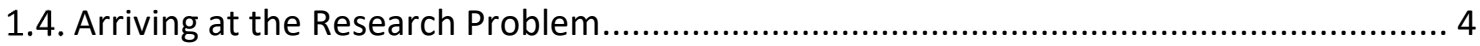

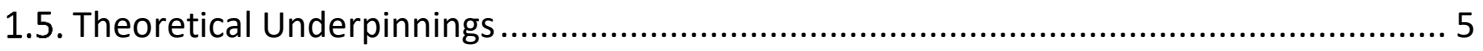

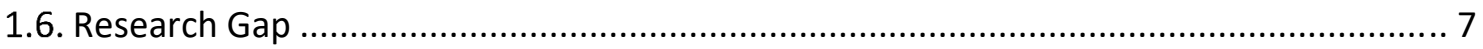

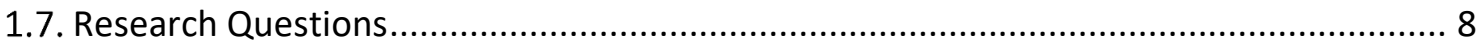

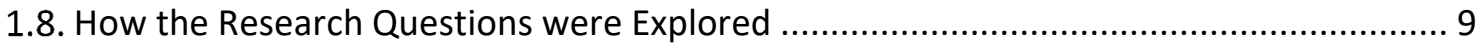

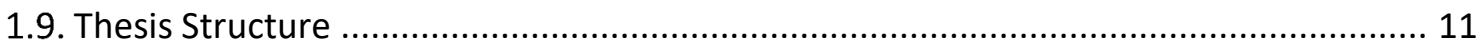

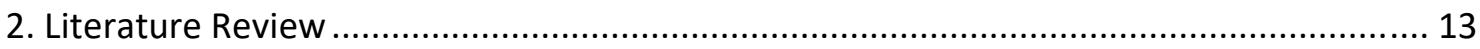

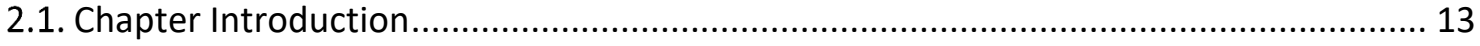

2.2. Business Model Concept - A Brief History ............................................................ 13

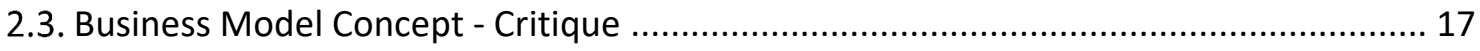

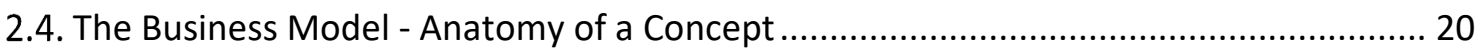

2.4.1. The Basic Level - The Nature of the Business Model Concept .................................. 22

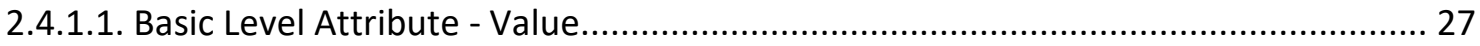

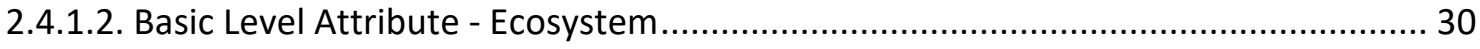

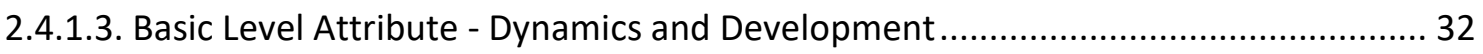

2.4.1.4. Basic Level Summary - Business Models and the Firm-Ecosystem Fit .................... 36

2.4.2. Secondary Level - Functions of the Business Model Concept................................... 37

2.4.3. Indicator Level - Components of the Business Model Concept ................................. 38

2.4.3.1. Indicator Level - Value and Value Propositions .................................................. 39 


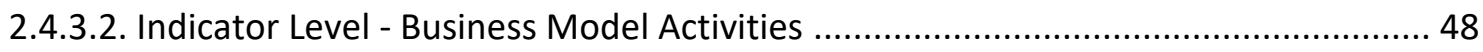

2.4.3.3. Indicator Level - Business Model Resources and Ties......................................... 53

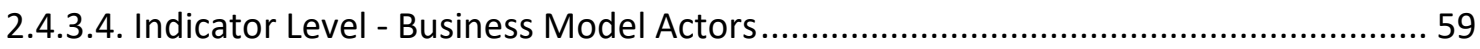

2.4.4. Indicator Level - Summary, Conceptual Model, Key Concepts................................ 67

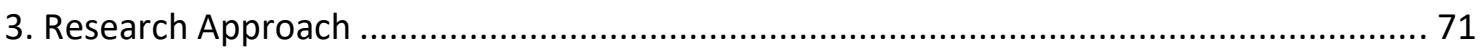

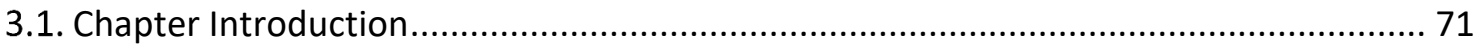

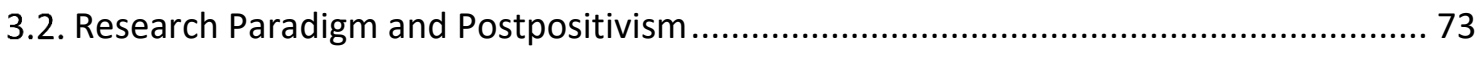

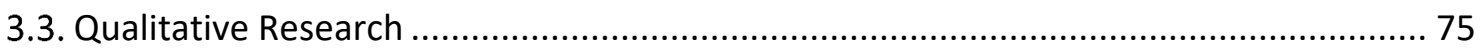

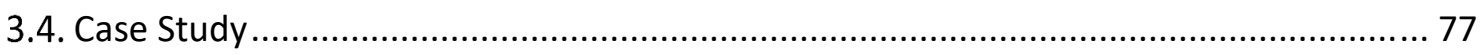

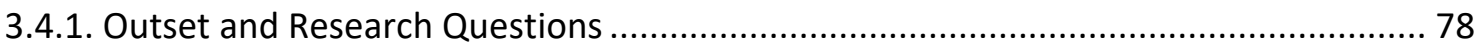

3.4.2. Unit of Analysis - The Business Model as a Case .................................................. 79

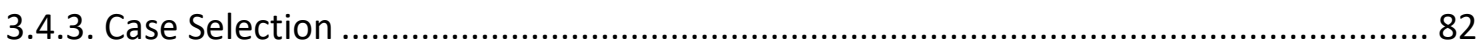

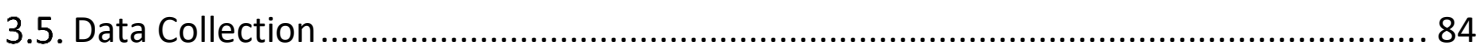

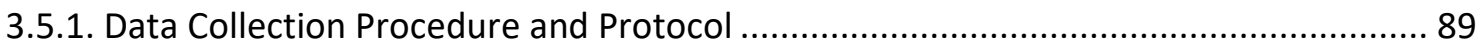

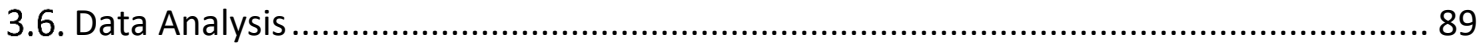

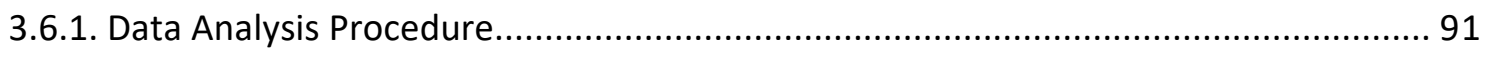

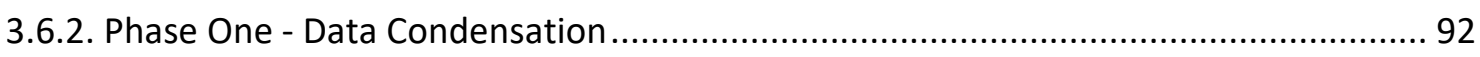

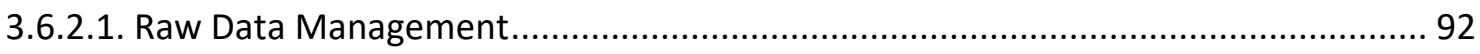

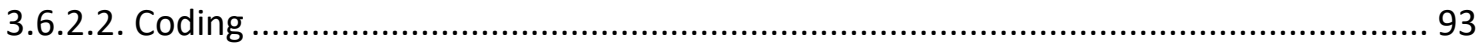

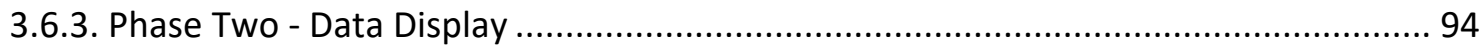

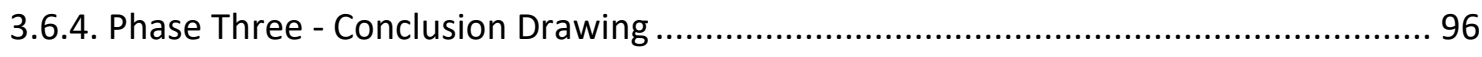

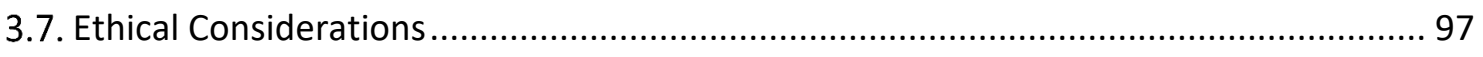

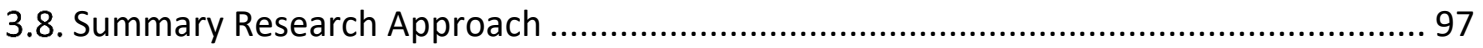

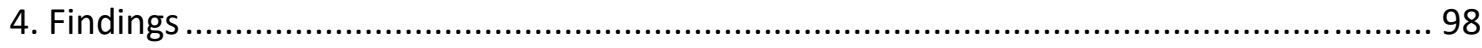

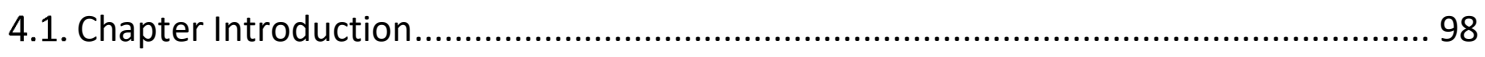

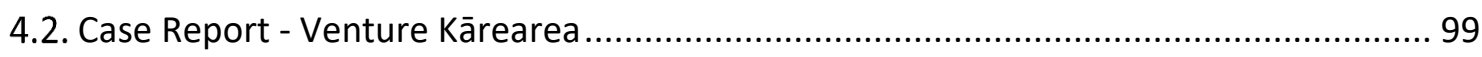

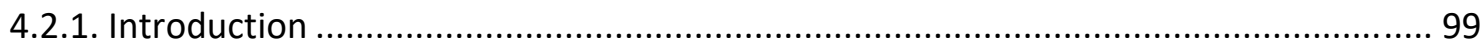

4.2.2. Development of Customer Value Co-Creation Mechanisms ..................................... 99 
4.2.3. Development of Actor Value Co-Creation Mechanisms ....................................... 103

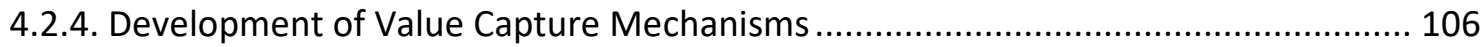

4.2.5. Summary Value Co-Creation and Capture Mechanisms......................................... 109

4.2.6. Development of Activity Links, Resource Ties, and Actor Bonds ............................ 111

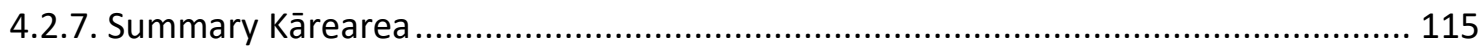

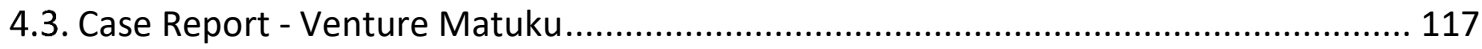

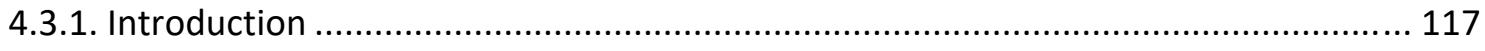

4.3.2. Development of Customer Value Co-Creation Mechanisms ................................. 117

4.3.3. Development of Actor Value Co-Creation Mechanisms ...................................... 120

4.3.4. Development of Value Capture Mechanisms ...................................................... 123

4.3.5. Summary Value Co-Creation and Capture Mechanisms ......................................... 125

4.3.6. Development of Activity Links, Resource Ties, and Actor Bonds ........................... 127

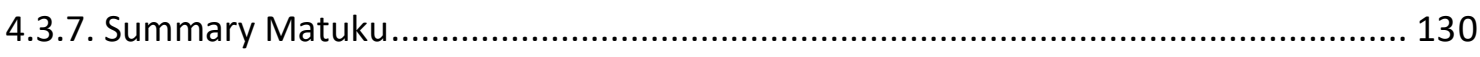

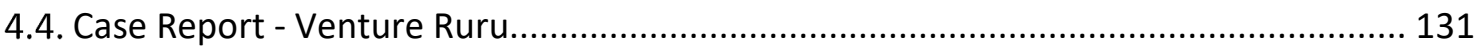

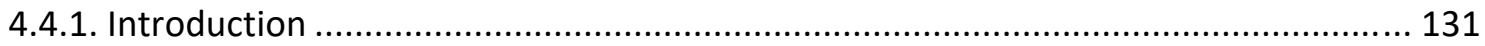

4.4.2. Development of Customer Value Co-Creation Mechanisms .................................. 131

4.4.3. Development of Actor Value Co-Creation Mechanisms ....................................... 135

4.4.4. Development of Value Capture Mechanisms ................................................... 138

4.4.5. Summary Value Co-Creation and Capture Mechanisms ......................................... 141

4.4.6. Development of Activity Links, Resource Ties, and Actor Bonds ............................ 142

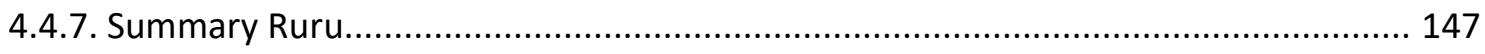

4.5. Case Report - Venture Kākāpō .................................................................. 148

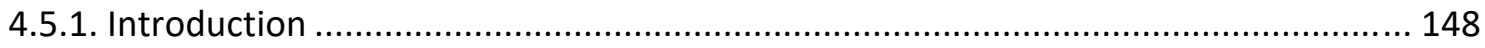

4.5.2. Development of Customer Value Co-Creation Mechanisms ................................... 148

4.5.3. Development of Actor Value Co-Creation Mechanisms ....................................... 152

4.5.4. Development of Value Capture Mechanisms .................................................... 156

4.5.5. Summary Value Co-Creation and Capture Mechanisms....................................... 159

4.5.6. Development of Activity Links, Resource Ties, and Actor Bonds ............................ 161 


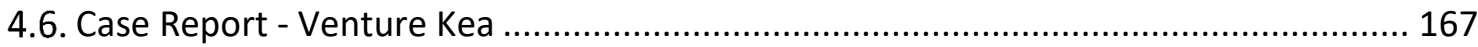

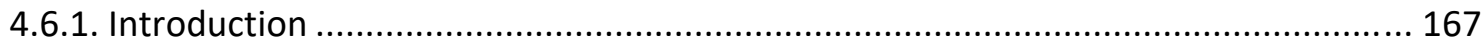

4.6.2. Development of Customer Value Co-Creation Mechanisms ................................... 167

4.6.3. Development of Actor Value Co-Creation Mechanisms ....................................... 170

4.6.4. Development of Value Capture Mechanisms ...................................................... 173

4.6.5. Summary Value Co-Creation and Capture Mechanisms ........................................ 175

4.6.6. Development of Activity Links, Resource Ties, and Actor Bonds ........................... 177

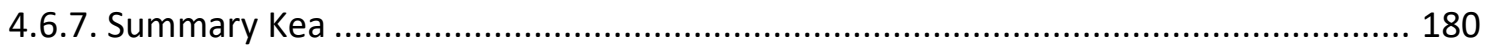

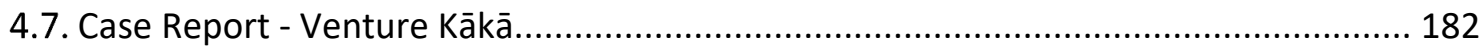

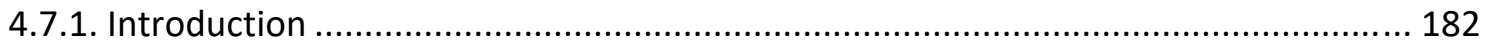

4.7.2. Development of Customer Value Co-Creation Mechanisms .................................. 182

4.7.3. Development of Actor Value Co-Creation Mechanisms ...................................... 185

4.7.4. Development of Value Capture Mechanisms ...................................................... 189

4.7.5. Summary Value Co-Creation and Capture Mechanisms......................................... 191

4.7.6. Development of Activity Links, Resource Ties, and Actor Bonds ........................... 193

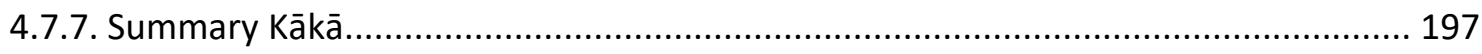

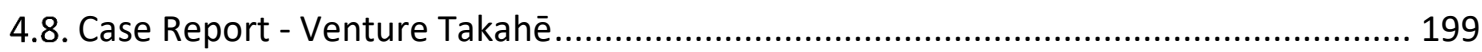

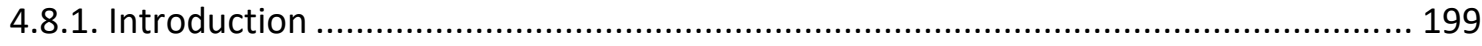

4.8.2. Development of Customer Value Co-Creation Mechanisms .................................. 199

4.8.3. Development of Actor Value Co-Creation Mechanisms ........................................ 202

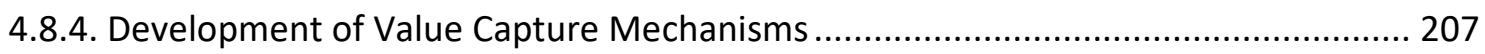

4.8.5. Summary Value Co-Creation and Capture Mechanisms....................................... 210

4.8.6. Development of Activity Links, Resource Ties, and Actor Bonds ............................. 212

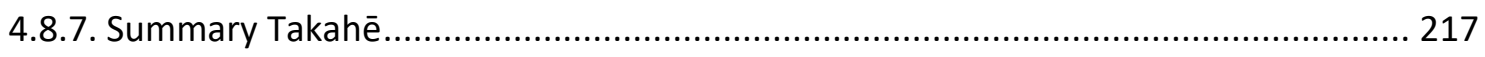

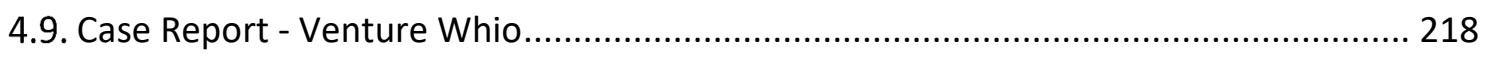

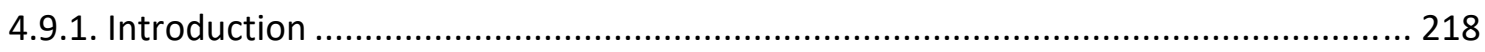

4.9.2. Development of Customer Value Co-Creation Mechanisms .................................. 218 
4.9.3. Development of Actor Value Co-Creation Mechanisms ....................................... 221

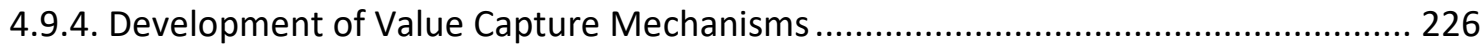

4.9.5. Summary Value Co-Creation and Capture Mechanisms......................................... 229

4.9.6. Development of Activity Links, Resource Ties, and Actor Bonds ........................... 230

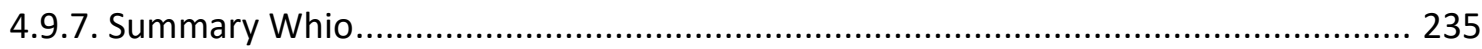

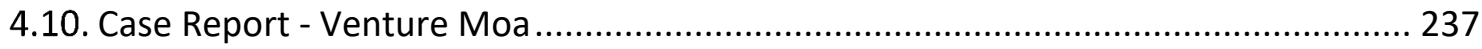

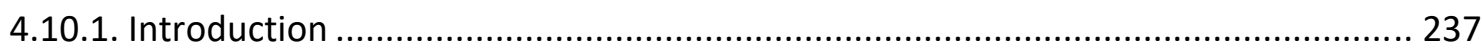

4.10.2. Development of Customer Value Co-Creation Mechanisms ................................ 237

4.10.3. Development of Actor Value Co-Creation Mechanisms ..................................... 238

4.10.4. Development of Value Capture Mechanisms .................................................... 239

4.10.5. Summary Value Co-Creation and Capture Mechanisms ....................................... 240

4.10.6. Development of Activity Links, Resource Ties, and Actor Bonds .......................... 240

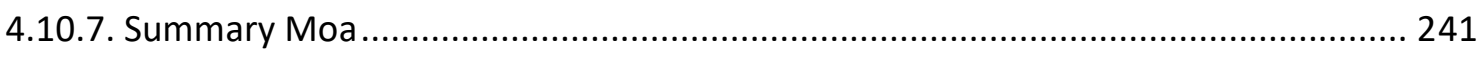

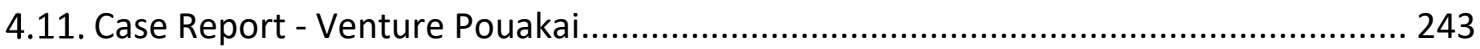

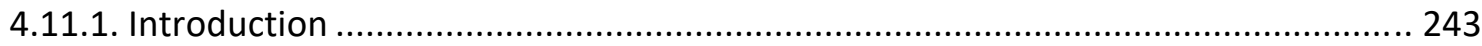

4.11.2. Development of Customer Value Co-Creation Mechanisms ................................ 243

4.11.3. Development of Actor Value Co-Creation Mechanisms ...................................... 244

4.11.4. Development of Value Capture Mechanisms .................................................. 245

4.11.5. Summary Value Co-Creation and Capture Mechanisms ........................................ 246

4.11.6. Development of Activity Links, Resource Ties, and Actor Bonds ......................... 246

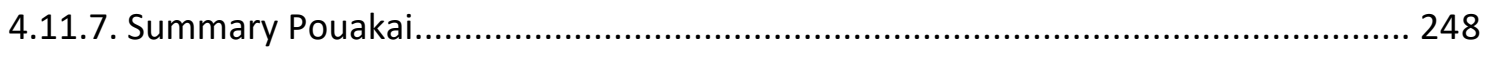

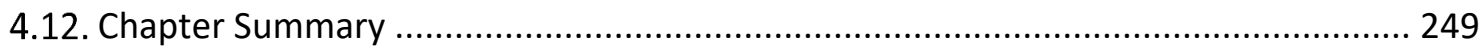

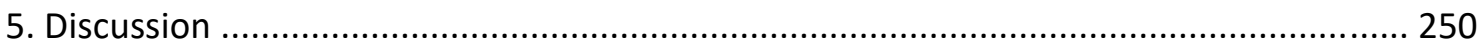

5.1. Inter-Case Comparison Business Model Development .......................................... 250

5.2. Business Model Development Strategies ............................................................ 254

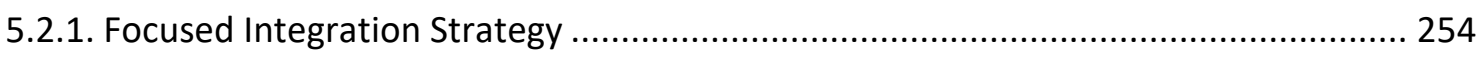

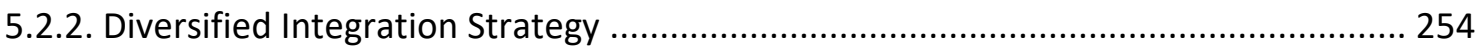

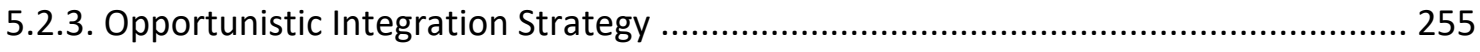


5.3. Value Co-Creation and Capture Mechanisms ...................................................... 256

5.3.1. Development of Customer Value Co-Creation Mechanisms .................................. 256

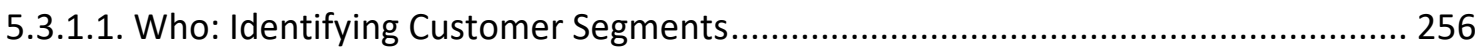

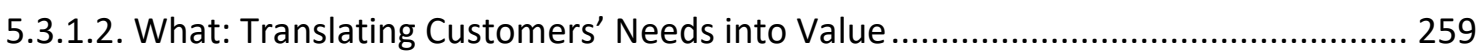

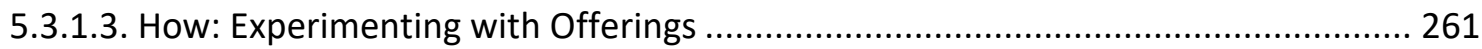

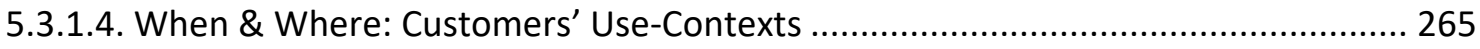

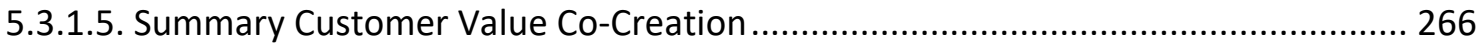

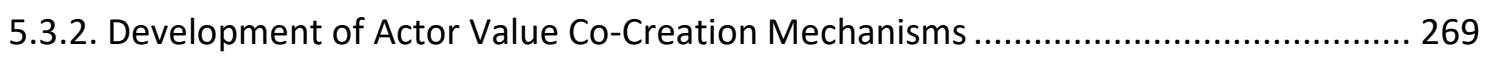

5.3.2.1. Who: Identifying and Engaging Strategic Partners ........................................ 270

5.3.2.2. What: Co-Creating Pecuniary and Non-Pecuniary Value ..................................... 271

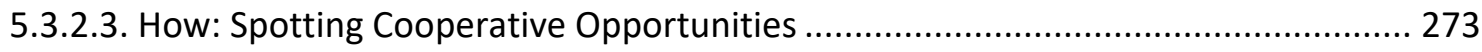

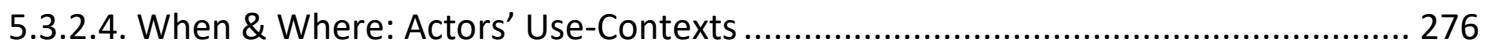

5.3.2.5. Summary Actor Value Co-Creation Mechanisms............................................ 278

5.3.3. Development of Value Capture Mechanisms ...................................................... 282

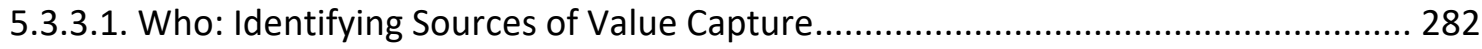

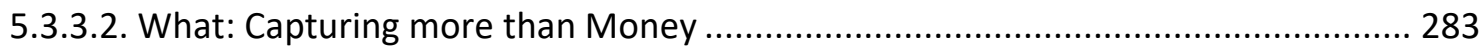

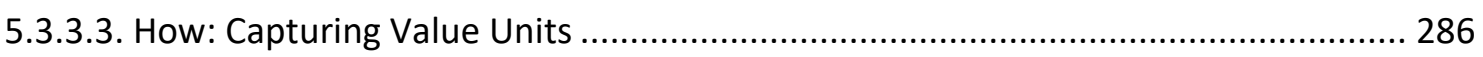

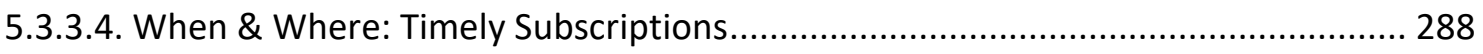

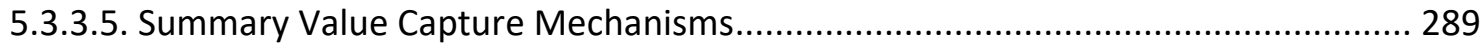

5.3.4. Summary Value Creation and Capture Mechanisms ........................................... 291

5.4. Activities, Resources, and Actors in Business Model Configurations.......................... 292

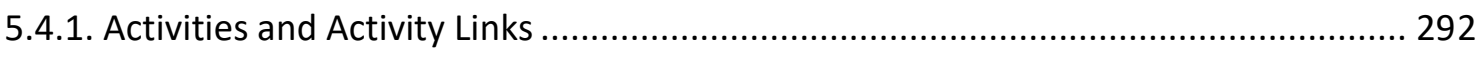

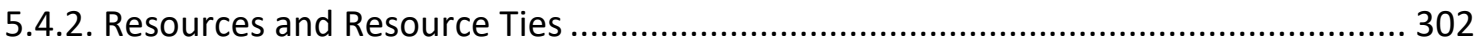

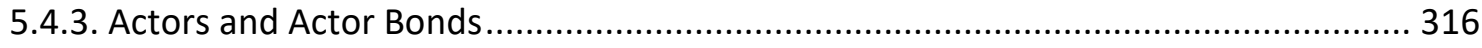

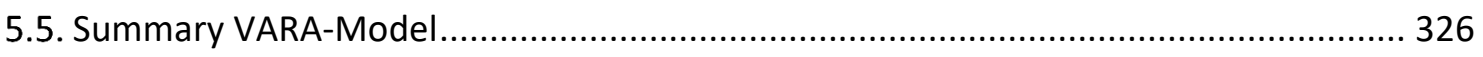

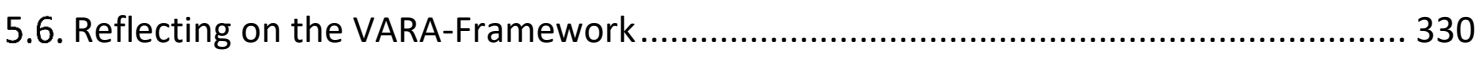

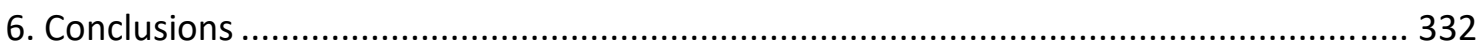

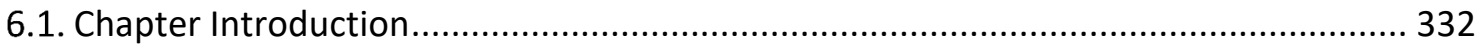




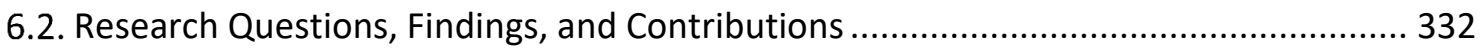

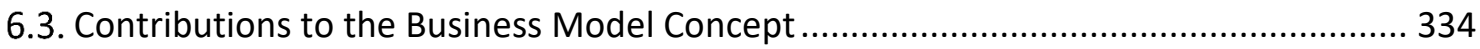

6.3.1. Value Propositions, Value Co-Creation and Capture in Business Models .................. 334

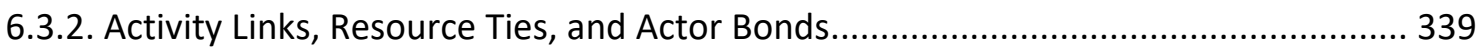

6.3.3. Summary Contributions to the Business Model Concept ...................................... 344

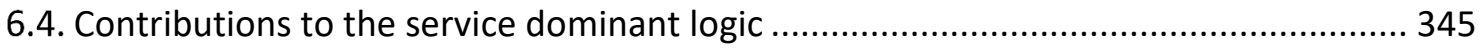

6.5. Contributions to the Industrial Marketing and Purchasing ..................................... 345

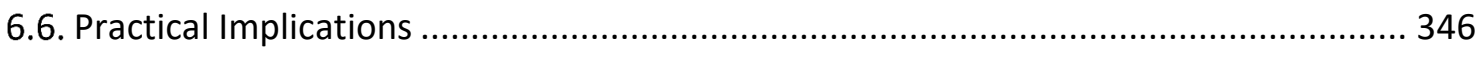

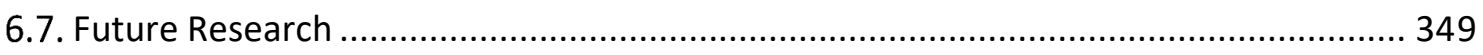

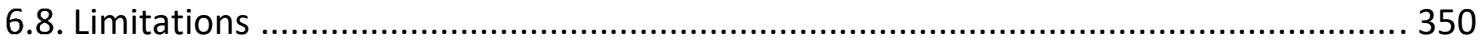

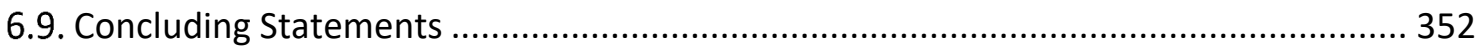

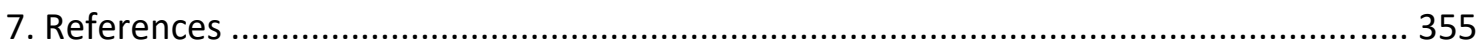

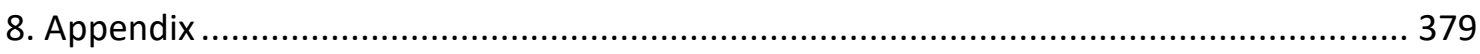

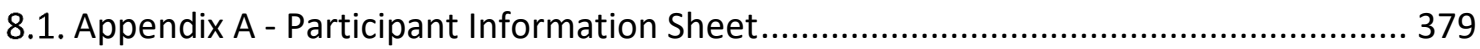

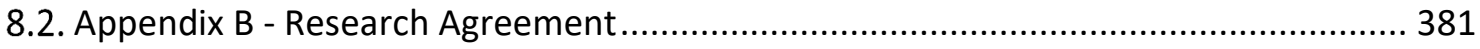

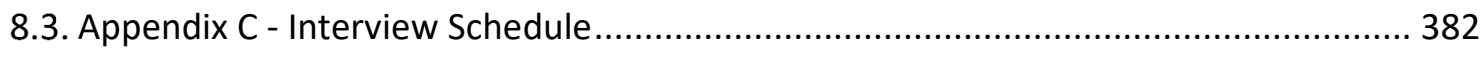

8.4. Appendix D - New Zealand Birds / Case Study Names ......................................... 384 


\section{List of Figures}

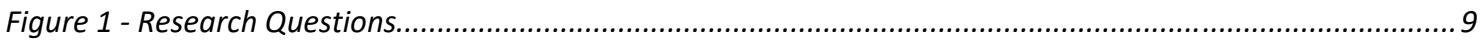

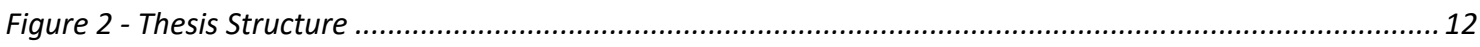

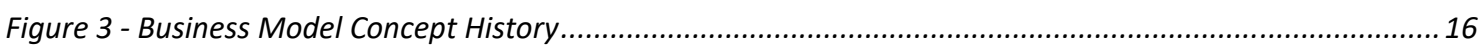

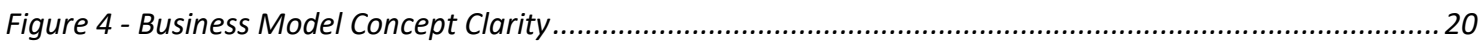

Figure 5 - Social Science Concept Framework (Goertz, 2012) ...................................................................22

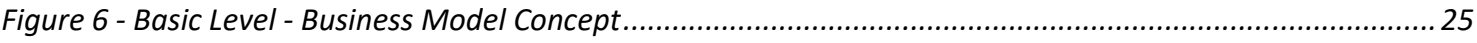

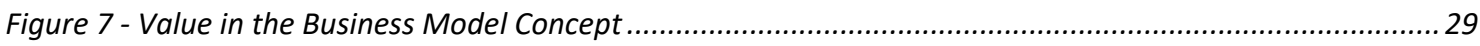

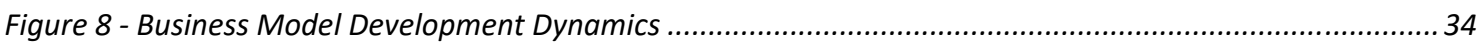

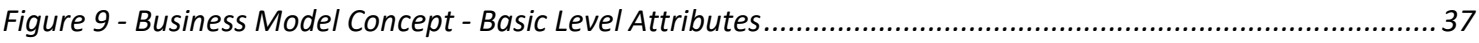

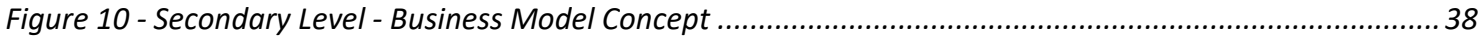

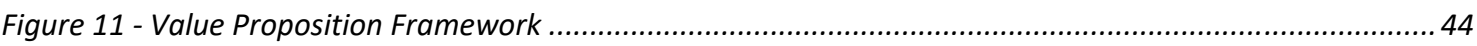

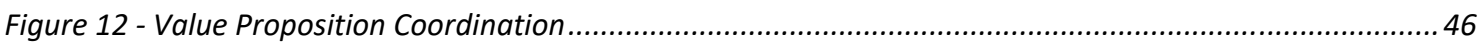

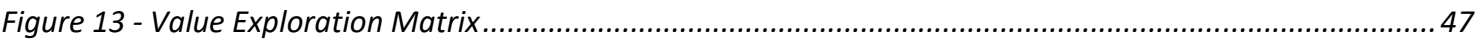

Figure 14 - Business Model Activity Configurations (Håkansson et al., 2009, pp. 109, 116) ...........................53

Figure 15 - Business Model Resource Collections (Håkansson \& Snehota, 1995, p. 145) ..................................58

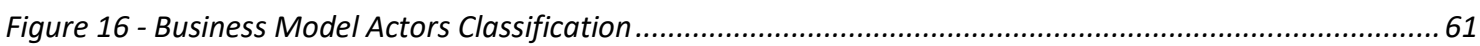

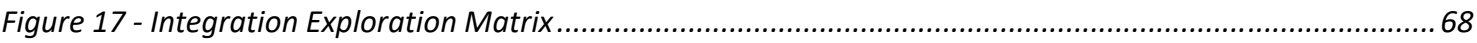

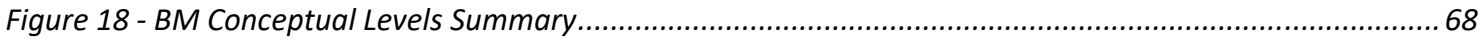

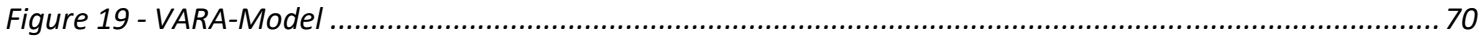

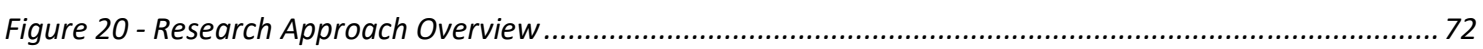

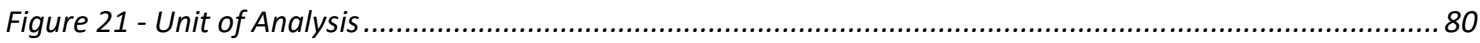

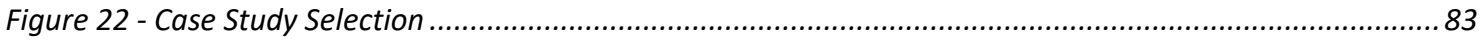

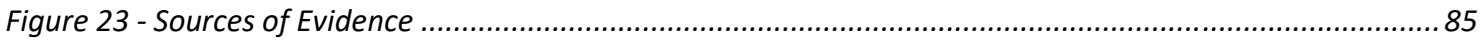

Figure 24 - Systematic Combining (Dubois \& Gadde 2002, p. 555) ............................................................... 91

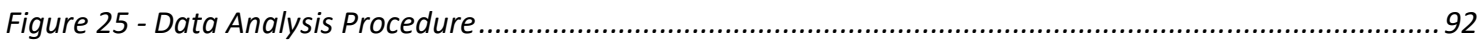

Figure 26 - Kārearea - Development of Customer Value Co-Creation Mechanisms ...................................... 103

Figure 27 - Kārearea - Development of Actor Value Co-Creation Mechanisms ............................................ 105

Figure 28 - Kārearea - Development of Value Capture Mechanisms...............................................................109

Figure 29 - Kārearea - Development of Value Co-Creation and Capture Mechanisms ................................... 110

Figure 30 - Kārearea - Development of Activity Links, Resource Ties, and Actor Bonds ................................116

Figure 31 - Matuku - Development of Customer Value Co-Creation Mechanisms .......................................120

Figure 32 - Matuku - Development of Actor Value Co-Creation Mechanisms ............................................... 122

Figure 33 - Matuku - Development of Value Capture Mechanisms ............................................................ 125

Figure 34 - Matuku - Development of Value Co-Creation and Capture Mechanisms ..................................... 126

Figure 35 - Matuku - Development of Activity Links, Resource Ties, and Actor Bonds .................................. 130

Figure 36 - Ruru - Development of Customer Value Co-Creation Mechanisms ............................................. 134 
Figure 37 - Ruru - Development of Actor Value Co-Creation Mechanisms

Figure 38 - Ruru - Development of Value Capture Mechanisms ................................................................ 140

Figure 39 - Ruru - Development of Value Co-Creation and Capture Mechanisms .......................................... 141

Figure 40 - Ruru - Development of Activity Links, Resource Ties, and Actor Bonds ..................................... 147

Figure 41 - Kākāpō - Development of Customer Value Co-Creation Mechanisms ........................................... 152

Figure 42 - Kākāpō - Development of Actor Value Co-Creation Mechanisms...............................................155

Figure 43 - Kākāpō - Development of Value Capture Mechanisms............................................................... 159

Figure 44 - Kākāpō - Development of Value Co-Creation and Capture Mechanisms.......................................160

Figure 45 - Kākāpō - Development of Activity Links, Resource Ties, and Actor Bonds..................................... 166

Figure 46 - Kea - Development of Customer Value Co-Creation Mechanisms .............................................170

Figure 47 - Kea - Development of Actor Value Co-Creation Mechanisms..................................................... 172

Figure 48 - Kea - Development of Value Capture Mechanisms................................................................. 175

Figure 49 - Kea - Development of Value Co-Creation and Capture Mechanisms.......................................... 176

Figure 50 - Kea - Development of Activity Links, Resource Ties, and Actor Bonds..................................... 181

Figure 51 - Kākā-Development of Customer Value Co-Creation Mechanisms ............................................... 185

Figure 52 - Kākā - Development of Actor Value Co-Creation Mechanisms.................................................... 188

Figure 53 - Kākā - Development of Value Capture Mechanisms............................................................... 191

Figure 54 - Kākā - Development of Value Co-Creation and Capture Mechanisms......................................... 192

Figure 55 - Kākā - Development of Activity Links, Resource Ties, and Actor Bonds......................................198

Figure 56 - Takahē - Development of Customer Value Co-Creation Mechanisms ............................................202

Figure 57 - Takahē - Development of Actor Value Co-Creation Mechanisms ...............................................206

Figure 58 - Takahē - Development of Value Capture Mechanisms..........................................................2 210

Figure 59 - Takahē - Development of Value Co-Creation and Capture Mechanisms.....................................211

Figure 60 - Takahē - Development of Activity Links, Resource Ties, and Actor Bonds.....................................217

Figure 61 - Whio - Development of Customer Value Co-Creation Mechanisms............................................221

Figure 62 - Whio - Development of Actor Value Co-Creation Mechanisms .................................................225

Figure 63 - Whio - Development of Value Capture Mechanisms .............................................................228

Figure 64 - Whio - Development of Value Co-Creation and Capture Mechanisms ..........................................2229

Figure 65 - Whio - Development of Activity Links, Resource Ties, and Actor Bonds ......................................236

Figure 66 - Case Clustering - Ventures' Development Trajectories ............................................................251

Figure 67 - Case Comparison VCC Mechanisms Development................................................................252

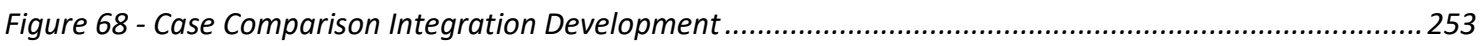

Figure 69 - Customer Value Proposition Development Capabilities...........................................................268

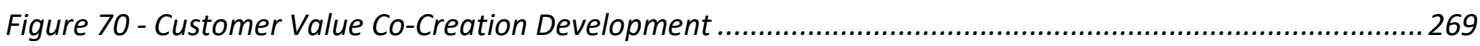

Figure 71 - Actor Value Proposition Development Capabilities ............................................................. 280

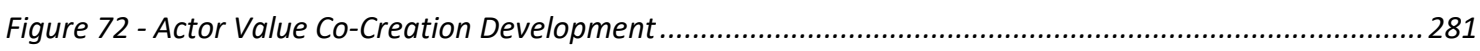

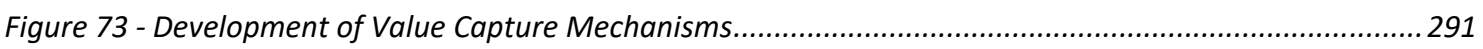

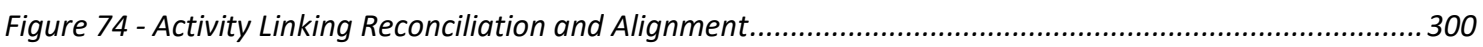


Figure 75 - Activity Configuration Characteristics in BMs

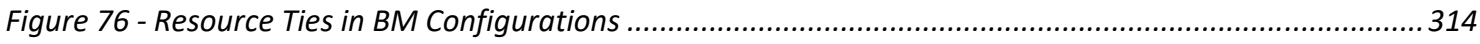

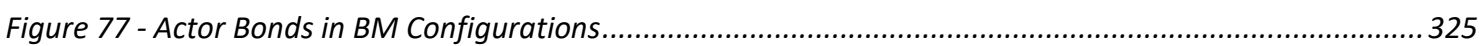

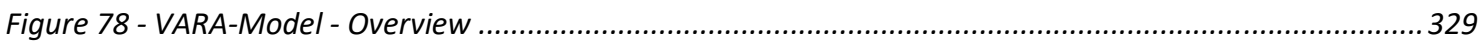

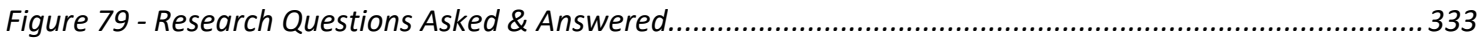

Figure 80 - Customer and Actor Value Proposition Development Capabilities..............................................337

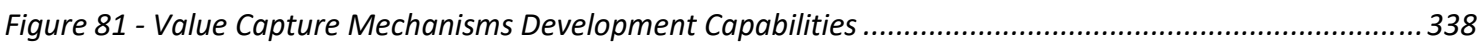

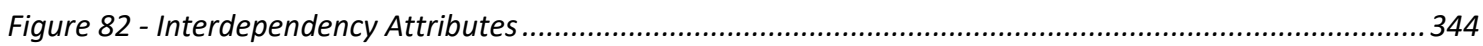




\section{List of Tables}

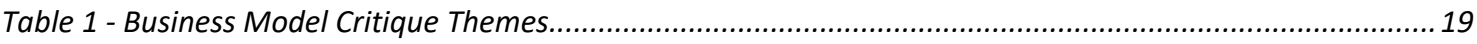

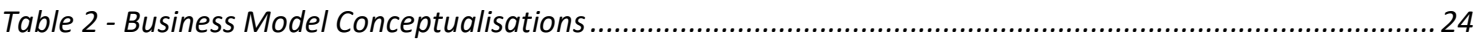

Table 3 - Base of Value Generation (Håkansson et al., 2009, p. 101) ..........................................................51

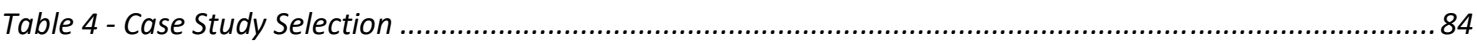

Table 5 - Kārearea - Development of Customer Value Co-Creation Mechanisms.............................................99

Table 6 - Kārearea - Development of Actor Value Co-Creation Mechanisms ................................................103

Table 7 - Kārearea - Development of Value Capture Mechanisms .............................................................. 106

Table 8 - Kārearea - Development of Activity Links, Resource Ties, and Actor Bonds ....................................111

Table 9 - Matuku - Development of Customer Value Co-Creation Mechanisms..............................................117

Table 10 - Matuku - Development of Actor Value Co-Creation Mechanisms ..............................................120

Table 11 - Matuku- Development of Value Capture Mechanisms ................................................................ 123

Table 12 - Matuku - Development of Activity Links, Resource Ties, and Actor Bonds ....................................127

Table 13 - Ruru Development of Customer Value Co-Creation Mechanisms ................................................. 131

Table 14 - Ruru - Development of Actor Value Co-Creation Mechanisms ................................................ 135

Table 15 - Ruru - Development of Value Capture Mechanisms ..................................................................... 138

Table 16 - Ruru - Development of Activity Links, Resource Ties, and Actor Bonds ........................................142

Table 17 - Kākāpō- Development of Customer Value Co-Creation Mechanisms ...........................................148

Table 18 -Kākāpō - Development of Actor Value Co-Creation Mechanisms ...............................................152

Table 19 - Kākāpō - Development of Value Capture Mechanisms................................................................ 156

Table 20 - Kākāpō - Development of Activity Links, Resource Ties, and Actor Bonds.......................................161

Table 21 - Kea - Development of Customer Value Co-Creation Mechanisms .............................................167

Table 22 - Kea - Development of Actor Value Co-Creation Mechanisms ..................................................... 170

Table 23 - Kea - Development of Value Capture Mechanisms ................................................................173

Table 24 - Kea - Development of Activity Links, Resource Ties, and Actor Bonds ........................................... 177

Table 25 - Kākā - Development of Customer Value Co-Creation Mechanisms .............................................182

Table 26 - Kākā - Development of Actor Value Co-Creation Mechanisms ................................................... 185

Table 27 - Kākā - Development of Value Capture Mechanisms ................................................................ 189

Table 28 - Kākā - Development of Activity Links, Resource Ties, and Actor Bonds.......................................... 193

Table 29 - Takahē - Development of Customer Value Co-Creation Mechanisms...........................................199

Table 30 - Takahē - Development of Actor Value Co-Creation Mechanisms ...............................................202

Table 31 - Takahē - Development of Value Capture Mechanisms ..........................................................207

Table 32 - Takahē - Development of Activity Links, Resource Ties, and Actor Bonds ......................................212

Table 33 - Whio - Development of Customer Value Co-Creation Mechanisms...............................................218

Table 34 - Whio - Development of Actor Value Co-Creation Mechanisms.....................................................221

Table 35 - Whio - Development of Value Capture Mechanisms .................................................................226

Table 36 - Whio - Development of Activity Links, Resource Ties, and Actor Bonds .........................................2230 


\section{Glossary}

\begin{tabular}{|c|c|}
\hline AML-CFT & Anti-Money Laundering/Combating the Financing of Terrorism \\
\hline API & Application Programming Interface \\
\hline ARA & Activity-Resource-Actor \\
\hline AWS & Amazon Web Services \\
\hline BM & Business Model \\
\hline $\mathrm{DI}$ & Diversified Integration \\
\hline ETF & Exchange Traded Fund \\
\hline $\mathrm{FI}$ & Focused Integration \\
\hline ID & Identity \\
\hline IMP & Industrial Marketing and Purchasing \\
\hline IP & Intellectual Property \\
\hline MF & Mutual Fund \\
\hline Ol & Opportunistic Integration \\
\hline PMSP & Practice Management Software Provider \\
\hline PSP & Professional Service Provider \\
\hline SME & Small- and Mid-sized Enterprise \\
\hline SMN & Social Media Network \\
\hline VARA & Value-Activities-Resources-Actors \\
\hline VCC & Value Co-Creation and Capture \\
\hline$\stackrel{\circ}{\circ}$ & Who of Value \\
\hline 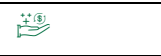 & What of Value \\
\hline 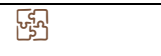 & How of Value \\
\hline$\underline{\underline{Z}}$ & When of Value \\
\hline P & Where of Value \\
\hline 6 & Activity Link \\
\hline 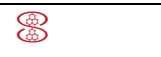 & Resource Tie \\
\hline 8 & Actor Bond \\
\hline
\end{tabular}




\section{Introduction}

\subsection{Chapter Introduction}

This thesis seeks to advance our understanding of how entrepreneurial ventures, henceforth referred to as ventures, develop business models (BMs) in ecosystems. At its heart, the thesis focuses on developing the BM concept as a dynamic construct. The predominant notion of BMs as almost static structures fails to reflect modern economic realities that are constantly rejuvenated by the forces of creative destruction (Schumpeter, 1911; Moore, 1996). The static BM concept perspective seems even more displaced in ventures' agile development context (Wirtz, Pistoia, Ullrich, \& Göttel, 2016). Consequently, a dynamic BM concept is proposed to close the theoretical void and provide insights into the BM development process in constantly evolving ecosystems.

The development of BMs was analysed through ten qualitative case studies conducted with ventures in the Greater Wellington area. The findings provided compelling evidence that BMs continuously develop in an interactive process with other actors' BMs in ecosystems. Next to the theoretical contributions made for the advancement of the BM concept and the capabilities required for the development of viable BMs, insights for practitioners, and potential future research avenues are provided. The following sections outline the study's context, research questions, and settings.

\subsection{The Entrepreneurial Society}

Entrepreneurship has been considered as a driving force of economic and social development for almost a century (Schumpeter, 1911; Knight, 1921). Despite the importance of understanding the process of entrepreneurship, research in the field remained almost dormant until the 1990s (Shane \& Venkataraman, 2000). The rejuvenated interest from scholars and policymakers is often attributed to the increasing consensus about young ventures' contributions to economic, social, and environmental welfare (Wennekers, Van Wennekers, Thurik, \& Reynolds, 2005; Acs, Desai, \& Hessels, 2008; Rotger, Gørtz, \& Storey, 2012; Morris, Neumeyer, \& Kuratko, 2015; Audretsch, 2018). For instance, ventures account 
for new job creations up to $55 \%$ in emerging and around $25 \%$ in developed economies (Decker, Haltiwanger, Jarmin, \& Miranda, 2014; Anyadike-Danes, Hart, \& Du, 2015; OECD, 2017). Since being a driving force in economic development and societal progress, developing an understanding of how ventures can be successfully conceptualised, realised, and achieve sustainable growth is crucial.

\subsection{Venture Creation Challenge}

The venture creation process has been regarded as inherently complex, multidimensional, and infused with decision making under conditions of uncertainty. Brush, Manolova, and Edelman (2008) outlined that "organizational formation is a dynamic process in which activities such as obtaining resources, developing products, hiring employees, and seeking funding are undertaken at different times and in different orders" (p. 547). Similarly, Wright and Marlow (2012) argued that the venture creation process is "likely to differ across the various phases of development, with major challenges to be addressed when moving across and between these phases" (p. 108). Finally, Villani, Linder, and Grimaldi (2018) summarised that "the process of new venture creation represents a particularly risky phenomenon because decisions related to how to develop a business idea, acquire necessary resources, and implement effective decision-making takes place under uncertain conditions" (p. 174). Overall, the venture creation process transcends multiple stages from the initial idea to a sustainable venture. The challenges, complexities, and uncertainty associated with transitions between the stages are often considered as the cause of ventures' high mortality rate in early years across almost all industries (J. V. Singh, Tucker, \& House, 1986; Acs \& Audretsch, 2010; OECD, 2017)

Business planning has been widely regarded as a process that increases ventures' chances of survival (Delmar \& Shane, 2003; Brinckmann, Grichnik, \& Kapsa, 2010). However, scholars agree that business planning is only beneficial when combined with a flexible decision-making logic in a continuous process (Chwolka \& Raith, 2012; Davidsson \& Gordon, 2012; Reymen et al., 2015) spanning different development stages. Several constructs such as business ideas (Normann, 1977, 2001), business concepts (Hamel, 2002), business plans (Shane, 2003; Shane \& Delmar, 2004), or new venture ideas (Davidsson, 2015) have been 
employed to balance planning and decision-making in the venture creation process. However, the combination of longitudinal planning and dynamic decision-making characterises the ambidextrous nature of the venture creation process that often transcends these constructs' temporal and limited scope.

Across the entrepreneurship literature there is growing consensus that the BM concept, as a missing link, can explain why ventures succeed or fail in the process of exploiting opportunities (Klang, Wallnöfer, \& Hacklin, 2014; Spieth, Schneckenberg, \& Matzler, 2016; Massa, Tucci, \& Afuah, 2017). Morris, Schindehutte, and Allen (2005) outlined that the BM concept represents a strategic framework to conceptualise, implement, and adapt valuebased ventures in dynamic environments over time. Casadesus-Masanell and Ricart (2007) emphasised that the "essence of entrepreneurship is the design of effective business models" (p. 21) via a process of experimentation, learning, and transformation to sustain performance in increasingly competitive and complex environments. Finally, Demil, Lecocq, Ricart, and Zott (2015) elucidated that the BM concept connects the formulation and implementation stages in a recursive process explaining differential firm performance in opportunity exploitation and thus the various ways of how firms do business. To sum up, the BM concept is seen to span different stages of the venture creation process and can provide insights into how ventures cope with the inherent complexity and uncertainty of opportunity exploitation (Sosna, Trevinyo-Rodríguez, \& Velamuri, 2010; Svejenova, Planellas, \& Vives, 2010; Saebi, Lien, \& Foss, 2017). As such, it can be understood as a vital tool for entrepreneurs and entrepreneurial managers to conceptualise, implement, and adapt ventures to exploit opportunities (George \& Bock, 2011; Demil et al., 2015; Massa et al., 2017). Moreover, the BM concept can advance our understanding of ventures' complex development process across different stages and offers insights into the entrepreneurial process itself (C. M. BadenFuller, Vincent, 2015a; Wirtz et al., 2016). 


\subsection{Arriving at the Research Problem}

99

Despite the undoubted relevance of openness and collaboration in today's networked economy, the majority of extant business model research is firm-centric.

Frankenberger, Weiblen, \& Gassmann

2014, p. 175
Foss \& Saebi

2018, p. 17

Little is known empirically about where BMs come from ... The reason for the lack of theorising on the dynamics of BMs can be found in the predominantly static view adopted.

My experience as a business consultant and the research conducted with start-ups for my bachelor and master thesis inspired this research project. Confronted with the question to describe their BMs, start-up founders and directors of large business units often had difficulties in articulating their BM. Despite the prominence of the BM concept as design tool through the business model canvas (Osterwalder \& Pigneur, 2010) and lean canvas (Maurya, 2016), the absence of coherent explanations of how value was created and captured was daunting. Why has the BM concept become a feature in any pitch-deck and annual report ${ }^{1}$ and yet lacks a single definition or view? Why do entrepreneurs and managers in charge of its design and execution have difficulties explaining it?

Moreover, stark contrasts between founders' anecdotes of initial BM ideas and the realised ventures raised several questions. What caused these, often significant, shifts, turns, and refinements in the BM development process?

These two questions were translated into the theoretical language of entrepreneurship, marketing, and strategy literature to contextualise value creation and capture (VCC) mechanisms as well as how underpinning BMs develop in ecosystems over time. VCC mechanisms were framed via value propositions (O'Cass \& Ngo, 2011; Frow et al., 2014; Payne, Frow, \& Eggert, 2017) to gain insights into how value was conceptualised in

12016 Annual reports of top 5 Fortune 500 companies (number of BM-term mentioned), Walmart (1), ExxonMobile (5), Berkshire Hathaway (2), Apple (1), United Health Group (2). Across the five annual reports reviewed a detailed description or formalisation of firm's BMs was missing. 
emerging organisations. Since VCC cannot happen in a vacuum (Hamel, 2002; Shafer, Smith, \& Linder, 2005), why and how developing organisations engage with others in their ecosystem is considered vital. The Activity-Resource-Actor model (Håkansson, 1982; Håkansson, Ford, Gadde, Snehota, \& Waluszewski, 2009) was employed to frame the emerging interdependencies between ventures and other actors over time.

\subsection{Theoretical Underpinnings}

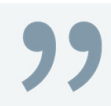

The success of an individual firm depends ultimately on its ability to transform the elements of its business model in rhythm with, and towards a 'fit' with (i.e., success in) its external business environment.

\section{Aspara, Lamberg, Laukia, \& Tikkanen}

2013, p. 459

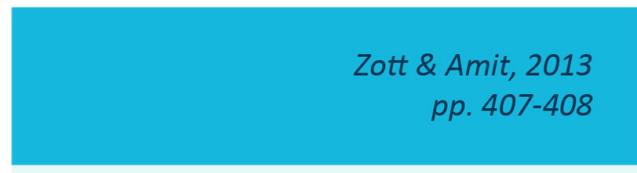

One important question is how firms adapt their business models to an evolving ecosystem. How can managers of focal firms achieve maximum fit between their business model and ecosystem, and what exactly defines such fit?

Dynamics: Already early conceptual developments of the BM emphasised the dynamic nature of the construct (Amit \& Zott, 2001; Tikkanen, Lamberg, Parvinen, \& Kallunki, 2005). However, the dominant notion of BMs as organisational blueprints as well as the advantages of rigidity for conceptual development have encouraged scholars and practitioners to adopt a static perspective on the BM concept (Yip, 2004; George \& Bock, 2011; Foss \& Saebi, 2018). Therefore, BM frameworks often provide only insights into what, why, and how ventures succeed or fail at a given point in time (C. Baden-Fuller \& Morgan, 2010). In a similar vein, we can judge the state of the Titanic when leaving the harbour of Southampton on the $10^{\text {th }}$ of April 1912, yet we will not understand what happened to the unsinkable ship on its maiden voyage.

Likewise, developing an understanding of the success and failure of early stage ventures requires an inquiry of how their BMs develop over time (Demil \& Lecocq, 2010; Storbacka, Windahl, Nenonen, \& Salonen, 2013; Ritter \& Lettl, 2018), from initial design , over 
the launch, to a successful maiden-voyage or transition to a sustainable organisation, or in many cases a tragic end. Attention has been drawn to the often "significant reconsideration of the business model ... during the early stages of the firm's existence" (Gerasymenko, De Clercq, \& Sapienza, 2015, pp. 79-80). Similarly a "growing consensus that firms need to change, adapt and innovate their business models in order to ... sustain success over time" (Hacklin, Björkdahl, \& Wallin, 2018, p. 83) has been noted in recent literature. In short, BMs have to be considered as dynamic constructs that develop throughout different stages of the venture creation process to provide insights into the success or failure of organisations (Klang et al., 2014; Gerasymenko et al., 2015; Saebi et al., 2017).

Ecosystem: The dynamic perspective on the BM concept is further stressed by the increasing agreement amongst scholars that different types of ecosystem engagement characterise ventures' VCC mechanisms. While VCC is widely recognised as an interactive process (Hamel, 2002; Hedman \& Kalling, 2002; Shafer et al., 2005), discussions about what, why, and how ecosystem interactions influence the process have been fuelled by the growing interests in BM development and long-term firm performance. To extend the ship analogy, when, where, and in what conditions a ship is arriving in a safe harbour when sailing through the uncertain and turbulent waters of ventures' early development stages, is often dependent on the course chosen, access to nautical maps, the crews' navigational skills, capabilities to leverage air and water currents, and changing weather conditions. Likewise, understanding the interactive forces and pressures ecosystems exert as well as how ventures react to, withstand or leverage them is crucial for our understanding of success and failure.

Amit and Zott (2001) argued that deliberately designing inter-firm networks encompassing suppliers, complementors, and customers with which firms must cooperate or compete is a crucial source of value creation. Likewise, Demil and Lecocq (2010) outlined that a firm's "sustainability depends on anticipating and reacting to sequences of voluntary and emerging changes"(p. 227) arising from ecosystems that shape the permanently linked core components of its BM. Finally, Foss and Saebi (2018) emphasised that firms' success is underpinned by the systemic properties of their "more or less interdependent activities [i.e., business model] that are shaped by and (in the aggregate) shape a macro environment" (p. 18). In short, the BM concept embraces choices of and interdependencies between actors in ecosystems and thus the selection of the environment in which ventures operate (Morris et 
al., 2005; C. Baden-Fuller \& Haefliger, 2013; Demil et al., 2015). Additionally, interactions of ventures and actors shape in a reciprocal process BMs and surrounding ecosystems over time.

\subsection{Research Gap}

Advancing our understanding of the BM concept as a dynamic and ecosystem-centric construct is crucial for our comprehension of the BM development process and in turn the success and failure of ventures (Massa et al., 2017; Täuscher, 2017; Fjeldstad \& Snow, 2018). Although widely acknowledged, the dynamic and ecosystem-mediated development process is rarely discussed in the literature. Sosna et al. (2010) noted that "while dynamic business model evolution has been recognised by several scholars, it lacks theoretical grounding in the established literature which would allow us to understand its underlying mechanisms" (p. 385). In a similar vein, Gerasymenko et al. (2015) outlined that "business models may undergo substantial change during the early stages of the firm's existence. Yet, relatively little attention has been devoted to the challenge that young firms encounter when modifying their business models" (p. 80). Finally, Ritter and Lettl (2018) summarised that "conceptual clarity of 'business models in motion' is weak as there is no general definition to build upon" (p. 6). In short, conceptual advancement and empirical research on the BM development process remains an under-researched domain.

Similarly, while embraced throughout the BM literature (Zott \& Amit, 2007, 2008; Storbacka et al., 2013), ecosystem-centric VCC mechanisms have been considered as neglected by scholars. For instance, Brettel, Strese, and Flatten (2012) concluded that "the current literature on business model design has not yet provided an extension of the theory that takes into consideration the specific requirements of the external relational exchange among business model participants" (p. 86). Likewise, Klang et al. (2014) noted that "existing research emphasises constituents closer to the firm rather than those in a firm's environment ... formalizing the boundary-spanning nature of the firm's business model would require significantly more knowledge of the relational mechanisms and external stakeholders" ( $p$. 468). Finally, the expert survey conducted by Wirtz et al. (2016) further stressed the importance of developing a better understanding of interactions, actors and networks, and underpinning VCC in BMs as the number one research priority in the field. In short, advancing 
our understanding of the BM concept and VCC mechanisms in ecosystems requires to identify external BM elements and relational mechanisms.

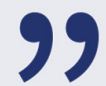

"the fit between the firm's business model and its environment may influence profitability .... in spite of recent strides forward in the understanding of the drivers, processes, and facilitators of business model change there is still little knowledge of how firms adapt their business models"

Saebi, Lien, \& Foss

2017, p. 568

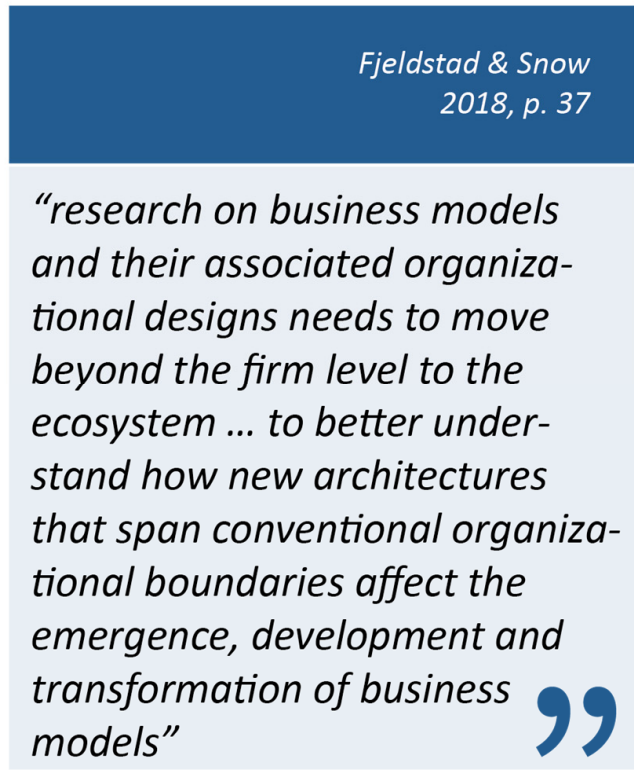

"research on business models and their associated organizational designs needs to move beyond the firm level to the ecosystem ... to better under stand how new architectures at span conventional organizational boundaries affect the transformation of business models"

To sum up, enhancing our understanding of the BM development process requires conceptual advancements along the dynamics and ecosystems domain of the concept. Since the development of BMs and ecosystems is interdependent, the importance of the dynamic development nexus and ecosystem domain has been stressed throughout the literature (Klang et al., 2014; Wirtz et al., 2016; Saebi et al., 2017; Fjeldstad \& Snow, 2018). As a crucial frontier of BM research it can yield valuable insights into BM development, firm performance, and the survival of ventures.

\subsection{Research Questions}

Elucidating the dynamic BM development process, underpinning forces, and how ventures manage them in ecosystems makes significant contributions to the advancement of the BM concept. At the heart of my investigation is the question: How do ventures develop viable BMs over time? The following sub-questions further focused the investigation (Figure 1). 


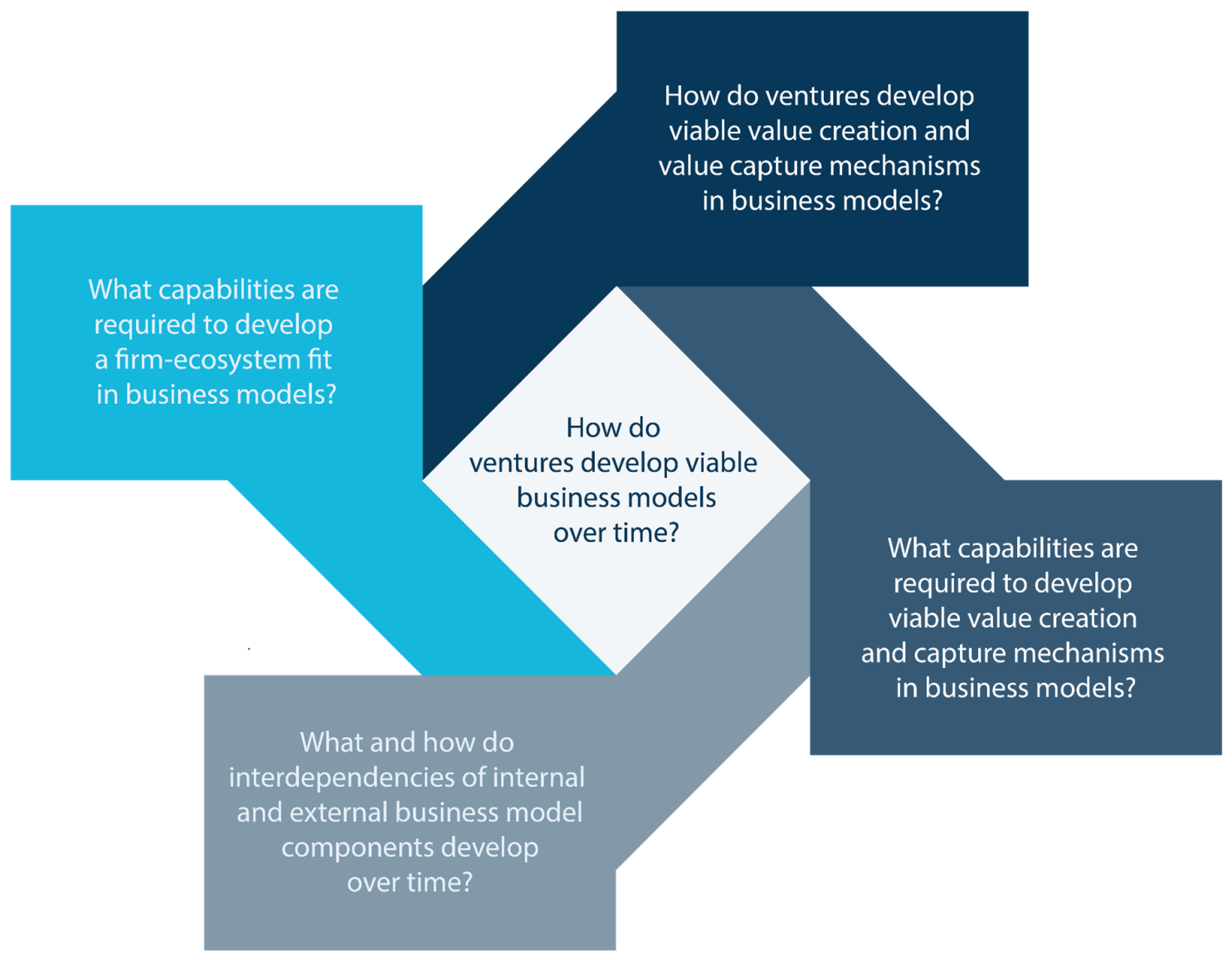

Figure 1 - Research Questions

\subsection{How the Research Questions were Explored}

Providing answers to the research questions outlined required an approach that accounts for the contextual intricacies and longitudinal aspects of dynamic BM development processes in ecosystems (Shafer et al., 2005; Massa et al., 2017). A BM expert of Wirtz et al.'s (2016) survey noted that "during implementation, contextual differences between different business models need to be acknowledged" (p. 49). Similarly, Teece (2018) drew attention to the ability to adapt BMs to changing circumstances. Since BMs are inherently contextual, selecting appropriate abstraction levels is vital for understanding the causal interdependencies of the concept and its context (C. Baden-Fuller \& Morgan, 2010; Demil \& Lecocq, 2010; C. Baden-Fuller \& Mangematin, 2013; Cortimiglia, Ghezzi, \& Frank, 2016). Therefore, a case study research approach was considered appropriate to assess contextual contingencies of BMs and their ecosystems (Yin, 2014; Patton, 2015). 
Moreover, BMs' interdependencies with ecosystems that are in constant flux mandated a research design that can cope with the multivalent and continuous interactions that drive BM development over time. Consequently, a longitudinal case study research design was selected (Zacharias \& Saldaña, 2002; Aaboen, Dubois, \& Lind, 2012) to allow for the investigation of how ventures develop their BMs. The advantages and potential of longitudinal case study research to provide novel insights into the complex BM development process has been stressed throughout the literature (George \& Bock, 2011; Osiyevskyy \& Dewald, 2015; Dopfer, Fallahi, Kirchberger, \& Gassmann, 2017).

The contextuality of BMs and the temporal nature of their development process dictated the empirical settings for the research design. As evident in literature and emphasised by Demil et al. (2015), "structured and rigorous research on the topic (in particular, theory-building work and empirical research beyond single-case studies) is relatively rare" (p. 2). In addition, Gerasymenko et al. (2015) outlined that "undertaking comparisons of the pressure for and complexities of business model change implementation across industries is a fruitful area for future research." (p. 95). As a result, a cross-industry and multiple case study research design was deemed appropriate to provide answers to the posed research questions and make valuable contributions to conceptual advancements.

Wellington's growing start-up ecosystem provided fertile ground for the study. As home to two research universities with dedicated technology transfer offices, several large public and private organisations, and multiple municipal and national start-up initiatives, the region became a hotbed of entrepreneurial activity and a suitable environment to study the development of BMs. Exclusively approaching ventures that participated in accelerator programs hosted and run by the same organisation in the Greater Wellington area ensured consistency and allowed for the control of environmental variables. A set of 23 ventures agreed to participate in a quarterly semi-structured interview series over nine to twelve months. Primary data was complemented with secondary data such as business plans, social media network posts, and media reports. The data corpus was analysed via a two-cycle coding method and displayed in a two-factor ordered temporal matrix. The patterns surfaced were compared across different cases and provided insights into the BM development process. Contrasting findings with contemporary literature and findings of other researchers fuelled the discussion, allowed to derive propositions, and led to several conclusions in the context 
of $\mathrm{BM}$ research.

\subsection{Thesis Structure}

This thesis is structured via seven sequential chapters comprised of an introduction, literature review, research approach, findings, discussion, and conclusion. A summary of each chapter is provided in Figure 2 to provide readers with an overview of the thesis. 

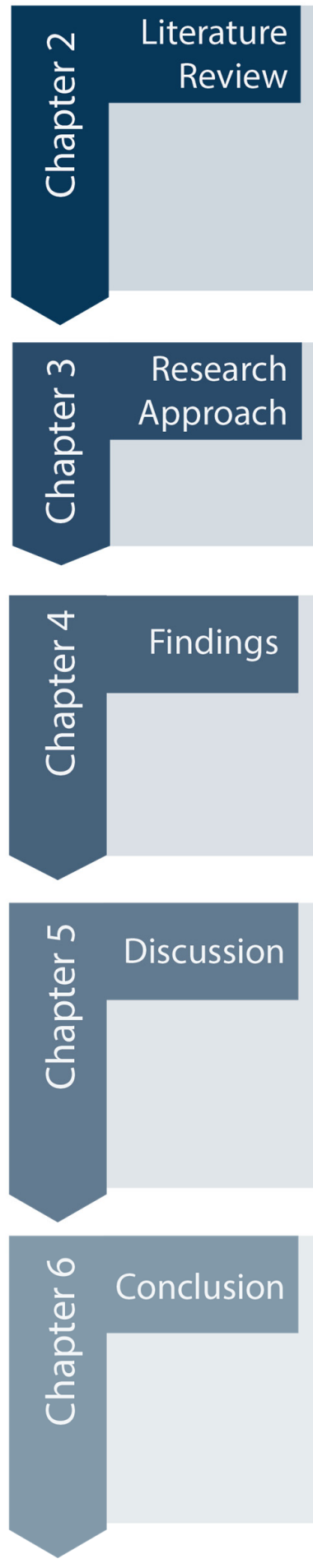

The literature review provides an overview of the BM concept. First, the foundations and structure of the BM concept is discussed at the intersection of the dynamic development process and ecosystem. The development of value propositions, activities, resources, and actors as well as interdependencies of these BM constituents are discussed and explored in detail. Finally, a conceptual model (VARA-model) is developed to analyse the BM development process in ecosystems and compare and contrast the success and failure of ventures.
The research approach chapter describes the postpositivist paradigm adopted and the research methods employed in the thesis. The longitudinal case study research approach, as well as the selection criteria for cases, are discussed in detail. Next to the collection of data via different methods, its triangulation, and the analysis procedures are described.

The findings chapter contextualises individual cases in the VARA-model and elicits how ventures developed and maintained a firm-ecosystem fit over time. Besides identifying different pathways of VCC mechanisms development, ventures' activities, resource, and actor interdependencies patterns in BM development trajectories are surfaced. Comparing contrasting cases revealed heterogenous development strategies and sets of critical capabilities required for their success over time.

The discussion chapter compares the findings with the BM literature. The comparison and description of BM development strategies is followed by a detailed discussion of BM components, their interdependencies, and how they influence the BM development process. The chapter concludes with an overview of the VARA-model comprised of individual component attributes as well as a set of proposed capabilities required for the development of viable BMs. The propositions emerged from the analysis of patterns across the investigated cases.

The concluding chapter outlines the contribution made to the conceptual development of the BM, its development process in ecosystems, and how it can be operationalised in empirical research. Explanations of how VCC mechanisms, activity, resource, and actor interdependencies in ecosystems shape and affect the BM development process are provided. Discussing contributions to the service-dominant logic and the Industrial Marketing Purchasing research stream are followed by practical implications for BM designers and potential future research avenues. 


\section{Literature Review}

\subsection{Chapter Introduction}

The following sections provide an overview of the nature of the BM concept, its theoretical foundations, conceptual shortcomings, and most important components. The chapter concludes with the development of the VARA-model, a conceptualisation that allows analysing and describing interdependencies of BMs and ecosystems and how ventures can create and sustain a firm-ecosystem fit.

\subsection{Business Model Concept - A Brief History}

The origin of the BM concept is obscure. The term 'business model' appeared the first time in academic articles on business education and executive training in 1957 (Bellman, Clark, Malcolm, Craft, \& Ricciardi) and 1960 (Jones)(Figure 3). BM games or simulations were often underpinned by mathematical (e.g. Mulvaney \& Mann, 1976) and later on by computer models (e.g. Konczal, 1975). In a similar vein, BMs or enterprise ontologies were employed for the design of business-management software in the early 1990s (Uschold, King, Moralee, \& Zorgios, 1998; Osterwalder \& Pigneur, 2002). Advancements of information and communication technologies (ICT) and the growing prominence of e-commerce further propelled the use of the BM concept as a management tool grasping the numerous opportunities to create and capture value in the rising information age (Venkatraman \& Henderson, 1998; Amit \& Zott, 2001). However, e-commerce start-ups' failure to abide by the fundamental laws of economics became evident in the dot-com bubble and waves of spectacular bankruptcies (Shafer et al., 2005; DaSilva \& Trkman, 2014). The prominence of the BM concept amongst dot-com start-ups, inconsistent definitions (Timmers, 1998; Mahadevan, 2000), and absent or incoherent theoretical foundations resulted in a fierce critique of the concept (e.g. Porter, 2001; Markides, 2015).

Despite theoretical infancy, technology and innovation management scholars developed the BM concept outside the e-commerce context. Capturing value from disruptive innovations such as Xerox's first desk-sized copier as well as incremental innovations such as 
equipping baring housings with sensors, often required innovative BMs that align firms, customers and partners to create and capture value (Chesbrough \& Rosenbloom, 2002; Björkdahl, 2009). Teece (2010, p. 172) emphasised that "without a well-developed business model, innovators will fail to either deliver or to capture value from their innovations". Moreover, the BM concept has become a dimension of innovation itself (C. Baden-Fuller \& Haefliger, 2013). For example, SouthWest Airlines' or Rolls Royce aero engines' BM innovations re-combined familiar elements in unprecedented ways. The reciprocity of technology, BM, and VCC innovations is discussed in literature but remains sometimes contradictory (Spieth \& Schneider, 2016).

Later on, entrepreneurship scholars adopted the concept to develop an understanding of ventures' success and/or failure. Morris et al. (2005) stylised the BM concept as a "strategic framework for conceptualizing a value-based venture" (p. 734) and thus enhanced the concept's focus on describing, explaining, and exploring the exploitation of opportunities (Demil et al., 2015; McAdam, Brady, Miller, \& Spieth, 2018). As such, the BM concept has been regarded as a tool to plan, experiment, and refine ventures' VCC mechanisms (Sosna et al., 2010; Zott, Amit, \& Massa, 2011). As a sense-making tool it can foster coherence in planning processes of new ventures (Furnari, 2015; Martins, Rindova, \& Greenbaum, 2015) and when narrated as consistent stories (Magretta, 2002), BMs allow ventures to develop legitimacy with heterogenous audiences when stressing different aspects such as market size for investors (Doganova \& Eyquem-Renault, 2009; Perkmann \& Spicer, 2010; Fisher, Kuratko, Bloodgood, \& Hornsby, 2017). Additionally, the BM concept's experimental functions enable entrepreneurs to enhance their understanding of the environment and how ventures can interact with it (Sosna et al., 2010). Experimenting with individual components makes BMs material (Demil \& Lecocq, 2015) and convinces partners that a "business model could fit into the ecosystem" (Bojovic, Genet, \& Sabatier, 2018, p. 154). Entrepreneurship research has drawn attention to the BM concept as a planning, communication, experimentation, and implementation tool in the venture creation process.

The BM concept was adopted and developed by strategy scholars as a potential source of competitive advantage (Zott et al., 2011; Wirtz et al., 2016). Whereas the theoretical overlap remains subject to discussion (Markides, 2015), different temporal aspects (shortmedium vs long term), foci (value creation and/or capture), and organisational levels 
(business unit or corporates) are commonly used to distinguish the two concepts (CasadesusMasanell \& Ricart, 2010; Aspara et al., 2013; Massa et al., 2017). Moreover, strategy scholars often understand BMs as sets of iterative choices and decisions made to realise strategies (Richardson, 2008; Fjeldstad \& Snow, 2018; Teece, 2018).

In conclusion, the BM concept found wide-spread application across various research streams in the past two decades. The increasing number of publications and special issues of peer-reviewed management journals ${ }^{2}$ emphasises the growing importance of the concept and its value to researchers and practitioners (Wirtz et al., 2016; Massa et al., 2017). However, continuous critique (Markides, 2015; Foss \& Saebi, 2018) raises questions about the BM concept's validity as a stand-alone construct in management research (Ritter \& Lettl, 2018). The next section analyses dominant themes in the conceptual critique and subsequently proposes recommendations to address the short-comings in future research.

2 Long Range Planning 43/4 (2010), 46/6 (2013), 51/1 (2018), R\&D Management 44/3 (2014), Strategic Entrepreneurship Journal Volume 9/1 (2015), Advances in Strategic Management 33 (2015), AMS Review (forth coming), Journal of Business Research (forth coming) 


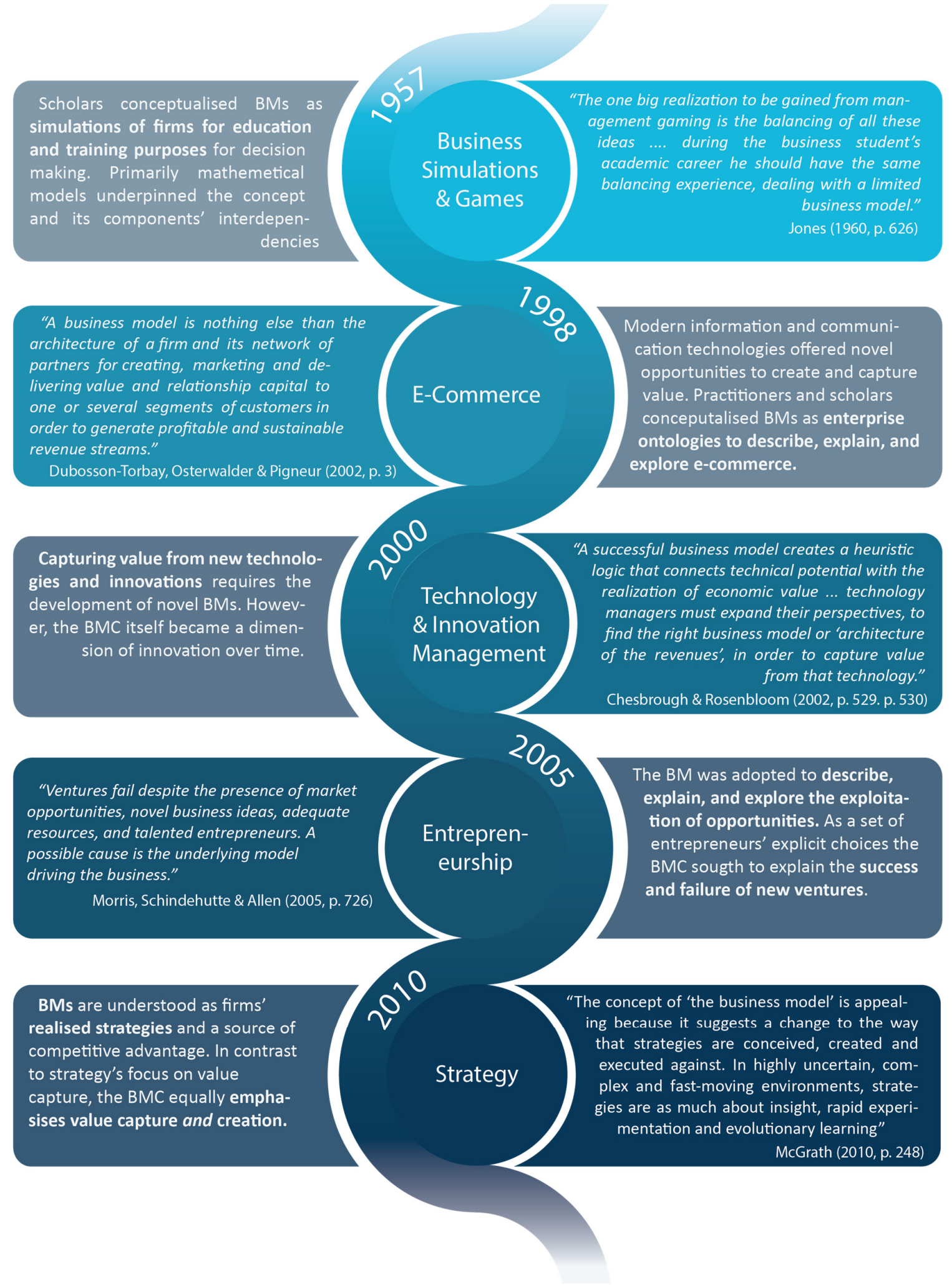

Figure 3 - Business Model Concept History 


\subsection{Business Model Concept - Critique}

Despite the conceptual advancements made in recent years, criticism of the BM concept continues (Täuscher, 2017). At its core, three distinct critiques can be identified (Table 1). Adequately addressing these themes is vital to enhance the BM's conceptual development and establish it as valid research construct and management tool in the development process of ventures (Suddaby, Hardy, \& Huy, 2011; Podsakoff, MacKenzie, \& Podsakoff, 2016).

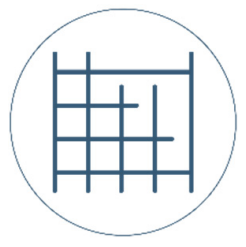

The (a) absent and/or inconsistent theoretical foundation has been stressed as a significant impediment for the advancement of the BM concept. Spieth et al. (2016) outlined that "scholars continue to struggle with the ambiguous theoretical foundation of the business model phenomenon" (p. 404). Likewise, Ritter and Lettl (2018) argued that "conceptual ambiguity hinders theoretical development and demands academic attention" (p. 2). In short, establishing a coherent foundation for the BM concept has been considered paramount to anchor the construct theoretically.

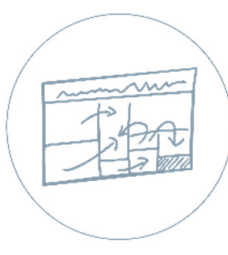

The fragmented theoretical foundations gave rise to (b) various subjectmatter lenses of the BM concept that funnelled conceptual development in isolated contextual silos (Zott et al., 2011). Klang et al. (2014) emphasised the dominance of subject-matter lenses or 'language games' amongst scholarly communities with shared sets of beliefs and rules, theoretical perspectives, and legitimate methodological approaches. The low rate of cross-citation further underpins the noncumulative nature of the research conducted in the field (Foss \& Saebi, 2016). BM research needs "to converge on the definition of basic constructs and then move systematically to the stages of explanation and prediction" (Fjeldstad \& Snow, 2018, p. 32). 


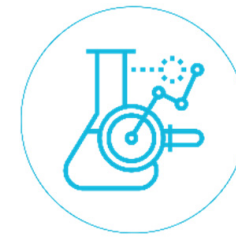

Finally, successfully operationalising the BM concept enables (c) converging lines of empirical research that have remained almost absent so far (BreaSolís, Casadesus-Masanell, \& Grifell-Tatjé, 2015; Täuscher, 2017). Defining and dimensionalising the basic constructs and units of analysis opens "the door for operationalization and measurement and therefore for the testing of empirical hypotheses" (Foss \& Saebi, 2018, p. 19). Snihur and Tarzijan (2018) highlighted the challenges of operationalising the BM concept since its dynamic environments are characterised by complexity. Hence, defining the boundaries and interdependencies of BMs is vital for convergent empirical research. A body of coherent empirical research can be considered as the linchpin for conceptual advancements (Kulins, Leonardy, \& Weber, 2016; Clauss, 2017).

Overall, the critiques highlight limitations of the BM concept and empirical research in past and contemporary literature. The inconsistent theoretical foundations, lack of coherence in conceptual development, and subsequently incongruent empirical research findings have been reinforcing and perpetuated the BM concept's contested status. At its core, the three themes can be mostly attributed to the concept's lack of clarity (Morris et al., 2005; Täuscher, 2017; Ritter \& Lettl, 2018).

The lack of conceptual clarity has undermined construct validity and inhibited the emergence of a common theoretical foundation (Foss \& Saebi, 2018) as well as the identification of essential BM elements and their properties (Klang et al., 2014) and thus led to poor choices of measures and indicators that lack coherence in empirical research (Podsakoff et al., 2016; Massa et al., 2017).

The concepts' proliferation and the rise of subject-matter lenses resulted in challenges to distinguish the BM concept from similar concepts and in turn undermined discriminant validity (Podsakoff et al., 2016). The resulting ambiguity further propelled primarily noncumulative conceptual research and made the BM concept challenging to distinguish from other related concepts (J. Singh, 1991; Klang et al., 2014).

Finally, the BM concept's ambiguous relationship as antecedent, consequence, or correlation of related constructs such as competitive advantage (Markides, 2015), opportunity (George \& Bock, 2011), or disruptive innovation (C. Baden-Fuller \& Haefliger, 2013) poses a significant challenge for the concept's nomological validity. The uncertainty resulting from the ambiguous nomological network has further decreased confidence in 
theoretical foundations and research findings (Arend, 2013; Ritter \& Lettl, 2018).

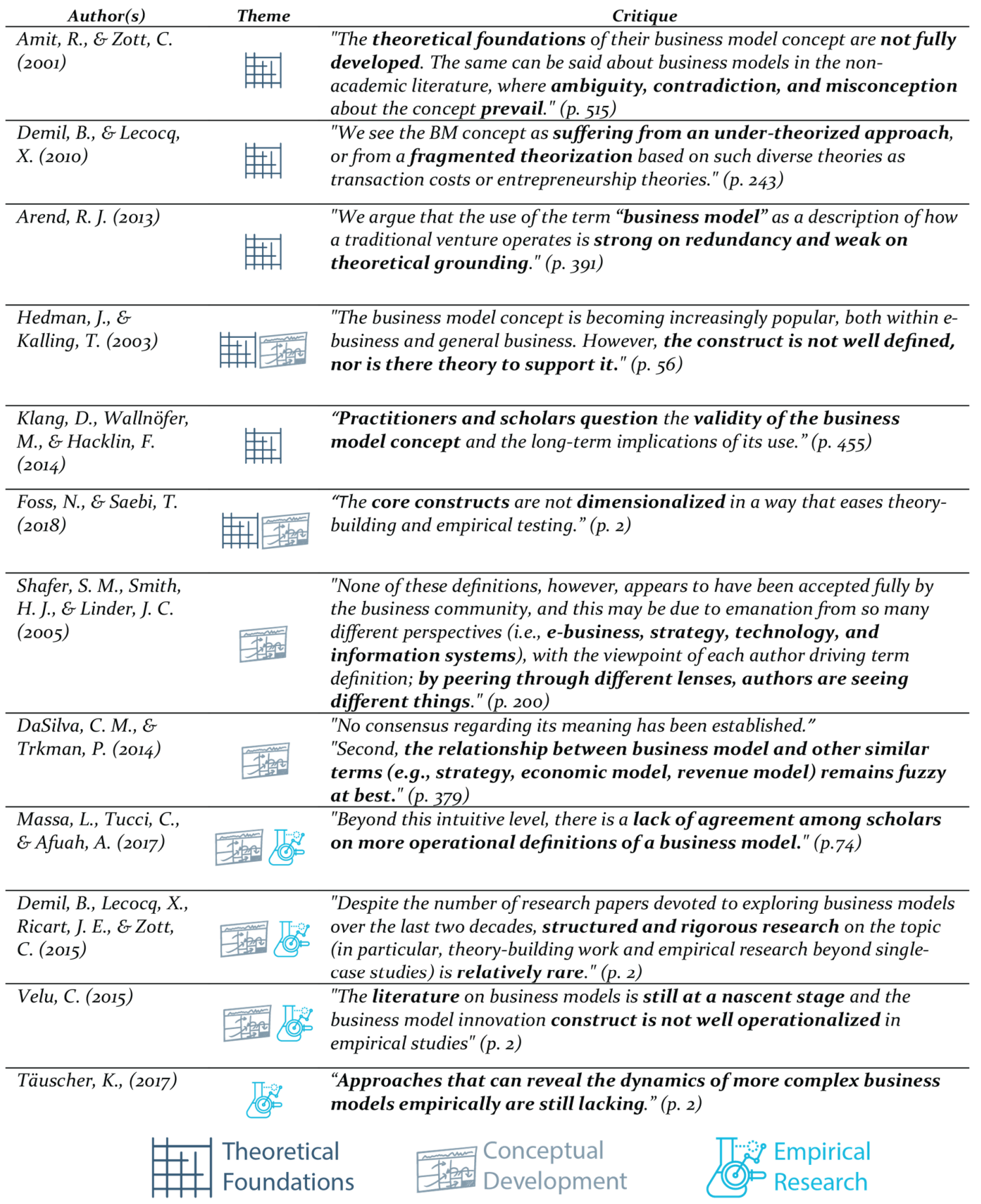

Table 1 - Business Model Critique Themes 
Overall, the three critiques can be attributed for the most part to the concept's lack of clarity. In order to foster theoretical convergence, conceptual advancements, and coherent empirical research, answers to the three questions of what is a BM, what a BM is not, and how does the BM concept relate to other concepts are required (Figure 4). The following section will introduce Goertz's (2012) social science concept framework that underpinned conceptual developments in this thesis. The structured development of a BM framework provided answers to all three critical questions of conceptual clarity.

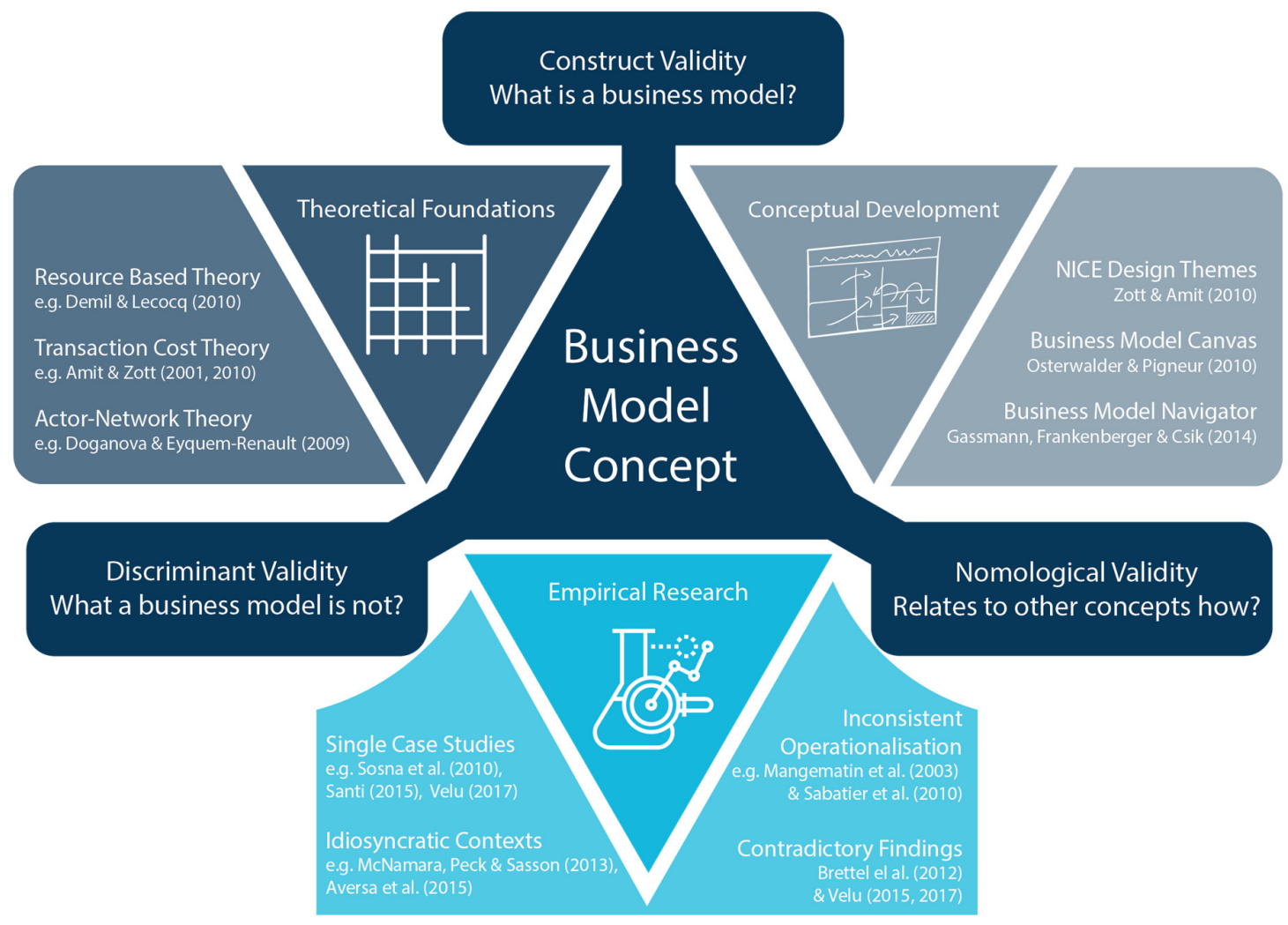

Figure 4 - Business Model Concept Clarity

\subsection{The Business Model - Anatomy of a Concept}

Understanding how BMs are developed requires a definition of the concept. In general, social science concepts can be defined as "cognitive symbols (or abstract terms) that specify the features, attributes, or characteristics of the phenomenon in the real or phenomenological world that they mean to represent and that distinguish them from other related phenomena" (Podsakoff et al., 2016, p. 161). This definition is consistent with Goertz's 
(2012) argument that concepts "constitute a theory of the ontology of the phenomenon under consideration" (p. 27). Concepts articulate attributes, constituent parts, and internal structures that define them as well as how they interact as a whole with their environment (Goertz, 2012, pp. 27-28) and thus foster a common understanding in scientific and professional communities.

Morris et al. (2005) outlined that the challenge of conceptualising BMs is to produce a framework that is "reasonably simple, logical, measurable, comprehensive, and operationally meaningful" and "is applicable to firms in general but which serves the need of the individual entrepreneur" (p. 729) at the same time. Foss and Saebi (2018) emphasised that in "theory-building dimensionalizing a construct should reflect the explanatory purposes to which the construct is put to use"(p. 14). In brief, conceptualising BMs requires clarity on core components, structure and conceptual levels, and explanatory purposes. The BM concept used in this thesis was designed along the social science concept framework proposed by Goertz (2012) to ensure clarity in regards to BM concept's components, structure, and explanatory scope.

Goertz (2012) argued that a concept can be dissected and analysed "by (1) how many levels they have, (2) how many dimensions each level has, and (3) what the substantive content of each of the dimensions at each level is" (p. 6). The proposed three-level structure distinguishes between a basic, secondary, and indicator level. The basic level specifies the nature of the concept and is used for theoretical propositions (Goertz, 2012, p. 30). The secondary level specifies the causal powers the concept has in virtue of its intrinsic nature (Harré, 1975, p. 86) and the relationships of the constituent parts (Goertz, 2012, pp. 15, 28). Finally, the indicator level, also referred to as the operationalisation level, permits the categorisation of phenomena, individuals and events that fall under the basic level concept (Goertz, 2012, p. 50). The proposed framework (Figure 5) has been applied in the analysis of the literature and employed to develop a structured BM conceptualisation. 

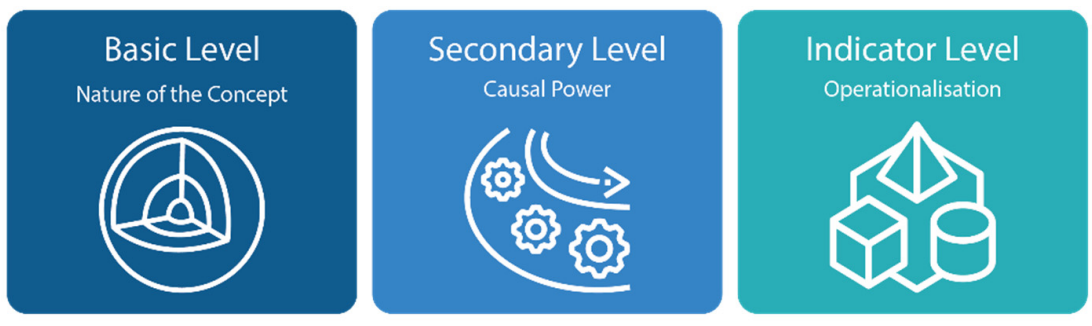

Figure 5 - Social Science Concept Framework (Goertz, 2012)

\subsubsection{The Basic Level - The Nature of the Business Model Concept}

Identifying the nature of the concept of interest has been considered as pivotal for achieving conceptual clarity and progress (Podsakoff et al., 2016). As the first step in that process an extensive literature review has been performed by searching for the terms 'business model' and 'business models' in the title, abstract, and keywords of publications in multiple databases (EBSCO, ISI Web of Science, Elsevier). The search has been limited to publications within the business, management, and economics subject area. A Google Scholar search yielded additional books and book chapters on BMs. The time horizon of the search has been set from January $\mathbf{2 0 0 0}$ to June $\mathbf{2 0 1 8}$ to ensure timeliness of the articles. The overall search produced 415 articles that were manually screened by the researcher for their contributions to the discussion and development of the BM concept based on their abstract and keywords. The remaining set of $\mathbf{1 1 3}$ articles and book chapters were imported into NVivo and analysed via a structured coding approach (Ridley, 2012). The patterns surfaced across the literature were complemented by and compared to the reported results of surveys conducted amongst practitioners (George \& Bock, 2011) and academics (Osterwalder, Pigneur, \& Tucci, 2005; Markides, 2015; Wirtz et al., 2016). Comparing literature review and survey results yielded insights into the anatomy of the BM concept, its ambidextrous basic level nature and attributes, secondary level functions, and indicator level dimensions. Table 2 provides and overview of the BM conceptualisations and key attributes proposed across the literature. 
Author(s)

Timmers, P. (1998).

\section{"An architecture for the product, service Definition} various business actors; and a description of the sources of revenues." (p. 2)

\begin{tabular}{ll}
\hline $\begin{array}{l}\text { Linder, J., E Cantrell, } \\
\text { S. (2000). }\end{array}$ & $\begin{array}{l}\text { "A business model is your company's logic for making money in the current business } \\
\text { environment. It includes the value propositions you work out with all your important } \\
\text { stakeholders and the operations you put in place to make good on your promises and to make } \\
\text { use of what you get in return. These are fundamental elements of every organization." (p. } 2)\end{array}$ \\
\hline $\begin{array}{l}\text { Afuah, A., \& Tucci, C. } \\
\text { L. (2001). }\end{array}$ & $\begin{array}{l}\text { "A business model can be conceptualized as a system that is made up of components, linkages } \\
\text { between the components, and dynamics." (p. 4) }\end{array}$
\end{tabular}

between the components, and dynamics." (p. 4)

\section{Key attributes}

* Products

* Service and information flows

* Description of various business actors

"Description of potential benefits for the various actors

${ }^{*}$ Description of the sources of revenues

* Business logic

* Stakeholder value proposition

Operations

* Returns

mer value

Scope (target customer, range of products/services)

* Pricing/Revenue source (Who pays for what value and when?)

${ }^{*}$ Connected activities (activities and connections)

* Implementation (Organizational structure, systems, people, environment)

* Capabilities (Types and sources of capabilities)

*Dynamics

Amit, R., E Zott, C. $\quad$ "A business model depicts the content, structure, and governance of transactions designed so

* Transaction content ( $g$

and capabilities required)

* Transaction structure (parties and ways in which they are linked; exchange sequencing, exchange mechanism)

* Transaction governance (ways in which flows of information, resources, and goods are controlled; legal forms, incentives for the participants)

$\begin{array}{ll}\text { Chesbrough, H., E } & \text { "The business model provides a coherent framework that takes technological characteristics } \\ \text { Rosenbloom, R.S. } & \text { and potentials as inputs, and converts them through customers and markets into economic } \\ \text { (2002). } & \text { outputs. The business model is thus conceived as a focusing device that mediates between } \\ \text { technology development and econic value creation." (p.532) }\end{array}$

Value Proposition

* Market segments

* Structure of the value chain

* Cost structure and profit potential

* Position of the firm within the value network

* Competitive strategy

Hedman, J., \&

"generic business model that includes the following causally related components, starting at

the product market level: (1) customers, (2) competitors (3) offering, (4) activities and

* Customers and offerings

Kalling, T. (2003).

organisation, (5) resources, and (6) supply of factor and production inputs... we also include a

longitudinal process component (7), to cover the dynamics of the business model over time" (p.

52-53)

Competitors

Activities and organization

* Resources

* Supply of factor and production input

*Dynamics

Shafer, S. M., Smith, $\quad$ "we define a business model as a representation of a firm's underlying core logic and strategic

H. J., E Linder, J. C. $\quad$ choices for creating and capturing value within a value network." (p. 202)

${ }^{*}$ Strategic Choices (customer, value proposition, capabilities, revenues,

competitors, output, strategy, branding, differentiation)

* Value Network (Suppliers, customer information, customer relationship,

information flow, product/service flow)

* Create value (resources/assets, processes/activities)

* Capture value (cost, financial aspects, profit) 
Osterwalder, A., Pigneur, Y., \& Tucci

C. L. (2005).
"A business model is a conceptual tool that contains a set of elements and their relationships and allows expressing the business logic of a specific firm. It is a description of the value a company offers to one or several segments of customers and of the architecture of the firm and its network of partners for creating, marketing, and delivering this value and relationship capital, in order to generate profitable and sustainable revenue streams." (p. 10) "
* Customer value

*Financial consequences

* Revenue stream

Customer segment(s)

*Value creation

${ }^{*}$ Value network

Customer value proposition

* Profit formula

* Key resources

* Key processes

Value Proposition

Customers and benefits

* Revenue and cost structure

* Organization reflects management's hypothesis about what customers want, how they want it, and how an enterprise can best meet those needs and get paid for doing so".

Demil, B., \& Lecocq, "Generally speaking, the concept refers to the description of the articulation between different X. (2010). $B M$ components or "building blocks" (resources and competences, organization, value propositions) to produce a proposition that can generate value for consumers and thus for the organization". (p. 227)

Resources and competences

*rganizational structure

* Value network

* Value proposition

\begin{tabular}{|c|c|c|}
\hline $\begin{array}{l}\text { Baden-Fuller, C., } \mathcal{E} \\
\text { Mangematin, V. } \\
\text { (2013). }\end{array}$ & $\begin{array}{l}\text { "The business model in this agenda is not a complete description of what the firm does, but } \\
\text { rather it should be a stripped down characterization, that captures the essence of the cause- } \\
\text { effect relationships between customers, the organisation and money. Hence, a business model } \\
\text { is a special example of a configuration (as defined by Fiss, 2011)." (p. 2) }\end{array}$ & $\begin{array}{l}\text { * Customers } \\
\text { *Customer engagement (value proposition) } \\
\text { * Monetization } \\
\text { *Value chain and linkages }\end{array}$ \\
\hline Arend, R. J. (2013). & $\begin{array}{l}\text { "We define the business model as a useful representation of how the organization creates value } \\
\text { through transforming and transferring matter, by drawing on available factors, fuelled by an } \\
\text { identifiable economic engine." (p.391) }\end{array}$ & $\begin{array}{l}\text { *Value } \\
\text { * Resources and capabilities } \\
\text { *Partners } \\
\text { * Structures (governance) }\end{array}$ \\
\hline $\begin{array}{l}\text { Amit, R., E Zott, C. } \\
(2015) \text {. }\end{array}$ & $\begin{array}{l}\text { "The business model describes the system of interdependent activities performed by a focal firm } \\
\left.\text { and its partners and the mechanisms that link these activities to each other." (p. } 33^{1}\right)\end{array}$ & $\begin{array}{l}\text { *Activities } \\
{ }^{*} \text { Human, physical and capital resources } \\
\text { * Partners } \\
{ }^{*} \text { Value creation }\end{array}$ \\
\hline $\begin{array}{l}\text { Cortimiglia, M. N., } \\
\text { Ghezzi, A., E Frank, } \\
\text { A. G. (2016). }\end{array}$ & $\begin{array}{l}\text { "a BM is a unit of analysis that explains, from a system-level perspective, how activities } \\
\text { conducted by a firm and external stakeholders create, deliver, and appropriate value. The } \\
\text { conceptual framework hence adopted includes the following five dimensions: (1) value } \\
\text { networking, (2) value creation, (3) value proposition, (4) value delivery, and (5) value } \\
\text { appropriation" (p. 415) }\end{array}$ & $\begin{array}{l}\text { *Value networking } \\
\text { *Value creation } \\
\text { *Value proposition } \\
\text { *Value delivery } \\
\text { *Value appropriation }\end{array}$ \\
\hline Velu, C. (2017). & $\begin{array}{l}\text { "Business models are a particular kind of configuration that link the inside of the firm with the } \\
\text { customer value proposition of the external market environment and how value is monetized. In } \\
\text { this sense, business models are the 'architecture' that provides the bridge between value } \\
\text { created for customers and the value captured by the business in terms of profit." (p. 605) }\end{array}$ & $\begin{array}{l}\text { * Customer value proposition } \\
\text { * External market environment } \\
\text { * Monetization }\end{array}$ \\
\hline
\end{tabular}

Table 2 - Business Model Conceptualisations 
The heterogeneous theoretical grounding of the BM concept resulted in an fragmented basic level nature where opposing stances have been fuelling scholarly debates, promoted disparity, and limited the potential for integrative research (Zott et al., 2011; Klang et al., 2014; Foss \& Saebi, 2016; Ritter \& Lettl, 2018). Analysing the fragmented theoretical roots surfaced two distinct understandings of the BM concept's nature. At its core, it can be understood as (a) firms' tangible and intangible structures and arrangement of its constituents, i.e. configurations or (b) entrepreneurs' and/or managements' cognition, i.e. rationales (Figure 6) (Tikkanen et al., 2005; Doz \& Kosonen, 2010; Massa et al., 2017).

The two basic level perspectives diverge in their level of abstraction (CasadesusMasanell \& Ricart, 2010; Aversa, Haefliger, Rossi, \& Baden-Fuller, 2015), research foci (Demil et al., 2015; Spieth et al., 2016; Ritter \& Lettl, 2018), and research methodology (Klang et al., 2014; Massa et al., 2017). As a result of the stark contrasts, the basic-level nature of the BM concept can be understood as firms' tangible and interdependent material attributes or individual and/or shared cognitive structures.

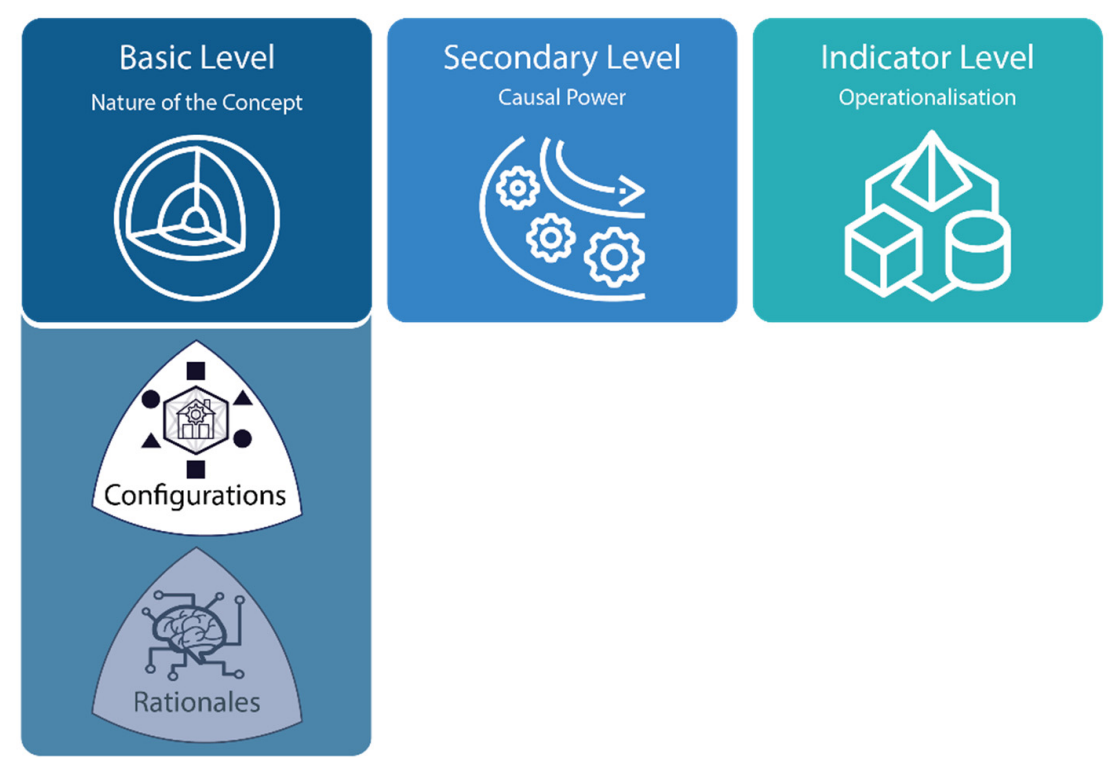

Figure 6 - Basic Level - Business Model Concept

The cognitive or intangible BM perspective can be referred to as BM rationales. These rationales describe and explain different forms of individual and shared cognition that have been used to define the BM concept (Chesbrough \& Rosenbloom, 2002; Porac, Ventresca, \& Mishina, 2002; Furnari, 2015). The proposed BM rationales encapsulate theories of causality that are believed to be true by BM designers (Casadesus-Masanell \& Ricart, 2007; Teece, 
2010). Rationales are rooted in mental model theory (Gentner \& Stevens, 1983; JohnsonLaird, 1983) and the theory of bounded rationality (March \& Simon, 1958). BM rationales describe and explain the content and structure of entrepreneurs' and managers' beliefs, hypotheses, and mental models and can be understood as one of two basic level natures of the BM concept in Goertz's (2012) social science concept framework.

In contrast, the tangible BM perspective can be denoted as BM configurations. The term 'configuration' has been employed across the literature to describe and explain how BMs' components are combined and orchestrated (Arend, 2013; C. Baden-Fuller \& Mangematin, 2013; Aversa, Furnari, \& Haefliger, 2015; Demil et al., 2015; Ritter \& Lettl, 2018). Configurations embrace a systematic perspective on "constellations of interconnected elements ... that bring about outcomes jointly and synergistically rather than individually and in a linear fashion" (Peer C Fiss, 2011; Peer C. Fiss, Cambré, \& Marx, 2013, p. 2). Configurations highlight the importance of the fit between organisations and their environments for performance outcomes (Ketchen Jr et al., 1997; Peer C Fiss, 2007; Ennen \& Richter, 2010). Assessing how different causes combine to affect performance within configurations over time allows us to express complex causal relations and equifinality ${ }^{3}$ that underpins theorybuilding (Ragin, 2009, 2014). Next to understanding what causes robustness amongst configurations, the strategic absence of cases may offer insights about shared assumptions of what components should or should not go together (Peer C Fiss, 2007). Overall, configurations embrace causal interactions of firms' components and their environment over time to explain firms' performance.

Similarly, BMs have been understood as causally related components of firms and their environments (Hedman \& Kalling, 2003; Burkhart, Krumeich, Werth, \& Loos, 2011; Kulins et al., 2016). Since the BM concept captures the cause-effect relationships, linking "the working inside of the firm to the outside elements" (C. Baden-Fuller \& Mangematin, 2013, p. 419), it can be considered as special example of configurations. Cortimiglia et al. (2016) emphasised that BMs articulate "the interwoven system dynamics between all its constituting parts ... providing a systemic view of all the relevant elements and relationships (inside and outside the firm)" (pp. 414, 417) and in turn highlighted the configurational nature of the

\footnotetext{
${ }^{3}$ Equifinality refers to non-linearity and the ways "a system can reach the same final state, from different initial conditions and by a variety of different paths" (Katz \& Kahn, 1978, p. 30).
} 
concept. Therefore, BMs can be understood as configurations of firms' and their environments' interacting components and thus as the second basic-level nature of the BM concept.

Overall, at the basic level, the BM concept can be seen as configurations of interacting components as well as rationales of individual and/or shared cognition. While BM rationales provide interesting research avenues, developing an understanding of the development process of viable BMs necessitates a configuration perspective. Although BM design and innovation might be considered as a primarily cognitive process (Osterwalder \& Pigneur, 2010; Martins et al., 2015), the underlying theories of causality might fail to hold up in reality (Casadesus-Masanell \& Ricart, 2007) and thus provide limited support to understand the development of viable BMs. Teece (2010) outlined that entrepreneurs and managers need to "validate conjectures and hunches about costs, customers, competitors, complementors, distributors and suppliers" and "being fast in learning and making the requisite adjustments to the model" (p. 188). Likewise, Saebi et al. (2017) argued that, similar to scientific hypotheses "business models are subject to market tests" and "may need to be changed or even rejected after confronting data" (p. 567). In short, viable BMs are developed in a dynamic process via interactions with ecosystems over time (Zott \& Amit, 2007; Sosna et al., 2010; Fjeldstad \& Snow, 2018). Consequently, this thesis will adopt the configuration stance to conceptualise the $\mathrm{BM}$ at its basic level nature. The next sections define the basic level attributes of BM configurations, henceforth referred to as BMs for the sake of clarity and readability.

\subsubsection{Basic Level Attribute - Value}

"The values of individual goods for everyone form a value system, the separate elements of which are mutually dependent" (Schumpeter, 1934, p. 40)

BMs are characterised by three central basic level attributes. First, while notions of value differ across the literature, value can be considered as the BM concept's foundation (George \& Bock, 2011; Klang et al., 2014; Foss \& Saebi, 2018). Traditionally the value construct 
is customer- and/or firm-centric and limited to predominantly pecuniary aspects (Porter \& Kramer, 2011; Arend, 2013; Markides, 2015). However, the BM concept extends that notion along the spectrum of engaged actors (Amit \& Zott, 2001; Wirtz et al., 2016; Fjeldstad \& Snow, 2018) and the type of value created (Weill \& Vitale, 2001; McGrath, 2010; C. Baden-Fuller, Giudici, Haefliger, \& Morgan, 2017). Early on, Timmers (1998) argued that BMs describe the "potential benefits of various business actors; and a description of the sources of revenues" (p. 2). Likewise, Demil and Lecocq (2015) noted that "a business model explains the logic of the firm, the way it operates, and how it creates and captures value for its stakeholders" ( $p$. 3). Finally, Massa et al. (2017) concluded that VCC in BMs is "a supply- and demand-side phenomenon - where value is created not only by producers but also by customers and other members of their value-creation ecosystem" (p. 75). The BM concept's locus of VCC focuses on an ecosystem of actors and is not limited to firms' boundaries.

Second, VCC is not limited to monetary-exchange for products and/or services. Arend (2013) noted that "unrealized value in the business model idea lies in what it can capture outside of the traditional business profit equation, where money is not the primary currency, and the customer and the firm are not the only primary players" (p. 395). For instance, Amazon opened its retail platform for third-party sellers. Amazon benefits by offering its endcustomers a wider range of products for competitive prices and also via subscription fees obtained from third-party sellers. Similarly, third-party sellers benefit from the reach of Amazon's website and the payment and administration services provided. Moreover, the logistics services offered for third-party sellers allow Amazon to improve their utilisation of warehouses and negotiation power with third-party logistics providers. In this case, Amazon, as well as third-party sellers, interact to co-create and capture value in various ways. In conclusion, since VCC mechanisms are two sides of the same coin (D. Lepak, K. Smith, \& S. Taylor, 2007; Priem, 2007), they have to be regarded as multi-actor and multi-value phenomenon resulting from a joint and interactive process (Priem, Li, \& Carr, 2012; Dyer, Singh, \& Hesterly, 2018). Neglecting one side would be naïve and jeopardises the economic viability of the BM.

Overall, while VCC is considered primarily as a firm-customer centric and monetary phenomenon in traditional strategy theories, with few exceptions such as shared value (Porter \& Kramer, 2011), BM theory extends that notion to the ecosystem and non-monetary 
value (Figure 7, textured box). VCC in BMs is considered as an ecosystem-centric phenomenon encapsulating various pecuniary and non-pecuniary value exchanges.

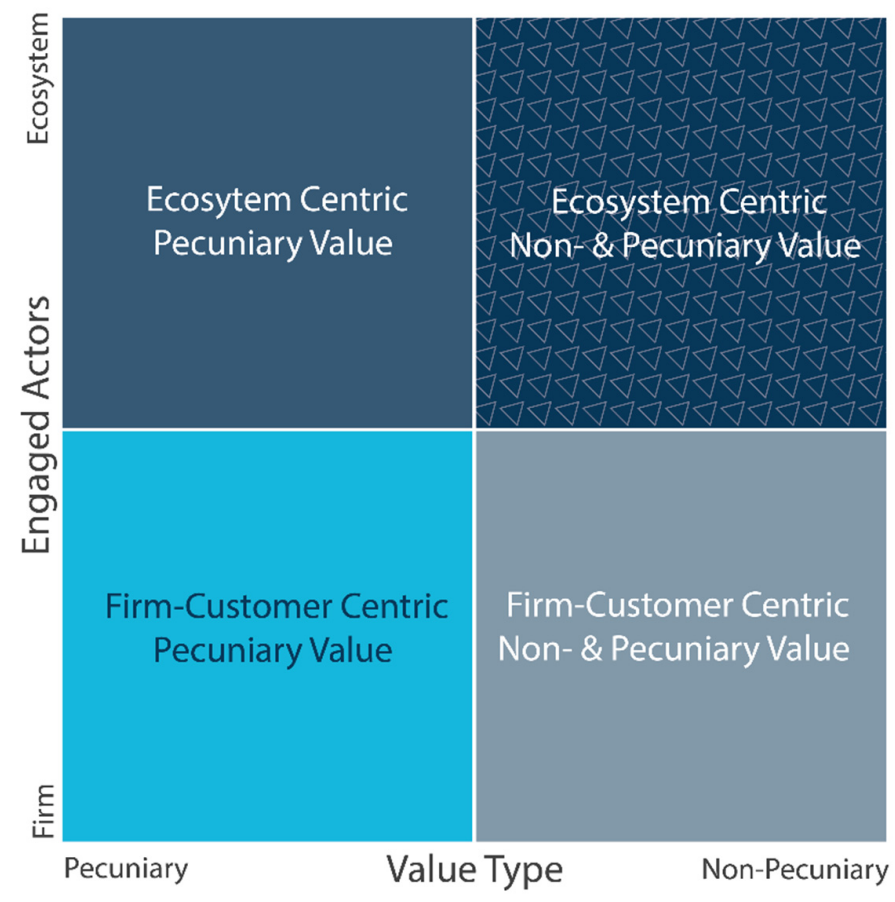

Figure 7 - Value in the Business Model Concept

The firm- and customer-centric perspective imposed on the BM concept by its theoretical grounding in traditional strategy frameworks (Amit \& Zott, 2001; Ritter \& Lettl, 2018) poses significant challenges for ecosystem-centric conceptualisations. Consequently, the service-dominant logic theory (Vargo \& Lusch, 2004; Lusch \& Vargo, 2006b; Vargo \& Lusch, 2016, 2017) was utilised to analyse VCC in ecosystems in this thesis. The service dominant logic has been employed in various BM conceptualisations (e.g. Nenonen \& Storbacka, 2010; Ritter, 2014; C. Baden-Fuller et al., 2017) to provide insights into how service-for-service and service-for-money exchanges can be a source of value in ecosystems. Service, i.e. value, can be defined as "the application of resources for the benefit of others ... provided either directly or indirectly (e.g., through a good)" (Vargo \& Lusch, 2017, p. 48). The service dominant logic considers services as the basic unit of exchange and in turn allows for pecuniary and non-pecuniary value to be co-created.

Moreover, value is always co-created due to the actions of multiple actors that 
contribute to each other's benefit (Vargo \& Lusch, 2016), rather than created by one actor and subsequently delivered (Vargo \& Lusch, 2017, p. 47). As a result, the service dominant logic draws attention to the importance of other ecosystem actors in the value creation process (Vargo \& Lusch, 2010a, 2011; 2016, p. 161).

In other words, the service dominant logic reflects (a) the decentralised locus of value co-creation beyond firms' boundaries (Zott \& Amit, 2013; Demil et al., 2015; Massa et al., 2017) and (b) the heterogenous notion of value inherent in the BM concept (Rappa, 2004; McGrath, 2010; Arend, 2013). Thus, the service dominant logic provides a valuable framework to conceptualise and analyse actors' multiple interactions undertaken to co-create value in BMs (Nenonen \& Storbacka, 2010; Echeverri \& Skålén, 2011; Grönroos, 2011).

\subsubsection{Basic Level Attribute - Ecosystem}

Since VCC cannot occur in a vacuum (Hamel, 2002), interactions with other actors in ecosystems are considered paramount. Early BM conceptualisations employed terms such as "value networks" (Hamel, 2002, p. 93; Shafer et al., 2005, p. 202), "value creation networks" (Morris et al., 2005, p. 728), "network structure of inter-organizational alliances" (Mangematin et al., 2003, p. 623) or "business networks" (Tikkanen et al., 2005, p. 795) to describe how interactions with other actors are facilitated. More recent conceptualisations explicitly use the term "ecosystem" (e.g. Amit \& Zott, 2015; Fjeldstad \& Snow, 2018; Foss \& Saebi, 2018) to explain how interactions with others are structured to create value.

The term "ecosystem" has various connotations largely depending on its context. Aarikka-Stenroos and Ritala (2017) reviewed the disperse literature and summarised, consistent with Moore $(1993,1996)$ who initially coined the expression, that business ecosystems are considered as generic overarching "concepts for distinct types of interdependent and co-evolving systems of actors" (p. 25).

In the BM literature the term (business) ecosystem is characterised by two distinct themes. First facilitating value creation is a characterising feature of ecosystems in the BM context. Amit and Zott (2015) argued that in a BM "the focal firm collaborates with business model stakeholders across its ecosystem (partners, customers, suppliers, financier) to craft a unique solution" (p. 341) to create value. In a similar vein, Wirtz et al. (2016) outlined that 
"networks and partnerships can have a great influence on the value creation of a company and must therefore be taken into consideration as part of a business model" (p. 41). The BM literature draws attention to the engagement of other actors in value creation as a central feature of ecosystems.

Second, the engagement of actors in value creation affects their BM development and performance in ecosystems. Saebi et al. (2017) argued that interactions with other ecosystem actors influence BMs' profitability and development. Similarly Fjeldstad and Snow (2018) noted that ecosystems "and the organisational designs that enable them ... make new business models viable" (p. 37) and allow for the development of value configurations. Finally, Foss and Saebi (2018) posed the question of "how does a change in the firm's BM affect the BM within its ecosystem/network relationships/stakeholders?" (p. 18). Actors' engagement in value creation highlights the importance of emerging interdependencies and how they affect BMs' performance in ecosystems.

In the context of modern BM literature ecosystems can be defined as systems of mutually interdependent actors connected via their BMs and engaged in value co-creation and capture affecting each other's development and profitability over time. In a similar vein, the service-dominant logic defines (service) ecosystems as "systems of resource-integrating actors connected by shared institutional arrangements and mutual value creation through service exchange" (Vargo \& Lusch, 2016, p. 161). Since actors within service ecosystems engage in reciprocal service provisions to enhance adaptability and survivability for themselves and others (Vargo, Maglio, \& Akaka, 2008; Vargo \& Lusch, 2017, p. 49), the relational, collaborative, and systemic value co-creation process "points towards the need to think in terms of dynamic service ecosystems" that "emerge and evolve through relationships among service-for-service providing, resource-integrating actors" (Vargo \& Lusch, 2010a, p. 176). Due to the de-centralised understanding of value co-creation no single actor controls ecosystems that are characterised by emergent properties (Greer, Lusch, \& Vargo, 2016).

The similar focus of ecosystems in the BM literature and the service dominant logic on value co-creation, co-evolution, actors' co-dependencies, and firms' performance emphasises the choice of the service dominant logic as an analytical framework to contextualise value cocreation and capture in ecosystems.

In conclusion, the BM concept embraces an ecosystem perspective of VCC analysis 
(Zott \& Amit, 2013; Fjeldstad \& Snow, 2018; Foss \& Saebi, 2018), allowing it to describe and explain how interactions with other actors are structured, resulting in interdependencies, and influencing the robustness of BMs over time. Since different types of actors and interactions with them have been considered as drivers of the BM development process (Morris et al., 2005; Sosna et al., 2010; Aspara et al., 2013), how BMs are embedded in ecosystems are regarded as basic level attributes of the BM concept .

\subsubsection{Basic Level Attribute - Dynamics and Development}

"As good as your business model may be today, it cannot and will not survive forever" (Simons, 2014, p. 54)

Since interactions with actors in ecosystems are often subject to change, the BM concept has to accommodate environmental dynamics to describe and explain the development of VCC mechanisms. Macro-level variations of ecosystems such as changes of consumer preferences (Magretta, 2002; Cavalcante, Kesting, \& Ulhøi, 2011), regulation and legislation (McGrath, 2010; Sosna et al., 2010) or new technologies (Chesbrough \& Rosenbloom, 2002; Björkdahl, 2009) can enable novel BMs and render existing ones obsolete (Morris et al., 2005; Sosna et al., 2010; Cortimiglia et al., 2016). For instance, changes in media consumption habits undermined traditional media's VCC mechanisms dependent on the size of audiences and related advertisement revenues.

Actors might proactively develop, adapt and even innovate their BMs in the absence of external changes and thus create meso-level change in ecosystems. Actors are developing entirely new BMs (Chesbrough, 2010; Demil et al., 2015), revamping existing ones (Demil \& Lecocq, 2010; Spieth et al., 2016), or adjusting isolated components (Björkdahl, 2009; Aversa, Haefliger, et al., 2015) by re-combining offerings, activities, and resources to improve their market positions. Heterogenous interests of ventures and actors can be considered as drivers of BM and ecosystem development (Hedman \& Kalling, 2003; Casadesus-Masanell \& Ricart, 2007; Martins et al., 2015; Foss \& Saebi, 2016; Saebi et al., 2017; Schneider, 2017; Hacklin et al., 2018). 
Finally, ventures can voluntarily develop, refine or innovate their BMs and/or components independent of external influences and cause micro-level change in ecosystems. Entrepreneurs' or managers' decision to change offerings, resources or their combinations can influence BMs to various degrees (Demil \& Lecocq, 2010, 2015). Broadly they can be distinguished between alterations of the inner workings and outwards facing elements (Cortimiglia et al., 2016) that can have implications for other actors (Cavalcante et al., 2011).

In conclusion, drivers of BM development can originate from macro-, meso- and micro levels of ecosystems. Internal as well as external ambitions to exploit opportunities and increasing efficiencies have been considered as antecedents of BM development (George \& Bock, 2011; Saebi et al., 2017; Schneider, 2017). Although internal and external triggers can be conceptually segregated, interactional structures and interdependencies of VCC mechanisms often mandate a co-evolution of actors in ecosystems.

The magnitude of change at different ecosystem-levels is vital for the scope of BM development (McNamara, Peck, \& Sasson, 2013; Aversa, Furnari, et al., 2015). However, the process is widely regarded as emergent. Demil and Lecocq (2010) drew attention to "business model evolution as a fine-tuning process involving voluntary and emergent changes in and between permanently linked core components, and find that firm sustainability depends on anticipating and reacting to sequences of voluntary and emerging changes"(p. 227). Likewise, Gerasymenko et al. (2015) emphasised that "as evident by both theory and practice, a firm's business model is not set in stone, but evolves over time" and adapts how it is organised internally and how it relates to external actors. The combination of the source and magnitude of change will influence the degree of BM development required to re-establish or maintain the firm ecosystem-fit as outlined in Figure 8. 


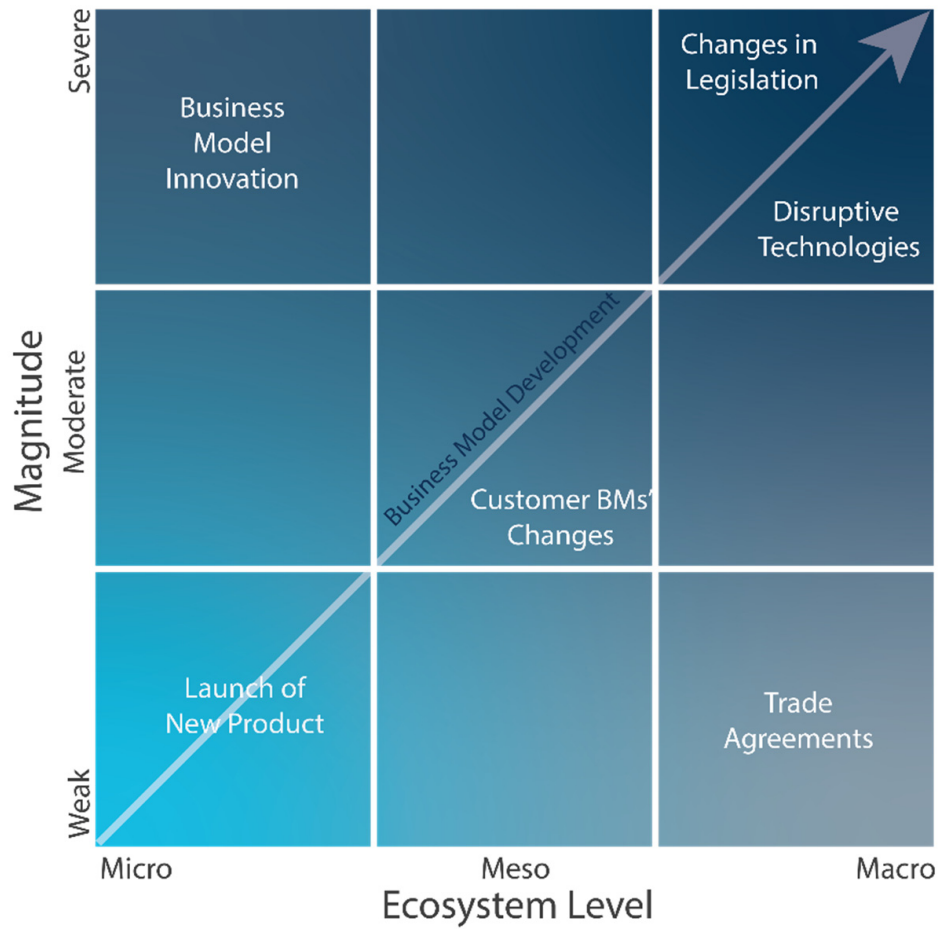

Figure 8 - Business Model Development Dynamics

The notion of dynamics is further emphasised by proposed BM life cycles (Morris et al., 2005; Brettel et al., 2012; C. M. Baden-Fuller, Vincent, 2015b). Stages in the BM life cycles are often differentiated by variations in foci on conceptualisation, experimentation, and refinement. Conceptualisation is widely referred to as BM planning or designing (Shafer et al., 2005; Osterwalder \& Pigneur, 2010; Demil \& Lecocq, 2015). Experimentation denotes an explorative and experimental process of implementing designed BMs (McGrath, 2010; Gerasymenko et al., 2015; Saebi, 2015). While "the probability of quickly arriving at an 'optimal' business model at the outset is low" (Gerasymenko et al., 2015, p. 82), ventures' resource constraints only allow for brief periods of experimentation (Sosna et al., 2010; Cosenz \& Noto, 2018). Consequently, ventures have to conduct insightful experiments and make adaptations in order to develop viable BMs (McGrath, 2010; Sosna et al., 2010; Bojovic et al., 2018). Finally, consolidation refers to refining or fine-tuning BMs over time (CasadesusMasanell \& Ricart, 2007; Sabatier, Mangematin, \& Rousselle, 2010; Saebi et al., 2017). While often understood as distinct and sequential processes, they can occur simultaneously in various development stages. For instance, even minor changes of isolated BM elements, such as adding an online-presence or a web-shop, require a conceptualisation, experimentation 
and consolidation process

Developing and sustaining a firm-ecosystem fit in constantly changing ecosystems requires ventures to balance conceptualisation, experimentation, and consolidation throughout different BM development stages (Demil \& Lecocq, 2010; Sosna et al., 2010; Gerasymenko et al., 2015; Teece, 2018). Across the literature, attention is drawn to the importance of interactions with actors for different BM development processes. Sosna et al. (2010) and Cavalcante et al. (2011) argued that entrepreneurs engage customers, suppliers, and partners to create hypotheses that provide the cornerstones for first BM designs. Additionally Teece (2010) and Saebi et al. (2017) highlight the importance of confirming, rejecting and adapting the hypotheses via "market tests", i.e. experimental interactions with actors in in the ecosystem. Finally, Demil and Lecocq (2015) and Wirtz et al. (2016) outlined the importance of fine-tuning BMs via interactions with "key actors". In brief, across all stages interactions with actors such as customers, suppliers, distribution partners, and even regulators that provide feedback on hypotheses, prototypes, business proposals, and submitted proposals (Frankenberger, Weiblen, \& Gassmann, 2014; Spieth et al., 2016; Bojovic et al., 2018) shape the BM development process (C. Baden-Fuller \& Morgan, 2010; Teece, 2010; Saebi et al., 2017). Consequently, developing and maintaining a firm-ecosystem fit requires ventures to interact with ecosystems and balance conceptualisation, experimentation and consolidation processes in differing BM development stages.

Analysing how these interactions of ventures and other actors influence and shape the $\mathrm{BM}$ development process requires a framework that compensates for the service dominant logic's lack of micro-foundations in that regard (Storbacka, Brodie, Böhmann, Maglio, \& Nenonen, 2016; Vargo \& Lusch, 2017). Consequently, the service dominant logic will be complemented by the framework developed by the Industrial Marketing and Purchasing group. While the Industrial Marketing and Purchasing group propagates a similar understanding of the business world as interactive ecosystems, the focal construct are business interactions that are defined as "a process that occurs between companies and which changes and transforms aspects of the resources and activities of the companies involved in it and the companies themselves" (Håkansson et al., 2009, p. 27). Thus, the Industrial Marketing and Purchasing group draws attention to direct interactions between customers, suppliers, and other related companies as well as governmental and non- 
governmental organisations and how their interaction shape the emergence of firms (Håkansson et al., 2009, p. 7). Interactions are "at the heart of business development" (Håkansson et al., 2009, p. 27) and allow for the analysis of how dyads of firms develop and affect each other over time. Subsequently, firms' ability to foster mutually beneficial relationships in ecosystems is considered critical to create and sustain a firm-ecosystem fit (Håkansson et al., 2009, pp. 24-25). In short, the Industrial Marketing and Purchasing framework unifies the notions of ecosystems and the mutually interdependent and dynamic development process reflected in the BM literature and thus provides a valuable additional theoretical frame.

\subsubsection{Basic Level Summary - Business Models and the Firm-Ecosystem Fit}

\footnotetext{
"Take a watch to pieces and examine, however carefully, its separate parts in turn, and you will never come across the principles by which a watch keeps time" (Polanyi, 1958, p. 47)
}

BMs orchestrate components, their interdependencies and interactions with the aim to co-create and capture value for all engaged actors that co-evolve in ecosystems over time. Conceptualising BMs as configurations allows us to incorporate the three most salient attributes of the concept (value- and ecosystem-centric dynamic configurations Figure 9). Engaging in VCC mechanisms requires interactions with other actors and a fit of what ventures can offer and what other actors value to realise designated benefits in ecosystems (Drucker, 1954; Adner, 2017; Fjeldstad \& Snow, 2018).

Moreover, the balance of engagements with other ecosystem actors has been considered pivotal as they define the scope of VCC mechanisms (Casadesus-Masanell \& Ricart, 2007; Arend, 2013; Tantalo \& Priem, 2016). Ecosystems that are populated by actors who continuously aim for bettering their situation are in constant flux and thus render any VCC interactional arrangement obsolete over time (Cavalcante et al., 2011; Saebi et al., 2017; Schneider, 2017). Therefore, interactional structures must be developed, maintained, and rejuvenated to remain viable and ensure a BMs' firm-ecosystem fit. 


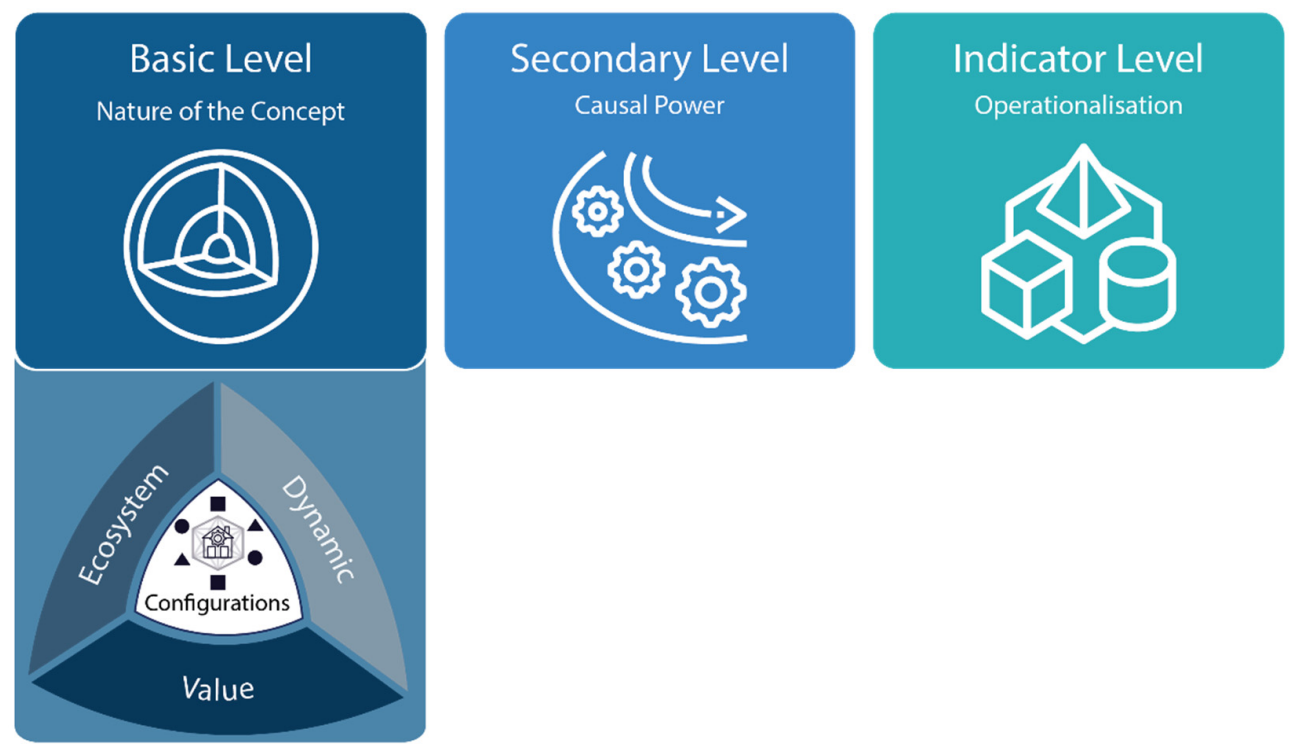

Figure 9 - Business Model Concept - Basic Level Attributes

Leveraging a combination of service dominant logic and Industrial Marketing and Purchasing research provides a frame to accommodate the basic level attributes of the BM concept in a dynamic and ecosystem-centric perspective. The combined frame allows us to zoom out and look at VCC across ecosystems as well as zoom in and investigate dyads of firmactor interactions and their broader implications over time. Thus, combining the service dominant logic and Industrial Marketing and Purchasing frameworks facilitates an understanding of how firm-ecosystem fits develop over time and underpin viable BMs. The following sections will discuss the function and operationalisation of the BM concept.

\subsubsection{Secondary Level - Functions of the Business Model Concept}

Secondary-level dimensions are attributed to the causal powers of the concept and how it interacts as a whole with its environment (Goertz, 2012, p. 28). Moreover, they provide the theoretical linkage between the abstract basic level and the indicator level of the concept (Goertz, 2012, p. 53). Across the literature, two primary functions of BMs can be identified. Chesbrough (2007b) argued that a BM explains how value is created and captured. Likewise, Klang et al. (2014) outlined that BMs are representation tools for articulating firms' current and future VCC mechanisms and for how interactions with business partners are structured. 
Finally, Amit and Zott (2015) described the function of BMs as the creation of value for all engaged participants and capture of a portion of that value. Despite the various notions of BMs as a planning, analysis, implementation and communication tool (Shafer et al., 2005; George \& Bock, 2011; Ritter \& Lettl, 2018), they all explicitly or implicitly relate to VCC mechanisms (Foss \& Saebi, 2016; Massa et al., 2017).

As a result, describing, explaining, and exploring VCC mechanisms and thus how a firmecosystem fit is created and maintained over time is widely regarded as the primary function of the BM concept (Figure 10). Therefore, VCC mechanisms can be defined as necessary conditions for the BM concept to distinguish it from other concepts (Goertz, 2012, p. 54). While VCC are considered as intertwined (D. Lepak et al., 2007), they have been conceptualised as individual secondary-level dimensions to enhance analytical precision and clarity.
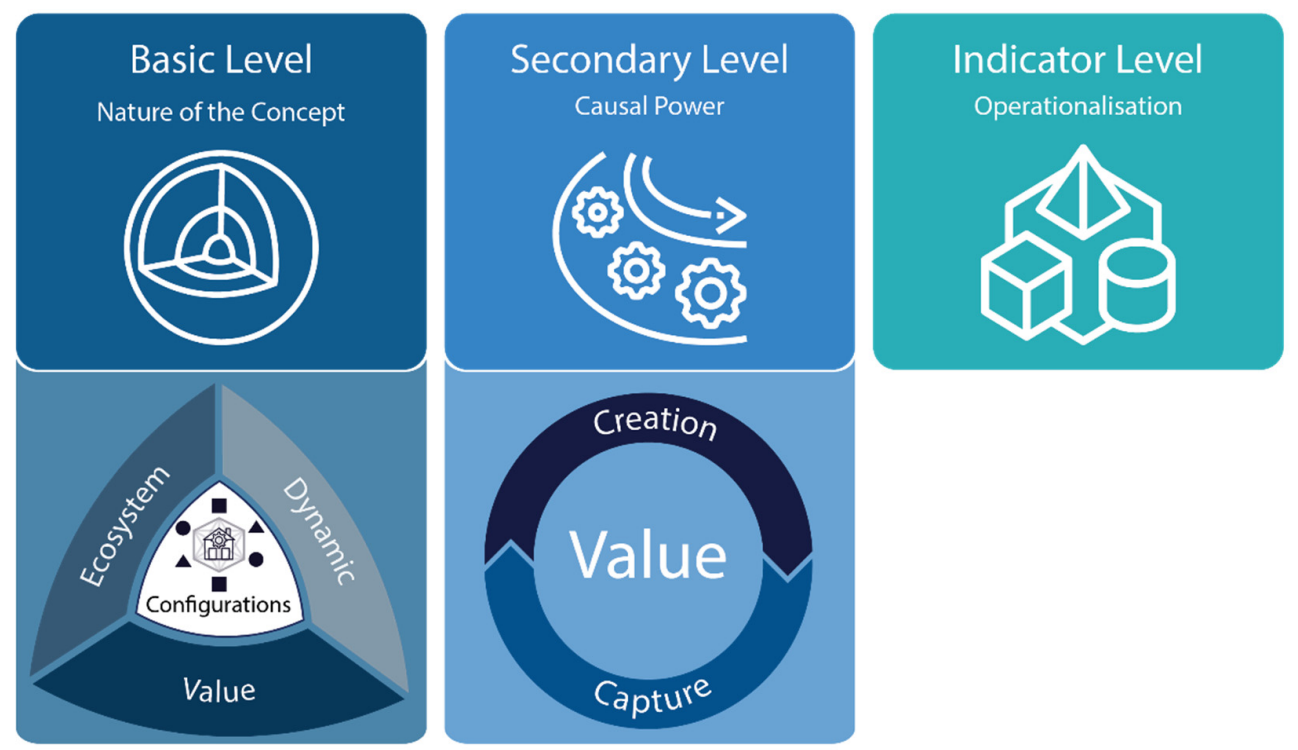

Figure 10 - Secondary Level - Business Model Concept

\subsubsection{Indicator Level - Components of the Business Model Concept}

The indicator-level or operationalisation level permits the categorisation of phenomena, individuals, and events that fall under the basic level concept (Goertz, 2012, p. 50). BM conceptualisations have incorporated vast ranges of components at the indicator level. Shafer et al. (2005) identified 42 different components across 12 conceptualisations. 
Klang et al. (2014) outlined that when neglecting the semantic overlap and disregarding mutual ontological differences, more than 100 different components can be identified across 54 publications. The multitude of components can be attributed to contrasting understandings of the BM concept, varying degrees of abstraction and diverging research foci (Foss \& Saebi, 2016; Wirtz et al., 2016; Massa et al., 2017).

However, the decomposability of BMs allows us to develop an understanding of the individual components' nature, functions, and interdependencies (Casadesus-Masanell \& Ricart, 2007; C. Baden-Fuller \& Morgan, 2010; Aversa, Haefliger, et al., 2015). Identifying and defining core components fosters clarity and supports the concept's consistent operationalisation (Foss \& Saebi, 2018; Ritter \& Lettl, 2018). Dissecting BM conceptualisations provides an overview of the most common components, functions, and interrelations. Across the literature, value propositions, activities, resources, and actors were identified as central BM components. The following sections discuss each of these components individually, outline how they are related and finally present the BM conceptualisation employed in this thesis.

\title{
2.4.3.1. Indicator Level - Value and Value Propositions
}

\begin{abstract}
"What the business thinks it produces is not of first importance-especially not to the future of the business and to its success. What the customer thinks he is buying, what he considers value, is decisive-it determines what a business is, what it produces and whether it will prosper" (Drucker, 1954, p. 37)
\end{abstract}

As a basic-level attribute, value has been reflected in almost all BM conceptualisations at the indicator level as well. The multivalent nature of the value concepts is dependent on the level of analysis ranging from individuals over organisations to societies (D. P. Lepak, K. G. Smith, \& M. S. Taylor, 2007). However, across a wide range of philosophy (Fleetwood, 1997), economic (A. Smith, 1776; Marx, 1867), strategy (Bowman \& Ambrosini, 2000; Prahalad \& Ramaswamy, 2004), innovation management (Christensen, Cook, \& Hall, 2005; Von Hippel, 
2005) and marketing (Vargo \& Lusch, 2004; Greer et al., 2016) literature two distinct types of value can be identified independent from the level of analysis. First, use-value is considered as the utility product and/or service combinations rendered to satisfy needs or solve problems. These product and/or service combinations, i.e. offerings, can be considered as mere means-to-an-end or as service-delivery vehicles (Vargo et al., 2008). Theodore Levitt's famous argument that "people don't want to buy a quarter-inch drill, they want a quarterinch hole" emphasises this point. Two important implications follow from this notion of value.

First, "there is no value until an offering is used" (Lusch \& Vargo, 2006a, p. 44) and actors have to "learn to use, maintain, repair and adapt the appliance to his or her unique needs, usage situation and behaviour" (Vargo \& Lusch, 2004, p. 11). Since offerings can be used differently in various use-contexts, they have heterogenous use-value (Vargo et al., 2008). The use-value of an offering is uniquely and phenomenologically determined by each actor and their use of the offering in different spatial and temporal contexts (Grönroos \& Voima, 2013; Vargo \& Lusch, 2017). A judgement of use-value is made by all actors such as consumers or managers when engaging in the exchange of services (Greer et al., 2016). This means that, use-value is subjective and determined by the use and context of actors.

While use-value is determined by individual benefits of actors (Vargo et al., 2008), it results from the combined efforts of all actors that are engaged in creating the offering. Subsequently, value creation is considered mutual and reciprocal as actors provide inputs for other actors' value creation activities and receive either indirectly, through money, or directly services in return (Vargo \& Lusch, 2010a). Vargo et al. (2008) emphasised that "value is created collaboratively in interactive configurations of mutual exchange" (p. 145) centred on interactions of activities, resources, and actors in service ecosystems. In that sense, the nature of value creation is relational and dependent on complex webs of service-relationships transcending isolated transactions (Vargo \& Lusch, 2010a). Consequently, value is always cocreated, jointly and reciprocally, via interactions of multiple actors seeking to enhance their adaptability and survivability in ecosystems (Vargo et al., 2008, p. 146; Vargo \& Lusch, 2017). In conclusion, while use-value is subjectively defined by actors based on their individual assessment, it is always co-created in ecosystems of interacting actors. 
"There is no business without a defined value proposition, and the creation of value provides a justification for the business entity" (Morris et al., 2005, p. 729).

As a result of use-value's heterogeneity, actors can only propose offerings that outlines how others will benefit when engaging in value co-creation (Vargo \& Lusch, 2004; O'Cass \& Ngo, 2011; Greer et al., 2016). These propositions for value co-creation, or simply value propositions, are vital connectors of actors across ecosystems (Spohrer, Maglio, Bailey, \& Gruhl, 2007; Vargo \& Lusch, 2010a). Fjeldstad and Snow (2018) even argued that "a business model must contain a value proposition" (p. 32) and stressed their importance as central structuring components for VCC mechanisms and underpinning resources, activities, and engaged actors in the BM concept (Morris et al., 2005; Björkdahl, 2009; C. Baden-Fuller \& Haefliger, 2013; Gassmann, Frankenberger, \& Csik, 2014).

However, the definition of the value proposition concept in BM conceptualisations is often limited to an 'offering' or a 'combination of products and/or services' and the intent to create value for customers (Chesbrough \& Rosenbloom, 2002; M. Johnson, Christensen, \& Kagermann, 2008; Demil \& Lecocq, 2010). Although value propositions are central to justify organisations' existence along the lines of value co-created with others, the concept has hardly been defined (Frow et al., 2014; Payne et al., 2017). Voima, Heinonen, and Strandvik (2010) proposed a value proposition framework contextualising use-value along the domains of what value will be co-created with whom, how, when, and where and thus provide a harness for the multivalent value construct.

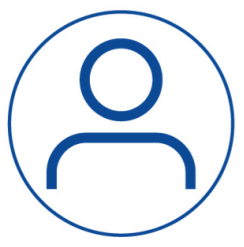

The who-dimension refers to the actor that is benefiting from value cocreation. In contrast to traditional customer-centric value propositions, more recently the emphasis has been on the importance of creating value for other actors as well in BMs (Amit \& Zott, 2001; Casadesus-Masanell \& Ricart, 2007; Tantalo \& Priem, 2016). 


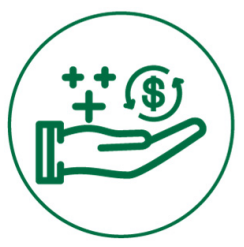

The type of use-value, i.e. what value is co-created with actors, can transcend pecuniary value and incorporate non-pecuniary functional, hedonistic, and symbolic aspects for actors. For instance, Morris, Shirokova, and Shatalov (2013) distinguished between the functional and hedonic value of restaurants and fast-food chains and their different offerings. Moreover, actors such as suppliers, complementors, or partners can benefit from a whole range of relational rents ${ }^{4}$ cocreated (Dyer \& Singh, 1998; Amit \& Zott, 2001; Dyer et al., 2018) such as reputational gains (Baum \& Oliver, 1991; Deephouse, Bundy, Tost, \& Suchman, 2017), the acquisition of capabilities (Gulati, Nohria, \& Zaheer, 2000; Gulati \& Sytch, 2007; Velu, 2015), exploring opportunities, and joint innovation projects (Björkdahl, 2009; Bonakdar, Frankenberger, \& Gassmann, 2014; Bojovic et al., 2018). In short, value co-created with and captured by other actors can be of pecuniary and non-pecuniary nature.

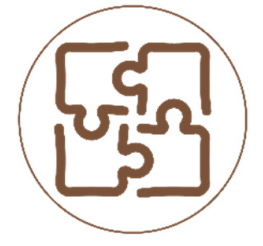

The how of value co-creation is often embodied in wide arrays of means employed to co-create value. Since product and/or service combinations are widely regarded as customer-centric (Priem, Wenzel, \& Koch, 2018) and ventures are unlikely to create them explicitly for other actors than customers, the means of value co-creation are referred to as offerings within this thesis. For the sake of clarity, customer value propositions that are targeting end-consumers of value cocreation mechanisms (J. Chandler \& Lusch, 2015; Vargo \& Lusch, 2017) and actor value propositions and that are geared towards value co-creation mechanisms with other actors will be distinguished.

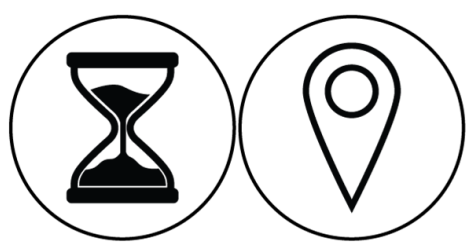

Finally, value propositions have to consider the temporal and spatial context of use-value since value can be accumulated by the use of offerings over a long period of time and/or in different locations (Grönroos \& Voima, 2013). Payne et al.

4 "We define value creation as the value created in an alliance (dyad/network) that is above and beyond the value created in competing arms-length market relationships. Value capture is defined as the absolute value or percentage of value created that is appropriated by each of the partners. Relational rents refers to the difference between the value created in a particular alliance and the value created in the next highest competing alliance or market relationship." (Dyer et al., 2018, p. 3141) 
(2017) emphasised the contextuality of value by outlining that designing effective value propositions requires a detailed understanding of other actors' processes and objectives in different contexts to understand and articulate how offerings co-create value-in-use.

Overall, the five proposed value proposition dimensions of who, what, how, when, and where provide a comprehensive framework to contextualise and structure value cocreation in ecosystems. Moreover, by providing a structured account for with whom, how, what, when, and where value is co-created, the value proposition framework introduced here provides a foundation for analysing VCC mechanisms.

In comparison to use-value, exchange-value is typically considered to be the amount paid by actors to obtain the utility of the value propositions (Bowman \& Ambrosini, 2000; D. P. Lepak et al., 2007). The willingness-to-pay has been considered a fundamental element of the value loop (Demil et al., 2015). However, limiting exchange-value to merely pecuniary exchanges often falls short in explaining value capture along two dimensions. First, value can be captured via mutually beneficial exchanges of services amongst actors (McGrath, 2010; Arend, 2013). Second, the value exchanged might not be related to one specific dyad or interaction of two actors (D. P. Lepak et al., 2007). For instance, Google's Gmail provides free e-mail services for everyone and captures value by selling advertisements according to the analysis of aggregated content of e-mails received and sent by the users. Google captures value from users by obtaining access to the aggregated content of e-mail conversations and in turn creates value via its advertisement services provided to firms that pay for that service. Overall, exchange-value can be understood as the flip side of use-value and can be based on pecuniary and non-pecuniary exchanges. Therefore, value propositions have to articulate how, what, with and from whom, where, and when value is co-created and captured in ecosystems. 


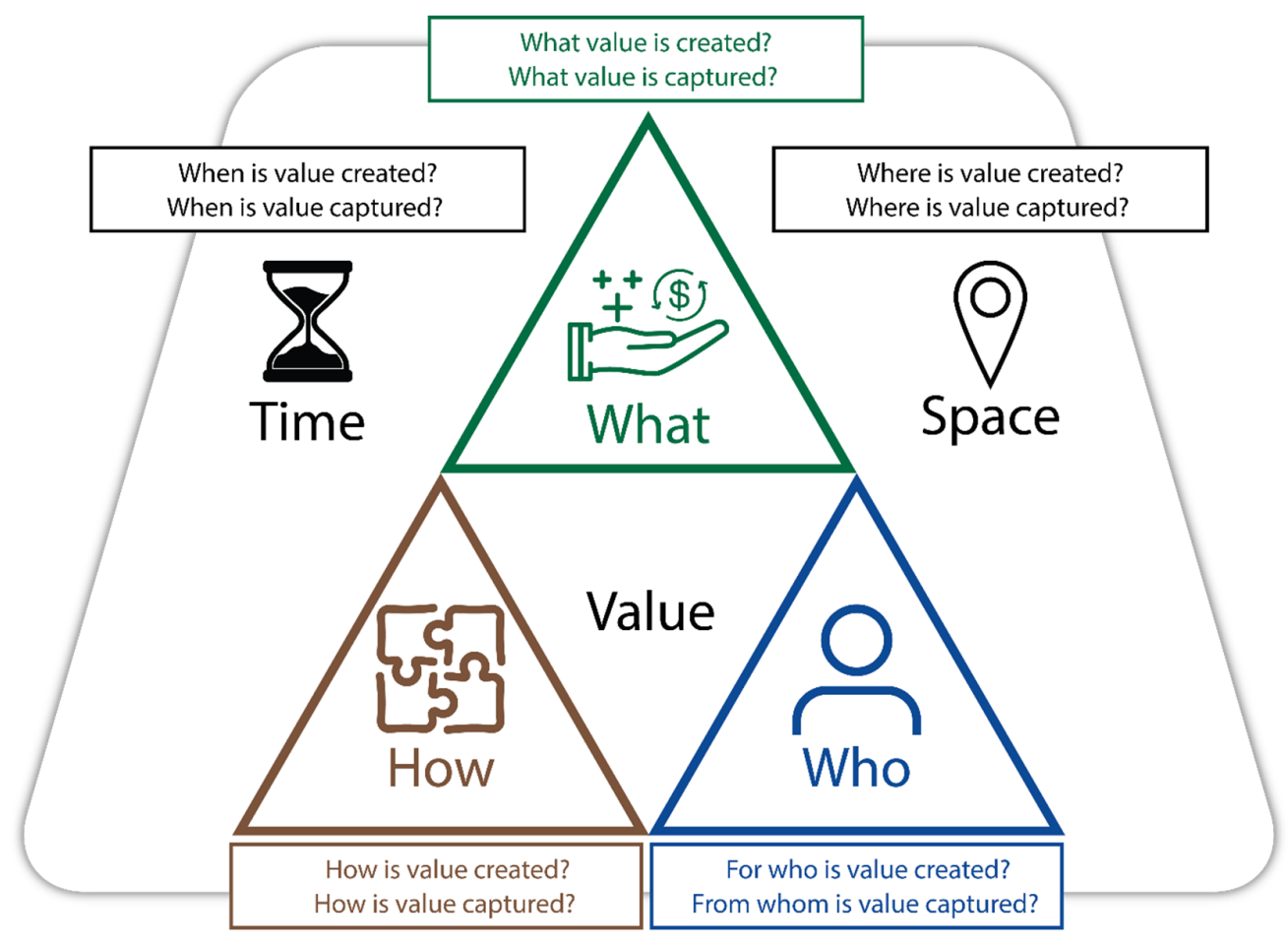

Figure 11 - Value Proposition Framework

Figure 11 illustrates the five dimensions of the value proposition concept and emphasises that VCC are two sides of the same coin. Björkdahl (2009) argued that value has to be created to be appropriated and thus neither of the mechanisms can be analysed in isolation. Since VCC mechanisms in BMs are not limited to customer-firm dyads and "firms may address value propositions to various kinds of customers - end customers, suppliers, complementors, competitors or sponsors" (Demil \& Lecocq, 2010, p. 231), they have to orchestrate them in BMs. Zott et al. (2011) stressed that BMs describe "the essential details of a firm's value proposition for its various stakeholders" (p. 1031). Likewise, CasadesusMasanell and Zhu (2013) noted that BMs define "value propositions for customers, suppliers and partners" (p. 464). Although most BM concepts often limit value propositions to customers (e.g. Osterwalder \& Pigneur, 2010; C. Baden-Fuller \& Haefliger, 2013), the ecosystem perspective on value inherent in the concept mandates the extension of value propositions with respect to with whom value is co-created and captured. In conclusion, BMs may address value propositions to several different actors to co-create and capture value in concert with them. 
Furthermore, VCC mechanisms are not bound to specific dyads, such as firm-customer or firm-supplier, but can be related to the provision of services in multiple engagements such as triads. For instance, Stewart and Zhao (2000) outlined that viable BMs create value for customers and "finding a means by which customers or someone else will pay for the value delivered" (p. 290). Similarly, Rumble and Mangematin (2015) argued that companies like AirBnB, BlaBlaCar, and Google illustrate how "the value created for one set of customers/users depends on some kind of interactions with other sets" (p. 98) in BMs. Finally Parmentier and Gandia (2017) stressed that networking and intermediation of complementary and interdependent actors can create positive network effects in BMs (Dyer \& Singh, 1998; Tantalo \& Priem, 2016; Dyer et al., 2018). By extending VCC mechanisms beyond isolated dyads of firm-actor interactions, positive network effects and actor synergies can be created that give rise to self-reinforcing cycles in BMs.

Overall, the BM concept lifts value propositions and VCC out of the traditional firmcustomer perspective to an ecosystem-level (Arend, 2013; Tantalo \& Priem, 2016; Fjeldstad \& Snow, 2018). Ventures have to design, align, and refine multiple interdependent value propositions to develop and maintain viable VCC mechanisms (Storbacka, Frow, Nenonen, \& Payne, 2012; Frankenberger et al., 2014). Since value propositions can be understood as the facilitators of interactions in ecosystems (Storbacka et al., 2012; Klang et al., 2014; Payne et al., 2017), VCC mechanisms can be analysed along the value propositions addressed to different actors (e.g. Grönroos \& Voima, 2013; Biloshapka, Osiyevskyy, \& Meyer, 2016). Therefore, successfully creating and orchestrating multiple value propositions is a prerequisite for ventures (Figure 12) to develop and maintain a firm-ecosystem fit. 


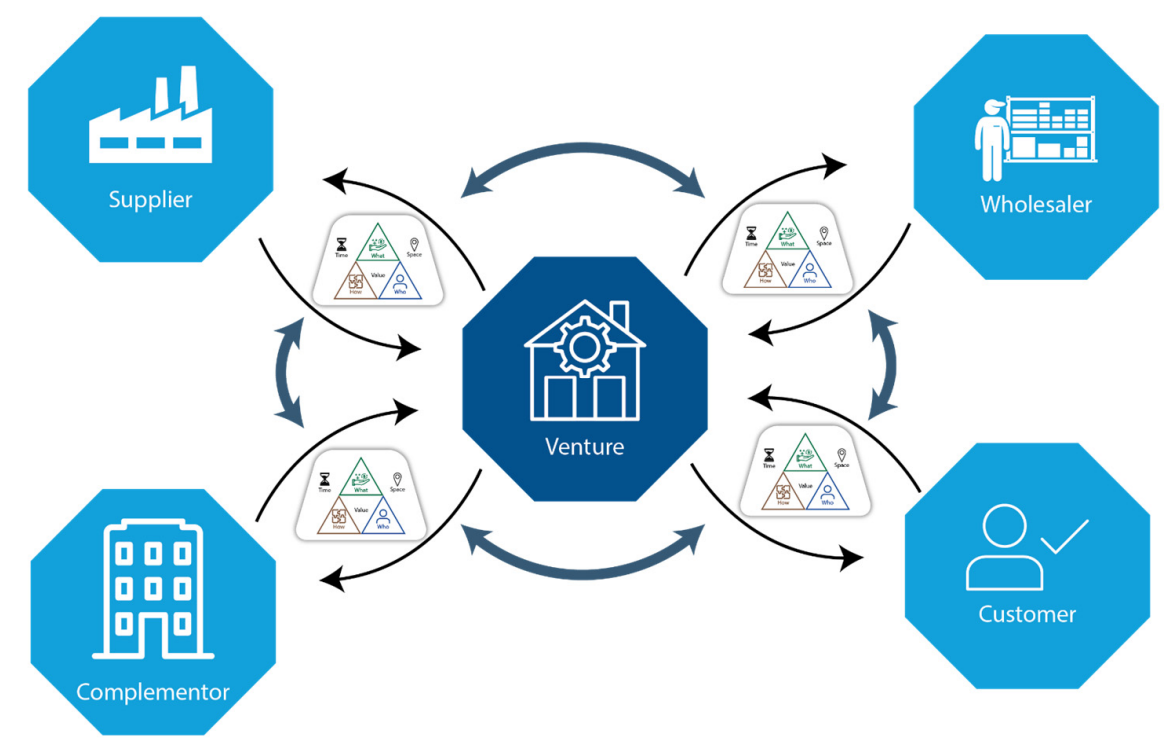

Figure 12 - Value Proposition Coordination

Since use-value can be heterogenous and difficult to articulate (Von Hippel, 1994; Björkdahl, 2009), developing effective value propositions requires an in-depth understanding of other actors' goals, processes, and use-context (Franke \& Von Hippel, 2003) and multiple iterations of conceptualisation, exploration, and consolidation (Payne et al., 2017). Moreover, engaging actors in value co-creation mechanisms via novel value propositions often requires furnishing their knowledge to foster and enhance the understanding of potential benefits (Stinchcombe, 1965; Shepherd \& Zacharakis, 2003). At the same time, ecosystem dynamics may render existing value propositions obsolete and thus require a continuous and coordinated development.

A value exploration matrix (Figure 13) was conceptualised to describe and explain the scale and scope of ventures' development of VCC mechanisms. While the scale refers to the number of actors value propositions were addressed to, i.e. the who of value, the scope denotes the what, how, when, and where of value propositions, i.e. the range of offerings developed. The value exploration matrix contextualises the proposed value propositions along the three basic-level attributes of the BM concept (value, ecosystems and dynamics). Figure 13 illustrates a potential trajectory of a venture that continuously explored and addressed an increasing range of customers with a marginally evolving offering (black triangle). Simultaneously, the venture increased the number of actors involved in VCC 
mechanisms with a broader scope of engagement (grey triangle). Moreover, the venture developed the scale and scope of value capture mechanisms over time (light-grey triangle).

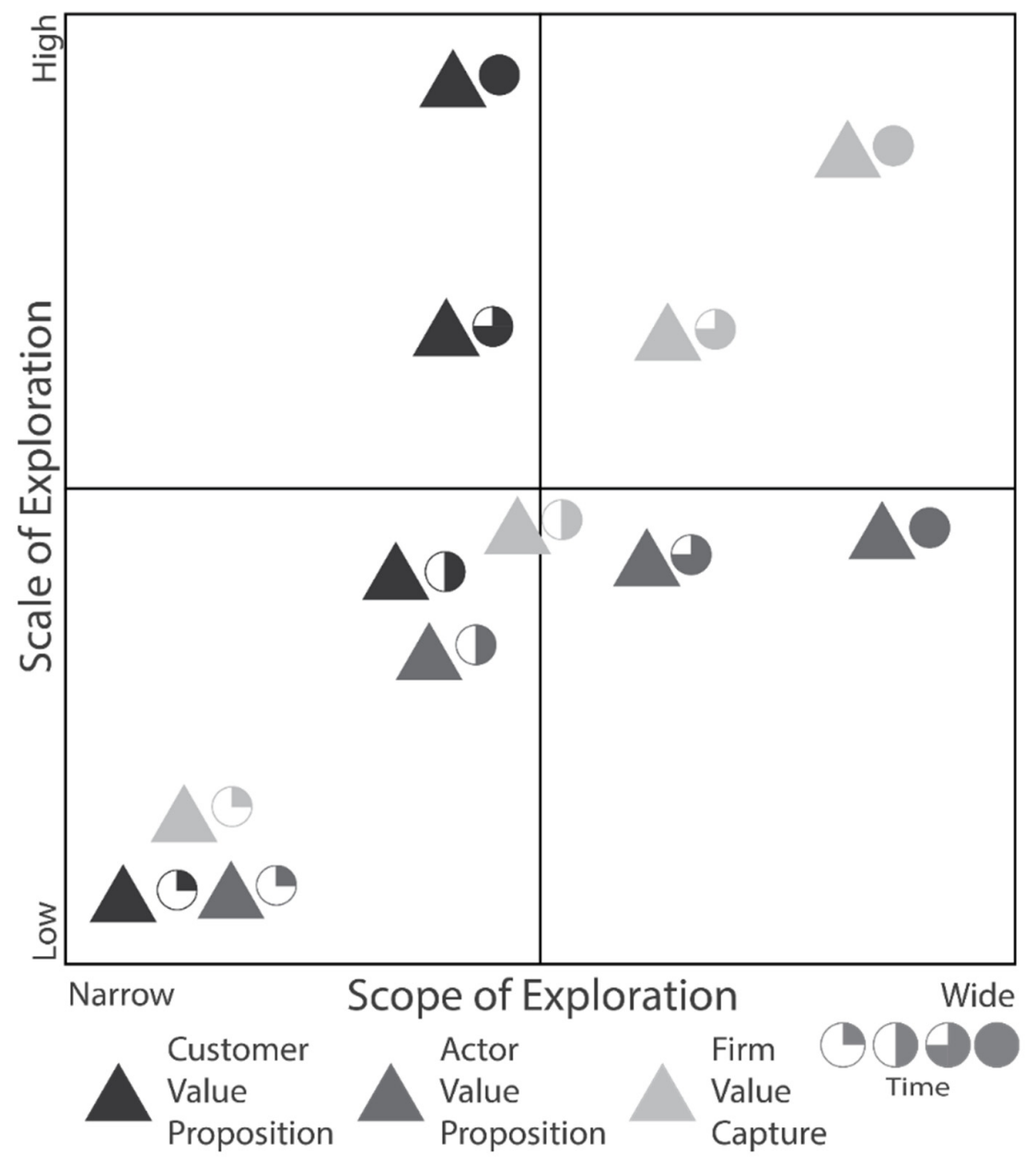

Figure 13 - Value Exploration Matrix 


\subsubsection{Indicator Level - Business Model Activities}

Activities have been considered as fundamental constituents of the BM concept. Morris et al. (2005) outlined that most BM perspectives include the firm's offering and activities undertaken to produce them within a value network of suppliers, partners and customers. Similarly, Amit and Zott $(2001,2015)$ promoted an understanding of the BM concept as configurations of internal and external activities enabled by stakeholders and the resources they deploy. Finally, Markides (2015) emphasised that the BM concept draws attention to the importance of conceptualising firms as a combination of activities. Although perspectives on activities vary across literature, what activities are performed, how they are performed, and who performs them are central questions for VCC mechanisms and the BM concept.

The discussion of activities and their interdependencies in BM literature is grounded in the value chain (Porter, 1985), value network, value shop (Stabell \& Fjeldstad, 1998), and activity system literature (Porter, 1996; Siggelkow, 2002). Scholars drew on single or combinations of these frameworks to conceptualise BMs (e.g. Osterwalder et al., 2005; Fjeldstad \& Snow, 2018). However, the BM concept transcends all three concepts and can easily be differentiated by its (a) ecosystem-level of analysis of activities and their interdependencies (Sabatier et al., 2010; McNamara et al., 2013; Zott \& Amit, 2013; Markides, 2015), (b) total value co-creation focus engaging multiple actors (Morris et al., 2005; Zott \& Amit, 2010; Arend, 2013; Klang et al., 2014; Demil et al., 2015; Massa et al., 2017), and (c) its dynamic perspective on evolving VCC mechanisms (Casadesus-Masanell \& Ricart, 2007; Demil \& Lecocq, 2010; Massa et al., 2017).

$\mathrm{BMs}^{\prime}$ interdependent sets of activities, performed by ventures and actors, are widely regarded as the foundations for VCC mechanisms (Amit \& Zott, 2001; Morris et al., 2005; Markides, 2015; Foss \& Saebi, 2018). Since interdependencies of activities have been stylised as value and cost drivers (Afuah \& Tucci, 2001; Hedman \& Kalling, 2002; Casadesus-Masanell

\& Ricart, 2007; Zott \& Amit, 2010), orchestrating internal and external activities can enhance value creation and/or reduce costs for engaged actors (Hamel, 2002; Morris et al., 2005; Zott et al., 2011; Massa et al., 2017). These interdependencies often define BMs' positions in ecosystems and thus what and how much value they can co-create and capture (Chesbrough, 2006; Sabatier et al., 2010; Ritter \& Lettl, 2018). As a result, actively managing activity 
interdependencies beyond organisations' boundaries allows for augmented interactions, takes advantage of actors' complementary capabilities, and leverages them in VCC mechanisms (Amit \& Zott, 2015; Tantalo \& Priem, 2016). In short, interdependencies of internal and external activities often structure the engagement of actors and therefore VCC mechanisms over time.

Since the most productive sets of interdependent activities may not be apparent (Morris et al., 2005), experimental learning is often required to reveal them (Siggelkow, 2002; McGrath, 2010). Wirtz et al. (2016) outlined that continuous interactions of actors to solve occurring problems can lead to changes of routines, structures and practices and thus drives the development of BMs. In a similar vein, Storbacka et al. (2013) drew attention to the importance of process harmonisation across actors' BMs and the resulting interdependencies. Developing interdependencies of internal and external activities is often considered as determining who performs what activities how (Doz \& Kosonen, 2010; Saebi et al., 2017). Consequently, bilateral experimental learning processes structure activities and activity interdependencies in BMs over time and, at the same time, provide an opportunity to harness actors' knowledge and capabilities to perform activities (Zott \& Amit, 2007, 2010; Demil \& Lecocq, 2015). However, developing activity interdependencies with multiple actors over time requires dedicated coordination. Thus, activity interdependencies result from continuous interactions with actors in ecosystems, affect VCC mechanisms, and in turn require active management to develop and maintain a firm-ecosystem fit.

Developing an understanding of activity interdependencies and how their fit affects VCC mechanisms requires the investigation of activities beyond isolated ventures. The approach has to account for the boundary-spanning nature of activity interdependencies that emerge over time. The Activity-Resource-Actor (ARA) model of the Industrial Marketing and Purchasing research stream fulfils these requirements (Håkansson \& Johanson, 1992, p. 28; Håkansson \& Snehota, 1995, p. 42; Håkansson, 2015). The activity-layer of the ARA-model allows for the investigation of how individual and sets of activities are embedded in ventures, their BMs and ecosystems (Hedvall, Dubois, \& Lind, 2016). The following section will introduce and define the context of the activity layer of the ARA-model.

The definition of activities in the Industrial Marketing and Purchasing Group has been heterogenous and dependent on relations to activities and resources (Håkansson \& 
Waluszewski, 2002). For the sake of clarity, activities will be defined as "a sequence of acts directed towards a purpose," (Håkansson \& Snehota, 1995, p. 52) "performed by actors which means that resources are combined, developed, exchanged or created by the use of other resources" (Håkansson, 2015, p. 15). The proposed definition of activities explicitly links activities to resources as well as actors and highlights the reciprocity of the components' interdependencies (Hedvall et al., 2016; Manser et al., 2016). The definition of activities in the Industrial Marketing and Purchasing Group reflects the understanding of activities in the BM concept. For instance, Amit and Zott (2015) argued that activities in BMs can be defined as "the engagement of human, physical and capital resources of any party to the business model to serve a specific purpose" (p. 331). Similarly, aligned with the understanding of activities as value and/or cost drivers in the BM concept, the Industrial Marketing and Purchasing Group denotes interdependencies of activities and subsequently the ways how they are performed as determinants of costs and revenues (Håkansson \& Snehota, 1995, p. 50; Holmen, Pedersen, \& Torvatn, 2005). The coherent understanding of activities in the BM literature and the Industrial Marketing and Purchasing Group emphasises the choice of the ARA-model as an analytical framework.

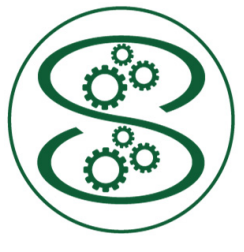

The Industrial Marketing and Purchasing Group particularly highlights the importance of analysing activities in ecosystems as their joint performance is characterised by their interdependencies developed over time. Ventures' sets of activities, referred to as activity structures (Håkansson \& Snehota, 1995, p. 53), are related to and dependent on activities performed by other actors (Håkansson et al., 2009, pp. 94, 96). Activities across ventures and other actors' activity structures can be aligned via activity links. Activity links "regard technical, administrative, commercial and other activities of a company that can be connected in different ways to those of another company as a relationship develops" (Håkansson \& Snehota, 1995, p. 26). In sum, analysing activities requires an understanding of the context of firms' internal activity structures and the activity links that connect them to other actors' activity structures.

Activity linking, as a form of coordination undertaken to bridge the physical and psychological distance of companies (Håkansson \& Snehota, 1995, p. 56), is achieved by purposeful design and mutual adjustments over time (Håkansson \& Snehota, 1995, p. 54). 
Activity linking refers to adoptions of activities jointly performed such as information exchanges as well as the reallocation of internal production processes (Håkansson \& Snehota, 1995, p. 55) to reduce costs and/or increase revenues (Håkansson \& Snehota, 1995, p. 50; Holmen et al., 2005; Håkansson et al., 2009; Hedvall et al., 2016). Hence, activity links reflect the synchronisation and matching of activities and are productive as they decrease the costs for performing activities and/or increase the outcome of combined activities (Håkansson \& Snehota, 1995, p. 62). While decreasing costs have been related to activity standardisation and economies of scale and scope (A. Chandler \& Takashi, 2009), an increase in outcome would be associated with activity differentiation and economies of effectiveness and the possibilities of realising exchanges (Scott, 1992) as summarised in Table 3. The coordination of activities can be underpinned by economic, behavioural, and relationship considerations. Since linking activities is considered as improving their joint performance, the involved costs are out-weighed by long-term benefits (Håkansson et al., 2009, p. 96). In brief, adjustments and mutual developments of activities allow firms to improve their functional performance when interacting with each other.

\begin{tabular}{|c|c|}
\hline Standardisation & Differentiation \\
\hline Cost efficiency & Variety \\
\hline Scale economies & Customization and uniqueness \\
\hline Table 3 - Base of Value Generation (Håkansson et al., 2009, p. 101)
\end{tabular}

While activity links provide opportunities for an advantageous balance of standardised and differentiated activities, they are also often binding and limit the flexibility to change firms' activity structures (Håkansson \& Snehota, 1995, p. 56; Håkansson et al., 2009, p. 97). As firms are involved in several relationships, activity links of varying types and strength can create a range of combination effects and tensions (Håkansson \& Snehota, 1995, p. 59). These combination effects have been translated as "an economically advantageous balance" (Håkansson \& Snehota, 1995, p. 60) of standardisation and differentiation of firms' activities crucial for "company's capacity to be effective in exchange with others" (Håkansson \& 
Snehota, 1995, p. 56). Ventures need to search for the right balance and develop and rationalise activities in continuous experimental interactions with each other (Ritter, Wilkinson, \& Johnston, 2004; Baraldi, Proença, Proença, \& De Castro, 2014).

Over time activities can become more specialised through adjustments and allow for the development of stable routines that capitalise on investments in physical and human resources (Williamson, 1975; Dyer et al., 2018). These organisational routines can enhance learning within and across firms and serve as reservoirs of tacit knowledge (Håkansson et al., 2009, p. 108). The quality of the relationship between the engaged actors affects the efficiency of activity coordination (Ritter et al., 2004; Munksgaard \& Medlin, 2014). Moreover, since firms' activities are embedded in multiple contexts, changes and specialisations will always call for adjustments and require an understanding of possible consequences (Håkansson et al., 2009, p. 104; Hedvall et al., 2016). Hence, activity structures and links can hardly be optimal for all actors and "it is meaningless to speak about optimal activity systems or configurations" (Håkansson \& Johanson, 1992, p. 31). Thus, firms engage with other actors to develop and optimise activity links to improve their activity structures' functional performance. The process of emerging routines is underpinned by a mutual learning process of the engaged actors (Håkansson et al., 2009, p. 104). Hence, activity structures and activity links emerge in a dynamic and interactive process over time (Håkansson \& Snehota, 1995, pp. 59, 61; Håkansson et al., 2009, p. 104).

In general, three types of activity interdependencies can be identified. Serial interdependencies result from the temporal dependence of activities as a specific activity cannot be performed until another one has been completed (Håkansson et al., 2009, p. 105). Dyadic interdependencies are defined as activities of simultaneous production and consumption where the services provided via one activity are inputs into another activity. For instance, the demand for engine maintenance services generated by operating an aircraft can be considered as dyadic interdependent activities (Håkansson et al., 2009, p. 106). Finally, joint interdependence occurs when two activities are interdependent because both of them are related to a third activity. For instance, headlights and bumper modules must be delivered at the same time to an automobile assembly line as they are installed together (Håkansson et al., 2009, p. 107). While the three activity interdependencies can be distinguished, it is not uncommon for them to be simultaneously present (Håkansson et al., 2009, p. 108; Hedvall et 
al., 2016).

Overall, the activity layer of the ARA-model draws attention towards the analysis of activities and their interdependencies, ventures' and actors' activity structures' embeddedness in ecosystems, and how the activity linking process shapes them over time. The emergence of stable activity routines in interactions with actors can provide a first indicator for a robust firm-ecosystem fit and thus the development of a viable BM. The activity-layer model of the ARA-model allows for the analysis of (a) BMs' boundary-spanning interdependencies of activities, (b) VCC mechanisms accounting for a range of engaged actors, and (c) the development of stable activity routines that strike an advantageous economic balance in ecosystems over time. Figure 14 illustrates potential activity links of ventures' BMs.

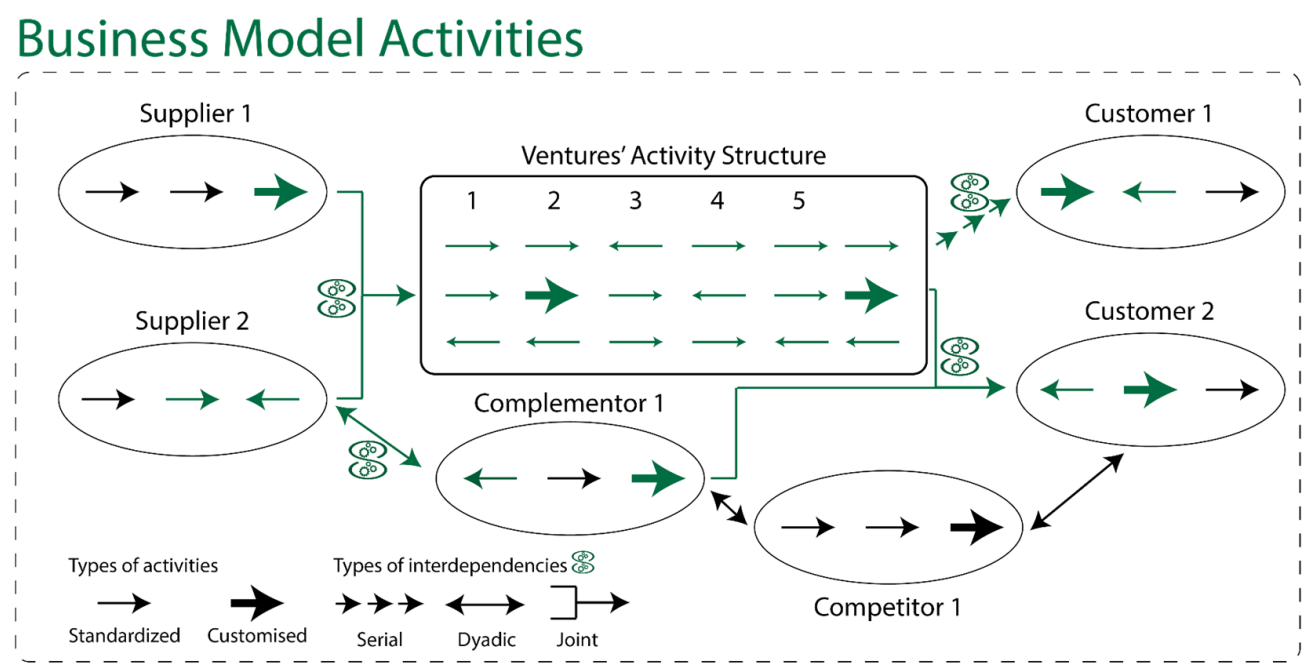

Figure 14 - Business Model Activity Configurations (Håkansson et al., 2009, pp. 109, 116)

\subsubsection{Indicator Level - Business Model Resources and Ties}

Explaining VCC mechanisms in ecosystems calls for an understanding of how activities and underlying resources are combined and developed over time (Hedman \& Kalling, 2002). Sabatier et al. (2010) outlined that performing activities requires the accumulation of strategically important resources that may or may not be possessed internally. In a similar 
vein, Demil et al. (2015) argued that the BM concept emphasises configuration of internal and external resources in use that enable activities. Therefore, understanding the functions of resource combinations, henceforth referred to as resource collections ${ }^{5}$, and how they are developed can be regarded as crucial to analyse VCC mechanisms and the evolution of firmecosystem fits in BMs.

The discussion of resources in the BM concept's context is grounded in the resourcebased view (RBV) of the firm (Penrose, 1959; Wernerfelt, 1984; Barney, 1991). Several scholars have been drawing from the RBV to conceptualise BMs (e.g. Amit \& Zott, 2001; Demil \& Lecocq, 2010). Central to the BM concept are the services resources yield in heterogenous combinations (Penrose, 1959, p. 25; Amit \& Schoemaker, 1993; Lippman \& Rumelt, 2003). Since ventures often do not control the resources required for VCC mechanisms, they must combine internal with external resources (Schumpeter, 1934; Venkataraman, 1997; Burns, Barney, Angus, \& Herrick, 2016). Yet, external resources and methods of combinations are rarely discussed in the RBV (David G Sirmon \& Hitt, 2003; Barney, Ketchen, \& Wright, 2011; David G. Sirmon, Hitt, Ireland, \& Gilbert, 2011). Consequently, developing an understanding of how internal and external resources are combined in BMs can inform theory development of the RBV (Demil et al., 2015; Ritter \& Lettl, 2018).

Developing resource collections requires identifying strategic as well as potentially strategic resources and their sources (Brush, Greene, Hart, \& Haller, 2001; Hedman \& Kalling, 2003; Wirtz et al., 2016). The importance of resources is based on expectations about BMs' future developments (Lichtenstein \& Brush, 2001; Mangematin et al., 2003; Alvarez \& Barney, 2005). While access to some strategic resources can be facilitated by acquisitions, ventures' limited funding often sets boundaries to internal resources' scope (Lichtenstein \& Brush, 2001; Zott \& Amit, 2008; Gerasymenko et al., 2015). Moreover, idiosyncratic resources, often required for VCC mechanisms, cannot be obtained via simple market transactions or are too costly to develop (Lavie, 2006; Velu, 2015; Burns et al., 2016; Cortimiglia et al., 2016). Hence, obtaining access to external resources is considered vital. Björkdahl (2009) argued that "even the most vertically integrated firms need to access external resources in order to be able to

\footnotetext{
${ }^{5}$ This thesis will adhere to the terminology of the IMP research stream that complies with Penrose's (1959) conceptualisation of the firm as "a collection of physical and human resources" (p. 9) rather than a set or bundle as commonly referred to in the RBV of the firm (Wernerfelt, 1984; Barney, 1991; Barney \& Clark, 2007).
} 
exploit inhouse resources" (p. 1469). Likewise, Frankenberger et al. (2014) provided evidence that firms compensate for the lack of internal resources by "integrating the missing resources and capabilities of partners" (p. 178). Obtaining access to and combining external with internal resources in resource collections enables ventures to perform critical activities.

BMs' initial resource collections' development is characterised by "bumps and turns, and multiple iterations" (Brush et al., 2001, p. 64). Before resource collections yield the desired services and capabilities, an iterative process of re-configuration is required (Lichtenstein \& Brush, 2001; D. Sirmon, Hitt, \& Ireland, 2007; David G. Sirmon et al., 2011). The explorative nature of the resource reconfiguration process can be attributed to information asymmetries and the anticipated value of individual resources in idiosyncratic resource collections (Schmidt \& Keil, 2013). The heterogeneity of resources' services in different combinations emphasises the importance of information on how to combine them (Penrose, 1959; Makadok \& Barney, 2001). While firms can discover new uses and combinations of resources independently (Warnier, Weppe, \& Lecocq, 2013), they can take advantage of other actors' knowledge and support in the process.

The information obtained via interactions facilitated by informal ties among individuals (Granovetter, 1973; Uzzi, 1996), interlocking affiliations such as shared boards and mentors (Mizruchi, 1996), formal inter-organizational relationships (Powell, Koput, \& SmithDoerr, 1996; Dyer \& Nobeoka, 2000; Gulati et al., 2000), and encountering iconic and dominant BM designs (Amit \& Zott, 2015; Mikhalkina \& Cabantous, 2015) can provide insights into how to use and combine resources (Dyer \& Nobeoka, 2000; Gulati et al., 2000; Schmidt $\&$ Keil, 2013). The importance of interactions with ecosystem actors to facilitate access to external knowledge and information has been apparent in BM literature. For instance, Demil and Lecocq (2010) emphasised the importance of knowledge in extracting services from the use and combination of resources for the development of BMs. Similarly, Velu (2015) argued that new ways of connecting factor and product markets requires new knowledge, skills, and capabilities as complementary resources that are accessed via partnering with third-party firms "are typically not available in competitive supply and are subject to unilateral or bilateral dependence" (p. 3). Finally Wirtz et al. (2016) summarised that continuous interactions with firms' key actors facilitate knowledge transfers that can yield insights into how to develop resource collections. In short, ventures' interactions with actors facilitate access to vital 
resources, knowledge on how to combine them, and in turn the unique services they can yield (Chesbrough, 2006; Björkdahl, 2009; Frankenberger, Weiblen, \& Gassmann, 2013).

Overall, ventures' interactions with actors are crucial for combining resources as they allow firms to (a) compensate for a lack of internal resources, (b) provide essential knowledge of how to configure resources, and even (c) align the development of internal with external resources to realise complementarities. Developing and maintaining the fit of internal and external resource collections enables ventures to harness unique services and complementarities in ecosystems.

The resource level of Industrial Marketing and Purchasing's Activity-Resource-Actor model (Håkansson \& Johanson, 1992) is built on Penrose's (1959) perspective of the firm and provides a conceptual framework for a resource dimension of the BM concept. The Industrial Marketing and Purchasing Group defines resources via a set of attributes. First, resources are not free in supply and thus access to and control of resources is pivotal (Håkansson \& Snehota, 1995, p. 132). Second, the value of resources depends on how they are combined and interact with other resources inside and outside of ventures (Håkansson \& Waluszewski, 2002; Håkansson et al., 2009, p. 69). Finally, through the process of interactions resources are "changed, recombined, developed, used and re-used" (Håkansson et al., 2009, p. 66) over time.

The resource propositions outlined reflect the three critical aspects of resources in the BM context. The resource scarcity highlights the importance of access to and availability of resources. The heterogeneity in use of resources emphasises that interactive nature of resources that can be embedded in multidimensional contexts (Håkansson \& Snehota, 1995). Finally, the interaction of firms' idiosyncratic resource collections facilitates joint learning about how to combine and configure resources and develop and adapt them over time (Håkansson, 1982, 2015).

To explicate, resource collections are defined as different types of resources obtained from various sources and "tied together by a company" (Håkansson \& Snehota, 1995, p. 133). While some resources within BMs' resource collections are owned by the ventures, access to external resources must be secured via relationships with other actors. The development of strong relationships has been considered as "essential for drawing upon complementary resources (Munksgaard \& Medlin, 2014, p. 613). The type and amount of resources a BM can 
mobilise will affect its capabilities, efficiencies in use of resources and thus the scope of VCC mechanisms over time (Håkansson \& Snehota, 1995, p. 142).

Håkansson and Snehota (1995) outlined that firms have to consider not only how they use available resources but also how they are used by others as providers of resources. Interactions with other actors enable the use of resources and their combinations via resource ties that affect the value of resources (Håkansson \& Snehota, 1995, p. 146). Håkansson and Snehota (1995) emphasised that "the potency of the resource collection of a company depends on how it is tied into those of others" (p. 137). Consequently, interactions with other actors are pivotal in two ways, (a) the combination of BMs' resource collections and (b) the interdependencies of firm's resource collections and resource ties with actors. In short, the development of ventures' BMs is dependent on the resources they can mobilise via interactions with other actors in its ecosystem.

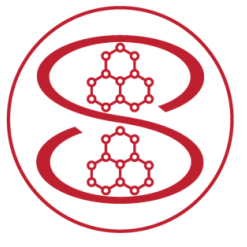

Resource ties facilitate the combination of resource collections enabling actors to acquire and access resources, develop and combine internal with external resources, and thus represent the resource layer of interactions. Resource ties result from resources' mutual orientation towards each other over time via resource interfaces (Håkansson \& Snehota, 1995, p. 30). Resource interfaces can be differentiated by physical (tangible) and organisational (intangible) interfaces. While the former refer to how resources are combined with each other, the latter are made up of "combinations of competence, skills and economic reasoning by the involved companies and organizations" (Bengtson \& Håkansson, 2008, p. 22). Resource interfaces allow for insights into resource interactions and thus their development over time. In short, resource ties are characterised by resource interfaces and describe and explain what, how, and why combinations of resources affect the development of BMs.

Forming resource ties requires ventures to learn about how to use, provide, and develop resources (Håkansson \& Snehota, 1995). While single actors can learn through experimentation, multiple actors can tap into each other's knowledge and experience as well as foster joint learning based on actors' accumulated knowledge and joint experimentation. As several resources are provided by actors, taking advantage of others' knowledge in the use of resources seems natural (Håkansson \& Snehota, 1995, p. 140). The more stability and 
variety BMs' resource collections provide, the more favourable is the environment for coordinated and joint learning over time. In sum, interactions with ecosystem actors allow ventures to leverage external knowledge of how to create resource ties and subsequently effective resource collections.

Overall, resource ties connect heterogeneous resource collections. The intensity and broadness of interactions and related interfaces is crucial for the use and development of resources. Håkansson and Snehota (1995) argued that "the borderline between internal and external resources becomes blurred" (p. 136) and emphasised the boundary-spanning nature of BMs' resource dimension (Demil et al., 2015). Figure 15 illustrates how BMs' resource collections can be structured and organised via resource ties. Although the use and provision of resources allows for a categorisation in internal and external, BMs can mobilise resources from all four fields. In short, ventures have to develop and maintain resource collections that 
The resource layer of the ARA-model provides a framework to investigate what and how resources are combined in BMs, how resources' services are accessed, and how the fit of resource collections are developed and maintained (Håkansson \& Snehota, 1995; Håkansson et al., 2009). The mobilised resources define the scope of what BMs can do and thus provide the foundation for BM activities (Håkansson \& Snehota, 1995, p. 142; Demil et al., 2015; Teece, 2018).

\subsubsection{Indicator Level - Business Model Actors}

Actors perform various functions in the BM concept and are considered integral components. Scholars have stylised actors as members of sectoral innovation systems (Mangematin et al., 2003), belief hierarchies (Tikkanen et al., 2005), sociological networks (Doganova \& Eyquem-Renault, 2009; Demil \& Lecocq, 2015), value systems or networks (Shafer et al., 2005; Demil \& Lecocq, 2010), ecosystems (Frankenberger et al., 2014), or as stakeholders (Amit \& Zott, 2015; Tantalo \& Priem, 2016). The heterogeneous theories employed to underpin BM actors diverge in their foci of analysis from individuals and teams of entrepreneurs and managers (Morris et al., 2005; Svejenova et al., 2010; Velu, 2017) over technologies (Doganova \& Eyquem-Renault, 2009; Demil \& Lecocq, 2015), to organisations (Casadesus-Masanell \& Ricart, 2010; McNamara et al., 2013), corporations (Aspara et al., 2013) and networks (Frankenberger et al., 2014). Although the theoretical plurality is intellectually stimulating, it poses significant conceptual challenges. Since this thesis focuses on the development of BMs, actors are defined as organisations that co-evolve in ecosystems over time.

Customers, suppliers, partners, and complementors engaged in VCC mechanisms are frequently listed as actors in the BM concept (Klang et al., 2014). Chesbrough and Rosenbloom (2002) argued that BMs describe value networks as "linking suppliers and customers, including identification of potential complementors" (p. 534). Likewise, Nenonen and Storbacka (2010) outlined that the BM concept has been used to "explain how firms interact with suppliers, customers, and partners" (p. 45). Finally, Zott and Amit (2013) emphasised that BMs include stakeholders with which the ventures interact to co-create and capture value. In short, actorhood has been attributed to actors that are engaged in BMs' VCC 
mechanisms, usually via performing activities and/or providing resources.

Nevertheless, the understanding of actors in BMs often transcends contributions to VCC. By selecting customer segments, ventures choose their competitors (Hedman \& Kalling, 2002), competitive dynamics influencing margins, and in turn the viability of their BMs (C. Baden-Fuller \& Haefliger, 2013). While indirect in nature, competitive interactions can severely affect VCC and as a result BM development. Moreover, competitors' BMs can provide guidance, templates, and direction for BM development (Amit \& Zott, 2015; Mikhalkina \& Cabantous, 2015). For instance, the market entry of low cost carrier airlines, such as Ryanair in Europe, has triggered competitive responses from other incumbent airlines ranging from minor changes in their BMs to the setup of low-cost carrier subsidiaries (Fageda, Suau-Sanchez, \& Mason, 2015).

Similarly, regulators can be considered as pivotal actors (Sosna et al., 2010; Amit \& Zott, 2015; Cortimiglia et al., 2016; Wirtz et al., 2016). Frankenberger et al. (2014) noted that external factors such as regulatory changes influence the development of BMs. Saebi et al. (2017) even argued that regulatory authorities are more relevant than technological and market-related forces. For example, changes in regulations regarding the length of short-term rentals has significantly affected AirBnB's VCC mechanisms (Palombo, 2015). In contrast, new privacy data regulations in the financial services sector provide ample opportunities for the development of innovative BMs (Zachariadis \& Ozcan, 2017). In conclusion, regulators and how they apply legislation can create threads as well as opportunities for BM development.

While competitors and regulators are not directly engaged in VCC mechanisms, their actions can affect them. Despite the absence of direct interactions, ventures can indirectly interact with this type of actors in ecosystems via competitive responses or participation in lobbying movements. Finally, investors and financiers present a particular case of actors. While interacting directly with ventures, they do not engage in VCC mechanisms. However, investors can provide vital resources such as human capital, competences, or established industry networks and thus push the boundaries of VCC mechanisms (Mangematin et al., 2003; Sabatier et al., 2010; Gerasymenko et al., 2015). Investors' wide spectrum of engagement deserves special attention.

Overall, actorhood in BMs can be attributed to the impact on VCC mechanisms. Similarly to the classification of stakeholders along the domains of power, interest and the 
legitimacy of their claims (R. K. Mitchell, Agle, \& Wood, 1997), the impact of actors can be defined via their (a) engagement in and/or (b) ability to push, set, or limit boundaries of VCC mechanisms as illustrated in Figure 16. Actors such as customers, suppliers and complementors can have a wide range of impacts as their engagement and ability to set boundaries can be insignificant, such as providing commodities, as well as unique resources, like granting access to vital intellectual property (Mangematin et al., 2003; Björkdahl, 2009; Sabatier et al., 2010). In contrast, competitors, regulators, and investors for example can be located in the left sectors of the impact matrix (Figure 16) since they hardly engage in VCC mechanisms but have the ability to delimit or enable them. The impact matrix can be employed to classify actors, their functions and how interactions with them can influence the BM development process.

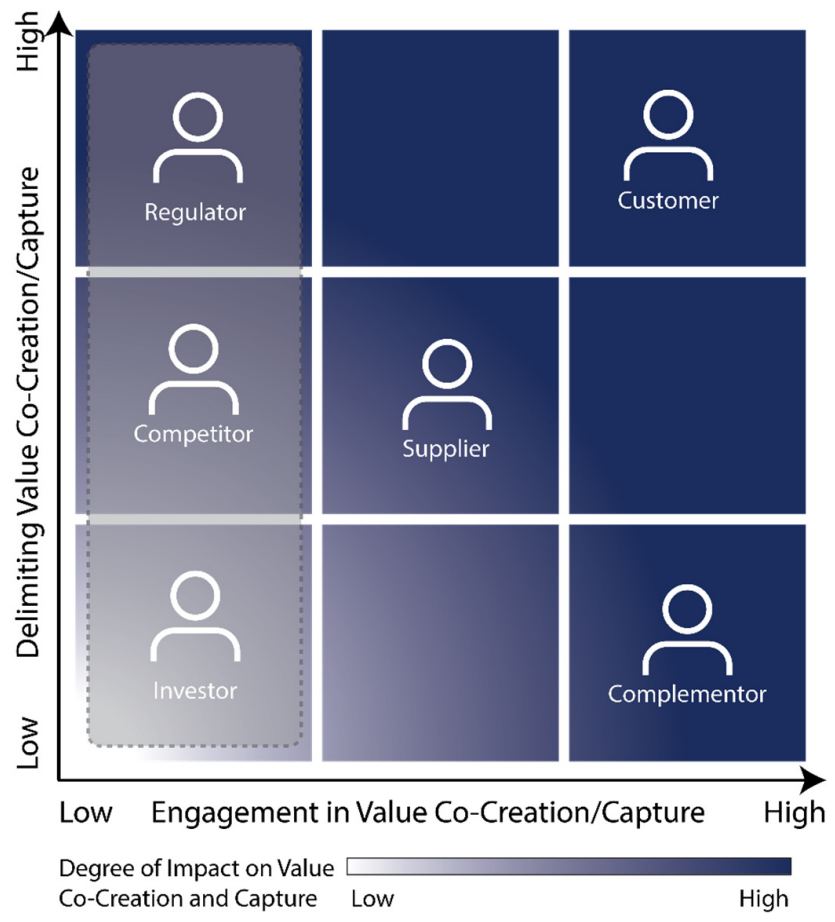

Figure 16 - Business Model Actors Classification

Since actors' actions can significantly affect VCC mechanisms, they are often considered as drivers of change in ecosystems (Figure 8, p. 34). Changes to ventures' or actors' $\mathrm{BM}$ components often require bilateral alterations due to the interdependencies of activities and resources (Casadesus-Masanell \& Ricart, 2007; Zott \& Amit, 2013; Saebi et al., 2017). 
Thus, BM development is an inherently ecosystem-centric and interactive process (Hamel, 2002; Shafer et al., 2005; Lecocq, Demil, \& Ventura, 2010; Massa et al., 2017). Wirtz et al. (2016) emphasised the argument by outlining that "the modification of a business model, or only certain parts, elements or components via continuous interactions of the respective firms' key actors ... can lead to changes of particular routines, structures, practices and finally the underlying business model over time" (p. 46). In a similar vein, Fjeldstad and Snow (2018) acknowledged that "firms increasingly work with their customers, suppliers, and partners when altering the elements of their business models" (p. 36). While triggers of change can originate inside or outside ventures, the iterative BM development process is inherently interactive.

Enrolling actors in BMs has been considered as critical for overcoming the liability of newness, providing access to vital resources, granting legitimacy as actor in ecosystems (Stinchcombe, 1965; Drori \& Honig, 2013) and thus increases ventures' chances of survival (Überbacher, 2014; Burns et al., 2016; Bojovic et al., 2018). By onboarding a first stakeholder a critical legitimacy threshold can be reached which facilitates the enrolment of others (Amit \& Zott, 2015). Fisher et al. (2017) argued that enrolling actors in BMs facilitates interactions and signals approval in "stakeholder environments of organizations that are increasingly complex and heterogeneous" (Fisher et al., 2017, p. 53). In a similar vein, Sosna et al. (2010) noted that "new business models must be externally validated, as well as being consistent with the internal facet of the organisation" and highlighted the importance of the approval of actors for the development process. In short, enrolling and obtaining commitment from actors legitimises a developing BM and provides identity as an acknowledged actor in an ecosystem.

Moreover, enrolling and engaging sets of actors such as suppliers, customers, and partners defines BMs' ecosystems (Lecocq et al., 2010). Hedman and Kalling (2002) outlined that "the interface towards customers and suppliers and possible alliance partners is a key issue" and "managing the relations is absolutely central" (p. 119). Similarly, Zott and Amit (2007) argued that delineating how new businesses transact with suppliers, customers, and partners is central to BM development. Finally, Demil et al. (2015) outlined that "through the choices of economic actors (suppliers, consumers, partners), the business model selects the environment in which the firm operates endogenous of its activities" (p. 4). Bonds established 
with actors define ventures' ecosystems and in turn the viability and currency of VCC mechanisms (Klang et al., 2014; Wirtz et al., 2016; Massa et al., 2017).

However, Casadesus-Masanell and Heilbron (2015) argued that "firms do not have unrestricted authorities over their interactions with other market agents; they must appeal to the self-interest of others to facilitate those transactions" (pp. 10, 11). Tantalo and Priem (2016) further outlined that coordinating several multi-attribute utilities allows to create actor synergies that "help to clarify and extend business model value determinations and thereby move beyond more typical firm-level performance measures" (p. 326). Therefore, ventures need to develop, maintain and coordinate value propositions that are attractive for other actors to sustain their engagement in VCC mechanisms.

Developing and maintaining an understanding of what constitutes engaging value propositions requires an awareness of other actors, their intentions, and interactions in the ecosystem (Payne et al., 2017). Nenonen and Storbacka (2010) argued that BM actors assess their fit via "similarities in business logics or the compatibility of value propositions" (p. 54). Likewise, Snihur, Reiche, and Quintane (2017) emphasised that engaging external actors is critical as they provide much-needed feedback for BM development. Actor bonds allow ventures to develop an understanding of actors' interests, bridge the internal organisation with external demands, and balance all actors' goals in VCC mechanisms (Sabatier et al., 2010; Amit \& Zott, 2015). In short, actor bonds can yield crucial insights into developing and maintaining compelling value propositions.

Finally, actor bonds yield insights about actors' capabilities and opportunities for ventures to acquire new capabilities. Frankenberger et al. (2014) noted that "strategic alliances and partnerships facilitate the learning of new competencies" (p. 180). Similarly, Teece (2018) summarised that "good business model design requires deep knowledge of customer needs and the technological and organisational resources that might meet those needs" (p. 48) acquired by developing and coordinating ventures' and actors' resources. In conclusion, actor bonds allow ventures to develop an understanding of actors' capabilities, how they can be leveraged in BMs, and yield opportunities to acquire new capabilities.

The knowledge about actors and their capabilities acquired via actor bonds has been considered as quintessential for the BM development process. In addition to understanding how to engage with actors and leverage their capabilities in BMs, knowledge about them 
allows to anticipate actions and reactions to BM exploration and refinement processes and thus provides a substantial advantage in the BM development process (Teece, 2010; Amit \& Zott, 2015). Cortimiglia et al. (2016) emphasised that "BM dynamics involve monitoring and identifying uncertainties that can impact the BM, anticipate potential consequences of external and internal change and proactively act" (p. 416) in the process. While the spectrum of actors' responses to experimentation can be broad, in-depth knowledge of actors, their roles in ventures' BMs, and how they are engaged in VCC mechanisms mitigates the risks of unintended and unfavourable retaliation. In addition, actors such as customers, suppliers, complementors, competitors, regulators, and investors can drive changes of ventures' BMs due to their engagement in or ability to delimit VCC (Björkdahl, 2009; Saebi et al., 2017). Knowledge about why, how, and when actors change their BMs provides an opportunity to influence and shape the development in ventures' favour (Winter \& Szulanski, 2001; Demil \& Lecocq, 2010; Schneider, 2017). In short, establishing and maintaining bonds with actors allows firms to obtain knowledge about them and thus provides an advantage in the BM development process.

In conclusion, actor bonds perform three critical functions in developing BMs. First, the bonds created with actors signal commitment to engage in the VCC mechanisms and legitimise BMs (Shafer et al., 2005; Doganova \& Eyquem-Renault, 2009; Amit \& Zott, 2015). Second, bonds created with actors position ventures' BMs within an ecosystem and thus define their identity and potential development paths (Chesbrough \& Rosenbloom, 2002; Morris et al., 2005; Sabatier et al., 2010; Wirtz et al., 2016). Third, bonds created with actors facilitate inter-organisational learning, capability development, and provide a repository for knowledge (Gulati, 1999; Dyer \& Hatch, 2006) that has been considered as paramount for successful BM development (Petrovic, Kittl, \& Teksten, 2001; Calia, Guerrini, \& Moura, 2007; Sosna et al., 2010; Massa et al., 2017). In short, firms need to build capabilities to identify potential partners, negotiate and manage agreements, and know when to enhance or end collaborations to develop and sustain a firm-ecosystem fit. 


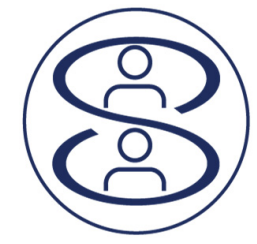

The actor layer of the ARA-model provides a framework for understanding the interdependencies of actor bonds and how they influence BMs' legitimacy, position in the ecosystem, and facilitate inter-organisational learning. Håkansson and Snehota (1995) defined organisations as "a 'mental construction' by people who get together - organise their activities - in order to overcome their individual limitations in resource terms" and that they "depend for their survival and growth on exchange with others" (p. 195). The interaction process that facilitates exchange gives rise to actor bonds that "connect actors and influence how the two actors perceive each other and form their identities in relation to each other" (Håkansson \& Snehota, 1995, p. 27). Being perceived by others as a distinct and intelligible entity allows organisations to acquire identity in the eyes of others (Håkansson \& Snehota, 1995, p. 195).

In contrast to economic literature, actors within the ARA-model are "a product of their bonds and never completely free" (Håkansson \& Snehota, 1995, p. 194). Håkansson et al. (2009) outlined that "how and to whom an actor becomes related has important consequences for how it is seen, how it can behave, what it can accomplish and how it can and will develop" (p. 139). Hence, "bonds determine the identity of companies " and are "an integral factor of an actor's capability to interact with and to others; they are thus important for an actor's development and performance" (Håkansson \& Snehota, 1995, p. 194). The perception of actors' actions and reactions result in the formation of intentions and attributes and thus an actors' identities as well as trust and commitment in relationships (Håkansson \& Snehota, 1995, p. 197). Håkansson and Snehota (1995) summarised that actor bonds are necessary "in order to acquire meaning, being considered, in other actors' perceptions and behaviours" (p. 202) and mobilise other actors. In short, establishing bonds with other actors provides ventures' BMs with legitimacy and thus the ability to mobilise other organisations as actors in VCC.

Håkansson and Snehota (1995) outlined that "no company can develop a relationship, and much less to acquire a position within a business network, independently of a least some others" (p. 203). Relating to a limited number of actors makes actors into what they are, determines the possibilities and constraints in the ecosystem and in turn characterises their development (Håkansson et al., 2009, p. 144). Since firms engage simultaneously in multiple relationships and form bonds that require adaptions and are often not easy to change, they 
"make the position of an actor in the web of bonds unique" (Håkansson \& Snehota, 1995, p. 200). Hence, actor bonds have an organising effect within ecosystems and often define actors' possibilities (Håkansson \& Snehota, 1995, pp. 199-200). Moreover, as businesses develop and emerge via relating their own to their counterparts' resources and activities towards each other over time, they have to co-evolve with others (Håkansson et al., 2009, p. 144). Coevolution is a process that is driven by the desire to improve technical performance, economic efficiency and compliance and is underpinned by mutual learning. Håkansson et al. (2009) outlined that within ecosystems new actors are born, change shape, and dissolve and concluded that "no company in a business network is immune from this continuous metamorphosis" (Håkansson et al., 2009, p. 146). In conclusion, actor bonds define ventures' positions within ecosystems and can significantly influence their BM development process.

Actor bonds are considered as the mechanisms through which companies learn about their environment, acquire specific characteristics and capabilities, and develop over time (Håkansson \& Snehota, 1995, pp. 201-202). Bonds allow actors to "acquire some, but never a complete knowledge of the resources, activities and intent of its counterparts" (Håkansson et al., 2009, p. 139) "or anticipate the behaviour of all other actors" (Håkansson et al., 2009, p. 141). Hence, as actors' ability to anticipate effects of interactions is limited by the knowledge of other actors, their autonomy to act and react becomes restricted (Håkansson et al., 2009, p. 139). Moreover, since knowledge and competencies develop and change through interactions during which new problems, opportunities and solutions are discovered, it can never be complete and there is always potential for development (Håkansson et al., 2009, p. 141). Furthermore, actor bonds allow ventures to identify trends and tendencies in ecosystems and leverage them in their development (Håkansson \& Snehota, 1995, p. 201). Håkansson et al. (2009) summarised that actor bonds impinge on an actor's knowledge and capabilities as its "knowledge and intent about combining activities, resources and actors are directly related to its specific counterparts and the bonds it has with them" (pp. 142, 145). Actor bonds facilitate inter-organisational learning that has been considered as pivotal for the survival and performance of ventures in ecosystems.

Overall, the actor layer of the ARA-model addresses the three critical functions of actor bonds in BM literature. Firms acquire legitimacy and identify via actor bonds and the actors they are associated with in ecosystems. Second, actor bonds provide a structure for 
ecosystems and characterise how BMs are embedded in it. Finally, actor bonds facilitate the acquisition of knowledge about other actors and in turn drive and/or participate in the coevolution of ecosystems.

\subsubsection{Indicator Level - Summary, Conceptual Model, Key Concepts}

Value propositions were employed to contextualise VCC mechanisms' development and in turn how ventures explored opportunities in ecosystems. Additionally, emerging activity, resource, and actor interdependencies further underpinned the development of viable VCC mechanisms. Due to the emergent nature of value propositions and interdependencies, ventures have to conceptualise, explore, and consolidate BMs to develop a firm-ecosystem fit (Zott \& Amit, 2013; Saebi et al., 2017; Foss \& Saebi, 2018). Following from this, BMs can be defined as emergent configurations of interdependent value propositions, activities, resources and actors that are developing in ecosystems over time. They can be used to describe, explain and explore how firms co-create and capture value.

Describing and explaining the BM development process requires a framework that accounts for the scale of actors and the depth of respective integrations developed. Consequently, an integration-exploration matrix is proposed (Figure 17) to elicit the dynamic development process. Figure 17 illustrates a venture that continuously developed medium depth integrations with an accelerating number of partners. For instance, a venture offering sensors for autonomous cars that cooperates with a tier-one automotive supplier to provide solutions for car manufacturers continuously extends and intensifies development activities, manufacturing resources, and actor bonds to create a firm-ecosystem fit. Since the venture seeks to maintain its independence for future developments it might only offer modular sensors and a customisation service and thus does not fully integrate its activities, resources, and organisational structure with the tier-one supplier. 


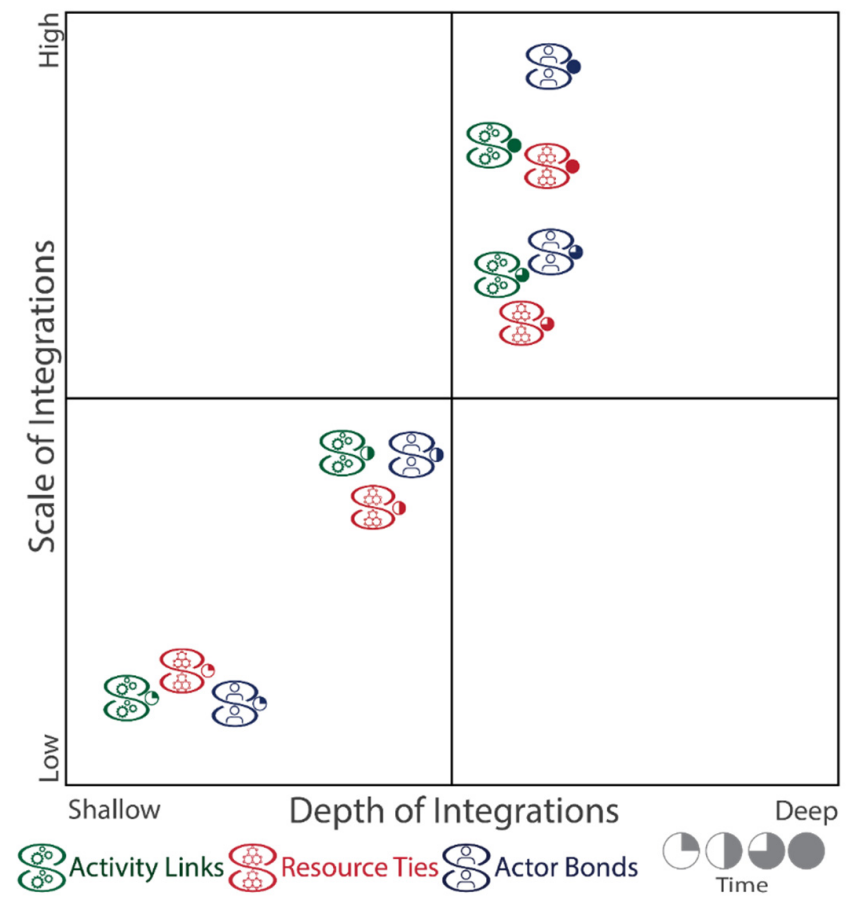

Figure 17 - Integration Exploration Matrix

The here proposed BM conceptualisation incorporates value propositions, activities, resources, and actors as well as the interdependencies between those components at the intersection of ventures and their ecosystems. Figure 18 summarises the basic, functional, and indicator level dimensions of the proposed BM conceptualisation.
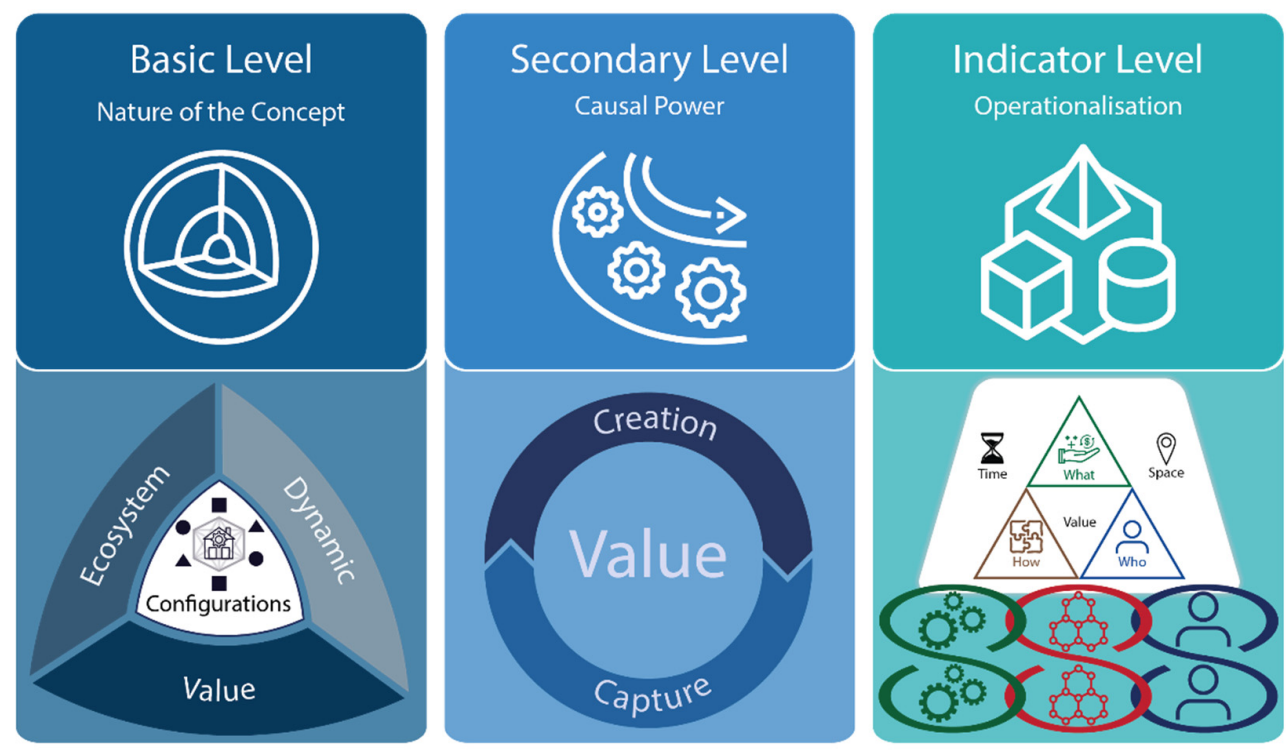

Figure 18 - BM Conceptual Levels Summary 
Combining the Value Exploration Matrix (Figure 13, p.47) and the IntegrationExploration Matrix provides a framework that can describe and explain the development of ventures' VCC mechanisms and the underpinning activity links, resource ties, and actor bonds over time. The proposed Value-Activities-Resources-Actors (VARA) model (Figure 19), can be employed to describe and explain how a firm-ecosystem fit is developed, maintained, and/or becomes obsolete. The VARA-model defines the relationships across its core components. As the fulcrum of VCC mechanisms, value propositions reside in the centre of the model and characterise all other components. The relationship between the activity, resource, and actor components have been further defined to facilitate the understanding of the concept. The VARA-model has been employed as a framework to describe, explain and explore how ventures developed viable BMs that are underpinned by a robust firm-ecosystem fit

The VARA-Model can be compared to the other BM and organisational design frameworks. Next to value chains (Porter, 1985), shops, networks (Stabell \& Fjeldstad, 1998; Fjeldstad \& Snow, 2018), constellation (Normann \& Ramirez, 1993), the actor-network theory comes to mind (Latour, 1996; Callon, 1999; Bijker, Hughes, Pinch, \& Douglas, 2012). The actornetwork theory has been employed by scholars to explain how narratives and calculations of BMs circulate across heterogenous audiences and gradually build "the network of the ventures that it represents" (Doganova \& Eyquem-Renault, 2009, p. 1560). The BM as a 'market device in action' that is materialised in documents and narratives and constantly evolves can provide insights into entrepreneurs' and other actors' process of sense-making (Doganova \& Eyquem-Renault, 2009; Furnari, 2015). Demil and Lecocq (2015) even extended that argument and pledged for a socio-material perspective on BMs as an emerging assemblage of artefacts.

In contrast to the actor-network theory (Law, 2009, p. 142), the VARA-model postulates that BM elements can have substance independent of the network of relationships they are embedded in. Although the VARA-model draws attention to the value and/or function that is assigned to individual elements as a product of the interdependencies with others, it does not conceptualise BMs as collectively perceived constructs. This epistemological difference sets the two frameworks apart. Second, the VARA-model does not ascribe agency to artefacts whereas the actor-network theory considers reality enacted by 
actors as well as objects (Latour, 1996). Finally, while the VARA-model accentuates the interdependencies on BM elements and actors in ecosystems, it allows for action to be an individual act and not mandatorily a collective process as in the actor-network theory (Muniesa, 2015). In conclusion, the VARA-model and the actor-network theory share commonalities, yet can be distinguished along different epistemological, agency and action stances.

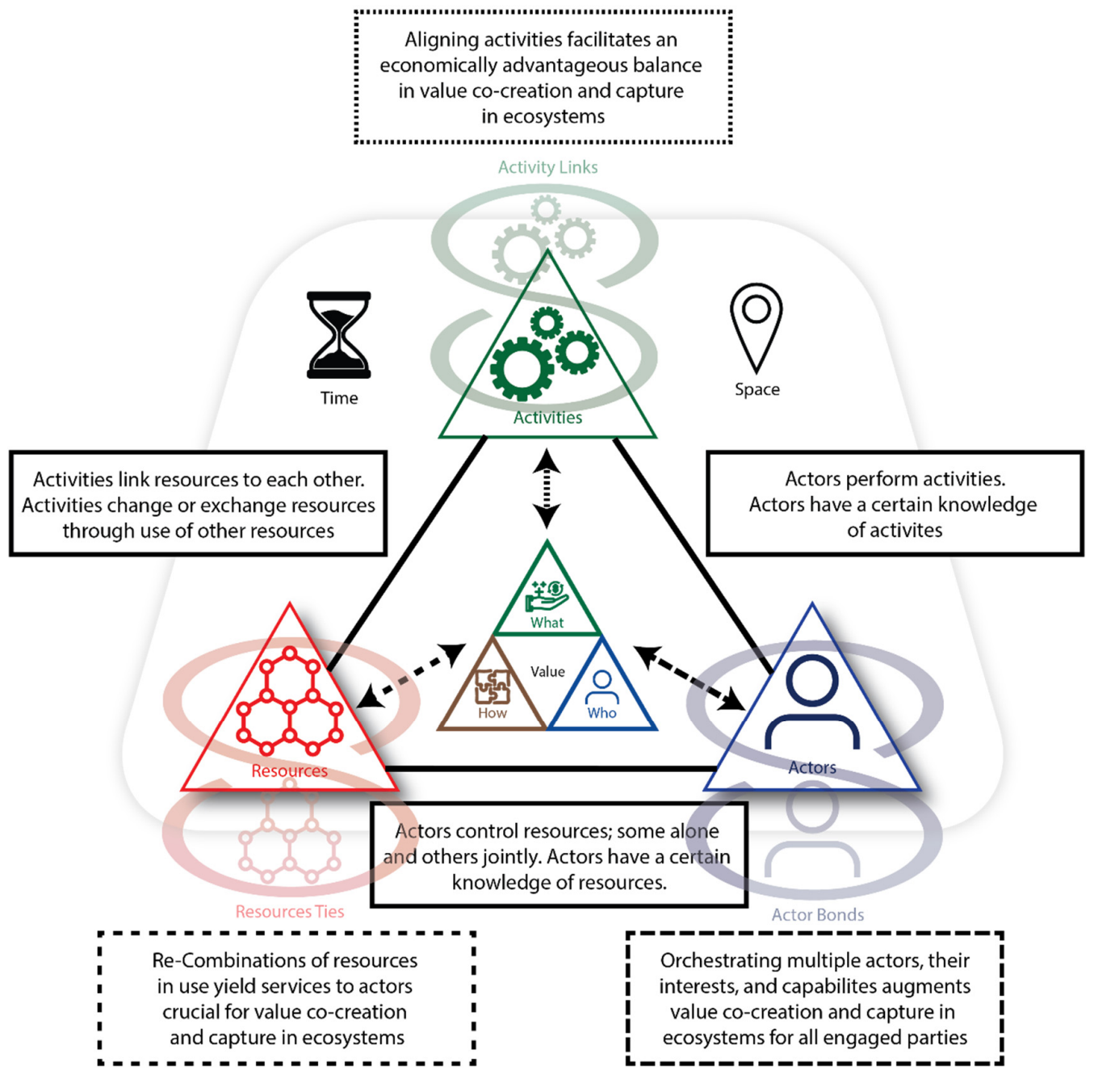

Figure 19 - VARA-Model 


\section{Research Approach}

\subsection{Chapter Introduction}

This chapter provides a detailed description of the research paradigm taken in this thesis project, the case study research approach applied, and subsequently of how the research questions were operationalised. Moreover, the selection criteria of the case studies as well as an overview of the investigated ventures is presented. Finally, data collection and analysis methods and procedures are described, followed by ethical considerations concerning the nature and confidentiality of the research conducted. Figure 20 provides an overview of the research approach, followed by detailed descriptions of each element. 

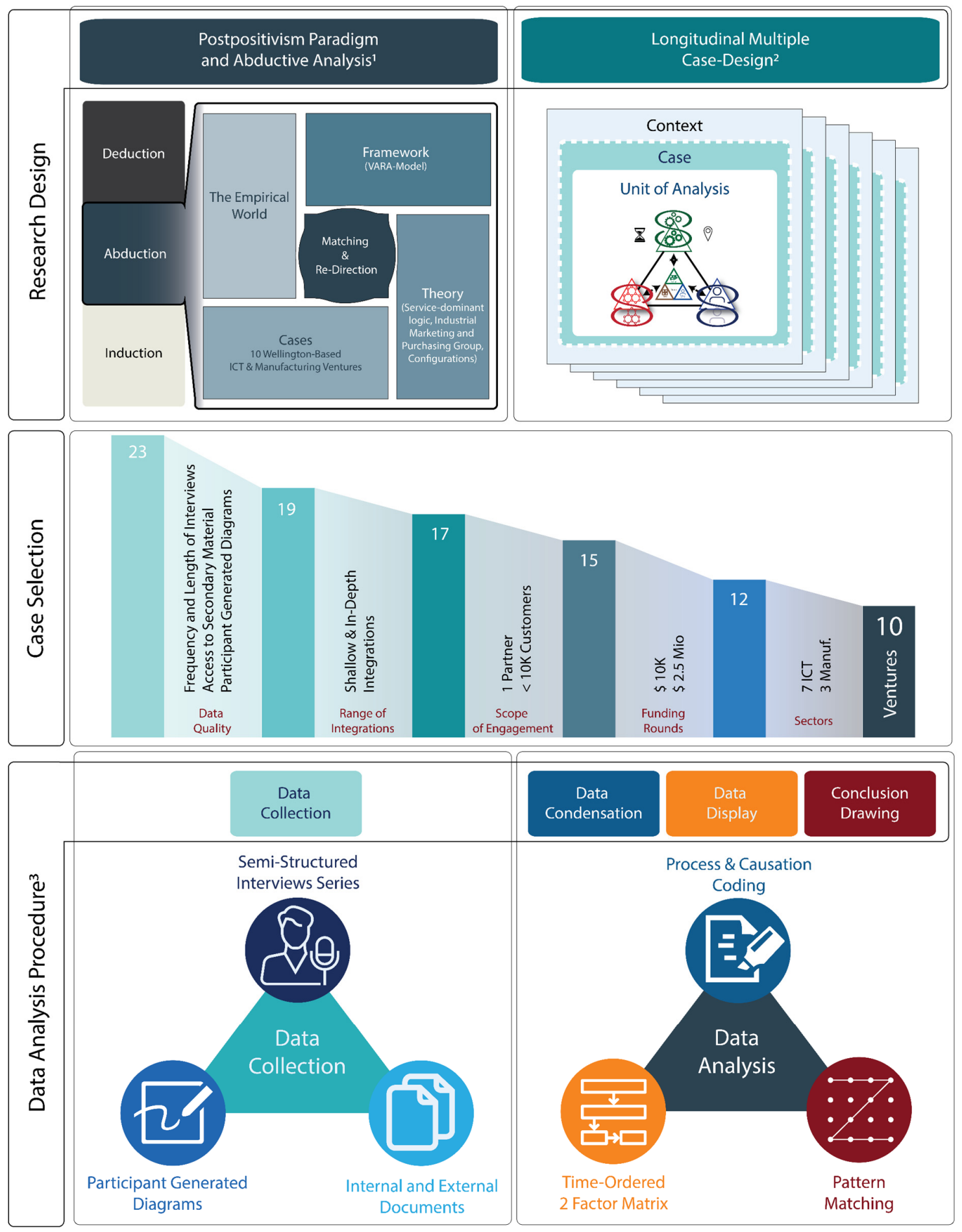

1 Research logic based on systematic combining (Dubois \& Gadde, 2002, 2014) 2 Basic Types of Designs for Case Studies (Yin, 2018) 3 Components of Interactive Data Analysis Model (Miles \& Huberman, 2014, p. 14)

Figure 20 - Research Approach Overview 


\subsection{Research Paradigm and Postpositivism}

The aim of science as a social activity is the production of knowledge of 'kinds and ways of acting of independently existing and active things' (Bhaskar, 2013, p. 14)

Research paradigms can be understood as "a net that contains the researcher's epistemological, ontological and methodological premises" (Denzin \& Lincoln, 2011, p. 13). While all approaches, ranging from scientific positivism at the one end to radical constructionism at the other, have merits, a postpositivist approach is appropriate to pursue this thesis' research objectives characterised by the complex interactions of ventures (S. Sharma \& Gutiérrez, 2010, p. 703). As a philosophical framework, postpositivism provides a middle ground between positivism and constructionism and addresses questions of ontology (concerned with the nature of reality), epistemology (what constitutes acceptable knowledge in post-positivist studies), and methodological approaches.

Postpositivism can be defined as the existence of an objective reality that is only imperfectly and probabilistically apprehendable (Denzin \& Lincoln, 2011, p. 98). Claims about reality are built on the conjunction of the existence and independence premises. The former premise implies that a certain domain with distinctive facts and entities exists (Niiniluoto, 1999, p. 26; Johansson, 2014) that can be discovered by means of scientific enquiry rather than constructed (Brock \& Mares, 2007, p.34). While this paradigm is predominant in natural sciences, investigations in social sciences require human-dependent non-physical entities, such as BMs, as a causal product of the existence and intentional as well as unintentional activities of humans and their minds (Sayer, 1999, p. 34; S. Sharma \& Gutiérrez, 2010). The interactions of humans and their minds create inescapably a social reality with objective entities and facts. This process can happen on purpose as well as unintentionally and does not require our knowledge of it. Thus, the existence of a phenomenon is independent of our knowledge or recognition of it as emphasised by the independence premise (Brock \& Mares, 2007, p. 38). In short, postpositivism allows for an understanding of social realities that are constructed but characterised by distinct objective facts (Teddlie \& Tashakkori, 2009, p. 69).

In contrast to positivism, postpositivism emphasises that empirical 'objective' evidence is only of limited utility in scientific evaluation appraisals (Lapid, 1989, p. 240) since 
knowledge is relative and shaped by cognition, social and cultural factors, and symbols and their interpretations (B. Sharma, 2010, p. 702). Consequently, different 'truths' or perspectives contextualised in cultural, historical, and ideological orientations and experiences fail to provide a universalistic and cumulative account (Ogbor, 2000). Moreover, since the complexities of human behaviour often inhibit the isolation of cause and effect relationships, postpositivist research methods rely on the triangulation of evidence and methods to counteract problems of validity and bias on the production of knowledge (B. Sharma, 2010). In short, absolute truth can never be found as empirical evidence is imperfect and fallible and thus is the knowledge that can be obtained from it (Teddlie \& Tashakkori, 2009, p. 69; Creswell, 2013, p. 7). Consequently, researchers advance theories by abduction (Figure 24, p. 91), an iterative process of making claims, refinements or abandoning the claims (Creswell, 2013, p. 7).

The ontological and epistemological postpositivist stance is open to a wide range of research methods. The postpositivist strand accommodates quantitative as well as qualitative research methods and combines the merits of both (Patton, 2002; Creswell, 2013). Overall, S. Sharma and Gutiérrez (2010) summarised that "postpositivism assumes an intersubjective world where reality is a social construction and the aim of research is to uncover the meaning of this reality as understood by an individual or a group" (p. 702)

The BM development process is characterised by a complex, dynamic, and emergent nature resulting from the interplay of components, contexts, and their interdependencies (Klang et al., 2014; Massa et al., 2017). Thus, the postpositivist paradigm allows for causalities of social interactions that mutually create and shape the social realities of the processes as understood by entrepreneurs (Tikkanen et al., 2005; Furnari, 2015). Accommodating the multiple individual and temporal contextualised perspectives is considered to be crucial for developing an understanding of the multi-faceted process of BM development .

Moreover, the postpositivist paradigm embraces triangulation in the research process (Guba \& Lincoln, 1994). By triangulating theories and sources of evidence, the postpositivist stance augments the advancements of theories and accounts for validity and reliability of the claims to knowledge (Phillips \& Burbules, 2000). The entailed methodological flexibility allows for the assessment of the causal effects of interactions and interdependencies in conjunction with the analysis of the viability of developing BMs (Casadesus-Masanell \& Ricart, 2007; Zott 
\& Amit, 2007). Overall, revealing the complex intertangled subtleties and causal interdependencies of the BM development process can be facilitated via the postpositivist stance that allows the incorporation of multiple perspectives on the process.

\subsection{Qualitative Research}

The dynamic BM concept perspective has gained traction and research efforts have provided important insights for theory development in recent years. However, existing research on the BM development process has been unstructured and primarily of conceptual nature (e. g. C. M. Baden-Fuller, Vincent, 2015a; Wirtz et al., 2016; Ritter \& Lettl, 2018), based on secondary data (e.g. Shafer et al., 2005; Casadesus-Masanell \& Ricart, 2007), single case studies (e.g. Doz \& Kosonen, 2010; Sosna et al., 2010; Demil \& Lecocq, 2015) or focused on large corporations (Aspara et al., 2013; Saebi et al., 2017; Schneider, 2017). Since important variables remain unknown, the phenomenon of BM development requires further exploration. Therefore, the study design has to maintain flexibility to allow for research to "unfold, cascade, roll and emerge" (Lincoln \& Guba, 1985, p. 210) and elicit tacit knowledge of unstructured processes in organisations, delve in-depth into complexities of ecosystems and seek to explore why and how interactions and interdependencies influence the development of viable BMs (Marshall, 2006, p. 53). Ghauri and Grønhaug (2005, p. 202) argued that when prior insights about a phenomenon under scrutiny are modest and thus present an 'unstructured' problem, an explorative and flexible qualitative research design is regarded as adequate. Likewise, Creswell (2013) outlined that if "a phenomenon needs to be understood and explored because little research has been done on it, then it merits a qualitative approach" (p. 20). Finally, Patton (2015) summarised that obtaining in-depth insights into how systems are functioning, documenting diversity in contextual factors that explain particular variations such as equifinality, and revealing patterns and themes across cases favours a qualitative research approach. In conclusion, a flexible and explorative qualitative research method can be considered as appropriate to reveal the complex causalities and contextual contingencies of the BM development process in ecosystems. In turn, quantitative research was rejected because of the difficulties to operationalise contextual factors and aspects of development paths over time and due to limitations 
regarding the depth of data collection.

The selection of an adequate qualitative research method depends on three criteria; the type of research question posed, the extent of control, and the degree of focus on contemporary or historical events (Yin, 2014, p. 8). First, Saunders, Lewis, and Thornhill (2009) and Yin $(2014$, p. 8) outlined that exploratory what- and how-questions, as proposed in this thesis, can be answered with case studies or surveys. Second, as the researcher has no influence on investigated BMs or ecosystems, experimental approaches are considered unfeasible. Finally, since the development of viable BMs can be regarded as a process, it is best observed in a series of contemporary events.

Amongst the three dominant qualitative research methods, namely grounded theory (Strauss \& Corbin, 1994, 1997), case studies (Eisenhardt, 1989; Eisenhardt \& Graebner, 2007; Yin, 2018) and process research (Langley, 1999; A. Langley, C. Smallman, H. Tsoukas, \& A. H. Van de Ven, 2013b), the nature of the research conducted speaks in favour for a case study research design.

Although BM theory and perspectives are heterogenous (Zott et al., 2011; Klang et al., 2014), they provide a foundation for advancing our understanding of how BMs emerge in ecosystems (Wirtz et al., 2016; Massa et al., 2017; Ritter \& Lettl, 2018). Consequently, a grounded theory approach would neglect previous theoretical and empirical contributions and further propel the fragmentation of the field (Demil et al., 2015; Täuscher, 2017). Likewise, the lack of variables, entities or attribute models in process research, which focuses on how events and activities are progressing, offers limited potential to spur integrative research (Van de Ven, 1992; A. Langley, C. Smallman, H. Tsoukas, \& A. Van de Ven, 2013a). In contrast, case study research incorporates existing frameworks and theories to guide the investigation and draws attention to the importance of identifying variables and causalities in the development process (Eisenhardt, 1989; Eisenhardt \& Graebner, 2007; Yin, 2018).

Moreover, grounded theory accentuates the variance in subjects' interpretivist perspectives (Gioia, Corley, \& Hamilton, 2013). Similarly, process research highlights the messiness of environmental variables, bringing about the outcome of a longitudinal process (Langley et al., 2013a). In contrast to the focus on the wide spectrum of environmental variance (Gehman et al., 2018), case study research seeks to control environmental factors and in turn derive an understanding of commonalities in processes and the underpinning 
causal relationships (Eisenhardt, Graebner, \& Sonenshein, 2016). Case studies focus on balancing variation, control and generalizability which reflects the aim of this project to advance our understanding of the causalities of strategic BM development in ecosystems and deriving a testable theory.

In sum, the case study approach appears like an appropriate theory-method fit for researching the strategic development of BMs in ecosystems. By acknowledging existing conceptual developments and empirical research as well as allowing new themes to emerge, the case study research approach gives way for an abductive development of theory (Eisenhardt et al., 2016; Gehman et al., 2018). Case study research often gives offspring to propositions that can be tested which in turn fosters the generalisability of emerging theories (Yin, 2018).

Although critics argue that incorporating existing theories and deriving propositions implies a positivistic approach (Piekkari \& Welch, 2018), the guidance and direction from previous and for future research is vital for the process of abduction (Dubois \& Gadde, 2002, 2014; Gadde, 2014). Yin (2018) as well as Eisenhardt and Graebner (2007) have drawn attention to the importance of emerging themes and rivalry theories in the process of abductive theory development. Consequently, case study research is deemed to be an adequate theory-method fit leveraging existing research and conceptual advancements for developing theory.

\subsection{Case Study}

Case study research designs have been widely used to develop an understanding of the BM development process (e.g. Sosna et al., 2010; Demil \& Lecocq, 2015; Bojovic et al., 2018). The essence of a case study is to elicit sets of decisions, why they were taken, how they were implemented, and with what results (Schramm, 1971). Thus, the case study research method allows to gain insights into the causalities and contingencies of the BM development process in ecosystems over time. Dubois and Gadde (2002) argued that "case studies provide unique means of developing theory by utilizing in-depth insights of empirical phenomena and their context" (p. 555). Eisenhardt and Graebner (2007) outlined that "case studies are rich, empirical descriptions of particular instances of a phenomenon that are typically based on a 
variety of data sources" (p. 25). Finally, Yin (2014, p. 18) emphasised that "a case study is an empirical inquiry that investigates a contemporary phenomenon in depth and within its reallife context, especially when the boundaries between phenomenon and context are not clearly evident". Since the ecosystem-centric BM perspective inhibits the demarcation of the concept from its context (Mangematin et al., 2003; Sabatier et al., 2010; Amit \& Zott, 2015;

Fjeldstad \& Snow, 2018), a case study research design can be considered as well-suited to investigate the BM development process.

This thesis followed an exploratory multiple case study approach to obtain meaningful characteristics and robust findings (Yin, 2014, p. 56; Patton, 2015). Yin (2014, p. 55) outlined that in the absence of identifiable subunits and a coherent nature of the underlying theory, as evident from the BM literature review (p. 22), a holistic case study approach should be preferred. Cases are considered as "specific, unique, bounded systems" (Stake, 2000, p. 436) and although this research concentrates on subunits of interactions and interdependencies, the effects on components and overall configurations require a focus on the whole BM as a unit of analysis. Although single case studies can provide rich and comprehensive understandings of phenomena, multiple case studies offer more robust evidence for analytical generalisations (Yin, 2014; Eriksson \& Kovalainen, 2015). While Easton (1995) argued that "researching greater numbers of cases, with the same resources, means more breath, but less depth" (p. 382), a focused investigation of multiple cases can yield in-depth insight into a specific phenomenon and enhances analytical generalisations. The selection of multiple cases follows a replication logic similar to multiple experiments (Hersen \& Barlow, 1976) to either predicting similar results (literal replication) or predicting contrasting results (theoretical replication) to allow for theory extension or rival interpretations (Yin, 2014).

\subsubsection{Outset and Research Questions}

Outlining a priory research questions and propositions has been considered as central for theory building in case study research. Eisenhardt (1989) emphasises the importance of the specification of a construct and questions to maintain a research focus and allow for the empirical grounded assessment in the case study protocol and interviews. Similarly, Yin (2014, p. 28) argues that case study research designs have to outline some study propositions to 
move in the right direction. The research questions as well as the theoretical framework, the VARA-model (Figure 19, p. 70) presented in the literature review, provided guidelines for the overall research design. The VARA-model serves as a means to explore the development process of BMs in dynamic ecosystems but allows for the maintenance of flexibility to incorporate emerging themes after the data collection and the development of contrasting theories.

\subsubsection{Unit of Analysis - The Business Model as a Case}

Defining the case, its boundaries, and thus the unit of analysis is regarded as paramount in case study research designs (Gerring, 2006; Gibbert, Ruigrok, \& Wicki, 2008; Yin, 2014). Demarcating the case focuses data collection and analysis and sets the stage for the theory building process (Eisenhardt \& Graebner, 2007). The BM concept's boundaries, as a unit of analysis, are ranging from individuals and teams (Svejenova et al., 2010), organizations such as SMEs (Furnari, 2015), corporations (Björkdahl, 2009) and sports teams or clubs (Demil \& Lecocq, 2010; McNamara et al., 2013; Aversa, Furnari, et al., 2015), corporations (Aspara et al., 2013), and even the wider society (Yunus, Moingeon, \& LehmannOrtega, 2010; Laasch, 2018) across the literature. Since the context of ecosystems and interactions with them is fundamental for the research conducted in this thesis, the BM concept and, thus, the unit of analysis, was defined as ventures' configuration of internal and external interdependent components that has been developed via interactions with other actors in ecosystems over a limited period of time.

While the nature of ecosystems implies an extensive contextualisation beyond what is ascertainable for ventures, it can be argued, in line with the definition of the unit of analysis, that direct and indirect interactions with components and actors that influence VCC mechanisms represent the boundaries of the case (Dubois \& Gadde, 2002). For instance, while logistic service providers, retailers and consumers are considered as actors in ventures' ecosystems, the logistic provider's subcontractor is considered as beyond the focal firm's ecosystem. A vast array of studies have embraced the here proposed 'narrow' ecosystem perspective to develop an understanding of the development of technologies (Utterback, 1994), innovations (Bower \& Christensen, 1995; Christensen, 2013), platforms (Eckhardt, 
Ciuchta, \& Carpenter, 2018), and firms (Gadde, 2014).

In conclusion, the unit of analysis and its boundaries are represented by and reflected in the VARA-model. The textured area in Figure 21 comprises the focal firm's BM and the narrow ecosystem of interdependent other BMs incorporating inherent value propositions, activities and activity links, resources and resource ties and actors and actor bonds. It illustrates the unit of analysis and its boundaries. As a result, the narrow ecosystem, i.e. BMs that the focal firm's BM relates to, is incorporated in the unit of analysis. However, the wider ecosystem, i.e. BMs that the focal firm's BM does not directly relate to, is not part of the unit of analysis. Despite the narrow ecosystem perspective, the study's focus is on how emerging interdependencies shape the focal firm's BMs. The VARA-model provides a bridging conceptualisation of a focal firm's BM and how it interacts with other actors' BMs. Thus, the boundaries of the case are defined by value propositions addressed to actors as well as direct activity links, resource ties and actor bonds.

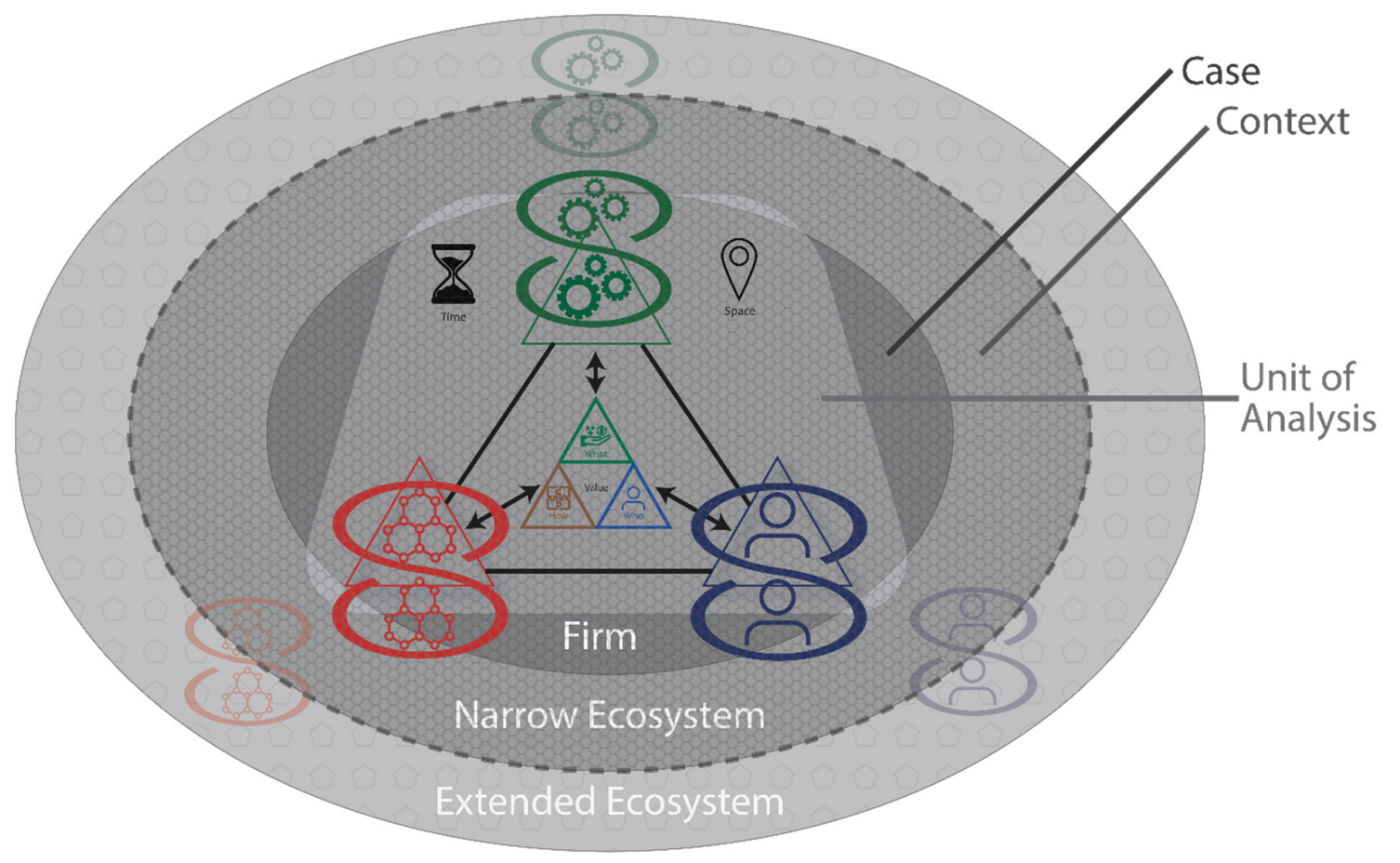

Figure 21 - Unit of Analysis

Defining developing BMs within the boundaries of narrow ecosystems as a unit of analysis poses a temporal conceptual challenge (Dubois \& Gadde, 2002). The inevitable 
question comes to mind; when does a BM come into existence? McGrath (2010) outlined that "business models often cannot be fully anticipated in advance. Rather, they must be learned over time, which highlights the centrality of experimentation in the discovery and development" (p. 248) "to capture better how a given set of resources translates into something a customer is willing to pay for" (p. 249). In a similar vein, Demil and Lecocq (2015) noted that BMs require the development and emergence of artefacts, and chains of relationships they create, to become an organisational reality. Finally, Saebi et al. (2017) argued that "business models are subject to market tests" and "need to be modified in face of external discontinuities and disruptions" (p. 567).

Following from this, it can be argued that BMs develop when testing and experimenting validates or disqualifies BM designers' underlying assumptions ${ }^{6}$. The emerging set of interdependent components, validated through interactions with other actors in ecosystems, can be considered as a developing BM. On the one hand, a BM becomes real when first interactions with other actors are facilitated to create and capture value. However, only BMs that are able to sustain value creation and capture over time can be considered as viable (Bojovic et al., 2018). While the time-frame for sustained VCC can vary to an extensive degree from several months in small brick-and-mortar stores in emerging markets to several years in technology- and knowledge-intense industries, such as pharmaceuticals (Mangematin et al., 2003; Sabatier et al., 2010), the degree of experimentation and stability of interdependencies with ecosystem actors in configurations provides a proxy for viable BMs in early stages (Gerasymenko et al., 2015; Bojovic et al., 2018). Consequently, an observation time frame of nine to twelve months was considered as appropriate for the analysis.

Overall, the unit of analysis for this thesis has been defined as ventures' BMs that emerge due to interactions with other actors in ecosystems in a period of nine to twelve months. The unit of analysis as well as its boundaries have been defined via the VARAframework and the temporal component of nine to twelve months of an explorative trial-anderror learning and stabilization process.

${ }^{6}$ For a detailed discussion of the difference between BMs as intangible cognitive structures and tangible configurations please refer to chapter 2.4 .1 p. 20 


\subsubsection{Case Selection}

Patton (2015) emphasised that "case selection is the foundation of qualitative inquiry" (p. 264) and needs to be aligned with the inquiry's purpose, primary questions, and data being collected. As this thesis' aim is to develop an understanding of the underlying mechanisms that lead to the development of viable BMs in ecosystems, it follows a theoretical sampling approach (Eisenhardt, 1989). The selection of case studies combined a replication and comparison focused sampling logic. Selecting seven ICT and three manufacturing sector ventures allowed for a purposeful comparison and the moderation of sector specific BM factors (Eisenhardt \& Graebner, 2007).

Since BMs are argued to develop in an explorative process, ventures have been considered as organisations of particular interest. Morris et al. (2005) argued that in ventures' experimentation process, a number of core decisions are made that define the development path of BMs. Similarly, Sosna et al. (2010) emphasised the importance of learning in the context of dynamic environments in the BM experimentation. Finally, Brettel et al. (2012) noted that ventures are characterised by smaller firm size, low age, above-average growth rates, and uncertain environmental contexts. The lack of existing structures, resources, and legitimacy indicates that ventures are more likely to extensively explore and test BMs' possibilities (Bojovic et al., 2018). In contrast, BM innovations of incumbents are more likely to be characterised by path-dependency and a less explorative approach (Chesbrough \& Rosenbloom, 2002; Spieth et al., 2016; Saebi et al., 2017). As ventures are often characterised by a lack of organisation and structure, uncertainty in the ecosystem, and thus being highly dynamic in their BM exploration, they can provide valuable insights into the development process.

Data has been collected from 23 ventures located in the Greater Wellington area in New Zealand to allow for the control of environmental variations (Eisenhardt, 1989). Over the period of observation ${ }^{7} 20$ ventures engaged in BM exploration efforts and thus have been selected for preliminary analysis. The preliminary analysis supported the refinement of the set of ventures selected for detailed analysis. Based on the quality of data available (frequent interviews and access to secondary material), scope of integration with customers and other

\footnotetext{
7 January 2017 till April 2018
} 
actors (shallow and in-depth integrations), scale of engagements (enrolling a first partner [e.g. Pouakai] to onboarding more than ten thousand customers [e.g. Kārearea]), successful funding rounds (raising several thousand via crowdfunding and awards or a venture capital backed A-series raising several millions), and a balance of sectors (ICT and manufacturing) a set of ten ventures was selected. The selection process and criteria have been illustrated in Figure 22.

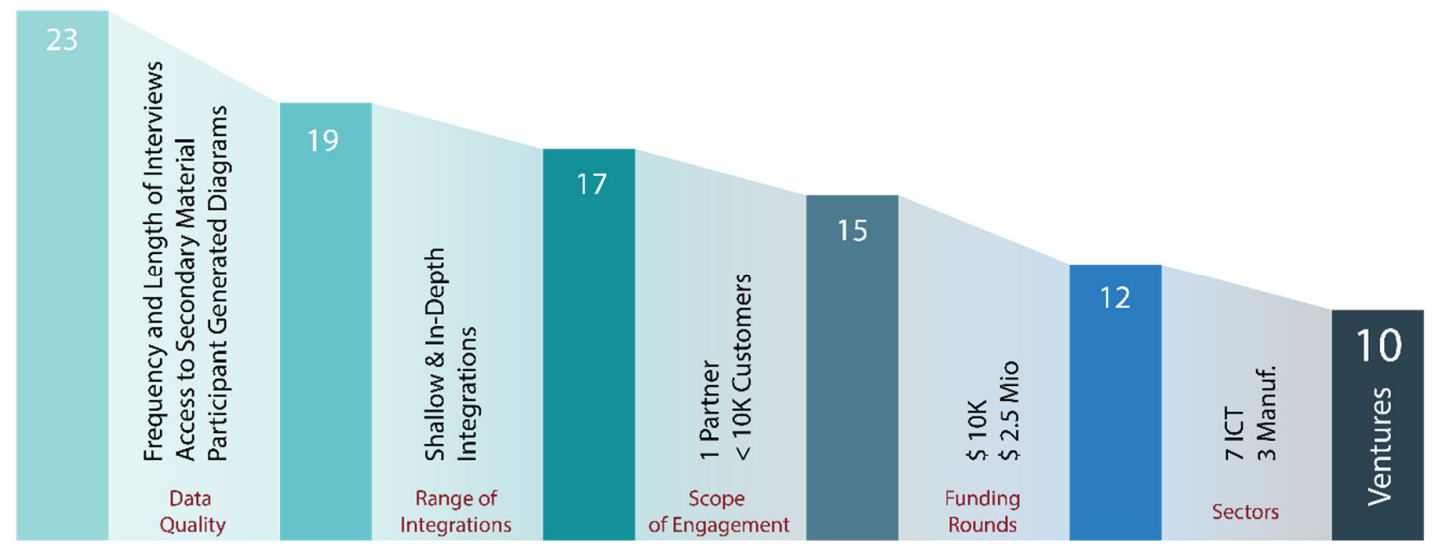

Figure 22 - Case Study Selection

Data from the remaining ventures provided additional insights to contrast the emerging theory. Overall, ten ventures were selected for detailed analysis as all of them have started to market value propositions within the investigation period of nine to twelve months, engaged continuously with actors in VCC mechanisms, and provided indications of the development of viable BMs. An overview of the selected cases is presented in Table 4. The ventures that have been presented in the case study reports have been selected to illustrate a broad spectrum of explorative dynamics in the BM development process. Contrasting ventures' approaches and BM development trajectories surfaced commonalities as well as differences in engagements with ecosystems and the viability of BMs over time.

Compliance with Victoria University Ethics code required to anonymise case data. Ventures' names were replaced with the Maori names of New Zealand endemic bird species ${ }^{8}$ to reflect the contextualities of this study. The clustering of cases relates to shared commonalties (FI-ventures are birds of prey, DI-ventures belong to the parrot family, OI-

\footnotetext{
${ }^{8}$ Brief descriptions of each species has been provided in appendix $D$ with links to the sources and further information (New Zealand Birds Online and the Department of Conservation)
} 
ventures are critically endangered birds, and failed ventures are extinct species).

\begin{tabular}{|c|c|c|c|}
\hline Case & Sector & \# Interviews & Characteristics \\
\hline Kārearea & $I C T$ & 5 & $\begin{array}{l}\text { Onboarded }<10,000 \text { customers } \\
\text { Raised }<2 \text { M NZD }\end{array}$ \\
\hline Matuku & $I C T$ & 3 & $\begin{array}{l}\text { Onboarded }<10 \text { customers (pot. } 29 \text { in NZ) } \\
\text { Raised }<250 K \text { NZD }\end{array}$ \\
\hline Ruru & Manufacturing & 4 & $\begin{array}{l}\text { Sold }<45,000 \text { products } \\
\text { Raised }<150 K \text { NZD }\end{array}$ \\
\hline Kākāpō & $I C T$ & 4 & $\begin{array}{l}\text { Onboarded }<300 \text { customers } \\
\text { Raised }<300 \mathrm{~K} \text { NZD }\end{array}$ \\
\hline Kea & $I C T$ & 3 & $\begin{array}{l}\text { Onboarded }<500 \text { customers } \\
\text { Raised }<2 \text { M NZD }\end{array}$ \\
\hline$K \bar{a} k \bar{a}$ & Manufacturing & 4 & $\begin{array}{l}\text { Onboarded first launch-partner } \\
\text { Raised }<75 K \text { NZD }\end{array}$ \\
\hline Takahē & $I C T$ & 4 & $\begin{array}{l}\text { Onboarded }<25 \text { customers } \\
\text { Raised }<50 K \text { NZD }\end{array}$ \\
\hline Whio & Manufacturing & 4 & $\begin{array}{l}\text { Sold }<300 \text { products } \\
\text { Raised }<150 \text { K NZD }\end{array}$ \\
\hline Moa & $I C T$ & 2 & $\begin{array}{l}\text { Onboarded } 0 \text { customers } \\
\text { Raised }<10 K \text { NZD }\end{array}$ \\
\hline Pouakai & $I C T$ & 2 & $\begin{array}{l}\text { Onboarded approx. } 35 \text { customers } \\
\text { Raised }<10 K \text { NZD }\end{array}$ \\
\hline
\end{tabular}

\subsection{Data Collection}

As qualitative data focuses on "naturally occurring, ordinary events in natural settings" and provides insights into what real life is like (Miles, Huberman, \& Saldana, 2013, p. 10), it can be considered as well-suited to investigate the BM development process. A case study research design allows for the collection of data from multiple sources and, thus, its triangulation. The advantages of combining and triangulating multiple sources of evidence to assess phenomena has been emphasised throughout the literature (Eisenhardt \& Graebner, 2007; Yin, 2014; Patton, 2015). In addition to enhancing convergence in the lines of inquiry, multiple sources of evidence can reveal emerging themes, tensions, and provide new insights (Dubois \& Gadde, 2002).

Case studies allow for the incorporation of a broad spectrum of evidence collected from documentation, archival records, interviews, direct observations, participant- 
observations, and physical artefacts (Eisenhardt \& Graebner, 2007; Yin, 2014, p. 106). While the wide range of possibilities offer an almost infinite number of combinations, picking complementary data sources with different strengths presents the best foundation for corroborating evidence (Miles et al., 2013, p. 299). While all sources of evidence can provide insights, interviews, participant-generated diagrams, and documents were considered as adequate data collection methods (Figure 23) to investigate the BM development process in ecosystems.

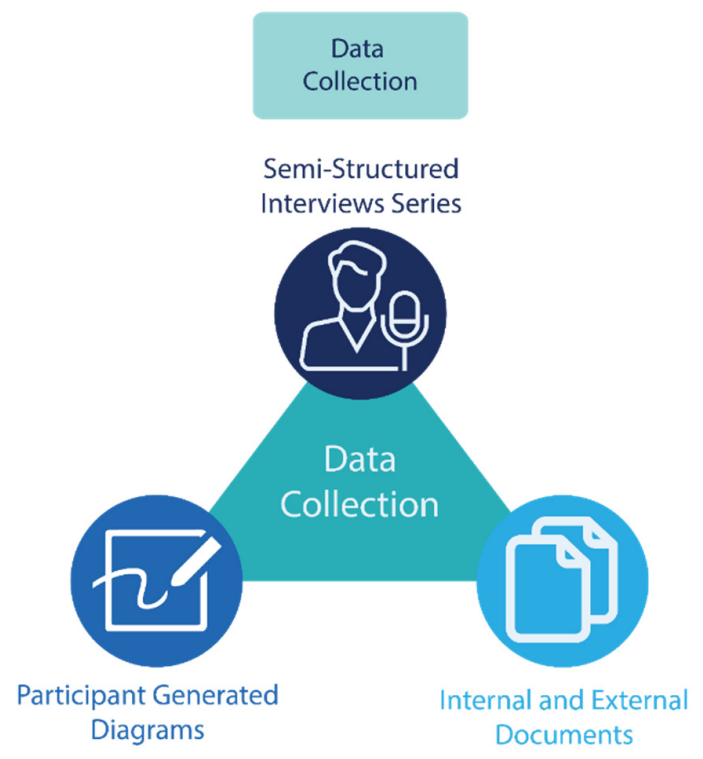

Figure 23 - Sources of Evidence

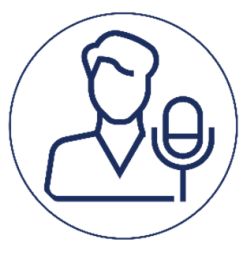

Interviews are a "highly efficient way to gather rich, empirical data especially when the phenomenon of interest is highly episodic" (Eisenhardt \& Graebner, 2007, p. 28). Interviews are one of the most important sources of case study evidence as they yield rich data and allow for immediate followup questions (Marshall, 2006, p. 102). A series of regular interviews, as conducted in this thesis, facilitate the in-depth insights into processes that unfold over an extended period of time (Yin, 2014). In short, interviews in business research "are an efficient and practical way of collecting information that you cannot find in a published form" (p. 94). Moreover, the opportunities and potential of longitudinal interview-based research on the BM development process has been amply emphasised by scholars (e.g. Demil et al., 2015; Saebi et al., 2017).

Conducting semi-structured interviews allows to balance structure and flexibility in 
the inquiry and account for variations in key informants and change of locus in the series of interviews (Manson, 2002; Marshall, 2006). The semi-structured interview approach maintained the research focus defined by the research questions and the VARA-framework and, in turn, provided boundaries for the inquiry. Simultaneously, the questions and probes outlined in the interview guidelines enabled to pursue emerging themes in the series of interviews (Rubin \& Rubin, 2012, p. 4; Barbour, 2013, p. 119; Patton, 2015, p. 437).

Furthermore, following a semi-structured approach allowed key informants to emphasise and elicit topics of great importance to them. This approach provided an efficient means to amass information about the BM development process that has often been considered as tacit, implicit, and undocumented (Doganova \& Eyquem-Renault, 2009; Massa et al., 2017). Across all cases, interviews became the most important source of evidence as almost all ventures showed a lean approach to documentation or as one of our participants outlined:

"We have got no business plan, we are a lean agile organization. Business plans are for dinosaurs" (CEO, Kākāpō)

The semi-structured interviews were underpinned by an interview guide (Appendix C) that was incorporated in the case study protocol. Interviewees' understanding of key concepts such as BMs, value creation and capture, and value propositions was further enhanced by prompts such as what product and/or service combinations does your venture offer and what activities, resources, and actors are engaged in creating them? The interview guide ensures convergence to the basic lines of inquiry across a series of interviews (King \& Horrocks, 2010, p. 35). It provides topic areas in which the interviewer is free to explore, probe, and ask questions to elucidate and illuminate a particular subject and thus works as a checklist to make sure all relevant topics are covered (Patton, 2015, p. 437). The questions and probes of the interview guide have been derived from the research questions in combination with the VARA-model.

Selecting participants is central to develop an understanding of the problem and the research questions in qualitative research (Creswell, 2013, p. 189). Key informants are regarded as knowledgeable people with an in-depth understanding of the phenomenon 
studied (Patton, 2015, p. 403). These key informants can include a wide range of actors outside and inside the organisation (Eisenhardt \& Graebner, 2007). Since this thesis focused on acquiring an understanding of how ventures' BMs are developed, entrepreneurs or members of the founding team were considered as qualified interviewees to provide in-depth insights (Gartner, Carter, \& Reynolds, 2010). While external key informants can offer interesting perspectives on the development of BMs, only entrepreneurs and founding team members are aware of how and what explorative means drove the development. To monitor the process three to four interviews have been conducted with one or two founding team members over a period of nine to twelve months. For the sake of consistency and clarity the same key informant(s) have been interviewed. The consecutive series of interviews allowed to mitigate situational, unilateral, and temporal biases of interviewees and accounted for the plurality of perspectives at different BM development stages (Eisenhardt \& Graebner, 2007).

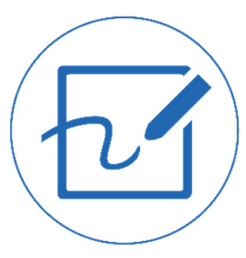

The semi-structured interviews were complemented by participantgenerated diagrams in conjunction with think-aloud protocols in which interviewees explain their thoughts while drawing. Participatory diagrams have been employed as source of evidence since graphical representations of BMs have been popular tools amongst practitioners (Linder \& Cantrell, 2000; Osterwalder \& Pigneur, 2010; Gassmann et al., 2014), as entrepreneurs can illustrate their perspectives in a familiar format. Burkhart et al. (2011) outlined that "expressing interrelated aspects in a textual manner is a heavy task with many obstacles" (p. 13) and graphical representation allows to elicit complex interdependencies.

Interviewees were prompted with the question to elicit their ventures' BMs and in due course to describe and explain what their venture was offering and how it produced that offering. In order to encounter tendencies of entrepreneurs to fit ventures' BMs into existing frameworks such as the BM canvas (Osterwalder \& Pigneur, 2010) or the lean canvas (Maurya, 2016), participants were provided with several blanc sheets of paper and four different coloured pens and asked to draw their venture's BM (M. J. Umoquit et al., 2008). Participantled diagrammatic elicitation has been considered as highly effective in providing rich and nuanced data (Crilly, Blackwell, \& Clarkson, 2006) and "unique insider perspectives" (Margolis \& Pauwels, 2011, p. 8) on abstract ideas that are difficult to capture via interviews (M. 
Umoquit, Tso, Varga-Atkins, O'Brien, \& Wheeldon, 2013). The technique stimulates participants to retrieve knowledge, reveal thoughts, and allows participants to articulate connection within a domain (Copeland \& Agosto, 2012). Participatory diagramming grants access to the complex and subtle cognitive maps of entrepreneurs that can hardly be verbalised (Meyer, 1991). In a similar vein, Y. Zhang (2008) emphasised that diagramming "can neatly illustrate the structural aspects of mental models" (p. 2089) and provides deep insights into participants' perspectives.

The graphical elicitation was complemented by a "thinking-aloud protocol" interview approach that further elicits inner thoughts and cognitive processes of individuals producing a graphical representation of their venture's BM (Patton, 2015, p. 486). Description of the drawings reduced the risk of misinterpretation (Jing Zhang, Souitaris, Soh, \& Wong, 2008). The "thinking aloud" approach to introspection is well suited to reveal participants' perspectives on a subject and is well-grounded in cognitive science (Johnson-Laird, 2010). Participants were asked to further specify the elements that have not been mentioned throughout the drawing process. The recording generated from the thinking-aloud-drawing process and subsequent questions provided rich evidence about the components and interdependencies of entrepreneurs' understanding of BMs.

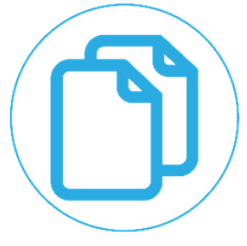

Secondary data has been considered as a pivotal source of evidence to complement data gathered in interviews and via participant-generated diagrams. Creswell (2013) argued that public documents such as websites or news coverage as well as private documents such as business plans can capture valuable information that interviews may miss. Similarly, Patton (2015) outlined that "records, documents, artefacts, and archives ... constitute a particularly rich source of information about many organizations" (p. 376) and act "as a stimulus for paths of inquiry that can only be pursued through direct observation and interviewing" (p. 377). Hence, in the ongoing course of the investigation access to internal documents such as sales pitches, financial plans, and in rare cases, business plans have been negotiated with ventures. Moreover, content in social media networks such as Facebook, Twitter and Reddit has been harnessed next to external documentation such as media coverage to complement internally sourced documents (Yin, 2014, pp. 105-109). 
Overall, combining semi-structured interviews, participatory diagramming and thinking-aloud protocols, and documentation provided a rich reservoir of evidence and helped to develop the thick descriptions that form the bedrock of qualitative inquiry (Patton, 2015 , p. 533). Combining a series of interviews and participatory-generated diagrams provided deep insights into participants' perspectives that have been complemented with internal and external documentation that revealed converging and contradictory evidence.

\subsubsection{Data Collection Procedure and Protocol}

The importance of a systematic and reliable procedure for collecting data in qualitative research has been emphasised by several authors (Denzin \& Lincoln, 2000; Creswell, 2013; Patton, 2015). Yin (2014) recommends a case-study protocol to maintain consistency in the data collection process across cases and over time. Before every interview, available primary (interviews and participatory generated diagrams) and secondary (business plans, media reports, social media network posts) data was reviewed, as outlined in the protocol. In addition, the case study protocol incorporated the semi-structured interview guide to direct the inquiry to fostered consistency in the data collection procedure. Collecting data from interviews, participant-generated diagrams and documentation allowed to triangulate the data of the individual case studies. The data in its raw form has been preserved, documented and administered in a NVivo database as recommended by Yin (2014, pp. 118-128).

\subsection{Data Analysis}

Data analysis has followed an abductive approach to allow for the development of a theory on BM development within the postpositivist paradigm. Peirce (1955) defined abduction as a "process of drawing conclusions that includes preferring one hypothesis over others which can explain the facts, when there is no basis in previous knowledge that could justify this preference or any checking done after the hypothesis was subjected to a trial period" (p. 151). Aligned with the postpositivist paradigm, abduction asserts that facts are always object of actors' interpretation and that the meaning phenomena are given directs the 
development of knowledge (Levin-Rozalis, 2000). Eriksson and Kovalainen (2015) defined abduction as "the process of moving from everyday descriptions and meanings given by people, to categories and concepts that create the basis of an understanding or an explanation to the phenomenon described" (p. 24).

Abductive analysis allows to develop robust theories by continuously advancing preliminary frameworks in an evolutionary process. Abduction can be understood as a combination of a deductive and inductive logic of data analysis and thus accounts for existing theories as well as emergent themes in the analysis of data (Reichertz, 2004; Patton, 2015, p. 560). Abduction focuses on theory development rather than on theory confirmation or falsification as in deductive analysis approaches or theory generation in inductive analysis approaches (Denzin \& Lincoln, 2011, p. 361). The underpinning process of systematic combining is driven by matching between theory and reality and the re-direction of the research locus (Dubois \& Gadde, 2002, 2014). The advantages of "constantly going 'back and forth' from one type of research activity to another and between empirical observation and theories" (Dubois \& Gadde, 2002, p. 555) to extend the understanding of both theory and empirical phenomenon have been emphasised by numerous scholars (Denzin \& Lincoln, 2011; Creswell, 2013; Miles et al., 2013; Patton, 2015).

Dubois and Gadde $(2002,2014)$ highlighted the unique means of non-linear case studies and the process of systematic combining as a non-linear and "path-dependent process of combining efforts with the ultimate objective of matching theory and reality" (Dubois \& Gadde, 2002, p. 556). The iterative process of matching framework, data sources, and analysis allows for the development of theories that reflect reality instead of force-fitting data in preconceived and pre-existing categories (Patton, 2015, p. 560). In a similar vein, Eisenhardt (1989) emphasised that conflicting results and/or theories present opportunities for a creative and frame breaking mode of thinking that allows for deeper insights into emergent theories and conflicting literature. The process of systematic combining is illustrated in Figure 24. 


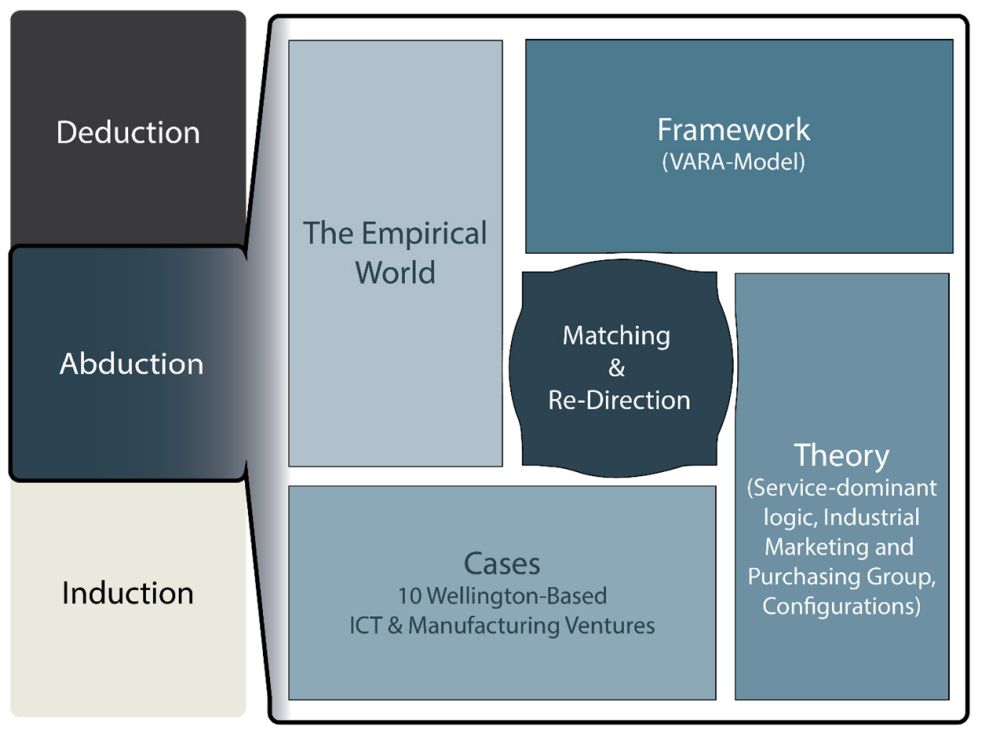

Figure 24 - Systematic Combining (Dubois \& Gadde 2002, p. 555)

\subsubsection{Data Analysis Procedure}

The data analysis approach follows the three phases of (1) data condensation, (2) data display, and (3) conclusion drawing/verification approach (Carney, 1990; Miles et al., 2013, p. 12). Data condensation is referred to as the continuous process of selecting, focusing, simplifying, abstracting, and/or transforming the data through writing summaries, first- and second cycle coding, developing themes and categories and writing analytical memos. Data display is considered as the compressed assembly of information in matrices, graphs, charts and networks that underpins and allows to draw conclusions (Miles et al., 2013, p. 12). Finally, conclusion drawing and verification starts with the data collection process by noting patterns, causal flows and propositions that are either supported, revisited or discarded in the analytical process (Miles et al., 2013, p. 13). Despite its sequential nature, the three steps have been interconnected and overlapping for most of the time to allow for the systemic combining analysis process outlined above. Figure 25 illustrates the interactive process of data collection and data analysis. 


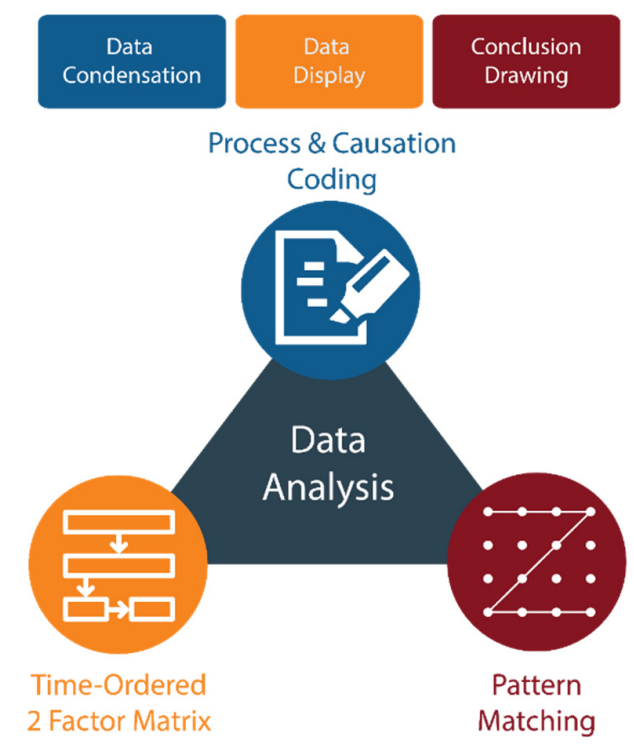

Figure 25 - Data Analysis Procedure

\subsubsection{Phase One - Data Condensation}

\subsubsection{Raw Data Management}

Data condensation is the first step of analysis and was a continuous process starting with the beginning of data collection. The concurrent data analysis allowed to "cycle back and forth between thinking about existing data and generating strategies for collecting new, often better data" (Miles et al., 2013, p. 384) to avoid blind spots. The audio recordings generated in the interviews were transcribed shortly after the interviews were conducted. Patton (2015) referred to the transcription process as a point of "transition between data collection and analysis" offering "an opportunity to get immersed in data, an experience that usually generates important insights" (p. 525). The transcription process provided first-hand and indepth insights and produced an array of preliminary jottings that underpinned analytical considerations (Miles et al., 2013, p. 21). The audio recordings were transcribed in conjunction with the participatory generated diagrams. In the joint process the diagrams were supplemented with analytical notes and insights from the audio recordings and elicited key informants' representations of the relationships, flows, and dynamics in the BM emergence process (Miles et al., 2013, p. 187; Patton, 2015, p. 486).

At the same time, internal and external documents were screened for similar and 
contradictory analytical insights. Internal documents as well as captures of social media and media coverage were harnessed to inform the preliminary analysis. All raw data and analytical memos have been preserved in its virgin form and were administered in a NVivo project database. The revisited raw data has been organized and prepared for the coding process.

\subsubsection{Coding}

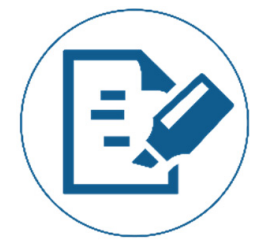

Coding is pivotal for qualitative data analysis and the process of systematically organizing and condensing data into analysable units (Creswell, 2013, p. 198; Bryman, 2015, p. 575). Miles et al. (2013) even argued that "coding is analysis" (p. 72) and proposed a two cycle-coding process. Whereas first-cycle coding methods assign codes to chuncks of data, second-cycle coding methods group the generated summaries into smaller numbers of categories, themes and constructs (Saldaña, 2016). The results provided the foundations for the theory building process (Saldaña, 2016, p. 277).

First-cycle coding methods have to be aligned with the research goals and questions, conceptual framework and study propositions (Saldaña, 2016, p. 69). Due to the thesis' focus on understanding the process of BM development, a process coding method was applied (Saldaña, 2016, p. 110). The initial coding scheme was derived from the VARA-model and continuously refined via insights obtained from analytical memos (Miles et al., 2013, p. 81). A coding layout in form of a horizontal matrix has been employed to code individual segments of interviews and documents. The coding layout has been supplemented with triggers and consequences of change (Saldaña, 2016, p. 114) that highlighted and illustrated the causal relationships and interdependencies amongst components over time. The combination of a process and causation coding approach "attempts to level the mental model participants use" (Saldaña, 2016, p. 187) and revealed the structure of entrepreneurs' causal theories of BM emergence (Miles et al., 2013, p. 79).

Additionally, the participatory-generated diagrams gave valuable insights into entrepreneurs' mental models as causal sequences are "not always apparently obvious or fully contained within narrative data" (Saldaña, 2016, p. 187). The generated diagrams have been decoded to produce visual data for analysis (Meyer, 1991). Each individual element, 
textual description, and link has been analysed in isolation and in the context of the whole diagram (Copeland \& Agosto, 2012) and provided additional measures for the items identified in the process-causation coding approach of the interview transcripts and documents. Overall the combination of a process-causation coding approach in combination with the analysis of participant-generated diagrams presented a valuable approach to organise the data and derive advanced analytical insights.

The second cycle of the process focused on pattern coding to elaborate on the development process and develop an understanding of entrepreneurs' reasoning of BM development (Miles et al., 2013, p. 86). Pattern codes are explanatory and "pull together material from first cycle coding into more meaningful and parsimonious units of analysis" (Saldaña, 2016, p. 236). Miles et al. (2013) argued that pattern codes are represented in categories of themes, causes and explanations, relationships, and theoretical constructs and commonly emerge from repeatedly observed actions, routines, and relationships. The indepth analysis of the broad segments arising from first-cycle coding allowed to examine comparable segments' commonalities, differences and relationships and identify patterns of interactions in the development of viable BMs (Guest, MacQueen, \& Namey, 2012, p. 54). The generated patterns were condensed in network displays and cognitive maps that "display a person's representation of concept or processes about a particular domain" (Miles et al., 2013, p. 187) and can be considered "as our best attempt to put into fixed form the dynamic and sometimes idiosyncratic thinking process of a participant"(Miles et al., 2013, p. 188).

Overall first- and second-cycle coding allowed for the condensation of the raw data in patterns and derived valuable analytical insights. The iterative revision of first-cycle codes and second-cycle patterns has been documented via analytical memos and informed the data display and inter- and intra-case analysis.

\subsubsection{Phase Two - Data Display}

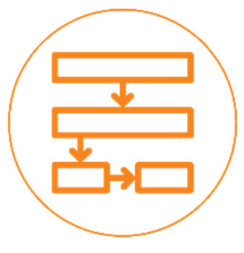

Creating matrices and networks presents an opportunity to display condensed data in systematic ways and thus enabled the researcher to grasp patterns and themes emerging from the data (Miles et al., 2013, p. 108). The patterns revealed by the two-cycle coding process have been employed to 
create a context chart, mapping interrelationships and interdependencies of the focal firms' components in graphic form (Miles et al., 2013, p. 166). The firm-ecosystem chart has been underpinned by the mapping of all value propositions, value matrices describing how value is created and captured in the realm of individual actors, and the related internal and external interdependencies of activities, resources, and actors. Porter's (1996) and Siggelkow's (2002) mapping of activity systems provided guidelines and valuable examples for the process. Moreover, the participatory-generated diagrams offered valuable insights into what, how and why individual components and interdependencies have been considered as pivotal for ventures' BMs. The firm-context chart has been continuously updated and revisited in each interview phase.

Exploring interdependencies in developing BMs allowed to develop a holistic understanding of the process and the inherent complexity resulting from the interdependencies of the components. Furthermore, exploring the interdependencies informed the identification of tensions arising from voluntary and emergent change in the BM and its ecosystem. Additionally to the firm-ecosystem chart, the sequential coding layout showed a time-ordered matrix illustrating the interaction of ventures and ecosystems over time and presented a frame to display the BM development process (Russell \& Ryan, 2010, p. 131; Hennink, Hutter, \& Bailey, 2011, p. 253; Miles et al., 2013, p. 202). Creating a timeordered matrix provided an additional means to display interdependencies, causalities and the emergence process. The comprehensive causal chains derived (Miles et al., 2013, p. 234) underpinned the resulting process-outcome matrix (Patton, 2015, p. 562). The processoutcome matrix revealed the causal path of how, why, and when ventures decided to change and adopt BMs to maintain a firm-ecosystem fit. Illustrative case studies displaying the development of BMs have inspired that approach to display the data (Sosna et al., 2010; Bojovic et al., 2018; Cosenz \& Noto, 2018). 


\subsubsection{Phase Three - Conclusion Drawing}

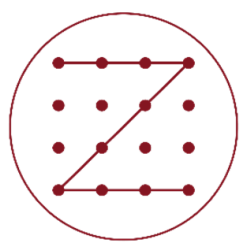

Condensing and displaying the raw data in a combination of a ValueExploration Matrix (Figure 13, p. 47) and an Integration Exploration Matrix (Figure 17, p. 68), yielded a process-outcome matrix for the development of each individual case study and gave rise to the patterns, themes, and relationships in the BM development process (Miles et al., 2013, p. 276). The interdependency and development patterns were organised and matched with the VARA framework to make sense of the empirical data. The patterns matching process confirmed aspects of the VARAframework and provided additional insights for the refinement of the original framework. This process has been referred to as clustering and allowed for the organisation of patterns in higher-order or meta-themes that informed the theory development process (Miles et al., 2013, p. 279). The resulting framework of patterns and themes presented a structure for the individual case reports (Chapter 4, p. 98) and underpinned the cross-case comparison (Chapter 5, p. 250)(Eisenhardt \& Graebner, 2007; Yin, 2014, p. 147).

The patterns of each individual case study were compared in a cross-case synthesis (Yin, 2014, p. 164). A two-variables case ordered matrix was created based on ventures' developed degree of integration (Activity Links, Resource Ties, and Actor Bonds) and degree of exploration (VCC mechanisms) (Miles et al., 2013, p. 152). This clustering approach facilitated the comparison of within and across group findings (Eisenhardt, 1989; Eisenhardt \& Graebner, 2007). The employed replication logic enabled the comparison of cases across segments and provided rich insights into how viable BMs emerge across different sectors (Yin, 2014 , p. 57). Finally, the emerging themes were interpreted by "attaching significance to what was found, making sense of findings, offering explanations, drawing conclusions ... and otherwise imposing order to an unruly but surely patterned world" (Patton, 2015, p. 570). Bringing together existing theories and compare and contrast them with the emerging framework and findings allowed to draw inferences and seek explanations (Dubois \& Gadde, 2002; Miles et al., 2013, p. 586). The frameworks that resulted from the iterative process are presented and discussed in Chapter 5, p.250. 


\subsection{Ethical Considerations}

This thesis' research was compliant with Victoria University of Wellington's Human Ethics policy. A detailed description of the research project, including the semi-structured interview guidelines, was submitted to the Human Ethics Committee for review and confirmed as appropriate. A participant information sheet as well as a research agreement can be found in the appendix (A, B). Protecting entrepreneurs, ventures, and their business interests required to anonymise the data to ensure confidentiality. The limited number of start-ups in the Greater Wellington area in New Zealand as well as the often idiosyncratic activities required to generalise areas of operations (ICT, manufacturing).

The interviewees were contacted personally by the researcher and provided with an overview of the research project and a confidentiality agreement to develop a relationship of mutual trust. For confidentiality reasons, the title of all interviewees was replaced with 'CoFounder'. However, all interviewees were members of the ventures' founding teams and actively engaged in the development of their BMs. In addition, external actors that cofounders referred to in interviews were anonymised to ensure confidentiality and mitigate risks of being identified in spite of ventures' public affiliation with partners. The measures undertaken to protect participating ventures' and entrepreneurs' anonymity and confidentiality were balanced with the information demands of the case study report.

\subsection{Summary Research Approach}

The chapter provided an overview of the philosophical stance taken (postpositivism), data collection procedures employed (semi-structured interviews, participatory generated diagrams, and secondary data), and described the individual steps in the analytical process and the methods used (two-cycle coding, data display, and pattern matching). In addition, a detailed description of the case study research methodology, unit of analysis, and selected case studies were presented to contextualise the analysis of ventures along the VARA-Model. 


\section{Findings}

\subsection{Chapter Introduction}

This chapter contextualises ten ventures selected to display diverging strategies used in the BM development process. Each case report follows the same structure and employs the VARA-framework to allow for a comparison of cases. First, the development of customer value propositions and actor value propositions are presented in conjunction with value capture mechanisms to provide an overview of ventures' VCC mechanisms. Radar-graphs

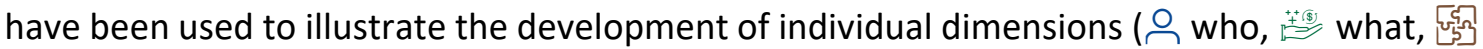
how, $\mathbb{Z}$ when, $\vartheta$ where) across value propositions to allow for a comparison of cases. The VCC section of each case study is summarised and illustrated using a Value Exploration Matrix (Figure 13, p. 47). Afterwards, the development of activity links, resource ties, and actor bonds with other actors in the ecosystem will be described. The development of these BM dimensions will be further elicited by a summary and an Integration-Exploration Matrix (Figure 17, p. 68). Throughout the case studies symbols were used to indicate interdependencies with Activity Links ( $($ \&), Resource Ties (贯), and Actor Bonds ( 8 ) developed over time. The exemplary comments of co-founders listed in tables have been complemented with references to the interview stages ( months $\sim 1-3$, months $\sim 4-6$, months $\sim 7-9$, months $\sim 10-12$ ) to illustrate the temporal development of ventures. 


\subsection{Case Report - Venture Kārearea}

\subsubsection{Introduction}

Kārearea attracted thousands of customers to its investment platform and acquired several millions of funding within the first twelve months of operation. Significant to the development was a focused approach to co-create value with a growing number of customer segments by leveraging a limited set of activity links, resource ties, and actor bonds developed across the venture's ecosystem.

\subsubsection{Development of Customer Value Co-Creation Mechanisms}

\begin{tabular}{|c|c|c|c|c|c|}
\hline \multicolumn{6}{|l|}{ Time } \\
\hline $\begin{array}{l}O C \\
\stackrel{0}{c}\end{array}$ & $\begin{array}{l}\text { "We're targeting the } \\
\text { millennial age group } \\
\text { between } 25 \text { to } 40 \text { but } \\
\text { realistically I think people } \\
\text { use it outside of that" }\end{array}$ & $\begin{array}{l}\text { "We refined it a bit, our key } \\
\text { target group is still } 25 \text { to } 35 \\
\text {... outside of that we } \\
\text { probably have a } 35 \text { to } 50 \\
\text { age group" }\end{array}$ & \multicolumn{2}{|c|}{$\begin{array}{l}\text { "We haven't really targeted } \\
\text { a generation, but we've } \\
\text { targeted a type of person ... } \\
\text { someone who is new to } \\
\text { investing and wants to do } \\
\text { it and learn about it" }\end{array}$} & $\begin{array}{l}\text { "We are scoping minors at } \\
\text { the moment, so kids, so } \\
\text { that is some sort of a start } \\
\text { of a club if you like, if mom } \\
\text { and dad say so" }\end{array}$ \\
\hline 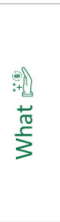 & $\begin{array}{l}\text { "We create an investment } \\
\text { platform that makes it a } \\
\text { safe and comfortable place } \\
\text { for people to make an } \\
\text { investment decision." }\end{array}$ & $\begin{array}{l}\text { "providing choice, and } \\
\text { break down high minimum } \\
\text { investment criteria, ... we } \\
\text { speak a language that you } \\
\text { understand, and ... an app } \\
\text { that you know } \\
\text { straightaway how to use” }\end{array}$ & \multicolumn{2}{|c|}{$\begin{array}{l}\text { "We will also bring on a } \\
\text { mutual fund offering very } \\
\text { soon which is a sustainable } \\
\text { offering." }\end{array}$} & $\begin{array}{l}\text { "Creating experiences on } \\
\text { the platform that people } \\
\text { want to have over and over } \\
\text { again ... making it exciting } \\
\text { to invest" }\end{array}$ \\
\hline 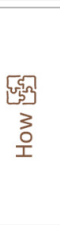 & $\begin{array}{l}\text { "the front-end, we have a } \\
\text { long way to go on this } \\
\text { because it is constantly } \\
\text { changing. Right now it is a } \\
\text { platform on which you go } \\
\text { on and it makes you feel } \\
\text { comfortable investing" }\end{array}$ & $\begin{array}{l}\text { "It involves us doing the } \\
\text { tax on behalf of our } \\
\text { customers as well, so we } \\
\text { are talking about } \\
\text { delivering value to the } \\
\text { customers" }\end{array}$ & \multicolumn{2}{|c|}{$\begin{array}{l}\text { "We are introducing } \\
\text { performance measures for } \\
\text { the whole portfolio, that is } \\
\text { probably going to happen } \\
\text { next week" }\end{array}$} & $\begin{array}{l}\text { "We will do } \\
\text { superannuation most } \\
\text { likely in the next few } \\
\text { months ... it's still } \\
\text { investing but it is different } \\
\text { from what we're doing } \\
\text { right now" }\end{array}$ \\
\hline 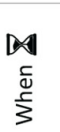 & \multicolumn{2}{|c|}{$\begin{array}{l}\text { "Saving and investing is you putting sacrifice into } \\
\text { something right now for somebody in the future or at least } \\
\text { perceived value in the future" }\end{array}$} & \multicolumn{3}{|c|}{$\begin{array}{l}\text { "Someone who understood that they had a financial } \\
\text { future." }\end{array}$} \\
\hline 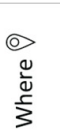 & \multicolumn{3}{|c|}{$\begin{array}{l}\text { "Mostly New Zealand and then we'll } \\
\text { look offshore." }\end{array}$} & \multicolumn{2}{|c|}{ "Move to Australia or the UK" } \\
\hline
\end{tabular}

Table 5 - Kārearea - Development of Customer Value Co-Creation Mechanisms

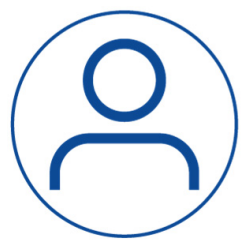

Kārearea continuously extended its customer target groups throughout the study. While initially relying on age and lifestyle as classification criteria, attributes such as disposable income, financial planning behaviour and 
investment literacy were added to refine and extend customer segments over time. Moreover, customer archetypes such as "millennials" and "newbie investors" emerged with the launch of the Beta version of the platform.

"It's a slightly older age group and tends to invest large amounts of money, but the reason that they are not involved in investing is that they have not got the confidence around it and don't want to ask someone because they don't want to feel stupid by doing so. We call them newbie investors" (Co-Founder, Kārearea)

Next to targeting millennials and newbie investors, the scale of target customers was widened to parents or grandparents that invest on behalf of minors. In sum, Kārearea extended its target customer groups in a continuous process. Emerging customer archetypes and the different types of value Kārearea aimed to co-create with them directed the development of features and investments offered on the platform

"ETFs" have tested reasonably well with customers. People understand what they are, and particularly when you read about them in plain English" (Co-Founder, Kārearea)

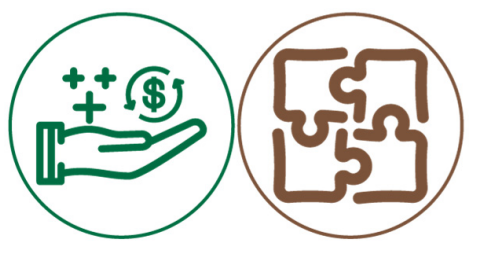

Kārearea focused on enabling customers to accumulate an investment portfolio by having access to a platform that allows them to (a) choose from a curated set of investments with high monetary entry barriers $(0)$, (b) track the development of an investment portfolio in a user-friendly environment $\odot$, and which (c) provides information in a convenient way to foster users' investment literacy and confidence \&. Kārearea explored a wide range of investments that could be made available on the platform such as volatile commodities or crypto-currencies 8

"We are starting with ETFs, but we will add cooler investment products such as cattle or forestry products, or something more speculative like gold or options" (Co-Founder, Kārearea)

However, customer testing revealed that sustainable funds were most sought after. Since Kārearea's ETF provider was not able to offer any funds focused on sustainable investments, the venture onboarded a $\mathrm{MF}^{10}$ provider 8 . In contrast to ETFs, MFs do not pay taxes on behalf of investors and therefore required Kārearea to develop a tax reporting

\footnotetext{
${ }^{9}$ Exchange Traded Funds

10 Mutual Funds
} 
feature for customers to maintain a convenient user experience on the platform $\circledast$. Early stage testing of wireframes (the skeletal framework of the platform) emphasised the users' need for convenience and the feeling of confidence in the investment process. While introducing features such as graphs to track performance enhanced the convenience, animations and clubs were added to augment the user experience further.

"We have implemented little animations to enhance instant gratification and make customers feel good when they invest money" (Co-Founder, Kärearea)

Additionally, a blog with guest postings of opinion leaders $\&$ providing plain English information about investment strategies and explaining financial products was created to foster users' investment literacy. Building users' confidence in making investment decisions and buying ETF/MFs was considered a key element of Kārearea's customer value proposition.

"Customers don't just want to have the ability to buy with \$50, but they also want the feeling that it is a good idea" (Co-Founder, Kārearea)

Users' confidence in making investment decisions and the trust in the venture as a reliable provider of investment services was leveraged via a referral system 8 that allowed existing customers to obtain financial remuneration for attracting additional customers.

"We will launch our referral system in February, so current members will get \$10 when they acquire a new customer" (Co-Founder, Kārearea)

Finally, introducing additional services such as superannuation was explored as possible avenue to co-create value with customers, yet these measures were not implemented during the study.

"We are thinking about other opportunities, like insurance, superannuation, cash savings, transactional payments, and lending as possible avenues to expand our business.”

(Co-Founder, Kärearea)

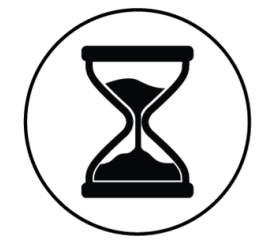

Since customers' understanding of long-term investing and financial planning was crucial, Kārearea's value co-creation mechanisms were characterised by a critical temporal component. The behaviour Kārearea wanted to encourage amongst its customers was to invest regularly (weekly, fortnightly, monthly, 
etc.) to realise dividend and capital gains from investments in index-based ETF/MFs $(.0$.

"We were talking about small regular investments, riding the highs and lows of the market via a passive investment strategy, but being active in knowing what you are doing and having the opportunity to choose in which direction you want to invest your money" (Co-Founder, Kārearea)

Subsequently, customers' understanding of regular investments and the realisation of "perceived value in the future" was a pivotal aspect of customer value co-creation. Overall, the temporal component was central from the very beginning onwards and reflected in the exclusive offering of index-based ETFs and MFs, widely considered as long-term investment products 雷.

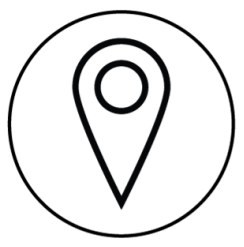

Since Kārearea's platform and blog were accessible online, the customer value proposition was considered location independent. However, AML$\mathrm{CFT}^{11}$ regulations required to ID verify every customer as a New Zealand resident and thus limited its offering to the domestic market the company planned on expanding its business to off-shore markets such as Australia and the UK and establishing partnerships with foreign financial service providers to comply with regional regulations 8 .

Overall, Kārearea followed a lean customer value proposition development strategy, starting with a limited set of the most basic functionalities and gradually extending the range of customer segments, matching platform features, and offering investment products 8 enhance customer value co-creation for different segments. Interactions with customers informed the development of platform features $\&$ and the extension of available investment products on the platform. The development of individual dimensions of customer value cocreation mechanisms throughout the study is illustrated in Figure 26.

11 Anti-Money Laundering and Countering Financing of Terrorism Act 2009 (AML/CFT) (http://www.legislation.govt.nz/act/public/2009/0035/latest/DLM2140720.html) 


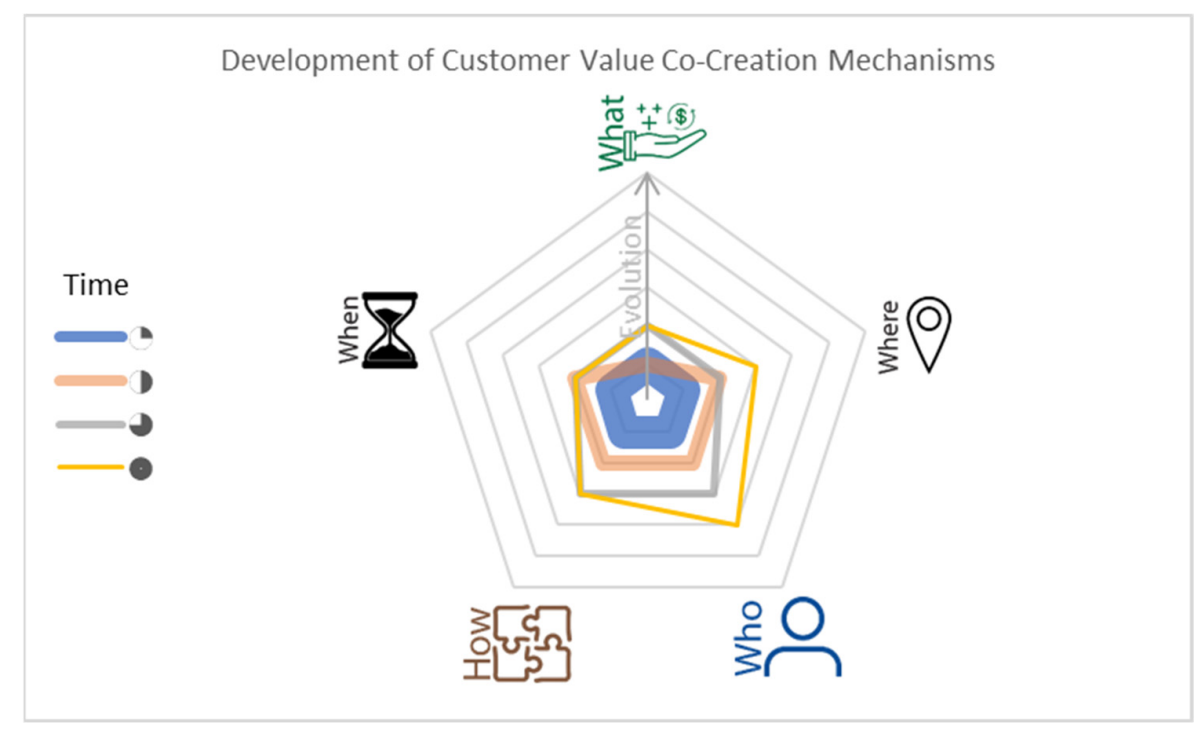

Figure 26 - Kārearea - Development of Customer Value Co-Creation Mechanisms

"We deliberately came out with a very basic Beta-version of the platform. The very minimum of our value proposition. The way it looks and feels is very basic but it's really important to us, because customers will tell us if there's something that you really want there and it's not, so that is the angle that we're taking" (Co-Founder, Kärearea)

\subsubsection{Development of Actor Value Co-Creation Mechanisms}

\begin{tabular}{|c|c|c|c|c|}
\hline Time & 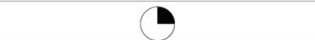 & 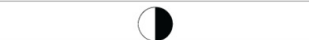 & & \\
\hline $\begin{array}{l}\text { OC } \\
0 \\
\frac{1}{3}\end{array}$ & $\begin{array}{l}\text { "We don't need a whole lot } \\
\text { of partners, we need } \\
\text { [ETF/MF providers] being } \\
\text { comfortable with showing } \\
\text { their brands on our } \\
\text { platform." }\end{array}$ & $\begin{array}{l}\text { "We are looking at } \\
\text { partnerships, possibly with } \\
\text { banks." }\end{array}$ & $\begin{array}{l}\text { "We're more interested in } \\
\text { media companies, or phone } \\
\text { platforms, or people who } \\
\text { have mass audience access } \\
\text {... looking towards the likes } \\
\text { of a Spotify-model." }\end{array}$ & $\begin{array}{l}\text { "We are looking at some } \\
\text { Australian options at the } \\
\text { moment. There is a big } \\
\text { company with whom we're } \\
\text { speaking with in } \\
\text { Australia." }\end{array}$ \\
\hline $\begin{array}{l}\text { D. } \\
\frac{1}{\pi} \\
\sum_{3}^{0}\end{array}$ & $\begin{array}{l}\text { "This is business that } \\
\text { [partner] wouldn't have ... } \\
\text { they will get a bunch of } \\
\text { customers that haven't } \\
\text { been investing in ETF/MFs } \\
\text { before." }\end{array}$ & $\begin{array}{l}\text { "With a little bit of work on } \\
\text { our side we could offer } \\
\text { their shares and we can } \\
\text { offer them direct access } \\
\text { back to their end-users." }\end{array}$ & $\begin{array}{l}\text { "We were paying } \$[X] \text { a day } \\
\text { in brokerage ... they can } \\
\text { see that we are building } \\
\text { something for them." }\end{array}$ & \multirow{2}{*}{$\begin{array}{l}\text { "[ETF provider] is } \\
\text { obviously getting value out } \\
\text { of our cooperation as far } \\
\text { as sharing back to their } \\
\text { investors at the NZX } \\
\text { saying that, we appreciate } \\
\text { innovation and have a } \\
\text { partnership strategy } \\
\text { incorporating } \\
\text { entrepreneurial ventures." }\end{array}$} \\
\hline 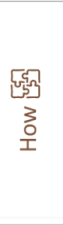 & $\begin{array}{l}\text { "We can say we will give } \\
\text { you another million dollars } \\
\text { or a few million dollars a } \\
\text { year in investments and it's } \\
\text { not going to be more work } \\
\text { on their part." }\end{array}$ & $\begin{array}{l}\text { "We have floated the idea, } \\
\text { and they seem to be } \\
\text { potentially ok with it. We } \\
\text { build our system and } \\
\text { expose a login portal for } \\
\text { them, so [partner] can log } \\
\text { in into our system." }\end{array}$ & $\begin{array}{l}\text { "It's like advertising and } \\
\text { the fact that we manage all } \\
\text { these parts for them, the } \\
\text { AML-CFT ID verifications" }\end{array}$ & \\
\hline (a) & & & & $\begin{array}{l}\text { "We are looking at } \\
\text { Australian partners at the } \\
\text { moment ... we would be } \\
\text { distributing their ETFs } \\
\text { here." }\end{array}$ \\
\hline
\end{tabular}

Table 6 - Kārearea - Development of Actor Value Co-Creation Mechanisms 


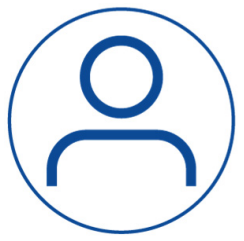

Kārearea's ETF provider supplied the financial products customers would buy and sell on the platform and thus was considered a vital actor engaged in value co-creation mechanisms throughout the study 8 . Likewise, by onboarding an additional MF provider, Kārearea was able to offer funds focused on a portfolio of firms committed to sustainable business practices on its platform (S) While partnerships with banks, media companies and even mobile phone network operators were explored, the venture refrained from entering in any relationships with those actors. Despite having received a partnership agreement from a media company, Kārearea declined a trial.

"We just don't think the time is right for any of those big partnerships because we don't want to become a slave to the man" (Co-Founder, Kārearea)

On the other hand, Kārearea negotiated with overseas partners to enlarge its range of investments offered 8 and to explore possible avenues for operating in other countries 8 . The venture was highly selective in its engagements and pursued only partnerships that offered opportunities to co-create additional value within the defined scale and scope of customer value co-creation mechanisms, e.g., additional investment products.

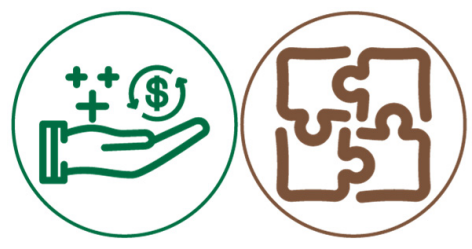

Kārearea created additional business for engaged actors such as ETF/MF providers and brokers. While additional business was primarily measured via pecuniary gains such as an increase in funds under management and brokerage fees, providing access to end-users as well as potential reputational benefits of being associated with a young and innovative venture emerged as additional non-pecuniary benefits 8 . Moreover, exploring the development of a login-portal from partners was evaluated

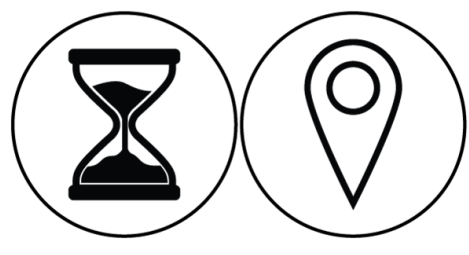

Kārearea's actor value co-creation mechanisms showed one noticeable temporal component. ETF/MF providers' amount of assets under management, and thus revenues generated from fees and commissions, was contingent on the enduring 
holding of Kārearea investment products on customers' behalf. Actor value co-creation mechanisms were spatially limited to New Zealand by domestic regulations. However, reciprocal to Kārearea's aims to seek engagement with off-shore partners to enter new markets, the venture was able to offer off-shore partners access to the New Zealand market. While Kārearea considered that scenario, it refrained from implementation throughout the study.

Overall, while Kārearea was not explicitly creating value propositions for other actors than customers, it was aware of the value co-created with engaged actors. The purely pecuniary focus on value for other actors was supplemented with reputational benefits in later development stages of the study 8 . Moreover, opening up the platform for MF providers and brokers to facilitate the buying and selling of investments customer orders can be regarded as an offering to engage in value co-creation. Despite the absence of an explicitly articulated actor value proposition, Kārearea explored several ways to co-create value with a narrow set of engaged partners. Figure 27 illustrates the development of actor value co-creation mechanisms throughout the study.

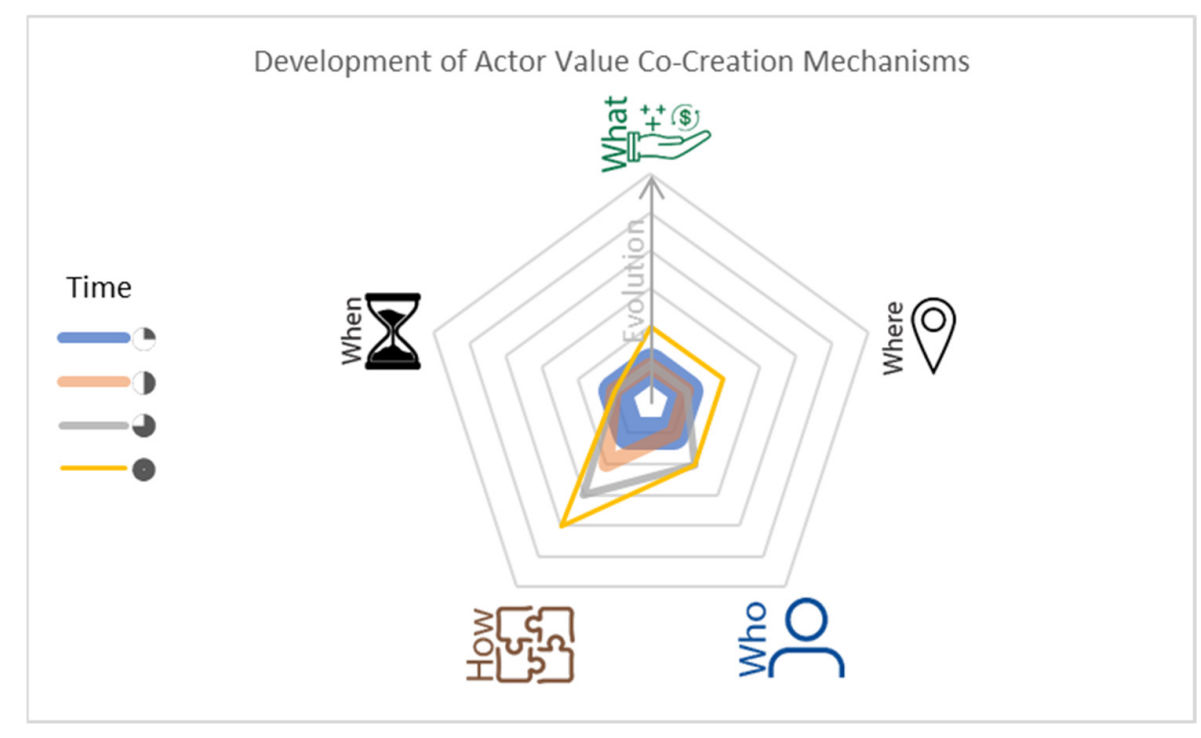

Figure 27 - Kārearea - Development of Actor Value Co-Creation Mechanisms 


\subsubsection{Development of Value Capture Mechanisms}

\begin{tabular}{|c|c|c|c|c|}
\hline Time & $D$ & & & \\
\hline 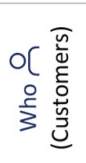 & $\begin{array}{l}\text { "In the MVP [Minimum } \\
\text { viable product] ... we will } \\
\text { charge customers a } \\
\text { platform SaaS" thing, } \\
\text { basically a dollar a month." }\end{array}$ & $\begin{array}{l}\text { "Customers pay } \$[x] \text { up } \\
\text { front annually, which gets } \\
\text { them into Beta and as } \\
\text { many trades as they want." }\end{array}$ & $\begin{array}{l}\text { "The last three months in } \\
\text { revenue were coming from } \\
\text { customer subscriptions." }\end{array}$ & $\begin{array}{l}\text { "We are scoping minors at } \\
\text { the moment,... so that is } \\
\text { some sort of a start of a } \\
\text { club if you like." }\end{array}$ \\
\hline 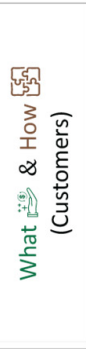 & $\begin{array}{l}\text { "We're having a goal thing } \\
\text { here, so we know these } \\
\text { people are saving, let's say, } \\
\text { for a house or holiday or } \\
\text { anything like that, so there } \\
\text { is no reason why we could } \\
\text { not sell that data to } \\
\text { someone who is selling } \\
\text { holidays or homes." }\end{array}$ & $\begin{array}{l}\text { "We will change that and } \\
\text { we will go forward with a } \\
\text { different pricing scheme." } \\
\text { "Top up with the debit or } \\
\text { credit card ... there has to } \\
\text { be a fee charge for that and } \\
\text { maybe we'll add a little clip } \\
\text { on that." }\end{array}$ & $\begin{array}{l}\text { "We make money by } \\
\text { earning interest, interest } \\
\text { received on free funds or } \\
\text { transactional balances." }\end{array}$ & $\begin{array}{l}\text { "That } \$[x] \text { value } \\
\text { proposition, if that is too } \\
\text { expensive for some people } \\
\text {... so we had this idea, that } \\
\text { people don't mind paying } \\
\text { transaction fees and we } \\
\text { would introduce them." } \\
\text { "There are some strong } \\
\text { relationships that can give } \\
\text { us a lot more data." }\end{array}$ \\
\hline $\begin{array}{l}\text { of } \bar{n} \\
\circ \stackrel{0}{0} \\
\frac{0}{3}\end{array}$ & & & \multicolumn{2}{|c|}{ ETF/MF providers $\mathcal{E}$ banks } \\
\hline 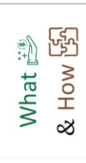 & $\begin{array}{l}\text { "You might get }[x] \text { base } \\
\text { points up front and } \\
\text { another }[x] \text { base points for } \\
\text { every year when the money } \\
\text { is still there." }\end{array}$ & $\begin{array}{l}\text { "We will not get that } \\
\text { rebate until we reached the } \\
\$[X] \text { of funds under } \\
\text { management and we are a } \\
\text { long way away from that." }\end{array}$ & $\begin{array}{l}\text { "We have renegotiated that } \\
\text { [rebate threshold] back to } \\
\$[X] \text {... so we were actually } \\
\text { getting paid a little bit } \\
\text { earlier." }\end{array}$ & $\begin{array}{l}\text { "I think if we had gone out } \\
\text { offering our own product } \\
\text { out of the bed with our } \\
\text { own custodian company, it } \\
\text { just wouldn't fly." }\end{array}$ \\
\hline 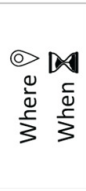 & $\begin{array}{l}\text { "Basically a dollar a } \\
\text { month" } \\
\text { "Another }[x] \text { base points } \\
\text { for every year when the } \\
\text { money is still there." }\end{array}$ & & & $\begin{array}{l}\text { "We're still exploring } \\
\text { monthly subscriptions, yet } \\
\text { there are other things that } \\
\text { we want to try first. We've } \\
\text { all of this levers we can } \\
\text { pull." }\end{array}$ \\
\hline
\end{tabular}

Table 7 - Kārearea - Development of Value Capture Mechanisms

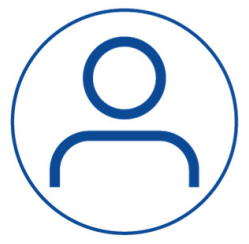

Kārearea captured value from customers as well as ETF/MF providers. While revenue streams were mostly dependent on customers in early stages of the study, the importance of ETF/MF providers as a source of revenue increased in later stages.

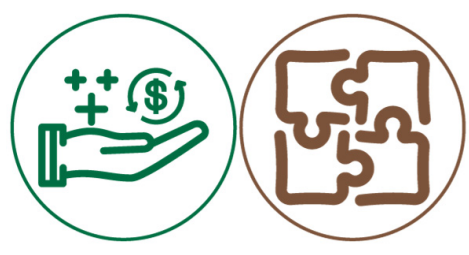

Kārearea captured pecuniary value from customers by charging subscription fees and by receiving interests on freeflowing cash reserves in customer accounts. Also, the venture captured valuable information from customers such as saving goals. While Kārearea considered capitalising this data in early stages of the study $\left(\mathrm{S}_{\mathrm{B}}\right.$, it refrained from implementing this approach. Moreover, Kārearea captured pecuniary value from ETF/MF providers by receiving marketing fees for selling as well as annual rebates for 
holding investments on behalf of customers from ETF/MF providers

"The majority of revenues is definitely from the customer in the last three months, the advertisement fees and rebates will take over in time" (Co-Founder, Kärearea)

While Kārearea maintained a single-price annual subscription scheme throughout the study, several variations of pricing schemes were explored. Factors such as number and volume of trades and withdrawals, brokerage fees, limitations of the range of available investments were considered to underpin the segregation of pricing plans.

"The basic account will give you access to standard funds or standard investments and you will get \$500o worth of trades, two or three withdrawals for \$10 per month, the pro account will allow ..." (Co-Founder, Kārearea)

Briefly after the last interview was conducted, Kārearea introduced multi-stage pricing plans dependent on users' portfolio value with monthly and annual subscription options. In short, Kārearea conceptualised, explored, and refined the foundations of its pricing scheme over the time of observation.

"We want to give people what they want at a price that feels fair and reasonable to them" (Co-Founder, Kārearea)

While subscription fees were initially paid and received by a simple bank transfer, Kārearea integrated with a payment service provider which enabled the venture to charge users' credit cards considered, it was not implemented. Next to the subscription fee, Kārearea captured pecuniary value by managing customers' free-floating cash reserves by receiving interests on term deposits.

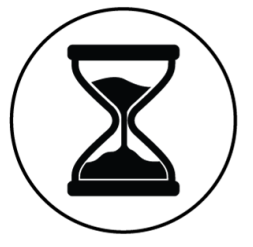

Kārearea's value capture mechanisms were characterised by three temporal components. The introduced customer subscription plan offered monthly and annual subscription options. The interest received from balancing customers' cash deposits requires long-term planning and cash-flow management from Kārearea. Finally, ETF/MF providers paid annual rebates for the volume of investments held on behalf of the customer 


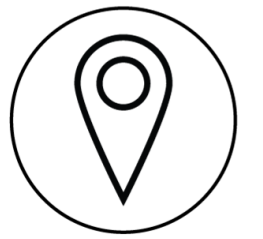

Kārearea's revenue streams were location independent in New Zealand. While revenues were generated in New Zealand, cooperation with Australian and other off-shore partners were explored as a future source of revenue.

Kārearea's value capturing mechanisms were multi-sided, reinforcing, and stable over time. However, the evolution of customer pricing plans based on users' portfolio value as the underpinning foundation further emphasised the focus on the reinforcing elements. The new pricing scheme was introduced to encourage users to grow their portfolio held by Kārearea and thus increase the venture's volume of total funds under management 雷. In turn, Kārearea realised growing revenue from annual rebates received from ETF/MF providers. Besides, the growing trade volume allowed Kārearea to renegotiate brokerage fees on a regular basis and thus reduced costs 8 . While increasing trade volume facilitated the reduction of brokerage fees, the resulting fluctuation in investments held reduced the annual rebates received from ETF/MF providers. Kārearea circumvented that problem by reallocating ownership of the limited set of investments available on its platform amongst its users. The internal brokerage of investments helped Kārearea to reduce the necessity of external brokerage services. The development of the individual dimension of Kārearea's value capture mechanisms is illustrated in Figure 28.

"We are knitting out trades in our platform. Buyers always get the buyer's price but sellers also get the buyer's price which is unique. We had about two sells in the whole time, one of those we forced because we wanted to find out if the system can do it." (Co-Founder, Kärearea) 


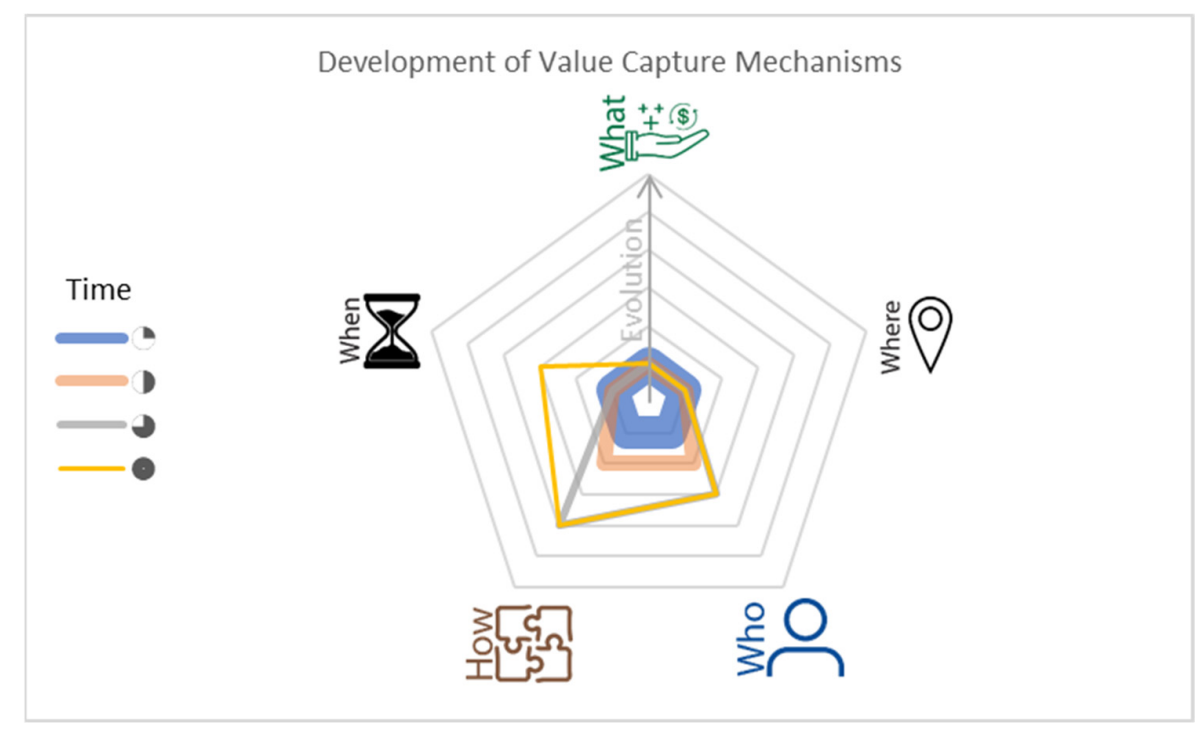

Figure 28 - Kārearea - Development of Value Capture Mechanisms

Kārearea explored various avenues to capture pecuniary and non-pecuniary value from its interactions with customers and other actors. However, three reinforcing value capture streams emerged in Kārearea's value capture mechanisms.

\subsubsection{Summary Value Co-Creation and Capture Mechanisms}

Kārearea continuously developed VCC mechanisms over the period of the study. In contrast to the consecutive expansion of customer value propositions' customer segments, Kārearea explored opportunities to co-create value with a wide scale of other actors in early stages, yet refined its focus to a small set of potential partners and a limited scope in later stages of the study. Similarly, Kārearea explored various opportunities to capture value from a wide range of actors via different means. However, the venture focused the development of value capture mechanisms on customers and ETF/MF providers. Figure 29 summarises the development of Kārearea's VCC mechanisms over the period of the study. 


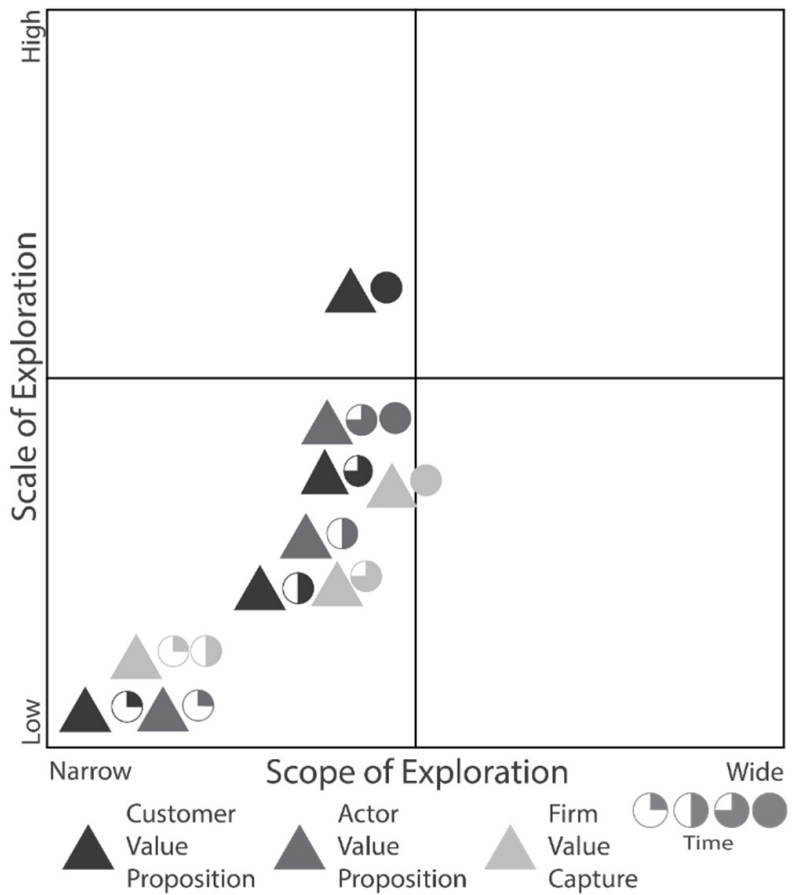

Figure 29 - Kārearea - Development of Value Co-Creation and Capture Mechanisms 


\subsubsection{Development of Activity Links, Resource Ties, and Actor Bonds}

\begin{tabular}{|c|c|c|c|c|}
\hline Time & $\mathbf{D}$ & & & \\
\hline 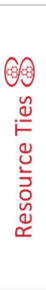 & $\begin{array}{l}\text { "We are starting with ETFs } \\
\text {... those guys don't deal } \\
\text { with people. They will get a } \\
\text { bunch of customers that } \\
\text { haven't invested in this } \\
\text { type of thing before." }\end{array}$ & $\begin{array}{l}\text { "We have committed to } \\
\text { those service providers } \\
\text { since we integrated with } \\
\text { them, but we've also tried } \\
\text { to write agnostic code so it } \\
\text { would be reasonably easy } \\
\text { to move away from them, } \\
\text { hoping that we don't have } \\
\text { to do that soon." }\end{array}$ & $\begin{array}{l}\text { "Transaction wise and } \\
\text { analytically, we developed } \\
\text { a little bot that does that } \\
\text { now for us." }\end{array}$ & $\begin{array}{l}\text { "If we would have gone out } \\
\text { offering our own product } \\
\text { out of the bed with our } \\
\text { own custodian company, } \\
\text { you know with all these } \\
\text { things, it just wouldn't } \\
\text { fly." }\end{array}$ \\
\hline 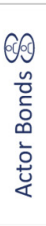 & $\begin{array}{l}\text { "We don't need a whole lot } \\
\text { of partners, we need those } \\
\text { people [ETF/MF providers] } \\
\text { being comfortable with } \\
\text { their brands being on our } \\
\text { website... they seemed to } \\
\text { be reasonably comfortable" }\end{array}$ & $\begin{array}{l}\text { "[X] was the chief } \\
\text { economist of [bank] and is } \\
\text { doing some blogging for } \\
\text { us" }\end{array}$ & $\begin{array}{l}\text { "We have renegotiated } \\
\text { with [broker] on that } \\
\text { brokerage to reduce that, } \\
\text { and we've set a date on } \\
\text { which we will review it } \\
\text { again" }\end{array}$ & $\begin{array}{l}\text { "The FMA is a partner that } \\
\text { we need to manage closely } \\
\text {... if they decide that they } \\
\text { didn't like us or something } \\
\text { like that, it can be pretty } \\
\text { crippling." }\end{array}$ \\
\hline
\end{tabular}

Table 8 - Kārearea - Development of Activity Links, Resource Ties, and Actor Bonds

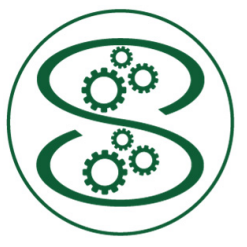

Kārearea's activity structure was dependent on the development of multiple activity links with different service providers. On the one hand, Kārearea synchronised the buy and sell process of ETF/MFs with the providing partners via serial activity links to streamline the process and increase efficiencies and timely responses 8 . While Kārearea pursued the idea to create an administration tool for its ETF/MFs providers to streamline the buy/sell process, it was not implemented during the time of the study.

"We have floated this idea to expose a login portal for them. It would be fantastic to automate it, but we might develop some half-way options that are easy to implement and gets us $90 \%$ of the game." (Co-Founder, Kārearea)

Moreover, Kārearea integrated with external providers of payment and ID verification services integration with activities performed by external partners. Integrating with a standardised ID

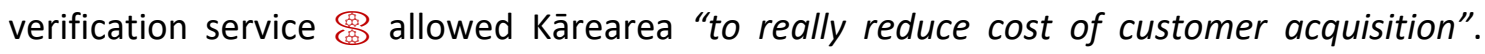


Moreover, to enable users to pay with credit cards, Kārearea coordinated its activities with an external payment service provider and, thus, streamlined payment processes. Finally, offering MF on the platform required the venture to pay tax on customers' behalf and coordinate joint activities of MF providers and customers to claim tax refunds

On the other hand, the absence of opportunities to link activities with other actors

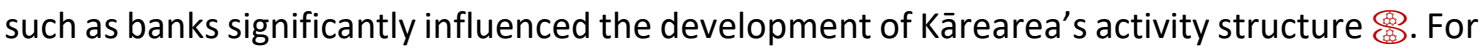
instance, transaction data from customers were imported manually in Kārearea's system via an administration interface developed for that purpose. The tedious manual process was further automated via a bot developed in stage three of the study $\left(\mathrm{S}_{0.0}\right.$.

"That's another thing we'll have to automate over time because we eyeball every single transaction and decide that this was a deposit for person $X$ and this was a deposit for person $X . "$

(Co-Founder, Kārearea)

Overall, the development of Kārearea's activity structure was characterised by serial and dyadic activity links of limited scope with a small set of actors. Facilitating buy and sell processes of investment products with brokers and ETF/MF providers, coordinating ID verification and payment processes, and aligning the information exchange to file tax claims on customers' behalf were amongst the activity links developed by Kārearea to streamline processes and reduce costs. Also, Kārearea coped with the absence of opportunities to link activities with other financial service providers by developing resources (e.g. transaction bot) to further automate processes or perform activities in-house Kārearea's activities and activity links with actors was summarised by one of the interviewees as:

"In the long term, this will be some sort of end-to-end solution. Not sure if you have ever seen a financial services start-up, it is a nightmare and will be very manual to start off" (Co-Founder, Kārearea)

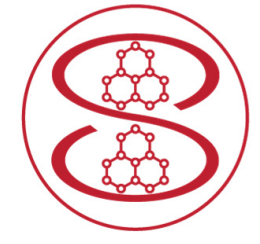

Kārearea developed several physical and organisational resource ties with a small set of actors. Central to Kārearea's VCC mechanisms was the offering of ETF/MFs that were provided by external partners and sold to customers G. While no adaption of these resources was required, linking the 
provision of ETF/MFs with the ownership of customers was pivotal from the beginning onwards $\underset{8}{6}$.

Likewise, Kārearea created physical resource ties with infrastructure, payment, and ID verification service providers via APIs ${ }^{12}$. On the one hand, Kārearea employed development techniques such as docker-containers to maintain a high level of independence from service providers such as Amazon Web Services ${ }^{13}$. On the other hand, integrating with infrastructure, payment, ID verification, and e-mail services providers via APIs required the development of bespoke software modules changes in Kārearea's resource collections and result in substantial development costs.

"Swapping out a service provider would be a big time sink" (Co-Founder, Kārearea)

The API integration was paramount for linking internal and external activities, such as ID verifications, and enabling cost-efficient transactions $\&$. In contrast, the challenges associated with creating resource ties such as the limited extent of other actors' resource interfaces and surrounding processes required Kārearea to unilaterally adopt its own resource collection to integrate with its ecosystem efficiently.

\begin{abstract}
"It would be great to get automated feeds of the banks. The depressing part, though ... it is a daily feed, and we can't even get that because we have to jump through hoops and loops and bureaucracy and all sorts of rubbish. It's awful, we can't even get the crappy thing. Instead we are doing it manually ... via the admin interface we built" (Co-Founder, Kārearea)
\end{abstract}

In response to the absence of bank feeds, Kārearea developed a bot to automate the import, export, and verification of customers' transaction data in stage four

Overall, Kārearea's resource collection development was driven by the initial and ongoing integration with technology service providers, on the one hand, and the absence of opportunities to create resource ties with banks to adapt processes the mutual development of resources in cooperation with partners was limited $\&$, Kārearea predominantly developed its resource collection to fit into the existing resource constellations of technology service providers and other actors.

\footnotetext{
${ }^{12}$ Application Programming Interface - Communication Protocols defining the exchange of data between software modules or programs.

${ }^{13}$ Amazon Web Services (AWS) - Provider of cloud computing infrastructure such as compute power, database storage, applications, and other IT resources.
} 


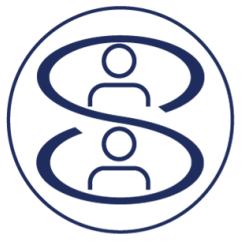

Kārearea was highly restrictive in the development of actor bonds throughout the study. However, actor bonds were considered important for the ventures' development. Firstly, being associated with reputable actors in the financial service industry allowed Kārearea to gain vital legitimacy and trust amongst customers.

"It is interesting because [ETF provider] talks about Kārearea quite often, we were in their last strategic report and can leverage their brand ... the accelerator program was another chance to use another big brand that is trusted with money" (Co-Founder, Kārearea)

The bonds created with and the engagement of opinion leaders in the industry via the blog further emphasised the focus on building trust through social capital and creating an identity for the entrepreneurial venture via recognisable brands. Creating and intensifying actor bonds via continuous interaction and public association with ETF/MF providers allowed

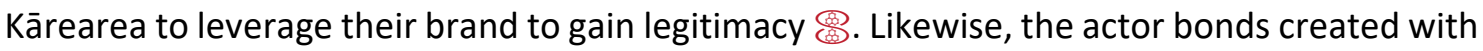
Financial Market Authorities (FMA), due to consultations with the agency in the beginning and participation in a lobbying movement in later stages, further contributed to creating an identity for the emerging venture in the ecosystem and enhanced trust amongst customers. Managing interactions and maintaining a good relationship with the FMA was considered pivotal since changes in regulations can render Kārearea's VCC mechanisms obsolete.

"We have spoken with the FMA, and they say we aren't regulated. We are in a legal grey area, and if they decided that they didn't like us, it would be pretty crippling" (Co-Founder, Kārearea)

Building actor bonds with established industry players positioned Kārearea in the ecosystem as a service provider to private micro-investors and outside of the competitive scope of its ETF/MF providers. The intensified relationships built with ETF/MF providers and brokers via daily synchronised interactions $\circledast$ enabled the renegotiation of contract terms and in turn a reduction in brokerage and an additional source of revenue from rebates earlier than expected.

In short, while Kārearea extensively explored how it can engage with various different actors, the venture was highly selective in the development of actor bonds. The restrictive development underpinned the venture's aim to maintain flexibility for agile development in 
the advent of open banking and the increasing popularity of APIs amongst financial service providers actors to position the venture in the ecosystem to create trust amongst customers as a reputable provider of financial service products.

\subsubsection{Summary Kārearea}

The development of Kārearea was contextualised in the VARA framework. Several interdependencies of VCC mechanisms and underpinning activity links, resource ties and actor bonds were identified. The development of Kārearea's VCC mechanisms was characterised by tensions such as an increases in the range of available investments and the ability to consolidate trades on the platform, on the one hand, and complementarities such as the volume of individual portfolios and the rebates earned from EFT/MF providers reinforced by the newly introduced pricing scheme on the other. Few activity links were developed with actors by adapting mainly internal activities. Simultaneously, Kārearea maintained flexibility by developing generic resource ties. For instance, developing sourcecode in docker-containers allowed to migrate software solutions and switch infrastructure providers. However, organisational resource ties created with ETF/MF providers, brokers, and financial service providers enhanced the scope of resource integration. For instance, synchronising buy and sell processes or developing a bot to automate transaction processes. Kārearea developed bonds with a small set of actors to gain legitimacy and position the venture in the ecosystem. Figure 30 summarises the development of Kārearea's activity links, resource ties, and actor bonds over the period of the study. Characterising for the development of Kārearea's BM was the limited depth of integrations with a small scale of other actors.

\footnotetext{
"Strategic partnerships, what do you think about them? I think in a world of APIs the fight right now is on for who owns the customer experience ... but that fight is already lost ... owning something and tying things down to strategic partnerships is no longer a thing."

(Co-Founder, Kārearea)
} 


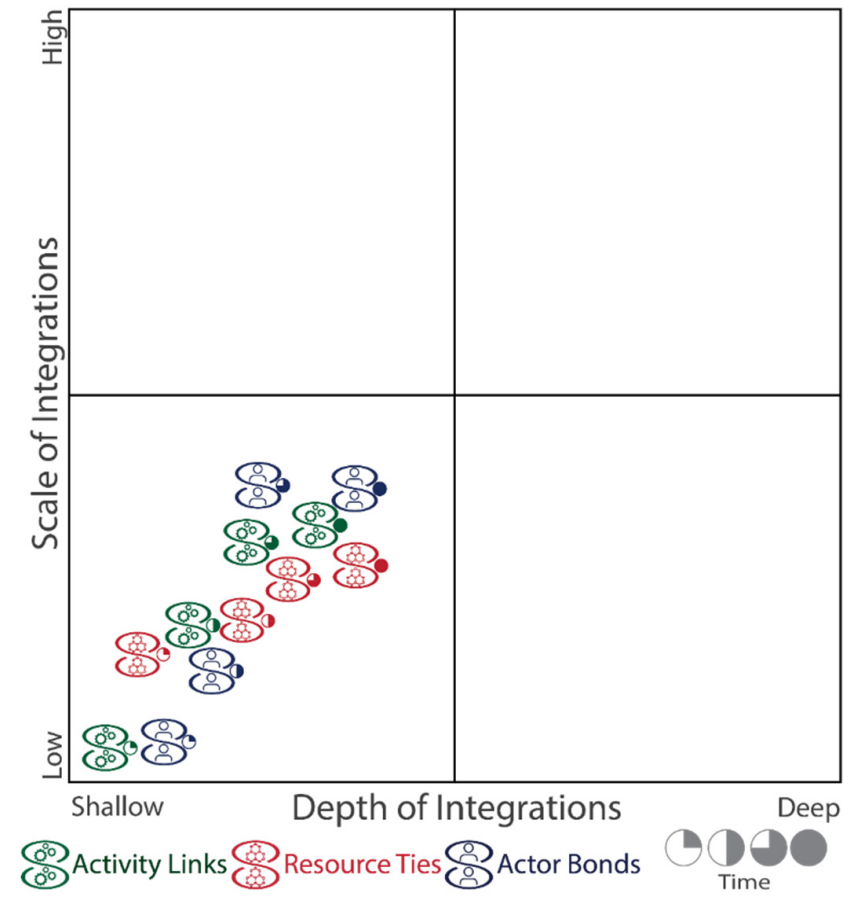

Figure 30 - Kārearea - Development of Activity Links, Resource Ties, and Actor Bonds 


\subsection{Case Report - Venture Matuku}

\subsubsection{Introduction}

Matuku provided analytical services to the electricity sector in New Zealand. Next to developing customer value propositions for lines companies, the venture explored the creation of value propositions for several additional customer segments by leveraging a growing data set. Moreover, the venture created actor value propositions for e-retailers to obtain access to user consumption data and provide business intelligence services. Matuku established integration with a small sets of actors in its ecosystem. The venture attracted several customers, received robust investment, and provided evidence of the development of a viable BM throughout the study.

"We are using smart meter data for our analysis of billing and consumption patterns of customers to provide services to lines companies" (Co-Founder, Matuku)

\subsubsection{Development of Customer Value Co-Creation Mechanisms}

\begin{tabular}{|c|c|c|c|}
\hline Time & $D$ & & \\
\hline $\begin{array}{l}o \complement \\
\stackrel{\circ}{3}\end{array}$ & $\begin{array}{l}\text { "We think that } 80 \text { to } 90 \% \text { of our } \\
\text { value will come from lines } \\
\text { companies." }\end{array}$ & $\begin{array}{l}\text { "Lines companies facing emerging } \\
\text { technologies, the electricity } \\
\text { authority, the commerce } \\
\text { commission." }\end{array}$ & $\begin{array}{l}\text { "Mainly lines companies, the EA, the } \\
\text { Commerce Commission, and } \\
\text { eventually TransPower." }\end{array}$ \\
\hline $\begin{array}{l}\text { ind } \\
+\frac{1}{\pi} \\
\stackrel{+}{\frac{1}{3}}\end{array}$ & $\begin{array}{l}\text { "Lines companies have a pricing and } \\
\text { network management focus, and we } \\
\text { provide analytical services to reveal } \\
\text { energy consumption patterns } \\
\text { influences inform day-to-day } \\
\text { management and drive capital } \\
\text { expenditures." } \\
\text { "Line network operators need to } \\
\text { provide competitive prices for } \\
\text { industrial and commercial } \\
\text { consumers." }\end{array}$ & $\begin{array}{l}\text { "Next to the EA's" mandate, lines } \\
\text { companies have a legitimate reason } \\
\text { trying to understand their network } \\
\text { better and make intelligent } \\
\text { investment decisions. Information } \\
\text { about consumption profiles provides } \\
\text { insights for network configurations } \\
\text { and can significantly contribute to } \\
\text { reducing of investment." }\end{array}$ & $\begin{array}{l}\text { "We help them to manage their } \\
\text { network, minimise outages, and } \\
\text { control and predict network loads } \\
\text { based on weather forecasts to } \\
\text { facilitate timely response in network } \\
\text { management." } \\
\text { "Our service can help lines } \\
\text { companies to mitigate the risk of } \\
\text { revenue losses from e-retailers' } \\
\text { consolidated billings." }\end{array}$ \\
\hline $\begin{array}{l}\text { 댁 } \\
3 \\
\text { 온 }\end{array}$ & $\begin{array}{l}\text { "We provide data analysis services } \\
\text { such as data warehousing, } \\
\text { aggregations and visualisations of } \\
\text { information to provide insights and } \\
\text { support decision-making for line } \\
\text { network development." }\end{array}$ & $\begin{array}{l}\text { "We try to understand customers' } \\
\text { problems and present data either } \\
\text { visually or another summarised } \\
\text { format so they can make an } \\
\text { informed decision. We provide a } \\
\text { network performance assessment } \\
\text { service for line companies." }\end{array}$ & $\begin{array}{l}\text { "We focus on providing business } \\
\text { intelligence and smart metering } \\
\text { tariff modelling for lines companies" } \\
\text { "We offer revenue assurance } \\
\text { services." }\end{array}$ \\
\hline 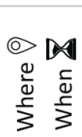 & $\begin{array}{l}\text { "New Zealand has } 29 \text { lines } \\
\text { companies, they are essentially } \\
\text { geographic monopolies and heavily } \\
\text { regulated." }\end{array}$ & $\begin{array}{l}\text { "We tend to focus on the network by } \\
\text { network basis and are thus } \\
\text { geographically focused." }\end{array}$ & \\
\hline
\end{tabular}

Table 9 - Matuku - Development of Customer Value Co-Creation Mechanisms 


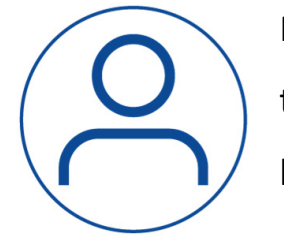

Matuku focused on lines companies as a core customer segment throughout the study. In addition, the venture leveraged available data 8 business intelligence services to regulatory and government authorities 8 .

"We are providing analytical services to the Electricity Authority. They are a fantastic channel because 7 CEOs of lines companies sit on the board." (Co-Founder, Matuku)

Other regulatory authorities such as the commerce commission and the state-owned national energy transmission company, TransPower, were explored as potential customers. Although electricity retailers (e-retailers) were initially considered as partners $\&$, the venture explored opportunities to provide services to them as customers.

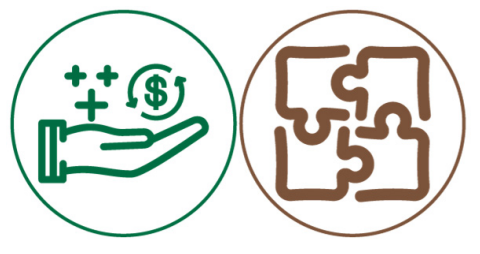

Matuku's customer value co-creation mechanisms were based on the provided business intelligence services. The venture cooperated with lines companies to develop data warehouses and models that allowed to (a) explore cost-reflective tariff scenarios, (b) inform the development of lines companies' networks, and (c) support the management of the network $\underset{\varnothing}{\infty}$.

"EA forced lines companies to develop cost-reflective pricing models and we are helping them in an analytical manner. We develop a data map to run billing scenarios and advice lines companies about proposed cost-reflective tariffs, appropriate billing structures, and the winners and losers in different transmission charge scenarios.” (Co-Founder, Matuku)

Matuku planned to enhance its offering for lines companies by developing an active outage monitoring system that supports maintenance management.

"We want to provide an outage monitor for lines companies. The console allows them to monitor individual smart meters, understand their network in a higher level of detail, and respond faster and more efficiently to outages." (Co-Founder, Matuku)

However, moderate interest in outage monitoring from lines companies was compensated by exploring alternative customer segments' interest in the service 8 .

"The commerce commission is interested in measuring electrical quality such as voltage fluctuations. Likewise, the EA wants to evaluate possible network shortages and outages. 
Despite lines companies' lukewarm interest, the outage monitor might still become a valuable service" (Co-Founder, Matuku)

Matuku's engagement with an increasing number of lines companies fuelled opportunities to leverage the growing data set that was available to the company $($.$) . The$ venture explored the provision of network analysis and modelling services to TransPower.

"Monitoring consumption patterns across line companies might provide value to TransPower and enable them to reduce overall consumption" (Co-Founder, Matuku)

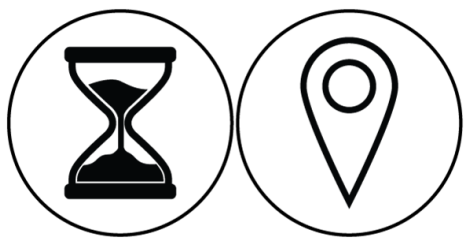

Matuku's customer value co-creation mechanisms were focused on servicing lines companies in New Zealand. Domestic regulations and initiatives created a demand for the venture's services. However, Matuku explored potential markets overseas and attended international conferences to explore opportunities in Asia. The venture's customer value-co creation mechanisms had no noticeable temporal components.

Overall, Matuku explored opportunities to augment customer value co-creation mechanisms for lines companies. In addition, opportunities to leverage existing data and capabilities in co-creating value with additional customer segments such as different regulatory authorities, industry interest groups, and the national transmission grid were explored 8 . The development of Matuku's customer value proposition has been illustrated in Figure 31. 


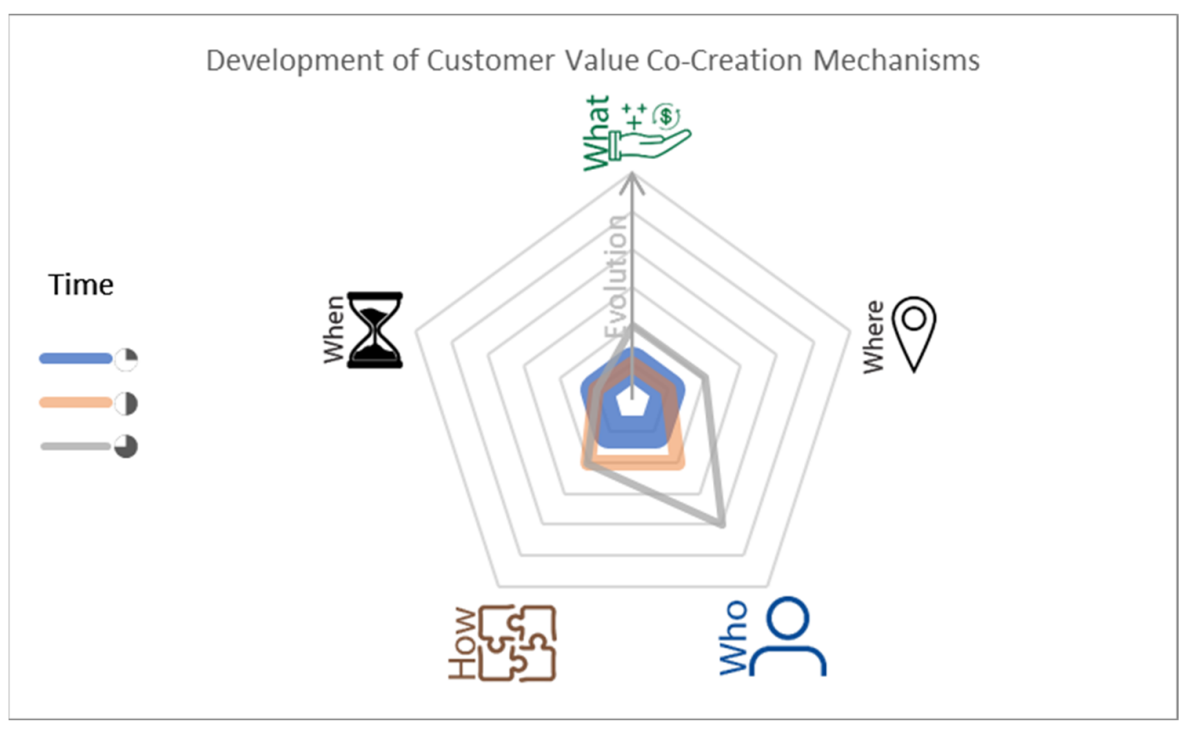

Figure 31 - Matuku - Development of Customer Value Co-Creation Mechanisms

\subsubsection{Development of Actor Value Co-Creation Mechanisms}

\begin{tabular}{|c|c|c|c|}
\hline Time & $\mathbf{D}$ & & \\
\hline $\begin{array}{l}\text { OC } \\
\stackrel{\circ}{\frac{1}{3}}\end{array}$ & "e-retailers are crucial stakeholders" & $\begin{array}{l}\text { "We started working with retailers to } \\
\text { get access to data, but we might } \\
\text { have more opportunities with them } \\
\text { then initially anticipated" }\end{array}$ & $\begin{array}{l}\text { "We have received consumption } \\
\text { data from three retailers" }\end{array}$ \\
\hline $\begin{array}{l}\frac{9.1}{i+1)} \\
\frac{\pi}{0} \\
\frac{c}{3}\end{array}$ & $\begin{array}{l}\text { "enhancing the rollout of smart } \\
\text { metering tariffs creates the need for } \\
\text { cost reflective billing and thus the } \\
\text { services of [partner1]" } \\
\text { "[partner2] sees the opportunity to }\end{array}$ & $\begin{array}{l}\text { "currently retailers share that data } \\
\text { for the benefit of the network, but we } \\
\text { are exploring how we can provide } \\
\text { value back to them in exchange. This } \\
\text { is where customer retention } \\
\text { modelling can come in. Establishing }\end{array}$ & $\begin{array}{l}\text { "We can help e-retailers to reveal } \\
\text { arbitrage opportunities and attract } \\
\text { customers from their competitors. } \\
\text { Introducing cost-reflective pricing } \\
\text { forces them into a competition and } \\
\text { no one can afford to stay behind of }\end{array}$ \\
\hline 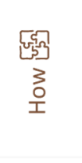 & $\begin{array}{l}\text { commercialise their IP and data in a } \\
\text { non-regulated market. The threshold } \\
\text { is very low for them and they can } \\
\text { talk about their strategies to benefit } \\
\text { from emerging technologies" }\end{array}$ & $\begin{array}{l}\text { a model that facilitates the exchange } \\
\text { of data for the benefit of the lines } \\
\text { companies, retailers, and meter } \\
\text { equipment providers is the biggest } \\
\text { challenge" }\end{array}$ & $\begin{array}{l}\text { others that offer smart-metering } \\
\text { tariffs" }\end{array}$ \\
\hline 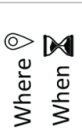 & $\begin{array}{l}\text { "lines companies work with different } \\
\text { regional e-retailers" }\end{array}$ & & \\
\hline
\end{tabular}

Table 10 - Matuku - Development of Actor Value Co-Creation Mechanisms

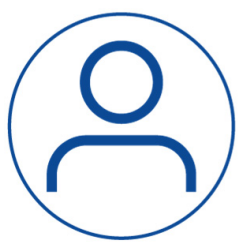

Matuku engaged with three actors in value co-creation mechanisms. Next to [partner1], a provider of software solution for the electricity sector, and [partner2], a lines company, that provided IP 8 , the venture engaged with various retailers and was developing value propositions for them. 


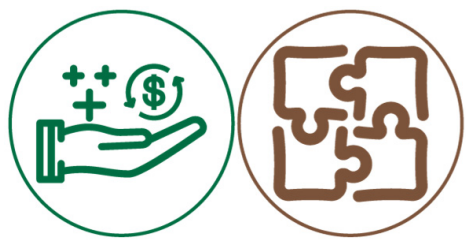

Matuku co-created value for the engaged actors in different ways. [Partner1] provided access to a billing engine retailers that allowed the venture to simulate and test proposed cost-reflective tariffs for lines companies result, the implementation of cost-reflective pricing tariffs created a demand for advanced billing services and thus demand for [partner1's] billing engine. For [parnter2] Matuku cocreated value by leveraging data and IP 盈 that the company was not allowed to commercialise itself because of regulatory limitations 8 .

“[partner1] has developed IP around how lines companies can use smart meter data to enhance networks. There is an opportunity for us to commercialise their IP" (Co-Founder, Matuku)

Moreover, [partner2] benefited by obtaining an understanding of strategies, technologies, and data analysis methods other lines companies employ to take advantage of the emerging technologies. Finally, [partner1] and [partner2] obtained reputational benefits from cooperating with a data science start-up 8 .

"Our partners benefit in multiple ways. They receive first hand intel on industry developments, can leverage their IP and resources, and support a young upcoming company in the field, that always looks good in a press statement" (Co-Founder, Matuku)

In addition, Matuku engaged with e-retailers to obtain pivotal consumer data underpinning the provided business intelligence services. The venture developed a customer retention modelling system and network analysis model for e-retailers in the second stage of the study. While the former allowed e-retailers to manage pricing and assess the risk of losing individual customers to competitors, the latter helped them to reduce their lines companies' connection charge for individual customers $\underset{\varnothing}{\varnothing}$.

"The challenge is to secure access to retailers' smart meter information. We plan to provide a customer retention tool in exchange as well as helping them to reduce their line network operator charges for each individual customer" (Co-Founder, Matuku)

Matuku extended its offering to e-retailers for a price comparison model that allowed them to attract customers from competitors. 


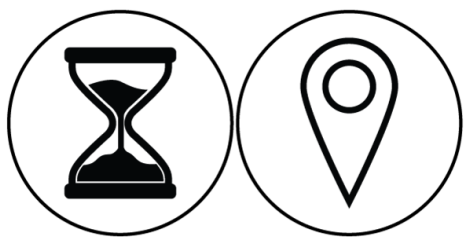

Matuku's customer value co-creation mechanisms were dependent on obtaining data from e-retailers operating in lines companies' regions retailers operate in the same geographical areas and therefore can provide customer data. The ventures' actor value co-creation mechanisms had no significant temporal component.

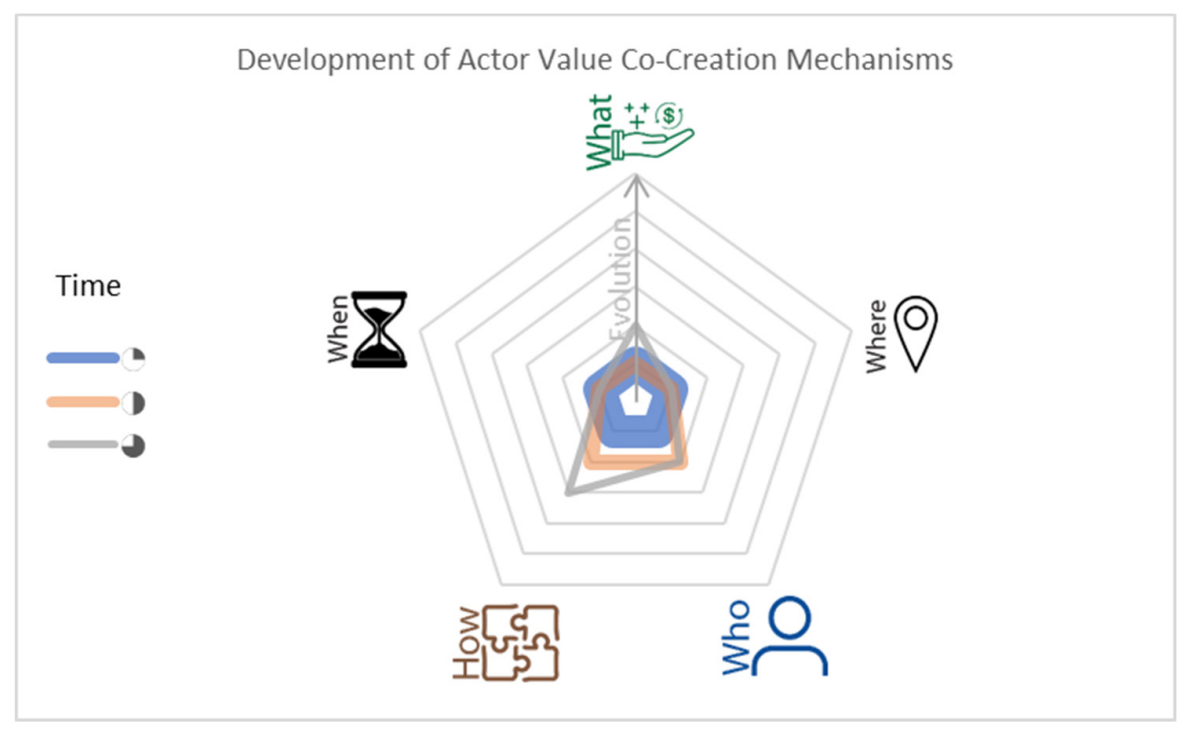

Figure 32 - Matuku - Development of Actor Value Co-Creation Mechanisms

Overall, Matuku's actor value co-creation mechanisms developed throughout the study. The venture focused primarily on co-creating value with partners providing IP and eretailers granting access to consumer data. Developing an offering for e-retailers to enhance access to data further underpins the venture's aims to engage a small set of actors to build and leverage a robust data set to provide business intelligence services to multiple customers. Figure 32 illustrates the development of Matuku's actor value co-creation mechanisms throughout the study. 


\subsubsection{Development of Value Capture Mechanisms}

\begin{tabular}{|c|c|c|c|}
\hline Time & $\mathbf{D}$ & & \\
\hline 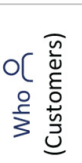 & $\begin{array}{l}\text { "We think that 8o to } 90 \% \text { of our } \\
\text { value will come from lines } \\
\text { companies" }\end{array}$ & $\begin{array}{l}\text { "Lines companies and e-retailers } \\
\text { facing emerging technologies." }\end{array}$ & $\begin{array}{l}\text { "Mainly lines companies, the EA, the } \\
\text { Commerce Commission, and } \\
\text { eventually TransPower" }\end{array}$ \\
\hline 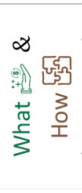 & $\begin{array}{l}\text { "One-off consulting fee for cost- } \\
\text { reflective pricing modelling or a } \\
\text { subscription fee for the network } \\
\text { outage monitoring service." }\end{array}$ & $\begin{array}{l}\text { "Pricing depends on the size of } \\
\text { client's networks, how congregated } \\
\text { the proposed tariff models are, and if } \\
\text { they want to validate an existing } \\
\text { model or develop several new ones." }\end{array}$ & $\begin{array}{l}\text { "We decided against an } X \text {-as-a- } \\
\text { service business model. We have } \\
\text { reoccurring revenues as a monthly } \\
\text { business intelligence service } \\
\text { providing expertise on how to take } \\
\text { advantage of emerging technologies." }\end{array}$ \\
\hline 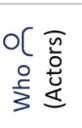 & "E-retailers are crucial stakeholders." & $\begin{array}{l}\text { "We started working with retailers to } \\
\text { get access to data, but we might have } \\
\text { more opportunities with them than } \\
\text { initially anticipated." }\end{array}$ & $\begin{array}{l}\text { "We have received consumption data } \\
\text { from three retailers now." }\end{array}$ \\
\hline 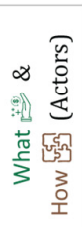 & $\begin{array}{l}\text { "Having access to the different } \\
\text { methodologies retailers use for billing } \\
\text { is incredibly valuable because it is } \\
\text { very complex. We need that to test } \\
\text { cost-reflective tariffs." }\end{array}$ & $\begin{array}{l}\text { "Currently retailers share that data } \\
\text { for the benefit of the network." }\end{array}$ & $\begin{array}{l}\text { "An ongoing subscription-based } \\
\text { service fee for customer retention } \\
\text { monitoring." }\end{array}$ \\
\hline $\begin{array}{l}0 \\
0 \\
\frac{1}{2} \\
\frac{5}{3} \\
\frac{5}{3}\end{array}$ & $\begin{array}{l}\text { "Annual subscription fee for outage } \\
\text { monitoring." }\end{array}$ & & $\begin{array}{l}\text { "Line charges apply to regional lines } \\
\text { companies." } \\
\text { "Subscription fee." }\end{array}$ \\
\hline
\end{tabular}

Table 11 - Matuku-Development of Value Capture Mechanisms

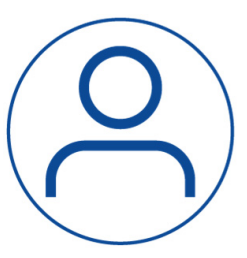

Matuku captured pecuniary and non-pecuniary value from customers as well as other actors in the ecosystem. While lines companies and regulatory authorities were a source of pecuniary value, e-retailers and partners were sources of non-pecuniary value 蜀. In the last stage of the study, Matuku explored opportunities to capture pecuniary value from e-retailers.

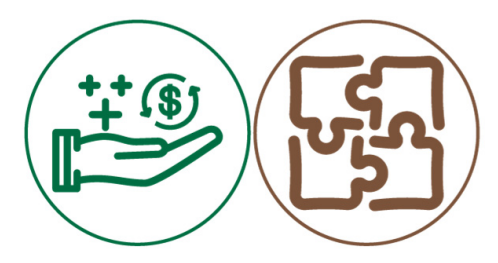

Matuku captured pecuniary value from lines companies by charging fees for reflective-price modelling services. Reoccurring revenues were generated by providing monthly intelligence services for lines companies. Moreover, the

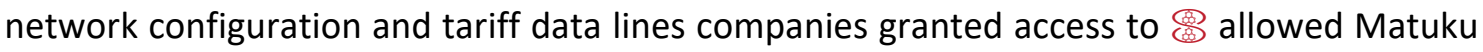
to provide services for e-retailers such as optimising connection charges $\frac{\pi}{6}$. 
"Based on the size of the network and the scope of services we provide, we draft a service agreement with a large number underneath. Currently, that's our main source of revenue" (CoFounder, Matuku)

Charging consulting service fees accounted for the majority of pecuniary value captured. However, lines companies provide a chance to capture non-pecuniary value by obtaining data that can be used to provide services to e-retailers as well as other customers.

In addition, Matuku captured non-pecuniary value from e-retailers by obtaining consumption data from smart meters of individual customers $\mathrm{S}$. Since the data underpinned the business intelligence services provided to lines companies, the venture started to develop an offering for e-retailers to enhance the exchange of data with them $\operatorname{S}$ (

"We want to kick off a project with a lines company, but we are waiting for data from eretailers. The challenge is securing access to retailers' smart meter information and providing a customer retention tool in exchange" (Co-Founder, Matuku)

Finally, Matuku captured value from [partner1] and [partner2] by having access to IP 蜀 that was considered paramount for performing cost-reflective pricing models.

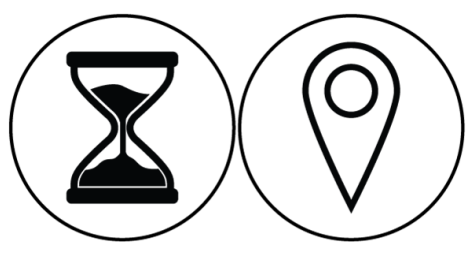

Matuku's value capture mechanisms were based on consulting services. While temporary engagements for cost-reflective pricing modelling characterised the venture's value capture mechanisms, the ongoing business intelligence service provided a foundation for monthly billings. Furthermore, Matuku explored opportunities to establish value capture mechanisms to ensure reoccurring revenues based on subscription to service platforms. However, none of that was realised over the period of the study. 


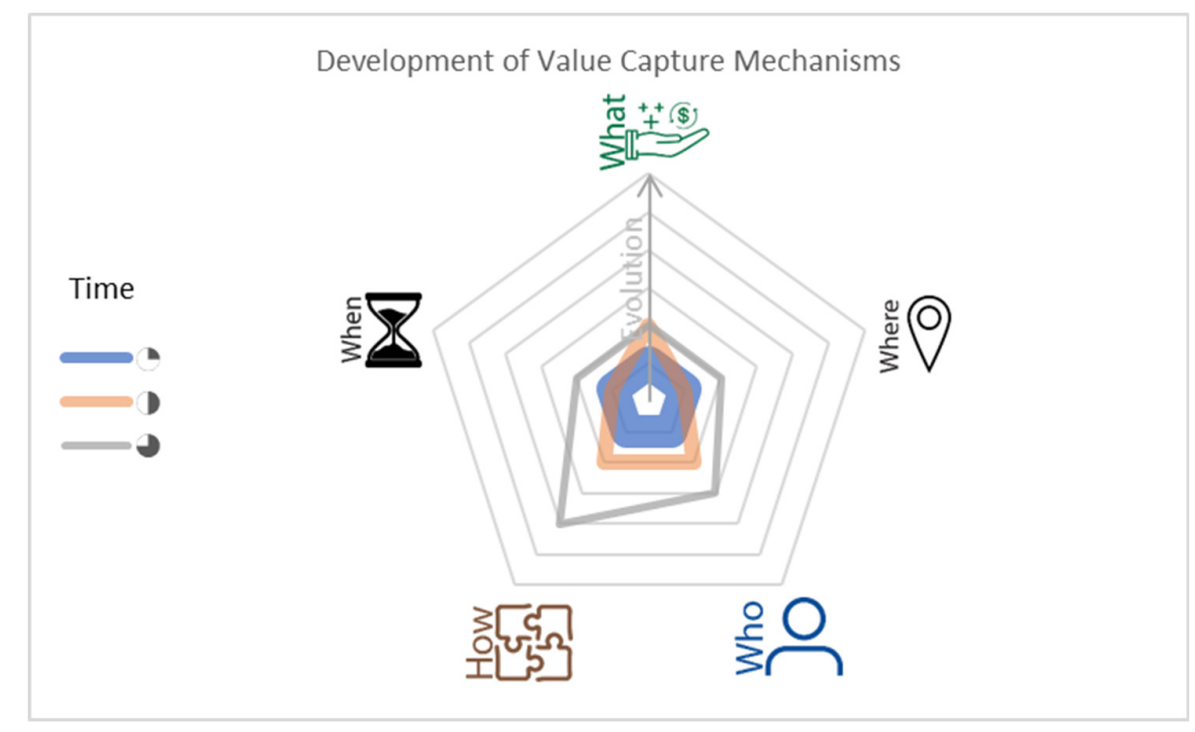

Figure 33 - Matuku - Development of Value Capture Mechanisms

Overall, Matuku's value capture mechanisms developed marginally over the period of the study. While capturing pecuniary and non-pecuniary value was immanent in the venture's value capture mechanisms, how and from whom value was captured developed over time. The development of Matuku's value capture mechanisms has been illustrated in Figure 33.

"The reality of our business model is not software-as-a-service, it might morph into one, but we realised that when drafting our service contracts, it doesn't make any sense. We provide a consulting service with reoccurring revenue, and we are not worried about how it is called rather about how to create value with our customers" (Co-Founder, Matuku)

\subsubsection{Summary Value Co-Creation and Capture Mechanisms}

Matuku's VCC mechanisms development process was governed by the approach to leverage a growing data set to provide services to an increasing scale of customers. Simultaneously the venture enhanced its engagement with actors such as e-retailers to capture non-pecuniary and potentially pecuniary value from them.

"We are exploring new ways how we can use existing data to develop new service and increase revenues without driving costs. Lines companies and e-retailers have quite different value drivers but it all ties back to similar skill sets that we have in terms of analytics and understanding customer needs" (Co-Founder, Matuku)

In contrast to customer value co-creation mechanisms, the venture marginally 
developed actor value co-creation mechanisms over time. Finally, capturing pecuniary and non-pecuniary value from customers as well as other actors was crucial for the viability of the ventures' BM. Matuku's development of VCC mechanisms over time has been illustrated in Figure 34 .

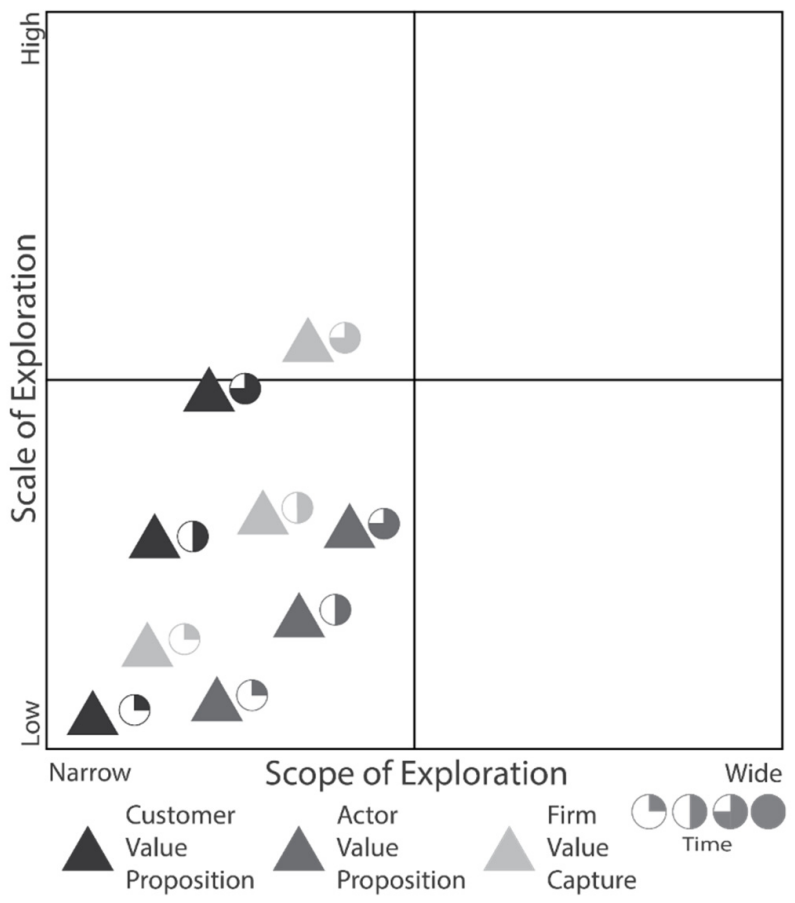

Figure 34 - Matuku - Development of Value Co-Creation and Capture Mechanisms 


\subsubsection{Development of Activity Links, Resource Ties, and Actor Bonds}

\begin{tabular}{|c|c|c|c|}
\hline Time & $B$ & & \\
\hline 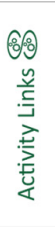 & $\begin{array}{l}\text { "We coordinate the data exchange } \\
\text { between retailers and line network } \\
\text { operators. We provide a platform that } \\
\text { anonymises the data to comply with } \\
\text { all privacy commission requirements, } \\
\text { enhances the data, and provides } \\
\text { insights for lines companies." }\end{array}$ & $\begin{array}{l}\text { "Some line network operators have } \\
\text { data science teams that use data } \\
\text { models for decision making. We have } \\
\text { to coordinate the development of the } \\
\text { data warehouse, engines, and models } \\
\text { with them quite frequently." }\end{array}$ & $\begin{array}{l}\text { "Negotiating with retailers and } \\
\text { advancing their policies and process } \\
\text { about how to release information. }\end{array}$ \\
\hline 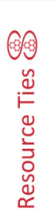 & $\begin{array}{l}\text { "Intellectual property is coming from } \\
\text { [parnter1] as well as [partner2], they } \\
\text { both provide IP, know-how, } \\
\text { references, and even sales } \\
\text { opportunities." }\end{array}$ & $\begin{array}{l}\text { "Line network operators provide } \\
\text { configuration data about their } \\
\text { infrastructure such as smart meter } \\
\text { connections, transformers, feeders, } \\
\text { substations, line tariffs. Retailers } \\
\text { provide consumption data." }\end{array}$ & $\begin{array}{l}\text { "Amazon offers machine learning } \\
\text { tools that are very interested. We } \\
\text { want to use machine learning to } \\
\text { predict potential network loads and } \\
\text { make recommendations for network } \\
\text { development." }\end{array}$ \\
\hline 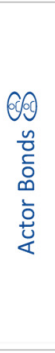 & $\begin{array}{l}\text { "We have gained access to consumer } \\
\text { data via retailers. Since they have a } \\
\text { shared responsibility with lines } \\
\text { companies to provide electricity } \\
\text { services to consumers e-retailers } \\
\text { often have to collaborate." } \\
\text { "Being associated with our partners is } \\
\text { very valuable. They have been in this } \\
\text { industry for more than } 20 \text { years and } \\
\text { provide credibility and standing." }\end{array}$ & $\begin{array}{l}\text { "The e-retailers Association of NZ, E- } \\
\text { Network Association, and Electric } \\
\text { Authority (EA) are all working on } \\
\text { standards to share data and the } \\
\text { challenges of introducing cost- } \\
\text { reflective pricing. Since e-retail is a } \\
\text { non-regulated market, the EA can } \\
\text { only leverage line networks to } \\
\text { influence pricing and promote } \\
\text { opportunities to provide smart } \\
\text { offerings to consumers." }\end{array}$ & $\begin{array}{l}\text { "We have established good } \\
\text { relationships with three retailers and } \\
\text { try to attract the fourth now. } \\
\text { However, there is another one who is } \\
\text { very interested but we are concerned } \\
\text { about what they are doing with the } \\
\text { solution we provide." }\end{array}$ \\
\hline
\end{tabular}

Table 12 - Matuku - Development of Activity Links, Resource Ties, and Actor Bonds

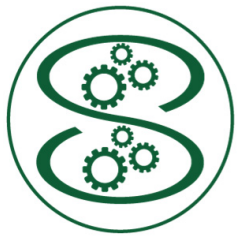

Matuku developed a limited number of serial activity links with a small set of actors. The exchange of data essential and required the venture to perform activities aligned with the requirements of other actors. For instance, e-retailers required to anonymise the individual households' smart metering data to (a) comply with the requirements of the privacy commission and (b) avoid potential competition with lines companies 8 . As a result, Matuku developed an anonymisation process to ensure the anonymity of individual consumers.

"The data we receive from retailers has to be tokenised and aggregated to anonymise datasets and make sure individual customers can't be identified. The process needs to be audited and certified by the privacy commissions" (Co-Founder, Matuku)

Moreover, cooperating with lines companies often required the development of tailored data warehouses to meet customers' requirements 蜀. Finally, Matuku engaged with e-retailers in the design of policies and processes to release smart-metering data to shape 
interdependencies of data exchange processes 8 .

"They have come up with guidelines on how and what data is shared in cooperations. Some of them are charging minimal costs others provide the data for the benefit of the network and potential cost reductions" (Co-Founder, Matuku)

In short, the development of activity links in Matuku's BM was characterised by the exchange of inbound and outbound data . Serial activity links were created with lines companies, i.e. customers, and e-retailers to facilitate the exchange of data aligned with the requirements of the privacy act 8 .

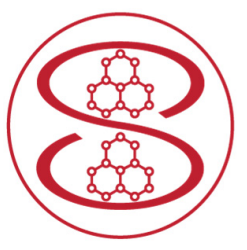

Matuku developed physical and organisational resource ties with a small set of actors. Obtaining access to external resources such as data modelling IP, a billing engine for the electricity sector, and smart metering data was pivotal for the venture's VCC mechanisms. The venture cooperated with [partner2] to make alterations to the billing engine required to facilitate the bulk modelling of smart metering tariffs

"[Partner2] provides the billing engine and a developer for adjusting functionalities to run bulk billing scenarios" (Co-Founder, Matuku)

Similarly, the venture negotiated access to consumer data with different e-retailers that enabled them to provide business intelligence services for lines companies

\footnotetext{
"The e-retailer usually owns the smart meter and the consumer owns the data that comes off it. Having access to data is crucial and difficult to negotiate since e-retailers are often reluctant to share it for privacy reasons and afraid of competition from lines companies. Lines companies can recommend consumers, based on their consumption data, to install solar panels or batteries in their house to balance peak loads and reduce network constraints. Consequently, the consumer buys less energy, and the e-retailer loses business" (Co-Founder, Matuku)
}

Finally, Matuku integrated with a cloud infrastructure provider and planned to enhance its commitment by leveraging a machine learning tool $\circledast$ to provide consulting services.

"We are exploring different cloud computing providers and trying to find the best environment ... we are using Amazon Web Services for our stack" (Co-Founder, Matuku) 
Overall, physical resource ties, i.e. access to external data of consumers and network configurations, IP, and cloud platform infrastructures dominated the development of the venture's resource collection. Moreover, organisational resource ties such as co-developing the billing engine to perform mass billing scenarios as well as data warehouses and models further enhanced the development of Matuku's resource collection. However, most resource ties were developed with a small set of actors and required only minor mutual adjustment efforts.

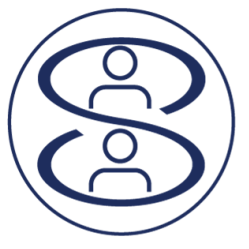

Matuku intensified actor bonds with two partners and a small set of eretailers. The actor bonds developed with partners provided access to IP and a billing engine 8,0 , know-how in the application 8 , credentials, and even sales leads. Both partners were engaged in the development of the venture from the beginning onwards.

Matuku developed actor bonds with e-retailers to obtain access to smart meter data to provide business intelligence services explored opportunities to co-create and capture value from e-retailers.

"Lines companies can push retailers to release information. However, they are not very responsive to those requests. We have had discussions with a couple of retailers, we need to get the sharing of information started before I can provide services. E-retailers are the most crucial partners in our processes" (Co-Founder, Matuku)

Moreover, Matuku's engagement as a service provider to regulatory authorities and other government agencies with interest in the electricity sector provided another chance for the venture to build legitimacy and position itself in the ecosystem.

In conclusion, Matuku developed actor bonds with two pivotal partners before the incorporation of the venture and leveraged its association with the two industry leaders to gain legitimacy, obtain crucial insights into the industry, and gain access to IP and know-how. Additionally, the venture successfully developed actor bonds with an increasing number of eretailers to secure access to smart meter data and shape the development of data release policies and procedures. 


\subsubsection{Summary Matuku}

Contextualising Matuku's BM in the VARA framework allowed to identify two crucial ecosystem interdependencies. First, VCC mechanisms were dependent on access to external data facilitated with e-retailers. Second, access to IP, a billing engine, and know-how on data modelling for lines networks facilitated through partnerships with [partner1] and [partner2] was important for the business intelligence services Matuku provided. The venture's developed activity links, resource ties, and actor bonds with a small set of actors engaged in VCC mechanisms throughout the study. However, the venture continuously explored opportunities to co-create and capture value with an increasing number of potential customers by leveraging an existing skill set and resources. The development of Matuku's activity links, resource ties and actor bonds have been illustrated in Figure 35.

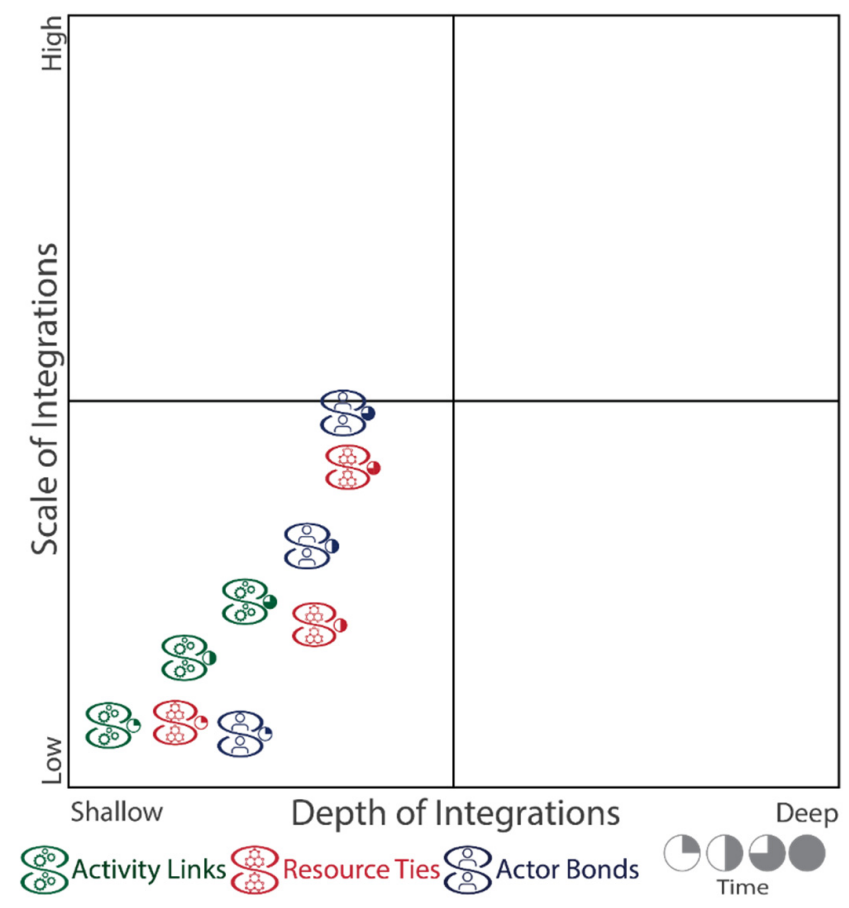

Figure 35 - Matuku - Development of Activity Links, Resource Ties, and Actor Bonds 


\subsection{Case Report - Venture Ruru}

\subsubsection{Introduction}

Ruru offered notebooks made from re-purposing printer paper and provided its services to SMEs and large public and private organisations in New Zealand. Ruru continuously developed customer value propositions to enhance VCC mechanisms throughout the study. In contrast, the venture only marginally refined a small set of actor value propositions to engage actors and developed few integrations with them throughout the study. Ruru attracted a large group of customers for its services, obtained funding from multiple sources, and provided indicators for the development of a viable BM throughout the study.

\subsubsection{Development of Customer Value Co-Creation Mechanisms}

"Have you ever thought of reusing your printed paper and turning it into something useful?"

\begin{tabular}{|c|c|c|c|c|}
\hline Time & $D$ & & & \\
\hline $\begin{array}{l}o[ \\
\frac{0}{3}\end{array}$ & $\begin{array}{l}\text { "Our customers are mostly } \\
\text { high-paper users such as } \\
\text { architects, and design } \\
\text { firms." }\end{array}$ & $\begin{array}{l}\text { "We onboarded a couple of } \\
\text { schools recently; they are } \\
\text { keen to educate students } \\
\text { about sustainability." }\end{array}$ & $\begin{array}{l}\text { "We added corporates to } \\
\text { small- and mid-sized } \\
\text { enterprises; we talked to a } \\
\text { few government agencies." }\end{array}$ & $\begin{array}{l}\text { "Conferences and their } \\
\text { bulk purchases ... they are } \\
\text { the big fish." }\end{array}$ \\
\hline 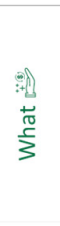 & $\begin{array}{l}\text { "We offer an extremely } \\
\text { easy to use service, that } \\
\text { helps organisations to } \\
\text { become more sustainable } \\
\text { and conveniently promote } \\
\text { that to customers and the } \\
\text { public." }\end{array}$ & $\begin{array}{l}\text { "Customers can see the } \\
\text { benefits in repurposing } \\
\text { their own paper and using } \\
\text { sustainable notebooks." }\end{array}$ & $\begin{array}{l}\text { "The big selling point for } \\
\text { them is a wide range of } \\
\text { customisation } \\
\text { opportunities in terms of } \\
\text { bindings, papers, foiling, } \\
\text { gold, photographs, } \\
\text { illustrations, or just text." }\end{array}$ & $\begin{array}{l}\text { "Offering gift notebooks or } \\
\text { make them purely } \\
\text { functional and drop the } \\
\text { price for office stationary } \\
\text { use." }\end{array}$ \\
\hline 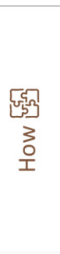 & $\begin{array}{l}\text { "We offer [service 1] and } \\
\text { [service 2], with the former } \\
\text { service we use customers' } \\
\text { waste paper to make } \\
\text { notebooks for them, later } \\
\text { we'll repurpose paper and } \\
\text { make notebooks for other } \\
\text { organisations." }\end{array}$ & $\begin{array}{l}\text { "We are working with } \\
\text { schools for fundraising } \\
\text { projects; students enter in } \\
\text { a picture competition, we } \\
\text { will scan the winning } \\
\text { picture and put it into the } \\
\text { notebooks they are } \\
\text { selling." }\end{array}$ & $\begin{array}{l}\text { "Customising covers has } \\
\text { always been an option, we } \\
\text { just haven't emphasised it } \\
\text { as much as we do it now, it } \\
\text { became a key selling point } \\
\text { for } 90 \% \text { of our customers." }\end{array}$ & $\begin{array}{l}\text { "The big orders are the } \\
\text { conferences and } \\
\text { organisations that want to } \\
\text { give our notebooks away; } \\
\text { it is quite affordable for a } \\
\text { corporate gift." }\end{array}$ \\
\hline$\frac{M}{3}$ & & $\begin{array}{l}\text { "We introduced a retainer } \\
\text { to encourage [service 1] } \\
\text { customers to purchase } \\
\text { notebooks at least twice a } \\
\text { year." }\end{array}$ & $\begin{array}{l}\text { "For private customers, we } \\
\text { offer subscription packages } \\
\text {... getting notebooks } \\
\text { delivered quarterly." }\end{array}$ & \\
\hline$\frac{0}{\frac{0}{2}}$ & $\begin{array}{l}\text { "Positioning collection } \\
\text { boxes next to the copy } \\
\text { machine or the recycling } \\
\text { isles works well." }\end{array}$ & $\begin{array}{l}\text { "Bigger market } \\
\text { opportunity up in } \\
\text { Auckland." }\end{array}$ & $\begin{array}{l}\text { "We collect nationwide } \\
\text { now and have customers in } \\
\text { Auckland, Christchurch, } \\
\text { and Queenstown" }\end{array}$ & $\begin{array}{l}\text { "Our first order from an } \\
\text { Australian customer." }\end{array}$ \\
\hline
\end{tabular}




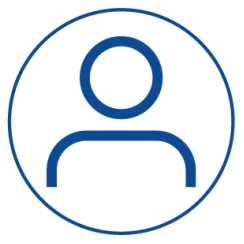

While focused on small and mid-sized architecture and design firms as well as schools and universities in the early stages of the study, Ruru extended its customer segments to large private and government organisations and conferences in the final stages of the study. The broad range of customers shared one distinct characteristic, the extensive use of copy-paper paired with concerns about the environmental impact.

"High paper users who don't want to feel guilty about it." (Co-Founder, Ruru)

Moreover, Ruru offered notebooks to private customers via an online shop offering individual sales of notebooks and a quarterly subscription service.

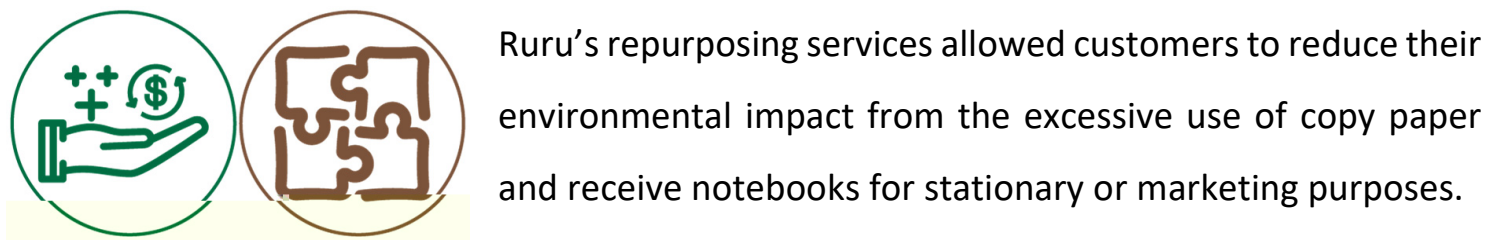

"In our sales pitch to large organisations, we emphasise sustainability aspects. Our services allow them to become more environmentally friendly by repurposing their wastepaper. Each notebook made saves 130 of water, and we provide details on how much water, paper, and carbon emission customers saved by buying our notebooks. The process is easier than recycling because we swap the collection box for customers" (Co-Founder, Ruru)

Next to the functional value of notebooks and the symbolic ecological value of repurposing one-sided copy-paper, customers appreciated the hedonic value of encountering old projects as part of their notebooks made from repurposed printer-paper.

\footnotetext{
"Architects and design agencies appreciate the visual appeal of our notebooks. They see value added for them in how our product is presented and the fun in discovering the previous life of your notebook, they love to see parts of old projects again" (Co-Founder, Ruru)
}

Ruru offered two types of repurposing services. For both services, collection boxes

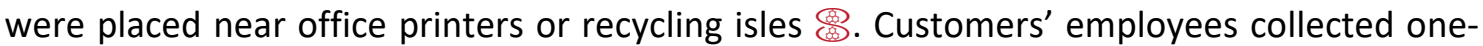
sided printer paper that was repurposed into notebooks 8 that were either [service 1] sold back directly to the customers the paper was collected from or [service 2] sold to other customers such as conferences. 
"[Service 1] organisations collect one-sided printer paper, we make notebooks from it and sell it back to them. We provide a sustainability report on how much paper and water customers saved via our service. They often use our statistics in their CSR reports."

"[Service 2] is targeting schools, universities, design firms and architects, these organisations often use so much paper that they do not necessarily need to turn all of it into notebooks, we take that paper, make notebooks and sell it on our websites, retail stores and to conferences" (Co-Founder, Ruru)

In the later stages of the study, the customisation of notebooks grew in importance and became a crucial aspect of Ruru's offering increasingly focusing on corporate gifting and conference notebooks $\circledast$. However, Ruru maintained an offering of standardised notebooks for functional stationary use and cost-conscious customers such as the hospitality industry.

"Our point of differentiation is the customisation of covers such as adding a conference program on the inside. Customers love the ability to customise notebook covers, and we are trying to get corporate gift notebook orders for Christmas" (Co-Founder, Ruru)

"We offer notepads for cafés and restaurants which are only marginally more expensive and try to get into that market as well. It is just an addition, we were thinking about other ways how people can use paper" (Co-Founder, Ruru)

Furthermore, Ruru pursued the extension of its services via developing repurposing workshops for its customers $\circledast$. In contrast to the various extensions of Ruru's offering, the venture discarded repurposing workshops for schools.

"We are thinking about creating repurposing workshops and educate customers about repurposing opportunities as part of our CRM" (Co-Founder, Ruru)

"We have put school programs on the back burner. They are hard to organise, and they weren't making money for us" (Co-Founder, Ruru)

Next to offering services to organisations, Ruru provided notebooks to private customers via an online shop and selected retailers, yet this branch of the business was considered of minor importance.

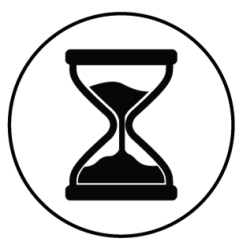

Two temporal components characterised Ruru's customer value co-creation mechanisms. First, repurposing old one-sided printer paper into new notebooks created hedonic value of re-discovering old projects. Second, Ruru introduced a retainer to [service 1] in the second stage of the study, 
encouraging customers to order at least 50 notebooks twice a year. In addition, Ruru offered quarterly notebook subscriptions for private customers.

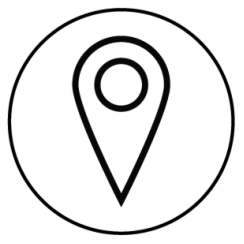

Positioning Ruru's collection boxes next to copy machines and office recycling isles presented a crucial spatial aspect for VCC 8.0 .00 . Moreover, Ruru focused primarily on serving customers in the Greater Wellington region in the early stages of the study. In the ongoing course, the venture expanded its geographical range and offered its services nationwide and in Australia. In short, Ruru continuously extended the geographical range of its customer value co-creation mechanisms.

"We have attracted customers throughout New Zealand and will ask them to package the collection box up and send it via a courier service to Wellington. Moreover, we delivered our first order to Australia last month, 1000 notebooks for a conference" (Co-Founder, Ruru)

Overall, Ruru customer value co-creation mechanisms developed throughout the study. Customers were's crucial value co-creators as providers and source of raw material. Ruru continuously extended the range of target customer segments and increasingly acknowledged the importance of customisation to enhance notebooks' functionality as corporate gifts or conference giveaways in the later stages of the study. Figure 36 illustrates the development of Ruru's customer value co-creation mechanisms over the period of the study.

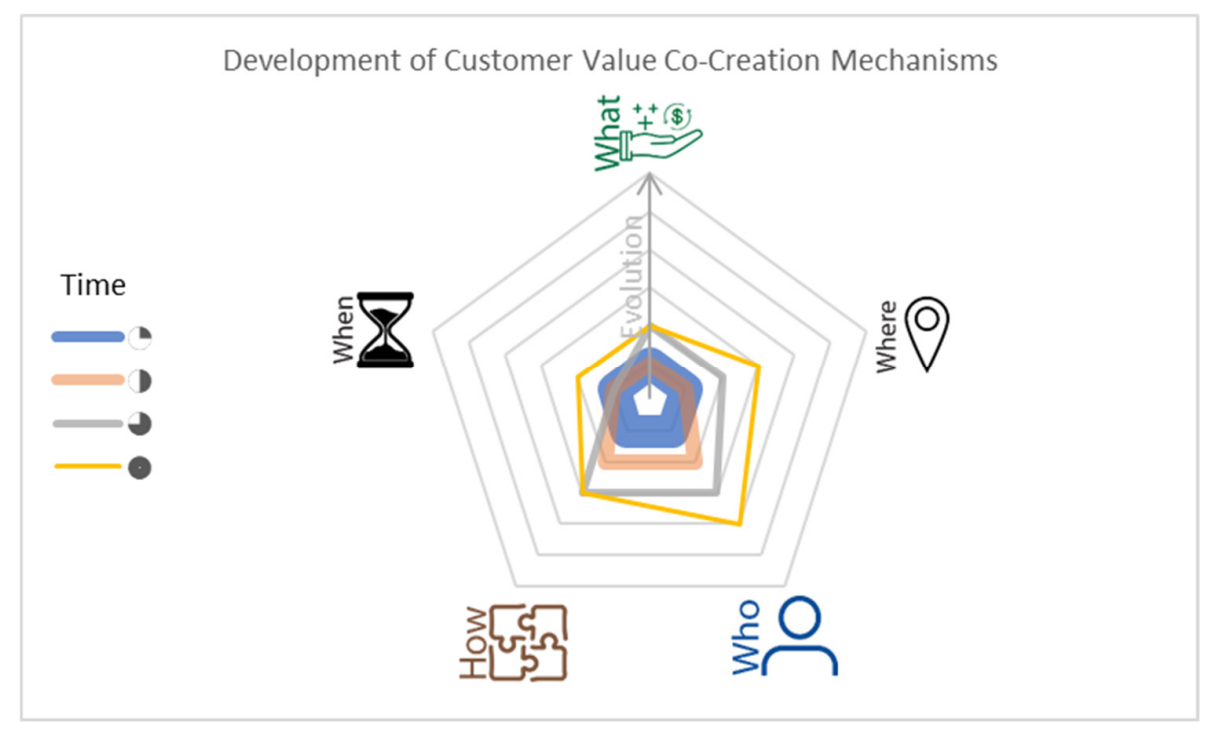

Figure 36 - Ruru - Development of Customer Value Co-Creation Mechanisms 


\subsubsection{Development of Actor Value Co-Creation Mechanisms}

\begin{tabular}{|c|c|c|c|c|}
\hline Time & & & & \\
\hline $\begin{array}{l}\text { oC } \\
\stackrel{0}{\frac{1}{3}}\end{array}$ & $\begin{array}{l}\text { "Small digital printing } \\
\text { companies." }\end{array}$ & $\begin{array}{l}\text { "We have a lot of } \\
\text { ambassadors and } \\
\text { advocates." } \\
\text { "Guest artists connected to } \\
\text { the artistic community" }\end{array}$ & \multicolumn{2}{|c|}{ "First, we need to find the right franchisee" } \\
\hline 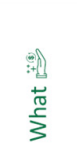 & $\begin{array}{l}\text { "They use a lot of paper } \\
\text { and produce a lot of waste, } \\
\text { the cooperation makes the } \\
\text { company look more } \\
\text { sustainable." }\end{array}$ & $\begin{array}{l}\text { "We provide them basically } \\
\text { with a notebook canvas } \\
\text { and mass exposure to } \\
\text { audiences interested in } \\
\text { art." }\end{array}$ & \multicolumn{2}{|c|}{$\begin{array}{l}\text { "We will create a franchise framework for interested } \\
\text { parties." }\end{array}$} \\
\hline 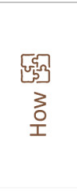 & $\begin{array}{l}\text { "We promote them [digital } \\
\text { printing company] by } \\
\text { having their logo on all of } \\
\text { our products and } \\
\text { frequently on our website } \\
\text { and in SMN." }\end{array}$ & $\begin{array}{l}\text { "We promote guest artists } \\
\text { via SMN and a dedicated } \\
\text { section on our website, and } \\
\text { they get a free notebook } \\
\text { subscription for a year." }\end{array}$ & $\begin{array}{l}\text { "We have thought about } \\
\text { building a software and } \\
\text { providing our franchisees } \\
\text { with machinery." }\end{array}$ & $\begin{array}{l}\text { "We are getting our } \\
\text { software developed and } \\
\text { that's going to be } \\
\text { calculating paper, and } \\
\text { environmental statistics." }\end{array}$ \\
\hline $\begin{array}{l}M 0 \\
\frac{1}{2} \\
\frac{1}{3} \\
\frac{5}{3}\end{array}$ & & & $\begin{array}{l}\text { "In Auckland, } \\
\text { Christchurch, or even } \\
\text { Australia." }\end{array}$ & $\begin{array}{l}\text { "We will franche the } \\
\text { Auckland region." }\end{array}$ \\
\hline
\end{tabular}

Table 14 - Ruru - Development of Actor Value Co-Creation Mechanisms

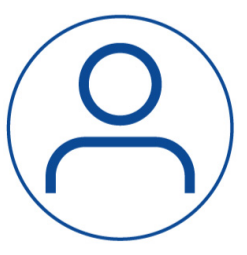

While Ruru developed explicit value propositions for ambassadors and guests, the venture was also aware of the benefits it creates for the local digital printing company it cooperated with. In the final stages of the study, Ruru developed an additional franchisee value proposition to expand its operations to different regions. However, Ruru only engaged with few partners in value cocreation throughout the study.

"We are setting up to move into Auckland. We had a few conversations with printers and have to find somebody willing to run the Auckland franchise" (Co-Founder, Ruru)

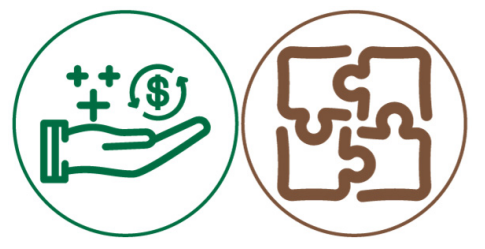

Ruru's actors value co-creation mechanisms developed over time. While initially focused on creating symbolic value via SMN promotions for the local digital printing company 8 , the increased demand in Ruru's notebooks allowed the sponsoring digital printing company to grow their business and increase asset utilisation. 
Moreover, Ruru extended the means of promoting the partnership beyond SMN promotions.

"There is cross promotion on social media networks that is beneficial for [digital printing company] and us; and we started to print their logo on all of our notebooks" (Co-Founder, Ruru)

Also, Ruru engaged with guest artists to source notebook designs them with annual notebook subscriptions.

"The guest artist's design notebooks are an excellent opportunity to connect to the artistic crowd and a great way to feature young upcoming artists" (Co-Founder, Ruru)

While pursuing the creation of a franchise program, underpinned by a software, machinery, and process offering, to penetrate local and foreign markets, Ruru established initial contact with interested parties in the final stages of the study 8 . However, an explicit offering remained absent.

"We are going to test the market first, de-risk the business as much as possible, find the right person and then we can sell the franchise" (Co-Founder, Ruru)

Ruru developed a reward-system for ambassadors, which were employees of customer organisations that facilitated the collection of paper customer organisation employees was further enhanced by the development of a referral scheme.

"Our ambassadors work for us and we try to reward them with a free notebook and encourage them to promote our services via a referral scheme" (Co-Founder, Ruru)

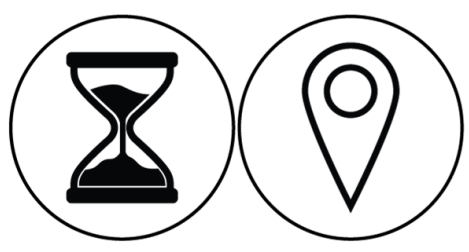

The quarterly issued guest artist designs represented the only temporal aspect of Ruru's actor value co-creation mechanisms. Moreover, manufacturing notebooks required the spatial proximity to the partnering digital printing company located in Wellington. Negotiations with printing companies in Auckland further underpin the spatial boundaries of Ruru's repurposing services. 


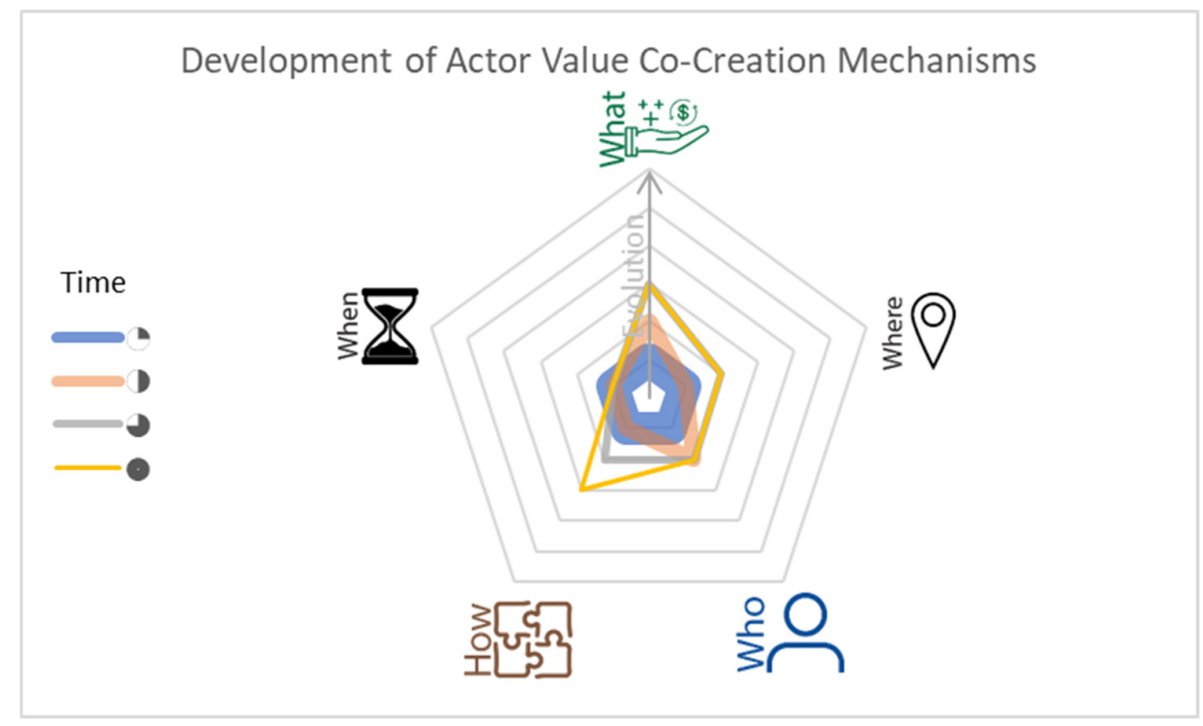

Figure 37 - Ruru - Development of Actor Value Co-Creation Mechanisms

Overall, Ruru's actor value co-creation mechanisms were limited by the number of engaged actors, i.e., one digital printing company, changing guest artists, and customer organisation ambassadors. Moreover, while the venture explored potential opportunities to co-create value with existing and new actors the scope of value co-creation only marginally evolved and was limited to cross-promotions. Figure 37 illustrates the development of Ruru's actor value co-creation mechanisms. 


\subsubsection{Development of Value Capture Mechanisms}

“There's a lot of potential, but our revenues are coming primarily from the notebook sales."

(Co-Founder, Ruru)

\begin{tabular}{|c|c|c|c|c|}
\hline Time & & & & \\
\hline 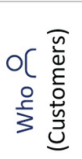 & $\begin{array}{l}\text { "Architects and design } \\
\text { firms." }\end{array}$ & "Cafés and restaurants." & $\begin{array}{l}\text { "We see an increase in } \\
\text { [service 1] orders, } \\
\text { customers order } \\
\text { notebooks more } \\
\text { regularly." }\end{array}$ & $\begin{array}{l}\text { "Big orders come mainly } \\
\text { from corporates and } \\
\text { conferences." }\end{array}$ \\
\hline 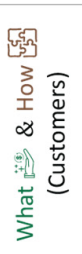 & $\begin{array}{l}\text { "Collection of used paper is } \\
\text { free for all our services, but } \\
\text { [service 1] requires you to } \\
\text { purchase 5o notebooks, } \\
\text { made with your paper back, } \\
\text { at least once per year ... this } \\
\text { is how we make the money." }\end{array}$ & $\begin{array}{l}\text { "[service 1] requires you to } \\
\text { purchase notebooks two } \\
\text { times a year, but we can't } \\
\text { ask some of our } \\
\text { customers to purchase } \\
\text { back all of the notebooks } \\
\text { we make from their } \\
\text { paper." }\end{array}$ & $\begin{array}{l}\text { "The eco-loop retainers } \\
\text { are just taking over and } \\
\text { that is a consistent } \\
\text { revenue stream." }\end{array}$ & $\begin{array}{l}\text { "the bulk purchases are } \\
\text { just boosting revenues up } \\
\text { every now and then, so } \\
\text { that we can balance our } \\
\text { revenues." }\end{array}$ \\
\hline 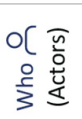 & $\begin{array}{l}\text { "[Digital printing } \\
\text { company]" }\end{array}$ & "Guest artists" & \multicolumn{2}{|l|}{ "Potential franchisees" } \\
\hline 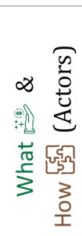 & $\begin{array}{l}\text { "We just pay for the } \\
\text { materials, but their labour } \\
\text { is free, they loved what we } \\
\text { were doing, and they } \\
\text { approached us with a } \\
\text { sponsorship deal." }\end{array}$ & $\begin{array}{l}\text { "Some of them do a lot of } \\
\text { promotion for us and we } \\
\text { get a massive uptake in } \\
\text { sales." }\end{array}$ & \multicolumn{2}{|c|}{$\begin{array}{l}\text { "We want to provide a whole franchise framework and } \\
\text { lease machinery and software to our franchisees." }\end{array}$} \\
\hline $\begin{array}{l}\text { (c) } \\
\frac{1}{0} \\
\frac{0}{2} \\
\frac{1}{3} \\
\frac{1}{3}\end{array}$ & & $\begin{array}{l}\text { "We actually found out } \\
\text { that most customers order } \\
\text { at least twice per year." }\end{array}$ & $\begin{array}{l}\text { "We can reach break-even } \\
\text { in Wellington. We would } \\
\text { just make more money if } \\
\text { we were in other cities } \\
\text { too." }\end{array}$ & \\
\hline
\end{tabular}

Table 15 - Ruru - Development of Value Capture Mechanisms

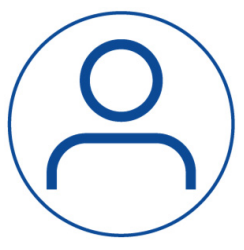

Ruru's value capture mechanisms focused on [service 1\&2] customers. Aligned with the development of customer target segments, the locus of value capture shifted from SMEs to large organisations and conferences in the final stage of the study. Actor value capture mechanisms focused on the engagements with customers, one local digital printing company, and regularly changing guest artists. 


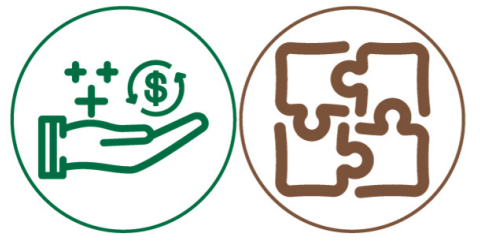

Ruru captured pecuniary and non-pecuniary value from customers and other actors engaged in value co-creation mechanisms. One the one hand, [service 1\&2] customers collected one-sided copy-paper in the collection boxes provided by Ruru $\odot$ and, on the other hand, purchased the notebooks that were made from it (only service 1 customers).

"[Service 1] requires customers to buy back notebooks. We have introduced a retainer to encourage corporations to buy more often and facilitate a consistent revenue stream"

"[Service 2] is free. We need the collected paper to produce notebooks for other customers" (Co-Founder, Ruru)

Ruru increased the required buy-back rate for [service 1] customers from once to twice a year in the second stage of the study. In turn, reoccurring revenues from [service 1] increased and accounted for more than half of overall sales from the third stage of the study onwards. In addition, Ruru captured pecuniary value from bulk purchases made by corporates and conferences.

Next to capturing pecuniary and non-pecuniary value from customers via sales and the supply of resources company. While in the first two stages Ruru only had to pay for material outlay, the increase in production resulted in a renegotiation of terms of the partnership agreement in the third stage of the study 8 .

"We have renewed our sponsorship deal with them, there were some minor increases in material price and we have to pay a little bit for labour from now on" (Co-Founder, Ruru)

Finally, Ruru captured value from guest artists that provided notebook designs and the cross-promotional efforts some of them made 8 . Furthermore, Ruru's development of a franchise framework was underpinned by the pursuit to capture pecuniary value from franchisees by providing software and hardware. However, since Ruru had not fully developed a franchise framework throughout the study, no value was captured via this avenue. 


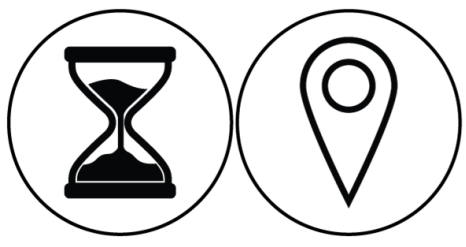

Ruru's value capture mechanisms were limited by the provision of services in the Greater Wellington area in the first two stages, and consecutively extended nation-wide, in the final two stages of the study. Moreover, increasing the retainer for [service 1] required customers to buy back notebooks at least twice a year from the second stage of the study onwards, and represented the only temporal component next to the quarterly changing guest artists designes.

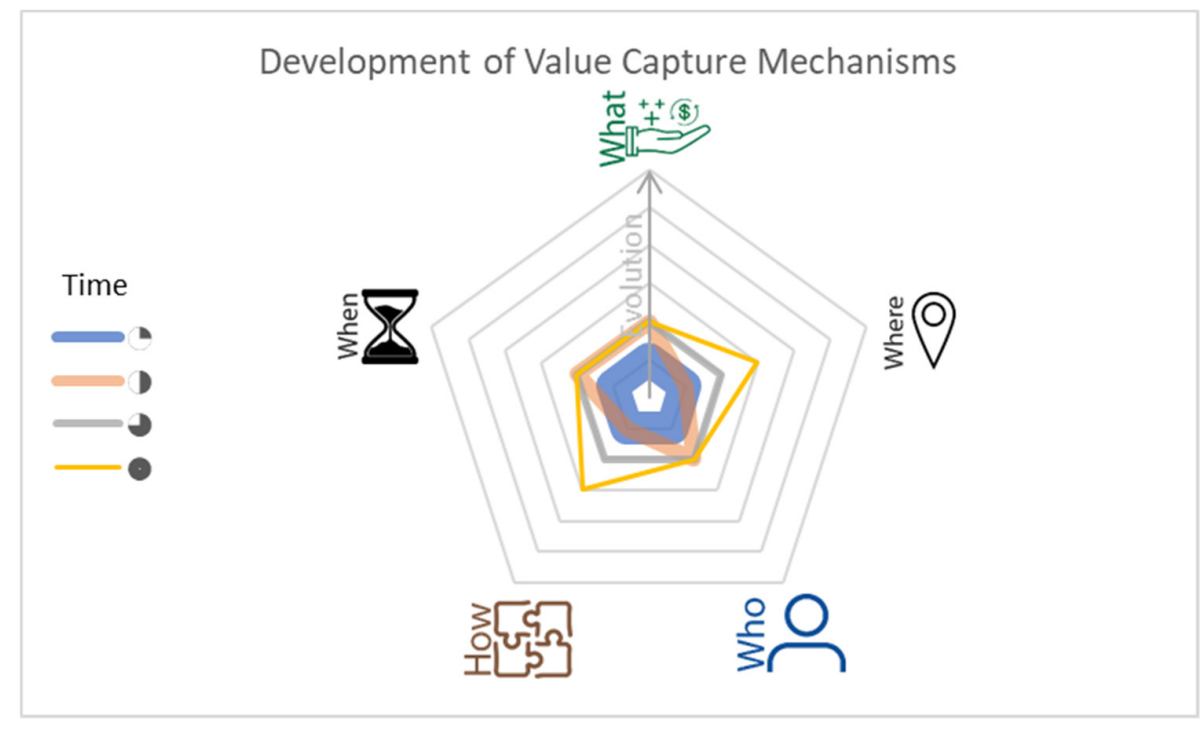

Figure 38 - Ruru - Development of Value Capture Mechanisms

Overall, Ruru's value capture mechanisms primarily focused on [service 1\&2] customers. Next to capturing pecuniary value from notebook sales, Ruru captured nonpecuniary value from customers by sourcing raw-materials through them. Besides, Ruru offered notebooks and quarterly notebook subscriptions for individual customers via its online shop. Additional revenues were generated via retailer channels, yet these sales channels only accounted for fractions of the overall revenue. However, the beneficial partnership agreement with a local digital printing company as well as the engagement with guest artists allowed the venture to capture value by reducing production costs and benefiting from the cross-promotional efforts of other actors. Aside from increasing a retainer for [service 1], Ruru's value capture mechanisms marginally evolved over the period of the study, as illustrated in Figure 38. 


\subsubsection{Summary Value Co-Creation and Capture Mechanisms}

Ruru explored and developed its customer value co-creation mechanisms in scale and scope. In contrast, the venture only marginally developed value co-creation mechanisms with a small set of engaged actors. However, the venture's ambition to create a franchisee program augmented an interest in the exploration of opportunities to engage other actors in the value co-creation mechanisms throughout the region. Ruru's value capture mechanisms were characterized by pecuniary and non-pecuniary value and by marginal developments. Figure 39 illustrates the development of Ruru's VCC mechanisms throughout the study.

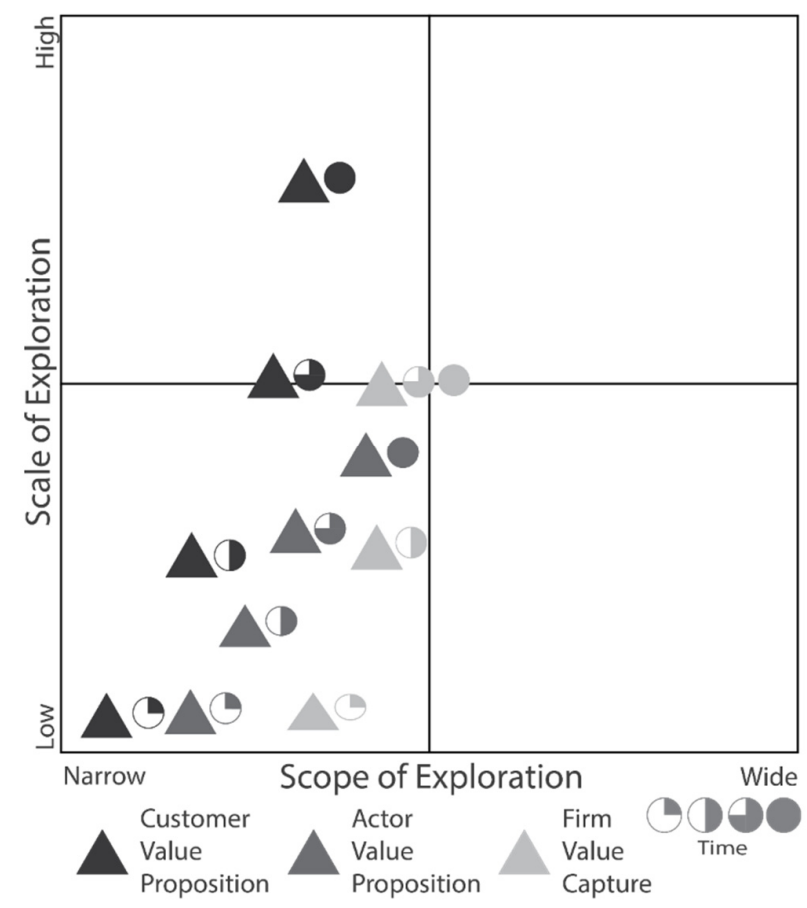

Figure 39 - Ruru - Development of Value Co-Creation and Capture Mechanisms 


\subsubsection{Development of Activity Links, Resource Ties, and Actor Bonds}

\begin{tabular}{|c|c|c|c|c|}
\hline Time & & & & \\
\hline 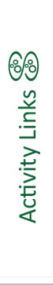 & $\begin{array}{l}\text { "We have people on the } \\
\text { inside who inform us about } \\
\text { full collection bins ... } \\
\text { usually the office manager } \\
\text { in businesses, and } \\
\text { advocates." }\end{array}$ & $\begin{array}{l}\text { "We prepare our stock in a } \\
\text { way it's easy for them to } \\
\text { quickly make the } \\
\text { notebooks, we have } \\
\text { tweaked how we divide } \\
\text { stacks of paper with } \\
\text { dividers and how we stack } \\
\text { them to facilitate an easy } \\
\text { transfer." }\end{array}$ & $\begin{array}{l}\text { "It is a process and really } \\
\text { about the people who want } \\
\text { to do it, it really depends } \\
\text { on if there is some } \\
\text { dedicated folk around, the } \\
\text { paper we receive varies, } \\
\text { sometimes it's smashed in } \\
\text { the collection bin and } \\
\text { double-sided printed." }\end{array}$ & $\begin{array}{l}\text { "We have been exploring } \\
\text { different methods to } \\
\text { transport our collection } \\
\text { boxes. Next to courier } \\
\text { services, we are discussing } \\
\text { with NZ Post potential } \\
\text { options." }\end{array}$ \\
\hline 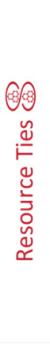 & $\begin{array}{l}\text { "[service 1] paper is sold } \\
\text { back to the customer, } \\
\text { [service 2] paper is used for } \\
\text { our wholesale and retail } \\
\text { notebook production." } \\
\text { "We were testing different } \\
\text { placements of our } \\
\text { collection boxes in offices, } \\
\text { close to the printer works } \\
\text { best." }\end{array}$ & $\begin{array}{l}\text { "Our most popular format } \\
\text { is } A_{5} \text {, it's easy to make } \\
\text { since most paper we get is } \\
\text { used } A_{4} . " \\
\text { "We work with a car- } \\
\text { sharing service offering } \\
\text { electric vehicles to collect } \\
\text { our bins." }\end{array}$ & $\begin{array}{l}\text { "We will outgrow [digital } \\
\text { printing company], but at } \\
\text { this stage, we're not } \\
\text { getting that repeated } \\
\text { monthly volumes to justify } \\
\text { leasing equipment and } \\
\text { establish our own little } \\
\text { binding station." }\end{array}$ & $\begin{array}{l}\text { "We are exploring various } \\
\text { ideas on what to do with } \\
\text { the paper we can't use for } \\
\text { notebooks ... making } \\
\text { hardback covers out of } \\
\text { shredded paper, sell it to } \\
\text { others to make furniture } \\
\text { or packaging, compost it } \\
\text { and grow mushrooms out } \\
\text { of it." }\end{array}$ \\
\hline 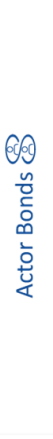 & $\begin{array}{l}\text { "They loved what we were } \\
\text { trying to do, and they } \\
\text { approached us with a } \\
\text { sponsorship deal, we just } \\
\text { pay for the materials, the } \\
\text { cover and the printing, but } \\
\text { their labour is free." } \\
\text { "We have also partnered } \\
\text { with another business } \\
\text { offering recycling bins, it's } \\
\text { not hundred per cent } \\
\text { working yet." }\end{array}$ & $\begin{array}{l}\text { "We have many advocates; } \\
\text { our customers are integral } \\
\text { to help us build our } \\
\text { business via referrals." } \\
\text { "We have thought about } \\
\text { other ways of facilitating } \\
\text { the collection or our boxes } \\
\text { by piggy-backing up with } \\
\text { other services." }\end{array}$ & $\begin{array}{l}\text { "Franchising requires } \\
\text { building relationships with } \\
\text { local printers such as we } \\
\text { have with [digital printing } \\
\text { company], it will be } \\
\text { challenging to replicate } \\
\text { across the entire country." } \\
\text { "Partnering with } \\
\text { international printing } \\
\text { firms, like Fuji-Xerox } \\
\text { allows scaling quickly." }\end{array}$ & $\begin{array}{l}\text { "At the moment we're } \\
\text { trying to get into } \\
\text { organisations likes } \\
\text { [stationary retailer] and } \\
\text { become a certified } \\
\text { supplier, that will } \\
\text { hopefully make it easier } \\
\text { for large organisations to } \\
\text { buy from us." } \\
\text { "We have engaged with } \\
\text { [partner] in a cross- } \\
\text { marketing friendship to } \\
\text { get SMEs on board." }\end{array}$ \\
\hline
\end{tabular}

Table 16 - Ruru - Development of Activity Links, Resource Ties, and Actor Bonds

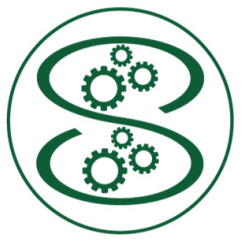

Ruru developed dyadic and joint activity links with actors in its ecosystem in the early stages. Most significant were the dyadic activity links created with customers. On the one hand, customers collected one-sided used copy paper to be repurposed by Ruru $:$ 雷 8 . Activity linking with customers was essential for Ruru's VCC mechanisms since the quantity and quality of the collected paper significantly influenced the efforts required for processing raw material such as screening paper for confidential information and manufacturing notebooks.

"We have found copies of bank records, passports, and other documents with serious confidentiality risk in collection boxes. To improve the quality of our raw material we encourage our ambassadors to circulate e-mails and emphasise that our collection bins are for non-confidential documents. We developed posters to enhance the learning process" (CoFounder, Ruru) 
On the other hand, Ruru coordinated the collection and sourcing of used copy paper with its customer organisation ambassadors and managed to sustain a reliable supply of raw materials 8.

\footnotetext{
"We have a monthly pick up scheduled. We contact our customers in advance to find out whose collection boxes are full and letting them know that we will pick them up" (Co-Founder, Ruru)
}

Ruru linked its in-house manufacturing processes with the partnering digital printing company's activities. Next to coordinating the timing of serial activity links, Ruru explored and refined its production and stacking activities to facilitate the integration with the partner's manufacturing processes.

"There was a lot of trial and error of how we delivered our notebooks in terms of stacking, dividing and paper orientation. Our local printing company prints the covers, binds the notebooks, trims them around the corners, and makes them look like a finished product" (Co-Founder, Ruru)

Ruru also explored potential activity links with other actors such as courier services to facilitate the collection of raw materials, yet none of these were realised during the study.

Overall, developing activity linking with customers was crucial for the development of Ruru's VCC mechanisms. While customers were required to adopt a new process $\&$, i.e., the collection of used one-sided copy paper in dedicated collection boxes 8 , Ruru refined its own manufacturing processes to align with the production activities of the partnering digital printing company. These integrations allowed Ruru to significantly reduce the cost of raw material sourcing and processing, production costs, and the capital required.

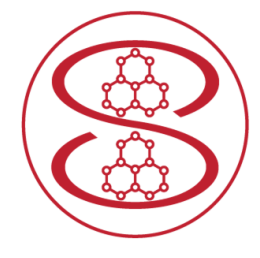

Ruru's VCC mechanisms were underpinned by the development of physical and organisational resource ties. Resource ties were developed with customers, a recycling bin manufacturer, a digital printing company, and a car-sharing service provider.

Most significant were organisational resource ties developed with customers. Encouraging customers' employees via posters, workshops, and ambassadors to collect onesided printer paper was crucial for sourcing raw materials organisational resource tie. Besides, installing collection boxes in customers' offices 
represented the matching physical resource ties to facilitate the collection process. The raw material resource ties were determining the size and binding options of Ruru's notebooks. Also, sourcing adequate qualities and quantities of raw material was pivotal for Ruru's VCC mechanisms.

\begin{abstract}
"We cut $A_{3}$ down to $A_{4}$, or $A_{1}$ to $A_{3}$, depending on what we need to make. We often run short on semi-blank paper which offers the interesting hedonic but also the functional bits for the notebooks. Recently we received a whole stack of pre-printed letterheads from clients, that kind of solves our lack of semi-blank paper" (Co-Founder, Ruru)
\end{abstract}

Also, Ruru's collection boxes were designed to match the packaging of recycling bins manufactured by a partnering company. Ruru created physical resource ties with the actors to take advantage of their rapid expansion in stage two 8 .

\footnotetext{
"We contacted them to use their recycling bins as our collection boxes, through long conversations we came up with the idea to use their packaging as collection boxes. It made sense as the cardboard box is visually different from the other recycling bins."

"We have rebranded their packaging boxes, we just pay for the screening and the printing costs. When customers buy recycling bins, they automatically come with one of our collection boxes with an info booklet about our services and us. This is our stealth way of getting our collection boxes into offices throughout New Zealand" (Co-Founder, Ruru)
}

Next to using a car sharing service to collect boxes in the Greater Wellington area, the nationwide expansion required Ruru to facilitate the shipping of collection boxes throughout New Zealand in stage three. Besides creating lids for collection boxes to allow for transportation, Ruru considered creating organisational resource ties with postal or courier services to facilitate national collection $\mathscr{G}$. No resource ties with transportation service providers were formed throughout the study.

\footnotetext{
"Our collection boxes currently don't have a lid and we have to fix that to facilitate transportation. We have to find ways how to ship boxes around New Zealand. We had several conversations with courier services and New Zealand Post" (Co-Founder, Ruru)
}

Increasing demand in Ruru's notebooks threatened to outgrow the capacities of the digital printing company and thus would have required to either insource production or develop resource ties with additional partners 8 . However, during the period of the study, Ruru only maintained and enhanced the existing organisational resource ties with its partnering printing company. Finally, Ruru explored the development of resource ties with 
potential partners to integrate the recycling of surplus paper place, no resource ties were developed during the study.

Overall, developing and enhancing resource ties with customer organisations, a local digital printing company, and a manufacturer of recycling bins was important for Ruru's VCC mechanisms. Ruru explored how resource ties with existing partners can be enhanced and created with potential franchisees.

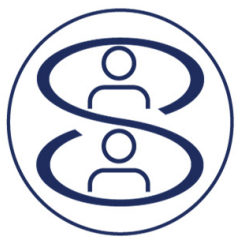

The bonds Ruru developed with actors positioned the company in the ecosystem, facilitated learning, and provided legitimacy for the venture. Ruru refined its approaches to establish actor bonds with customers in early stages. The venture focused on the development of a referee model 6 and enhancing customer relationships via regular contacts. Moreover, Ruru strategically rewarded outstanding customers with a monthly award and further enhanced its identity and position in the ecosystem as a service provider of reputable organisations.

\footnotetext{
"We honour outstanding customers with a re-purposer of the month award and promote their dedication to becoming a sustainable company, some of them were well-known corporates" (Co-Founder, Ruru)
}

In addition, Ruru conducted workshops to educate customers, improve the quality of raw materials, and enhance existing actor bonds.

"We offer customer workshops to engage managers in that area where collection bins are placed in a hands-on experience and sort paper out what we can and can't use. They can then educate other staff and we can reduce the rejection rate of paper" (Co-Founder, Ruru)

Ruru developed and maintained crucial bonds with the sponsoring digital printing company. That actor bond allowed to obtain access to resources and informed the development, adjustment, and coordination of the manufacturing process spanning the two ventures stage of the study onwards and renewed the contract in the final stage of the study.

\footnotetext{
"We started to print our story on the inside cover of notebooks outlining who we are, what we do, that [partner] support us. We renewed our sponsorship deal with them, they have increased their prices just for inflation adjustments and we pay a little bit of labour for some of the products" (Co-Founder, Ruru)
} 
Ruru developed actor bonds with a manufacturer of recycling bins that allowed the company to leverage their product packaging for distribution and marketing purposes However, the partner's rapid expansion outgrew Ruru's capacities.

\footnotetext{
"We need to redefine the terms of our cooperation. They are expanding across New Zealand, Australia, and the UK. We have to figure out how we can cope with their fast growth rates because we focus on New Zealand exclusively, the conversion of customers is not as strong as we would like it to be" (Co-Founder, Ruru)
}

Finally, Ruru developed and leveraged actor bonds created with local artists by developing a limited series of guest designs a provider of visually different notebooks.

\footnotetext{
"Featuring guest artists is a great way to engage the community in the making of our notebooks and an opportunity to promote upcoming artists. Customers love the design variation, it is a fantastic marketing tool" (Co-Founder, Ruru)
}

Ruru continuously explored opportunities to partner with other actors to facilitate the transport of collection boxes and raw materials from customers in preparation for a national wide rollout of its services international expansion was underpinned by the development of a franchise framework $\frac{\pi}{6(S)}$ in the final stages of the study. The development was supported by learnings facilitated through actor bonds created with mentors of the accelerator program the venture participated in. Aligned with that, Ruru developed first actor bonds with potential investors to financially back its plans. Finally, Ruru explored potential partnerships with established stationary suppliers to become listed as a certified supplier of large organisations Despite Ruru's exploration of establishing actor bonds with potentially interested franchisees, transportation partners, stationary wholesalers, and investors in the final stages of the study, no integrations were realised.

In short, Ruru developed lasting actor bonds with customers, a local digital printing company, and a manufacturer of recycling bins. The venture communicated these affiliations on its website and social media, e.g. monthly re-purposer awards, as well as on notebooks, to obtain legitimacy as a reliable partner of established organisations, position the company as an office services and stationary product provider, and facilitate learning to drive development. While Ruru explored the engagement with other actors in the later stages of 
the study, the set of actor bonds developed and partners engaged in VCC mechanisms remained limited.

\subsubsection{Summary Ruru}

In conclusion, Ruru's VCC mechanisms evolved over the period of the study. Customer value co-creation mechanisms developed in regard to scale and scope. In contrast, the development of actor value co-creation mechanisms was limited except for conceptual and explorative efforts to develop a franchise framework in the final stages of the study. Moreover, Ruru integrated mechanisms to capture pecuniary and non-pecuniary value from customers and other actors. However, the development of value capture mechanisms was marginal throughout the study. Similarly, activity links, resource ties, and actor bonds were developed with a limited set of actors and marginally extended in scope to develop and refine the fit of the firm and its ecosystem. Figure 40 illustrates the development of activity links, resource ties, and actor bonds of Ruru over the period of the study.

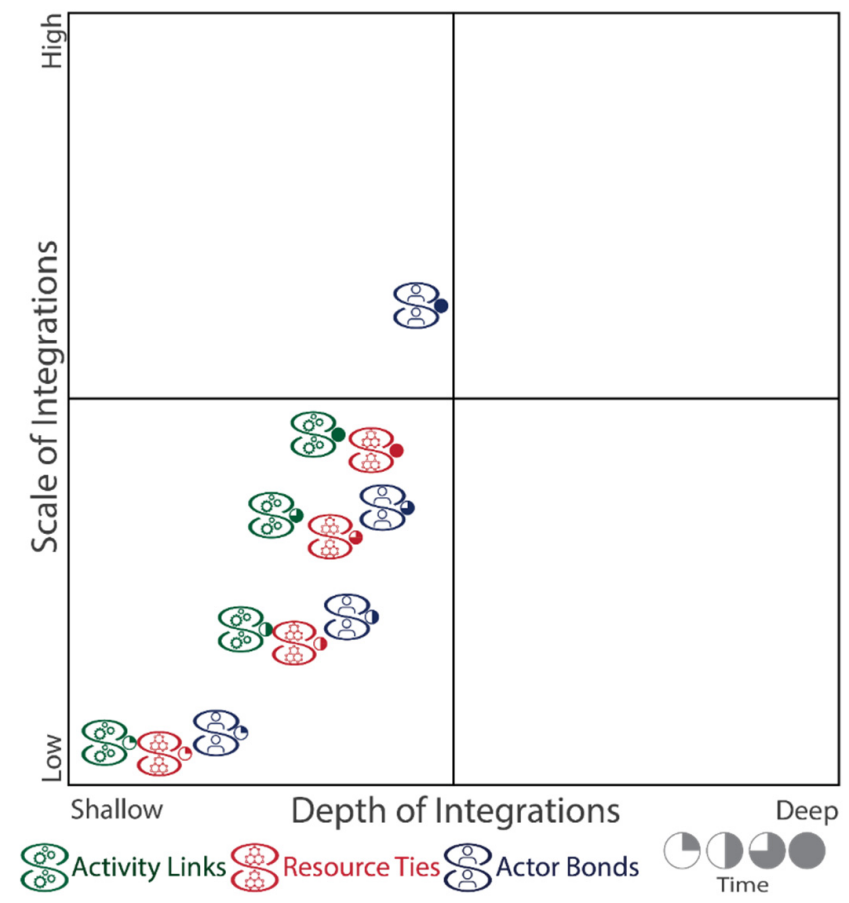

Figure 40 - Ruru - Development of Activity Links, Resource Ties, and Actor Bonds 


\subsection{Case Report - Venture Kākāpō}

\subsubsection{Introduction}

Kākāpō provided software for bookkeepers and accountants to facilitate the onboarding and ongoing interactions with clients. The venture continuously advanced the functionality of the provided software suite and integrated with several government agencies and other organisations, bookkeepers and accountants interact with on their client's behalf. Kākāpō's VCC mechanisms were characterised by the development of multiple integrations with other actors in the ecosystem.

\subsubsection{Development of Customer Value Co-Creation Mechanisms}

"That's where we develop and build value, in doing all of these bespoke integrations." (Co-Founder, Kākāpō)

\begin{tabular}{|c|c|c|c|c|}
\hline Time & $B$ & & & \\
\hline $\begin{array}{l}o[ \\
\frac{1}{3}\end{array}$ & $\begin{array}{l}\text { "Bookkeepers get value by } \\
\text { using our system." }\end{array}$ & $\begin{array}{l}\text { "We are forking a little bit } \\
\text { and go out to the next } \\
\text { group, accountants." }\end{array}$ & $\begin{array}{l}\text { "We've spoken to some } \\
\text { lawyers, it is usable for } \\
\text { them." }\end{array}$ & $\begin{array}{l}\text { "A really large } \\
\text { organisation and they are } \\
\text { kicking off a big } \\
\text { digitalisation project." }\end{array}$ \\
\hline $\begin{array}{l}\text { ind } \\
\text { ind } \\
\frac{+10}{3} \\
\frac{1}{3}\end{array}$ & $\begin{array}{l}\text { "We're giving them time } \\
\text { back, that's real value we } \\
\text { are creating for them, by } \\
\text { getting their admin out of } \\
\text { their way during the day." }\end{array}$ & $\begin{array}{l}\text { "Signing off the TECs1 is } \\
\text { probably one of the biggest } \\
\text { concerns for small } \\
\text { businesses." }\end{array}$ & $\begin{array}{l}\text { "We give them a little bit of } \\
\text { help. Basically, the } \\
\text { information they need to } \\
\text { capture in order to do their } \\
\text { customer due diligence for } \\
\text { AML-CFT." }\end{array}$ & $\begin{array}{l}\text { "Customer onboarding } \\
\text { was a noisy process, and } \\
\text { we changed it to a single } \\
\text { convenient step for } \\
\text { bookkeepers, accountants, } \\
\text { and their clients." }\end{array}$ \\
\hline $\begin{array}{l}\text { 댈 } \\
3 \\
0 \\
0\end{array}$ & $\begin{array}{l}\text { "It creates an agreement } \\
\text { between the client and the } \\
\text { bookkeeper, and at the } \\
\text { same time we can set up all } \\
\text { the authorities, and we do } \\
\text { that in the background." }\end{array}$ & $\begin{array}{l}\text { "The biggest focus now is } \\
\text { the development of the } \\
\text { AML-CFT2 extension ... } \\
\text { helping our customers to } \\
\text { identify beneficial owners } \\
\text { of entities they represent." }\end{array}$ & $\begin{array}{l}\text { "We have just finished off } \\
\text { to integrate two-factor } \\
\text { authentication using } \\
\text { Google Authenticator. It } \\
\text { makes our platform more } \\
\text { secure for our customers." }\end{array}$ & $\begin{array}{l}\text { "On-boarding customers } \\
\text { and capturing the } \\
\text { authorities and the AML } \\
\text { due diligence are } \\
\text { considered as two different } \\
\text { product features." }\end{array}$ \\
\hline 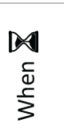 & \multicolumn{4}{|c|}{$\begin{array}{l}\text { "You actually give them the time. The onboarding is an administration task and a big hassle for them. They will stay late } \\
\text { and fill in the paperwork and post it off to the government department or scan and email it." }\end{array}$} \\
\hline $\begin{array}{l}\text { (c) } \\
\frac{0}{2} \\
\frac{\stackrel{5}{3}}{3}\end{array}$ & $\begin{array}{l}\text { "You don't have to come } \\
\text { back in and sign all the } \\
\text { papers with your } \\
\text { bookkeeper, that doesn't } \\
\text { exist anymore." }\end{array}$ & $\begin{array}{l}\text { "Signing off TECS is } \\
\text { probably one of the biggest } \\
\text { concerns for small } \\
\text { businesses around the } \\
\text { world." }\end{array}$ & $\begin{array}{l}\text { "Australia and the UK... } \\
\text { what we need to do is a } \\
\text { scaled-down version that } \\
\text { could be used by our target } \\
\text { market and others as well." }\end{array}$ & $\begin{array}{l}\text { "We have about } 60 \\
\text { international customers } \\
\text { now ... mostly Australia } \\
\text { and the UK, some in the } \\
\text { US and South Africa." }\end{array}$ \\
\hline
\end{tabular}




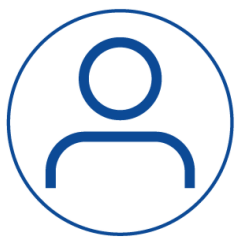

Kākāpō explored and developed various dimensions of its customer value cocreation mechanisms throughout the study. While initially focused on small and mid-sized bookkeepers, Kākāpō added accountants as target customer segment. In addition, lawyers were explored as possible customer groups but neglected since initial feedback for the application of Kākāpō’s solution was modest.

"We talked to a few lawyers and you would think that they worried about the new AML-CFT regulations, but they have been hardly interested" (Co-Founder, Kākāpō)

Kākāpō tested the application of a generic version of its on-boarding software for the international market targeting SMEs in the third stage of the study.

"We are doing a global generic version and it is a little bit of a pivot." (Co-Founder, Kākāpō)

Finally, large commercial and government organisations were explored as possible future customers. Despite Kākāpō's explorative efforts to enlarge customer segments, the venture maintained a focus on bookkeepers and accountants as "evangelical customer group". Kākāpō's integration with a complementary practice management software for bookkeepers and accountants 8 characterised them as the customer group capable to derive the most value from Kākāpō's offering.

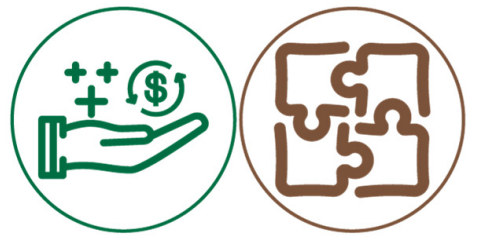

Kākāpō co-created primarily funcational value with engaged customers. The provided solution allowed customers to streamline repetitive administrative processes and electronically sign documents in the customer onboarding and annual filing processes to act on clients' behalf with government authorities, insurance companies, and banks. Nevertheless, intangible aspects such as reducing emotional stress resulting from continuously following-up clients and emphasising the importance of timely submissions of forms and applications in the initial phase of the relationships was described as valuable to customers.

"It takes away the awkward nagging during that initial part of the relationship. We take away a worry and frustration of filling in forms over and over again to act on somebody's behalf with 
different agencies. We are providing a proper widget to set up an agreement to act on clients' behalf and sign it straightaway via an e-signature ... and that's a big deal for our customers" (Co-Founder, Kākāpō)

Kākāpō continuously developed additional features such as signing up multiple entities, agreement renewals, and a customer due diligence tool supporting customers to identify their clients as required by the AML-CFT regulations. Since cyber security was considered as paramount for signing-up clients, documenting service agreements and setting up of authorities to act on behalf of clients, Kākāpō took advantage of the Ethereum blockchain to provide secure external proof for the validity of the documents. Moreover, twofactor authentication was integrated by using Google authenticator as an external service to provide additional security

"Our customers create with their clients a contract of services that is electronically signed. We use the block-chain to proof that the document existed, at a specific time, and hasn't been altered since" (Co-Founder, Kākāpō)

The development of additional features underpinned the emphasis of the company to explore new ways to co-create value with its core customer segments.

"Since our customers have to identify the beneficial owners of the entities they represent, we will create a solution that is helping them with that" (Co-Founder, Käkāpō)

In sum, Kākāpō focused on bookkeepers and accountants as core customers in New Zealand. However, Kākāpō launched a generic global version targeting small and mid-sized enterprises.

"It's a generic version of our software and it will appeal to a wide group of enterprises“ (Co-Founder, Kākāpō)

While the generic version of the software provides potential to co-create value for different types of organisations, primarily bookkeepers and accountants took advantage of the offering around the world since the software was offered on the marketplace of partner1 8. 


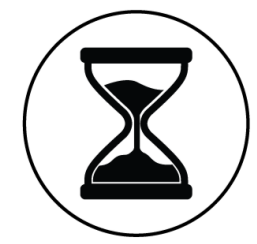

Temporal and spatial aspects of customer value co-creation were pivotal since Kākāpō's solution allowed to reduce and shift time spent on administrative work that is regarded as non-billable time, and thus often conducted after regular work hours.

"The value that we are creating for them is basically getting their admin out of the way during the day, they can go home at 5 o'clock and do not have to feel guilty and have administrative work hanging over them "(Co-Founder, Kākāpō)

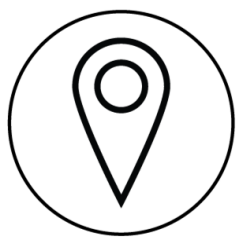

Furthermore, bookkeepers and accountants were able to reduce the number of spatially bound face-to-face meetings with their clients since Kākāpō's solution enabled electronic signatures of documents redundant administrative tasks was bound to Kākāpō's bespoke integration with New Zealand based authorities and thus localised to constantly follow up clients and spatial disparities of signing documents was not limited by geographical boarders. While Kākāpō's market was initially limited to New Zealand, the global version of the software was used across various countries. However, the global distribution pattern follows the geographic expansion of partner1's marketplace 8 .

Overall, Kākāpō's customer value co-creation mechanisms' development was intertwined with the venture's commitment to partner with a complementary practice management software provider for bookkeepers and accountants international software version was available via its website, partner1's marketplace as a distribution channel 8 influenced the diffusion of the software globally. In short, the development of Kākāpō's customer value co-creation mechanisms were significantly influenced by the venture's engagement with partner1 Kākāpō's customer value co-creation mechanisms' development was characterised by an expansion of features offered and spatial aspects. 


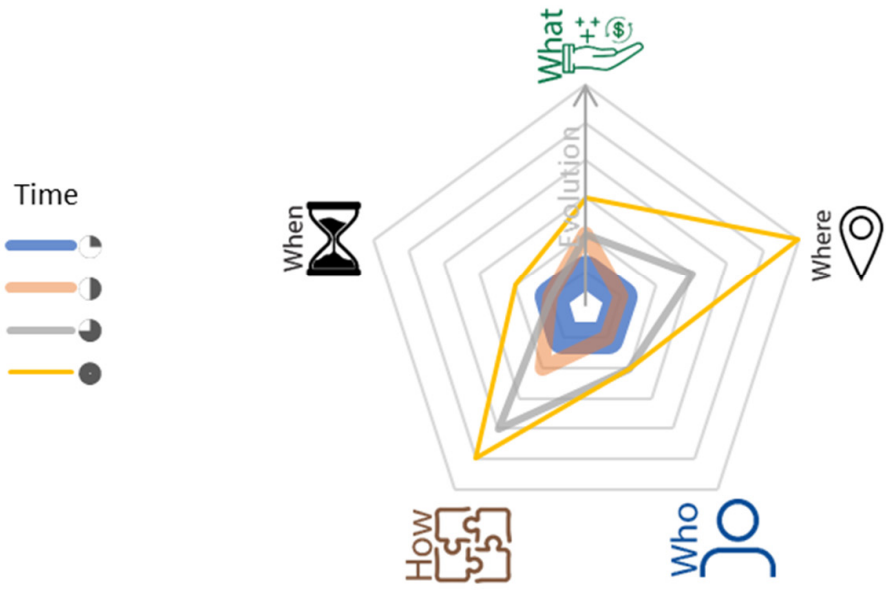

Figure 41 - Kākāpō - Development of Customer Value Co-Creation Mechanisms

\subsubsection{Development of Actor Value Co-Creation Mechanisms}

"They are stakeholders and absolutely part of the business model" (Co-Founder, Kākāpō)

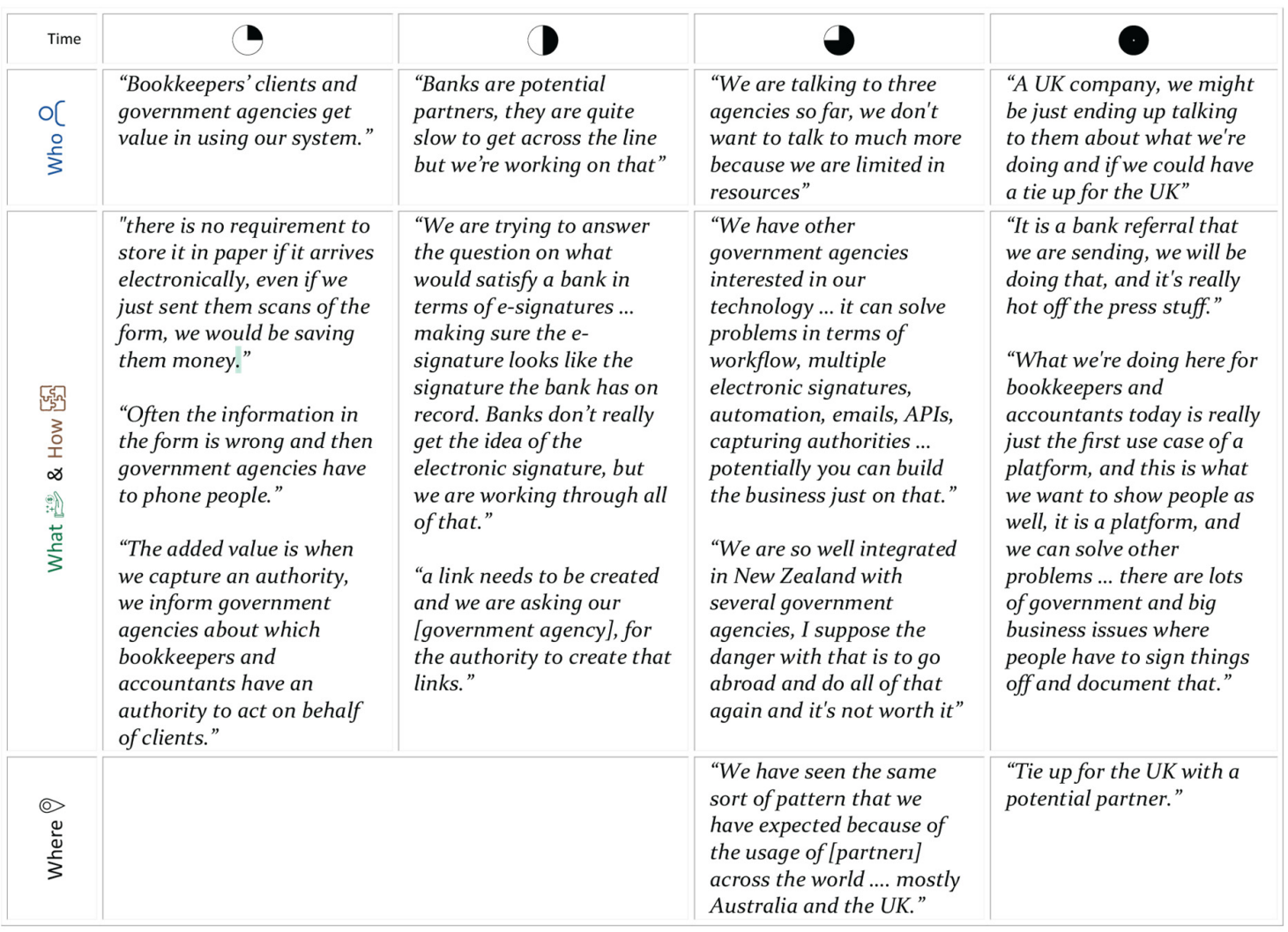

Table 18 -Kākāpō - Development of Actor Value Co-Creation Mechanisms 


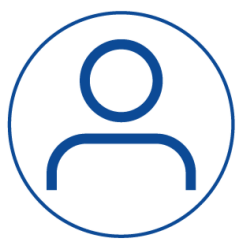

The engagement of a broad range of actors was considered pivotal in Kākāpō's VCC mechanisms. Next to three government agencies that were engaged from the beginning onwards Kākāpō continuously explored opportunities to co-create value in cooperation with other actors such as insurances and banks. The exploration and selection of partners was driven by the needs of bookkeepers and accountants and opportunities to co-create value with partners target customers interact with 8 .

"We have made excellent progress. It's looking good for getting an electronic authority into a bank"(Co-Founder, Kākāpō)

On the other hand, Kākāpō explored opportunities to co-create value with and for other actors in its ecosystem such as government agencies not related to their primary customer group as well as potential overseas partners 8 .

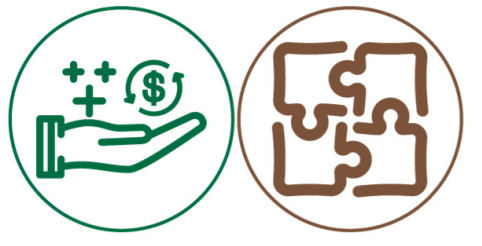

Kākāpō co-created value for actors in its ecosystem by ensuring data validity, facilitating the flow of data, and making paper submissions redundant by introducing e-signatures and thus reducing the amount of administration across engaged organisations reporting, next to its growing customer base, the number of government hours, and pages of paper saved due to the electronic data flows across government agencies its system facilitated

"We create value with all of them, obviously our customers' clients don't have to fill in hundreds of forms. Authorities don't have to manually put in the data anymore and follow-up clients' customers to push information through, are having a better idea with whom they are dealing with since clients don't just forward their username and password to their bookkeepers and accountants anymore to set-up authorities, and don't have to archive paper submission anymore." (Co-Founder, Kākāpō)

Kākāpō continuously explored opportunities to engage other actors in value cocreation mechanisms, such as the development of APIs to advance integrations and focused on the reduction of administrative tasks and costs $\mathscr{Q}$. Similarly, Kākāpō engaged with new 
partners such as insurances and banks to facilitate the interaction of its onboarding software with partners' existing systems software systems, government agencies invited Kākāpō to explore how its system can reduce

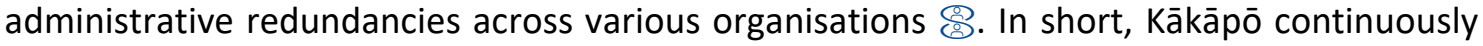
explored opportunities with the aim to find synergies for value co-creation via facilitating esignatures as well as the exchange and integrity of data across ecosystems.

„We developed a paper-based proof of concept for another use case for our technology. Our system can be used digitising the authority and consent process via electronic signatures can significantly improve the workflow in large organisations.” (Co-Founder, Kākāpō)

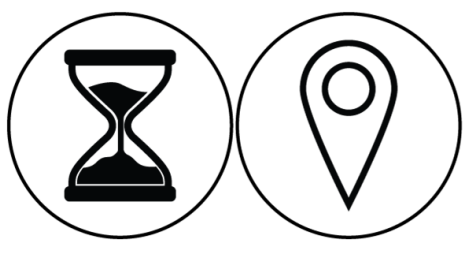

While temporal aspects were of minor importance for Kākāpō's actor value co-creation mechanisms, spatial aspects of the software's global roll-out were important. Since Kākāpō's actor value co-creation processes required the costintense development of bespoke software interfaces 贯 and sometimes the alterations of processes 8 , the venture limited its integrations to countries that provide (a) a fast-growing base of bookkeepers and accountants, often using partner1's practice management software (S) and (b) government agencies willing to provide integration interfaces, i.e., APIs 8.

Overall, Kākāpō explicitly considered actors and value co-creation with them as part of its BM. Explorative efforts to advance VCC mechanisms were underpinned by the reduction of administrative tasks facilitated by Kākāpō's solution. The second structural element guiding exploration was Kākāpō's focus on bookkeepers and accountants as primary customers. Figure 42 illustrates the actor-, product feature, and location-driven development of Kākāpō's actor value co-creation mechanisms. 


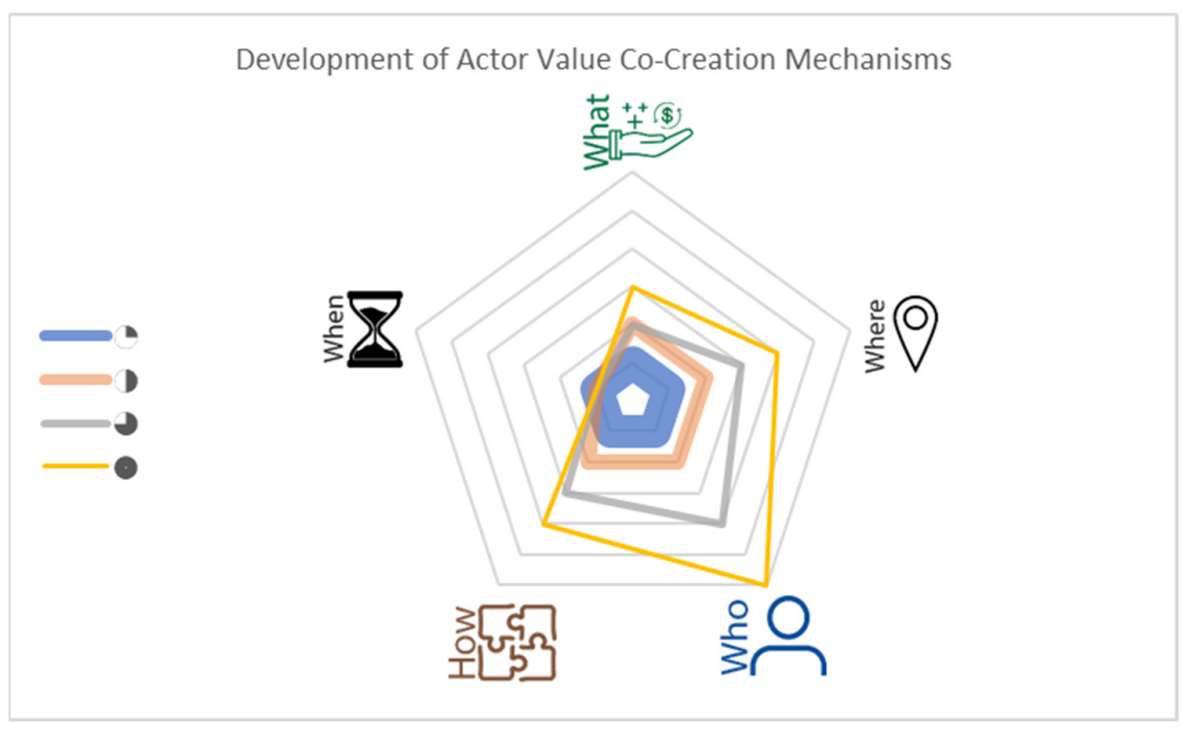

Figure 42 - Kākāpō - Development of Actor Value Co-Creation Mechanisms 


\subsubsection{Development of Value Capture Mechanisms}

\begin{tabular}{|c|c|c|c|c|}
\hline Time & $\boldsymbol{\theta}$ & & & \\
\hline 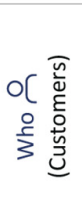 & $\begin{array}{l}\text { "Bookkeepers are the only } \\
\text { people that are currently } \\
\text { paying." }\end{array}$ & $\begin{array}{l}\text { "There are a lot of new } \\
\text { bookkeepers who wanted to } \\
\text { use it but going straight } \\
\text { into the \$3o per month plan } \\
\text { was just too much." }\end{array}$ & $\begin{array}{l}\text { "We will revise our pricing } \\
\text { plans, we will always have a } \\
\text { free plan ... it's still fitting } \\
\text { bookkeepers more than } \\
\text { accountants." }\end{array}$ & $\begin{array}{l}\text { "About 6o international } \\
\text { customers ... mainly } \\
\text { bookkeepers and } \\
\text { accountants acquired } \\
\text { through [partneri's] } \\
\text { marketplace." }\end{array}$ \\
\hline 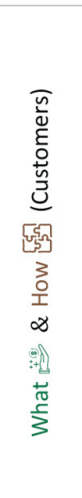 & $\begin{array}{l}\text { "We are charging } \\
\text { customers via the typical } \\
\text { SaaS model, a monthly } \\
\text { subscription, we have two } \\
\text { paid and one free plan at } \\
\text { the moment." }\end{array}$ & $\begin{array}{l}\text { "We have three plans } \\
\text { currently ... we had } \\
\text { previously been doing a free } \\
\text { trial this was either do } \\
\text { three sign-ups within } 14 \\
\text { days, but we didn't feel that } \\
\text { this is working because it } \\
\text { was quite hard for people to } \\
\text { set up the platform." } \\
\text { "Where people actually see } \\
\text { its working for them they } \\
\text { convert to a subscription } \\
\text { and we put them on a } \\
\text { repeated invoice." }\end{array}$ & $\begin{array}{l}\text { "Our top plan now is on } \\
\$[X] \text { a month and I can see } \\
\text { a space for } \$[X] \text { a month } \\
\text { from the people I have } \\
\text { talked to." } \\
\text { "With our new AML feature } \\
\text { there is the big question } \\
\text { mark of how we're getting } \\
\text { paid. I'm going to sit down } \\
\text { and look at the parameters, } \\
\text { the costs, the value for } \\
\text { different sectors and revise } \\
\text { that. So far we haven't had } \\
\text { a features-based model." }\end{array}$ & $\begin{array}{l}\text { "Because of a better } \\
\text { understanding about what } \\
\text { our clients need and the } \\
\text { price points that they are } \\
\text { sensitive to and a better } \\
\text { understanding of our costs } \\
\text {... we are moving to an } \\
\text { agreements-based model." } \\
\text { "Verify the address which is } \\
\text { part of AML... so [partner] } \\
\text { charges us the fee and we } \\
\text { charge a fee with a bit of a } \\
\text { mark-up." }\end{array}$ \\
\hline 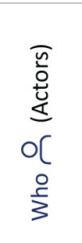 & $\begin{array}{l}\text { "Government agencies } \\
\text { are not } 100 \% \text { against } \\
\text { paying for the benefits } \\
\text { they receive. We tried it a } \\
\text { couple of times to make } \\
\text { them pay, yet } \\
\text { unsuccessfully." }\end{array}$ & $\begin{array}{l}\text { "We are basically doing } \\
\text { work for them and we } \\
\text { should get paid for it. It's } \\
\text { open, it has been discussed } \\
\text { but we are miles away of it } \\
\text { ever becoming a reality." }\end{array}$ & & $\begin{array}{l}\text { "If we were part of } \\
\text { [partner1], and they } \\
\text { integrate our platform in } \\
\text { their practice management } \\
\text { software, I think it would } \\
\text { be a really big selling point } \\
\text { for them." }\end{array}$ \\
\hline $\begin{array}{l}D Q 0 \\
\frac{1}{2} \\
\frac{5}{2} \\
\frac{1}{3}\end{array}$ & $\begin{array}{l}\text { "Initially the contract } \\
\text { was free forever ... we } \\
\text { negotiated that it was } \\
\text { free for now and in the } \\
\text { future that could } \\
\text { change." }\end{array}$ & $\begin{array}{l}\text { "A free trial plan was } \\
\text { limited to three sign-ups } \\
\text { within } 14 \text { days." }\end{array}$ & "A monthly fee" & $\begin{array}{l}\text { "The more uptake we will } \\
\text { get in each territory will } \\
\text { inform the development of } \\
\text { bespoke integrations." }\end{array}$ \\
\hline
\end{tabular}

Table 19 - Kākāpō - Development of Value Capture Mechanisms

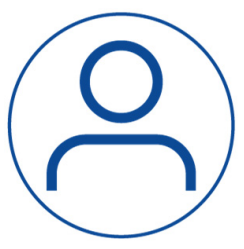

Kākāpō implemented and explored a wide range of opportunities to capture value from customers and actors in its ecosystem 8 . Charging bookkeepers and accountants was the primary source of Kākāpō's revenues throughout the duration of the study. While SMEs were targeted as potentially paying 
customers via the international version of the software, the absence of integrated credit card payments stalled the value capture mechanism from international customers. Moreover, the engagement with partner1 allowed to target bookkeepers and accountants as primary international customers and fuelled expansion.

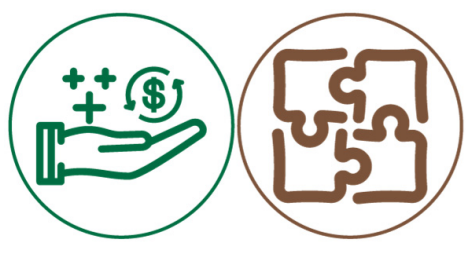

Kākāpō continuously refined the monthly subscription plans over the period of the study. The refinement of the free plan from three sign-ups within 14 days to ten sign-ups within a year marked a significant change informed by insights about the efforts and learning required from customers to set-up the software platform.

„It takes a little bit of time investment to get yourself set up on our platform, the first free plan just wasn't really enough to get people across the line. "(Co-Founder, Kākāpō)

In consecutive stages, Kākāpō refined its paid subscription plans and explored variations in its plans ranging from the sign-up of 4 to 1000 entities for $\$ 20$ to $\$ 60$ per month. Finally, Kākāpō changed the underpinning unit of sign-ups from entities to clients to reflect the fact that bookkeepers and accountants often represent one client but multiple of his/her entities. As a result, the venture limited its pricing schemes to one free plan, a pay-as-you-go plan, and one monthly subscription plan for its customers in the final stage of the study. Moreover, while initially reluctant to introduce a feature-based pricing model, Kākāpō decided to charge a fee for every ID verification of beneficial owners for AML-CFT requirements.

\section{"Verify the address and ID as part of the AML screening. We're making a little bit of money" (Co-Founder, Kākāpō)}

Kākāpō charged customers a monthly fee paid via bank transfers. The integration with a payment service provider in the last stage of the study allowed Kākāpō to charge customers' credit cards and opened the opportunity to charge international customers

"We're going to integrate with a credit card payment service. This way it's much easier to refine and introduce new monthly pricing plans“ (Co-Founder, Kākāpō)

In contrast to customers, Kākāpō explored opportunities to capture pecuniary and non-pecuniary value from other actors. Kākāpō captured value from other actors in its 
ecosystem in two significant ways. First, co-developing and testing integrations with other actors allowed Kākāpō to influence the development of interfaces such as APIs in their favour and obtain a first-mover advantage such as processing the electronic submissions Kākāpō forwarded $\mathscr{\wp}$. In addition, Kākāpō continuously explored ways to capture pecuniary value from partnering organisations, which remained reluctant to pay for the value obtained 8 .

"We don't want to make it confrontational with the government agencies. It requires a little bargaining chip of 100,0oo active customers to say, we can either print it out and send it to you or you get a simple CSV file which you can upload in your system" (Co-Founder, Kākāpō)

Moreover, Kākāpō's engagement with partner1 allowed it to leverage the partner's marketplace as a domestic and international distribution channel. Kākāpō explored further synergies with partner1 as a possible core-extension to their software packages 8 . In short, Kākāpō explored and implemented opportunities to capture value from a large scale of actors in its ecosystem via co-developing, testing, and leveraging digital data integration interfaces.

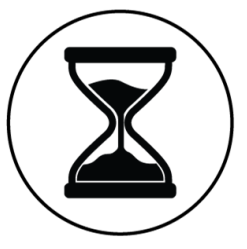

Finally, Kākāpō's value capture mechanisms had two immanent temporal components. First, while initially customers were charged a monthly subscription fee for different numbers of entities that can be onboarded within a year, pricing plan refinements eradicated annual subscriptions and resulted in monthly subscriptions plans based on numbers of entities that can be on-boarded in a month. The final pricing plan incorporated a carry-over feature to encourage customers to stay on the platform.

Second, while Kākāpō was not able to capture pecuniary value from actors such as government agencies, the contract signed with one institution outlined that the service Kākāpō provides would be "free for now" @. However, Kākāpō seeks to renegotiate the terms of the contract in the future to obtain remunerations.

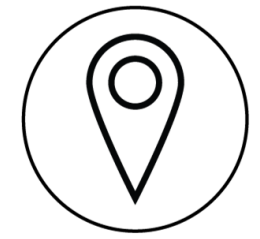

Kākāpō's value capture mechanisms had two distinct spatial aspects. First, value capturing was limited to the domestic market since credit card payment options were only available in stage four of the study. Second, 
Kākāpō primarily captured value via obtaining free services from integrations with domestic government agencies and thus was limited to integrations with New Zealand-based agencies . Moreover, Kākāpō's integration with a provider of ID-verification services to comply with AML-CFT requirements was limited to New Zealand-based individuals venture's international version represented an experiment to test international markets and decide for which other countries' government agencies bespoke integrations will be developed in the future.

Overall, Kākāpō's value capture mechanisms were refined and developed congruent with value co-creation mechanisms throughout the study. The reciprocity of customer and actor value co-creation was underpinned by the added value of additional integrations developed over the period of the study. Figure 43 illustrates the development of Kākāpō's value capture mechanisms. As evident across the case, Kākāpō continuously explored opportunities to co-create and capture pecuniary and non-pecuniary value across its ecosystem.

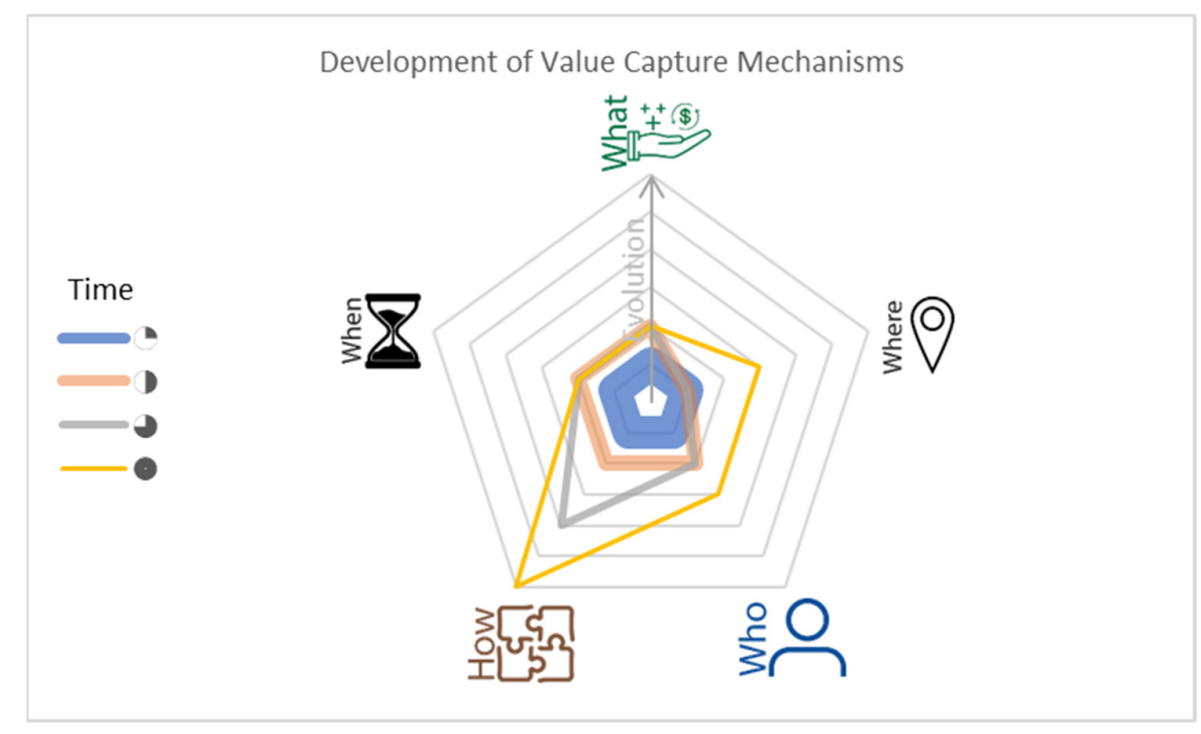

Figure 43 - Kākāpō - Development of Value Capture Mechanisms

\subsubsection{Summary Value Co-Creation and Capture Mechanisms}

Kākāpō explored opportunities to co-create and capture value via interactions with 
multiple different actors. The venture continuously developed the scope of offerings to customers as well as other actors. Similarly, the venture engaged with various actors to facilitate the exchange of data by offering support for the design and implementation of electronic data interfaces i.e., APIs. Finally, Kākāpō captured value primarily via (a) subscription fees collected from customers and (b) the data exchange and processing services provided by engaged actors. Figure 44 illustrates the development of Kākāpō's VCC mechanisms over time.

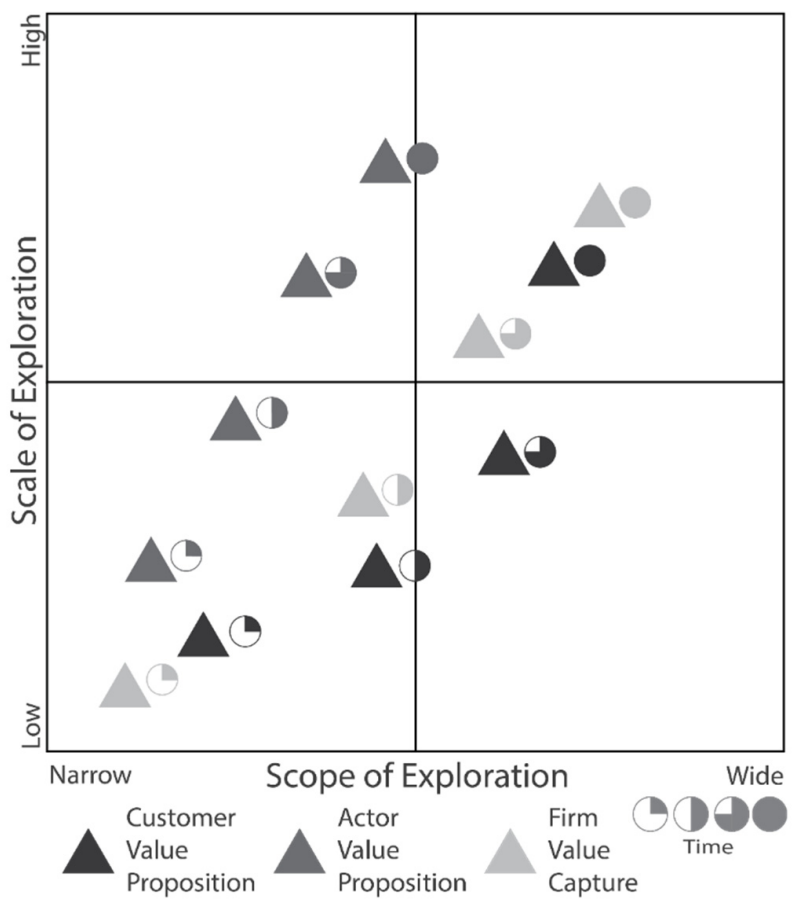

Figure 44 - Kākāpō - Development of Value Co-Creation and Capture Mechanisms 


\subsubsection{Development of Activity Links, Resource Ties, and Actor Bonds}

\begin{tabular}{|c|c|c|c|c|}
\hline Time & $B$ & & & \\
\hline 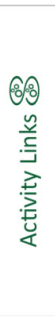 & $\begin{array}{l}\text { "We take all of this } \\
\text { information and put it into } \\
\text { a CSV file. We encrypt it } \\
\text { and send it through to } \\
\text { them, then they decrypt, } \\
\text { and automatically process } \\
\text { it using a batch, it's not } \\
\text { quite an API but it is an } \\
\text { electronic data } \\
\text { interchange." }\end{array}$ & $\begin{array}{l}\text { "We are working our way } \\
\text { through this, banks still go } \\
\text { back and verify against a } \\
\text { record of somebody's } \\
\text { signature. We are just } \\
\text { trying to answer the } \\
\text { question what would } \\
\text { satisfy a bank with } \\
\text { electronic signatures." }\end{array}$ & $\begin{array}{l}\text { "It became obvious that } \\
\text { the best thing to do is to } \\
\text { outsource ID verifications } \\
\text {... we do not add value } \\
\text { through ID verifications, } \\
\text { we add value because we } \\
\text { can integrate ID } \\
\text { verification into our } \\
\text { process." }\end{array}$ & $\begin{array}{l}\text { "We would love to work } \\
\text { with [partner 1] on that, } \\
\text { we cheekily mentioned it } \\
\text { to them, we should be } \\
\text { working much closer } \\
\text { together because we are } \\
\text { doing stuff that all of our } \\
\text { customers need." }\end{array}$ \\
\hline 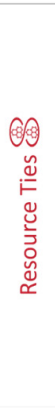 & $\begin{array}{l}\text { "Our system is stable, but } \\
\text { relies on several APIs of } \\
\text { external service providers" } \\
\text { "These guys can often do it } \\
\text { electronically, and if it's } \\
\text { not on paper they don't } \\
\text { have to archive it is part of } \\
\text { the public records act." } \\
\text { "NZBN's' API allows us to } \\
\text { pull down information } \\
\text { about NZ-based firms." }\end{array}$ & $\begin{array}{l}\text { "We are going with a more } \\
\text { generic solution for banks, } \\
\text { because there are just too } \\
\text { many to integrate with, so } \\
\text { we have allowed people to } \\
\text { create authorities for } \\
\text { whichever companies they } \\
\text { want ... it just creates the } \\
\text { PDF letter which is getting } \\
\text { signed by their clients } \\
\text { giving them authority." }\end{array}$ & $\begin{array}{l}\text { "We have just finished off } \\
\text { to integrate two-factor } \\
\text { identification, we build } \\
\text { two-factor identification } \\
\text { using Google } \\
\text { authenticator" } \\
\text { "[partner] have created the } \\
\text { API, but as far as I'm } \\
\text { aware now it is publicly } \\
\text { available, they built it and } \\
\text { piloted it with us" }\end{array}$ & $\begin{array}{l}\text { "Because we don't } \\
\text { integrate with the } \\
\text { common [partner1] } \\
\text { application yet. We } \\
\text { probably will, and then } \\
\text { will be able to do a whole } \\
\text { bunch of other stuff" } \\
\text { "You know we have spent } \\
\text { many thousands of dollars } \\
\text { integrating all of that into } \\
\text { the process." }\end{array}$ \\
\hline 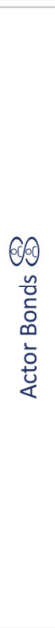 & $\begin{array}{l}\text { "We negotiated that the } \\
\text { contract was free for now } \\
\text { and in the future that } \\
\text { could change, and they } \\
\text { have signed it off... we are } \\
\text { not getting paid for it but } \\
\text { we laid the foundation." } \\
\text { "Through the work that we } \\
\text { were doing with } \\
\text { [accelerator] we were able } \\
\text { to secure Microsoft's top- } \\
\text { level sponsorship ... it is } \\
\text { huge for us, because it } \\
\text { saves us a fortune." }\end{array}$ & $\begin{array}{l}\text { "Changes to any of the } \\
\text { work the people we are } \\
\text { integrating with affects } \\
\text { our business, so we are not } \\
\text { in control of that and we } \\
\text { need to have as strong as } \\
\text { possible relationships so } \\
\text { we're getting notified when } \\
\text { stuff is changing" } \\
\text { "We have been speaking to } \\
\text { a few banks and just } \\
\text { working through even the } \\
\text { simplest things ... and the } \\
\text { odd hiccup tends to come } \\
\text { around the organisations' } \\
\text { lack of knowledge of } \\
\text { electronic signatures, and } \\
\text { lack of having a policy } \\
\text { around it" }\end{array}$ & $\begin{array}{l}\text { "[Government agency] is } \\
\text { very receptive, they are } \\
\text { very good at listening and } \\
\text { sort of saying how would } \\
\text { you guys do it in the } \\
\text { industry ... they said that } \\
\text { they would be happy to } \\
\text { work with us and consult } \\
\text { us as part of the } \\
\text { development" } \\
\text { "I think you should go and } \\
\text { talk to your competitor, } \\
\text { you might end up having a } \\
\text { joint thing, you might } \\
\text { learn from each other but } \\
\text { unless you have a } \\
\text { conversation with them } \\
\text { you will never know" }\end{array}$ & $\begin{array}{l}\text { "At the moment we are } \\
\text { just feeling each other out, } \\
\text { you know [partner] helped } \\
\text { us to build the AML } \\
\text { solution but at the same } \\
\text { time there are other things } \\
\text { that we want to do, we } \\
\text { want to be able to } \\
\text { integrate a bank authority } \\
\text { for our customers" } \\
\text { "[Partner] didn't just } \\
\text { provide the funding they } \\
\text { also wanted to show how } \\
\text { the technology that we } \\
\text { have been developing can } \\
\text { be used in different areas" }\end{array}$ \\
\hline
\end{tabular}

Table 20 - Kākāpō - Development of Activity Links, Resource Ties, and Actor Bonds

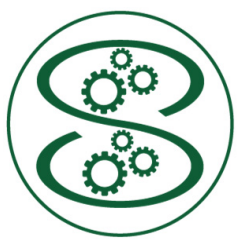

Kākāpō's VCC mechanisms were dependent on several activities performed by other actors in the ecosystem. Facilitating the onboarding and set-up of authorities required activities performed in concert with external service providers and processing by government agencies 屬. Kākāpō explored and created, in cooperation with various actors in its ecosystem $\&$, predominantly dyadic activity links. 
"We sent them [government agency] a digest of the information in the message body ... the only thing that they have to do is copy that string into their system, so it takes them two seconds to process a form when it's coming from us" (Co-Founder, Kākāpō)

The venture applied a broad spectrum of activity links ranging from submitting a form via e-mail to facilitating the exchange of data via APIs co-developed with other actors 8 specifically for Kākāpō's platform. Since linking activities that facilitate the exchange of data was considered as a value driver, the venture explored a wide range of activity linking opportunities 8 .

"That doesn't necessarily mean that they are going to change their processes. We can make it happen without them changing their process. Give us the email address, that's all that's needed, we can do the rest. If it goes to an API to do a whole bunch of stuff that's awesome" (Co-Founder, Kākāpō)

Kākāpō primarily invested resources in the development of activity links with homogenous integration partners such as government agencies. Nevertheless, the venture explored possible integration with heterogeneous actors such as banks and insurance companies with idiosyncratic opportunities to create activity links 8.

\footnotetext{
"Every organisation is different, we integrate with their existing processes as best as we can" (Co-Founder, Kākāpō)
}

Kākāpō aligned internal with external activities such as texting, identity verification, and credit card payment services performed by other actors. Next to exploring and developing vital dyadic activity links with government agencies, Kākāpō's VCC mechanisms were dependent on activity interdependencies with external service providers.

In short, Kākāpō continuously developed and extended the scale of activity links with other actors to automate the cost-efficient exchange of data. Every additional integration allowed the venture to provide additional value to customers and actors i.e., created positive network effects, and thus differentiated its offering from that of competitors.

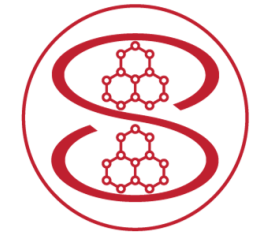

Kākāpō developed several resource ties with various partners to facilitate the linking of activities. Developing integrations with various actors required the development of organisational resource ties to enhance a shared understanding of how to facilitate and streamline transactions. 
"Initially government agencies were reluctant to work with us. We even got warned off a few times, but we were creating a lot of noise and finally manged to convey the idea of electronic submissions, e-signatures, and the advantages to them. We are facing the same problems with banks and insurance companies." (Co-Founder, Kākāpō)

Moreover, organisational resource ties facilitated the co-development of physical resource ties, i.e. bespoke software modules and interfaces and thus the mutual development of engaged actors' resource collections.

"We often work with their developers to create APIs that serve their and our systems' needs. Some of them were happy to get us involved or at least consult with us in the process. Each partner's system is different and that's where we develop and build value, in doing all of these effectively bespoke integrations into these other organisations, so our customers don't have to repeat the same processes over and over again" (Co-Founder, Kākāpō)

The resource ties developed even shaped the resource collection of actors such as government agencies, for instance the necessity to store paper submission. Besides, Kākāpō created resource ties to leverage external resources such as the NZBN database to prepopulate forms for customers and provide data to list beneficial owners of represented entities in its AML-CFT software feature.

"We pull down the company's proper name, company number, address, directors, shareholders from NZBN and save our customers from typing it in over and over again. We have all of our ancillary systems such as text messaging services, e-mail services, Microsoft Azure cloud computing, things that we rely on and have to integrate our system with" (Co-Founder, Kākāpō)

Simultaneously, Kākāpō developed several software interfaces to integrate with external service providers such as Google's two-factor authentication and identity verification services. While external service providers provide generic APIs, integrating these services requires adaptations of Kākāpō's software.

In short, Kākāpō continuously explored opportunities to create resource ties for various purposes. For instance, the venture consulted on several occasions with various government agencies to co-develop APIs. Besides, the resource ties created with external service providers were pivotal for linking important activities in Kākāpō’s VCC mechanisms. 


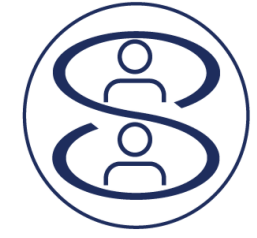

Kākāpō developed a broad spectrum of actor bonds that allowed the venture to obtain legitimacy by communicating social capital, position it in the ecosystem, and facilitate learning and capability development bonds with several government agencies that have publicly committed to provide financial and other support for the venture's development emerged over the period of the study.

"[Government agency] mentioned the cooperation with us in their annual report and inserted a link to us on their website." (Co-Founder, Kākāpō)

The bonds formed with government agencies provided insights and pivotal understanding of opportunities to engage with partners in value co-creation mechanisms.

"When doing this sort of thing, it's basically a coalition of the willing, talking to your partners can provide an understanding of how you can provide value to them." (Co-Founder, Käkāpō)

Moreover, strong bonds with government agencies provided the opportunity to influence the design of data transfer interfaces $\left(\mathbf{S}^{\mathbf{D}}\right.$, heads-up information on up-coming changes of these, and even insights into competitors' scope of activities.

"[Competitor] is saying that they are doing things that we are quite surprised by. We thought we would be the only ones with this type of government integrations, I will go and ask my insider at [government agency] about that" (Co-Founder, Kākāpō)

Next to government agencies, Kākāpō developed strong actor bonds with special interest groups for bookkeepers and accountants that allowed for insights into the requirements and needs of customer segments.

\footnotetext{
"We always had a good relationship with [interest group]. Their executives worked with us to develop the product, they invited us to their annual conference as panel speakers, and are telling their members about us" (Co-Founder, Kākāpō)
}

Finally, Kākāpō's strong ties with partner1, an established provider of bookkeepers' and accountants' practice management software, positioned the venture in the ecosystem. In addition, partner1 promoted Kākāpō's software solution by incorporating it in a comparison of onboarding software in its user magazine.

\footnotetext{
"Since we became a [partner1] connected app, we are on their marketplace. We have got a pretty good relationship with them. Their user magazine did a comparison for onboarding
} 
software, and we have been one of them. They are telling their customers about us"

(Co-Founder, Kākāpō)

\subsubsection{Summary Kākāpō}

Kākāpō's VCC mechanisms developed considerably throughout the study. The development was driven by the aim to create complementarities and enhance positive network effects that can provide benefits for customers as well as other engaged actors such as government agencies. Kākāpō developed integrations of considerable depth with a high scale of actors across its ecosystem. The venture engaged with several actors to coordinate the mutual development of resource collections that underpinned serial and dyadic activity links created to exchange and process information. Moreover, Kākāpō's public association with government agencies, interest groups, and established software providers legitimised the venture amongst its target customer group. In addition, strong actor bonds informed the development of platform features as well as opportunities for integration with other actors. Finally, actor bonds embedded and positioned Kākāpō in the ecosystem and significantly influenced the development of VCC mechanisms. Figure 45 summarised the development of Kākāpō's activity links, resource ties, and actor bonds. 


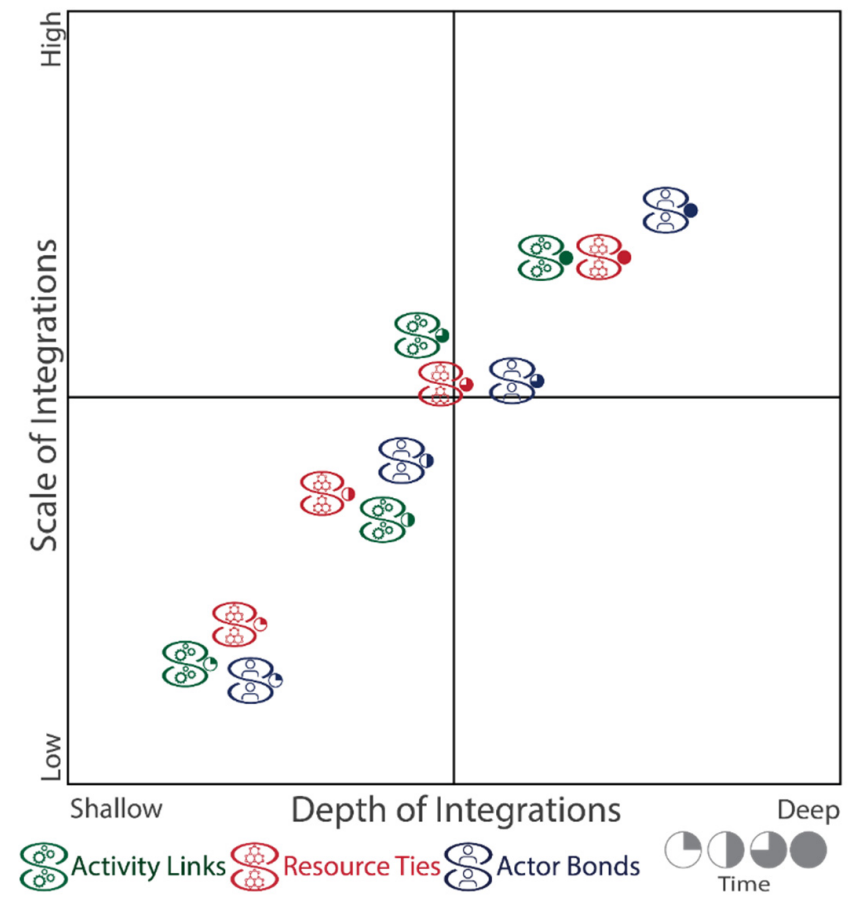

Figure 45 - Kākāpō - Development of Activity Links, Resource Ties, and Actor Bonds 


\subsection{Case Report - Venture Kea}

\subsubsection{Introduction}

Kea developed an online platform to enhance accountants' capabilities to engage with customers and provide compliance services. The venture aimed to engage other professional services providers (PSP) to offer services on its platform via a marketplace. Kea developed a robust set of VCC mechanisms underpinned by various integrations over the period of the study.

"We want to provide an ecosystem for PSPs, such as accountants and lawyers, to manage their clients' compliance requirements” (Co-Founder, Kea)

\subsubsection{Development of Customer Value Co-Creation Mechanisms}

\begin{tabular}{|c|c|c|c|}
\hline Time & $B$ & & \\
\hline $\begin{array}{l}\text { of } \\
\frac{0}{3}\end{array}$ & $\begin{array}{l}\text { "We have two customer groups, } \\
\text { accountants and end-users. These } \\
\text { are the direct beneficiaries of the } \\
\text { functionality our platform offers." }\end{array}$ & $\begin{array}{l}\text { "Two of the big five accountancies } \\
\text { have signed contracts with us." }\end{array}$ & $\begin{array}{l}\text { "95\% of our customers are } \\
\text { accountants, but in the next six } \\
\text { months we will open the platform to } \\
\text { end-users." }\end{array}$ \\
\hline 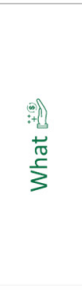 & $\begin{array}{l}\text { "It's really about improving the } \\
\text { workflow capabilities, so } \\
\text { accountants can perform their } \\
\text { perpetual service duties. That is the } \\
\text { value they can derive from our } \\
\text { offering." } \\
\text { "Companies receive one central hub } \\
\text { for all compliance issues." }\end{array}$ & $\begin{array}{l}\text { "The value created for accountants is } \\
\text { the convenience of communicating } \\
\text { with their portfolio of clients, } \\
\text { distributing documents, reviewing } \\
\text { and signing of tax returns. We } \\
\text { basically facilitate a virtual CFO } \\
\text { model, accountants can provide } \\
\text { using our platform." }\end{array}$ & $\begin{array}{l}\text { "Efficiency in managing clients and } \\
\text { workflow, accountants can act as a } \\
\text { compliance officer for their clients } \\
\text { and ensure that deadlines are met, } \\
\text { the shareholder and director registry } \\
\text { is maintained, and conducting } \\
\text { formal activities companies have to } \\
\text { perform, and directors have to } \\
\text { oversee." }\end{array}$ \\
\hline 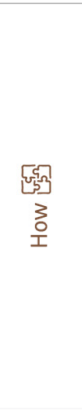 & $\begin{array}{l}\text { "We provide templates to produce } \\
\text { legal documents, offer electronic } \\
\text { signing, issue tax returns and } \\
\text { resolutions in an advanced CRM } \\
\text { system with the functionalities of a } \\
\text { practice management system." } \\
\text { "Companies can manage all } \\
\text { company records such as } \\
\text { employment contracts, health and } \\
\text { safety, policies and regulations, and } \\
\text { in turn fulfil their compliance } \\
\text { requirements on our platform." }\end{array}$ & $\begin{array}{l}\text { "We have just released some } \\
\text { functionality to maintain a share } \\
\text { register that is targeting larger firms } \\
\text { that goes beyond the purely } \\
\text { professional advisor role and allows } \\
\text { companies to calculate dividends, } \\
\text { issues share certificates and } \\
\text { communication. That is something } \\
\text { that companies do since accountants } \\
\text { often limit themselves to tax issues. } \\
\text { This is one area where we are seeing } \\
\text { companies picking up subscriptions } \\
\text { directly." }\end{array}$ & $\begin{array}{l}\text { "We are continuing to develop the } \\
\text { accountants and end-user } \\
\text { interaction, document packages and } \\
\text { functionalities around them will be a } \\
\text { good part of that but also improving } \\
\text { the personal workspace and } \\
\text { increasing the user-friendliness. In } \\
\text { addition, we are developing an AML } \\
\text { feature for identity verification and } \\
\text { exploring potential mobile aspects of } \\
\text { the platform." }\end{array}$ \\
\hline 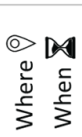 & $\begin{array}{l}\text { "We are assessing several off-shore } \\
\text { markets at the moment." }\end{array}$ & $\begin{array}{l}\text { "Potentially Australia, UK, and } \\
\text { Canada" }\end{array}$ & $\begin{array}{l}\text { "Despite Brexit, the UK seems to be } \\
\text { a promising market, and we are } \\
\text { considering Singapore as a gate to } \\
\text { Asia." }\end{array}$ \\
\hline
\end{tabular}

Table 21 - Kea - Development of Customer Value Co-Creation Mechanisms 


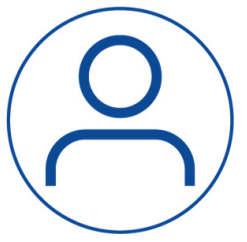

Kea focused initially on accountants and their clients as customer segments.

The venture managed to attract large accountancy practices in stage two and henceforth focused on the development of features to meet their and their corporate clients' needs

"Two big accountancies have signed contracts with us and are driving developments on our platform. We have been short-listed for two other accountancies, one is currently doing a security review on us." (Co-Founder, Kea)

Kea explored individuals, mainly directors and employees of accountants' clients, as potential additional customer segments.

"In the next six months we will release the individual platform and expect to offer subscriptions to individual customers." (Co-Founder, Kea)

Finally, the venture explored a large travel agency as a potential client of their compliance platform.

"Travel agencies have to store and process credit card data and thus have to comply with Payment Card Industry standards. It's early stages but might work out nicely and would be a beachhead into that market" (Co-Founder, Kea)

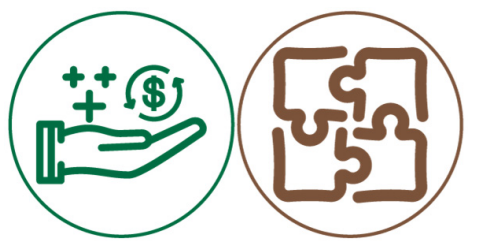

Kea co-created value with accountants and their clients by facilitating compliance with their duties of documentation and timely submissions to government agencies. The venture aimed to enhance the workflow and communication between

accountants and clients $\leftrightarrow$.

"Our platform allows to maintain policies and procedures, demonstrate compliance, detect risks, and support the auditing process. It basically enables accountants to provide compliance services on a subscription base to their clients. This is how they derive benefits from the platform. The second part is allowing their clients to capture some value from what we offer, in a pure compliance sense there's a lot that can be managed by accountants. It's really about providing this value allocation capabilities corporate clients can adopt." (Co-Founder, Kea)

While Kea initally targeted small accountancy practices, the engagement with large industry leaders drove the development of features 8. 
"Small accountancies are more interested in the efficiency gains of our platform. However, we are expanding our offering including health and safety policies and procedures, employment contracts, electronic signature and the ability to maintain a history of these documents for large accountancies." (Co-Founder, Kea)

In addition, Kea developed an offering exclusively for corporations and further extended the features for accountancies on its platform.

"We have developed a shareholder management suite for corporations. We will provide tools to trace beneficial owners and are developing an AML ID-verification feature for accountants" (Co-Founder, Kea)

Finally, Kea focused on developing features that targeted individual users related to accountancies or corporate clients in the final stages of the study.

"Individuals, such as directors or trustees, receive a fault storage capability to store documents like director certificates, insurance policies, last will, etc. and the ability to associate family members. It will be free for individuals." (Co-Founder, Kea)

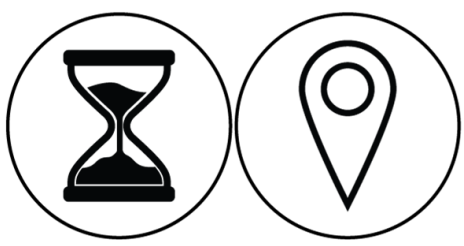

Kea's platform allowed accountancies and clients to electronically sign documents and submit them to government agencies bound face-to-face meetings were rendered obsolete. Although Kea explored several offshore markets for geographical expansion throughout the study, the venture has not provided services to customers outside of New Zealand.

Overall, Kea focused on accountancies and their clients as customer target segments. Throughout the study customer segments were refined and focused on large accountancy practices and corporate clients. At the heart of customer value co-creation was the compliance of customers' documentation and reporting duties to government agencies. The venture engaged with various customers to develop features for compliance assurance throughout the study. Finally, Kea explored opportunities to co-create value for individuals related to accountancies or corporate clients. The development of Kea's customer value proposition is illustrated in Figure 46. 


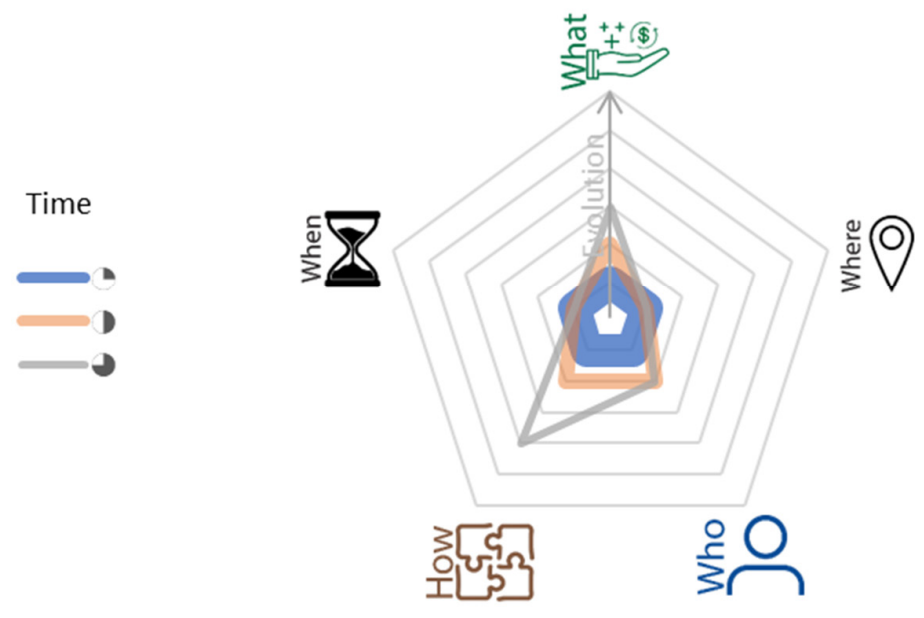

Figure 46 - Kea - Development of Customer Value Co-Creation Mechanisms

\subsubsection{Development of Actor Value Co-Creation Mechanisms}

"This venture is around the business propositions, and how they are navigated" (Co-Founder, Kea)

\begin{tabular}{|c|c|c|c|}
\hline Time & D & D & \\
\hline $\begin{array}{l}\text { of } \\
\circ \\
\frac{\rho}{3}\end{array}$ & $\begin{array}{l}\text { "We plan to cooperate with an AML } \\
\text { and an IT security consultant to } \\
\text { provide tailored policies and } \\
\text { procedures for accountants and } \\
\text { corporate clients." }\end{array}$ & $\begin{array}{l}\text { "We are looking at bringing on an } \\
\text { insurance broker or an insurance } \\
\text { company." }\end{array}$ & "We are providing value to MBIE." \\
\hline 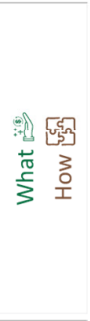 & $\begin{array}{l}\text { "We are working on a marketplace } \\
\text { where accountants can purchase } \\
\text { template products our partners } \\
\text { provide for specific areas and } \\
\text { augment what we are already } \\
\text { offering. They have the opportunity } \\
\text { to sell templates but also } \\
\text { consultancy services and } \\
\text { subscription services such as annual } \\
\text { IT security audits." }\end{array}$ & $\begin{array}{l}\text { "We will develop the marketplace } \\
\text { further when we managed to } \\
\text { leverage our existing channels and } \\
\text { acquired more customers. We don't } \\
\text { really need the marketplace } \\
\text { capability to sign partners up and } \\
\text { cooperate with them at the } \\
\text { moment." }\end{array}$ & $\begin{array}{l}\text { "We are developing a whole suite of } \\
\text { capabilities and sell it directly to } \\
\text { clients in which case there is no need } \\
\text { to have a marketplace. End-users } \\
\text { can subscribe to the products } \\
\text { directly and receive the benefits, } \\
\text { that's where we are heading } \\
\text { towards." }\end{array}$ \\
\hline 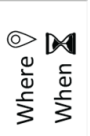 & $\begin{array}{l}\text { "Our marketplace will be open to } \\
\text { partners from all around the world." }\end{array}$ & $\begin{array}{l}\text { "We are discussing opportunities } \\
\text { with an Australian template } \\
\text { supplier." }\end{array}$ & $\begin{array}{l}\text { "We focus on New Zealand based } \\
\text { organisations at the moment." }\end{array}$ \\
\hline
\end{tabular}

Table 22 - Kea - Development of Actor Value Co-Creation Mechanisms

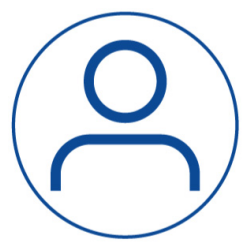

Kea explored the development of a marketplace for PSPs to engage them in the value co-creation process with accountants and their clients. Initially, the venture engaged with an AML-CFT and an IT security consultant to provide a 
"proof-of-concept" \&.

"We partner with an AML-CFT consultant and an IT security consultant to provide compliance assessment services, reveal potential threats, and propose a solutions to help accountants and their clients" (Co-Founder, Kea)

Potential engagements with insurance brokers were explored to leverage compliance and risk assessments conducted on the platform to generate sales leads 6 . Also, Kea engaged with government agencies and practice management software providers venture decided to cease the development of a marketplace and focus on direct cooperation with partners to provide services.

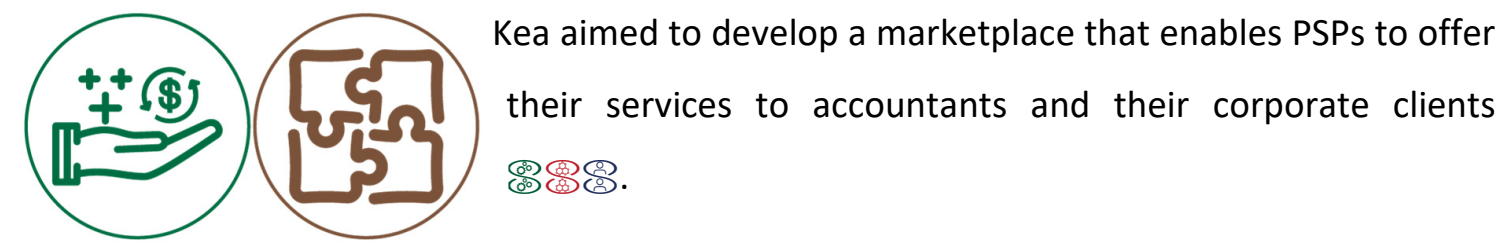

"Our platform acts as an enabler for PSPs to deliver services. They have the opportunity to partner with others and create joined offerings." (Co-Founder, Kea)

The venture engaged with an AML-CFT consultant to explore opportunities to cocreate value in stage two.

"We are focusing on the roll-out of an AML-CFT solution because it is the most pressing problem for accountants at the moment. IT security and health and safety solutions are on our roadmap" (Co-Founder, Kea)

After having successfully integrated content and processes of two partners on the platform were planned to be engaged to deliver a suite of services for accountants and their clients. Kea integrated government agencies to submit annual filings electronically

"We are leveraging their APIs for annual return filing and thus minimise their workload on paper-based returns and call centre requests." (Co-Founder, Kea)

Finally, opportunities to partner with other complementary software providers to cocreate value for customers were explored. 
"We have some continuity tracking, analysis, and paper set up in our shareholder management suite that [software provider] expressed an interest in. We consider different modes of integration currently" (Co-Founder, Kea)

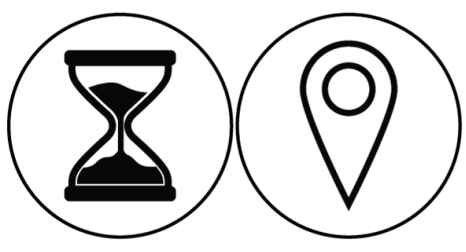

While initially Kea's marketplace was intended to be open to partners from around the world, the venture focused primarily on engaging New Zealand-based companies. The idiosyncratic legislation and compliance requirements of the domestic market required local counsel. However, potential partnerships with an Australia-based provider of templates and procedures were explored in the final stage of the study 8 .

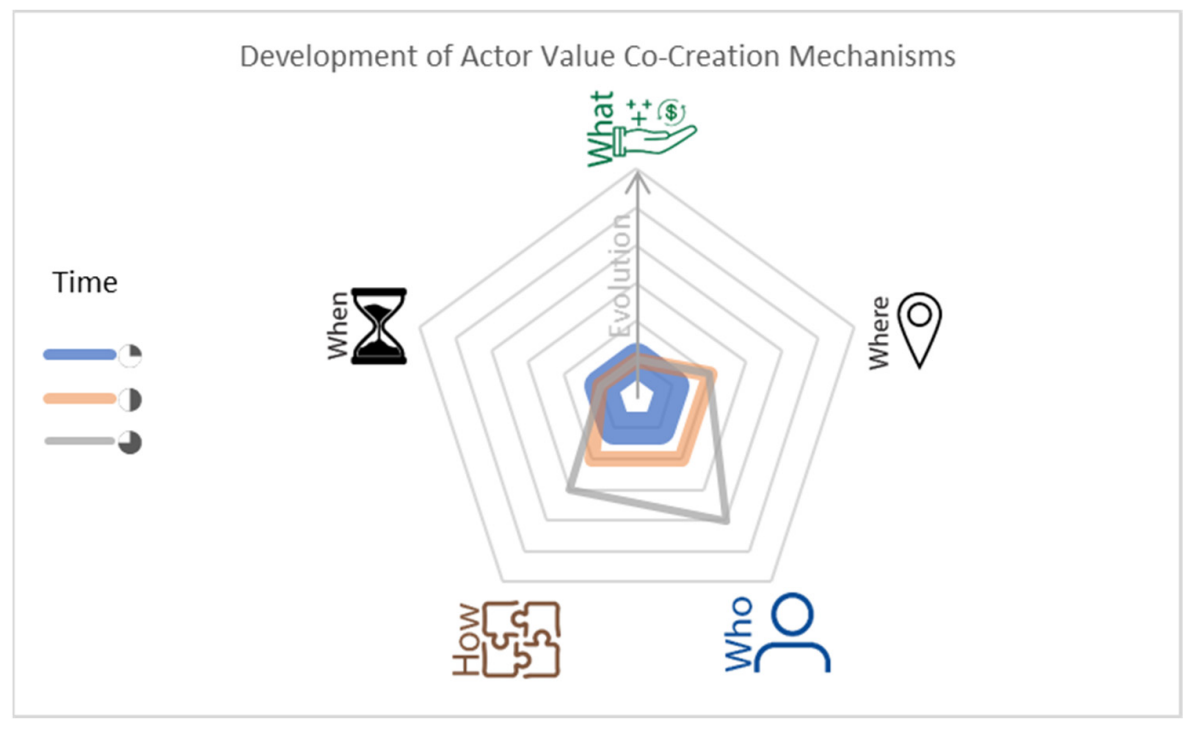

Figure 47 - Kea - Development of Actor Value Co-Creation Mechanisms

Overall, Kea's actor value co-creation mechanisms were continuously refined throughout the study. Despite discarding the marketplace development, Kea continuously extended the number of integrated actors. The venture primarily co-created pecuniary value via facilitating sales for partners and reducing costs by enabling the electronic exchange of data with actors. In addition, non-pecuniary value was co-created by engaging with them in the development of procedures and routines over time. The development of Kea's actor value co-creation mechanisms throughout the study has been illustrated in Figure 47. 


\subsubsection{Development of Value Capture Mechanisms}

\begin{tabular}{|c|c|c|c|}
\hline Time & D & & \\
\hline 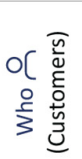 & $\begin{array}{l}\text { "The principal source of revenue are } \\
\text { accountants." }\end{array}$ & $\begin{array}{l}\text { "Accountants still account for the } \\
\text { most of our revenues." }\end{array}$ & $\begin{array}{l}\text { "We will introduce individual } \\
\text { subscription plans within the next six } \\
\text { months." }\end{array}$ \\
\hline 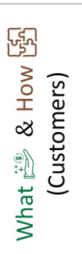 & $\begin{array}{l}\text { "Accountants pay on a per client } \\
\text { basis, so it scales on the number of } \\
\text { clients they onboard. Moreover, they } \\
\text { buy licenses and receive access to } \\
\text { checklists, workflows, and templates } \\
\text { that provide guidance for how to use } \\
\text { our partners' products on our } \\
\text { platform." }\end{array}$ & $\begin{array}{l}\text { "We are moving towards a } \\
\text { combination of accountants, } \\
\text { ventures, and individual or user } \\
\text { revenues. Accountants have annual } \\
\text { subscriptions while end-users will } \\
\text { have monthly subscription fees." }\end{array}$ & $\begin{array}{l}\text { "We are working through our } \\
\text { subscription plans to find ways how } \\
\text { we can create value for our clients via } \\
\text { the different administration tools. } \\
\text { We might capture value from ID } \\
\text { verifications of trustees and you } \\
\text { know some of them will convert to } \\
\text { end-users on our platform." }\end{array}$ \\
\hline 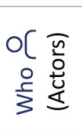 & "AML and IT security providers." & $\begin{array}{l}\text { "AML and IT security consultants } \\
\text { provide value to accountants, and } \\
\text { also to end-users. We capture a } \\
\text { margin on their services." }\end{array}$ & $\begin{array}{l}\text { "AML, IT security, health and safety } \\
\text { consultants that provide templates } \\
\text { and services via our platform." }\end{array}$ \\
\hline 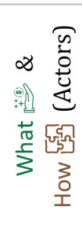 & $\begin{array}{l}\text { "We have a rough idea, } 30 \% \text { split on } \\
\text { our side for anything that is delivered } \\
\text { through our platform. The share } \\
\text { depends on what is delivered." }\end{array}$ & $\begin{array}{l}\text { "We will take a revenue share of the } \\
\text { templates and services our partners } \\
\text { sell to accountants on our market } \\
\text { place. } 40 \% \text { margin seems decent to } \\
\text { us. We might end up negotiating a } \\
\text { different split depending on the } \\
\text { nature of the service. }\end{array}$ & $\begin{array}{l}\text { "For example, if it is just a service- } \\
\text { based clip we just take } 5-10 \% \text {, if it's } \\
\text { purely content its 30\%." }\end{array}$ \\
\hline 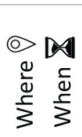 & $\begin{array}{l}\text { "Our marketplace will be open to } \\
\text { partners from all around the world." }\end{array}$ & $\begin{array}{l}\text { "We are discussing opportunities } \\
\text { with an Australian template } \\
\text { supplier." }\end{array}$ & $\begin{array}{l}\text { "We focus on New Zealand based } \\
\text { organisations at the moment." }\end{array}$ \\
\hline
\end{tabular}

Table 23 - Kea - Development of Value Capture Mechanisms

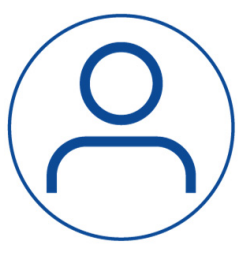

Kea captured value from customers, such as accountants and from their clients, with different subscription plans. Moreover, opportunities to introduce subscription plans for individuals were explored. Finally, Kea captured value from actors engaged in value co-creation mechanisms from

stage two onwards.

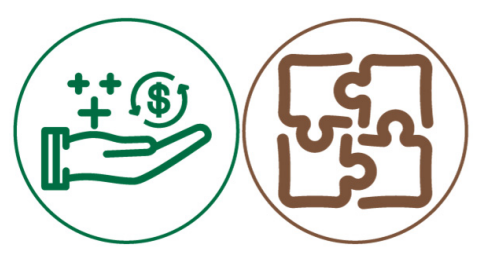

Kea captured pecuniary value from accountants and their clients via subscription plans. The subscription plans for accountants were initially bound to the number of clients administered on the platform and different functionalities

provided to them in the final stages $\varnothing$. 
"All scales with the number of end-users, but we offer a very low entry point. Accountants can upload 100 or 1000 clients, and we charge them just $\$ X X$ a year. If they want to engage those end-users it goes up to \$XXX per end-user per year" (Co-Founder, Kea)

The continuous development of features as well as the integration of other actors' services platform.

"We have constantly been growing functionalities and opening up opportunities for a featurebased revenue model. For instance, the shareholder management suite requires additional subscription fees. It's a little bit crawling back and there will be some sort of premium subscription available in the next six months." (Co-Founder, Kea)

Briefly after introducing a feature-based pricing model, competitive pressures forced to refine pricing plans again 8 .

"We had a price adjustment because one of our major competitors lowered their rates. We will be recovering from that within the next six months" (Co-Founder, Kea)

Kea captured value from actors by charging a fee based on content and services they provided via its platform 8 .

"We provide PSPs with a channel to sell templates and services as subscriptions to accountants and corporate clients. We take a clip on that as well." (Co-Founder, Kea)

Finally, Kea captured non-pecuniary value from customers via onboarding their clients. The "way to market" via accountants allowed to leverage customers' client networks to advertise organisational and individual user services captured from engaged actors since every additional service augmented Kea's platform attractiveness.

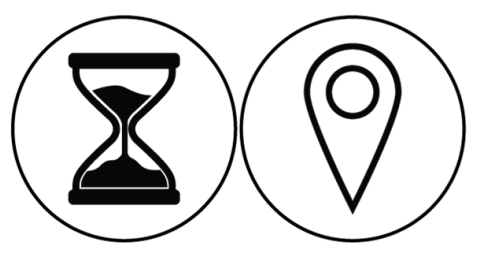

While Kea provided annual subscription plans for accountants and corporate clients, individual plans were planned to be introduced on a monthly basis. The differences reflected the idiosyncratic use of the platform. Besides subscription plans' timely heterogeneity, no other temporal or spatial aspects influenced the development of value capture mechanisms. 
Overall, Kea's value capture mechanisms were extended and refined throughout the study. Customer driven development of features required the adjustment of pricing plans based on the diverging use of functionalities. Also, changes in actor offerings i.e., marketplace vs. direct engagement, mandated a refinement of value capture mechanisms targeting PSPs providing content, processes, and services on the platform. Finally, pricing adjustments were driven by competitive pressures. The development of Kea's value capture mechanisms is illustrated in Figure 48.

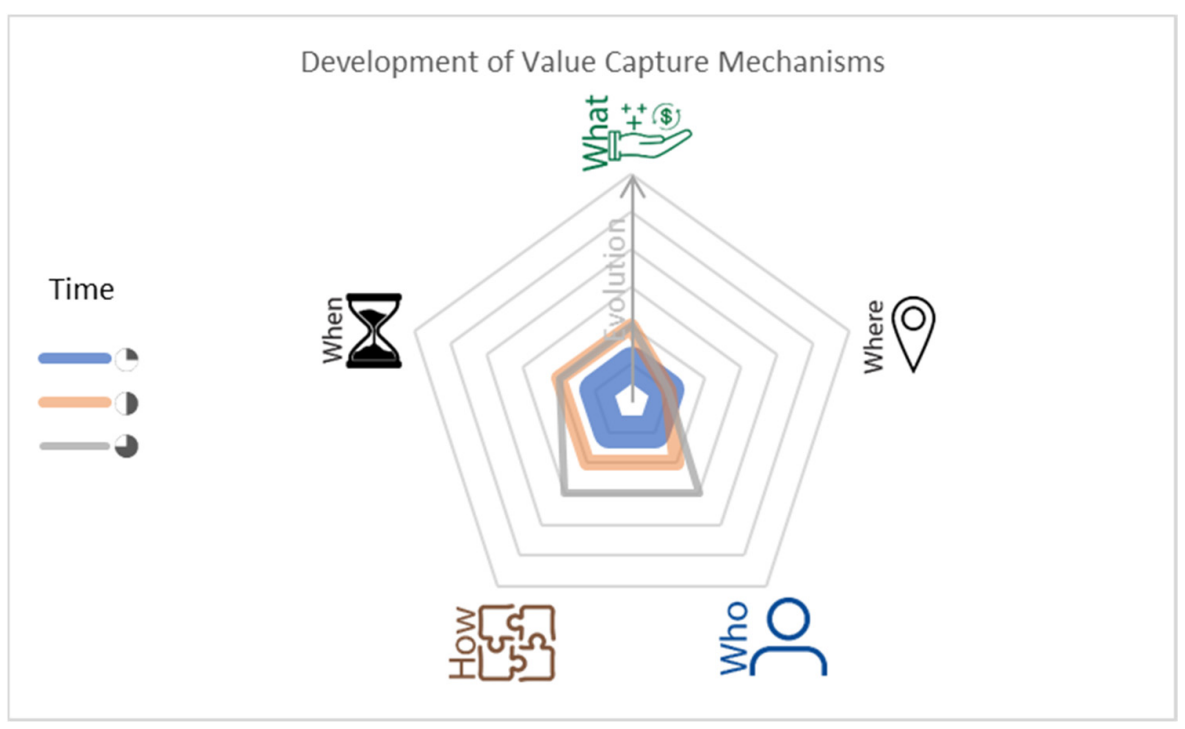

Figure 48 - Kea - Development of Value Capture Mechanisms

\subsubsection{Summary Value Co-Creation and Capture Mechanisms}

Kea's VCC mechanisms developed significantly throughout the study. The venture's customer value proposition development was underpinned by enhancing functionalities for accountants and corporate clients. In contrast to customer-driven feature development, actors' value co-creation mechanisms were refined to a direct engagement instead of a marketplace. In turn, Kea engaged with other actors directly to co-create value on the platform. Both developments drove the evolution of value capture mechanisms such as the refinement of subscription plans and new pricing structures for the engagement of PSPs on the platform. The development of VCC mechanisms is summarsied in Figure 49. 


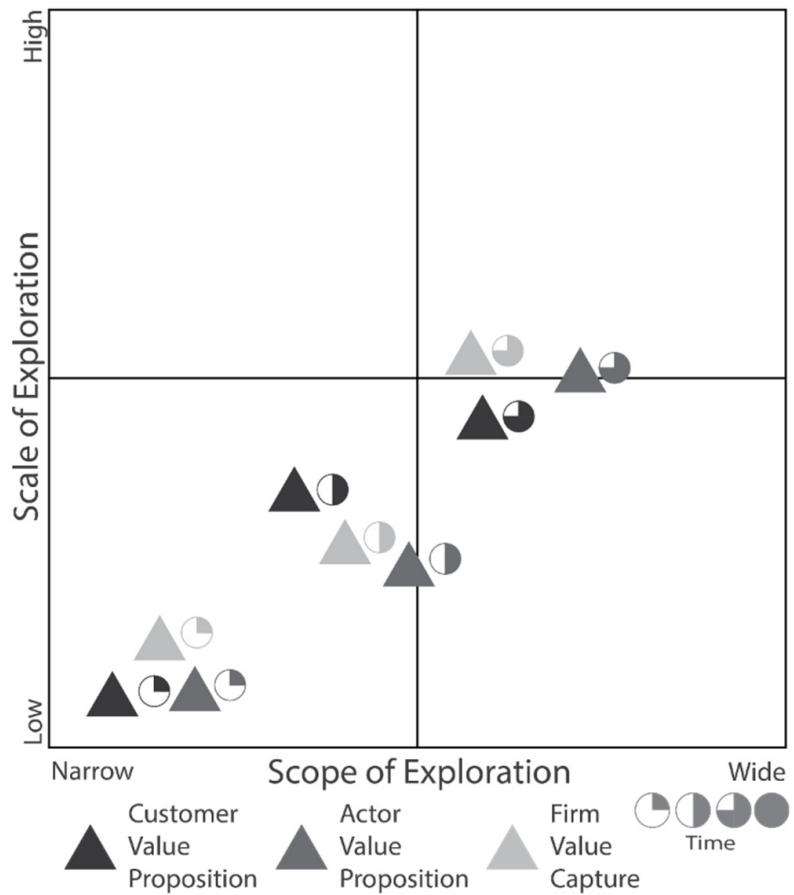

Figure 49 - Kea - Development of Value Co-Creation and Capture Mechanisms 


\subsubsection{Development of Activity Links, Resource Ties, and Actor Bonds}

\begin{tabular}{|c|c|c|c|}
\hline Time & $D$ & & \\
\hline 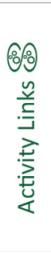 & $\begin{array}{l}\text { "The development of our platform is } \\
\text { based on AWS. We use their tools, } \\
\text { development environment, and we } \\
\text { have to hire people that have the right } \\
\text { skills." }\end{array}$ & $\begin{array}{l}\text { "it's mostly based on a document } \\
\text { exchange, so they will produce text } \\
\text { documents, and we will distribute } \\
\text { them. We engage with other partners } \\
\text { on more integral levels to offer their } \\
\text { solutions and make mutually } \\
\text { adjustments to facilitate the } \\
\text { provision of services." }\end{array}$ & $\begin{array}{l}\text { "We partner with [service provider] } \\
\text { to facilitate the identification of the } \\
\text { shareholders, directors, and trustees, } \\
\text { anybody you have to verify for AML- } \\
\text { CFT purposes." }\end{array}$ \\
\hline 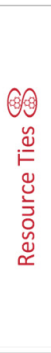 & $\begin{array}{l}\text { "AWS has been crucial for us to be } \\
\text { able to launch our platform in a } \\
\text { scalable way, being a start-up } \\
\text { company we are limited in resources. } \\
\text { Being able to leverage a platform like } \\
\text { AWS to deliver services to large } \\
\text { numbers of parties has been crucial. } \\
\text { Back ten years ago that would not } \\
\text { have been possible in a very cost- } \\
\text { effective way, so as an enabler that } \\
\text { has been absolutely pivotal." }\end{array}$ & $\begin{array}{l}\text { "Since accountants use practice } \\
\text { management systems such as [PMS1"] } \\
\text { or [PMSP2]. We have to integrate } \\
\text { with them via APIs, so our platform } \\
\text { can synchronise their client details, } \\
\text { have the ability to move documents } \\
\text { back and forth. These providers of } \\
\text { practice management software are } \\
\text { potential barriers to us entering into } \\
\text { the market if we are not able to } \\
\text { integrate with their products." }\end{array}$ & $\begin{array}{l}\text { "We have focused on integrating with } \\
{\left[\mathrm{PMSP}_{2}\right] \text { and managed to pull }} \\
\text { information out but still can't upload } \\
\text { documents. We have a lot more work } \\
\text { to do to make that happen, their } \\
\text { integration is not that good." }\end{array}$ \\
\hline 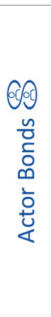 & $\begin{array}{l}\text { "We hope we can convince } \\
\text { integration partners to develop } \\
\text { necessary APIs by creating client } \\
\text { pressure. When clients understand } \\
\text { and appreciate our value proposition } \\
\text { they want to utilise the product } \\
\text { across the software packages they are } \\
\text { using" }\end{array}$ & $\begin{array}{l}\text { "We are focusing on establishing } \\
\text { good relationships with our AML-CFT } \\
\text { and IT security partners at the } \\
\text { moment. We currently are discussing } \\
\text { a cooperation with an Australian- } \\
\text { based venture that provides many } \\
\text { documents on various workflows, but } \\
\text { that's a long shot. When we have } \\
\text { some more traction, we will approach } \\
\text { other partners." }\end{array}$ & $\begin{array}{l}\text { "Our engagement with some of the } \\
\text { big five drives certain developments } \\
\text { of our business model. They are } \\
\text { looking for ways how to develop } \\
\text { digital channels and looking towards } \\
\text { products that are helping them to } \\
\text { enhance their offerings." }\end{array}$ \\
\hline
\end{tabular}

Table 24 - Kea - Development of Activity Links, Resource Ties, and Actor Bonds

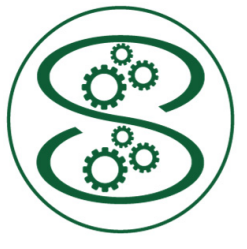

Kea developed activity links with several other actors. Next to the joined activity links developed with cloud computing infrastructure providers, the venture engaged with actors, such as external service providers $:$, in the development process of the platform.

"We have outsourced the development of user experience and visual design" (Co-Founder, Kea)

Also, Kea established joined activity links with PSPs to develop features and solutions such as AML-CFT compliance processes. Mutual adjustments of activities were required to facilitate value co-creation mechanisms for customers. Finally, the venture developed dyadic activity links with a provider of ID verification services to underpin its AML-CFT due diligence feature on the platform 8 . Moreover, integration with government agencies requires the unilateral adjustments of document processing activities to file reports. 
"We develop for most partners bespoke integrations. Some of them provide standardised APIs others require the co-development of a tailored solution. However, in both cases we have to adjust how we are developing our platform and how we are processing data" (Co-Founder, Kea)

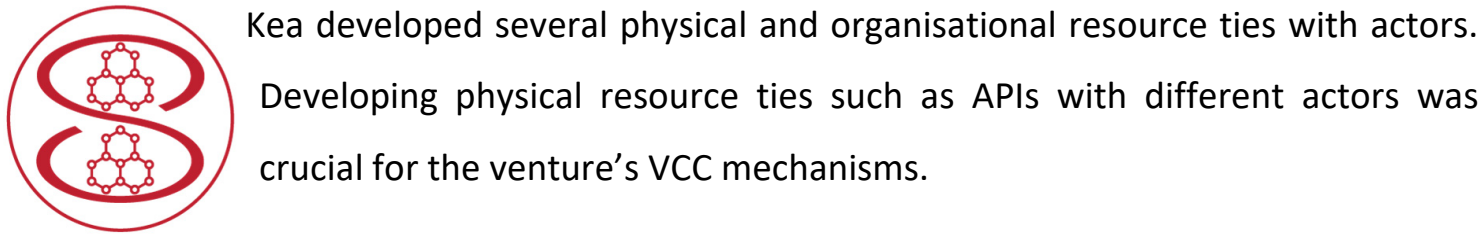

“We have integrated the Companies Office' API to download details of New Zealand based firms. Most registers have an electronic filing process. In order to be able to file against those we need to develop bespoke software to do annual filings for companies" (Co-Founder, Kea)

In contrast to the standardised APIs some government agencies provide, integrating with practice management software packages that are complementary to Kea's platform required adapting internal resources and significant development effort $ळ$.

"[PMSP $\left.{ }^{14}\right]$ has most recently started to develop an API offering. We haven't been able to integrate with PMSP1 or PMSP2 because their APIs are a nightmare and they don't put any effort into their development. These integrations are highly desirable to make our software of greater value to accountants and their clients" (Co-Founder, Kea)

Also, developing organisational resource ties with customers and other actors such as the AML-CFT and IT security consultant that engaged with Kea to co-create value on the platform was vital. Developing a converging understanding of what and how accountants can provide services to clients was critical for Kea's VCC mechanisms 8 .

"It is more about them integrating with us then the other way around. It's based on the exchange of documents and the co-development of procedures on our platform, as well as their provision of services to users of our platform" (Co-Founder, Kea)

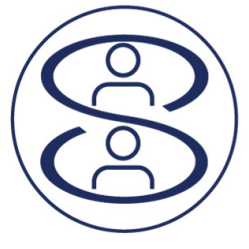

Kea developed strong bonds with various actors that provided legitimacy, positioned the venture in the ecosystem, and facilitated learnings and capability development. The venture leveraged the bonds created with customers to reach out to corporate and individual clients and position itself

\footnotetext{
${ }^{14}$ Practice Management Software Provider
} 
in the ecosystem as a service provider for accountancies and their clients

"We take the relationship-based selling approach which means that accountancies are our channel to the market. It basically means that we are going out there hit the streets and talk to them, and discuss access to their clients" (Co-Founder, Kea)

In addition, actor bonds developed with customers such as large accountancies, enhanced the legitimacy of Kea as a reliable provider of services.

"We have been working with three large accountancies, that's very gratifying and provides standing in the industry" (Co-Founder, Kea)

Besides leveraging the reputation of large accountancies, the bonds developed with them enhanced the development, testing, and refinement of platform features

"We have engaged with customers to drive the development of several product features. They provided valuable insights into the design and development of functionalities. We've been testing the doc-pack and e-signature features with them and their corporate clients and received great feedback" (Co-Founder, Kea)

Next to customers, Kea developed actor bonds with actors engaged in VCC mechanisms on its platform such as an AML-CFT and an IT-security consultant. The bonds developed facilitated the integration of know-how into services provided on the platform such as AML due diligence procedures

"We have established a relationship and onboarded the AML-CFT consultant. We will be working with them for the next two months to facilitate the roll-out of their templates on our platform" (Co-Founder, Kea)

Bonds with additional partners such as insurance brokers, tax management software providers, and a PMSP were explored. While some actor bonds were further developed, others remained dormant.

"[PMSP] approached us about a cooperation a couple of weeks ago but that went silent since they have been sold. It would have been fantastic to integrate with them because some of the large accountancies use their software" (Co-Founder, Kea)

Finally, Kea established first actor bonds with a multinational partner and explored opportunities to license its software platform. 
"We have been approached by a large multinational that wants to sell their documents through our marketplace. That would be a fantastic lead into the Australian, European, and US market. Their interest has changed the way we are looking at our platform. We have to find out how we can white-label our product without losing our identity, maybe we can co-brand our platforms and provide reciprocal access to both marketplaces" (Co-Founder, Kea)

\subsubsection{Summary Kea}

The development of Kea's customer value proposition was governed by the venture's focus on large accountancies and their corporate clients. Kea's actor value co-creation mechanisms were refined from a marketplace to the direct integration of their offerings on the venture's platform. The continuous development of features for customers and direct engagement of actors had several ramifications for the development of value capture mechanisms. Next to the introduction of features-based pricing plans, the venture refined the share taken of partners' content and processes sold via its platform multiple times. Developing activity links as well as resource ties was crucial for the evolution of VCC mechanisms over time. Moreover, Kea created actor bonds with multiple customers and other partnering organisations to facilitate learning, gain legitimacy, and position the venture in the ecosystem. Figure 50 summarises Kea's development of activity links, resource ties, and actor bonds over time.

\footnotetext{
"Nothing has really changed in terms of the vision, I think that has been very sound, it might seem that we are pivoting in some places and yes we have received some competitive pressure, which was pushing changes in the roadmap a little bit, but we have not had something too significant." (Co-Founder, Kea)
} 


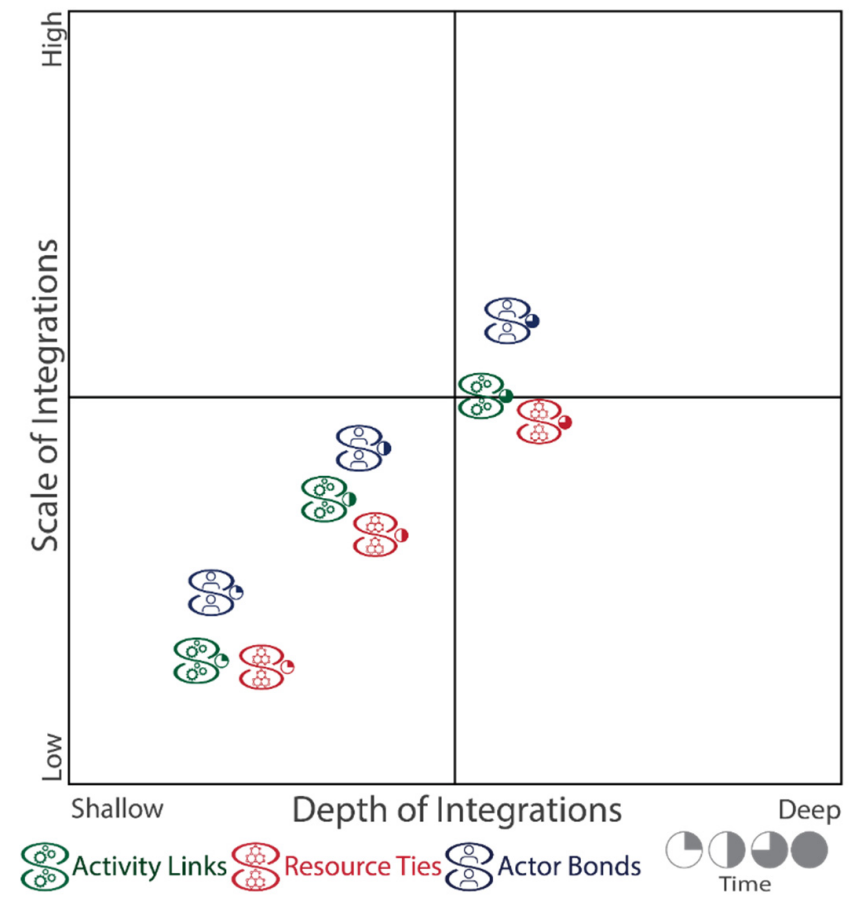

Figure 50 - Kea - Development of Activity Links, Resource Ties, and Actor Bonds 


\subsection{Case Report - Venture Kākā}

\subsubsection{Introduction}

Kākā offered flight simulator services for pilots and aviation students in cooperation with aero clubs and flight schools. The development of VCC mechanisms was influenced by the cooperation with an initial launch partner and integrations developed with multiple actors over time. Kākā engaged with several actors to successfully develop a firm-ecosystem fit and a viable $\mathrm{BM}$.

\subsubsection{Development of Customer Value Co-Creation Mechanisms}

"Offering flight simulators and providing innovative and cost-effective training opportunities."

(Co-Founder, Kākā)

\begin{tabular}{|c|c|c|c|c|}
\hline Time & $B$ & & & \\
\hline $\begin{array}{l}\text { OC } \\
\frac{0}{3}\end{array}$ & $\begin{array}{l}\text { "Pilots are members of } \\
\text { aero clubs that own and } \\
\text { operate simulators." }\end{array}$ & $\begin{array}{l}\text { "Aviation students are } \\
\text { looking for realism." }\end{array}$ & $\begin{array}{l}\text { "Pilots have to maintain } \\
\text { their currency on } \\
\text { instrument ratings." }\end{array}$ & $\begin{array}{l}\text { "Selling individual } \\
\text { hardware elements to } \\
\text { home-users." }\end{array}$ \\
\hline 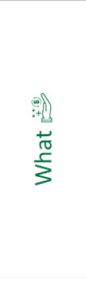 & $\begin{array}{l}\text { "The simulator becomes } \\
\text { more cost-effective when } \\
\text { simulating twin-engine } \\
\text { aircraft. Doing } 20 \text { hours of } \\
\text { instrument ratings in the } \\
\text { simulator at } \$ 159 / \mathrm{h} \\
\text { instead of } \$ 600 / \mathrm{h} \text { makes a } \\
\text { difference in costs." }\end{array}$ & $\begin{array}{l}\text { "Some training exercises } \\
\text { are too dangerous to be } \\
\text { done in real aircraft, it is } \\
\text { safer to do them in the } \\
\text { simulator." }\end{array}$ & $\begin{array}{l}\text { "Maintaining a currency } \\
\text { for instrument flying } \\
\text { requires to find the time at } \\
\text { the right weather } \\
\text { conditions, and a safety } \\
\text { pilot accompanying the } \\
\text { pilot." }\end{array}$ & $\begin{array}{l}\text { "Flying to airports with } \\
\text { appropriate navigation } \\
\text { aids, repositioning aircraft } \\
\text { for approaches, and } \\
\text { finding the required } \\
\text { weather conditions, these } \\
\text { added expenses of real } \\
\text { aircraft training fall } \\
\text { away." }\end{array}$ \\
\hline $\begin{array}{l}\text { जुद्ध } \\
3 \\
\text { o }\end{array}$ & $\begin{array}{l}\text { "Aircraft are getting more } \\
\text { technically advanced and } \\
\text { have quite complex GPS } \\
\text { units; it makes sense to } \\
\text { train of that equipment in } \\
\text { a simulator." }\end{array}$ & $\begin{array}{l}\text { "In the simulator, you can } \\
\text { fail certain pieces of } \\
\text { equipment, like your } \\
\text { navigation instruments. } \\
\text { You can't do that for real." }\end{array}$ & $\begin{array}{l}\text { "When the simulator has } \\
\text { been certified by the CAA, } \\
\text { pilots can log their time in } \\
\text { their logbooks when an } \\
\text { instructor was present." }\end{array}$ & $\begin{array}{l}\text { "In the simulator, you can } \\
\text { load any airport, } \\
\text { approach, weather, and } \\
\text { failure. It's a great } \\
\text { advantage for every pilot } \\
\text { that has to maintain its } \\
\text { currency." }\end{array}$ \\
\hline 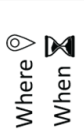 & & $\begin{array}{l}\text { "If the weather is good, } \\
\text { you go flying outside. } \\
\text { Otherwise, you use the } \\
\text { simulator." }\end{array}$ & & $\begin{array}{l}\text { "Flying weather was so } \\
\text { good; everybody was flying } \\
\text { aircraft, they will use the } \\
\text { simulator in winter." }\end{array}$ \\
\hline
\end{tabular}

Table 25 - Kākā - Development of Customer Value Co-Creation Mechanisms 


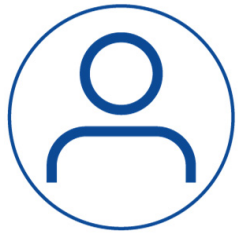

Kākā developed and maintained consistent target customer segments of aviation students and qualified pilots in their customer value co-creation mechanism. However, private home-users of simulators were explored as a potential customer segment in stage four.

"It's a popular hobby across the world. People are spending millions of dollars on private flight simulator equipment" (Co-Founder, Kākā)

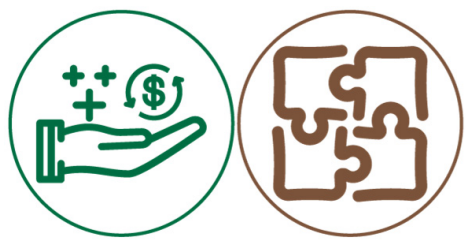

Kākā provided flight training opportunities for pilots and aviation students by offering a CAA ${ }^{15}$ certified simulator to aeroclubs and flight training schools 8 . CAA certification was required to allow pilots to record simulator approaches in their log books ${ }^{16}$ when an instructor is present $\Phi$. The range of aircraft that can be simulated provided an array of training scenarios. While cost efficiency was considered as significant value driver of Kākā's offering, other advantages such as simulating a wide range of weather conditions, airports, and failure scenarios that hardly can be trained in real aircraft were enhanced in the final stages of the study.

\footnotetext{
"Every 90 days pilots have to do X approaches to maintain their licence's currency. It's quite difficult to get those done, flying in Wellington you might get two instrument approaches done in one hour. On the simulator you get six or eight done because you fly the instrument approach, reset it and fly again. You can upload any type of approach at any airport in the world."

"It is quite hard to simulate failures in real aircraft, instructors will cover up instruments with cardboard whereas on the simulator it can be done discreetly and pilots have to recognise that something is wrong. Aviation students are looking for realism these days and are expecting simulators that are equipped with technology that matches the advancements of aircrafts" (Co-Founder, Kākā)
}

Besides, opportunities to simulate a wide range of scenarios allowed pilots to train in various conditions and enhanced the hedonic value experienced by pilots.

${ }^{15}$ Civil Aviation Authority

${ }^{16}$ Pilots are required to maintain a log book, according to CAA standards, and document trained approaches to maintain their license's currency. 
"They started a simulation with 12oknp wind and tried to hover over the runway at Wellington airport. They were not trying to bush up their skills, they were just messing around for fun" (Co-Founder, Kākā)

Modes of how simulators were operated to provide pilots or aviation students with training opportunities were co-developed with aero clubs and flight training schools Finally, the venture explored opportunities to provide individual simulators hardware elements to private users in the final stage of the study.

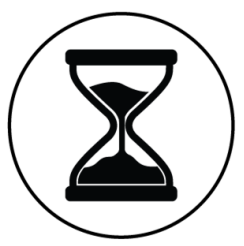

Kākā's customer value co-creation mechanisms allow pilots to fly at all times and thus provide a significant advantage over real aircraft training. Flying approaches independent of weather conditions and other air traffic was considered a crucial advantage of simulators.

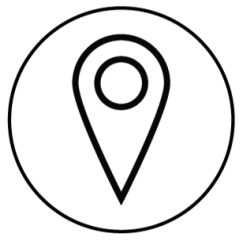

Kākā's customer value co-creation mechanisms were spatially bound to the facilities of the aero club or the flight schools. However, Kākā's simulators allowed pilots to fly approaches at every airport worldwide and thus provided geographical flexibility. In contrast to pilots conducting training in

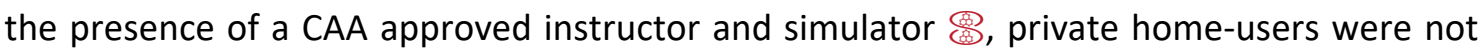
bound by any regulatory or geographic boundaries. In short, the where of customer value cocreation remained constant throughout the study.

In conclusion, Kākā's customer value co-creation mechanisms developed only marginally throughout the study. The venture offered cost-efficient and realistic training opportunities for aviation students and pilots. Nevertheless, a shift in focus from costefficiency to realistic training experiences, as well as hedonic value of simulating challenging conditions, was apparent in the process. Figure 51 illustrates the development of customer value co-creation mechanisms. The well-known benefits of simulator training explains the absence of significant developments. 


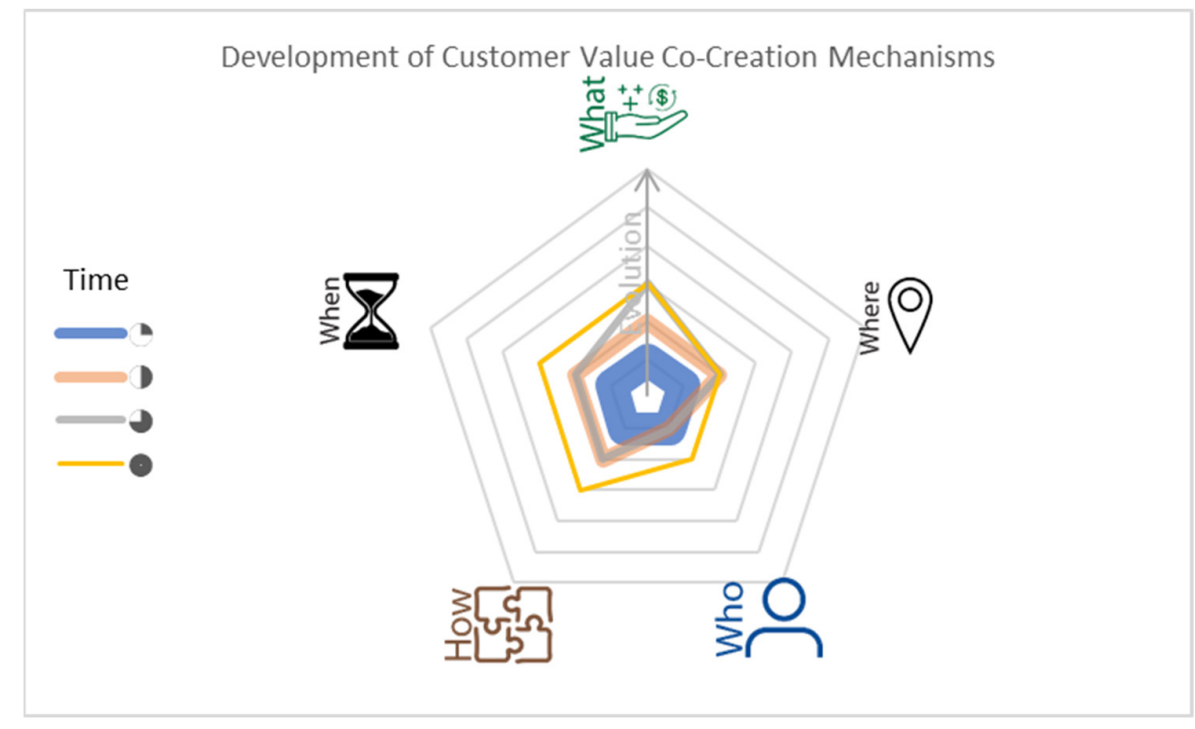

Figure 51 - Kākā - Development of Customer Value Co-Creation Mechanisms

\subsubsection{Development of Actor Value Co-Creation Mechanisms}

\begin{tabular}{|c|c|c|c|c|}
\hline Time & 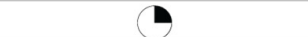 & & & \\
\hline $\begin{array}{l}\text { OC } \\
\frac{0}{3}\end{array}$ & $\begin{array}{l}\text { "Smaller aero clubs } \\
\text { offering flight training and } \\
\text { are run by volunteers; } \\
\text { professional training } \\
\text { schools run on a for-profit } \\
\text { basis." }\end{array}$ & $\begin{array}{l}\text { "Primarily aero clubs and } \\
\text { flight training schools, } \\
\text { there is a significant } \\
\text { difference." }\end{array}$ & $\begin{array}{l}\text { "Our Dutch software } \\
\text { partner is very keen to } \\
\text { promote our simulators." }\end{array}$ & $\begin{array}{l}\text { "Aircraft manufacturers } \\
\text { wanting tailored } \\
\text { simulator." }\end{array}$ \\
\hline $\begin{array}{l}\text { and } \\
i+\frac{1}{2} \\
+\pi \\
\frac{\pi}{3}\end{array}$ & $\begin{array}{l}\text { "Aero clubs usually have } \\
\text { members with an } \\
\text { instrument rating, but } \\
\text { aero clubs often don't have } \\
\text { the 'facilities or aircraft } \\
\text { that allows them to } \\
\text { maintain their currency, } \\
\text { with simulators they can } \\
\text { offer that." }\end{array}$ & $\begin{array}{l}\text { "Simulators allow to } \\
\text { change aircraft types, } \\
\text { depending on the required } \\
\text { approaches to maintain a } \\
\text { currency, a Piper, Cessna, } \\
\text { or Moony can be } \\
\text { simulated with different } \\
\text { flight models." }\end{array}$ & $\begin{array}{l}\text { "We are discussing a } \\
\text { cross-promotion deal for } \\
\text { flight and air-shows they } \\
\text { visit in the US and Europe, } \\
\text { and it's still on the table." }\end{array}$ & $\begin{array}{l}\text { "Aero clubs and flight } \\
\text { schools charge members } \\
\text { or students for using the } \\
\text { simulators, it provides } \\
\text { another revenue stream } \\
\text { for them." }\end{array}$ \\
\hline 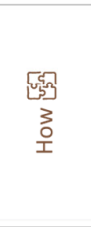 & $\begin{array}{l}\text { "We offer four different } \\
\text { models where we can } \\
\text { customise colours of } \\
\text { instruments, types of } \\
\text { switches, and the layout of } \\
\text { the gauges to some } \\
\text { extent." }\end{array}$ & $\begin{array}{l}\text { “We will provide a short } \\
\text { warranty, but partners will } \\
\text { not have to look at } \\
\text { maintenance contracts.” }\end{array}$ & $\begin{array}{l}\text { "Maybe we can provide } \\
\text { just the front section as a } \\
\text { display to demonstrate } \\
\text { their software." }\end{array}$ & $\begin{array}{l}\text { "We want to offer } \\
\text { simulators as a service, } \\
\text { installation, training, } \\
\text { organising re-certification, } \\
\text { and maintenance services, } \\
\text { so they don't have to } \\
\text { worry about anything." }\end{array}$ \\
\hline 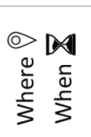 & & $\begin{array}{l}\text { "Our initial target markets } \\
\text { are New Zealand and } \\
\text { Australia. }\end{array}$ & $\begin{array}{l}\text { "We will focus initially on } \\
\text { the Australasian market." }\end{array}$ & $\begin{array}{l}\text { "Expansion to Asia is the } \\
\text { next step." }\end{array}$ \\
\hline
\end{tabular}

Table 26 - Kākā - Development of Actor Value Co-Creation Mechanisms 


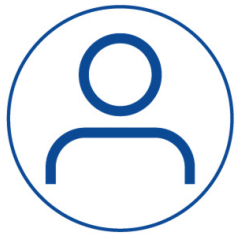

Kākā continuously extended the scale of actors engaged throughout the study. Aero clubs and flight training schools were crucial actors in value cocreation mechanisms simulators, they were considered as distinct. Additionally, Kākā considered creating an offering for a partnering software provider to enhance cross-promotion of software and flight simulators 8 , engaged with a pilot testing and accreditation institute to distribute flight simulators 8 , and explored aircraft manufacturers as additional actor group 8

"Different training organisations will have different needs depending on their current fleet. Aero clubs train to the private pilot level and do a little bit of in-house training whereas flight training schools offer instruction programs that last three to six months. The different customer dynamics require different ways to market" (Co-Founder, Kākā)

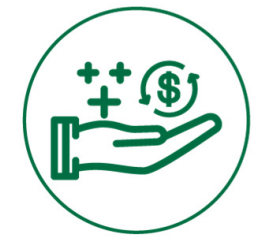

Kākā co-created value with engaged actors in different ways. Kākā's simulators increased aero clubs' attractiveness to members since they provided multivalent training opportunities and means to maintain pilot licenses' currency attractiveness of flight schools amongst students since they provided cost-efficient training opportunities matching real aircraft as well as allowing realistic training scenarios independent of weather conditions and geographic infrastructure limitations.

"Across New Zealand, most of the simulators are quite old and outdated. They still do the job but the technology has moved on, and students are looking for realism these days and are expecting better technology such as the latest LCD-displays" (Co-Founder, Kākā)

Moreover, offering flight training via simulators provided an additional revenue stream for aero clubs and flight schools. Next to charging members of the aeroclub for the use of simulators, aero clubs could offer flight experiences to the public.

"Pilots wanting to record time in the logbook need to have an instructor alongside them, there will be a higher hourly rate than somebody who wants to basically go and have a bit of a play with it. There's potential for any pilot to brush up on their skills by using the simulator but not logging the time. Our launch partner even offers vouchers for a flight in a simulator for nonpilots. It represents a potential value stream for them" (Co-Founder, Kākā) 
Conducting flight training on simulators allows aero clubs and flight schools to reduce the operational hours of aircraft, reduce maintenance costs, and potentially increase fleet utilisation. Moreover, providing individual modules allows partnering companies to demonstrate their software without having to arrange for the transportation of bulky flight simulators on roadshows. Finally, by providing flight simulators to a well-renown pilot testing institute 8 , Kākā enables the partner to enlarge the portfolio of flight simulators offered.

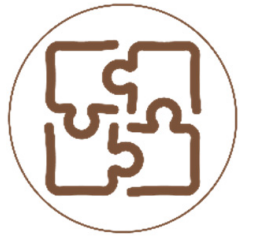

Kākā's offering for aero clubs and flight schools evolved throughout the study. While providing simulators was at the core, Kākā explored the scope of the offering including simulator types, customisations, and maintenance contracts as well as means of providing the offering via sales, leasing, and vending-type models. While initially product focused, Kākā increasingly adopted a service approach in the ongoing course of the study. Next to providing instructor training, Kākā offered a flight syllabus, maintenance and recertification services for aero clubs and flight training schools

"CAA certifies the simulator, training syllabus, and the instructor, we have to provide it all in one package and train the instructors. It's hardware as a service because aero clubs and flight schools don't have the time, knowledge or interest to deal with all maintenance and recertification. The simulator as a service model requires at least a minimum number of hours to be financially viable" (Co-Founder, Kākā)

In short, Kākā's offerings developed in scope such as simulator customisation, training syllabus, and maintenance services throughout the study 屬. Likewise, Kākā offered simulators of individual modules to an increasing scale of actors such as software partners, pilot testing institutes, or aircraft manufacturers.

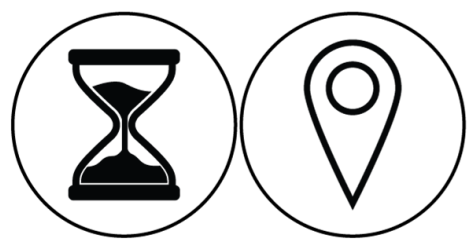

The biannual CAA re-certification of simulators and the limited mobility of the simulator characterised Kākā's actor value cocreation mechanisms

Kākā explored opportunities to provide simulators to aero clubs and flight schools in 
Australia in the final stage of the study. While the venture was encouraged by partners to enter the European market, the venture refrained because of existing competition and variations in regulatory standards.

"The European and US markets are well penetrated. EASA's ${ }^{17}$ standards are very stringent and difficult to meet in the certification process. We focus on Australasia first" (Co-Founder, Kākā)

Overall, Kākā's actor value co-creation mechanisms evolved throughout the study. The scale of actors engaged in VCC increased constantly as well as the scope of the offering, i.e. simulator as a service. Figure 52 summarises Kākā's development of actors value co-creation mechanisms over time.

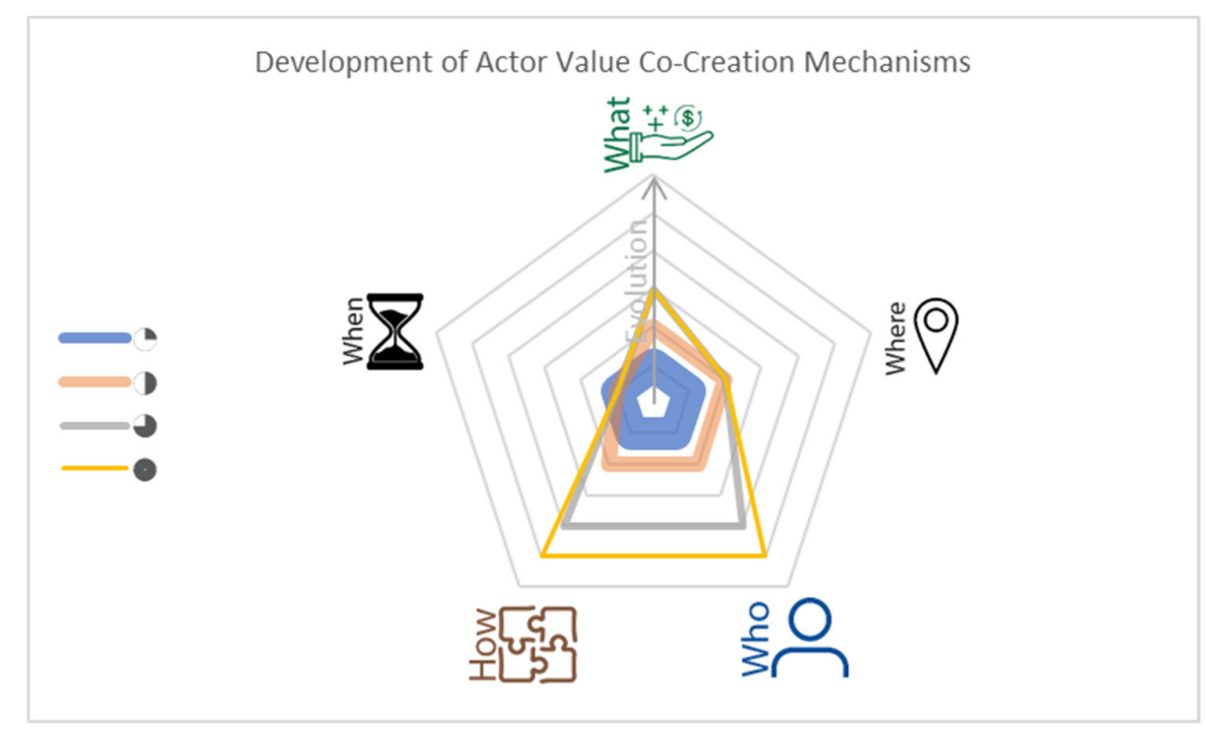

Figure 52 - Kākā - Development of Actor Value Co-Creation Mechanisms

\footnotetext{
${ }^{17}$ European Aviation Safety Agency
} 


\subsubsection{Development of Value Capture Mechanisms}

\begin{tabular}{|c|c|c|c|c|}
\hline & $B$ & & & \\
\hline $\begin{array}{l}O C \\
\frac{0}{3}\end{array}$ & $\begin{array}{l}\text { "Smaller aero clubs offer } \\
\text { flight training and are run } \\
\text { by volunteers; flight } \\
\text { training schools are run } \\
\text { on a for-profit basis." }\end{array}$ & $\begin{array}{l}\text { "Primarily aero clubs and } \\
\text { flight training schools, } \\
\text { there is a significant } \\
\text { difference." }\end{array}$ & $\begin{array}{l}\text { "Targeting aero clubs and } \\
\text { flight training schools at } \\
\text { the same time." }\end{array}$ & $\begin{array}{l}\text { "Selling individual } \\
\text { elements to home-users." } \\
\text { "Aircraft manufacturers } \\
\text { wanting tailored } \\
\text { simulators." }\end{array}$ \\
\hline 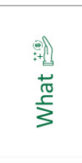 & $\begin{array}{l}\text { "It will be either a one-off } \\
\text { sale or a lease ... we } \\
\text { haven't developed all of } \\
\text { that yet." }\end{array}$ & $\begin{array}{l}\text { "We are currently looking } \\
\text { at leasing, purchasing, } \\
\text { and vending type models." } \\
\text { "We want to promote the }\end{array}$ & $\begin{array}{l}\text { "The leasing model creates } \\
\text { a bit of a cash-flow } \\
\text { problem since it takes over } \\
\text { a year to recover the costs } \\
\text { for building a simulator; }\end{array}$ & $\begin{array}{l}\text { "Despite having a leasing } \\
\text { model and a sales model, } \\
\text { we need room to } \\
\text { manoeuvre in between to } \\
\text { meet customer's needs. If }\end{array}$ \\
\hline 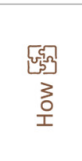 & $\begin{array}{l}\text { "The sales and leasing } \\
\text { dynamics depend on how } \\
\text { many hours they use the } \\
\text { simulator at the end of the } \\
\text { day." }\end{array}$ & $\begin{array}{l}\text { leasing model because it } \\
\text { creates more revenue... } \\
\text { we will push the retail } \\
\text { price of the simulator to } \\
\text { make it more attractive." }\end{array}$ & $\begin{array}{l}\text { hence a combination of } \\
\text { sales and leasing revenue } \\
\text { streams is required to be } \\
\text { financially viable." }\end{array}$ & $\begin{array}{l}\text { we have to find a } \\
\text { compromise and meet } \\
\text { somewhere in the middle, } \\
\text { we will do that." }\end{array}$ \\
\hline 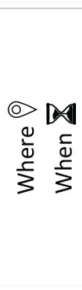 & $\begin{array}{l}\text { "The product life-cycle of } \\
\text { our simulators are around } \\
\text { eight years, maybe LCD- } \\
\text { displays and computers } \\
\text { start failing earlier, but } \\
\text { the mechanical } \\
\text { components are mostly } \\
\text { genuine aircraft parts and } \\
\text { will last." }\end{array}$ & $\begin{array}{l}\text { "The lease will run initially } \\
\text { for four years to make } \\
\text { sure we will get some } \\
\text { return back and then } \\
\text { anything after that is a } \\
\text { bonus, the lease will be } \\
\text { extended on a biannual } \\
\text { basis in line with CAA } \\
\text { recertification." }\end{array}$ & $\begin{array}{l}\text { "After four years of leasing } \\
\text { and two certification } \\
\text { periods, the simulator has } \\
\text { created some returns, and } \\
\text { we can afford to take it } \\
\text { back." }\end{array}$ & $\begin{array}{l}\text { "We have done all the } \\
\text { costings on leasing and } \\
\text { sales, and we are offering } \\
\text { both options, we offer a } \\
\text { minimum initial leasing } \\
\text { model for four years with } \\
\text { renewals every two years." }\end{array}$ \\
\hline
\end{tabular}

Table 27 - Kākā - Development of Value Capture Mechanisms

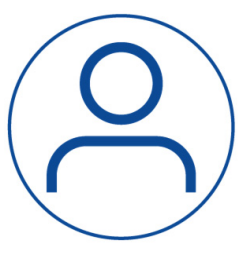

The customer and actor target profile of Kākā's value capture mechanisms developed along customer value propositions and actor value propositions. Next to flight schools and aero clubs, Kākā explored how value can be captured directly from aviation students via a vending model, private home users, aircraft manufacturers, and other partners throughout the study. However, value capture was limited to the engagement with a launch aero club throughout the study.

“It all depends on aero clubs' and flight schools' finances. Aero clubs might not have the capital and are more interested in the leasing model" (Co-Founder, Kākā)

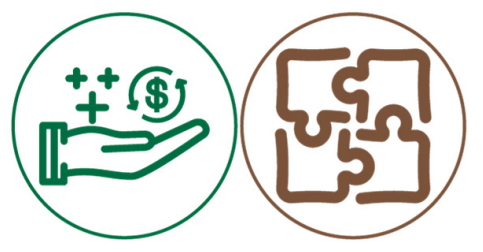

Kākā captured primarily pecuniary value from aero clubs and flight schools. In contrast to the what of Kākā's value capture mechanisms, the how developed through the study. Kākā developed a combination of sales and leasing models. Next to creating constant cash flow, aero clubs' and flight schools' usage of simulators were driving 
the adaptation of how value was captured.

"We might offer combined models with a minimum leasing rate including $X$ hours and a defined price for every additional hour. We will customise it to different preferences. In the vending model, we install simulators at flight schools for free, and students or pilots can buy hours on the simulator directly from us" (Co-Founder, Kākā)

Kākā offered its launch partner a flexible leasing contract with favourable conditions. Kākā's sales forecasts incorporated a balance of leasing and sales to capture pecuniary value in the final stage cross-promotions and distribution of offerings with different partners such as software providers and a pilot certification institute.

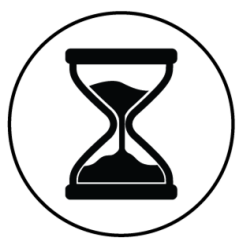

Kākā's value capture mechanisms had two significant temporal components. First, Kākā offered a leasing model based on a four-year initial lease followed by biannual renewals coinciding with CAA recertification of simulators $\circledast$. Kākā proposed leasing models with decreasing rates after four years to encourage aero clubs and flight schools to hold on to simulators. The leasing rates charged were dependent on how many hours the simulator was employed by partners to co-create value.

"We want to relate the leasing model to the use of the simulator. When customers charge three hours per week it allows them to recover the monthly leasing costs and anything more will be revenue for them" (Co-Founder, Kākā)

Second, Kākā's obligation to replace failing components, inherent in maintenance and leasing contracts, required to ensure the availability of spare parts that become technically obsolete yet crucial for sustaining the operation of simulators

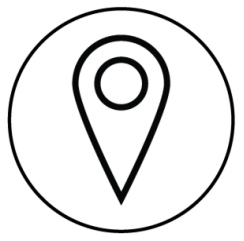

Kākā's value capture mechanisms were limited by the spatial boundaries of its simulators' certification by CAA in New Zealand. However, capturing value from providing flight simulator modules for commercial or private users were not limited by regionally regulations.

Overall, Kākā's value capture mechanisms developed throughout the study. The 
emergence of a leasing model bound to operational hours as well as balancing sale and leasing revenues to secure a constant cash flow was characterising in the process. Figure 53 illustrates the development of Kākā's value capture mechanisms.

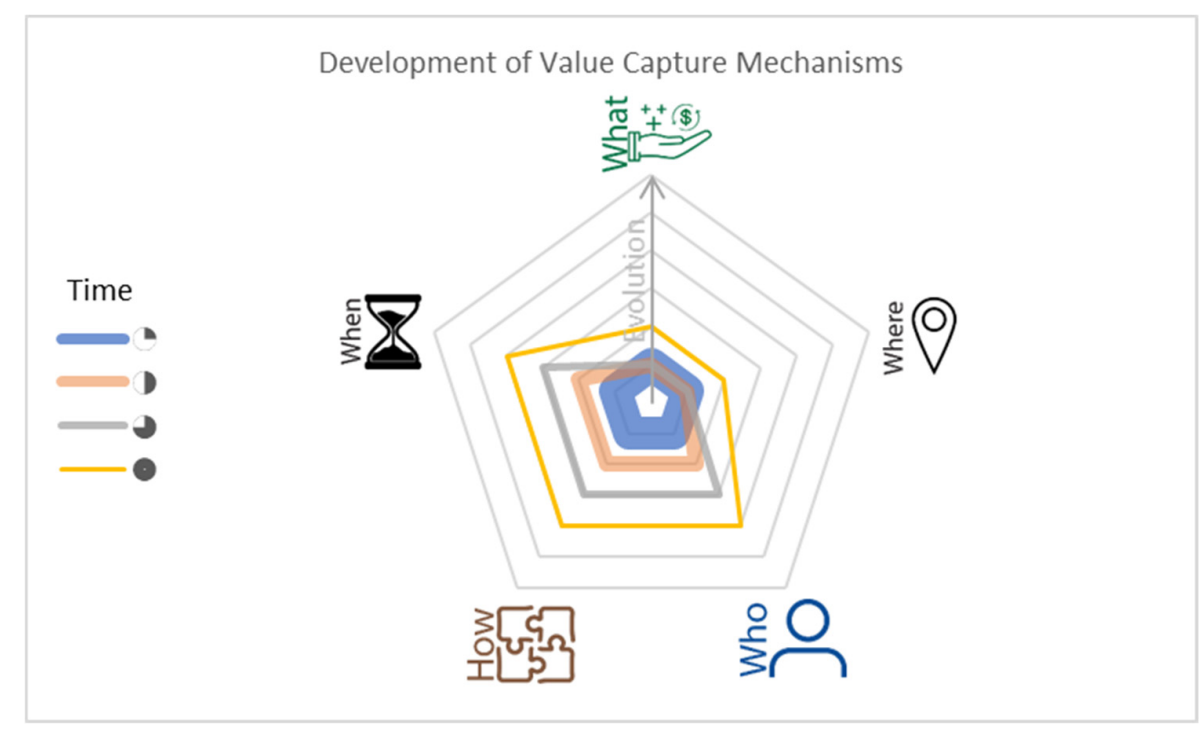

Figure 53 - Kākā - Development of Value Capture Mechanisms

\subsubsection{Summary Value Co-Creation and Capture Mechanisms}

Kākā engaged with several actors to explore opportunities to co-create and capture value. The venture explored the scale of value co-creation mechanisms, i.e. addressing offerings to private customers, software providers, and aircraft manufacturers. Besides, Kākā extended the scope of its offerings, e.g. tailored simulators, training syllabi, maintenance, and recertification services, i.e., simulator-as-a-service.

Likewise, Kākā's value capture mechanisms evolved significantly throughout the study. Next to exploring the scope of sales, leasing, and vending models for aero clubs and flight schools, Kākā investigated opportunities to capture value from other actors. Significant for the development were interactions with a launch partner and the usage of simulators or individual modules for other actors. Figure 54 summarises Kākā's VCC mechanisms development over time. 


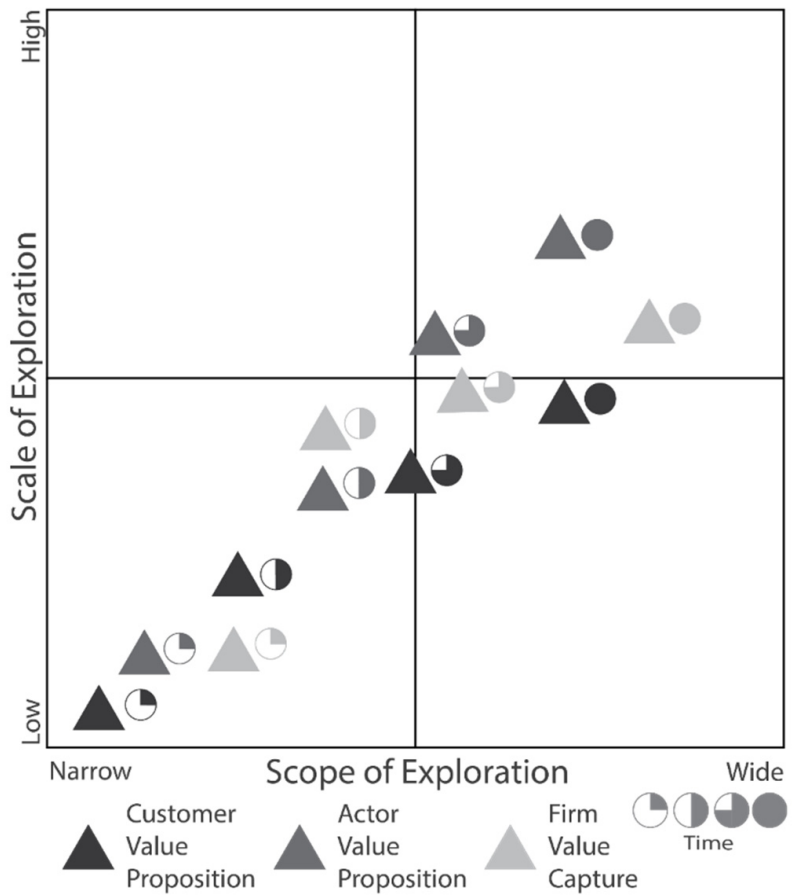

Figure 54 - Kākā - Development of Value Co-Creation and Capture Mechanisms 


\subsubsection{Development of Activity Links, Resource Ties, and Actor Bonds}

\begin{tabular}{|c|c|c|c|c|}
\hline \multicolumn{5}{|l|}{ Time } \\
\hline 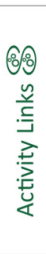 & $\begin{array}{l}\text { "We have been the first } \\
\text { commercial user of the } \\
\text { instrument and instructor } \\
\text { station software. We } \\
\text { tested it with the provider, } \\
\text { and gave feedback that } \\
\text { informed development to } \\
\text { meet our requirements." }\end{array}$ & $\begin{array}{l}\text { "We co-developed a new } \\
\text { gauge which is tailored to } \\
\text { the needs of our simulators } \\
\text { and manufactured by our } \\
\text { Dutch partner." }\end{array}$ & $\begin{array}{l}\text { "The chief instructor at } \\
\text { our launch partner is a } \\
\text { CAA approved instructor } \\
\text { on the simulator. We have } \\
\text { created a training package } \\
\text { for him to train and } \\
\text { approve other instructors } \\
\text { on our simulators." }\end{array}$ & $\begin{array}{l}\text { "Every two years there will } \\
\text { be a recertification, which } \\
\text { is a quick } 30-6 \text { o minute } \\
\text { process, before that we } \\
\text { send somebody to go over } \\
\text { the machine, replacing the } \\
\text { components, and perform } \\
\text { needed software updates." }\end{array}$ \\
\hline 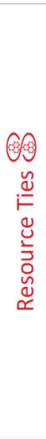 & $\begin{array}{l}\text { "Five different software } \\
\text { packages are coming } \\
\text { together in our } \\
\text { simulators." } \\
\text { "Some of the components } \\
\text { are genuine aircraft parts, } \\
\text { others are replicas, all of } \\
\text { them need to be interfaced } \\
\text { to manipulate the software } \\
\text { realistically, every } \\
\text { movement has to match a } \\
\text { real aircraft exactly." }\end{array}$ & $\begin{array}{l}\text { "The simulator is } \\
\text { complementarity to } \\
\text { customers' existing } \\
\text { aircraft flees. The } \\
\text { simulator can replicate } \\
\text { their aircraft within } \\
\text { reason, plus one which is } \\
\text { equipped to maintain } \\
\text { instrument ratings of } \\
\text { members." }\end{array}$ & $\begin{array}{l}\text { "Our instrument provider } \\
\text { brought out a new version } \\
\text { of their software which is } \\
\text { significantly different, they } \\
\text { offered to convert all the } \\
\text { instruments for us for } \\
\text { free." } \\
\text { "CAA certifies the } \\
\text { simulators, the } \\
\text { instructors, and the } \\
\text { training syllabus that was } \\
\text { designed in cooperation } \\
\text { with the instructor." }\end{array}$ & $\begin{array}{l}\text { "Some of our software } \\
\text { providers offer } \\
\text { subscription-based } \\
\text { services, but we have } \\
\text { avoided that whenever } \\
\text { possible, we don't want it } \\
\text { to be a hassle for our } \\
\text { customers to maintain the } \\
\text { software licenses of our } \\
\text { simulators." }\end{array}$ \\
\hline 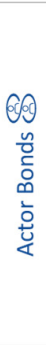 & $\begin{array}{l}\text { "We have struck up an } \\
\text { excellent relationship from } \\
\text { the start, and we are still } \\
\text { communicating with them } \\
\text { on a daily basis ... most } \\
\text { recently they have raised } \\
\text { their prices but honour the } \\
\text { favourable rates of our } \\
\text { initial agreement." }\end{array}$ & $\begin{array}{l}\text { "We had problems with } \\
\text { interfacing the navigation } \\
\text { and the instructor station. } \\
\text { We arranged a video } \\
\text { conference where the } \\
\text { suppliers took over our } \\
\text { system and tried to } \\
\text { troubleshoot the issues. } \\
\text { One of them changed their } \\
\text { software to avoid the } \\
\text { conflict." }\end{array}$ & $\begin{array}{l}\text { "Most feedback from our } \\
\text { launch partner is informal } \\
\text { but helped us to make } \\
\text { quite good improvements." } \\
\text { "as part of our agreement, } \\
\text { our launch partner } \\
\text { promotes our simulator as } \\
\text { much as possible, they } \\
\text { became more of a } \\
\text { channel." }\end{array}$ & $\begin{array}{l}\text { "We have received a sales } \\
\text { lead from our launch } \\
\text { partner, the [undisclosed] } \\
\text { aviation college." } \\
\text { "we are meeting with the } \\
\text { marketing guru from } \\
\text { [accelerator program] next } \\
\text { week and are going to put } \\
\text { a strategy together." }\end{array}$ \\
\hline
\end{tabular}

Table 28 - Kākā - Development of Activity Links, Resource Ties, and Actor Bonds

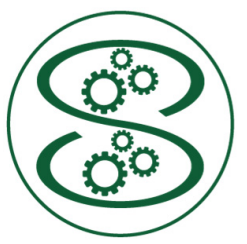

Kākā developed several deep activity links with providers of software packages, a launch partner $(0,0)$ and even CAA. Establishing dyadic activity links with software providers in the development process of the simulator prototype was crucial for interfacing hardware and software modules meeting the requirements of tight CAA standards.

“Their software hasn't been able to meet our requirements, but we have been working closely with them to develop their APIs to facilitate software communication and hardware interfacing" (Co-Founder, Kākā)

Serial activity links were developed with the launch partner to operate the simulator. Moreover, dyadic activity links were developed with the launch partner to facilitate the 
training and certification of additional instructors of Kākā's simulators certification of Kākā's simulators required the development of joint activity links of the venture, aero clubs or flight schools, and the CAA. Overall, Kākā developed in-depth activity links with several actors that were engaged in VCC.

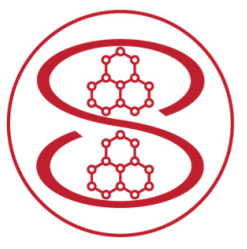

Kākā developed physical and organisational resource ties with various actors across its ecosystem. Most significant were physical and organisational resource ties developed with software and hardware providers. Developing organisational resource ties allowed to draw on the expertise of suppliers to combine 8 and interface six different software packages and various hardware components.

"The hardware and software interfacing are the difficult parts, designing and interfacing individual modules is quite tricky. The simulator is built around six software packages, changing software providers would require changes in the physical aspect of the simulator and require a recertification. We rely on our software providers" (Co-Founder, Kākā)

Moreover, organisational resource ties allowed to co-develop instruments to meet the narrow specification for CAA requirements as well as provided an opportunity to upgrade

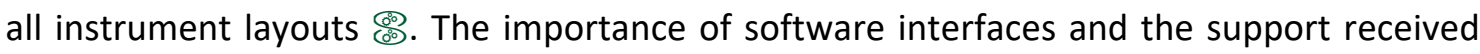
from providers in their implementation was further emphasised by swapping the GPS unit briefly before the first simulator was installed and certified by CAA.

"Swapping the GPS unit was important because many people are coming to our launch partner to have a look at our simulator and we want it to be great. Using RXP makes a huge difference for GPS navigation and the functionality of the simulator. We have been in close contact with them to facilitate the implementation of their GPS module. They are probably going to provide hardware in the future as well which will be interesting for us" (Co-Founder, Kākā)

Interfacing hardware components underpinned the development of physical resource ties. Although electronic components were readily available and required no adaptations, genuine aircraft parts were hard to come by and represented a crucial physical resource interface for Kākā's simulators.

"The rudder pedals are genuine aeroplane pedals, they have potentiometers attached to them to steer rudders and brakes, and need to be self-centring to the point, they are a quite complex and not manufactured by us" (Co-Founder, Kākā) 
Hardware and software resource ties were crucial for sustaining Kākā's VCC mechanisms since the availability of spare parts determined the life-cycle of simulators and

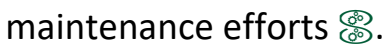

\begin{abstract}
"Wherever possible we use high lifecycle components and parts that don't need lubrication to reduce maintenance and align it with the biennial recertification process. However, the components become outdated quickly, for instance the main screen behind the panel showing all the instruments is not available anymore, but the layout of the simulators is fabricated around its size. One of our biggest fears is the failure of a LCD screen. Thus, we might stock them and other spare parts, albeit some of them will become redundant" (Co-Founder, Kākā)
\end{abstract}

Also, Kākā developed resource ties with its initial launch partner in the final stages of the study. Next to installing the simulators at the aero club's premises, the training syllabus was co-developed $\circledast$. Furthermore, a chief instructor was trained and educated to train other

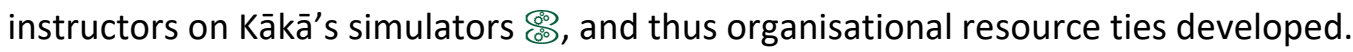

\footnotetext{
"We have reached an agreement with our launch partner. We are allowed to use the training syllabus for other aero clubs and flight schools ... which is a big hurdle for those who never had a simulator before and thus any training syllabus, that is a big benefit for us."

"The trainer has to be trained and feel competent to teach on the simulator ... it's about managing the instructor station, setting up flights, weather, and failures, it's just learning a bit about the software in a day's training" (Co-Founder, Kākā)
}

Developing physical, i.e. simulator and syllabus complementary to existing fleets, and organisational resource ties, i.e. co-developing instruments with suppliers and training instructors of aero clubs and flight schools, were crucial for Kākā's VCC mechanisms. Overall, Kākā developed in-depth resource ties with various actors as evident in mutually adjusted resources over time.

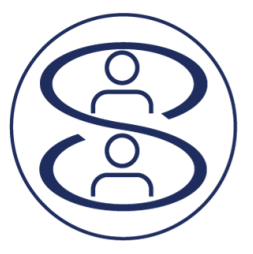

Kākā developed bonds with various actors across its ecosystem that underpinned the emergence of activity links and resource ties. The actor bonds facilitated pivotal learning, provided legitimacy, and positioned Kākā in the ecosystem. The sustainable and robust actor bonds established with software suppliers facilitated inter-organisational learning allowing to interface software packages as well as cross-promotions 
"We have been in close contact with RXP to facilitate the transition from the old GPS software package, a lot of e-mails were sent back and forth" (Co-Founder, Kākā)

Moreover, Kākā leveraged changes in regulations to establish actor bonds that positioned the venture in the ecosystem and provided legitimacy as a reliable provider of simulators in the final stages of the study.

"CAA changed their regulations around operating simulators, an aviation training certificate is required now. They suggested leasing the license from [pilot accreditation institute] which is deeply rooted in the industry. We considered them as competitors because they offer imported simulators, but we agreed on a monthly price to lease their certificate for our partners [aero clubs and flight schools] to operate our flight simulators. Moreover, they agreed to promote our simulators for a commission. They are in close contact with training organisations and aero clubs around the country and know if somebody is thinking about buying a new simulator. Funnily enough, a flight training school rang me for a particular type of simulator which we can't provide, but we know that [pilot accreditation institute] can access those simulators and actually sells a second-hand unit on behalf of somebody ... so we might have a sales lead for them, we might end up working in both ways" (Co-Founder, Kākā)

Likewise, developing strong actor bonds with the launch partner provided legitimacy as well as opportunities to promote Kākā's simulators $\underset{\varnothing 0}{\infty}$.

"Feedback from our launch partner has been fairly informal, yet crucial since Wellington Airport is a hub for pilots coming in and out and having a look at our simulator. Also, we had Airways Corporation and CAA coming in and have a look ... the word of mouth is huge because of the small community of pilots in New Zealand" (Co-Founder, Kākā)

In addition, actor bonds created and maintained with the accelerator program, Kākā participated in, provided access to marketing and business expertise.

"We are meeting with experts from [accelerator program] every two weeks to develop our business, financial, and marketing model to identify channels to market" (Co-Founder, Kākā)

Kākā explored the development of additional actor bonds to enhance its position in the ecosystem further.

"Airways Corporation runs air-traffic control in New Zealand and provides all navigation charts, they had a look at our simulators because they can see a need for it, we might establish a great partnership that further enhances the trust in our simulators."

"We might partner with an aircraft manufacturer here in New Zealand, potentially get on board with them to develop simulators for their type of aircraft" (Co-Founder, Kākā) 
In contrast to software providers, Kākā aimed to reduce its dependency on manufacturers of hardware modules in the final stages of the study

"As the business evolves, we want to increase the number of off-the-shelf components to become less dependent on custom-made parts and their suppliers" (Co-Founder, Kākā)

In conclusion, Kākā established strong actor bonds with software providers to facilitate learnings crucial for the development of simulators. Moreover, the venture continuously developed and explored the creation of new actor bonds with aero clubs and partners in the industry to obtain legitimacy as a reliable provider of services and position the firm in the ecosystem. In short, developing and sustaining strong actor bonds was crucial for Kākā's VCC mechanisms.

\subsubsection{Summary Kākā}

Overall, the development of Kākā's VCC mechanisms was underpinned by a wide range of activity links, organisational and physical resource ties, as well as actor bonds created with pivotal partners. Since Kākā entered the well-established market of simulators, the evolution of customer value co-creation mechanisms was limited. In contrast, actor value cocreation mechanisms evolved to facilitate access to cost-efficient and realistic training opportunities through aero clubs and flight schools. Figure 55 summarises Kākā's development of activity links, resource ties, and actor bonds over time. 


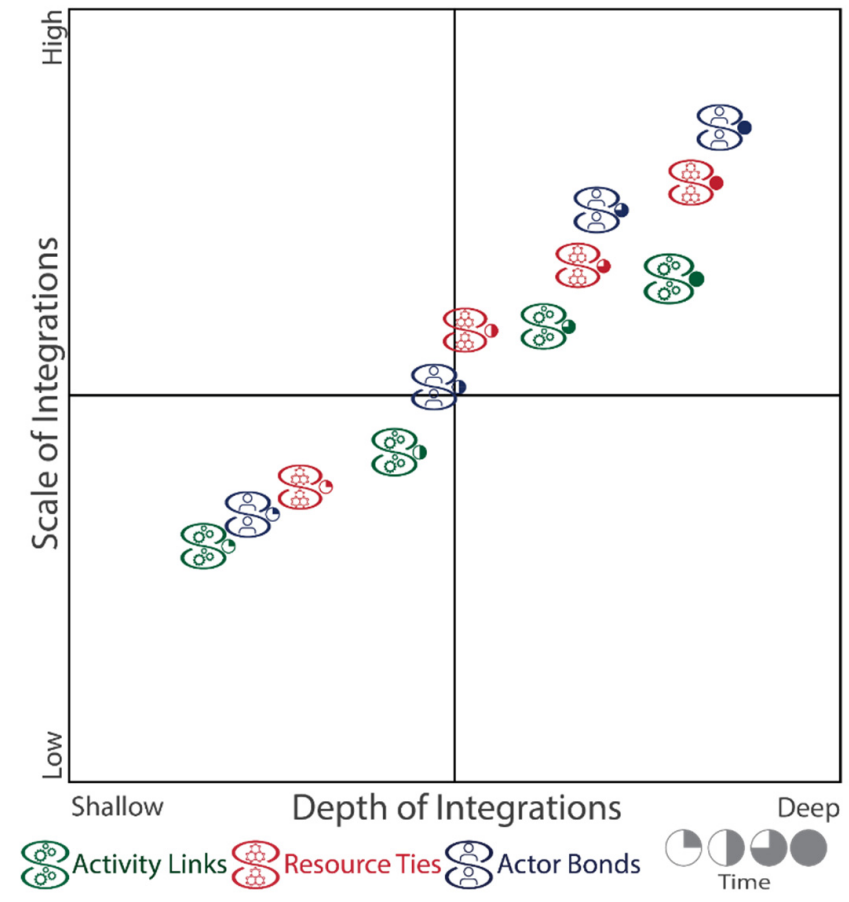

Figure 55 - Kākā - Development of Activity Links, Resource Ties, and Actor Bonds 


\subsection{Case Report - Venture Takahē}

\subsubsection{Introduction}

Takahē provided patients, physiotherapists, and physiotherapy clinics with a system that engaged all actors in physiotherapy. The ventures extensively refined its value proposition and in turn VCC mechanisms throughout the study to align the interests of all engaged customers and actors. Although several integrations were developed with other actors, multiple iterations characterised the long and challenging process.

\subsubsection{Development of Customer Value Co-Creation Mechanisms}

"It's a complex value proposition, there are several layers and a lot of actors engaged" (Co-Founder, Takahē)

For the sake of clarity, users such as patients, professional and amateur athletes were considered as end-customers, while physiotherapists, clinic managers, trainers, and licensees were defined as actors in this case study.

\begin{tabular}{|c|c|c|c|c|}
\hline Time & D & & & \\
\hline $\begin{array}{l}\text { OC } \\
\frac{0}{3}\end{array}$ & $\begin{array}{l}\text { "We took our solution to } \\
\text { athletes who are the most } \\
\text { common physiotherapy } \\
\text { patients." }\end{array}$ & $\begin{array}{l}\text { "Physiotherapy patients } \\
\text { don't fit any one } \\
\text { demographic, they are } \\
\text { anyone and everyone." }\end{array}$ & "Games for elderly." & $\begin{array}{l}\text { "The amateur athlete } \\
\text { market is always } \\
\text { something we wanted to } \\
\text { look at." }\end{array}$ \\
\hline 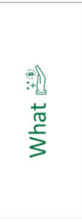 & $\begin{array}{l}\text { "Our games motivate } \\
\text { patients to engage in } \\
\text { exercises, get the best } \\
\text { therapeutic value out of } \\
\text { physiotherapy, and reduce } \\
\text { the chances to get } \\
\text { reinjured." }\end{array}$ & $\begin{array}{l}\text { "We are getting patients to } \\
\text { do the assigned exercises } \\
\text { and therefore getting the } \\
\text { benefits of balance training } \\
\text { in physiotherapy." }\end{array}$ & $\begin{array}{l}\text { "We are engaging patients } \\
\text { in physiotherapy, and if } \\
\text { your patients are not } \\
\text { engaged then they do not } \\
\text { recover." }\end{array}$ & $\begin{array}{l}\text { "For patients, it is an } \\
\text { adventure, ongoing } \\
\text { exercises to prevent } \\
\text { reoccurring injuries, that's } \\
\text { important for customer } \\
\text { value." }\end{array}$ \\
\hline 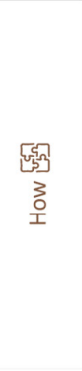 & $\begin{array}{l}\text { "We offer a motivation } \\
\text { platform, take therapy } \\
\text { balance and training } \\
\text { exercises, turn them in fun, } \\
\text { and engaging games } \\
\text { provide better therapeutic } \\
\text { value." } \\
\text { "Balance boards we offer } \\
\text { have a lower height and are } \\
\text { easier to use for injured } \\
\text { patients." }\end{array}$ & $\begin{array}{l}\text { "The ability to track } \\
\text { progress and improvement } \\
\text { can be very motivating. } \\
\text { When patients can't feel } \\
\text { improvement, it's tempting } \\
\text { for them to stop doing the } \\
\text { exercises." }\end{array}$ & $\begin{array}{l}\text { "We offer three different } \\
\text { types of games at the } \\
\text { moment, all of them target } \\
\text { to some extent different } \\
\text { muscles." } \\
\text { "The boards are just an } \\
\text { enabler to our software. } \\
\text { Selling software has } \\
\text { become our focus." }\end{array}$ & $\begin{array}{l}\text { "Our game development is } \\
\text { very much focused on } \\
\text { enabling channels for the } \\
\text { addressed customers such } \\
\text { as athletes or elderly rehab } \\
\text { patients." } \\
\text { "We encourage people to } \\
\text { use their own balance } \\
\text { boards." }\end{array}$ \\
\hline $\begin{array}{l}10 \\
10 \\
\frac{1}{0} \\
\frac{1}{3} \\
\frac{1}{3}\end{array}$ & "Patients play from home." & $\begin{array}{l}\text { "When patients are coming } \\
\text { back to the clinic they are } \\
\text { getting re-tested." }\end{array}$ & $\begin{array}{l}\text { "Games became part of } \\
\text { sessions with } \\
\text { physiotherapists. Patients } \\
\text { are engaged before, during, } \\
\text { and after consultations." }\end{array}$ & $\begin{array}{l}\text { "It's not just throughout } \\
\text { the physiotherapy, but it's } \\
\text { potentially ongoing." }\end{array}$ \\
\hline
\end{tabular}

Table 29 - Takahē - Development of Customer Value Co-Creation Mechanisms 


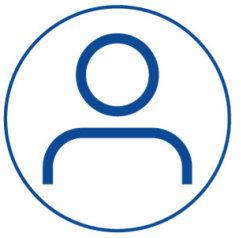

Takahē's customer profile developed significantly throughout the study. While initially targeting professional athletes as end-users for injury prevention, Takahē refined its customer segment to injured athletes engaged in physiotherapy.

"We discovered that physiotherapists are the channel to patients." (Co-Founder Takahē)

Focusing on physiotherapy patients as primary end-customers, next to maintaining professional athletes as separate segment, required several alterations. First, Takahē's endcustomer profile was extended from young recovering professional athletes to a wide range of demographics with various ramifications for software and user interface design 8 .

"Physiotherapy patients are ten-year-olds that played soccer and hurt their ankle as well as your grandpa, who had a fall" (Co-Founder, Takahē)

In turn, physiotherapists and clinics emerged as important distribution channels 8 , Takahē explored, in cooperation with a Canadian exercise equipment retailer, amateur athletes as potential end-customer segment 8 in stage four. In short, customer segments were explored, refined, and extended throughout the study. Partnerships with distribution partners such as physiotherapists and sport device retailers shaped the development $\mathscr{8} \theta$.

"The channel influences our business model and product quite heavily" (Co-Founder Takahē)

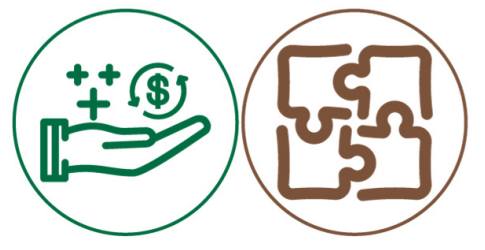

Takahē's means of customer value co-creation remained constant throughout the study. Patients' compliance with assigned exercise programs and thus their recovery/training progress was the heart of customer value co-creation mechanisms. Gamifying exercises allowed to create exciting and engaging user experiences and consequently increased compliance rates. In addition, providing a tracking tool for monitoring progress objectively in cooperation with physiotherapists motivation to continue their exercise and physiotherapy programs.

\footnotetext{
"Our system works in two different ways. It makes balancing training exercises exciting and fun and achieving goals assigned by physiotherapists can be often more motivating than the
} 
games. For some patients tracking progress becomes particularly important with chronical injuries where it's difficult to feel physical progress." (Co-Founder, Takahē)

Takahē continuously extended the range of games employed to address varying interests and aesthetical preferences of different demographics within its broad physiotherapy patient customer segment.

"We created games that were flashy, fast, challenging, and encouraged competition, designed primarily for athletes that were physically fit, young, and tech-savvy. We realised that we had to create a very different product for physiotherapy patients. We had to introduce new games, create appealing experiences, and make exercising fun for all users" (Co-Founder, Takahē)

Moreover, Takahē designed and manufactured in cooperation with external partners, custom-made balance boards to cater for the needs of recovering physiotherapy patients. Due to limited interest and despite performance differences, Takahē's encouraged the use of conventional balance boards in consultation with a physiotherapist

\footnotetext{
"Users place their smartphone in a centred compartment of our custom-made balance board that works like a joystick and allows you to play the games on our platform. Existing balance boards are a little bit more difficult to balance and you get quite different results. However, physiotherapists know best what balance boards are appropriate for patients. Our balance boards are physical ambassadors of our product and part of the experience, but they are not the main source of value." (Co-Founder, Takahē)
}

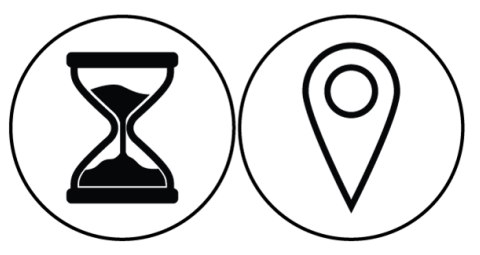

Several temporal and spatial aspects characterised Takahē's customer value co-creation mechanisms. Keeping patients and athletes engaged in longitudinal exercise programs was paramount for therapy and training success. Spatial aspects of where patients performed exercises were significant. While patients exercised primarily at home, physiotherapists measured and tracked progress via balance tests conducted in clinics to control for factors such as shoes and balance boards

Overall, Takahē's end-user value co-creation mechanisms developed throughout the study. Takahē's what of value co-creation i.e., compliance with physiotherapy plans and exercises, remained constant throughout the study. However, the means, i.e. games developed and balance boards used, evolved over time to reflect customer segment developments. The development of Takahē's customer value co-creation mechanisms is 


\section{illustrated in Figure 56.}

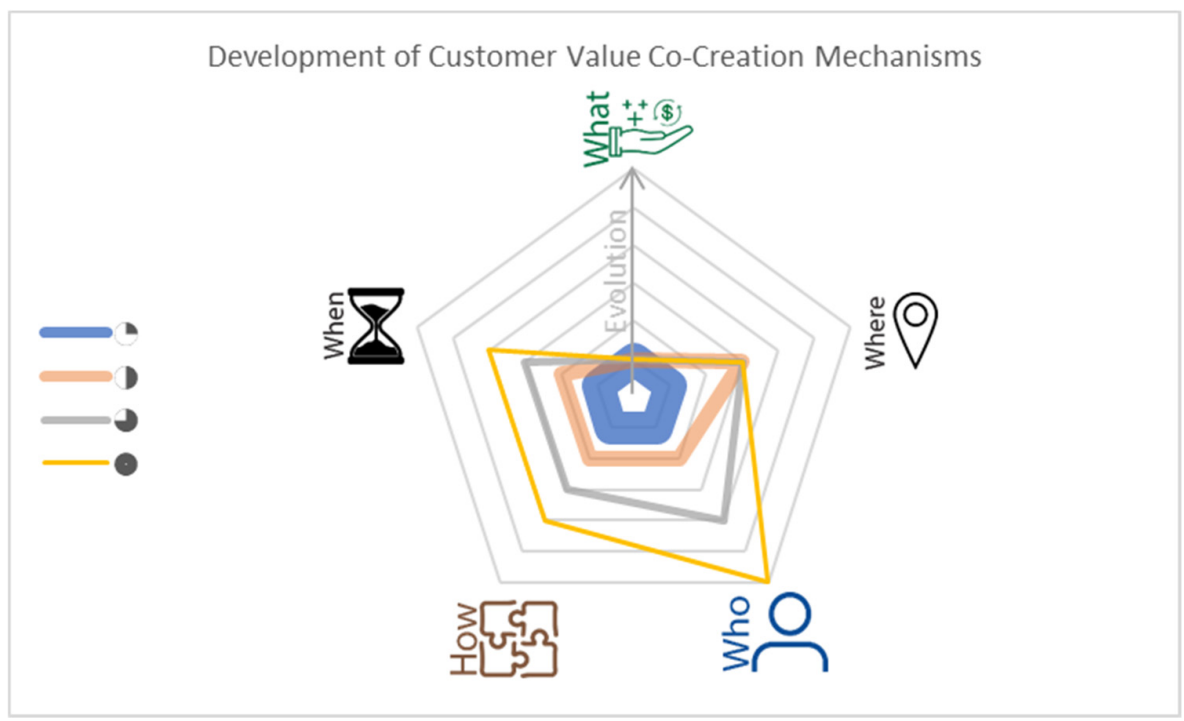

Figure 56 - Takahē - Development of Customer Value Co-Creation Mechanisms

\subsubsection{Development of Actor Value Co-Creation Mechanisms}

\begin{tabular}{|c|c|c|c|c|}
\hline Time & $\mathbf{D}$ & & & \\
\hline $\begin{array}{l}\text { OC } \\
\frac{0}{3}\end{array}$ & $\begin{array}{l}\text { "Patients, } \\
\text { physiotherapists, and there } \\
\text { is the clinic." }\end{array}$ & \multicolumn{2}{|c|}{ "Physiotherapists and physiotherapy clinic managers." } & "Sports device wholesaler." \\
\hline $\begin{array}{l}\text { of } \\
\frac{1}{\pi} \\
\frac{\pi}{3}\end{array}$ & $\begin{array}{l}\text { "Physiotherapists can } \\
\text { track patients'activities, } \\
\text { which is crucial for } \\
\text { adapting physiotherapy } \\
\text { plans, exercises and } \\
\text { enhance recovery } \\
\text { processes for patients." }\end{array}$ & $\begin{array}{l}\text { "We see a higher level of } \\
\text { retention, patients are } \\
\text { coming back to the clinic } \\
\text { for more appointments and } \\
\text { are paying more fees." }\end{array}$ & $\begin{array}{l}\text { "An additional source for } \\
\text { differentiation and image } \\
\text { around being a modern } \\
\text { and forward-thinking } \\
\text { physiotherapy clinic." }\end{array}$ & $\begin{array}{l}\text { "Providing a positive and } \\
\text { effective experience for } \\
\text { patients creates referrals, } \\
\text { and they are the main } \\
\text { driver of business growth } \\
\text { of clinics." }\end{array}$ \\
\hline $\begin{array}{l}\text { 댈 } \\
3 \\
0 \\
0\end{array}$ & $\begin{array}{l}\text { "entertainment and } \\
\text { continuous engagement in } \\
\text { therapy allows } \\
\text { physiotherapists to build } \\
\text { relationships with } \\
\text { patients." } \\
\text { "We provide software and } \\
\text { hardware for the clinic." }\end{array}$ & $\begin{array}{l}\text { "test and measure balance } \\
\text { objectively using the same } \\
\text { system either through the } \\
\text { games or the balance } \\
\text { tests." } \\
\text { "Data flows to the clinic, } \\
\text { patients do balance tests in } \\
\text { sessions, and } \\
\text { physiotherapists assign } \\
\text { exercises." }\end{array}$ & $\begin{array}{l}\text { "The dashboard allows } \\
\text { physiotherapists to assign } \\
\text { exercises, measure the } \\
\text { engagement progress and } \\
\text { conduct balance tests." }\end{array}$ & $\begin{array}{l}\text { "We will be adding } \\
\text { reporting capabilities for } \\
\text { the purpose of ACC } \\
\text { reimbursement and } \\
\text { funding, but it's currently } \\
\text { not part of our offering." }\end{array}$ \\
\hline $\begin{array}{l}M 0 \\
\frac{11}{2} \\
\frac{5}{3} \\
\frac{1}{3}\end{array}$ & & $\begin{array}{l}\text { "When patients are coming } \\
\text { back to the clinic they are } \\
\text { getting re-tested." }\end{array}$ & $\begin{array}{l}\text { "For international markets } \\
\text { like China or the US, } \\
\text { Europe." }\end{array}$ & $\begin{array}{l}\text { "Maybe our games need to } \\
\text { change, mostly visually to } \\
\text { adhere to regional } \\
\text { aesthetic preferences." }\end{array}$ \\
\hline
\end{tabular}




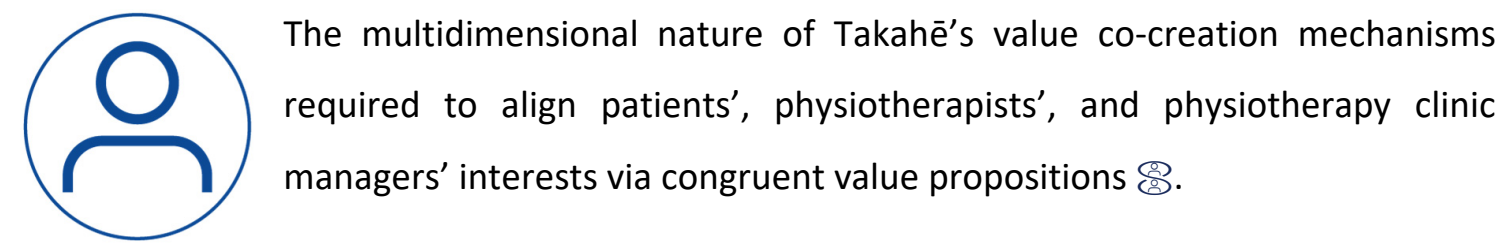

"We rather sell directly to physiotherapists and clinics than patients. This way we can convert a single patient into a whole clinic worth of sales." (Co-Founder, Takahē)

Takahē developed a licensee value proposition to engage with a potential Chinese partner and a Canadian wholesaler of sports equipment in the final stages of the study.

"We are looking for international partners in China, Europe and North America, mostly wholesalers who know about regional nuances of selling" (Co-Founder, Takahē)

Takahē continuously explored opportunities to extend the scale of actors engaged in value co-creation mechanisms.

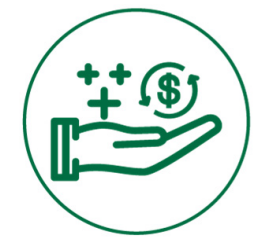

The stark contrasts in what and how value was co-created with actors, required Takahē to shift value co-creation efforts from end-users to physiotherapists and physiotherapy clinic managers in the early stages of the study 8 .

"We realised that patients having fun is not enough value to physiotherapists that allows them to pay for it. We are providing value to physiotherapists by enabling them to objectively measure balance that usually requires $\$ 50$, ooo worth of equipment. Having access to patients' exercise data allows physiotherapists to identify areas of strength and weakness, and make informed decisions on what kind of exercises to assign." (Co-Founder, Takahē)

Takahē's joined value proposition had to ensure value is co-created for clinic managers. The use of Takahē's system was initially considered as counter-productive by clinicmanagers since it required more time per patient consultation.

"The therapeutic business runs basically on how many 25 minutes consultations can you get within a day. Using our system takes five minutes extra per patient." (Co-Founder, Takahē)

Consequently, Takahē focused on communicating benefits such as customer retention, improved reputation, and the potential to charge patients 8 as value co-creating 
aspects of its offering in their sales approach with clinic managers.

"Engaging patients allows clinics to increase customer retention and consultations per patient. The better the experience, the more likely are patients to refer the clinic."'

(Co-Founder, Takahē)

Takahē enhanced value co-creation for clinics by encouraging them to charge patients for the use of the software to at least recoup the cost for monthly subscription fees in later stages of the study.

\footnotetext{
"Providing extra value to patients allows clinics to charge patients. They can recoup subscription costs and make money from using our software even if it does take two to five minutes extra per patient per consultation. Depending on their client base, clinics charge five to ten dollars a week, that's what we recommend" (Co-Founder, Takahē)
}

Despite recommendations on pricing, how and to what extent clinics seized the opportunity to create additional revenue streams was only limited by the subscription fee of the individual patient option.

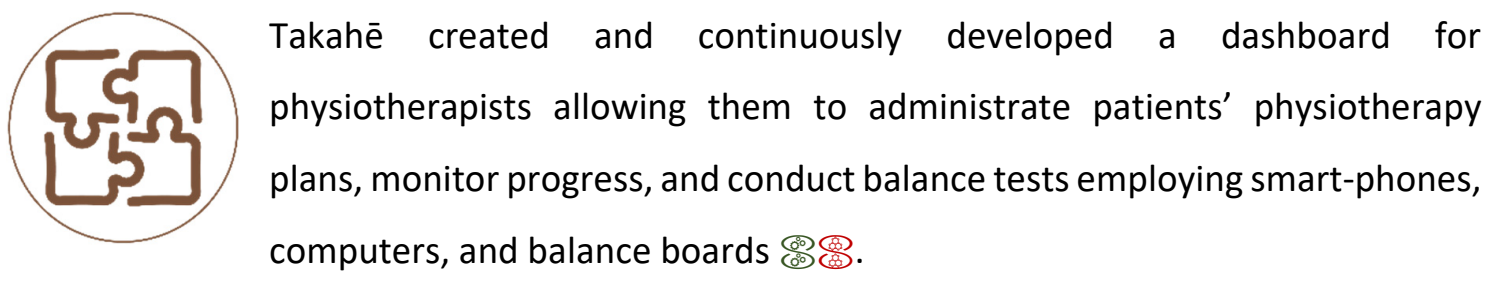

"Physiotherapists assign exercises and directions they want patients to focus on in the therapy games via the provided dashboard." (Co-Founder, Takahē)

Due to Takahē's primary focus on physiotherapists as actors, the system lacked features for clinic managers. A user-interface for clinic managers was envisioned to provide value directly to them.

"Clinic managers don't use the system yet, but we are adding reporting capabilities for ACC reimbursements" (Co-Founder, Takahē)

Takahē engaged with potential partners in China and North America 8 and drafted initial licensee proposals. In spite of various explorative engagements with partners, no licensee agreement was put into effect during the study. 


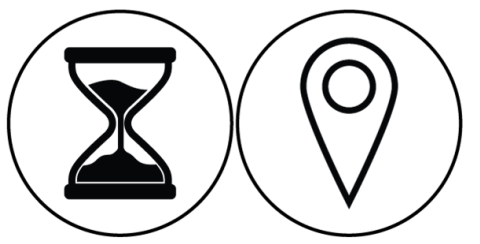

Finally, Takahē's actor value co-creation mechanisms were characterised by two significant temporal and spatial aspects. Takahē's system allowed physiotherapists to track and assess the progress of patients throughout the therapy independent of where and when the exercises were conducted. Moreover, by making balance tests only available to physiotherapists and thus location-dependent, regular clinic visits were encouraged.

"Patients can relate advancements towards their assigned goals back to the test scores. When they get retested, which only happens in the clinic, they can see, this week they improved 5\% in comparison to last week." (Co-Founder, Takahē)

Overall, Takahē developed and refined its actor value co-creation mechanisms throughout the study.

"The system came a long way and we're really proud of where it is now." (Co-Founder, Takahē)

Most significant was the shift from an end-user to the physiotherapist- and clinic manager-focused value proposition evident in the development of a dashboard and other features. Also, articulating and communicating a clinic manager value proposition was central for Takahē.

"Our system needs to please three very distinct segments with different goals. First, patients want to get better and don't want to hate doing their exercises. Second, physiotherapists want to help patients to get better and prove to their boss and ACC their impact. Finally, clinic managers want to make money from it. We designed and refined our business model to make sure that we are providing value in different ways to different segments" (Co-Founder, Takahē)

Finally, engaging regularly with a potential licensee in China as well as discussing business proposals with a North American sports device retailer underpinned Takahē's approach to growth via engaging external channel partners

In short, Takahē developed and refined actor value co-creation mechanisms significantly throughout the study. The development of Takahē's actor value co-creation mechanisms is illustrated in Figure 57. 


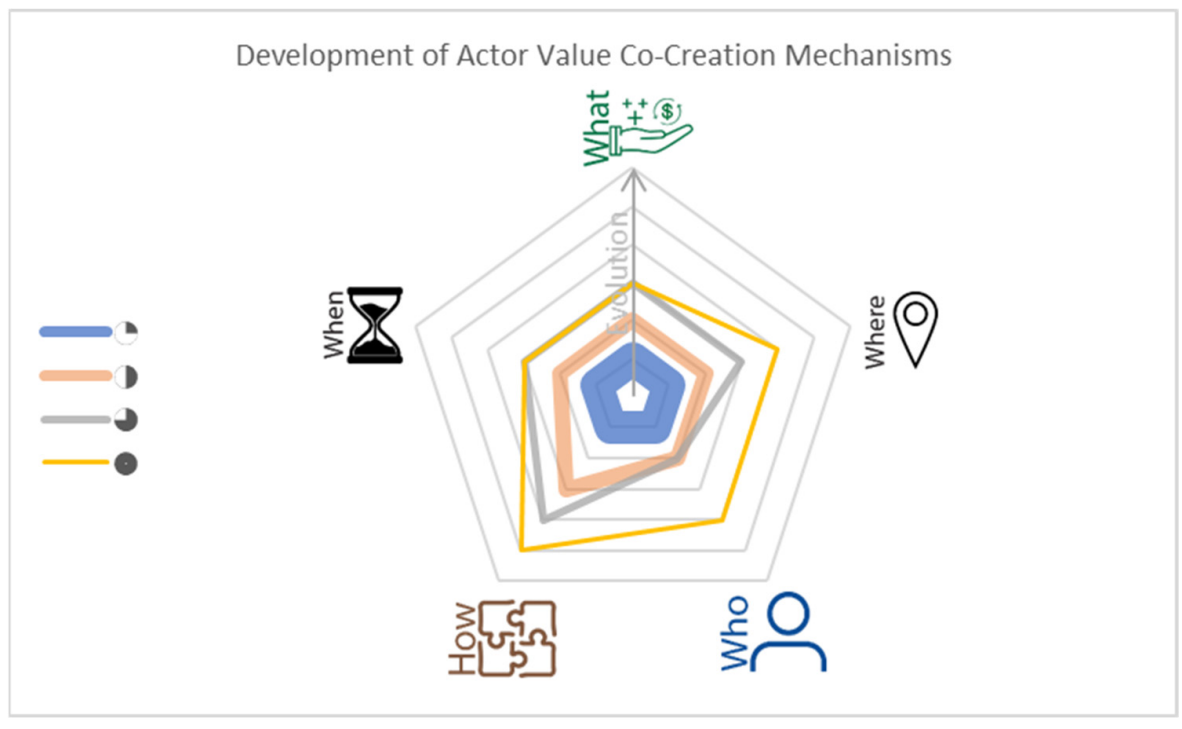

Figure 57 - Takahē - Development of Actor Value Co-Creation Mechanisms 


\subsubsection{Development of Value Capture Mechanisms}

\begin{tabular}{|c|c|c|c|c|}
\hline Time & $D$ & & & \\
\hline 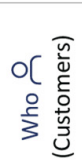 & $\begin{array}{l}\text { "We sell directly to } \\
\text { patients." }\end{array}$ & $\begin{array}{l}\text { "An independent patient } \\
\text { option." }\end{array}$ & & $\begin{array}{l}\text { "It is about individual } \\
\text { people rather than through } \\
\text { the physiotherapist in } \\
\text { Canada." }\end{array}$ \\
\hline 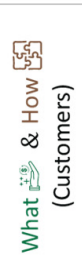 & $\begin{array}{l}\text { "For \$20 a month each or } \\
\text { almost five dollars a week. } \\
\text { However, if the patient } \\
\text { buys it, physiotherapy } \\
\text { clinics won't get the data } \\
\text { flow." }\end{array}$ & $\begin{array}{l}\text { "You can subscribe to our } \\
\text { software for } \$ 20 \text { per } \\
\text { month." }\end{array}$ & $\begin{array}{l}\text { "\$20 a month and that's } \\
\text { more or less a cap on what } \\
\text { physiotherapist clinics can } \\
\text { charge." }\end{array}$ & $\begin{array}{l}\text { "Patients can buy directly } \\
\text { from our company, and at } \\
\text { the moment we are } \\
\text { servicing that. I'm not sure } \\
\text { if that is something we } \\
\text { want to continue doing." }\end{array}$ \\
\hline 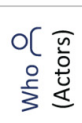 & $\begin{array}{l}\text { "Physiotherapists are part } \\
\text { of clinics, and clinics pay } \\
\text { us." }\end{array}$ & $\begin{array}{l}\text { "The clinic manager is } \\
\text { paying for our services." }\end{array}$ & "Mainly physiotherapists." & $\begin{array}{l}\text { "Launch an international } \\
\text { partnership with a } \\
\text { Canadian sports retailer." }\end{array}$ \\
\hline 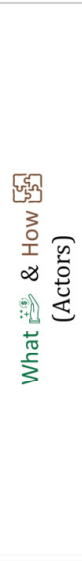 & $\begin{array}{l}\text { "The physiotherapy clinic } \\
\text { pays us subscription fees of } \\
\$[X] \text { a month, which allows } \\
\text { them to create [X] } \\
\text { concurrent patient } \\
\text { accounts." } \\
\text { "selling pre-orders, which } \\
\text { means that we are selling } \\
\text { balance boards we can } \\
\text { show but can't give them, } \\
\text { for some indefinite amount } \\
\text { of time, so the way how } \\
\text { you make the deal is by } \\
\text { giving away two months of } \\
\text { subscription for free for } \\
\text { every commitment of }[X] \\
\text { boards." }\end{array}$ & $\begin{array}{l}\text { "We are selling them a trial } \\
\text { for a } \$[X] \text {, they get the } \\
\text { software for free plus one } \\
\text { of our boards to give it a } \\
\text { try or they can use their } \\
\text { boards we don't care, so } \\
\text { that is how we are selling } \\
\text { at the moment." }\end{array}$ & $\begin{array}{l}\text { "So selling pre-orders is } \\
\text { very difficult especially } \\
\text { with the levels of } \\
\text { uncertainty we have had, } \\
\text { we want to give people } \\
\text { options, so either you will } \\
\text { pre-order our boards and } \\
\text { we will give you a discount, } \\
\text { or we sell off-the-shelf } \\
\text { boards even though the } \\
\text { experience is not as } \\
\text { smooth, we will have that } \\
\text { low-cost option alongside } \\
\text { our high-priced custom- } \\
\text { made boards" }\end{array}$ & $\begin{array}{l}\text { "If physiotherapy clinics } \\
\text { want to have ten } \\
\text { additional patient slots } \\
\text { they will have to pay \$[X] a } \\
\text { month." } \\
\text { "We are focusing on } \\
\text { physiotherapists because it } \\
\text { gives us an advantage in } \\
\text { terms of the quality and } \\
\text { value of the data, allow us } \\
\text { to leverage their expertise, } \\
\text { and it is a higher value } \\
\text { target sale with longer } \\
\text { lifetime value." }\end{array}$ \\
\hline 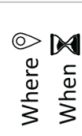 & & $\begin{array}{l}\text { "Clinic managers can make } \\
\text { the decision right there } \\
\text { and that is super } \\
\text { important." }\end{array}$ & $\begin{array}{l}\text { "China's health sector is } \\
\text { organised and structured } \\
\text { completely different." }\end{array}$ & $\begin{array}{l}\text { "We're focused on Canada } \\
\text { and China at the moment." }\end{array}$ \\
\hline
\end{tabular}

Table 31 - Takahē - Development of Value Capture Mechanisms

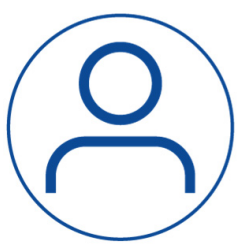

Takahē established three different revenue streams throughout the study. Next to physiotherapists and physiotherapy clinics, trainers and athletes, and independent patients, became sources of revenue.

In line with the developments of customer and actor value co-creation, Takahē's value capture mechanisms developed and shifted from professional athletes and trainers to a physiotherapy-focused approach 8 . Despite maintaining an independent patient option, 
Takahē focused sales efforts on physiotherapists and physiotherapy clinics as primary partners.

"Very few independent users. We are pushing sales through the physiotherapy clinics because it gives us more advantage in terms of the quality and value of the data." (Co-Founder, Takahē)

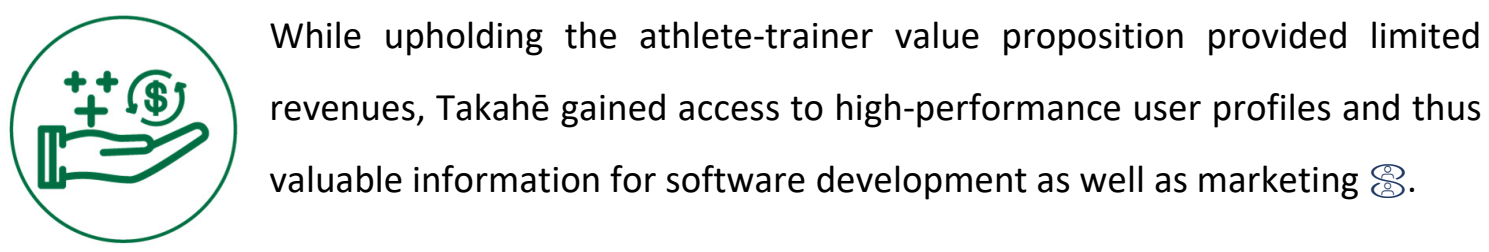

"Revenue is less reliable than in the physiotherapy model but it provides us with access to highperformance profiles of athletes and their trainers which is available from the marketing perspective, validation, and connections" (Co-Founder, Takahē)

Next to capturing the performance data of professional athletes, the aggregated performance data of physiotherapy patients provided additional non-pecuniary value was leveraged in the development of system features and user experiences.

\footnotetext{
"User statistics are precious for developing a better understanding of what users are struggling with, what they are using, and how. This data informs game developments in our system" (CoFounder, Takahē)
}

Takahē captured pecuniary value, primarily from physiotherapy clinics and few independent customers as well as professional athletes and trainers. In the final stage of the study, Takahē's engagement with a potential licensee, a Canadian retailer of sports equipment 8 , rejuvenated the venture's interest in individual customers no revenues were generated from sales to hobbyist athletes or a licence agreement throughout the study.

\footnotetext{
"We need to be able to sell products to the customers of our Canadian partner. Most of his customers are interested in or are already using balance boards for training. Having won that first half of the battle in terms of sales, we just need to show them that our software provides a better experience for them" (Co-Founder, Takahē)
} 


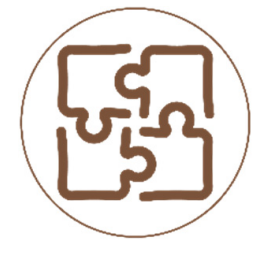

Most of Takahē's revenues were generated via software subscription and a limited number of balance board sales in the study. The venture focused on pre-selling custom-made balance boards to accumulate orders enabling costefficient sourcing from a Chinese manufacturer 8 .

"We need to sell 500 boards worth of orders before we can start production with our Chinese partner." (Co-Founder, Takahē)

Since sourcing custom-made balance boards from abroad would have allowed to significantly reduce the price, Takahē substituted the sale of pre-orders by providing discounts of software subscription plans. Nevertheless, the lack of interest in pre-purchases of ten custom-made balance boards encouraged the creation of a hardware-independent trial offering in the third stage of the study.

"We were asking physiotherapists to put in money to get a product that they haven't seen, at a time that they don't know. Pre-orders haven't worked out." (Co-Founder, Takahē)

Deprioritising the sales of custom-made balance boards shifted the focus of value capture to software subscriptions three different pricing plans for physiotherapists and clinics to provide a range of choices.

"We wanted to make sure that physiotherapists and clinic managers feel that they have as much choice as possible. We provide various options for them" (Co-Founder, Takahē)

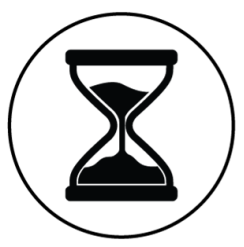

The physiotherapist/clinic value capture mechanisms were refined based on primarily monthly software subscription plans. The temporal distance and commitments associated with pre-orders of custom-made balance boards was considered as an inhibitor of sales in hindsight.

"It is important that they can see that it is functional, and they can get the value from it as soon as possible. The fact that physiotherapists or clinic managers can make the decision right there and then is super important" (Co-Founder, Takahē) 


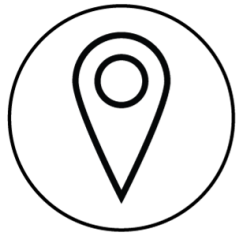

In line with Takahē's aim to leverage partners' expertise and foothold in its market expansion plans 8 , the development of value capture mechanisms from licensee agreements was bound to regions. While several regional adaptations were considered to engage licensees, none were realised during the study.

"Different markets, such as China or Canada, as well as different channels, require different revenue models when working with partners. We will have to find new ways how to collect our cut" (Co-Founder, Takahē)

Overall, the development of Takahē's value capture mechanisms was congruent with the evolution of the customer and actor value co-creation mechanisms. Focusing primarily on selling software subscriptions and neglecting the provision of custom-made balance boards were amongst the most significant developments athletes and trainers to capture non-pecuniary value such as performance data and the opportunities of celebrity endorsements. Also, capturing user statistics informed the development of games and other features of Takahē's systems. Takahē explored various avenues to capture pecuniary and non-pecuniary value from actors as illustrated in Figure 58.

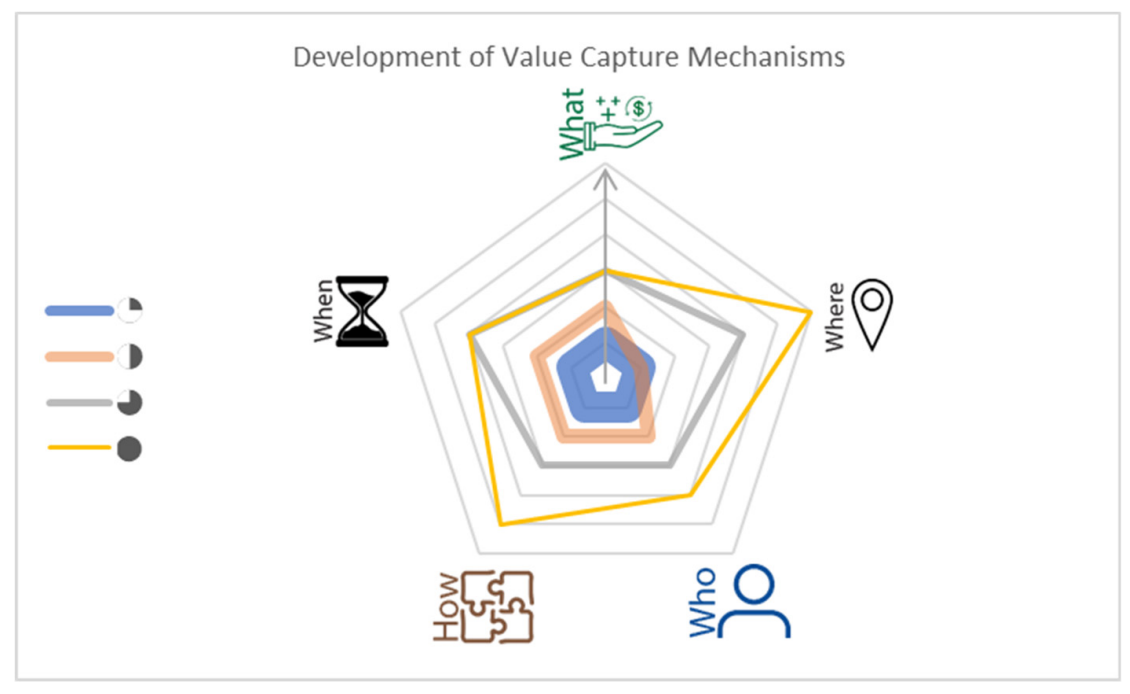

Figure 58 - Takahē - Development of Value Capture Mechanisms

\subsubsection{Summary Value Co-Creation and Capture Mechanisms}

Takahē explored VCC mechanisms along scale and scope. The most significant development was the shift in focus from individuals to physiotherapy clinics. Also, Takahē 
explored how value can be co-created and captured in cooperation with international partners. Despite the explorative efforts undertaken, Takahē only engaged a limited number of actors in VCC mechanisms. The development of Takahē's VCC mechanisms is illustrated in Figure 59.

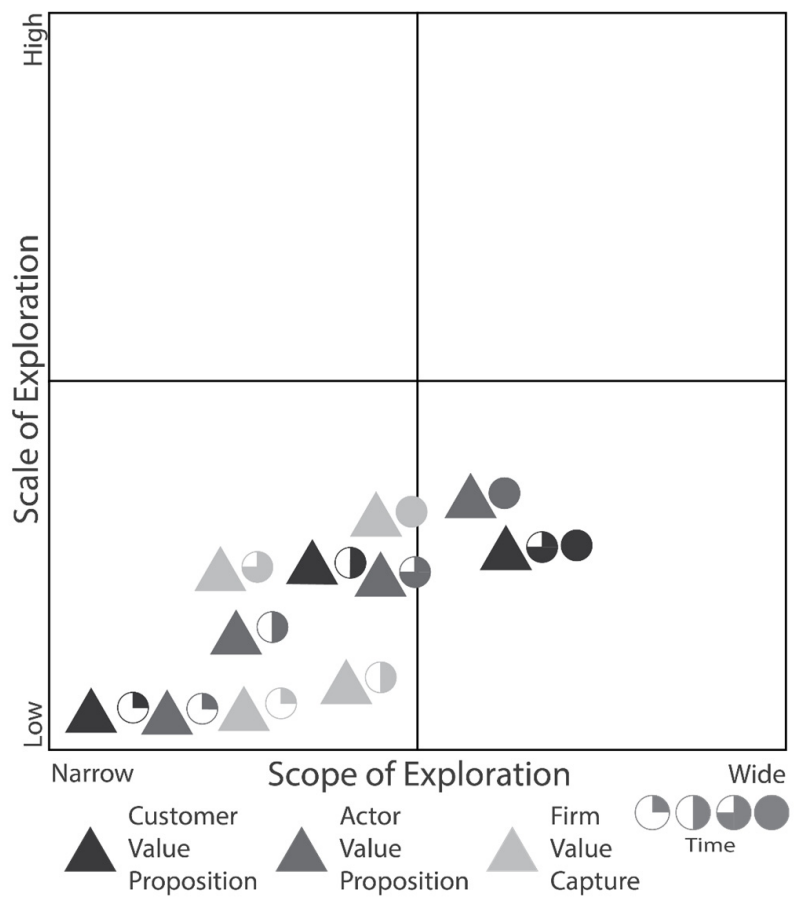

Figure 59 - Takahē - Development of Value Co-Creation and Capture Mechanisms 


\subsubsection{Development of Activity Links, Resource Ties, and Actor Bonds}

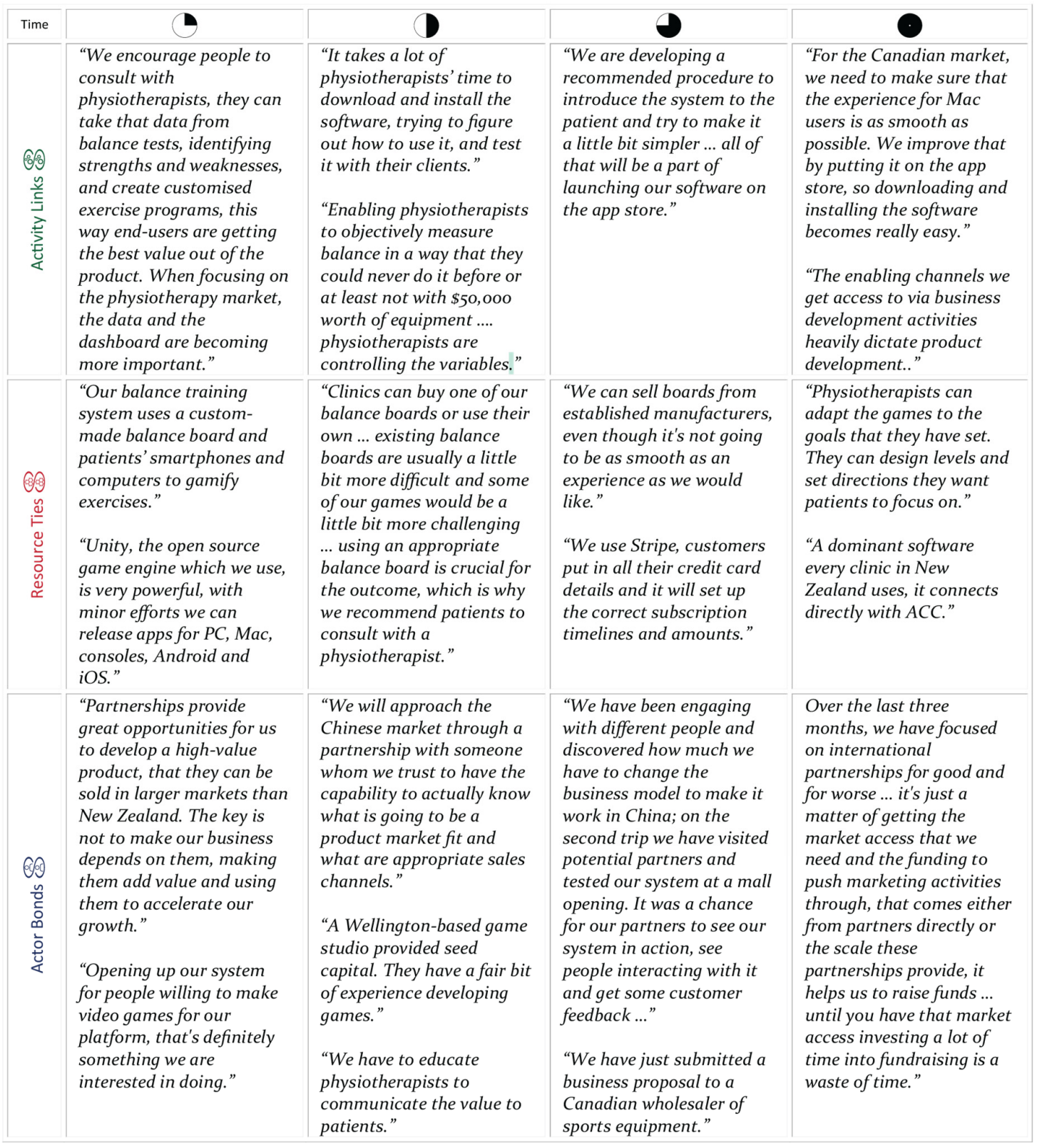

Table 32 - Takahē - Development of Activity Links, Resource Ties, and Actor Bonds 


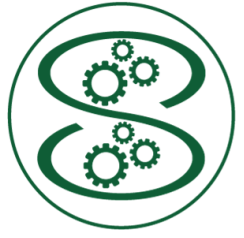

The development of Takahē's VCC mechanisms was characterised by the development of serial and dyadic activity links of patients, physiotherapists, and physiotherapy clinics. First, Takahē's offering facilitated the dyadic interdependencies of patients performing exercises and physiotherapists assigning, monitoring, and adjusting physiotherapy exercises which were crucial for the outcome (i.e., the success of the therapy) 8 . Physiotherapists' integration of Takahē's system in their therapy requires the alterations of their consultation processes. The venture's aim to develop a procedure for introducing the system to patients and improving the onboarding experience for patients further underpins this activity links 8 . Similarly, Takahē's recommendation to charge patients for the use of the system encouraged clinics to adjust billing processes. In contrast, Takahē adopted several of its software development processes to the need of channel partners it aimed to leverage in distribution activities.

"We were developing our product for our Australian distribution partner, mostly the system around the games, the dashboard and data flow as well as the design of the boards were influenced by our partnership with them" (Co-Founder, Takahē)

In a similar vein, Takahē focused on the release of its software via the Apple app-store to enhance the customer experience and cater for the need of its Canadian distribution partner in the final stage of the study. Finally, partnering with a Chinese manufacturer of balance boards required Takahē to change its sales processes and promote pre-sales to reach the minimum order quantity 8 .

Overall, activity linking was necessary for the development of Takahē's VCC mechanisms. While activity linking with physiotherapists and clinics was primarily actorscentric, engaging with potential distribution partners required the venture to adopt internal game and platform development activities to fit the requirements of partners. Nevertheless, the activity links developed with physiotherapists/clinics and distribution partners were shallow.

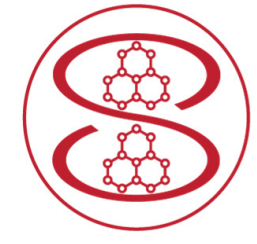

Takahē developed physical and organisational resource ties with other actors in its ecosystem. The emergence of three physical resource ties was significant for the development of VCC mechanisms. First, Takahē decided against a custom-made embedded electronic computer system and instead 
utilised a combination of smartphone, personal computer, and Bluetooth or Wi-Fi connections to facilitate the measurement of users' movements on balance boards.

"Initially we used Arduino boards, but an embedded electronic system would have been quite expensive. The gyroscope and accelerator sensors in every smartphone are as good. The program itself runs on your PC, the app runs on your smartphone and uses Wi-Fi or Bluetooth for communication" (Co-Founder, Takahē)

Although Takahē offered and promoted its custom-made balance boards, the use of existing balance boards was encouraged to increase the adoption rate of its system in later stages of the study. The success of the diffusion of Takahē's system depended on the availability of balance boards. For this reason, Takahē aimed to engage with a Canadian retailer of exercise equipment. To further enhance the user experience, Takahē undertook developments to release its app via the Apple iTunes store $\circledast$. Additionally, resource ties were developed by using Unity, a game development environment and engine as well as AWS as a cloud infrastructure provider.

\section{"AWS allows us to deploy our software to pretty much any device. Switching our infrastructure provider has some technical depth regarding moving everything over" (Co-Founder, Takahē)}

Takahē's integration with Stripe allowed to streamline billing processes and accept credit cards for payment $\underset{\infty}{\sigma}$. Finally, Takahē considered an integration with the dominant clinic management system via an API to improve the embeddedness of its system in the processes of clinics and their interactions with ACC.

Next to physical resource ties, the development of Takahē's VCC mechanisms depended on the emergence of organisational resource ties with physiotherapists and distribution partners. Most significant was the adaption of physiotherapists' technical expertise in using Takahē's system to design, monitor, and steer physiotherapies and conduct balance tests 8 .

"Physiotherapists need to learn how to use our system and feel confident in using it with their patients. We rely on the physiotherapists' existing expertise in selecting balance boards and direct the therapy" (Co-Founder, Takahē)

Takahē aimed to develop organisational resource ties with distribution partners to leverage existing channels abroad. While partnering with a retailer of physiotherapy equipment to promote sales in Australia failed in the first stage of the study 8 , the 
cooperation significantly influenced the evolution of Takahē's VCC mechanisms.

"The business model from our perspective is to find local partners, leverage their knowledge and channels in existing markets such as the Americas, Europe and China" (Co-Founder, Takahē)

Overall Takahē's VCC mechanisms were underpinned by the development of physical and organisational resource ties with physiotherapists, clinics and distribution partners. Educating physiotherapists to harness their expertise in the use and application of Takahē's offering was pivotal. Despite the explorative efforts, the resource ties developed with a small set of partners were of limited depth.

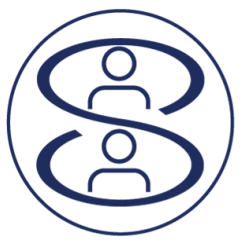

Takahē developed a range of bonds with actors in its ecosystem to facilitate learning, gain legitimacy, and position the venture in the ecosystem. Most significant for the development of Takahē's VCC mechanisms were actor bonds with distribution partners $\circledast$. On the one hand, Takahē's early engagement with a well-established wholesaler of physiotherapy equipment in Australia provided a source of legitimacy and pivotal financial resources.

"Having agreements with legitimate partners who have a proven track record in their markets is pivotal for raising funds ... [partner] covered tens of thousands of dollars on travel budget, trade shows and marketing expenses, and legal fees." (Co-Founder, Takahē)

On the other hand, this partnership allowed Takahē to apprehend the physiotherapy clinic business and informed the development of offerings for physiotherapists.

"We are developing our product for our Australian distribution partner, mostly the system around the games, the dashboard and data flow as well as the design of the boards were influenced by our partnership with them." (Co-Founder, Takahē)

Despite the promising engagements and commitments on both sites, "the partnership didn't work out". Nevertheless, the partnership contributed to the positioning of Takahē as a provider of hardware, initially, as well as software and services for distributors of physiotherapy and sports exercise equipment. 
"We see partners as a big part of our future and hope we can flesh out a partnership model to launch international partnerships in Canada and China. Depending on their development, they can make the company profitable within a year" (Co-Founder, Takahē)

Despite the importance of establishing actor bonds with distribution partners for market access and sales, the extent of engagement was limited to a memorandum of understanding with the Chinese partner and a business proposal sent to the Canadian partner. In addition, actor bonds created with a local game development study provided access to seed capital as well as insights into game design and development

"They have supported us with seed investment and with ad hoc advice on commercialisation and game development" (Co-Founder, Takahē)

As part of an accelerator program Takahē was provided with access to a contact network of experienced business professionals and mentors that enhanced learning.

"Our mentor, who was a physiotherapist, has provided substantial support. The [accelerator program] has provided various valuable contacts, for instance, the contact to our Chinese partner was set up through them" (Co-Founder, Takahē)

Takahē aimed to develop actor bonds with foreign distribution partners to obtain market access and leverage existing channels for sales developed, enhanced learnings on how Takahē's system can be commercialised, positioned Takahē in the ecosystem as a software and service provider for physiotherapy clinics and physiotherapy/sports equipment retailers, and provided a source of legitimacy. However, relying on distribution partners as primary sales channel resulted in a significant shortage of sales and thus revenues.

"We were basically outsourcing all of our sales activities but at the point of signing they couldn't get all required permissions and our sales lag behind now" (Co-Founder, Takahē)

While Takahē established direct sales in New Zealand to compensate for the shortage, the venture's focus on developing partnerships with foreign distributors remained strong.

"Finding partners that you can trust and work with is challenging. We talked to a lot of people and wasted a lot of time. We have to bring all of the decision-makers in as early as possible, and develop multiple partnerships, don't put all of our eggs into one basket" (Co-Founder, Takahē)

In conclusion, although Takahē developed a strong bond with its Australian 
distribution partner, it was only of temporary nature. As a result of the failure of the partnership and the ramifications, Takahē became more cautious in developing actor bonds. However, Takahē continued to explore and develop actor bonds with potential international distribution partners and dedicated resources to their establishment. The actor bonds created with the local game development studio as well as with mentors from the accelerator program were of limited depth.

\subsubsection{Summary Takahē}

Takahē extensively explored and refined VCC mechanisms across all dimensions. The absence of deep integration, even in isolated instances, further highlighted the vivid development of Takahē's BM. Also, the limited number of direct customers acquired as well as the absence of a sustained relationship with a distribution partner indicates a limited firmecosystem fit. Figure 60 illustrates the development of Takahē's activity links, resource ties, and actor bonds throughout the study.

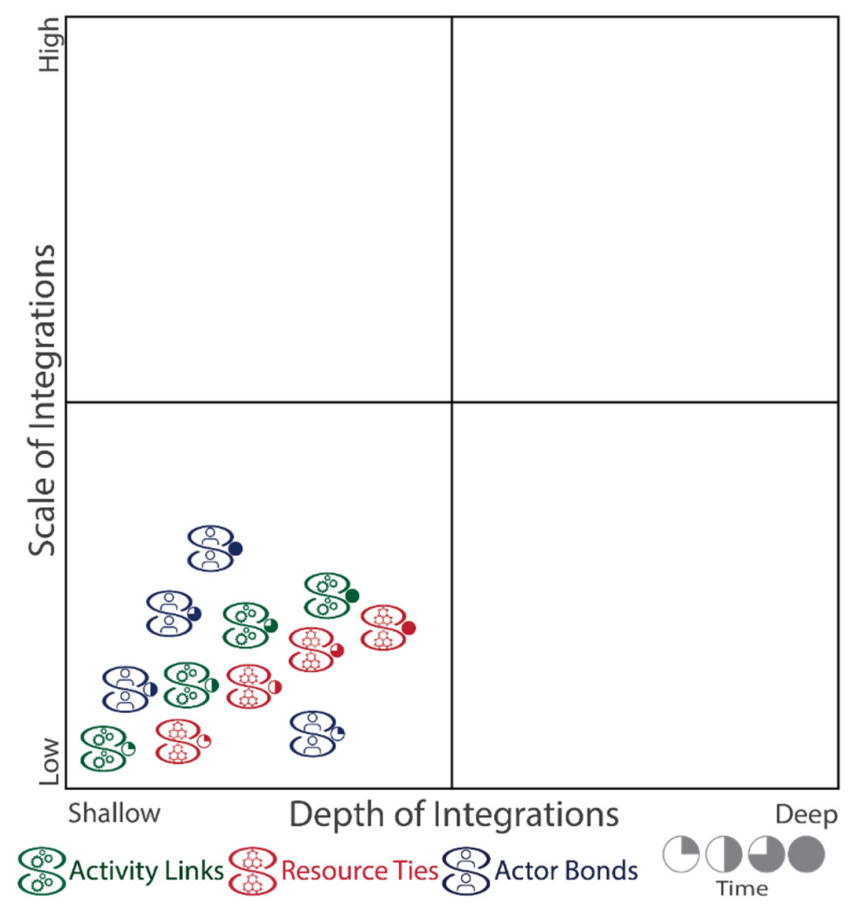

Figure 60 - Takahē - Development of Activity Links, Resource Ties, and Actor Bonds 


\subsection{Case Report - Venture Whio}

\subsubsection{Introduction}

Whio developed an innovative manufacturing process for surfboards made from sustainable materials. The venture refined customer value co-creation mechanisms and extensively revamped actor value co-creation mechanisms during the study to develop a firmecosystem fit. The development of VCC mechanisms was underpinned by different approaches to integrate with several key actors that remained reluctant to make commitments until the final stage of the study.

"We are trying to change the way how surfboards are made and figure out how to maximize profits of the company by selling high-tech machinery. We need to have a business to business model to make it viable" (Co-Founder, Whio)

\subsubsection{Development of Customer Value Co-Creation Mechanisms}

\begin{tabular}{|c|c|c|c|c|}
\hline Time & $\Delta$ & & & \\
\hline $\begin{array}{l}O C \\
\frac{0}{3}\end{array}$ & $\begin{array}{l}\text { "Primary customers will be } \\
\text { surfers." }\end{array}$ & $\begin{array}{l}\text { "Trying to make a fun } \\
\text { product for recreational } \\
\text { surfers." }\end{array}$ & \multicolumn{2}{|c|}{$\begin{array}{l}\text { "Surfers who are buying the boards care about the } \\
\text { environment." }\end{array}$} \\
\hline $\begin{array}{l}\text { की } \\
+\frac{1}{\pi} \\
\frac{+}{3}\end{array}$ & $\begin{array}{l}\text { "A robust surfboard, } \\
\text { surfers just want to go } \\
\text { surfing and have a good } \\
\text { time and don't want to } \\
\text { worry about breaking it." }\end{array}$ & $\begin{array}{l}\text { "A surfboard that is more } \\
\text { conducing to the whole } \\
\text { lifestyle and the mindset of } \\
\text { surfers and the } \\
\text { environment in which } \\
\text { surfing occurs." }\end{array}$ & $\begin{array}{l}\text { "Our boards produce a 1oth } \\
\text { of the carbon emissions, } \\
\text { and are probably going to } \\
\text { last three or four times } \\
\text { longer ... this is value for } \\
\text { money, it's a very good } \\
\text { value proposition." }\end{array}$ & $\begin{array}{l}\text { "People attending the } \\
\text { workshops want to get } \\
\text { their hands dirty ... the } \\
\text { new facility is built around } \\
\text { workshop weekends." }\end{array}$ \\
\hline 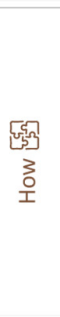 & $\begin{array}{l}\text { "Offer something visually } \\
\text { and structurally different. } \\
\text { They are paying more } \\
\text { upfront but get a surfboard } \\
\text { that saves them money in } \\
\text { the long run on repairs and } \\
\text { breakages." }\end{array}$ & $\begin{array}{l}\text { "If someone really wants to } \\
\text { have a custom-made } \\
\text { board, we will make it for } \\
\text { them. I'm trying to design } \\
\text { retro shapes different to } \\
\text { what other shapers offer, } \\
\text { no one is doing } 60 \text { to } 73- \\
\text { inch designs at the } \\
\text { moment." }\end{array}$ & $\begin{array}{l}\text { "We've done a few } \\
\text { workshops, but I think it } \\
\text { was a waste of time." } \\
\text { "Boards, products made } \\
\text { from offcuts of timber such } \\
\text { as wax combs, and } \\
\text { clothing." }\end{array}$ & $\begin{array}{l}\text { "Workshops are now } \\
\text { booked three months in } \\
\text { advance... it's an easy } \\
\text { thing to sell because it is } \\
\text { an experience." } \\
\text { "The new retail space will } \\
\text { have some kind of } \\
\text { atmosphere and vibe going } \\
\text { on." }\end{array}$ \\
\hline $\begin{array}{c}M \\
\frac{0}{3} \\
\frac{1}{3}\end{array}$ & $\begin{array}{l}\text { "Every time when they take } \\
\text { it out it's fun, it's a } \\
\text { different connection." }\end{array}$ & & & $\begin{array}{l}\text { "Whereas many people buy } \\
\text { surfboards only in } \\
\text { summer, with workshops } \\
\text { people don't care about } \\
\text { what season it is." }\end{array}$ \\
\hline$\frac{0>}{3}$ & $\begin{array}{l}\text { "You cannot get more } \\
\text { immersed in nature than } \\
\text { going out there in the } \\
\text { middle of the ocean and } \\
\text { harnessing the waves' } \\
\text { energy." }\end{array}$ & & $\begin{array}{l}\text { "That's a problem of } \\
\text { almost every company in } \\
\text { New Zealand ... you hardly } \\
\text { find the level of business to } \\
\text { sustain yourself." }\end{array}$ & $\begin{array}{l}\text { "Customers coming to } \\
\text { Wellington for the } \\
\text { workshops. We can } \\
\text { probably strike a deal with } \\
\text { a hotel." }\end{array}$ \\
\hline
\end{tabular}

Table 33 - Whio - Development of Customer Value Co-Creation Mechanisms 


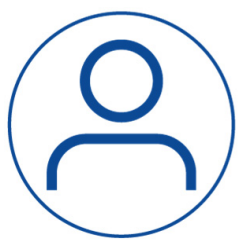

Lifestyle attributes such as recreational surfers and environmentallyconscious surfers concerned about sourcing and production practices of surfboards underpinned the refinements of Whio's customer segments throughout the study.

"Surfers are passionate about how to connect with nature and care about the environment. They want to know where their products are coming from and want to support local shapers." (Co-Founder, Whio)

The offering of primarily retro-shaped surfboards and surf-board shaping workshops further enhanced the selection of recreational and environmentally-conscious surfers.

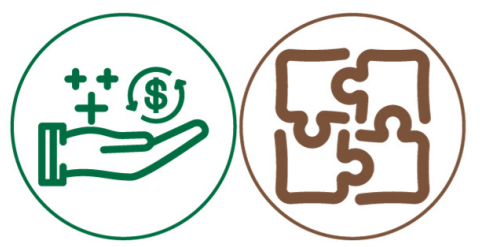

While initially value co-creation focused on functional and symbolic aspects of having a long-lasting and eco-friendly manufactured surfboard $\circledast$, hedonic aspects such as shaping one's own board in a DIY-workshop became central in the final stage of the study. Moreover, aesthetic or visually different retro-shaped surfboards grew in importance over time for two reasons. First, it reflected a growing trend amongst surfers to favour recreational retro-shaped over modern performance-shaped boards. Whio's surfboards' wooden surface augmented the visual appeal and authenticity of the offered

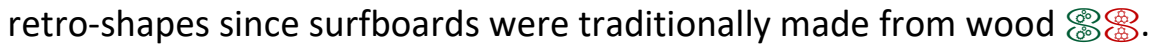

\footnotetext{
"We want to make surfboards that last longer and surf really well. Customers like the aesthetic of our boards, the wooden deck fits the retro-shapes very well." (Co-Founder, Whio)
}

Second, Whio aimed to cooperate with other surfboard shapers in New Zealand and thus wanted to avoid entering their core market of performance-shape boards 8 . However, the most salient development was the growing importance of surfboard shaping workshops. While initially belittled, shaping workshops became central for Whio's value creation mechanisms and projected on the layout of the new facility featuring two shaping bays for shaping workshops value of the created boards, became the central locus of customer value co-creation. 
"You can put a personal touch on the board and become part of that process. Running a board that you've shaped yourself is pretty cool, every time when you take it out it is fun and a different connection. When you meet someone out in the ocean you can articulate, why, how and what your surfboard is made from." (Co-Founder, Whio)

In addition, Whio provided branded products such as t-shirts and changing towels and emphasised the importance of symbolic aspects of customer value co-creation mechanisms. In short, what and how value was co-created for recreational surfers changed from a productto a service and brand focused-approach in the final stage.

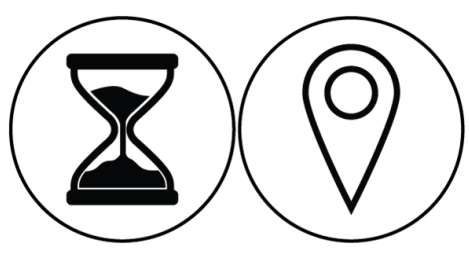

The durability of Whio's surfboards was crucial for customer value co-creation since it justified the price premium and underpinned eco-friendliness. Customer value was accumulated over time with every surfing experience. While Whio offered repair kits and services to augment the longevity of the surfboards, very few repairs were conducted throughout the study. In a similar vein, being "immersed in nature in the middle of the ocean" further underpinned spatial aspects of Whio's customer value cocreation mechanisms.

The growing importance of shaping workshops in the final stages of the study enhanced temporal and spatial aspects of customer value co-creation mechanisms. Since the experiential value of shaping-workshops was independent of weather and surfing conditions, it allowed Whio to balance off-peak seasonal demand. The spatial aspect for surfboard shaping-workshops was considered of great importance since workshops can be bundled with a weekend surfing-trip. The development of Whio's customer value co-creation mechanisms is illustrated in Figure 61. 


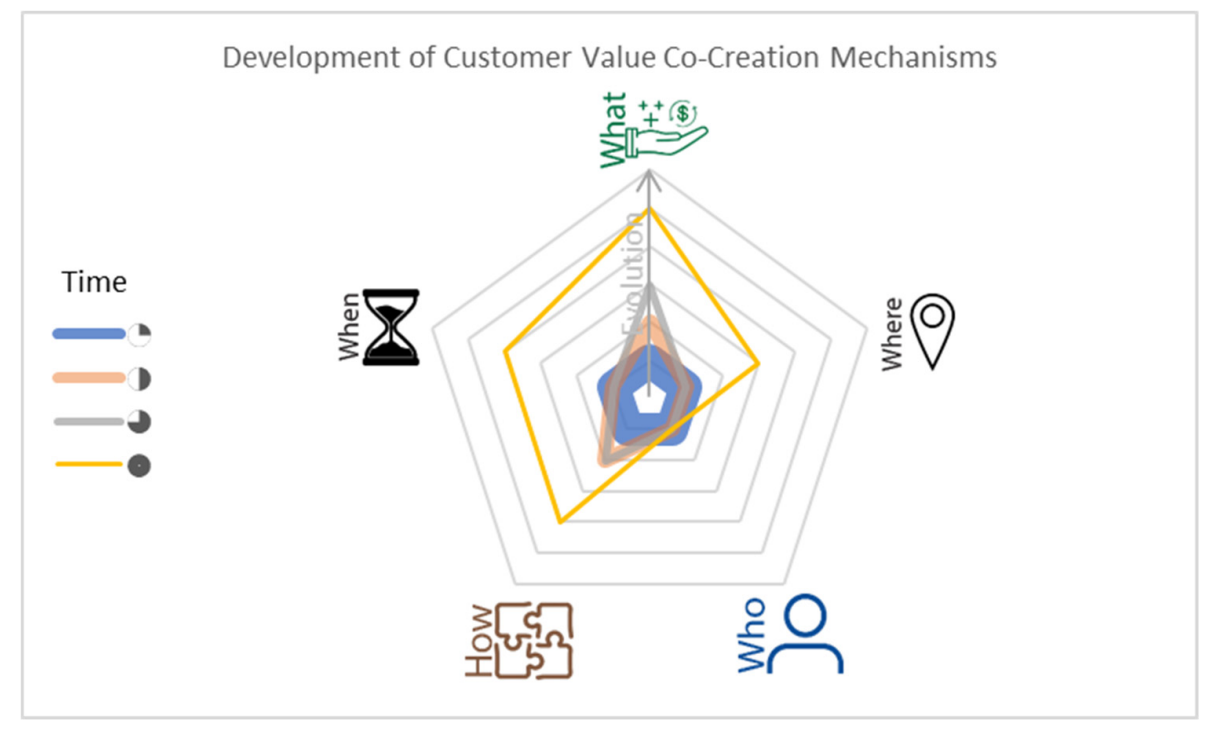

Figure 61 - Whio - Development of Customer Value Co-Creation Mechanisms

\subsubsection{Development of Actor Value Co-Creation Mechanisms}

\begin{tabular}{|c|c|c|c|c|}
\hline Time & & & & \\
\hline $\begin{array}{l}\text { OC } \\
\stackrel{\circ}{\frac{1}{3}}\end{array}$ & $\begin{array}{l}\text { "Small shapers who have } \\
\text { just a shop and one or two } \\
\text { staff members." } \\
\text { "Surfboard makers in New } \\
\text { Zealand and around the } \\
\text { world." }\end{array}$ & $\begin{array}{l}\text { "These are our favourite } \\
\text { shapers, they are all young } \\
\text { guys, who are keen." } \\
\text { "[Subcontractor] does eco- } \\
\text { boards for large } \\
\text { manufacturers } \\
\text { California." }\end{array}$ & $\begin{array}{l}\text { "If shapers want to } \\
\text { collaborate, we will } \\
\text { assemble and shape the } \\
\text { blanks and send it in to } \\
\text { them for finishing." }\end{array}$ & $\begin{array}{l}\text { "A few shapers are } \\
\text { interested in giving it a go, } \\
\text { but they're still a little bit } \\
\text { uncertain about some } \\
\text { things." } \\
\text { "We have been in contact } \\
\text { with interested licensees } \\
\text { from Chile and Germany." }\end{array}$ \\
\hline \multirow[b]{2}{*}{ 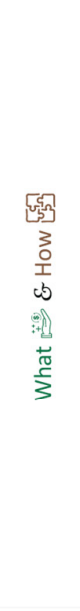 } & Machine, Software, Comp. ${ }^{1}$ & Machine, eco-blanks & Contract Manufacturing & Semi-finished eco-blanks \\
\hline & $\begin{array}{l}\text { "Trying to facilitate and } \\
\text { enable other shapers to } \\
\text { offer their customers a } \\
\text { more environmentally } \\
\text { friendly option ... it's tough } \\
\text { for these guys to compete } \\
\text { on price." } \\
\text { "You need to provide them } \\
\text { with the technology that } \\
\text { allows them to use our style } \\
\text { of construction, so that is } \\
\text { what the machine does we } \\
\text { offer. It reduces the } \\
\text { manufacturing costs, } \\
\text { shapers can make a good } \\
\text { margin, and we think this is } \\
\text { key." }\end{array}$ & $\begin{array}{l}\text { "Selling the machine based } \\
\text { on the premises that you } \\
\text { can make wooden boards... } \\
\text { because all fibreglass work } \\
\text { can be done on the machine } \\
\text { and in turn reduces the } \\
\text { finishing work. That's kind } \\
\text { of where the actual money } \\
\text { is" } \\
\text { "A lot of shapers are not } \\
\text { keen to shape anything by } \\
\text { hand ... they want to do } \\
\text { everything in a CNC } \\
\text { machine, the main reason } \\
\text { for that is time." }\end{array}$ & $\begin{array}{l}\text { "You need sandpaper, a } \\
\text { brush, and epoxy to finish a } \\
\text { board. Our contract } \\
\text { manufacturing service } \\
\text { doesn't require any fancy } \\
\text { machines." } \\
\text { "You need less labour, less } \\
\text { material, and have higher } \\
\text { margins. Our boards sell } \\
\text { for } \$ \text { [X], which is way more } \\
\text { than a conventional } \\
\text { surfboard, it's a better } \\
\text { margin than they would } \\
\text { make from other boards." } \\
\text { "Licensing the machine via } \\
\text { a software interface." }\end{array}$ & $\begin{array}{l}\text { "Shapers send the CAD } \\
\text { files, we make semi- } \\
\text { finished blanks, and send it } \\
\text { to them for finishing. We } \\
\text { will offer them in our store. } \\
\text { That's another way of } \\
\text { getting shapers involved } \\
\text { without them having to } \\
\text { commit to anything." } \\
\text { "they sand it, install fin } \\
\text { boxes, and coat it. It is a } \\
\text { small amount of work for a } \\
\text { decent margin." } \\
\text { "The new workshop can be } \\
\text { like an education centre." }\end{array}$ \\
\hline 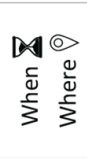 & $\begin{array}{l}\text { "You know, you might be } \\
\text { better off by choosing } \\
\text { California, you know a } \\
\text { really densely populated } \\
\text { surfing community." }\end{array}$ & $\begin{array}{l}\text { "Because of the laws of } \\
\text { trading unfinished timber, } \\
\text { we can't send blanks } \\
\text { overseas. It's almost } \\
\text { impossible, or unviable." }\end{array}$ & $\begin{array}{l}\text { "Portugal ... and that is a } \\
\text { strictly business to } \\
\text { business model." }\end{array}$ & \\
\hline
\end{tabular}




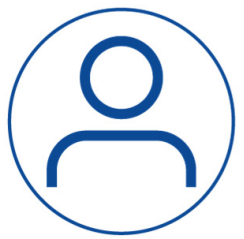

Whio aimed to co-create value for different actors in its ecosystem and developed three explicit actor value propositions throughout the study. First, Whio offered small retail shops tailor-made surfboards with customised branding 8 . Since only one retailer engaged in the offering, Whio refrained from the pursuit of a retailer focused value proposition.

\footnotetext{
"We're currently working on getting the boards into retail stores, but that is going very slow." (Co-Founder, Whio)
}

Second, Whio developed value propositions for New Zealand-based surfboard shapers as well as global surfboard manufacturers was informed by actor bonds created with them 8 and characterised by the development of activity links $\underset{6}{6}$ and required resource endowments 8 .

"We met and connected with several shapers and try to engage progressive ones in our offering. There are many shapers we want to work with, but they are mostly older and set in their ways." (Co-Founder, Whio)

Shapers were considered pivotal actors engaged in VCC mechanisms throughout the study. In contrast, surfboard manufacturers' importance as technology licensees grew in the final stages and represented the third value proposition developed by Whio.

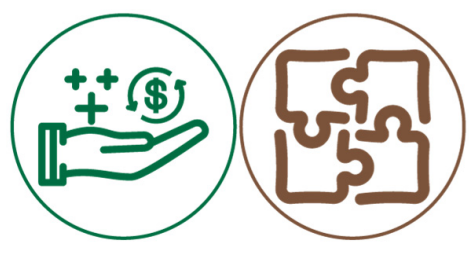

Whio aimed to offer New Zealand-based shapers a new ecofriendly production method for surfboards proposition was refined several times throughout the study to engage shapers in VCC mechanisms. The new efficient and eco-friendly surfboard production method Whio offered allowed shapers to provide their customers with a long-lasting and eco-friendly alternative to conventionally manufactured surfboards. The combination of a newly developed machinery, a vacuum-press with adjustable cradle, and a software interface allowed shapers to streamline production processes 蜀.

"We sell the machine and maintain the supply of components. Sending components such as rails, decks and sheets to shapers and surfboard manufacturers that assemble them according to their needs." (Co-Founder, Whio) 
Since engaging in Whio's initial value proposition required shapers to adopt new

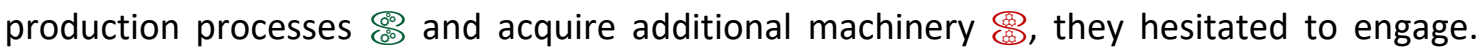
Consequently, Whio refined its shaper value proposition to an offering of machinery, software, and assembled still unfinished eco-blanks

\footnotetext{
"At the moment we are working with shapers that can put our blanks into their CNC machine and then shape the rails. Others are happy to shape the rails by hand, but it is a very time intense process" (Co-Founder, Whio)
}

Due to the limited interest and feedback from the target group, Whio further refined the shaper value proposition and offered a semi-finished eco-blank contract manufacturing service. The refined shaper value proposition required only to provide $C A D^{18}$ design files and perform minor finishing tasks $\infty$ and obliviated the development of significant activity links and resource requirements.

"Many shapers don't have a CNC machine, but will send the CAD files to a CNC machinist and receive the shaped blank. We offer to jump in the supply chain with our construction method, tailored wooden blanks made from shapers' CAD files." (Co-Founder, Whio)

However, shapers largely remained reluctant to engage since semi-finished blanks provided a limited scope for manual shape refinements concerned about the durability of Whio's boards and the associated loss of credibility amongst their customers, and contaminations of workshops with wood-dust

"We can provide our contract manufacturing service only for boards that come off the CNC machine perfectly. There is no buffer for shape refinement. Taking off a $1 \mathrm{~mm}$ when you are finishing the board jeopardizes strength, that's a major problem" (Co-Founder, Whio)

The limited interest amongst shapers led to further refinements of the value proposition to only cooperate in design and finishing tasks to convey the advantages of its production method to shapers without them having to make any commitments and increase the adoption rate. In short, Whio refined its shaper value proposition several times throughout the study due to insights obtained from interactions with shapers 8 . Significant for the refinement were alterations of activity links 8 and resource ties required from shapers to learn, engage, and adopt the new surfboard

\footnotetext{
${ }^{18}$ Computer Aided Design
} 
production method offered by Whio.

Finally, Whio aimed to offer machinery and software to produce eco-friendly blanks to surfboard manufacturers around the world licensees were refined due to initial inquiries from interested parties abroad 8 . While initially Whio was looking for licensees overseas to engage in the co-development of machinery and the production processes, the venture was creating an offering comprised of inhouse developed machinery, software interface, and a training program in the final stage of the study.

"There will be one big machine, a whole new software interface, and they will be trained and learn about the whole production process." (Co-Founder, Whio)

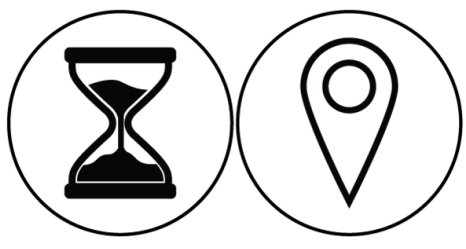

Whio's actor value propositions were characterised by two significant spatial aspects. Due to laws and regulations regarding the export and import of unfinished timer products such as eco-blanks, Whio's shaper value proposition was limited to New Zealand. Consequently, geographical expansion required foreign operations and/or subsidiaries. Whio aimed to attract the attention of licensees in regions with a dense population for surfers such as Australia and California. However, initial interest from potential licensees was coming from countries such as Chile and Germany. The temporal aspect of Whio's shaper value proposition was related to the alignment of co-production of surfboards with off-seasonal demand.

"Potentially the middle of winter when business for shapers is modest, we would engage in the limited production of a run of five boards for our shop." (Co-Founder, Whio)

Overall, Whio developed, explored, refined and even abandoned different actor value propositions over the time of the study. Primarily interactions with target actors 8 and the integration and adaption with existing processes and resources propelled of actor value co-creation mechanisms. Figure 62 summarises Whio's actor value co-creation mechanisms development process over time. 


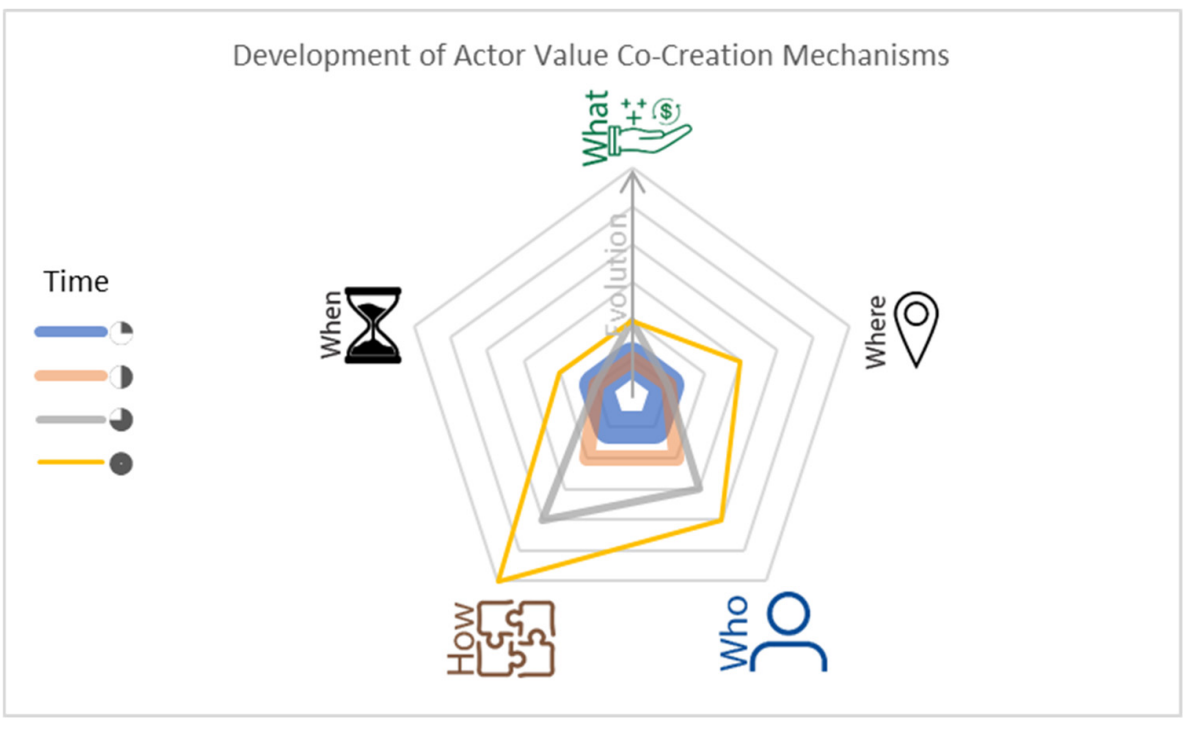

Figure 62 - Whio - Development of Actor Value Co-Creation Mechanisms 


\subsubsection{Development of Value Capture Mechanisms}

\begin{tabular}{|c|c|c|c|c|}
\hline 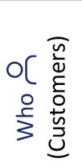 & $\begin{array}{l}\text { "Primary customers will be } \\
\text { surfers." }\end{array}$ & $\begin{array}{l}\text { "Trying to make a fun } \\
\text { product for recreational } \\
\text { surfers." }\end{array}$ & \multicolumn{2}{|c|}{$\begin{array}{l}\text { "Surfers who are buying the boards care about the } \\
\text { environment." }\end{array}$} \\
\hline [ु, 3 & Machine, Software, Comp. & Machine, eco-blanks & Contract Manufacturing & Semi-finished eco-blanks \\
\hline 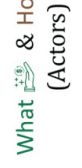 & $\begin{array}{l}\text { "They will get software for } \\
\text { a monthly fee. Shapers will } \\
\text { go online, upload their file, } \\
\text { and then the whole thing } \\
\text { automates the design." }\end{array}$ & $\begin{array}{l}\text { "It's all web-based, and the } \\
\text { idea is to deploy the } \\
\text { machines at minimal costs } \\
\text { to the shaper, and then } \\
\text { charge them per board." }\end{array}$ & $\begin{array}{l}\text { "We charge shapers } \\
\text { around } \$[x] \text { for each semi- } \\
\text { manufactured blank, of } \\
\text { course depending on shape } \\
\text { and size." }\end{array}$ & $\begin{array}{l}\text { "We will enable them to } \\
\text { produce the whole thing } \\
\text { and make money. We sell } \\
\text { the machine and the whole } \\
\text { process for } \$[X] . "\end{array}$ \\
\hline 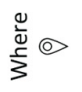 & \multicolumn{2}{|l|}{ New Zealand } & rnia & Global \\
\hline
\end{tabular}

Table 35 - Whio - Development of Value Capture Mechanisms

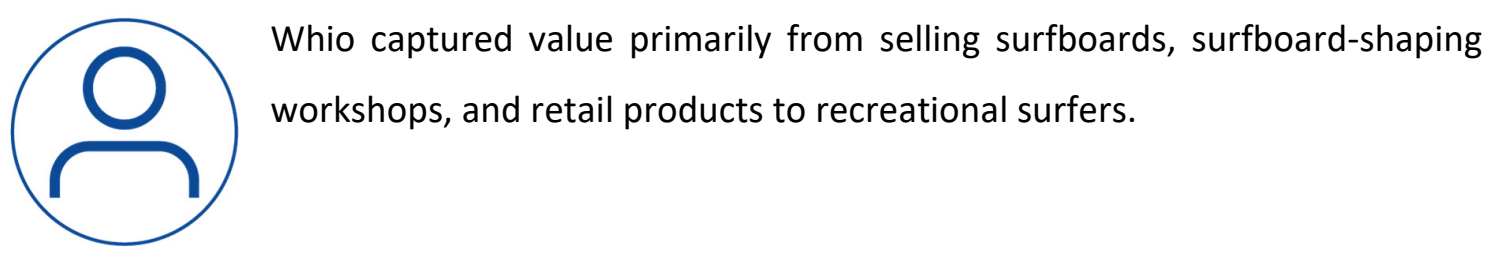

"Recreational shapes are becoming increasingly popular and fetch around \$[X] depending on the shape and size" (Co-Founder, Whio)

Whio's engagement with a small number of shapers allowed to capture limited value from its eco-blanks manufacturing service in the final stage of the study. Likewise, Whio explored potential opportunities to capture value from technology licensees in the final stages of the study. 


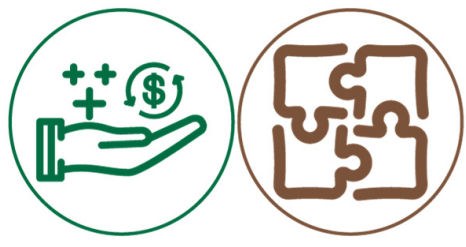

Whio captured pecuniary value from customers via selling surfboards, offering surfboard-shaping workshops, and branded retail products such as t-shirts, changing-towels, and wax combs. Aligned with the evolution of customer value cocreation mechanisms, the focus of value capture shifted from selling surfboards towards conducting surfboard-shaping workshops in the final stages of the study hedonistic and emotional value experienced by customers in the surfboard shaping workshop was reflected in an increase in prices. Sales of surfboards and workshops were primarily facilitated via Whio's website and a crowd-funding campaign. In short, the development of custom value co-creation mechanisms was underpinned by the increasing importance of symbolic and hedonistic aspects of customer value.

Whio's refinement of shaper value co-creation mechanisms mandated an evolution of shaper value capture mechanisms. Initially, Whio intended to capture pecuniary value via a subscription fee for a software interface, sale of machinery, and components that allowed shapers to employ the novel manufacturing process.

Shapers' hesitation to invest in the machinery, software interface, and changing processes provided by Whio mechanisms. In line with providing contract-manufacturing services for semi-finished blanks (6) manufacturing service and per board charge.

"In the semi-finished eco-blank supply model, we charge shapers a fee per board." (Co-Founder, Whio)

Whio's licensee value capture mechanisms evolved in the final stages of the study. However, since no licensee was attracted during the study, no value was captured via this revenue stream. Finally, Whio captured pecuniary value from providing contract manufacturing services for a producer of hand-plains. 


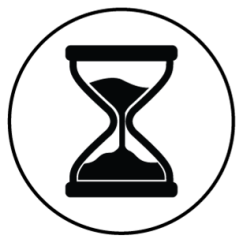

Two significant temporal components were identified in Whio's value capture mechanisms. First, customers were allowed to pay for surfboards and surfboard-shaping workshops in $50 \%$ instalments when ordering surfboards or scheduling workshops. Moreover, surfboard shaping workshops allowed Whio to balance off-seasonal demands and create a steady cash flow. Second, the initially envisioned shaper value proposition incorporated a monthly subscription paid to receive access to the necessary software interface to use the machinery.

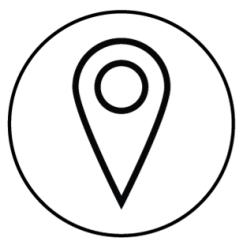

Finally, the shaper value capture mechanisms were delimited by the regulations of shipping unfinished timber overseas and thus limited to New Zealand. In contrast, the licensee value capture mechanism was location independent, and actors from unanticipated parts of the world showed interest.

Overall, Whio's value capture mechanisms developed over the period of the study. The evolution of customer value capture mechanisms was limited to pricing refinements. In contrast, to cope with significant changes in shaper value co-creation mechanisms, value capture mechanisms evolved across the how, who and where dimension of the value proposition. The development of individual dimensions of Whio's value capture mechanisms is illustrated in Figure 63.

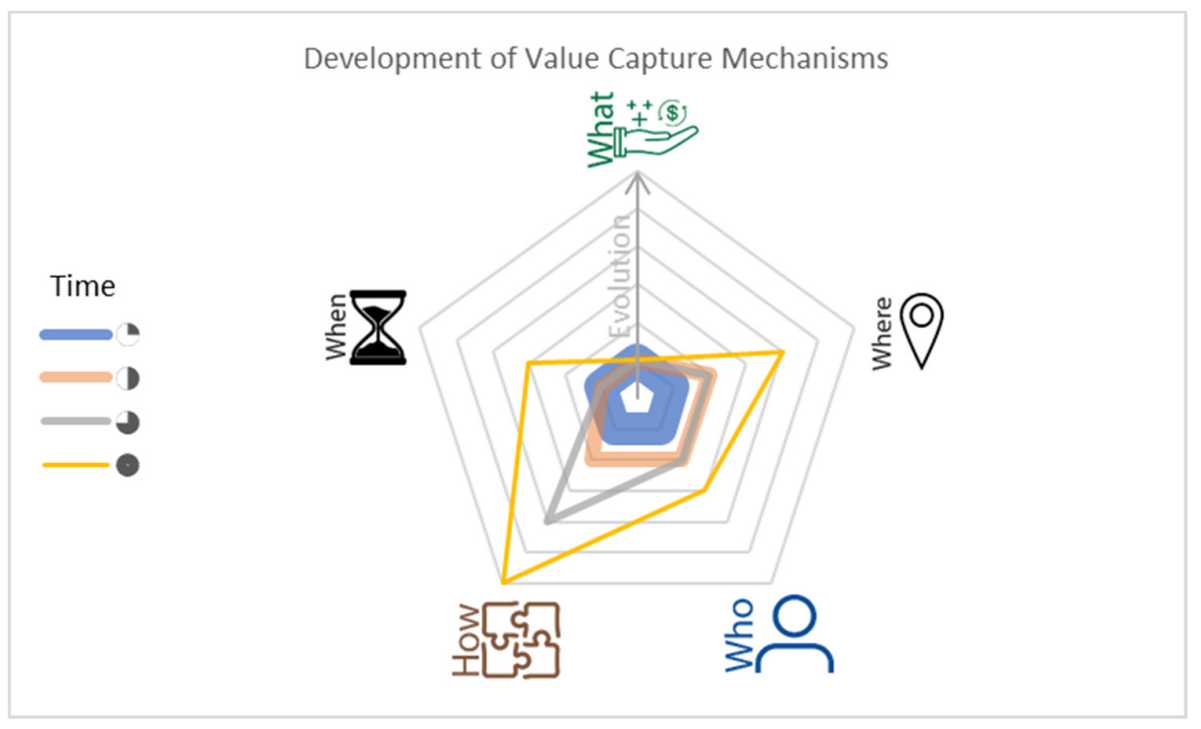

Figure 63 - Whio - Development of Value Capture Mechanisms 


\subsubsection{Summary Value Co-Creation and Capture Mechanisms}

Whio's VCC mechanisms significantly evolved throughout the study. Whio's customer value proposition was extended and refocused on conducting shaping workshops next to providing long-lasting and eco-friendly surfboards. Moreover, Whio conceptualised, explored, and refined several shaper value propositions to engage shapers in value cocreation processes. The venture continuously reduced the scope of its shaper value proposition to lower the commitments required from shapers to engage in value co-creation mechanisms. Likewise, Whio's value capture mechanisms evolved over the period of the study to accommodate for the adaption of the shaper value proposition. Figure 64 illustrated the development of Whio's VCC mechanisms over time.

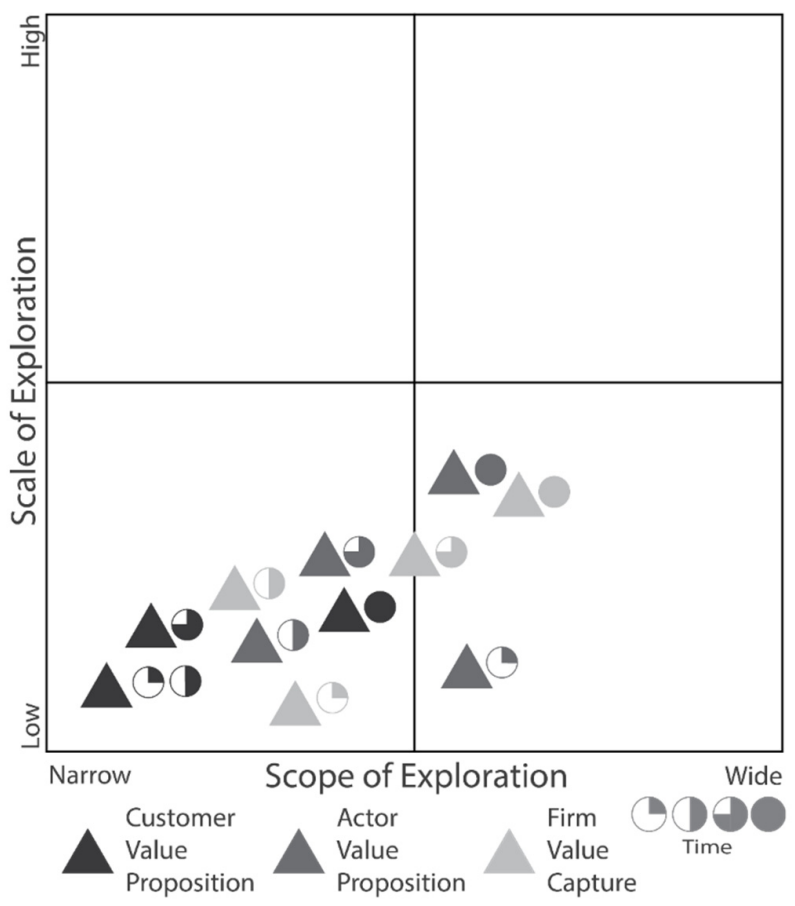

Figure 64 - Whio - Development of Value Co-Creation and Capture Mechanisms 


\subsubsection{Development of Activity Links, Resource Ties, and Actor Bonds}

\begin{tabular}{|c|c|c|c|c|}
\hline Time & $D$ & & & \\
\hline 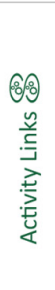 & $\begin{array}{l}\text { "We managed to adapt and } \\
\text { figure out a process that } \\
\text { works really well for using } \\
\text { recycled polystyrene." } \\
\text { "trees are cut and } \\
\text { sawmilled in the format } \\
\text { and length we require and } \\
\text { dried for us." }\end{array}$ & $\begin{array}{l}\text { "Shapers are better board } \\
\text { designers. The design and } \\
\text { finish work is done by some } \\
\text { of them in New Zealand." } \\
\text { "There are businesses with } \\
\text { larger machines that can } \\
\text { process wood faster and } \\
\text { cheaper than we can." }\end{array}$ & $\begin{array}{l}\text { "Shapers mostly have got } \\
\text { good processes and } \\
\text { systems in place. They are } \\
\text { mostly happy with how } \\
\text { things are going, and there } \\
\text { is no benefit for them } \\
\text { changing their system and } \\
\text { trying something differ- } \\
\text { ent." }\end{array}$ & $\begin{array}{l}\text { "Shapers had to hand } \\
\text { shape that curve into the } \\
\text { board, and they are not } \\
\text { accustomed to doing that } \\
\text {... so when we're getting the } \\
\text { machine set up, it is going } \\
\text { to be faster and easier and } \\
\text { does not require any hand } \\
\text { shaping anymore." }\end{array}$ \\
\hline 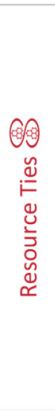 & $\begin{array}{l}\text { "We pay rent and get the } \\
\text { space that we are working } \\
\text { in, access to all the } \\
\text { machinery, and the joinery } \\
\text { shop. The machinery out } \\
\text { there is probably around } \\
\$ 150, \text { ooo, and we use } \\
\text { around three quarters on a } \\
\text { daily basis, so for astart-up } \\
\text { who tries to get into } \\
\text { production, it's a great } \\
\text { thing." }\end{array}$ & $\begin{array}{l}\text { "Some shapers will have the } \\
\text { ability to use our } \\
\text { construction method and } \\
\text { machine rails in their CNC } \\
\text { mill." } \\
\text { "Every time when we get } \\
\text { timber and trim it, we save } \\
\text { the off-cuts for contract } \\
\text { manufacturing for } \\
\text { [partner], he makes } \\
\text { handplanes for body } \\
\text { surfing." }\end{array}$ & $\begin{array}{l}\text { "We can only do those } \\
\text { blanks that come off the } \\
\text { machine perfectly ... there } \\
\text { is not very much that they } \\
\text { are able to take down." }\end{array}$ & $\begin{array}{l}\text { "Sawdust contamination, } \\
\text { that's another thing that } \\
\text { shapers are worried about, } \\
\text { that shouldn't be really an } \\
\text { issue but has stalled } \\
\text { progress." }\end{array}$ \\
\hline \multirow[t]{2}{*}{ 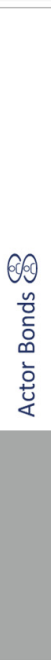 } & $\begin{array}{l}\text { "We've got down to the } \\
\text { point where our two main } \\
\text { suppliers of raw material } \\
\text { are flexible ... [supplier] } \\
\text { moulds the polystyrene ... } \\
\text { and we will only buy wood } \\
\text { from [supplier] ... he gave } \\
\text { us a tour on his farm, and } \\
\text { we were pretty much sold } \\
\text { on that." } \\
\text { "It has taken us a little bit } \\
\text { of time to build those }\end{array}$ & $\begin{array}{l}\text { "Our wood supplier is } \\
\text { having trouble to keep up } \\
\text { with demand ... he keeps } \\
\text { sending us wet wood. We're } \\
\text { actually reaching out to } \\
\text { another supplier ... he can } \\
\text { produce the thin sheets } \\
\text { that we need, we're } \\
\text { thinking that it might be a } \\
\text { better option." } \\
\text { "We have been in touch } \\
\text { with three investors whom }\end{array}$ & $\begin{array}{l}\text { "We're still working with } \\
\text { [wood supplier], we are } \\
\text { going to see him this } \\
\text { weekend. We are going to } \\
\text { be on a TV show together." } \\
\text { "The road trip was a great } \\
\text { opportunity to connect } \\
\text { with shapers, because they } \\
\text { haven't seen the newest } \\
\text { boards. Basically, we had to } \\
\text { convince them to } \\
\text { collaborate." }\end{array}$ & $\begin{array}{l}\text { "If we wouldn't have got } \\
\text { matched funding from the } \\
\text { City Council, we wouldn't } \\
\text { be able to move on." } \\
\text { "We will showcase } \\
\text { everything and won't be } \\
\text { secretive about anything } \\
\text { because the idea is that it is } \\
\text { a service technology and } \\
\text { you want to be transparent } \\
\text { and open about it." }\end{array}$ \\
\hline & $\begin{array}{l}\text { celationshins with shapers } \\
\text {... trying to understand } \\
\text { their problems, understand } \\
\text { how each shaper operates, } \\
\text { how they use machinery, } \\
\text { and then trying to figure } \\
\text { out how we can actually } \\
\text { make their life easier." }\end{array}$ & $\begin{array}{l}\text { we really want to work } \\
\text { with." }\end{array}$ & $\begin{array}{l}\text { "The [accelerator] platform } \\
\text { helped us to develop our } \\
\text { crowdfunding campaign } \\
\text { and guided us through the } \\
\text { process." }\end{array}$ & $\begin{array}{l}\text { "They itike the drana,' to seil" } \\
\text { that stuff you need to focus } \\
\text { on brand value, and that is } \\
\text { hard when you haven't got } \\
\text { some sort of a shop or any } \\
\text { sort of presence." }\end{array}$ \\
\hline
\end{tabular}

Table 36 - Whio - Development of Activity Links, Resource Ties, and Actor Bonds

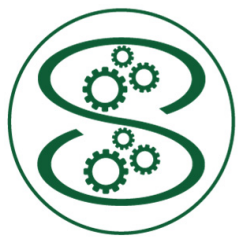

The development of Whio's VCC mechanisms was underpinned by emerging serial and dyadic activity links. The production process of surfboards, conducting surfboard shaping-workshops, and the engagement of shapers required the coordination of several activities across various actors. First, Whio and its two main suppliers engaged in an activity linking process. On the one hand, Whio adopted internal processes to use recycled polystyrene 8 and produce eco-friendly surfboard blanks. On the other hand, the supplier customised the density of the polystyrene 
sheets 8 and stocked large quantities of freezer-panel foam gathered from demolition projects for Whio.

"When our polystyrene supplier recycles freezer panels, they stock them for us. This foam is perfect for making surfboards, perfect density and size" (Co-Founder, Whio)

Similarly, Whio's supplier of wood coordinated the processing of trees to ensure a reliable supply of tailor-sized wood up to quality specifications

"We are ordering two different wood profiles, tree cutting, milling and drying needed to be adjusted by the farmer and the sawmill to get the right profiles and perfect quality wood." (Co-Founder, Whio)

Different arrangements of processing wood internally as well as in cooperation with different external actors were explored over the period of the study 8 .

"We have gone back and forth on timber processing. There are several options available, but we can do most of it on our own with our new CNC machine” (Co-Founder, Whio)

Second, Whio's shaper value proposition was dependent on the dyadic activity links developed with external shapers and their resource endowments 8 . Producing surfboards with Whio's machinery, software, and eco-blanks required shapers to adopt new production processes. Whio's shift to offering unfinished and semi-finished eco-blanks activity linking requirements for shapers. A limited set of shapers engaged in Whio's semifinished eco-blank value co-creation mechanisms and thus established dyadic activity links with the venture. In spite of extensive exploration, activity linking remained mostly limited to interdependencies of design and finishing processes of surfboards.

Overall, activity linking significantly influenced the development of Whio's VCC mechanisms. On the one hand, linking sourcing activities with suppliers allowed Whio to

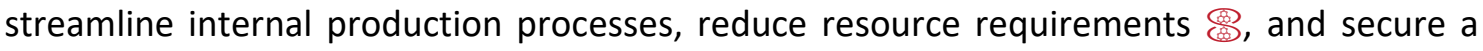
reliable supply of eco-friendly and high-quality raw materials. On the other hand, shapers' hesitation to engage in linking production activities propelled the development of the shaper value proposition. 


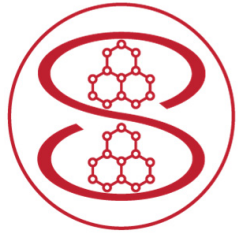

Whio developed physical and organisational resource ties throughout the study. The most salient resource ties were developed with a joinery workshop that provided a work-space and access to capital-intense machinery. Whio also created resource ties with its suppliers of paulownia wood and recycled polystyrene. The supplier of paulownia wood provided tailor-made raw materials well-suited to produce surfboards.

"Paulownia wood is an excellent material for making surfboards, it has a very good strengthto-weight ratio and is resistant to saltwater so perfect for marking surfboards."

(Co-Founder, Whio)

Resource ties developed with the supplier of polystyrene were strengthened by introducing a recycling process of offcuts that were mulched and compressed in new polystyrene blocks $\underset{80}{\circ}$.

"Polystyrene offcuts are getting recycled by [supplier] and come into the next patch of sheets." (Co-Founder, Whio)

Moreover, resource ties were formed with a manufacturer of handplanes by processing wood offcuts and performing contract manufacturing services $\varnothing$. These resource ties allowed Whio, on the one hand, to reduce waste material and qualify for a Gold Level Ecoboard certification 8 , and, on the other hand, to leverage internal production capabilities.

"It's hard to get a gold level eco-board certificate ... waste management is part of the assessment" (Co-Founder, Whio)

Also, Whio's aim to create resource ties with shapers evolved with the development of the shaper value proposition. Initially the venture aimed to develop physical resource ties via the development of machinery, software and later on eco-blanks for the surfboard manufacturing process.

"for the development of the machine we will run pre-sales and hope to find ten shapers willing to invest $\$[X X K]$. This way we will have a budget of $\$[X X X K]$ to produce ten machines and develop the software" (Co-Founder, Whio)

However, the reluctance of shapers to engage in VCC mechanisms resulted in a refinement of the shaper value proposition finally relying on the combination of design and finishing skills and thus organisational resource ties 8 . 
Moreover, the structure of unfinished and semi-manufactured eco-blanks was considered as characterising resource tie. While unfinished eco-blanks required access to a CNC mill and the capabilities to operate it $\circledast$, semi-finished eco-blanks limited the scope of manual hand-shaping refinements due to its sandwich structure

Opening a new workshop required the development of physical resource ties such as shop-fitting, machinery installation and a workshop layout. Matching a rental space with a machine layout that allows for a lean manufacturing process 8 required several adaptions.

\section{"... lighting, infrastructure and shop-fitting, the landlord will pay for some of that. We will have to invest time and resources to set up the new workshop and the retail presence." (Co-Founder, Whio)}

Overall, Whio explored the development of several resource ties with various actors. The resource ties realised with suppliers were crucial for the production of eco-friendly surfboards in an efficient manner. In contrast, the lack of opportunities to establish resource ties with shapers drove the development of actor VCC mechanisms.

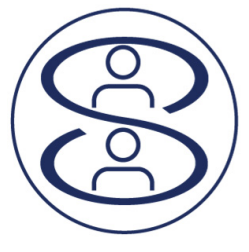

Whio developed bonds with several actors in its ecosystem to acquire an identity as a reliable provider of products and services, develop an understanding of the needs of other actors, and position itself in the ecosystem. Whio's suppliers were established providers of ecologically sourced raw-materials. While the supplier of wood was a national pioneer in sustainable agricultural and forestry practices from recycled packaging shows, enhanced Whio's identity as an eco-conscious manufacturer of surfboards.

"[Wood supplier] explained to me his combination of sustainable agricultural and forestry practices which enhanced our mission." (Co-Founder, Whio)

Likewise, actor bonds created with shapers allowed Whio to develop an understanding of their production processes and resource endowments and thus supported the development of activity links and resource ties. The learning facilitated via actor bonds with shapers was paramount for the evolution of Whio's shaper value proposition. 
"We are working with shapers around New Zealand on a blank supply model ... we are trying to understand all of their problems, how we can help them to make more money, so they are more likely to adopt this process." (Co-Founder, Whio)

"Shapers do not instantaneously trust our services. We are newcomers and bring a very different production method in the industry. I try to put myself in their shoes, and if somebody would ask me to change the whole manufacturing system, I can understand their apprehension."

(Co-Founder, Whio)

Whio enhanced its credibility as reliable provider of eco-friendly surfboards and manufacturing services amongst shapers by getting accredited as a Gold Level Ecoboard manufacturer @i:

"The gold level eco-board certification is hard to obtain. They are looking at what raw materials sourcing, production processes, waste management, lighting, etc., and there are only five companies on the same level around the world" (Co-Founder, Whio)

In addition to bonds created with actors directly involved in VCC mechanisms, Whio engaged with two accelerator programs. These actor bonds allowed Whio to enhance its legitimacy, obtain access to pivotal financial resources, and enabled the development of marketing and business capabilities.

"In the three-month program we were able to learn a lot about supply chains, how automation can help to reduce costs, and they also provided a space where we can assemble the machines." (Co-Founder, Whio)

Moreover, participation in another program allowed Whio to obtain access to advisors and marketing capabilities and as a result run a successful crowd-funding campaign. Whio received matched funding from sponsors of the program and managed to attract investors.

"As part of the [program] we were getting access to advisors, they helped us working out how to get the message and rewards of our crowd-funding campaign in line with what we are trying to achieve ... we have got matched funding as well from the City Council and [sponsor]" (Co-Founder, Whio)

Whio continuously explored the creation of new actor bonds, for example, to establish a reliable supply of high-quality wood or bio-resin $\operatorname{~}$ 
"Our supplier of bio-resin is unreliable and really messes up our systems. We are currently looking at some Australian made bio-resin and trying to become a distributor for that as well." (Co-Founder, Whio)

Finally, Whio created latent actor bonds with overseas licensees to develop a finegrained understanding of the requirements of a value proposition and potential value capture mechanisms.

In conclusion, Whio developed various actor bonds with suppliers, shapers and accelerator programs. Actor bonds with suppliers were important to coordinate mutual learning and linking of activities. Likewise, bonds created with shapers facilitated the development of VCC mechanisms and allowed Whio to introduce its novel manufacturing process to shapers. The actor bonds developed with shapers as a contract manufacturer positioned the company in the surfboard-manufacturing ecosystem as a service provider. Finally, actor bonds with established suppliers, credible shapers, and renown accelerator programs provided legitimacy for Whio and thus an identity for the emerging venture.

\subsubsection{Summary Whio}

Overall, the development of Whio's VCC mechanisms were governed by extensive explorations to create a firm-ecosystem fit. On the one hand, activity links and resource ties with suppliers were maintained and provided stability for the reliable provision of a customer value proposition, i.e. surfboards and surfboard-shaping workshops. On the other hand, the development of activity links and resource ties with shapers was significant and of limited success as evident by the moderate engagement of shapers. The tensions resulting from the required development of activity links and resource ties and the perceived value for shapers were crucial drivers of the development of Whio's VCC mechanisms. Figure 65 illustrates the development of activity links, resource ties, and actor bonds over the period of the study. The evolution trajectories were characterised by a limited development in scale and depth throughout the study. The latent evolution of realised activity links, resource ties, and actor bonds was mostly related to the engagement with suppliers. 


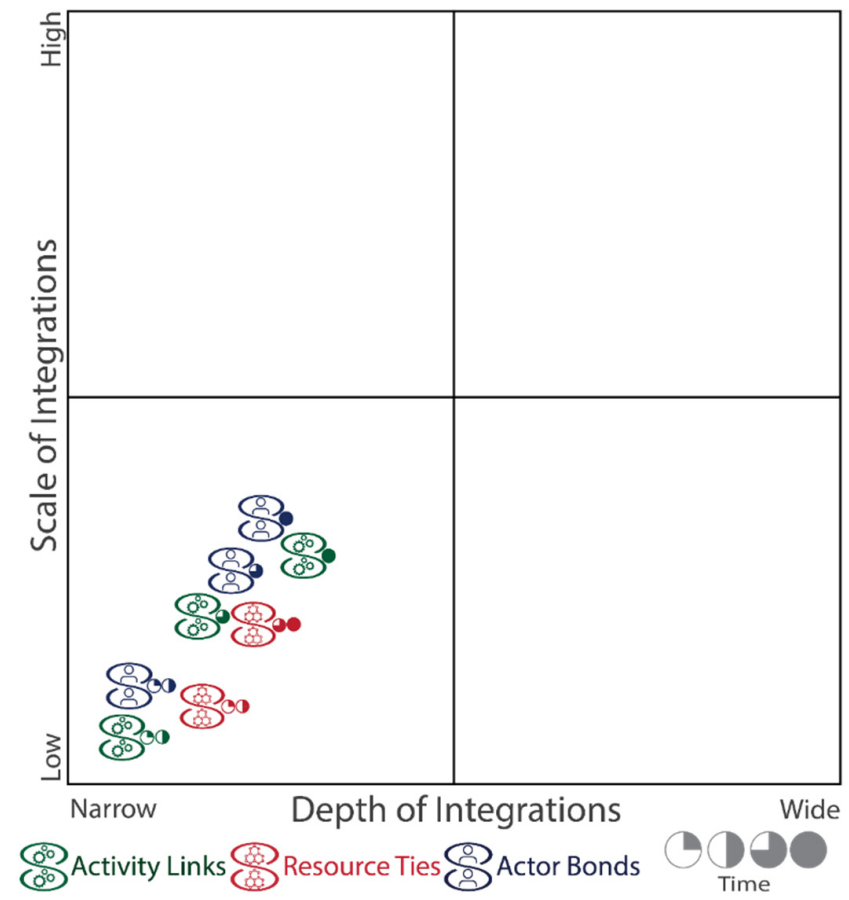

Figure 65 - Whio - Development of Activity Links, Resource Ties, and Actor Bonds 


\subsection{Case Report - Venture Moa}

\subsubsection{Introduction}

Moa aimed to provide money transaction services for Pacific Islanders living in New Zealand. The venture extensively explored VCC mechanisms. However, the meagre support for core assumptions underpinning customer value co-creation mechanisms the conducted market research provided resulted in the abandonment of further BM development activities.

"We are at the early stages of customer discovery and problem validation. If people don't think the fees are too high then this is a big push back for us because we are not addressing the right problem." (Co-Founder, Moa)

\subsubsection{Development of Customer Value Co-Creation Mechanisms}

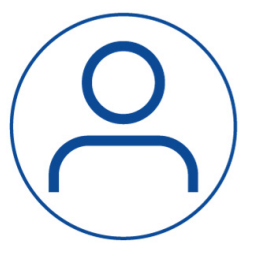

Moa focused on Pacific Islanders living and working in New Zealand as a primary customer group. This ethnicity-based customer segmentation approach was driven by the assumed unifying need to transfer money to friends and family in the Pacific islands.

"People from the Pacific Islands with friends and family back home." (Co-Founder, Moa)

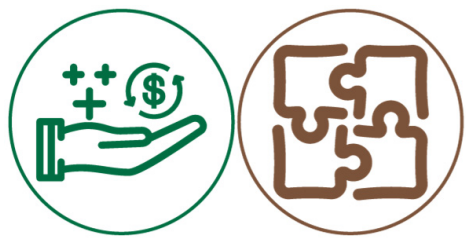

What and how value was intended to be co-created for Pacific Islanders in New Zealand and their relatives at home was characterised by the increasing conveniences of money transfer processes and cost reductions 8 .

“Customers have to go to a Western Union office during office hours, identify themselves, and transfer the money. Then friends and family have to go to a Western Union Office in the islands and pick the money up. We want to make the process more convenient, less time-intense, and cost-efficient" (Co-Founder, Moa)

Moreover, Moa explored opportunities to co-create value with customers by 
introducing a referral scheme $\circledast$.

"Another way of capturing value is to grow our customer base via a referral model. Customers get free transactions for every other customer they attract." (Co-Founder, Moa)

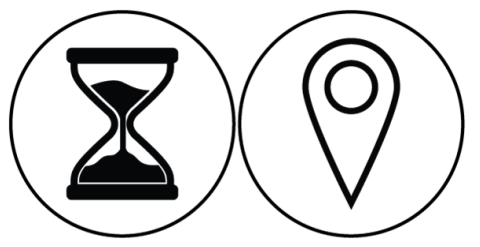

Moa's customer value co-creation mechanism was underpinned by the convenience of rendering temporal and spatial limitations of financial service providers such as Western Union obsolete.

"Customers can always transfer money, independent of opening hours" (Co-Founder, Moa)

\subsubsection{Development of Actor Value Co-Creation Mechanisms}

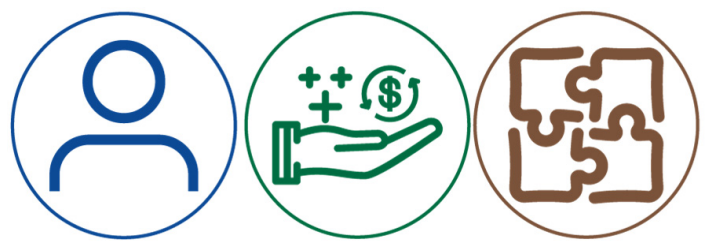

Moa explored opportunities to co-create value with banking rail service providers, supermarkets in the Pacific islands, and banks 间會禺. Banking rail service providers would benefit from the cooperation via additional transactions generated in underutilised corridors.

"Working with banking rail system providers creates additional value for them. Most of them have the infrastructure but don't operate in the corridor New Zealand-Pacific Islands. We would bring with our customers additional business to them" (Co-Founder, Moa)

Moa explored opportunities to co-create value with supermarkets in the Pacific islands by leveraging their infrastructure as well as balancing inbound and outbound foreign exchange flows to reduce the cost of overseas transactions

"There is an opportunity for us to partner with supermarkets in the Pacific islands. We can balance inbound, i.e. people sending money to the islands, and outbound, supermarkets paying their foreign exchange bills, flows to reduce the number of money transfers. Supermarkets can benefit from our cooperation by increasing their customer frequency. People will go there to pick-up money and potentially spend it there" (Co-Founder, Moa)

Finally, Moa considered opportunities to co-create value with banks as a provider of 
banking rail services.

"We might provide services to banks to facilitate cost-efficient transactions to the Pacific islands. They might want to offer that as a service to their customers and attract a substantial part of Pacific Islanders living in New Zealand as customers." (Co-Founder, Moa)

Overall, Moa explored several opportunities to engage with other actors in value cocreation mechanisms, yet did not engage in negotiations of partnership agreements during the study.

\subsubsection{Development of Value Capture Mechanisms}

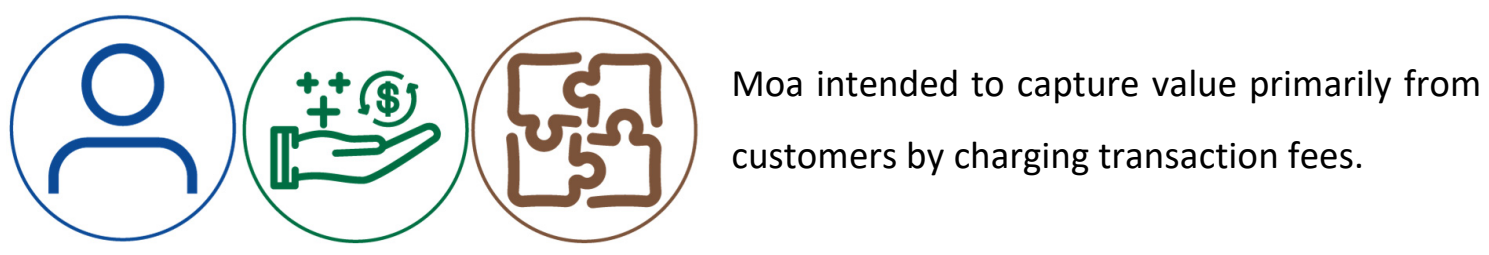

"At this stage, there are two ways how to make money. Either we charge a fixed cost or take a percentage difference in spread. We want to be transparent about it and provide customers with a choice." (Co-Founder, Moa)

Nevertheless, value capturing mechanisms were dependent on the development of partnerships with other actors and the modes of money transfer they facilitated 8 .

"The way how we capture that value is going to be different depending on which channel we use to transfer money and what partners we cooperate with." (Co-Founder, Moa)

Finally, cooperation with supermarkets or other cash intense import businesses in the Pacific islands would have yielded opportunities to balance financial in- and outflows and provide foreign exchange and transaction services below market rates 8 .

"We might provide money transfer services cheaper than banking rail providers to banks and charge fees for that." (Co-Founder, Moa)

Overall Moa explored value capture mechanisms in line with opportunities to cocreate value with customers and other actors. 


\subsubsection{Summary Value Co-Creation and Capture Mechanisms}

Moa explored various opportunities to co-create value with customers and other actors such as banking rail providers, supermarkets in the Pacific islands, and banks. In line with that, the venture explored the scope of potential value capture mechanisms.

\subsubsection{Development of Activity Links, Resource Ties, and Actor Bonds}

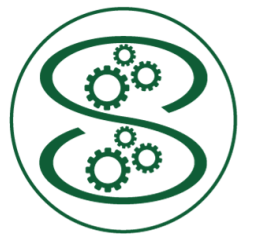

Moa explored the development of different activity links with banking rail providers, banks, and supermarkets since they allowed to reduce transaction costs and enable VCC mechanisms.

"The banking rail system requires us to coordinate ID verifications on both ends, wire the money to be transferred, and pay on a per transaction basis." (Co-Founder Moa)

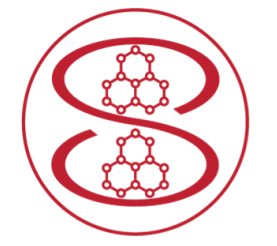

Moa explored the development of physical and organisational resource ties along different opportunities to partner with banking rail providers, banks, and supermarkets in the Pacific islands.

"Working with banking rail systems requires us to find skilled developers that know how to build on theses existing systems and develop our whole stack along with their requirements. We would not have to care about cybersecurity as much and can focus on delivering a great customer experience" (Co-Founder Moa)

In a similar vein, decisions on a cloud infrastructure provider required Moa to align its human resource base.

"The cloud infrastructure platform we are using, like Microsoft or AWS, will influence the people we are going to hire." (Co-Founder, Moa)

Finally, the convenience of the customer experience was dependent on developing resource ties with other actors to facilitate the exchange of data for ID verification purposes.

"We will import ID verification data from other online platforms to streamline the process of customer onboarding and money transfers." (Co-Founder, Moa) 
While Moa explored the development of physical and organisational resource ties with several actors, none were realised during the study.

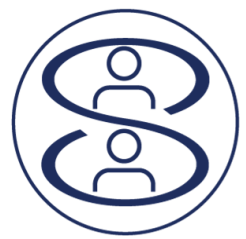

Moa scoped the development of actor bonds within potential partners in the ecosystem and their requirements.

"We have made some contact with supermarkets in the islands, yet we have to find a partner that is large enough to balance the in- and outflows of currencies. We are reaching out to others and will further pursue this idea" (Co-Founder, Moa)

Moa assessed the regulatory environment and explored opportunities to engage with financial market authorities to ensure compliance.

"We will work with financial market authorities to ensure we operate within their boundaries." (Co-Founder Moa)

However, Moa refrained from the development of actor bonds until customer value co-creation mechanisms would solidify.

"We have made some initial contact with partners but will only start to develop relationships until we fully understand the customers' problems." (Co-Founder, Moa)

\subsubsection{Summary Moa}

While Moa's aim of customer value co-creation remained constant, the means how value was co-created and captured was explored along three idiosyncratic scenarios underpinned by the development of different BM configurations. Moa engaged in market research activities in New Zealand to further enhance the understanding of customers' problems and opportunities to co-create value with customers. In the second stage of the study, Moa extended market research activities to Pacific islands such as Samoa. Since findings regarding customer problems in New Zealand and Samoa and thus the underpinning value co-creation mechanisms were incongruent, the venture abandoned the development of the BM.

"The company had a very late pivot in the accelerator program. We did some research in Samoa, and our findings in New Zealand and the Pacific islands didn't line up with our ideas 
and what we wanted to do. We would just have been another company in the mix and not a disruptor." (Co-Founder, Moa)

Nevertheless, the founders were keen to continue their explorative efforts to drive the development of a future business model.

"Moa is starting as a new venture all over again. We need to figure out what we want to do, and what problems we want to solve." (Co-Founder, Moa)

Moa undertook extensive explorative efforts, yet decided to cease the development of VCC mechanisms due to incongruencies of assumptions and validation about customer value co-creation. 


\subsection{Case Report - Venture Pouakai}

\subsubsection{Introduction}

Pouakai aimed for the development of a platform that allowed SME owners to manage insurances in one convenient place. While early cash-flows and the engagement of a venture capitalist provided a proxy for robust VCC mechanisms, the venture ceased BM development activities in stage three. Despite initial successes, the venture failed to raise sufficient funds for the development its envisioned platform.

\subsubsection{Development of Customer Value Co-Creation Mechanisms}

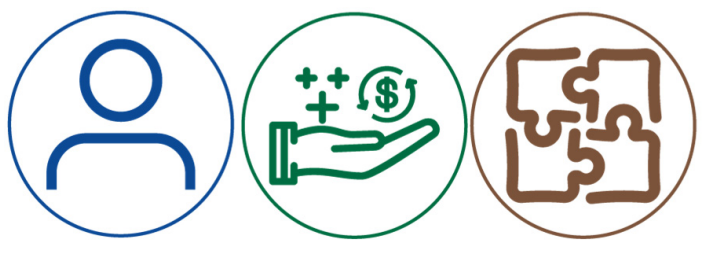

Pouakai co-created value with small and midsized business owners by assessing and monitoring their risks and providing comprehensive insurance policies. The

platform the venture intended to develop proposed customers a selected set of policies and a convenient portal to manage them.

"The insurance business is still dominated by paper forms, time-consuming phone and faceto-face conversations, and slow processes. We want to cater for the tech-savvy generation that is coming through now and demands good quality service, streamlined process, and a convenient platform that allows business owners to manage all their insurances in one place. We are planning to work with different insurers to provide customer selected policies that provide cover." (Co-Founder, Pouakai)

The extent of individual advice on business insurance policies that can be proposed based on machine processed information was limited by regulations Consequently, Pouakai provided only class advice for business insurances in the early stages of development.

"Providing class advice based on generic data such as industry or sector is perfectly fine. However, providing individual advice requires at least a qualified advisor to take a look and confirm the proposed policies." (Co-Founder, Pouakai)

However, as qualified insurance advisors, Pouakai provided advice on private 
insurances, e.g. life insurances for SME owners.

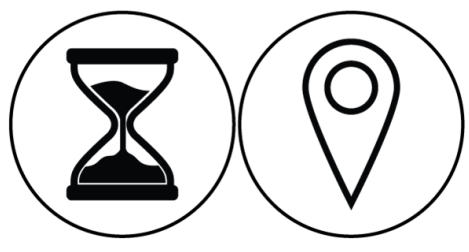

Pouakai's customer value co-creation mechanisms were characterised by the temporal relevance of insurance policies for SMEs and their development over time. The continuous assessment of risks and the adjustment of required policies were at the heart of Pouakai's customer value co-creation mechanisms. Moreover, the venture's platform intended to render face-to-face meetings with insurance agents or brokers obsolete $\circledast$. Finally, Pouakai's customer value co-creation mechanisms were limited by regulations to the domestic market.

\subsubsection{Development of Actor Value Co-Creation Mechanisms}

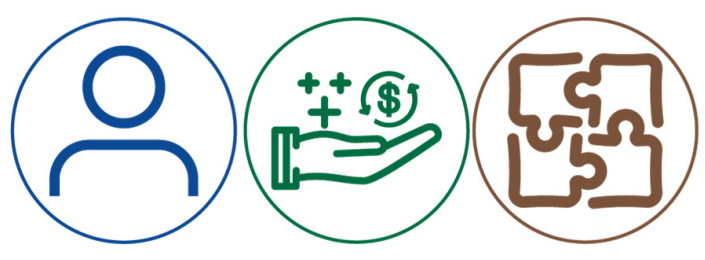

Pouakai co-created value for a partnering insurance broker by generating sales leads and coordinating the conversation and fulfilment with them

"We generate sales leads for them. The broker benefits by receiving the lion's share of the commission and fees for the fulfilment." (Co-Founder, Pouakai)

Pouakai intended to co-create value with insurances by providing information on customers underpinning the underwriting process and in turn obtain favourable pricing 8 .

\footnotetext{
"We are working with two large insurance groups and want to onboard others. At the moment we are just selling their policies, but we want to create value for them by streamlining and automating data collection and processing. By adding value we might be able to negotiate better prices." (Co-Founder, Pouakai)
}

While Pouakai cooperated with the insurance broker almost from the beginning onwards, the venture did not engage directly with any insurance companies for the fulfilment of business policies throughout the study $\&$. 


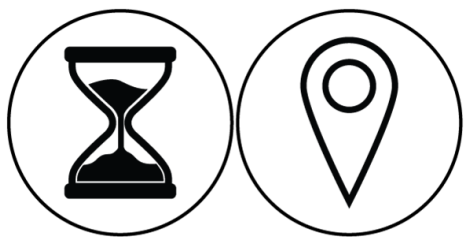

Pouakai's continuous assessment of customers' business risk and information sharing would have benefited brokers and insurers. Adequate risk assessment underpinned the adjustments of insurance premiums and thus customer retention and/or risk management of insurers and brokers.

\subsubsection{Development of Value Capture Mechanisms}

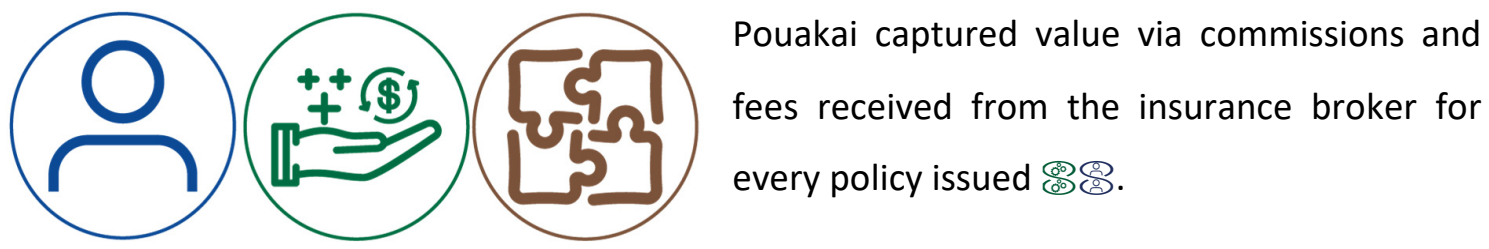

"On the one hand we are making money by receiving commissions and fees from insurers. We capture value by taking [XX]\% of the fees and commission for every insurance policy issued with our partnering broker. We are selling life insurances to our customers and get the full commission and fees from that." (Co-Founder, Pouakai)

Pouakai planned to introduce subscription fees for the platform provided.

On the other hand, we can charge our customers. However, we need to be transparent about the process and how much value we capture, that came through in our customer research" (Co-Founder, Pouakai)

Pouakai generated sufficient revenues to sustain a basic service to customers via selling business and individual insurance in the first stage of the study.

"We already have a viable business model and make money by selling insurance policies. We generate enough revenues to pay the bills but it is not enough the develop the platform and grow a customer base." (Co-Founder, Pouakai)

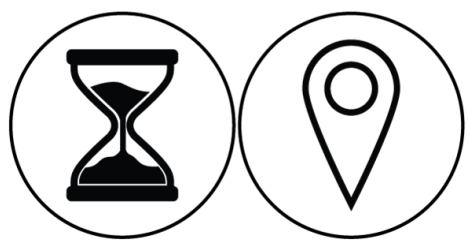

Pouakai received annual premiums for continuing policies and renewals from insurers. Moreover, the planned subscription fee for the platform, paid by customers every month, represented a second temporal aspect of Pouakai's value capture mechanisms. Finally, the venture's value capture mechanisms were not characterised 
by any spatial limitations.

\subsubsection{Summary Value Co-Creation and Capture Mechanisms}

Pouakai's VCC mechanisms evolved in the first stage of the study. While facilitating the fulfilment of policies via an insurance broker was only a temporal solution, the cooperation was characterising for VCC mechanisms of Pouakai in early stages of the study. Intentions to develop an online platform and charge customers subscription fees and developing direct and close relationships with insurers underpinned the development of the venture's BM in the second stage of the study.

\subsubsection{Development of Activity Links, Resource Ties, and Actor Bonds}

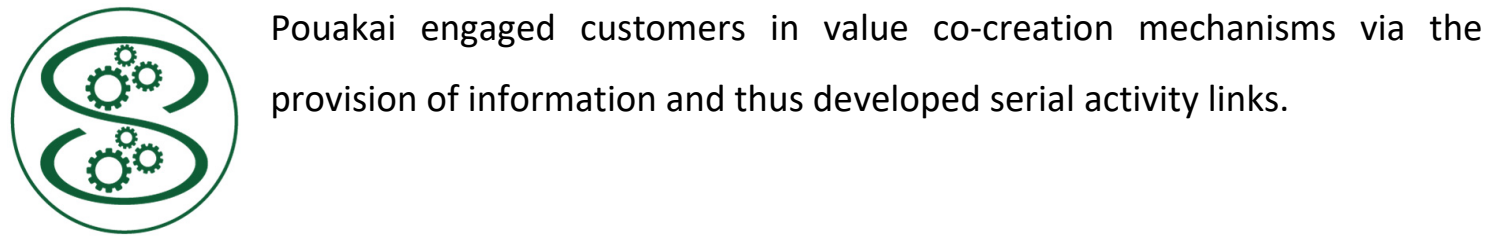

\footnotetext{
"Customers provide information about their profession, industry, and type of business. Based on that we assess risks and propose insurance policies to consider" (Co-Founder, Pouakai)
}

In a similar vein, Pouakai developed dyadic activity links with a partnering insurance broker to facilitate the fulfilment of business insurance policies 8 .

\footnotetext{
"We partner with [insurance broker] to facilitate the selection and offering of policies to small and mid-sized business owners. They are doing all the fulfilment like providing advice for customers, quotes, payments, invoicing. It is not ideal and only a temporary solution but good to get some revenues on the door until we can automate the process, hire staff, and manage workload" (Co-Founder, Pouakai)
}

In short, Pouakai developed serial and dyadic activity links with other actors to underpin VCC mechanisms. 


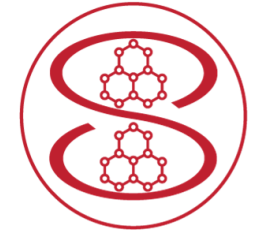

Pouakai developed physical and organisational resource ties. Significant for VCC mechanisms were the integration of APIs with NZBN and other sources of data that informed the risk assessment of customers' business activities.

\begin{abstract}
"Integrating with NZBN allows us to gather data about our customers' business from public records for an initial risk assessment. Also, integrating bookkeeping and other software packages can inform us about developments of customers' business, their need for risk cover, and in turn a change in policies. The data informs a continuous risk assessment process and can provide better cover for our customers" (Co-Founder, Pouakai)
\end{abstract}

Whereas having developed an integration with NZBN, the venture intended to further expand its engagement with other actors' resource collections.

\begin{abstract}
“We are currently integrating with NZBN's API to download all the data for our customers. Moreover, we want to integrate APIs that large insurance companies are developing at the moment. This allows us to provide data about customers to the insurer and thus streamlines the underwriting process to get policies in place" (Co-Founder, Pouakai)
\end{abstract}

Pouakai leveraged AWS in the development of its online platform and thus developed resource ties with a cloud infrastructure provider.

\footnotetext{
"We are using Amazon Web Services and thus have to adjust our stack to some extent to their platform" (Co-Founder, Pouakai)
}

Overall, Pouakai developed physical resource ties, i.e. API integration and a platform based on could infrastructure as well as organisational resource ties, i.e. standardised processes with an insurance broker over the period of the study.

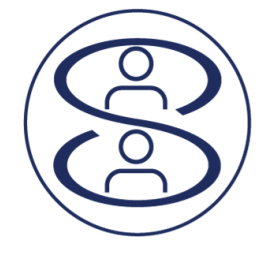

Pouakai developed actor bonds with a partnering insurance broker, a venture capitalist, and regulatory authorities. Despite only a temporary arrangement, the actor bond developed with the partnering insurance broker was crucial for VCC mechanisms and positioned the venture in the ecosystem.

"We have a memorandum of understanding with our broker. They are getting the lions-share for converting the sales lead we are generating and their fulfilment but the customers remain ours. It's not ideal since we have to introduce them to our customers but that is currently the only way how we can sell insurance products to businesses" (Co-Founder, Pouakai)

Moreover, Pouakai engaged with the financial market authorities to ensure 
compliance and gain legitimacy as a provider of insurance advice services. In addition, the development of machine guided risk assessments, as intended on Pouakai's platform, required new regulations that the venture aimed to influence in its favour.

\footnotetext{
"Automating the process of risk assessment and policy advice based on data gathered from customers and other sources pushes the legal boundaries. We will have to consult with authorities on what we can and can't do. We found a partner that can provide legal advice on that. She was on the insurance leadership team of the Financial Market Authority and we consulted with her on several issues" (Co-Founder, Pouakai)
}

Finally, Pouakai created actor bonds with a venture capitalist willing to provide funds and other resources for the development of the venture's platform.

\begin{abstract}
"we have married ourselves to one venture capitalist that is interested in providing funding and talent that we need to develop the platform. We had long discussions and they were keen to invest and come onboard, yet nothing happened. In the meantime, our partnering insurance broker has mentioned an interest to invest" (Co-Founder, Pouakai)
\end{abstract}

In conclusion, Pouakai created bonds with several actors to gain a foothold in the ecosystem, legitimise the venture with authorities, and obtain access to pivotal funding and talent for the development of the platform.

\title{
4.11.7. Summary Pouakai
}

Overall, Pouakai developed VCC mechanisms in coordination with a partnering insurance broker, insurers, a venture capitalist, and regulatory authorities. While revenues were already generated in early stages of the venture, the reluctance of the engaged venture capitalist to provide seed funding required the exploration of alternative sources of funding.

\footnotetext{
"We will have to raise $[X X X K]$ to develop our platform. Our venture capitalist is hesitating to negotiate a deal with us and we are hamstrung by the shortage of funding. We don't have enough money to move forward and will try to raise funds via other partners. The data set we are building about business owners can open other opportunities such as lending, health, and superannuation schemes in cooperation with other partners that can provide funding for our business" (Co-Founder, Pouakai)
}

Despite Pouakai's early positive cash flow, engagement with reputable partners in the insurance industry, and regulatory compliance, the venture failed to raise sufficient funds to 
develop the intended platform and automate the risk assessment process for small- and midsized business owners and ceased the development of the BM in the third stage of the study.

"The last couple of months have been a little bit of a tough time and we can't see the light at the end of the tunnel" (Co-Founder, Pouakai)

\subsection{Chapter Summary}

This chapter presented ten ventures that were contextualised in the VARA-model. Each case synthesised the data collected in order to answer the research questions on how VCC mechanisms and their underpinning activity links, resource ties, and actor bonds were developed over time. The presented BM configurations were chosen because they presented some of the most salient ventures data was collected and analysed on. The next chapter will discuss the findings in the context of the VCC mechanisms and BM development process. 


\section{Discussion}

\subsection{Inter-Case Comparison Business Model Development}

Analysing and comparing the cases revealed two characterising attributes for the development process of firm-ecosystem fits. First, ventures' foci varied when exploring value propositions and developing VCC mechanisms, as illustrated in the value-exploration matrix (Figure 67). Second, activity links, resource ties, and actor bonds were heterogeneously developed across ventures, as displayed in the integration-exploration matrix (Figure 68). Both matrices were combined in Figure 66 to elicit the development of ventures' firmecosystem fit and cluster development trajectories. While Figure 66's degree of integration refers to ventures' range of interactions with customers and other actors, the degree of exploration is described by ventures' efforts undertaken to engage customers and ecosystem actors in interactions via different means. Across all firm-ecosystem fit development trajectories, three strategies surfaced (Focused, Diversified, and Opportunistic) and will be compared and discussed in greater detail in the following sections. 


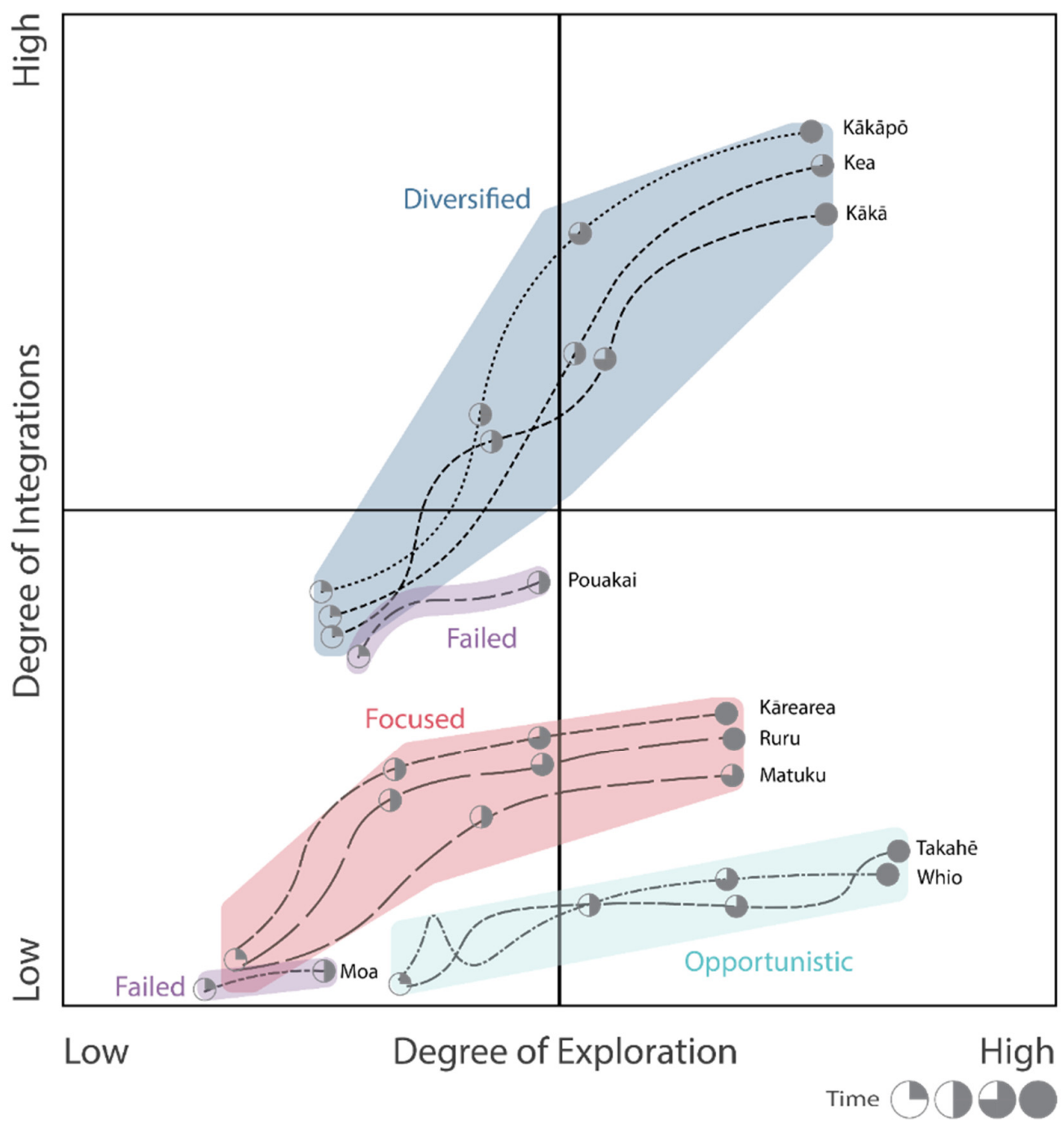

Figure 66 - Case Clustering - Ventures' Development Trajectories 


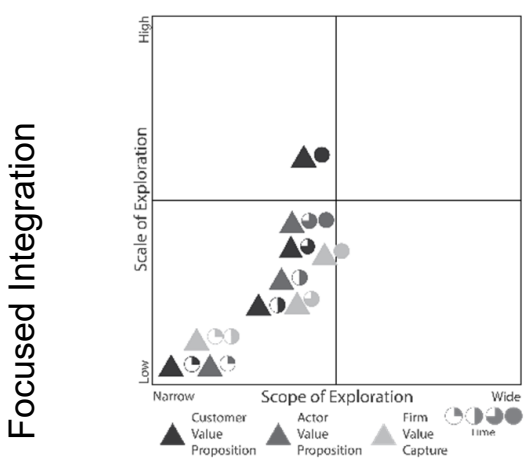

Kārearea

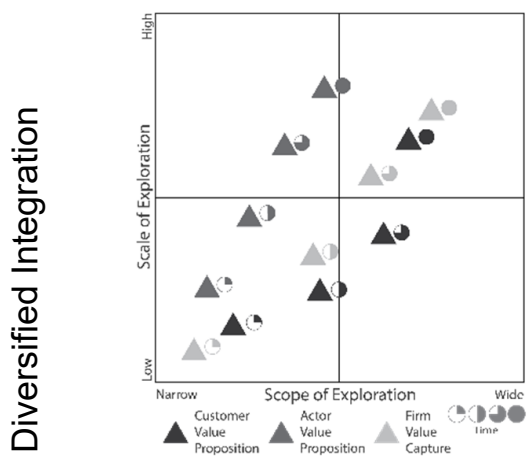

Kākāpō

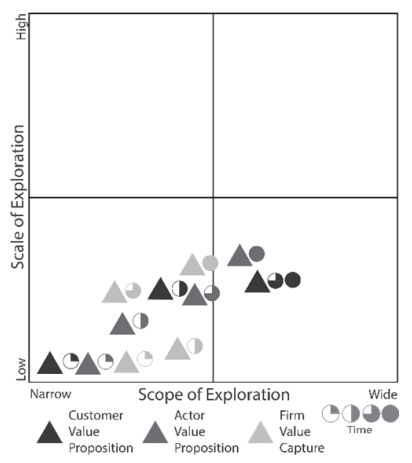

Takahē

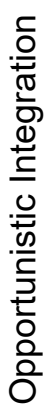

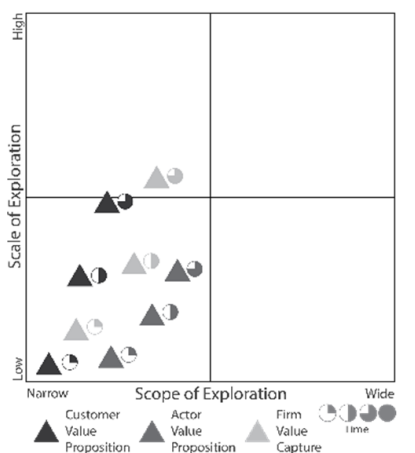

Matuku

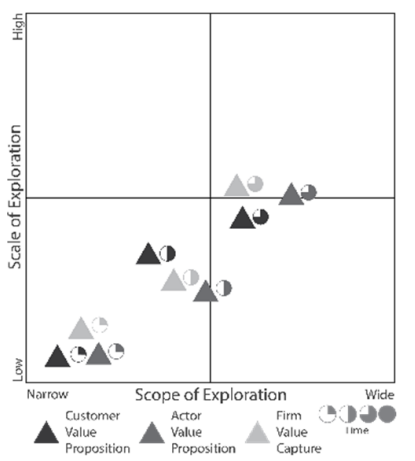

Kea

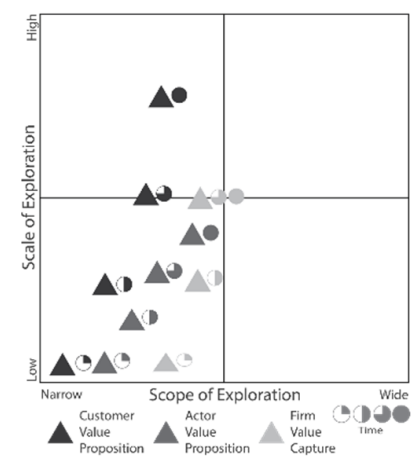

Ruru

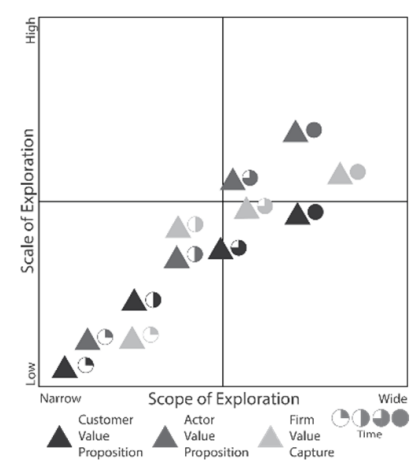

Kākā

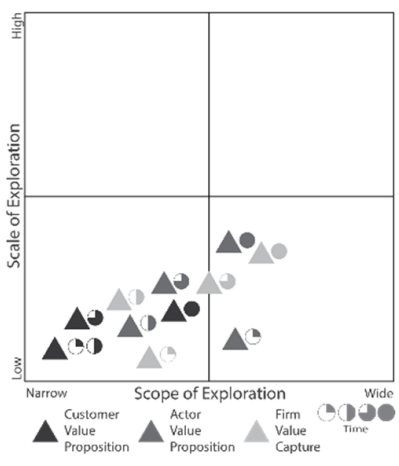

Whio

Figure 67 - Case Comparison VCC Mechanisms Development 


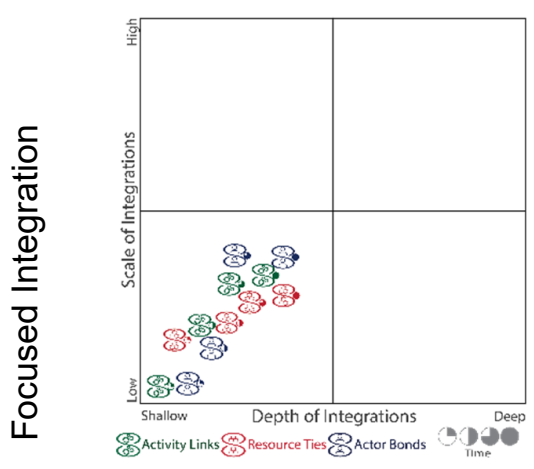

Kārearea

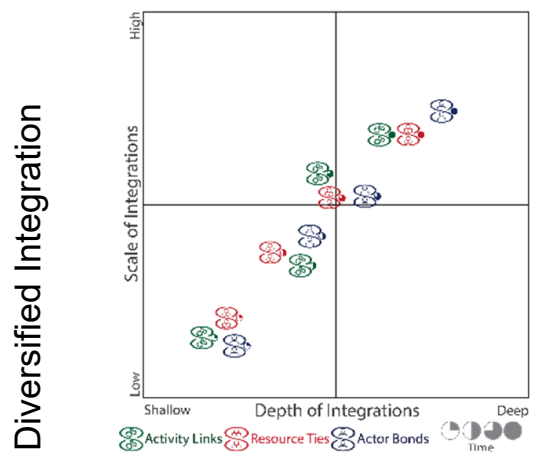

Kākāpō

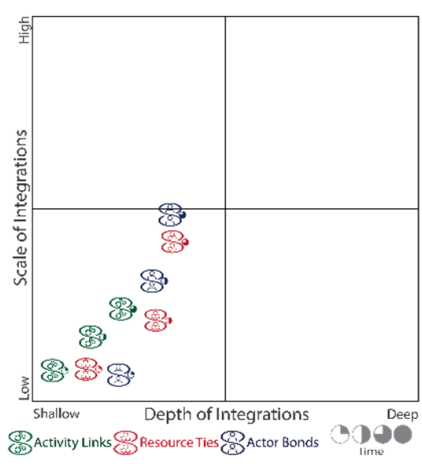

Matuku

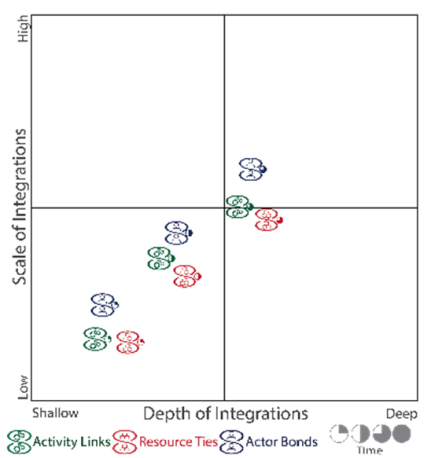

Kea

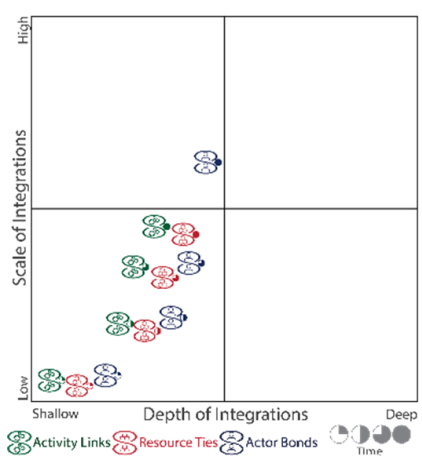

Ruru

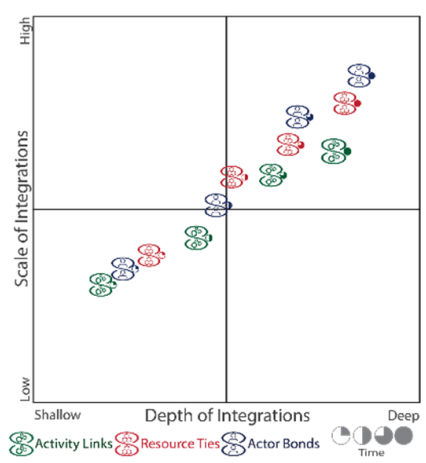

Kākā

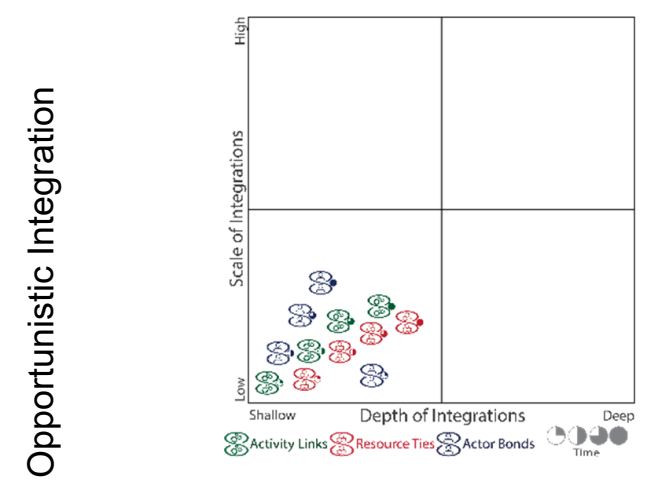

Takahē

Figure 68 - Case Comparison Integration Development 


\subsection{Business Model Development Strategies}

\subsubsection{Focused Integration Strategy}

The first approach can be referred to as focused integration (FI) strategy (Figure 66 red trajectory). Focusing on intensifying integration with small sets of actors and diversifying customer segments characterises the development of an effective firm-ecosystem fit via this strategy. Leveraging incrementally refined offerings to serve additional customer segments fuels growth in the Fl-strategy. In contrast, only few offerings are developed for actors to enhance value co-creation mechanisms. Fl-ventures capture pecuniary and non-pecuniary value from the growing number of customer segments and small and often constant sets of actors.

Adjusting internal activities, resources, and organisational structures to conform with existing ecosystem arrangements underpins FI-ventures' VCC mechanism development. Adaptations of internal activities present an opportunity to rapidly develop integrations with other actors and in turn allow for operational activity structures. Similarly, altering internal resources enables $\mathrm{FI}$-ventures to quickly progress resource ties and capitalise on external resources. In advanced development stages, intensified actor bonds often facilitate mutual development and fine-tuning of activities and resources in cooperation with others to streamline processes, reduce coordination efforts, and enhance mutual benefits. In brief, the Fl-strategy relies on low degrees of integrations that are slowly increased via explorative efforts to refine VCC mechanisms.

\subsubsection{Diversified Integration Strategy}

The diversified integration (DI) strategy (Figure 66 blue trajectory) is characterised by multiple mutually developed integrations with a wide range of actors from early stages onwards. DI-ventures augment value co-creation by developing new offerings for an increasing number of actors and enhancing existing offerings for one or two 'evangelical' customer segments via new features. Opportunities to capture pecuniary and non-pecuniary value from customers and various actors are commonly explored in DI-strategies.

Developing growing arrays of activity links, resource ties, and actor bonds underpins 
the evolution of VCC mechanisms and in turn a firm-ecosystem fit of DI-ventures. While creating new integrations as well as fine-tuning existing ones is crucial, the former enhances the firm-ecosystem fit in the DI-strategy. Relying on growing numbers of integrations requires increasing coordination across the ecosystem to sustain coherence in VCC mechanisms. However, co-developing integrations with multiple actors allows to shape the ecosystems in ventures' favour. In short, exploring VCC opportunities with large sets of actors and developing bespoke integrations with them characterises DI-ventures' development strategy next to focusing on one or two customer segments.

\subsubsection{Opportunistic Integration Strategy}

Fl- and DI-strategies can be contrasted with other ventures' volatile explorations in the BM development process. The opportunistic integration (OI) strategy (Figure 66 green trajectory) is characterised by timeserving integrations, extensive refinements of VCC mechanisms, and slowly emerging firm-ecosystem fits. Although developing activity links, resource ties, and actor bonds in early stages, low to moderate actor engagement indicates incongruencies in VCC mechanisms. Extensive refinements of value propositions highlight OIventures' explorative and iterative approaches to co-create value with customers and actors. Additionally, limited success to raise funds and attract growing numbers of customers provided another proxy for an inconsistent firm-ecosystem fit. Despite Ol-ventures' often resource- and time-intense refinements, none of them failed within a year after the last interview.

In contrast, Moa and Pouakai (Figure 66 purple trajectories) only integrated with ecosystem actors to a limited degree and failed to develop viable VCC mechanisms. Moa's significant pivot, based on a shift in understanding customer value, can be considered as the reason it halted further explorations. In comparison, Pouakai's BM development was hamstrung by its limited success in raising funding despite the venture's early engagement with a venture capitalist. While ventures' mortality can have multiple causes, Moa's and Pouakai's demise was reinforced by a limited coherence of VCC mechanisms, the absence of effective integrations in their respective ecosystem, and therefore a lack of firm-ecosystem fit. 


\subsection{Value Co-Creation and Capture Mechanisms}

Understanding the BM development process requires to contextualise VCC mechanisms (D. Mitchell \& Coles, 2003; Sosna et al., 2010; Fjeldstad \& Snow, 2018). The proposed value proposition framework (Figure 11, p. 44) and value-exploration matrix (Figure 13, p. 47) made it possible to surface developments across value proposition dimensions (who, what, how, when, and where) and evolutionary patterns of VCC mechanisms. The following sections outline how and by what means ventures developed VCC mechanisms.

\subsubsection{Development of Customer Value Co-Creation Mechanisms}

The purpose of a business is "to create a customer" (Drucker, 1954, p. 36) and what customers consider value is decisive and defines whether a business will prosper. In a similar vein, Priem et al. (2018) referred to value creation for customers as the conditio sine qua non ${ }^{19}$ for value capture and emphasised its importance for BM development. Since market and technology uncertainties make customer value propositions unforeseeable, they need to be conceptualised, explored, and refined in an iterative process (Chesbrough \& Rosenbloom, 2002; Sosna et al., 2010; Teece, 2010). Analysing ventures' fine-tuning of value proposition dimensions towards a coherent customer value proposition facilitated an understanding of how customer value co-creation mechanisms developed.

\subsubsection{Who: Identifying Customer Segments}

Drucker (1954) considered the questions of "Who is the customer? - the actual customer and the potential customer? Where is he? How does he buy? How can he be reached?" (p. 52) as paramount for successfully developing BMs (Magretta, 2002; Fjeldstad \& Snow, 2018). Defining initial customer segments was pivotal for exploring what, how, when, and where value can be co-created in an efficient manner. From early stages onwards FI-

19 Latin: Indispensable condition 
ventures extended customer segments by catalysing demographics, lifestyles, and other attributes into groups, unified by a common problem (M. Johnson et al., 2008; Christensen, Hall, Dillon, \& Duncan, 2016). Whereas customer segment diversification has been widely regarded as a growth strategy of incumbents (e.g. Fjeldstad \& Snow, 2018; Teece, 2018), it has hardly been discussed in the context of ventures. As evident in the findings, customer segment diversification can be an efficient approach to enhance customer value co-creation when minor refinements of offerings allow to cater for the needs of additional target segments.

In contrast, DI-ventures focused on one or two interrelated customer segments. Extending offerings to serve different needs of 'evangelical customer segments' highlights the narrow focus. The findings align with Björkdahl (2009) who provided evidence that focusing on one customer segment can be successful when the additional value co-created can be appropriated. However, the absence of a large customer or installed asset base (Storbacka, 2011; Velamuri, Bansemir, Neyer, \& Möslein, 2013) makes the development of new features counterintuitive to enhance value co-creation. Nevertheless, DI-ventures maintain a single or double customer focus but segment offerings and underpinning pricing structures to enhance value capture mechanisms ${ }^{20}$.

Finally, Ol-ventures hardly specified customer segments in stage one but extensively re-fined them. Shifts in customer segmentation, as evident in Takahē, have several ramifications for the development of offerings. In a similar vein, Moa and Pouakai (failed ventures) defined their customer segments generically as 'Pacific Islanders living in New Zealand' and 'tech-savvy small business owners'. While Ol-ventures revamped customer segments over time, failed ventures had limited opportunities to do so and to develop effective offerings. The findings stressed Teece's (2010) argument that ventures have to validate assumptions about customers in early development stages. The often extensive explorative efforts $\mathrm{Ol}$ - and failed ventures undertook to discover their customer segments imply that defining customer segments to a high degree, even if only preliminary, is crucial to develop effective customer value propositions in a resource and time efficient manner.

To sum up, $\mathrm{FI}$ - and DI-ventures precisely defined customer segments early in the BM

${ }^{20}$ Refinements of pricing structures are discussed in greater detail in chapter 5.3.3, p. 282 
development process and continuously extended or refined them. While FI-ventures' customer diversification represented a stark contrast to DI-ventures' single or double customer segment focus, both approaches provided a foundation for the development of robust customer value co-creation mechanisms. In comparison, the extensive refinement of Ol-ventures' customer segments hampered the development of effective customer value propositions. Across ventures' strategies, identifying preliminary customer segments and enhancing one's understanding of what, how, where, and when value can be co-created with them seems to be vital for developing a first viable customer value proposition.

The findings align with the widely accepted notion that defining customer segments will affect the development of offerings and thus underpinning BMs (Hedman \& Kalling, 2002; Morris et al., 2005). The sequence of defining customer segments or offerings is often attributed to differences in demand-pull or technology-push approaches (Chesbrough, 2007a; Priem et al., 2012). However, a preliminary definition of customer segments seems to be beneficial in both cases (Mahadevan, 2004; Zott \& Amit, 2010).

Customer segmentation can be considered as part of the development process to create a customer-value fit (Zott \& Amit, 2008). The definition of preliminary customer segments focuses firms' explorative efforts towards potential value co-creation opportunities. Since customers often have difficulties in articulating their needs, interests, or problems (Von Hippel, 1994; Ardichvili, Cardozo, \& Ray, 2003), ventures have to engage with specific target segments to successfully conceptualise, explore, and refine potential offerings. As emphasised by Magretta (2002), "a good business model begins with an insight into human motivation and ends in a rich stream of profits" (p. 86).

Overall, defining preliminary yet precise customer segments is crucial since it (a) provides direction for exploring customers' needs and thus value co-creation opportunities (FI- and DI-ventures), (b) drives pivotal target segment refinements (Ol-ventures), and, in turn, (c) informs the development of offerings. Amit and Zott (2015) as well as Bojovic et al. (2018) illustrated that BM design starts by identifying key customers, their needs, and how VCC is balanced across customers and actors in BM development. The importance of considering different levels of commitment with key customers in the BM development process has been stressed in part by Brettel et al. (2012). Consequently, defining and refining customer segments as well as exploring ranges of potential engagements can be stylised as a 
critical capability ventures have to develop in early BM development stages to create effective customer value propositions. The findings here provide robust support for Teece's (2018) argument that "identifying the customer segment(s) to focus on first in order to learn and achieve proof of concept and business model viability is a critical capability" (p. 48). However, ventures' customer segment diversification (FI-ventures) or customer segment focus (DIventures) in the BM development process provide novel insights into how different customer segmentation approaches can enhance customer value co-creation and augment growth.

\subsubsection{What: Translating Customers' Needs into Value}

Drucker (1954) highlighted that the most challenging questions are "what does the customer consider value? What does he look for when he buys the product?" (p. 54). While in traditional strategy theory value is often limited to differentiation or cost-leadership (Afuah \& Tucci, 2001; Priem et al., 2012), BM literature emphasises the importance of understanding customers' needs and problems (e.g. Klang et al., 2014; Wirtz et al., 2016; Massa et al., 2017).

While widely acknowledged across the marketing literature (Zeithaml, 1988; B. Smith \& Colgate, 2007; Greer et al., 2016), the BM literature commonly subsumes customer value as a solution to a need and rarely differentiates between functional, hedonic, symbolic, or other aspects of those needs (M. W. Johnson, 2010; Teece, 2018). Although the often embraced functional value, i.e. solving customers' problems, provides essential insights into the development of offerings (Osterwalder \& Pigneur, 2010), hedonic and/or symbolic value were considered vital for customers' value co-creation. In line with Chesbrough and Rosenbloom (2002), Teece (2010) criticised the prevailing assumptions of economists that "customers will buy if the price is less than the utility yielded"(p. 175) and emphasised that developing appealing solutions requires an in-depth knowledge of customers' perceived multivalent needs and the different performance dimensions offerings require to fulfil.

Ventures' development of customer value propositions draws attention to the different types of value co-created with customers. Offerings were conceptualised and refined to engage customers and enhance the co-creation of functional, hedonic, and symbolic value. The multivalent nature of value co-creation was immanent in customer value proposition development from early stages onwards. However, experimental interactions 
that enhanced ventures' understanding of what customers considered valuable significantly informed the development of offerings to augment hedonic and symbolic next to functional value. For instance, Whio co-created functional value by providing long-lasting surfboards. Nevertheless, the hedonic value of surfboard shaping workshops as well as the symbolic value of having a surfboard made from sustainable and recycled material was paramount for the evolution of Whio's offering. As evident in this example, even apparent functional value (longlasting surfboards) might not translate directly into product features (surfboards made from sustainable and recycled material).

Moreover, production and/or service features might fail to grasp the nature of the value co-created for customers. To revise Theodore Levitt's drill example, customers might not want to have a hole in the wall (functional value of a drill) but rather the ability to drill a hole in a wall (capability) when needed. In a similar vein, Kārearea argued that value is cocreated by providing customers with the ability to 'ride the highs and lows of the market'. Likewise, Kea emphasised that accountants' 'capability to provide services to their clients' is crucial for value co-creation.

Ventures' capability to identify customers' needs and translate them into different value dimensions is crucial for creating a customer-value fit. In contrast to popular product and service design tools, such as the house-of-quality, translating customer needs directly into product or service features might fail to provide conclusive answers to what is of value to customers beyond purely functional aspects (Webb, Ireland, Hitt, Kistruck, \& Tihanyi, 2011). Demil et al. (2015) emphasised that how ventures understand customer needs is paramount for the form of their engagement in value co-creation. In a similar vein, Hedman and Kalling (2002) highlighted the importance of addressing and managing customers' different value perceptions.

Difficulties to adequately translate customer needs into different value types and address them via offerings was highlighted in the refinements of Ol-ventures' customer value propositions. In a similar vein, failed ventures' customer value co-creation was often limited to functional convenience. In short, customers' perceived needs can be multivalent, difficult to articulate (Von Hippel, 1994; Von Hippel \& Von Krogh, 2013), and need to be elicited via explorative interactions.

To sum up, effectively addressing customers' needs requires ventures to translate 
them into different latent value types and incorporate them in the offering development process. Whereas the importance of delivering value to customers is stressed throughout the literature (McGrath, 2010; Teece, 2018), what is of value to customers and how ventures manage that value has hardly been discussed. Following recent calls for a more customerintimate focus on BM development (e.g. Priem et al., 2018), the findings draw attention to the multivalent nature of value co-created with customers and how offerings can enhance heterogenous value types. In contrast to the literature, the investigated customer value proposition development process stressed the importance of hedonic and symbolic next to functional value for customer value co-creation over time. As a result, ventures should consider multiple value types when developing offerings and managing customers' value experiences via different offering features.

\subsubsection{How: Experimenting with Offerings}

Offerings have to specify "the nature of the product/service mix, the firm's role in production or service delivery, and how the offering is made available to customers" (Morris et al., 2005, p. 729). Therefore, the development of offerings and how customers are engaged in value co-creation mechanisms is central to the customer value proposition development process. While all ventures refined offerings, the focus in the process varied. Fl-ventures incrementally added features and/or emphasised different value aspects of existing offerings to serve additional customer segments. For instance, Kārearea created a visually appealing interface for children that was based on the existing platform and its functionalities to attract them as additional customer segment. This finding corroborates the argument that firms can leverage existing resource collections when developing additional customer value propositions. In contrast to Demil and Lecocq's (2010) findings, FI-ventures primarily developed new offerings for customer groups rather than other actors until the final stages. Thus, the findings highlight the narrow bandwidth of FI-ventures' approach to enhance VCC mechanisms, i.e. focused on customers.

In comparison, DI-ventures often tailored their offerings to co-create value with one

or two customer segments. For instance, Kākāpō specifically developed offerings and enhanced them via new features for bookkeepers and accountants. Developing 
comprehensive solutions for specific customer segments has been amply discussed in literature (Hedman \& Kalling, 2002, p. 117; Morris et al., 2005; Bojovic et al., 2018). For instance, Chesbrough (2006) explained Dell's success via the extensive hardware and software management offering, i.e. IT infrastructure-as-a-service for large corporations (p. 127). In a similar vein, Storbacka et al. (2013) discussed the bundling of products, services, systems, and knowledge as a strategy to create holistic solutions. The findings of DI-ventures' offering development process draw attention particularly to the bundling of networks and systems to enhance offerings. Combining systems and their functionalities, e.g. seamless integration of software packages, provided more value than the sum of their parts. Simultaneously, DI-ventures introduced feature-based and flexible pricing plans and progressed the unbundling of offerings. Combining multiple systems' functionalities, paradoxically, required an increasingly fine-grained segmentation of offerings to allow for customers' heterogeneous use. In comparison to Björkdahl's (2009) findings on systems integration and in contrast to Storbacka et al.'s (2013) argument against unbundling, DIventures' fragmentation of offerings emphasised the opportunity to growth by catering for heterogenous needs of homogenous customer segments. The findings imply that tensions arise from the bundling of offerings, as often promulgated in servitisation (Coreynen, Matthyssens, \& Van Bockhaven, 2017), and customers' idiosyncratic use needs to be balanced in the offering development process.

Finally, Ol-ventures significantly refined their offerings throughout the study. For instance, Takahē moved on from offering custom-made balance boards and challenging games for athletes to providing gamifying exercises for elderly patients and therapy management software for physiotherapists. Similarly, Whio re-focused its offering to surfboard-shaping workshops and thus changed the set-up of its workshop to accommodate them. In contrast, Moa and Pouakai provided limited evidence of offering refinements. The findings align with Weill and Vitale (2001) who argued that "firms learn what constitutes a compelling value proposition through constant experiments and feedback" (p. 1). OIventures' extensive offering development process can be partially explained by shifts in customer segmentation as well as discontinuous explorative efforts to enhance one's understanding of what customers value.

As evident in the findings, ventures engaged in the process of developing and refining 
offerings to either create product and/or service combinations for new customer segments or enhance the value co-created for existing customers. In FI- and DI-ventures the process was informed by explorative and experimental interactions. The findings are congruent with Chesbrough's (2007b) argument that firms need to experiment with different offerings without risking any damage to their reputation. Since especially in the early development stage ventures' legitimacy ${ }^{21}$ is fragile (Fisher, Kotha, \& Lahiri, 2016), balancing experimentation and broadcasting associated signals is required to carefully manage customers' perception of the offerings and ventures.

FI-ventures continuously tested offerings with existing and new customer segments. For instance, Kārearea tested different investment products with customers before introducing them on the platform. The findings align with Teece's (2010) argument that offerings, like hypotheses, are subject to tests and need to be modified or even rejected when facing a lack of support. In contrast to previous findings (Saebi et al., 2017), FI-ventures' development of new offerings was independent of external discontinuities and disruptions but was rather proactively progressed. Moreover, the findings suggest that continuously testing and refining product and/or service combinations allowed Fl-ventures to rapidly deploy novel offerings across several customer segments in a resource-lean manner.

In contrast, DI-ventures co-developed features with customers to enhance value cocreation. Kea, for example, collaborated with several large accountancy practices to codevelop features catering for their needs to service corporate clients. As a result, the findings provide evidence for Baden-Fuller and Haefliger's (2013) proposition that greater customer engagement in offering development can increase value co-creation for both sides. Moreover, the findings draw attention to the intricacies of selecting customers and manage co-development efforts. Although co-development allowed to draw upon external knowledge and resources in the process, DI-ventures had to balance customers' idiosyncrasies with the applicability of offerings for other customers. As such, the co-development of offerings transcended customer tool-kit enabled configurations of product and/or service combinations (e.g. Franke \& Hader, 2014) and provided insights into how it can affect the evolution of VCC mechanisms, e.g. bundling and fragmentation of offerings.

\footnotetext{
${ }^{21}$ While reputation is based on firms' retrospective performance (Bitektine, 2011), the term legitimacy was used to reflect the prospective nature of ventures' performance (Fisher et al., 2017).
} 
Explorative and experimental testing or co-development of offerings was central to co-creating value with customers and thus the development of effective VCC mechanisms. While the importance of experimentation for the development of offerings has been emphasised in the literature (Sosna et al., 2010; Cavalcante et al., 2011), Bojovic et al. (2018) only recently elicited the process by distinguishing between purposeful interactions and experimental projects. In contrast to Bojovic et al. (2018), the prevalence of testing or codeveloping offerings across different ventures implies that aligning experimentation modes with other aspects of customer value proposition development appears crucial.

Moreover, successful experimentation was characterised by ventures' capabilities to (a) design experiments and (b) draw conclusions. Experiments need to allow for intelligent failures' that inform ventures' decisions to retain or discard offerings (Weill \& Vitale, 2001; Velu, 2017). FI- and DI-ventures engaged in a continuous process of explorative experimentation and provided evidence for the development of analytical skills. Accurately assessing the outcomes of experiments and advancing one's understanding of how customers use features was vital for successful explorative experimentation. In contrast, OI- or failed ventures often advanced their understanding of the environment via trial-and-error experiments. While even poorly designed and/or failed experiments yield valuable information, the iterative as well as time- and resource-intense process might provide limited direction, can send confusing signals to customers, and therefore reduces ventures' chances of developing effective offerings. Moreover, explorative experimentation often requires resource redundancies (Velu, 2017) that can stall the BM development process.

Overall, explorative experimentation underpins the successful development of offerings. Central for the process were ventures' experimentation capabilities, i.e. the design of experiments and analytical skills. While FI- and DI-ventures developed heterogenous sets of experimentation capabilities (testing vs co-development), OI-ventures often had difficulties to continously conduct intelligent experiments and/or draw viable conclusions. Ventures' experimentation capabilities underpin the rapid development of offerings accepted by customers and free-up resources for BM development. Although the importance of experimentation has been stressed in literature (e.g. Cortimiglia et al., 2016) structured approaches are rare (e.g. Bojovic et al., 2018). Explorative experimentation, as evident in the findings, transcends initial stages and continuously informs the development and refinement 
of offerings. Additionally, ventures' focus on either testing or co-development implies that heterogenous experimental capabilities can support the development of effective offerings and the evolution of robust VCC mechanisms. Ventures' experimental capabilities have to align with other customer value proposition development capabilities (identifying customers, translating needs) to enhance customer value co-creation. However, combining different explorative experimental capabilities can yield additional insights for the development of offerings.

\subsubsection{When \& Where: Customers' Use-Contexts}

Despite the growing importance of service-focused customer value propositions, i.e. servitisation, and inherent changes in temporal and spatial contexts across multiple sectors, the topic enjoys limited attention in scholarly discussions (Demil \& Lecocq, 2015; Foss \& Saebi, 2018). Understanding when and where customers segments use offerings to co-create value was crucial for their development and refinement. For instance, rendering spatial disparities between ventures, customers, and other beneficiaries obsolete, as enabled by Kārearea's, Kākāpō's or Kea's software-based offerings, significantly contributed to the co-creation of value. In a similar vein, Takahē's offering allowed customers to conduct physiotherapy exercises in an orderly manner outside of clinics. Likewise, temporal aspects of value cocreation can yield insights into opportunities to enhance customer value. Whereas Kārearea's, Kākāpō's or Kea's offerings enabled customers to engage with clients independent of time limitations, Whio's customer value accumulated over a long use-period.

The findings align with Storbacka et al.'s (2012) argument that timing and location of offerings is crucial and when made available at the wrong time or place can even destroy value. In a similar vein, Velu's (2017) findings suggested that seasonal variations in the demand need to be reflected in the offering development process. As implied in the literature and evident in the findings, understanding customers' spatial and temporal use-contexts is vital for customer value co-creation. However, several scholars (e.g. Christensen et al., 2016; Massa et al., 2017; Priem et al., 2018) have emphasised the limited attention devoted to customers' use-context and the opportunities to leverage insights into spatial and temporal contingencies of how customers use offerings. Moreover, digital technology advancements 
further augment the potential for variations in customers' use-context and thus the development of innovative offerings (Amit \& Zott, 2001; Berman, 2012; Joanne Zhang, Lichtenstein, \& Gander, 2015).

As a result, comprehending customers' use-context and its contingencies set the stages for explorative experimentation and in turn the development of effective offerings. Consequently, ventures' capabilities to probe spatial and temporal contingencies can be considered as complementary to the translation of customers' needs into value dimensions and the explorative experimentation underpinning the development of offerings. The proposed temporal and spatial dimension and their intertwined nature draws attention to the heterogeneity of customers' use-contexts and its implications for value co-creation. Thus, it provides a foundation for exploring and harnessing the multivalent opportunities of customers' use-contexts and integrates it with the development of other customer value proposition dimensions. In contrast to value proposition frameworks (e.g. Osterwalder, Pigneur, Bernarda, \& Smith, 2015; Payne et al., 2017), the findings draw attention to the interdependencies of who, what, how, and the use-context in the customer value proposition development process.

\subsubsection{Summary Customer Value Co-Creation}

Overall, FI- and DI-ventures successfully developed customer value propositions underpinning robust customer value co-creation mechanisms. The contrasts of the two groups illustrated that different approaches can support the development of viable BMs. However, ventures have to combine and align sets of capabilities to develop appealing customer value propositions and engage customers in value co-creation mechanisms. Identifying preliminary customer segments is crucial since it focuses ventures' efforts to translate customer needs into value, provides direction for explorative experimental developments of offerings, and scopes boundaries for spatial and temporal use-context. Nevertheless, the findings draw attention to the interdependencies of individual customer value proposition dimensions in the development process. Moreover, it is the continuous development, i.e. diversification of customer segments, value types, and/or offerings, that provides a foundation for the development of effective customer value propositions and VCC 
mechanisms over time. Following from that, ventures have to orchestrate heterogenous sets of capabilities and balance complementarities and tensions in the experimental customer value proposition development process.

The findings align with Velu's (2015) results that ventures' learning capabilities that augment an understanding of value propositions and VCC significantly influence their chances of survival. Also, the findings corroborate Cortimiglia et al.'s (2016) argument that "BM implementation can be a period of great experimentation, especially in terms of the value proposition dimension" (p. 423). Finally, Velu (2017) provided further evidence that ventures' need to "refine customer value propositions in order to develop a business model that has a coherent configuration of key activities within the firm that also fits the external environment" (p. 606). In contrast to the literature, the findings provide insights into what dimensions of customer value propositions are refined over time and why. Furthermore, they highlight what capabilities are required to develop and refine individual customer value proposition dimensions in the explorative experimentation process that remained mostly unexplored in contemporary research (Velu, 2017; Foss \& Saebi, 2018). Based on the insight obtained from the findings and their discussion in the literature it is suggested that:

\footnotetext{
Proposition Vıa: Developing and maintaining effective customer value propositions requires ventures to combine customer identification, value translation, and experimental capabilities with a grasp of customers' use-contexts.
}

Figure 69 illustrates the combination of customer value proposition development capabilities required to engage customers successfully in value co-creation mechanisms. Combinations of all capabilities are argued to be vital for developing and sustaining effective customer value propositions over time. 


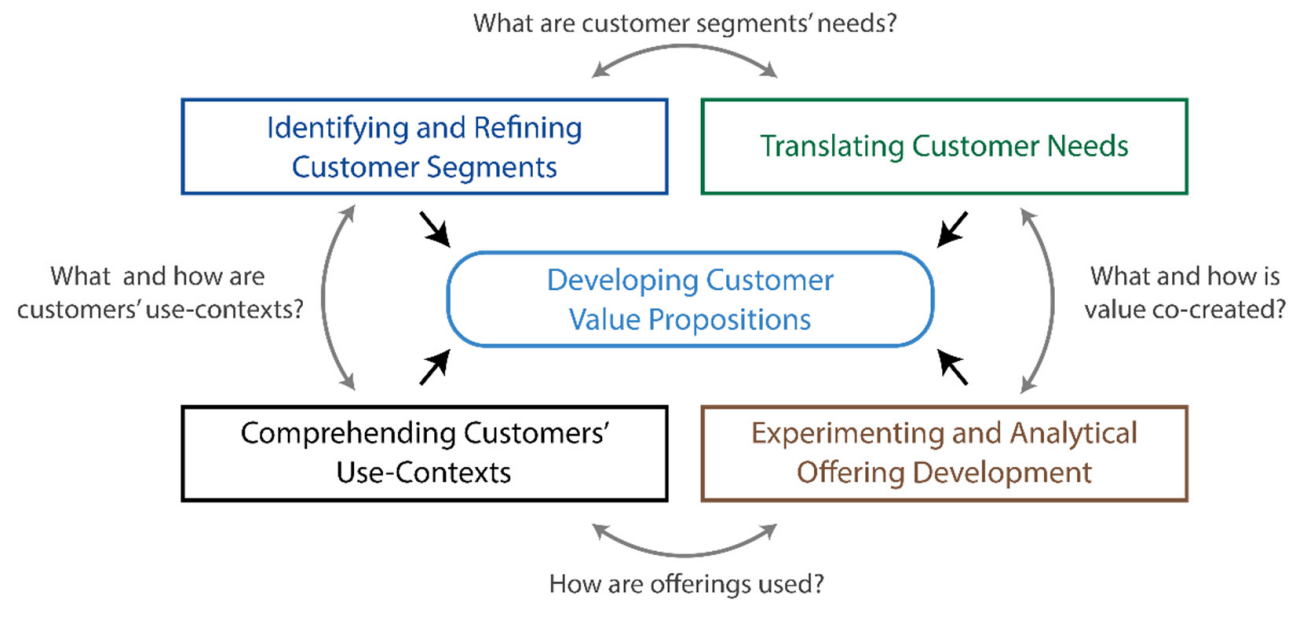

Figure 69 - Customer Value Proposition Development Capabilities

The findings support the argument that customer identification and comprehending use-context might be more important for Fl-ventures' customer segment diversificationcentered strategy. In contrast, DI-ventures' offering diversification strategies benefit from strong value translational and experimental co-development capabilities. The heterogeneity of customer value proposition development capabilities amongst FI- and DI-ventures can be illustrated in a matrix borrowing from Ansoff (1968). Whereas Fl-ventures expand customer value co-creation mechanisms along customer segments, DI-ventures enhance customer value co-creation via new offerings, as illustrated in Figure 70. Following from this it can be suggested that:

Proposition VIb: FI- and DI-ventures' development of effective customer value propositions and thus viable customer value co-creation mechanisms is supported by heterogenous capability sets. 


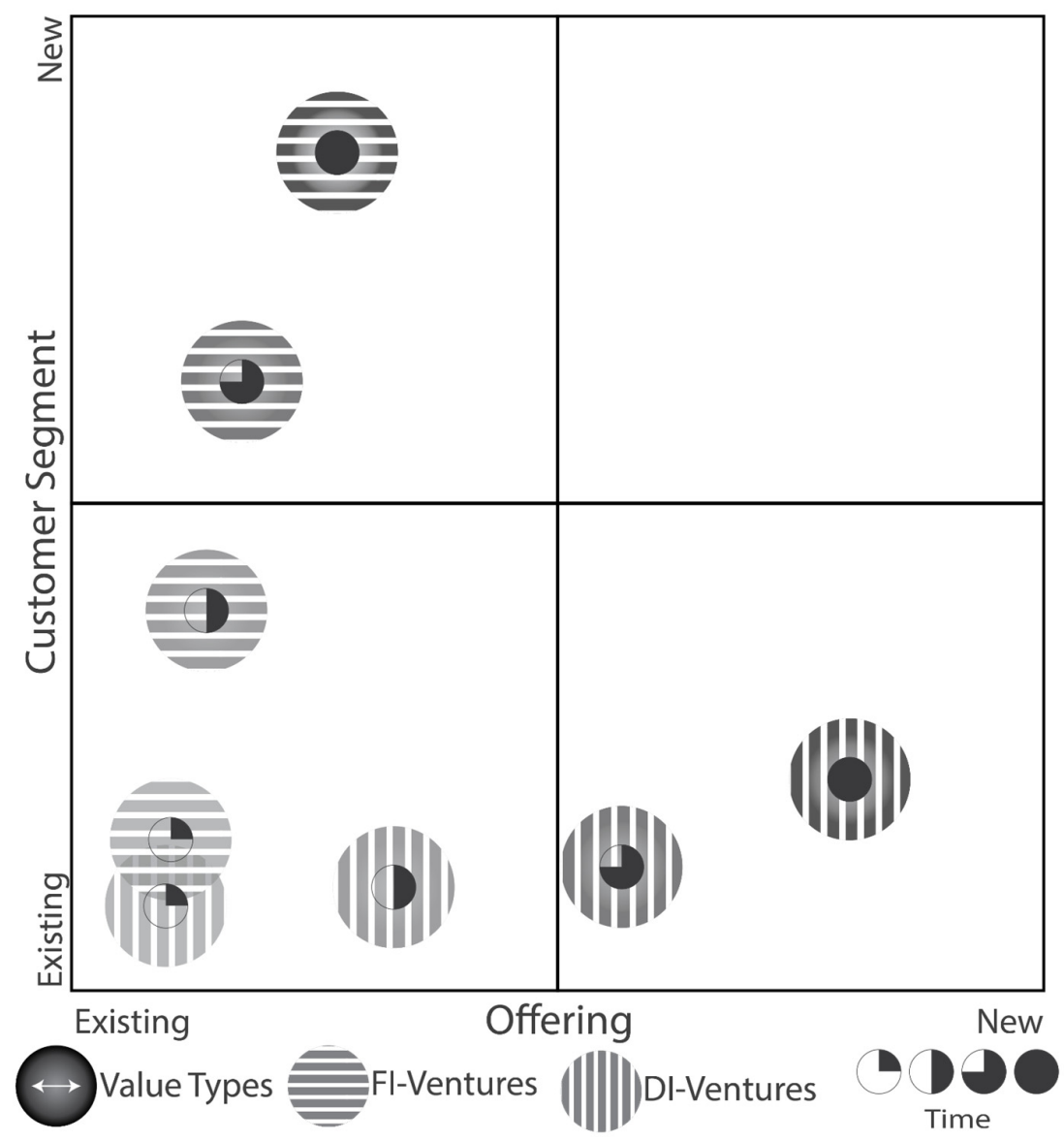

Figure 70 - Customer Value Co-Creation Development

\subsubsection{Development of Actor Value Co-Creation Mechanisms}

As commonly described in the literature (Hamel, 2002, p. 73; Morris et al., 2005), ventures engaged actors in their value co-creation mechanisms. However, the findings draw attention to the ambidextrous nature of value co-creation as demand- and supply-side phenomenon, i.e. engaging ventures and actors in the process (Zott et al., 2011; Wirtz et al., 2016; Massa et al., 2017; Priem et al., 2018) rather than a unidirectional sequence of valueadded activities. Ventures' different approaches of developing actor value propositions, engaging actors in value co-creation, and balancing heterogenous interests and tensions provided insights into how a firm-ecosystem fit can be created and sustained. 


\subsubsection{Who: Identifying and Engaging Strategic Partners}

$\mathrm{FI}$-ventures often described actors as suppliers and complementors that provide generic inputs for customer value co-creation. In contrast, DI-ventures emphasised the importance of actors' often unique contributions to VCC mechanisms. Similarly, OI-ventures relied on actors, yet failed to identify or had to refine effective modes of actor engagement throughout the study. Finally, failed ventures identified arrays of potential actors, but only managed to engage with few of them in isolated transactions.

Since selecting actors often defined ecosystems (Demil et al., 2015), the process characterised adaptations of ventures' BMs to those of others (Chesbrough, 2006) and in turn the VCC mechanisms' evolution (Morris et al., 2005; Amit \& Zott, 2015). While FI- and DIventures relied on external actors for value co-creation, they followed different strategies when selecting and engaging with actors. Fl-ventures deliberately selected actors that can be replaced to avoid becoming overly dependent or locked-in at early stages. The selection of redundant actors can be explained by ventures' aim to maintain flexibility for BM development (Gerasymenko et al., 2015). However, due to the reluctance to commit to actors, Fl-ventures did not take advantage of the opportunity to rapidly create complementarities and a potential lock-in of actors in early stages (Amit \& Zott, 2015). In contrast, DI-ventures deliberately selected key actors in ecosystems to develop complementarities and first-mover advantages that became difficult to imitate (Hamel, 2002; Teece, 2018). Finally, Ol-ventures explored an array of potential actors to engage with for VCC, yet reduced the number of actors as well as the extent of engagements throughout the study.

The findings align with Mangematin et al. (2003) and Sabatier et al. (2010) who drew attention to ventures' need for external resources and capabilities. While the importance of external inputs in the BM development process has been acknowledged in the literature (Velu, 2015), varying degrees of unilateral and bilateral dependence remained ambiguous. The findings emphasise that ventures pursue different strategies when selecting and engaging actors in value co-creation mechanisms despite their dependency on external inputs.

Selecting actors and negotiating interdependencies is characterised by tensions arising from ventures' aim to maintain flexibility for BM development, the need for 
idiosyncratic inputs in VCC mechanisms, and opportunities to strategically position the venture in ecosystems. Engaging wide ranges of actors in explorative experimentation can yield multivalent opportunities for the BM development process (Velu, 2017). However, ventures have to balance multiple actors' interests (Rumble \& Mangematin, 2015) and synergies with coordination costs (Tantalo \& Priem, 2016; Saebi et al., 2017) in early interactions. The contrast of FI-, DI-, and Ol-ventures' actor selection and engagement mode provides evidence that actor value proposition development processes are governed by dedicated strategies rather than by ad-hoc buy, make, or cooperate decisions of isolated instances (Ritter \& Lettl, 2018). The nexus of selecting actors and defining interdependencies characterised actor value proposition development processes. Consequently, selecting, refining, and balancing sets of actors and the interdependencies created with them for VCC mechanisms can be considered as a critical capability. Navigating these choices is vital for developing viable BMs and can be referred to as ecosystem navigation.

\subsubsection{What: Co-Creating Pecuniary and Non-Pecuniary Value}

Co-creating value with actors is paramount for ventures to develop an effective firmecosystem fit (Amit \& Zott, 2015; Brea-Solís et al., 2015; Ritter \& Lettl, 2018). As evident in the findings, actor value co-creation focused primarily on economic value realised via additional revenues or cost-savings as commonly described in literature (Afuah \& Tucci, 2001; Chesbrough \& Rosenbloom, 2002; Teece, 2010). Nevertheless, several ventures emphasised the co-creation of non-pecuniary value such as reputational benefits. Also, actors often benefited from the co-development of offerings with ventures. In brief, independent of actors' function in ventures' BMs, their engagement in value co-creation mechanisms often resulted in realised pecuniary and non-pecuniary value. For instance, Kārearea's and Kākāpō's actor value co-creation mechanisms allowed engaged actors to realise pecuniary (Kārearea [increase in sales], Kākāpō [reduction of administration costs]) and non-pecuniary value (Kārearea and Kākāpō [reputational benefits]).

While the ecosystem-perspective of BMs embraces a more comprehensive understanding of value co-creation, the heterogeneity of actor value is hardly discussed in literature (Priem, Butler, \& Li, 2013; Klang et al., 2014). Actors' benefits have been classified 
as (1) improved operational performance, (2) increased asset effectiveness, (3) market expansion, and (4) risk mitigation (Velamuri et al., 2013). In contrast to Velamuri et al.'s (2013) findings, ventures focused on enhancing actors' operational performance and market expansion, i.e. offering of additional services, while neglecting asset utilisation and risk mitigation in value co-creation. Moreover, additional intangible benefits such as an increase in reputation or the acquisition of capability from joined R\&D projects are highlighted by the findings while hardly discussed in BM literature (Brettel et al., 2012; Velu, 2015).

In general, the utility co-created with actors can be distinguished in tangible and intangible value (Tantalo \& Priem, 2016). Developing an advanced understanding of opportunities to co-create different types of value with other actors is central for the ecosystem perspective and appears to be overdue. On the one hand, the proliferation of services underpinned by modern ICTs mandates a multivalent understanding of value for different actors (Hedman \& Kalling, 2002; McGrath, 2010). However, limiting the discussion to online and/or two-sided BMs (Rumble \& Mangematin, 2015; C. Baden-Fuller et al., 2017) falls short of explaining how engaging different actors can enhance value co-creation in ecosystems (Adner, 2017; Fjeldstad \& Snow, 2018). The findings draw attention to a widening scope of value that can be co-created in ecosystems. Moreover, enhancing the value cocreated by all participants can support the development of customer and actor lock-ins and thus a dominant position in the ecosystem (Amit \& Zott, 2015; Hannah \& Eisenhardt, 2018).

Overall, the what of actor value co-creation of actor value propositions was marginally refined by ventures throughout the study. While pecuniary value often characterised the early stages, almost all ventures emphasised non-pecuniary benefits of their engagements with actors over time. However, since DI-ventures' VCC mechanisms were often highly dependent on actors' resources and capabilities, they were more likely to explore a wider scope of opportunities to co-create value with them from the beginning onwards. By appealing to actors' self-interest (Casadesus-Masanell \& Heilbron, 2015), DI-ventures aimed to secure their participation in VCC mechanisms. Furthermore, value co-creation mechanisms of DI-ventures' expanding actor sets were often enhanced by positive network externalities (Gulati et al., 2000; Amit \& Zott, 2001, 2015) and the creation of various relational rents (Dyer et al., 2018). Likewise, Ol-ventures intended to engage actors in value co-creation mechanisms, yet often had to refine their understanding of what other actors value and in 
turn their offerings to successfully engage them.

The findings draw attention to the range of tangible and intangible value types ventures explored in the actor value proposition development process. A progressive understanding of what actors value is vital to engage them in the co-creation of relational rents (Dyer et al., 2018). Additionally, the findings suggest that the multivalent nature of value in ecosystems provides an array of opportunities to structure and enhance interactions with actors and develop a firm-ecosystem fit. Thus, the findings contribute to the theory of value in ecosystems and stress the importance of increasing academic attention to the topic.

\subsubsection{How: Spotting Cooperative Opportunities}

Developing and refining offerings was vital to facilitate actors' engagement in value co-creation mechanisms. The offerings developed ranged from standardised manufacturing services to bespoke data interfaces. FI- and Ol-ventures created homogenous and explicit offerings for actors predominantly in the study's final stages. In contrast, DI-ventures created bespoke product and/or service combinations to engage actors in early stages. The sequentially different development of explicit offerings can be attributed to ventures' dependence on external inputs in VCC mechanisms.

FI-ventures primarily focused on co-creating value with actors via the combination of complementary activities and resources in stage one and two (discussed in greater detail in chapter 5.4.1, p. 292 and chapter 5.4.2, p. 302). However, designated offerings, such as online interfaces envisioned by Kārearea and Matuku in final stages, with the aim to structure interactions and reduce transaction costs (Zott \& Amit, 2007; C. Baden-Fuller et al., 2017) can be regarded as a driver of actor value co-creation of FI-ventures. The findings align with Brettel et al.'s (2012) argument that ventures and actors benefit from increased efficiencies resulting from investments in interactions when basic routines have been established. Similarly, Pati, Nandakumar, Ghobadian, Ireland, and O'Regan (2018) found that ventures and actors benefit from streamlining interactions in advanced stages of the BM development process. FI-ventures' combination of complementary resources with other actors in early stages as well as the creation of explicit offerings to reduce transaction costs in later BM development stages drove the development process. Whereas FI-ventures' combination of 
complementary resources in early stages required none or low levels of activity or resource co-specialisation (Teece, 2007), developing explicit offerings indicated their adaptation in later stages.

In contrast, DI-ventures developed offerings that enhanced combinations of complementary activities and resources to augment productivity gains, reduce transaction costs, and facilitate inter-organisational learnings in early stages. The findings confirm that combining multiple value drivers (Zott \& Amit, 2010; Storbacka et al., 2012) can amplify the co-creation of relational rents and thus increase ventures' chances of survival (Aversa, Furnari, et al., 2015; Kulins et al., 2016). However, while developing and refining offerings can be time- and resource-intense, DI-ventures focused on actors that provided access to idiosyncratic resources, high transaction volumes, or vital knowledge to justify significant resource endowments in early stages. For instance, Kākāpō and Kea engaged in the development of bespoke integration with government agencies to facilitate the electronic filing of documents. The critical capability to electronically submit annual filings and the high transaction volumes rendered the development of dedicated offerings for these organisations a priority for these ventures. The findings suggest that DI-ventures prioritise the development of offerings for specific actors along several criteria selected to enhance VCC mechanisms.

Ol-ventures' initial offerings were characterised by novelty as a value driver. However, offerings required unilateral resource endowments from actors, such as buying custom-made balance boards (Takahē) or machinery and software (Whio). The subsequent reluctance to engage in value co-creation mechanisms was contested with refinements of offerings to reduce this entry barrier. Ecosystem actors' resistance to innovative offerings that require alterations of existing processes has been well documented in the entrepreneurship and innovation management literature (Schumpeter, 1934; Utterback, 1994). Finally, failed ventures leveraged complementary inputs of actors, yet had not developed implicit or explicit offerings that transcended isolated transactions.

FI-, DI-, and Ol-ventures' contrasting approaches highlight the idiosyncrasies of the strategies. Fl-ventures' circumspect development of offerings emphasises ventures' reluctance to commit to actors, develop co-specialised activities and/or resources, and maintain flexibility for BM development. Moreover, the absence of established processes threatens the viability and durability of any offering developed. 
In comparison, DI-ventures' development of offerings for vital actors provided boundaries for adaptations of internal activities and/or resources, yet allowed to co-create value with actors from early stages onwards. As evident from the findings, the creation of relational rents (Dyer et al., 2018) can be underpinned by offerings that allow for (a) combinations of complementary activities and resources in VCC mechanisms (Teece, 2010; Brettel et al., 2012), (b) the reduction of transaction costs (Williamson, 1975; Zott \& Amit, 2010), and (c) facilitate inter-organisational learning (Gulati et al., 2000; Gulati \& Higgins, 2003; Björkdahl, 2009).

Although Frankenberger et al. (2014) and Aversa, Furnari, et al. (2015) provided evidence that combining complementary activities and resources can result in superior performance, the temporal heterogeneity of co-specialisation and offering development provides novel insights into ventures' different approaches to co-create relational rents. Likewise, the co-specialisation of activities and resources with the aim to reduce transaction costs is often discussed in the context of established organisations (Williamson, 1975; Teece, 2007). In contrast, the findings draw attention to approaches ventures can pursue to enhance transaction efficiences. Developing explicit actor value propositions in early stages contests Brettel et al.'s (2012) and Pati et al.'s (2018) findings that ventures primarily benefit from combining complementary activities and resources as well as increasing transaction efficiences in advanced development stages.

Since low-levels of activity and/or resource specificity as well as fully fledged actor offerings can contribute to the co-creation of relational rents, ventures in different development stages can benefit from enhancing engagements with actors beyond armslength market transactions. While developing offerings for actors in the absence of established processes bears the risk of obsolescence, ventures can leverage the boundaries set by actor value propositions to establish internal structures. In brief, FI- and DI-ventures are following opposing strategies when developing offerings for actors. However, since engaging actors is vital for VCC mechanisms, all ventures have to develop a capability to identify cooperative opportunities to co-create and enhance a firm-ecosystem fit.

Similarly to the development of customer offerings, ventures either used routinised interactions with actors or co-development as a means to reveal cooperative opportunities. While FI-ventures primarily accessed knowledge via everyday interactions and weak bonds 
developed with actors (Granovetter, 1973), DI-ventures enhanced strong bonds and interorganisational learning in the process (Gulati, 1999; Gulati \& Sytch, 2007). After having identified complementary opportunities, ventures engaged in an experimental process to develop offerings. Difficulties in identifying cooperative opportunities or misleading assumptions about them (Shafer et al., 2005) often resulted in resource- and time-intense refinements as evident in the cases Takahē and Whio. Velu (2017) emphasised the importance of balancing experimental resource endowments when exploring opportunities with multiple actors. Since the development of offerings signals ventures' ambition to engage in value co-creation, the process can be considered as important for attracting potential partners and gaining legitimacy.

Ventures have to develop offerings that leverage or balance actors' complementary or contradictory interests in value co-creation mechanisms (Sabatier et al., 2010; Tantalo \& Priem, 2016). As evident in the findings, ventures coordinated and aligned multiple actors' interests via the development of offerings to realise complementarities with individuals and across sets of actors. For instance, Matuku and Kea developed distinct offerings to engage and balance interests of multiple actors in value co-creation mechanisms. In contrast, Takahē's multi-actor value co-creation mechanisms were hamstrung by actors' conflicting interests that required refinements to align engaged actors' benefits. Developing an understanding of and matching actors' interests with different offerings that align their value co-creation mechanisms is a critical capability ventures have to develop when engaging partners in ecosystems.

In conclusion, the findings are in sharp contrast to Kazanjian's (1988) argument that organisational interactions only change marginally in early stages. Moreover, ventures must develop capabilities to identify cooperative opportunities and develop and refine offerings in an explorative experimental and iterative process often balancing multiple actors' interests in value co-creation mechanisms to realise relational rents.

\subsubsection{When \& Where: Actors' Use-Contexts}

Temporal and spatial contexts of actor value co-creation were of minor consideration for ventures. However, ventures' overseas expansion plans created the need to engage with 
other actors outside the domestic market. Differences in overseas actors' processes and local regulations required adjustments in offerings. The findings reflect Landau, Karna, and Sailer's (2016) argument that institutional environments, quality of actors, and overseas market characteristics require BM adjustments. Although ventures planned the internationalisation of BMs, they limited their operations mainly to New Zealand with the exception of Kākāpō. Aspects of site-specificity, e.g. APIs of New Zealand Government Organisations or domestic industry structures, set boundaries to the applicability of ventures' actor value co-creation mechanisms to international expansions.

The temporal coordinated use of resources or sequencing of activities allowed ventures to enhance relationship rent generation. For example, Whio coordinated the use of machinery with a co-operating joinery shop. Also, considerations of the longevity of value cocreated with actors can provide an additional structuring attribute that ventures can consider in the development of actor value propositions. Actor value co-creation can be distinguished timewise in instance, continuous, and cumulative. Instance value results from a single occurrence such as a specific product or process innovation project that was mutually developed (Björkdahl, 2009). Continuous value results from actors' ongoing engagement with the venture as it realises additional revenues or cost savings (Chesbrough, 2006). Finally, cumulative value is co-created over time such as through reputational and image gains. In particular, tacit benefits such as the development of R\&D capabilities (Zobel, 2017) or a brand and/or reputation (Lange, Lee, \& Dai, 2011) resulting from short- or long-term engagements can transcend the duration of the relationship. The temporal nature of actor value becomes paramount when resource endowments outweigh immediate returns for the engagement in ventures' uncertain exploitation of opportunities and BM development (Burns et al., 2016). The ratio of potential value obtained from the engagement and the risk of losing committed resources further stresses the importance for ventures to enhance value co-creation with other actors.

In brief, although rarely discussed in literature, the spatial and temporal context provides ample opportunities to develop novel or to enhance existing actor value co-creation mechanisms. Developing capabilities to leverage insights into actors' spatial and temporal context in the development of actor value propositions can be crucial for BMs' firmecosystem fit evolution. 


\subsubsection{Summary Actor Value Co-Creation Mechanisms}

The creation of relational rents was central to all ventures' approaches of developing a firm-ecosystem fit. Fl-ventures focused on combining complementary activities and/or resources in early stages and via minor investments in relation-specific actor value propositions to reduce transaction costs towards the end of the study. In contrast, DIventures' offerings enhanced relation-specific investments and interfirm knowledge-sharing routines from early stages onwards (von Hippel, 1988; Powell et al., 1996; Gulati et al., 2000). Moreover, DI-ventures actively structured engagements with actors by developing actor value propositions in early stages (Chesbrough \& Rosenbloom, 2002; Morris et al., 2005; Velu, 2017). Finally, Ol-ventures' offering refinements aimed to reduce the idiosyncratic investments required from actors to engage in value co-creation mechanisms.

The findings contribute to our understanding of complementarities in the co-creation of relationship rents in BMs. Low levels of complementarities, such as the combination of resources without relationship-specific investments, can provide a source of actor value cocreation. Likewise, enhancing complementarities via relationship-specific investments and the exchange of knowledge allows ventures to leverage actors' resources and capabilities in the creation of relational rents. Finally, complementarities that require unilateral relationship-specific investments are less likely to engage actors in value co-creation mechanisms. In short, a curvilinear relationship of complementarities and relationshipspecific investments for actor value co-creation can be postulated. This finding yields valuable contributions to the discussion of contradictory results from different configurational studies on the influence of transaction efficiencies and complementarities in organisationalboundary spanning BM configurations (Täuscher, 2017) and how they affect ventures' performance.

In conclusion, the creation of relational rents requires ventures to identify actors that provide input for VCC mechanisms and structure their engagement. Next to customers, selecting actors and negotiating interdependencies with them is characterising for ventures' ecosystems. As a result, the importance of ecosystem navigation cannot be understated. Besides the multiple opportunities to co-create pecuniary value with actors, ventures can 
consider a range of non-pecuniary value to enhance actors' engagement in VCC mechanisms. Realising relational rents requires explorative experimentation of cooperative opportunities via different means that allow ventures and actors to obtain value from their engagement. Tensions of actors' diverging interests need to be balanced, yet can be leveraged to create reinforcing VCC mechanisms spanning ventures' boundaries. Finally, although ventures hardly considered temporal and spatial factors except for cross-geographical boundaries, exploring actors' different value co-creation contexts can reveal novel cooperative opportunities. Based on the insight obtained from the findings and their discussion in the literature it is suggested that:

Proposition V2a: Developing and maintaining effective actor value propositions requires ventures to combine ecosystem navigation, cooperative opportunity identification, and experimental capabilities with an advanced understanding of actors' use-contexts.

Proposition V2b: Developing and maintaining multiple effective actor value propositions requires ventures to balance and resolve tensions via refinements.

Proposition V2c: Developing reinforcing actor value propositions provides a foundation for superior performance.

Figure 71 illustrates the combination of actor value proposition development capabilities required to engage actors successfully in value co-creation mechanisms. The combination of all these capabilities is argued to be important for developing and sustaining effective actor value propositions and thus a robust firm-ecosystem fit over time. 


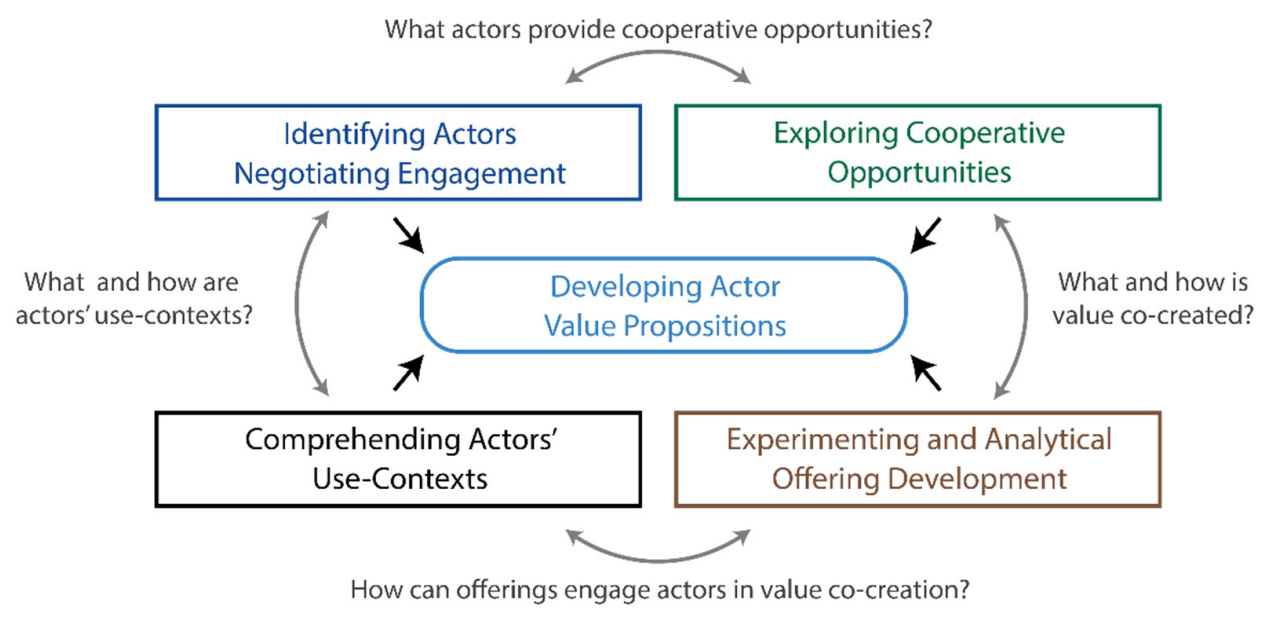

Figure 71 - Actor Value Proposition Development Capabilities

Similar to the development of customer value co-creation mechanisms (Figure 70, p. 269), the findings suggest that implementing different BM development strategies requires heterogenous sets of capabilities. FI-ventures are likely to benefit from capabilities to negotiate engagements with a small set of actors from early stages and leverage an advanced understanding of their context. For instance, Kārearea renegotiated the terms with ETF/MF providers and brokers to reduce fees and increase rebates received. In contrast, DI-ventures might benefit from exploring cooperative opportunities with a wide range of actors. However, the often limited opportunities to leverage idiosyncratic resources and/or large transaction volumes, requires the careful selection and identification of any additionally engaged actor. For example, Kākāpō only developed tailored offerings for deliberately selected actors that were able to provide large transaction volumes. FI- and DI-ventures' actor value co-creation trajectories and their diverging focus on actor segments and offering diversification are illustrated in Figure 72. In brief, the success of different BM development approaches is underpinned by heterogenous sets of capabilities. Moreover, the sets of capabilities required to develop and maintain effective actor value propositions is likely to evolve over time. 


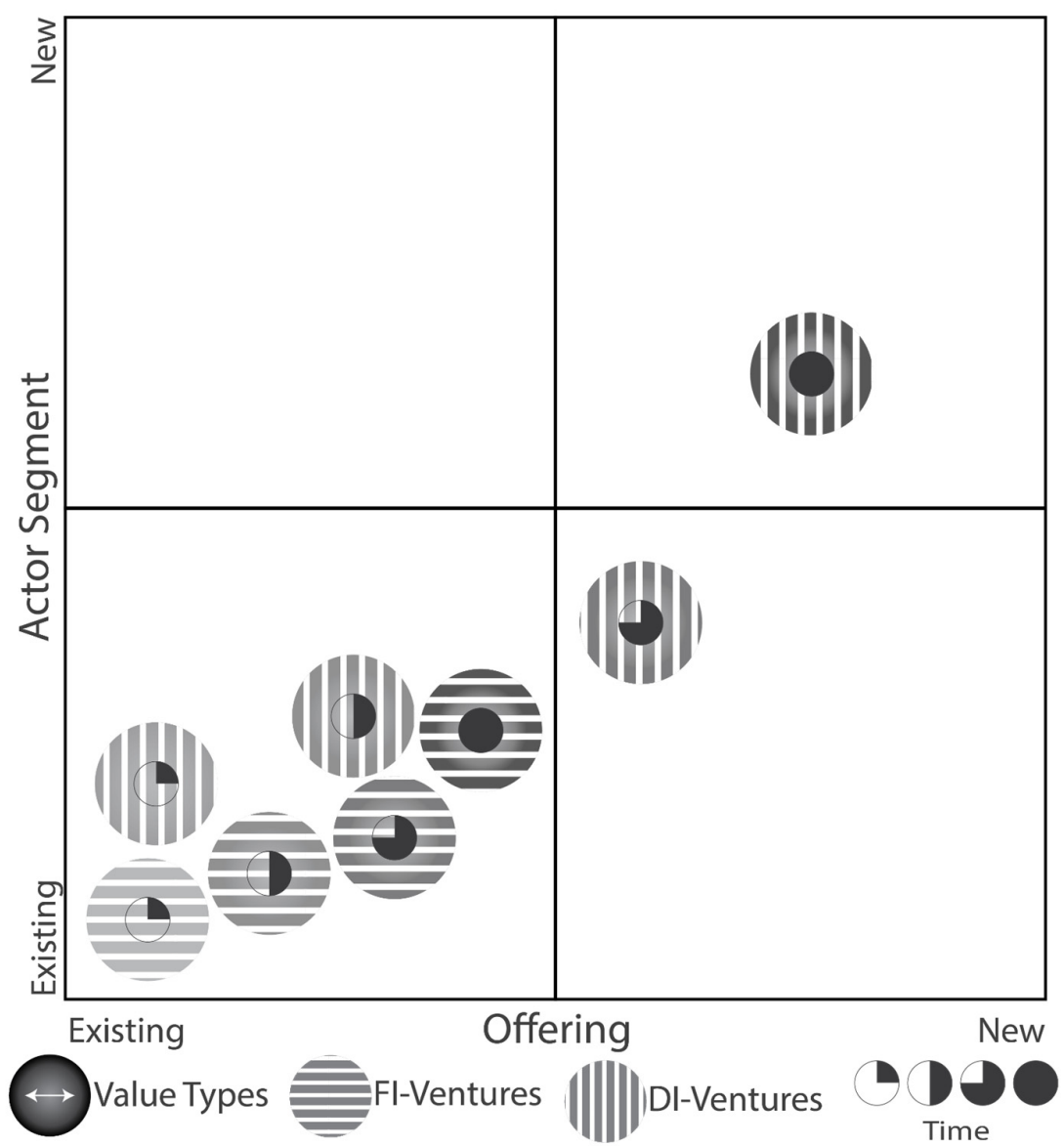

Figure 72 - Actor Value Co-Creation Development 


\subsubsection{Development of Value Capture Mechanisms}

Capturing value is paramount for the viability of BMs. However, value appropriation is often limited to pecuniary value captured from customers in the literature (Zott et al., 2011; Wirtz et al., 2016; Massa et al., 2017). In contrast, the findings draw attention to the ecosystem as a rich reservoir to capture different types of value, employing multiple means, and from various sources. The next sections discuss the development of ventures' value capture mechanisms along individual dimensions of the value proposition framework.

\subsubsection{Who: Identifying Sources of Value Capture}

Ventures explored wide ranges of customers and actors engaged in value co-creation as potential sources of value capture. Defining from whom value is captured and how it is distributed amongst BM participants represents the third and final structuring element for ventures' ecosystems (Morris et al., 2005; Casadesus-Masanell \& Heilbron, 2015). Ventures focused on capturing value directly from customers and actors engaged in value co-creation in early stages. The challenges of identifying and distinguishing between users and customers who benefit and pay (Stewart \& Zhao, 2000; C. Baden-Fuller \& Haefliger, 2013) was evident across several case studies. For instance, Takahē distinguished between home-users and physiotherapy patients as distinct end-customer segments since value was appropriated via different channels. In a similar vein, ventures should identify customer segments that are willing to pay a price that renders BMs viable (Bojovic et al., 2018). The co-founder of Kākāpō emphasised this point by outlining that "bookkeepers and accountants are the people who massively benefit and thus should be paying for the benefits".

As evident in the cases, the diversification of customer segments (FI-ventures) or offerings (DI-ventures) underpinned the evolution of customer value capture mechanisms. For instance, Kea developed additional offerings for bookkeepers' clients (corporations) and introduced a distinct subscription plan for them. Next to customers, distribution partners were the most significant source of value. The findings provide evidence that several ventures captured pecuniary and non-pecuniary value from suppliers, complementors, and other actors. Consequently, the argument that ventures explore and realise opportunities to capture value outside of the pecuniary customer-firm dyad (Arend, 2013; Velu, 2017) was 
confirmed. For instance, Kārearea captured value from ETF/MF providers. This suggests that ventures explore an array of sources to capture value in ecosystems. Moreover, the findings draw attention to the importance of orchestrating the development of sources of value capture with the refinements of means, i.e. pricing plans (discussed in section 5.3.3.2, p. 283).

In conclusion, developing and refining sources of value capture defines the 'architecture of revenues' (Chesbrough, 2006) and how and by whom value that is co-created will be captured. Identifying and distinguishing users, customers, and other actors as sources of value was central for that process. The findings draw particular attention to ventures' considerations of customers and actors as sources of value capture in early stages. Consequently, they emphasise the opportunities inherent in the ecosystem perspective of developing value capture mechanisms and ventures' strategies to appropriate value from multiple sources that amounted to reliable revenue streams. Although total-value creation (Brandenburger \& Stuart, 1996) has drawn attention beyond individual firm-actor dyads, the notion of a pre-defined amount of value hardly reflects the opportunities embraced by the ecosystem perspective. The creation of relational rents for mutual benefits emphasises the array of opportunities to augment value capture for engaged actors rather than negotiating individual shares (e.g. Arend, 2013; Casadesus-Masanell \& Heilbron, 2015). Following from this it can be argued that ventures have to develop a capability to identify and delineate sources of value capture to appropriate parts of the value co-creation and develop a firmecosystem fit.

\subsubsection{What: Capturing more than Money}

BMs describe how ventures capture value via a mechanism commonly referred to as their revenue model. In contrast to revenue models' almost exclusive monetary focus, ventures captured pecuniary and non-pecuniary value from customers and actors. Although revenues generated from customers accounted for the lions-share, ventures captured pecuniary value from distribution partners and other actors as well. For instance, Kārearea received distribution fees and annual rebates from ETF/MF providers. Moreover, ventures captured non-pecuniary value by receiving access to complementary resources and services that were paramount for value co-creation mechanisms. For example, Matuku obtained 
access to vital smart metering data from e-retailers.

Capturing a combination of pecuniary and non-pecuniary value from customers and other actors was considered by most ventures in early stages. However, since value capture is bound to value co-creation, the evolution was often intertwined. The development of customer value propositions and actor value propositions catalysed the evolution of value units in value capture mechanisms. Value units can be understood as exchange units of value and thus the foundation for ventures' value capture mechanisms. Developing and refining value units that reflect and match customers' perceived value co-creation allowed ventures to appropriate value effectively (Casadesus-Masanell \& Heilbron, 2015). For instance, Kākāpō transitioned from the sign-up of legal entities to the sign-up of clients as a basis for charging customers. As evident in the findings, developing robust customer value capture mechanisms requires an understanding of customers' value units, i.e. what customers value, and what they are willing to pay for. In contrast to the prevalent willingness-to-pay, value units are understood as the fine-grained partition of what and how value is co-created with customers and in turn what and how value can be appropriated. The findings align with McGrath's (2010) arguments that the 'unit of business' is a supremely important choice and represents the basis of ventures' value capture mechanisms. Similarly, Storbacka et al. (2013) drew attention to the development and refinement process of value capture mechanisms informed by a deepening understanding of what customers value. The value unit concept provides a safeguard against a desynchronised development of VCC mechanisms that can unbalance ventures' firm-ecosystem fit. Moreover, it emphasises the need to develop value capture mechanisms in concert with value co-creation mechanisms.

Value units can be of pecuniary and non-pecuniary nature and can be captured from customers and actors as evident across the presented cases. Pecuniary value units were characterised by the ratio of value co-created and the money charged. In contrast, nonpecuniary value units were underpinned by benefits derived from cooperative exchanges. For instance, Ruru captured non-pecuniary value from customers by collecting one-sided copy paper, i.e. raw material for notebooks. The benefit for customers was a convenient and free paper waste disposal service. In comparison, Kākāpō captured non-pecuniary value from the processing of electronic submissions to government agencies. The findings corroborate Arend's (2013) argument that capturing non-pecuniary value provides a wide range of 
opportunities to enhance the viability of BMs (Priem et al., 2012).

Pecuniary and non-pecuniary value units, as apparent in the presented cases, further emphasise the importance of acknowledging the multivalent nature of value in ecosystems and the inherent opportunities. Capturing non-pecuniary value units often requires the combination of complementary capabilities and resources. Consequently, the findings corroborate Chesbrough's (2007b) argument that utilising complementary external resources allows ventures to capture value from other actors than customers. Similarly, Velu (2017) provided evidence that by leveraging complementors' sales organisations, ventures can capture non-pecuniary value such as instant market access, a reliable distribution network, and established customer relationships.

Capturing a portion of the relational rents created required ventures to identify actors' benefits and develop an understanding of matching value units (Amit \& Zott, 2015). Whereas capturing pecuniary value units can be negotiated with other actors, capturing non-pecuniary value required an understanding of the value units in actors' heterogeneous contexts. For instance, Kākāpō's non-pecuniary value capture mechanisms were dependent on government agencies' "time, costs, and quality of cases processed" and in turn facilitated digital submission of annual filings. Similar to customer value capture, ventures had to advance their knowledge of actors' value units and how they can appropriate value cocreated with them. While receiving access to vital resources and/or capabilities was important, developing means to capture a portion of the relationship rents generated beyond the pure use of complementary resources can enhance the viability of ventures' BMs.

Overall, ventures' development of value capture mechanisms was driven by aims to appropriate pecuniary and non-pecuniary value from customers and actors engaged in value co-creation. Exploring different avenues to capture pecuniary and non-pecuniary value as well as balancing these mechanisms was pivotal in the development of viable BMs. The findings align with Achtenhagen et al.'s (2013) propositions outlining that strengthening existing value capture mechanisms while exploring additional opportunities is crucial for the development of viable BMs. The findings draw particular attention to the value unit - pecuniary and nonpecuniary - as the facilitator of engagements and thus provide a potential foundation for the discussion of value capture in the literature (Arend, 2013; C. Baden-Fuller \& Haefliger, 2013). Similarly to value co-creation mechanisms, ventures' development of value capture 
mechanisms emphasises the demand-and supply-side nature of underpinning interactions in BMs.

\subsubsection{How: Capturing Value Units}

Ventures employed various means to capture value from customers and actors. However, periodical subscription-based revenue models dominated customer value capture mechanisms (Hamermesh, Marshall, \& Pirmohamed, 2002; Osterwalder \& Pigneur, 2002; Rappa, 2004). Whio represented an exception, as it only captured value from the offering of surfboards and surfboard-shaping workshops. Similarly, Matuku's primary customer value capture mechanism was bound to project-based consulting fees. However, the venture established a source of reoccurring revenue by providing monthly business intelligence services. The development of pricing plans was underpinned by the refinement of value units across all ventures throughout the study.

The focus on subscription-based pricing plans was enhanced by two factors. First, a periodical subscription provided access to ventures' offerings and thus the services they rendered. This emphasises the nature of value as being co-creational (Stabell \& Fjeldstad, 1998; Prahalad \& Ramaswamy, 2004; Vargo \& Lusch, 2004) and translational only when perceived needs are satisfied in different use-contexts. As such, value capture mechanisms must reflect contingencies of value co-creation mechanisms (Priem, 2007; Velu, 2017; Priem et al., 2018). Second, periodical subscriptions provide flexibility for customers to start and end engagements in value co-creation when needed. The findings align with the previously discussed increase in servitisation of offerings and related 'on-demand' solutions (Demil \& Lecocq, 2015; Foss \& Saebi, 2018). Despite the flexibility of periodical pricing plans, ventures enhanced the development of customer lock-ins. As already outlined by Williamson (1975), the use of offerings over time augments relationship specific human-resource investments and often results in a lock-in (Amit \& Zott, 2015). Moreover, ventures' homogeneity in periodical-based subscription plans reflects the convergence to industry- and sector-spanning dominant designs in pricing structures (Stinchcombe, 1965; Utterback, 1994).

In conclusion, the findings suggest that ventures introduced periodical pricing schemes to (a) reflect the value co-creational nature of offerings and (b) enhance perceived 
flexibility while augmenting lock-in effects for customers. The process of capturing pecuniary value from customers was facilitated via reoccurring billing plans and direct debit collection orders in early stages. However, almost all ventures integrated with a payment service provider to charge customers' credit cards, automate related transactions, and reduce coordination efforts in stage three or four.

Actor value capture mechanisms were often underpinned by reoccurring streams of pecuniary and non-pecuniary value realised via the continuous combination of complementary capabilities and resources. For instance, distribution partners engaged in value co-creation mechanisms were charged fees based on the use of ventures' offerings as evident in the cases Kākā and Takahē. Likewise, Kea's pecuniary actor value capture mechanisms were based on a percentage of complementary services provided from actors to the ventures' customers. The importance of capturing value from complementary services has been emphasised by Teece (2010) and C. Baden-Fuller and Mangematin (2013). The findings provide evidence that ventures appropriated a portion of the co-created relational rents via introducing (a) periodical pricing schemes, (b) charging actors a share of complementary services provided to customers, and/or (c) enhancing the productivity of resource collections by developing resource ties and/or the reduction of transaction costs via activity linking. In contrast to the dominant notion of extracting value from engaged actors via bargaining power (Porter, 1985; Hamel, 2002; Casadesus-Masanell \& Heilbron, 2015), the findings provide evidence that capturing value from ecosystem actors is dependent on relationships that transcend isolated market transactions at an arms-length and the means developed by ventures to appropriate a share of the value co-created.

In conclusion, almost all ventures developed means to capture non-pecuniary value from customers and other actors engaged in value co-creation mechanisms. The findings suggest that next to identifying sources of value, value units, and developing means to capture value units, ventures can enhance value capture mechanisms by aligning sources, value units, and means across multiple actors. Following from this, ventures' grasp of customers' and actors' pecuniary and non-pecuniary value units enabled the development of means to effectively appropriate value. As evident in the findings, ventures explored different value unit appropriation schemes to match the development of customer value propositions and actor value propositions and capture a portion of the value co-created. 


\subsubsection{When \& Where: Timely Subscriptions}

Ventures' value capture mechanism development was characterised by temporal and spatial aspects. Most significant was the almost unilaterally adopted monthly pricing plan across ventures. Whereas Kārearea refined its annual pricing plan to monthly periods, Kea maintained the monthly subscription plans for customers. Ruru was an exception to periodical pricing plans, yet the venture increased the retainer to biannual purchases of notebooks for customers. In addition, Whio refined the temporal components of customer value capture mechanisms by introducing instalment payments. In short, pecuniary value capture mechanisms were characterised by temporal aspects. In contrast, non-pecuniary value capture mechanisms were denoted by ongoing temporal defined interactions but not significantly influenced by spatial contexts. Kākāpō and Whio being the exception, since the former provided services to international customers and the latter was bound by the spatial boundaries of a local Wellington-based workshop.

The findings corroborate Chesbrough and Rosenbloom's (2002) argument that ventures can explore wide ranges of options such as renting, licensing, charging by transactions, or only after-sales services to explore temporal variations of value capture mechanisms. Likewise C. Baden-Fuller and Haefliger (2013) noted that subscription and rental systems require different timings for value capture mechanisms. As evident in the findings, ventures' value capture means were characterised by temporal instances such as monthly subscriptions. Aligned with the increasing servitisation but in contrast to the research focus on capital intense investments (e.g. Björkdahl, 2009; Priem et al., 2018), attention is drawn to temporal variations and their functions to mitigate risk and uncertainty as well as ensure consistent revenue streams. Monthly subscription plans allowed to mitigate customers' and/or actors' perceived risk to invest in offerings of ventures that commonly lack legitimacy in early development stages (Stinchcombe, 1965; Fisher et al., 2016).

Interestingly the scope of freemium models, where services are provided for free to customers, was limited in the set of investigated ventures. Only Ruru and Kākāpō offered free service options from the first stage onwards while Kārearea introduced a free pricing plan briefly after the final stage of the study. In contrast to findings presented by Günzel-Jensen 
and Holm (2016), providing free services was not conceived as a means of experimentation by ventures but exclusively to promote offerings and attract customers. This suggests that even when providing free services, ventures intend to signal reliability of offerings when engaging with customers to build trust and reliable customer relationships.

Overall, value units and means to capture them were characterised by critical temporal use-contexts. Consequently, ventures experimented with temporal aspects of value capture mechanisms (on-demand, monthly, annually, etc.) and conformed with increasingly common monthly subscription-based pricing plans. Although spatial aspects of value capture mechanisms were only explored in isolated cases, geographical boundaries affected the where of value capture significantly and thus influenced ventures' value appropriation opportunities. This suggests that ventures have to explore and experiment with the temporal and spatial context of customers' and actors' value units to effectively appropriate a share of the value co-created.

\subsubsection{Summary Value Capture Mechanisms}

The development of value capture mechanisms was central to ventures' firmecosystem fit. Although the process was heterogeneous across the investigated ventures, patterns emerged in the analysis. First, the development of customer value propositions and actor value propositions catalysed the evolution of value units. Whereas the importance of understanding customers' willingness-to-pay has been emphasised throughout the literature, it can only be understood as a proxy for value units. Since value is always co-created and heterogeneously perceived by customers (Vargo \& Lusch, 2008; Greer et al., 2016; Vargo \& Lusch, 2017), the value unit provides a common basis to assess the value co-created amongst ventures, customers, and actors (value sources) and in turn develop effective means to appropriate value. Moreover, the value unit concept emphasises the bilateral nature of value co-creation in ecosystems and draws attention to the opportunities to appropriate pecuniary and non-pecuniary value in the process. In short, the findings suggest that:

Proposition V3a: Ventures must identify different sources of value, value units, and develop means to appropriate value to create a firm-ecosystem fit. 
Moreover, the findings draw attention to the importance of developing VCC mechanisms in concert to create and maintain a firm ecosystem fit and the viability of BMs. As evident in the findings, the evolution of customer value propositions and actor value propositions propelled refinements of periodical-pricing plans. As a result, it can be argued that the development of value units needs to be reflected in the means to capture them. In addition, the development of means to capture value was contextualised by crucial temporal considerations (Priem et al., 2018). The importance of periodical aspects of pricing plans is highlighted by the findings and provides valuable insights into how and why ventures refined means of value capturing over time. In contrast to the literature (Demil et al., 2015), the implications for temporal aspects were not limited to financing functions. Following from this it can be argued that:

Proposition V3b: Ventures must continuously adapt value capture mechanisms to match the evolution of customer value propositions and actor value propositions to maintain the firm-ecosystem fit.

Finally, whereas customer and actor value capture mechanisms can be detached, creating reinforcing interdependencies can create virtuous value loops (Casadesus-Masanell \& Ricart, 2010; Casadesus-Masanell \& Heilbron, 2015) and boost ventures' profits. For instance, Kārearea's, Kākāpō's, and Kea's customer and actor value capture mechanisms were reinforcing each other. In contrast, incongruencies in Takahē's value capture mechanisms significantly hampered the development of robust revenue streams. This implies that ventures' capability to create reinforcing interdependencies in customer and actor value capture mechanisms can significantly enhance value appropriation and in turn augment the firm-ecosystem fit. In contrast to the literature (Amit \& Zott, 2015; Casadesus-Masanell \& Heilbron, 2015), leveraging different pecuniary and non-pecuniary value streams allowed ventures to explore a wider range of opportunities to identify and develop reinforcing value loops. For instance, Ruru's value capture mechanisms depended on the union of capturing pecuniary value from notebook sales and non-pecuniary value from sourcing used copypaper. Moreover, the absence of atypical multi-sided freemium BMs, such as Google's search engine (Rumble \& Mangematin, 2015), emphasises that capturing value from multiple sources across the ecosystem can enhance the creation of value loops, independent of 
ventures' business logic. This suggests:

Proposition V3c: Ventures' ability to create and maintain reinforcing value loops across customers and actors enhances the firm-ecosystem fit.

Figure 73 illustrates the combination of capabilities required to develop value capture mechanisms that underpin viable BMs. In the context of customer value capture it can be argued that identifying and delineating sources of value and translating and refining value units are capabilities that are more crucial for Fl-ventures. However, since DI-ventures require similar capabilities to identify and delineate actors in ecosystems as source of value, the distinction appears arbitrary. As a result, a combination of all value capture capabilities is required by ventures to develop and sustain robust value capture mechanisms over time.

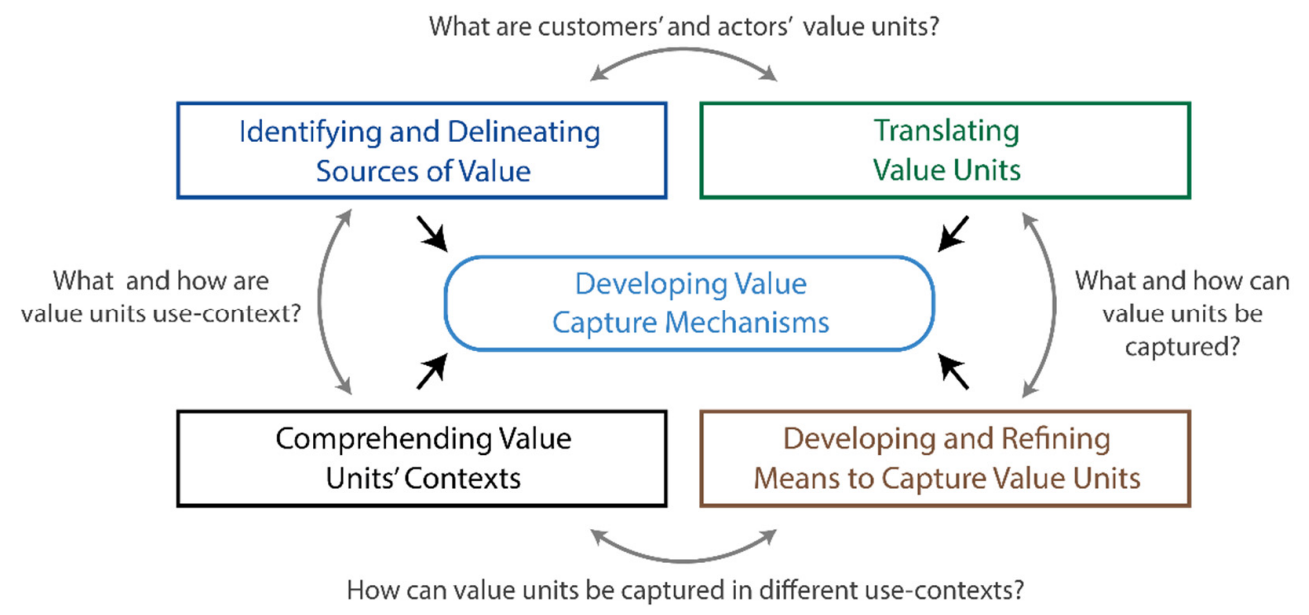

Figure 73 - Development of Value Capture Mechanisms

\subsubsection{Summary Value Creation and Capture Mechanisms}

The previous sections applied the proposed value proposition framework to contextualise ventures' VCC mechanisms, their development over time, and in turn derived sets of capabilities that support the development of a firm-ecosystem fit. Ventures' heterogenous approaches and locus of customer value propositions, actor value propositions, and value capture mechanism development was underpinned by diverging yet consistent sets of capabilities. The findings amount to the argument that ventures do not need to develop a comprehensive set of capabilities to create a firm-ecosystem fit in early development stages. 
However, the set of capabilities must be coherent and support a particular design strategy. Nevertheless, the findings indicate that ventures' advancements to sustainable organisations require the extension of capability sets. In short, the successful development of VCC mechanisms underpinning a firm-ecosystem fit and enabling viable BMs is contingent on a coherent set of capabilities developed in early stages and advanced over time.

\subsection{Activities, Resources, and Actors in Business Model Configurations}

\subsubsection{Activities and Activity Links}

Activity linking was vital for the development of ventures' VCC mechanisms and firmecosystem fits (Amit \& Zott, 2001; Zott \& Amit, 2010; McNamara et al., 2013). Heterogeneous approaches to link internal to external activities were identified across ventures' clusters.

Since customers' engagement in value co-creation mechanisms was paramount, ventures had to establish activity links with them. Using offerings often requires customers to unilaterally adapt activities. This process can be referred to as outbound activity linking and was prevalent across ventures' interactions with customers. Ventures provided information and guidance as well as conducting workshops to enhance customers' capabilities to use offerings. For instance, Kārearea provided information about investing to augment users' financial literacy and as a result facilitate the sale of investment products. Thus, educating customers on how to use offerings can be regarded as a prerequisite to engage them in value co-creation (Stinchcombe, 1965; Lusch \& Vargo, 2006a). Frankenberger, Weiblen, and Gassmann (2013) and Velamuri et al. (2013) demonstrated that educating customers can significantly affect value co-creation mechanisms. Nevertheless, the underpinning activity linking process has been largely neglected in research so far (Massa et al., 2017; Priem et al., 2018).

The findings draw attention to the importance of developing serial as well as dyadic activity links in order to change activities performed by customers to facilitate value cocreation mechanisms. Linking activities enabled ventures to (a) engage customers while (b) standardise offerings in the interactive process. Activity linking allowed ventures to shape customers' capabilities, enhance the use of the provided offerings and in turn the value co- 
created. Additionally, linking customers' activities to ventures' offerings incurred switching costs for them and created a customer lock-in.

However, outbound activity linking and unilateral customer capability development can delimit offerings' value since customers' idiosyncratic contexts may require a creative use of provided product and/or service combinations (Priem et al., 2013; Greer et al., 2016). This suggests that ventures have to balance the education of customers with the potential heterogeneous use of offerings when crafting activity links with them. Consequently, successful outbound activity linking requires ventures to develop customers' capabilities to use the provided offering in idiosyncratic contexts. The interdependencies of outbound activity linking with customers and the development of customer value proposition dimensions are apparent in the findings. In brief, outbound activity linking with customers is vital for VCC mechanisms and the development of a firm-ecosystem fit.

In contrast, ventures followed heterogeneous approaches when linking activities with other actors than customers. Fl-ventures developed and maintained a small set of serial and dyadic activity links with actors by almost unilaterally adopting internal activities to those of other actors engaged in value co-creation. This process can be referred to as inbound activity linking and although enhancing the rapid development of a firm-ecosystem fit, adopting internal activities to those of multiple actors' activity structures often increases coordination efforts (Thompson, 1967; Stabell \& Fjeldstad, 1998). For instance, Matuku had to manually anonymise the smart metering data received from e-retailers. In conclusion, the rapid development of a coherent activity configuration comes at the expense of increased coordination costs.

In order to cope with increasing coordination efforts resulting from growing sets of actors, FI-ventures developed standardised activities in cooperation with actors to streamline, and in some cases even automate, interaction process. The findings align with Amit and Zott's (2015) argument that complying with multiple actors' activities can increase coordination costs unless properly managed. Despite ventures' efforts to reduce transaction costs in due course, the inbound activity linking approach delimited opportunities to create aligned activity configurations. For instance, Kārearea's manual import of bank transaction records was not supporting the automated consolidation of trades on the platform. The findings suggest that inbound activity linking can accelerator the development of firm- 
ecosystem fits but requires ventures to compensate for activity incongruencies with increased coordination efforts. In contrast to the literature (Wirtz et al., 2016; Ritter \& Lettl, 2018), the findings draw attention to the ramifications of linking activities with other actors for firms' activity structures. Moreover, the challenges of coordinating internal with external activities, as evident in the findings, cast new light on the discussion of transaction costs (Williamson, 1975). Next to the costs of safeguarding contractual agreements, the increased internal coordination efforts resulting from inbound activity linking contributes to transactions costs of interactions. In contrast to the literature (Zott \& Amit, 2010; Priem et al., 2012; Massa et al., 2017), the findings add to our understanding of the challenges of coordinating BM activities across ecosystems.

In contrast, DI-ventures focused on bilateral activity linking and mutually developed serial, dyadic, and joint activity links with actors from the beginning onwards. Internal and external activities were adapted in concert with several actors to combine complementary processes, reduce transaction costs (Williamson, 1979; DaSilva \& Trkman, 2014), and shape surrounding ecosystems (Moore, 1996; Fjeldstad \& Snow, 2018). For instance, Kākāpō engaged with several government agencies in bilateral activity linking to facilitate the costefficient transmission and processing of data. While bilateral activity linking requires higher coordination efforts in the co-development process upfront, it allows ventures to (a) develop an advantageous balance of internal and external activity adaptations and in turn decreases tensions across BMs' activity configurations, (b) reduce transaction costs and enhance efficiency from the beginning onwards, and (c) allows ventures to adopt advantageous positions in ecosystems. However, developing in-depth activity links with several actors renders ventures exposed to ecosystem changes. DI-ventures mitigated this risk by developing strong bonds with actors that will be discussed in the following section 5.4.3 (p. 316).

In comparison to Brettel et al. (2012), the findings provide ample evidence that bilateral activity linking in early stages can be beneficial in the BM development process. The divergence might be partially explained by the limited focus on customers that this study transcended. Also, the findings imply that bilateral activity linking is advantageous when the benefits are shared by engaged actors, despite dependence asymmetries and differences in bargaining power. Thus, the findings provide evidence for one of the foundational premises 
for the co-creation of relational rents (Gulati \& Sytch, 2007; Dyer et al., 2018). Moreover, Amit's and Zott's (2015) argument that relying on reputable partners promotes a lock-in for ventures has not been reflected in the findings.

Finally, Ol- and failed ventures were often challenged by the development of activity links. Inbound activity linking significantly shaped ventures' activity structures. For instance, Takahē engaged with an Australian physiotherapy equipment wholesaler to distribute its offerings and in turn hardly developed any sales and marketing capabilities in early stages. As a result of the limited interaction with customers and actors, outbound activity linking with patients and physiotherapists often required significant refinements of customer value propositions and actor value propositions throughout the study. OI- and failed ventures only engaged in bilateral activity linking by developing standardised activities in isolated instances and late development stages. The findings align with Demil and Lecocq's (2010) argument that trial-and-error approaches of developing activity links can be time- and resource-intense. While partnerships can enhance discovery driven learning (McGrath, 2010), the findings draw attention to the importance of ventures' interaction with and feedback from customers and actors engaged in value co-creation mechanisms in the ecosystem for the successful development of value propositions.

The findings from Ol- and failed ventures provide interesting insights into how the reluctance of other actors to link activities is reflected in the development of individual customer value proposition and actor value proposition dimensions. The late development of inbound, outbound, and/or bilateral activity links in the final stages elicits a slowly emerging (OI) or absent (failed) firm-ecosystem fit. The findings re-emphasise the importance of firms' experimental capabilities when engaging with actors. In contrast to the activity system literature (Porter, 1996; Siggelkow, 2002; Zott \& Amit, 2010), attention is drawn on ventures' experimental capabilities to link internal and external activities.

Although linking activities has been widely regarded as crucial for VCC in BM literature, what, how, and with whom activities are linked beyond organisational boundaries has hardly been discussed in literature (e.g. Storbacka et al., 2012; Frankenberger, Weiblen, \& Gassmann, 2013). Various classifications such as pooled, sequential, and reciprocal (Thompson, 1967, pp. 54-55), simple consistency, reinforcing, and optimisation (Porter, 
1996), or value chain, shop, and network (Stabell \& Fjeldstad, 1998) of activity linking have been proposed to describe the intra-organisational interdependencies of activities. Similarly, the process of activity linking over time has been described as patching, thickening, and coasting with respect to the centrality of activities performed by the firm (Siggelkow, 2002). Whereas all approaches acknowledge the importance of activities performed by external actors for the overall activity configuration, the contributions for understanding activity linking in the context of BMs' ecosystems remained fairly limited (Klang et al., 2014).

The scale, the depth, and differences between inbound, outbound, and bilateral activity linking has remained underdeveloped in activity centred constructs (Pati et al., 2018). However, Amit and Zott (2015) drew attention to the coordination of actors as the foundation for realising complementarities of interdependent activities (Amit \& Schoemaker, 1993). Similarly, Foss and Saebi (2018) emphasised the importance of specifying which actors conduct which activities and how they are linked. The four activity configuration themes ${ }^{22}$ proposed by Zott and Amit (2010) provide one of the very few approaches introduced to comprehend design themes of firms' activity configurations. Nevertheless, the empirical research focused on intra-organisational activity linking provided inconclusive results on how individual and combinations of design themes that govern how activities are linked influenced ventures' performance over time (Täuscher, 2017; Pati et al., 2018). Moreover, design themes provide limited insights into how, with whom, and why ventures link activities beyond firms' boundaries.

The proposed categorisation of inbound, outbound, and bilateral activity linking mechanisms provides a first foundation for understanding the inter-organisational activity linking processes. After having identified important activities for VCC mechanisms, ventures have to decide which are conducted by whom and how they are connected. Whereas performing activities in-house allowed ventures to reduce transaction and coordination costs (Williamson, 1975), outsourcing activities allowed to leverage actors' capabilities and resources (Dyer \& Singh, 1998; Gulati \& Sytch, 2007; Dyer et al., 2018). The tensions arising from these counteracting forces can be resolved via different activity linking approaches. FIventures are able to rapidly take advantage of other actors' complementary capabilities and activities via inbound activity linking. Moreover, the standardisation of inbound activity links

${ }^{22}$ (Novelty, Lock-In, Complementarities, and Efficiencies) 
with multiple actors - via the development of actor value propositions - allowed them to reduce transaction and coordination costs in later stages of the study.

In contrast, DI-ventures develop bilateral activity links that allow them to leverage actors' complementary capabilities and activities. However, linking activities with multiple actors is a resource- and time-intense development process and needs to be balanced. Moreover, idiosyncratic activity linking was only productive when reducing coordination costs due to relationship-specific investments which were justified by high transaction volumes as indicated in literature (Dyer \& Singh, 1998; Dyer \& Hatch, 2006; Dyer et al., 2018). Bilateral linking of idiosyncratic activities was evident in the development of DI-ventures from early development stages onwards. However, after having developed idiosyncratic activity links with actors providing large transaction volumes, DI-ventures aimed to develop a set of standards to link activities with heterogeneous sets of actors. For instance, whereas Kākāpō developed bespoke integrations for government agencies, the venture aimed to design standardised processes for a wide range of banks and insurance firms to accept electronic submissions of authorities.

While FI- and DI-ventures often combined inbound, outbound, and bilateral activity links, both development strategies aimed to leverage complementary capabilities and activities of actors across different development stages. The findings can be compared to Zott and Amit's (2010) efficiency and complementarity design themes of activity systems. However, distinguishing standardised (FI) and idiosyncratic (DI) activity linking provides a detailed account of how and what activities were linked across organisational boundaryspanning BMs. Moreover, insights into the sequence of activity linking processes revealed how complementarities (Dyer \& Singh, 1998; Gulati et al., 2000; Gulati \& Sytch, 2007) and the reduction of transaction costs via standardisation (Williamson, 1975) can be pursued to enhance value co-creation and the development of viable BMs over time.

The outbound, inbound, and bilateral activity linking categories proposed provide an important extension for understanding how different types of activity links and in what sequence can be crafted by ventures to successfully develop a firm-ecosystem fit. Consequently, the findings have several implications for activity linking in the BM development process. First, the extent of inbound, outbound, and bilateral activity linking requires ventures to engage in a reconciliation process of internal and external activities. Foss 
and Saebi (2018) and Fjeldstad and Snow (2018) emphasised the importance of interdependencies of activities across organisational boundaries in ecosystems and drew attention to the absence of a coherent understanding of the subject.

The process of reconciliation of activity configurations in ecosystems can be compared to Thompon's (1967) proposed organisational rationality in open systems that seeks to smooth environmental interactions. Similarly, the findings provide evidence that ventures have to identify and reconcile inbound, outbound, and bilateral activity links in BMs' activity configurations. Since ventures' activity configurations underpin VCC mechanisms that were dependent on other actors, activity reconciliation can be considered as a requirement for the development of viable BMs. While the heterogeneity of internal and external activities often results in incongruencies that cannot be fully resolved by activity linking, it can be argued that activity configurations must overcome a consistency threshold to underpin viable BMs. For instance, Kārearea had to coordinate the identification of customers, receipt of bank transfers, and the buy and sell orders of customers to overcome the activity configuration consistency threshold to enabel the most basic value creation and capture mechansism. It can be argued that the consistency threshold is overcome when ventures coordinate and undertake activities with other actors to successfully produce an offering and engage customers and/or other actors in VCC mechanisms.

Therefore, the capability to reconcile internal and external activities can be argued as critical to sustain the consistency of activity configurations in ecosystems. Following from this, it is suggested that:

Proposition A1a: Activity reconciliation capabilities are vital for the development of effective activity configurations in ecosystems.

In addition, aligning internal and external activities in activity configurations allows ventures to create reinforcing effects across multiple actors' activities (Casadesus-Masanell \& Ricart, 2007, 2010). In contrast to intra-firm reinforcing activities (Porter, 1996), inter-firm activity links can create positive network effects, relational rents, and a lock-in for customers and other actors (Amit \& Zott, 2001, 2015; Dyer et al., 2018). However, aligning internal and external activities via activity links requires ventures to coordinate and facilitate the development of activity links and activities across multiple actors. As evident in the findings, DI-ventures engaged in the development of multiple bilateral activity links that shaped the 
adaptation of actors' activities. For instance, Kākāpō engaged with a government agency in the development of a custom-made data interface to facilitate the fully automated submission of documents and forms. Thereby the venture aligned internal with external data processing procedures and created positive network effects (Gulati et al., 2000). In contrast to the customer focus of the BM literature (Stampfl, Prügl, \& Osterloh, 2013; Priem et al., 2018), the findings emphasise the importance of positive network effects generated with other actors.

This suggests that, next to identifying cooperative opportunities, ventures have to develop the capabilities to coordinate and direct the development of external activities in order to align internal and external activities and craft reinforcing activity configurations across multiple actors in BMs. Following from this, it can be argued that:

Proposition Aıb: Activity alignment capabilities allow ventures to create reinforcing activity configurations across ecosystems.

Similarly to Herzberg's (1966) two-factor theory, the reconciliation of internal and external activities was required to overcome a consistency threshold and maintain the viability of BMs' activity configurations over time. Additionally, the alignment of inter-firm activities can enhance BMs' VCC mechanisms and create reinforcing effects. As evident in the findings the reconciliation and the dedicated alignment of activities vary in the activity linking efforts undertaken and related resource endowments. Following from this and building on related internal activity linking research (e.g. Porter, 1996; Siggelkow, 2002) a positive relationship of activity configuration alignment and ventures' performance can be postulated. As described in Figure 74, ventures' activity configurations have to overcome a consistency threshold to enable value creation and capture. Additionally, a positive relationship of consistency, ranging from mere coherence to reinforcing alignment, and performance is emphasised. The development of viable BMs of FI- and DI-ventures underpins the two-factor theory of activity reconciliation and alignment. Moreover, challenges to overcome consistency thresholds were evident in the development of Ol- and failed ventures. 


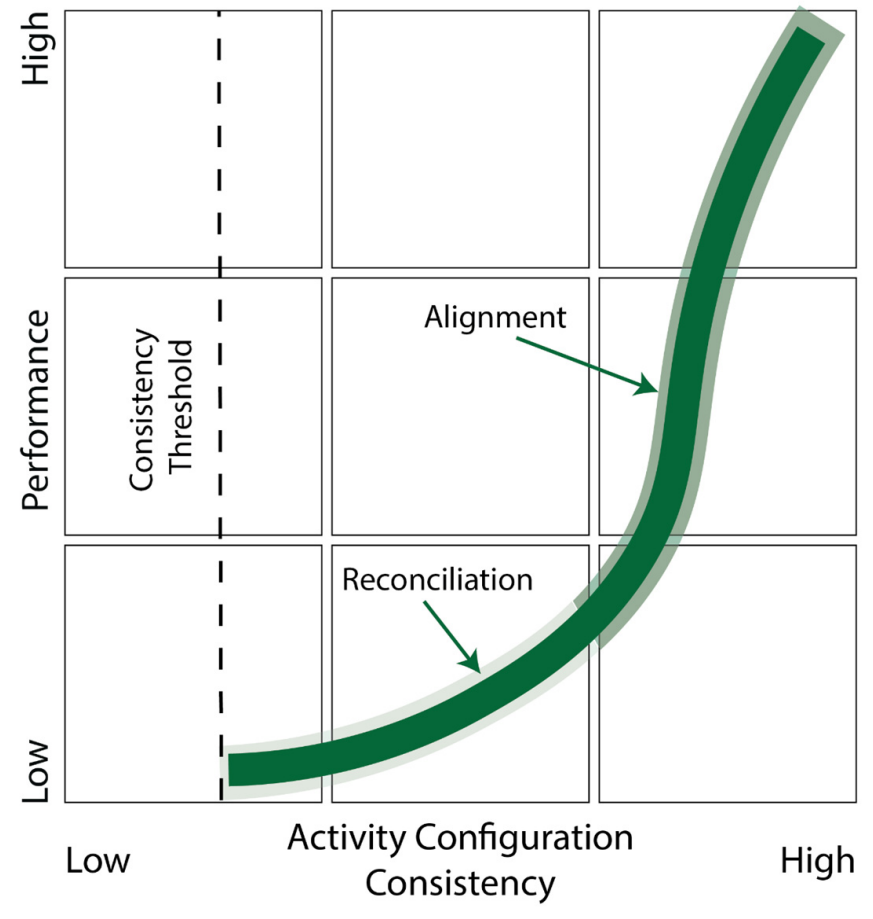

Figure 74 - Activity Linking Reconciliation and Alignment

What level of reconciliation and alignment enhances ventures' performance is dependent on the dynamics of the respective ecosystem. Consequently, ventures' have to manage an activity configurations' velocity to develop effective activity configurations that balance consistency and flexibility (Demil \& Lecocq, 2010). For instance, the constant flux of dynamic ecosystems that emerges around disruptive technologies without dominant design renders, often resource-intense, alignments obsolete within brief periods of time (Utterback, 1994; Christensen, 2013). In comparison, activity configuration alignment efforts are more likely to augment ventures' performance in stable ecosystems. The need to reconcile activities on a regular basis and the appropriate degrees of activity alignment is affected by the ecosystem dynamics. As a result, ventures have to maintain their ability to adapt to external changes and thus maintain adequate levels of activity configuration velocity by actively crafting and managing activity links. For instance, Kārearea maintained a medium velocity activity configuration via inbound activity linking in order to maintain flexibility in the advent of Open Banking APIs. In contrast, Kākāpō's activity configuration was characterised by the development of bilateral activity links with government agencies that are less likely to change radically. Therefore, it can be argued that: 
Proposition Alc: Matching activity configuration's velocity with ecosystem dynamics is vital for firms' performance.

Overall, ventures have to develop activity linking capabilities to (a) reconcile internal and external activities to overcome thresholds and maintain the consistency of activity configurations over time, (b) align internal and external activities to create reinforcing effects, and (c) maintain different degrees of activity configuration's velocity to accommodate for heterogeneous ecosystem dynamics. The development of activity configuration attributes across all three venture groups has been illustrated in Figure 75 . The distinct development trajectories highlight the different foci of each strategy. Although the surfaced patterns imply a relationship of reconciliation, alignment, and velocity attributes a myriad of potential configuration development paths can be envisioned.

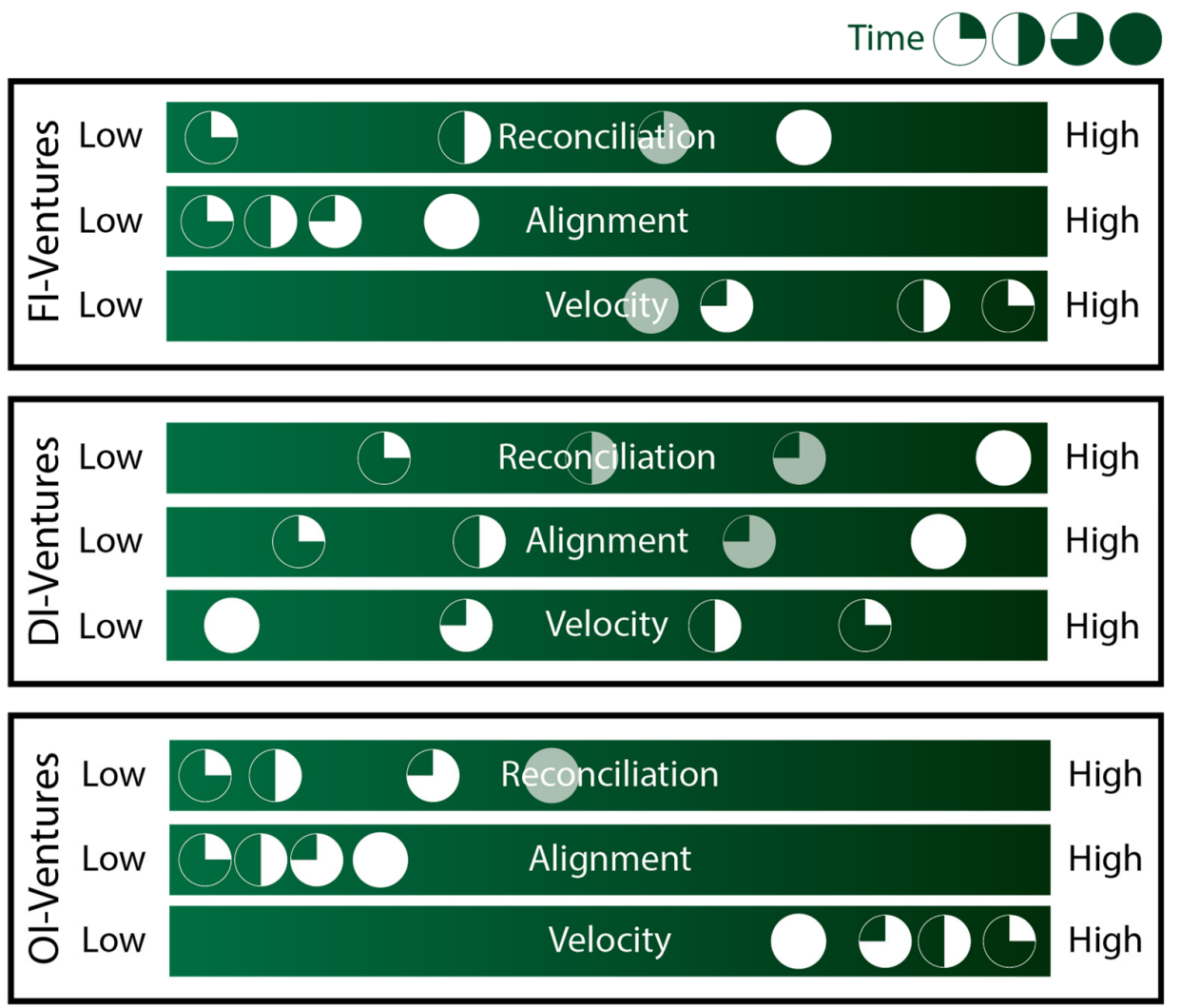

Figure 75 - Activity Configuration Characteristics in BMs 


\subsubsection{Resources and Resource Ties}

Developing physical and organisational resource ties in order to assemble effective resource collections is crucial for the emergence of robust BMs (Shafer et al., 2005; Sosna et al., 2010; Demil et al., 2015). Next to gaining access to resources, resource ties enable ventures to combine complementary internal and external resources and drive the mutual development of resource collections in ecosystems. Differences in scale (low vs high), depth (shallow vs deep), and type (physical and organisational) of resource ties ventures developed provided insights into how evolving resource collections can support a firm-ecosystem fit.

FI-ventures developed a limited number of shallow organisational and physical resource ties with actors. Specifically, the development of organisational resource ties establishing a common understanding and reasoning in the use and combination of resources (Håkansson et al., 2009) - was important for Fl-ventures to gain access to resources. For example, Matuku had to convince e-retailers of the benefits of sharing consumer data to improve the network management of lines companies. In line with Gerasymenko et al. (2015) and Demil et al. (2015), the findings draw attention to the challenges of accessing resources across ecosystems.

Moreover, developing organisational resource ties was vital for coordinating the deployment of resources in BMs. This process can be compared with the enrolment of stakeholders in order to encourage extra-role behaviour (Burns et al., 2016; Snihur et al., 2017) that transcends the mere contractual provision of resources. For example, Ruru educated customers' employees on why, how, and what waste copy paper to collect to facilitate the sourcing of high-quality raw material. In contrast to the focus on internal resources (e.g. Casadesus-Masanell \& Ricart, 2010; Demil \& Lecocq, 2010), the findings highlight the challenges and multivalent opportunities of deploying external resources in novel ways. While scholars have emphasised the potential of leveraging external resources (Amit \& Zott, 2015; Demil et al., 2015), the findings cast new light on how organisational resource ties facilitate novel forms of internal and external resource deployment and coordinate the process.

FI-ventures strategically developed organisational resource ties to accumulate organisational capital (Barney, 1991; Dopfer et al., 2017) that provided a foundation for the 
emergence of physical resource ties in late development stages. For instance, Kārearea enrolled ETF/MF providers and interacted with them for several months before it planned the development of an online interface to streamline the buy and sell process of financial products. Besides developing physical resource ties, i.e. often in form of actor value propositions, minor resource adaptations contributed to enhancing the services resource collections yielded and in turn the generation of relational rents (Gulati et al., 2000; Gulati \& Sytch, 2007). For instance, Ruru and its partner explored adaptations of the venture's paper collection boxes to match the packaging of a recycling container provided by the partner.

While resources were adapted and sometimes even mutually developed, shared ownership of resources remained largely an absent phenomenon. The findings imply that resources of various actors can be deployed and adapted in cooperation, independent of conditions of individual or mutual ownership (Lavie, 2006; Casadesus-Masanell \& Heilbron, 2015). Consequently, the findings challenge the proprietary assumption of the RBV (Wernerfelt, 1984; Amit \& Schoemaker, 1993) and emphasize Penrose's (1959) argument that the combination of resources yields services. Therefore, the findings draw attention to the deployment and combination of resources as vital mechanisms for firms' performance rather than their ownership or exclusive control.

As evident in the findings, the coordinated deployment of resources (Dothan \& Lavie, 2016) does not require a shared ownership of resources and can be managed via organisational resource ties. Nevertheless, developing physical resource ties via unilateral or mutual development can enhance the fit with other actors' resource collections and allows ventures to realise complementarities (Amit \& Zott, 2015). Even adaptations of minor nature can be beneficial and do not have to affect the ownership of resources or result in significant dependencies.

The findings corroborate ventures' dilemma of maintaining productive relationships while preventing dependence on other actors (Hedman \& Kalling, 2002; Frankenberger et al., 2014; Hacklin et al., 2018). Fl-ventures' approach of accumulating organisational capital and developing limited physical resource ties elicits how firms can successfully deploy and combine strategically important resources in ecosystems (Demil \& Lecocq, 2010). Additionally, the findings challenge assumptions of dependencies with other actors when leveraging external resources. Gulati and Sytch (2007) outlined that resource dependence 
asymmetries can diminish ventures' chances of value appropriation. In contrast to the literature, FI-ventures provide evidence that the innovative deployment allows ventures to take advantage of external resources while maintaining low levels of dependence. Since FIventures only developed physical resource ties with redundant actors, they mitigated dependence asymmetries and the risk of value migration (Hacklin et al., 2018). In brief, FIventures leveraged external resources via novel forms of deployment and minor resource adaption with sets of redundant actors enhancing combination effects while mitigating dependence asymmetries.

Balancing the productive use of internal and external resources and dependencies allowed FI-ventures to maintain their resource collections' fungibility (Velu, 2017) throughout the explorative experimentation process. Although Hacklin et al. (2018) argued that firms need to be capable of rapidly redeploying resources to accommodate for shifts in VCC mechanisms across ecosystems, Fl-ventures' resource collection development process was not characterised by volatility. In contrast, the findings draw attention to the importance of managing resource flexibility for experimental exploration within the boundaries of the consistent development of resource collections. For example, Matuku consistently accumulated data from various actors in the electricity sector, i.e. building a database, while exploring innovative combinations of data sets aiming for the development of new services.

Although already Demil and Lecocq (2010) emphasised the importance of maintaining a "dynamic consistency", the findings provide novel insights into how sequencing the development of organisational and physical resource ties can help to balance ventures' resource collections' consistent evolution and fungibility. Specifically, attention is drawn to managing dynamic consistency across BMs' resource collections spanning several actors in an ecosystem (Ritter \& Lettl, 2018). Whereas the deployment and combination of external resources can support a dynamic development (Frankenberger et al., 2014), maintaining consistency requires ventures to direct the deployment and combination of resources across several actors (Fjeldstad \& Snow, 2018). Consequently, Demil and Lecocq's (2010) dynamic consistency argument can be extended to the development of BMs' resource collections spanning organisations' boundaries. While FI-ventures' accumulated organisational capital allowed to explore the innovative deployment and combination of resources, the conservative development of physical resource ties safeguarded the consistency of resource 
collections. In brief, the findings cast light on how dynamic consistency of resource collections can be developed and maintained in ventures' early development stages.

DI-ventures developed several in-depth physical and organisational resource ties with actors from early stages onwards. Developing organisational resource ties was crucial to draw upon actors' skills and capabilities that enabled vital relationship-specific adaptations of ventures' and actors' resource collections. Bilateral resource ties allowed ventures and actors to orchestrate resource deployment (Frankenberger et al., 2014), combine complementary resources (Amit \& Zott, 2015), and mutually develop resources to enhance the creation of relational rents (Dyer et al., 2018). Parallels can be drawn to Ozcan and Eisenhardt (2009), who argued that developing portfolios of partnerships that provide resources allows to realise advantages when synchronising joined activities and combining information to understand ecosystem uncertainties.

The findings accentuate the importance of balancing the effort-intense development of resource ties with other actors and the resulting increase in dependencies. In contrast to the literature (Dyer \& Nobeoka, 2000; Ozcan \& Eisenhardt, 2009; Hannah, Bremner, \& Eisenhardt, 2016), DI-ventures developed resource ties in a consecutive manner rather than adding multiple ties at once. DI-ventures strategically developed in-depth organisational resource ties with key actors in ecosystems in order to accumulate organisational capital and leverage external capabilities. For instance, Kea drew on external consultants' know-how and skills when developing compliance procedures. The findings further highlight the crucial function of organisational capital (Dopfer et al., 2017) as an advantage when shaping physical resources in ecosystems. For instance, Kākāpō regularly liaised with government agencies to facilitate the mutual development of data interfaces.

The often unique organisational resource ties DI-ventures developed emphasise the multivalent opportunities to leverage bottle-neck assets in ecosystems (Hannah et al., 2016; Hannah \& Eisenhardt, 2018). In line with the development of activity links, DI-ventures prioritized the development of resource ties along the transaction volume with actors to justify the often resource-intense relationship specific adaptations and/or development of resources (Dyer \& Singh, 1998; Dyer \& Hatch, 2006; Dyer et al., 2018). In contrast to Björkdhal's (2009) and Frankenberger et. al's (2014) argument, the development of ventures' resource collections was driven by the aim to leverage external key resources rather than to 
compensate the lack of internal resources. For example, Kea focused on developing data exchange interfaces with major providers of bookkeeping and practice management software that were commonly used by its customers. Although Kea took advantage of external capabilities to develop these data interfaces, the mutual development of physical resources was motivated by the creation of relational rents. Thus, the findings cast new light on the reasons why ventures develop resource ties with other actors in ecosystems. Moreover, the findings highlight the malleability of resources inside and outside of ventures (Dopfer et al., 2017) and in turn draw attention to the emergence of mutually developed resources in resource collections.

Additionally, tying resources with established organisations was beneficial for DIventures since their, often established, resource collections provided stability. The findings confirm Chesbrough's (2006) and Demil and Lecocq's (2010) argument that developing resource ties with strategic partners allows firms to exploit internal resources more efficiently and frees up resources for BM development. In turn, the evidence contrasts Brettel et al.'s (2012) and Pati et al.'s (2018) findings that partnering with incumbents and aligning resources in early development stages is disadvantageous for performance. Moreover, in comparison to Amit and Zott's (2007) and Brettel et al.'s (2012) findings, the development of novel resource combinations augmented transaction efficiencies across BMs. As a result, BMs' resource collections can be characterized simultaneously by novelty and efficiency (Zott \& Amit, 2010) and are not contradictory forces of value creation (Hock, Clauss, \& Schulz, 2016) when managed via a set of coherent resource ties.

Developing multiple bilateral resource ties allowed DI-ventures to capitalise on external resources and structural voids in ecosystems (Hannah et al., 2016; Adner, 2017). Unlike Teece's (2010) argument, the findings suggest that ventures can develop viable BMs and capture value without owning or controlling key bottleneck assets (Foss \& Saebi, 2018; Hannah \& Eisenhardt, 2018). Thus, the findings emphasise the importance of orchestrating the deployment, combination and development of multiple resources for ventures' performance. Hence, coordinating how resources provide services in ecosystems casts new light on how individual ventures can direct ecosystem development. In contrast to the dominant actor (Moore, 1993, 1996) or key bottleneck assets argument (Hannah et al., 2016; Teece, 2018), ventures can shape the way how resources are used by establishing sets of 
resource ties and thus foster consistency in the development of resource collections.

While the consecutive development of resource ties in order to adapt resources across ecosystems increased DI-ventures' resource collection consistency, the increasing interdependencies of internal and external resources reduced resource collections' fluidity (Hock et al., 2016; Dopfer et al., 2017). Since the combination of different systems' functionalities, e.g. combining government and bookkeeping software data interfaces, was central for the evolution of DI-ventures' VCC mechanisms, the process governed and perpetuated DI-ventures' resource collection development. As a result, the idiosyncratic development of individual resources or resource ties had often several ramifications for ventures' resource collections. The findings highlight the early path dependency of DIventures' resource collection development and the resulting limited flexibility to react to ecosystem dynamics (Foss \& Saebi, 2018). Although crafted resource ties facilitated flexibility in the mutual deployment, combination, and development of resources, the range was confined by actors' resource collection flexibility. Thus, the findings shed new light on aspects of developing resource ties with actors that maintain flexible or stable resource collections. Additionally, attention is drawn to the risk of value migration across actors and even ecosystems related to the flexibility of resource collections (Slywotzky, Morrison, \& Andelman, 1997; Hacklin et al., 2018). However, DI-ventures mitigated the risk of value migration across actors by focusing on the development of bilateral resource ties and in turn reducing chances of actors' opportunistic behaviour.

In brief, DI-ventures' approach stresses the importance of firms' embeddedness in the ecosystem and their function as a focal actor orchestrating the deployment, combination and development of ecosystem resources. Following from this, it can be argued that DI-ventures' developed in-depth bilateral resource ties in early BM development stages to (a) capitalise on external resources and capabilities while (b) mitigating risks of value migration due to bilateral dependence, and (c) obtaining strategic positions in ecosystems over time.

Finally, Ol-ventures aimed for the development of resource ties with several actors. Developing physical and organisational resource ties with suppliers allowed ventures to take advantage of complementary external resources from stage one (Lichtenstein \& Brush, 2001; Demil \& Lecocq, 2010). However, Ol-ventures had difficulties to develop resource ties with 
other actors engaged in the distribution of offerings. The potential benefits were outweighed by the often unilateral relationship-specific resource investments Ol-ventures expected for other actors. Already Shafer et al. (2005) warned of the pitfalls of confusing potential value with real value and the implication for actors' willingness to commit resources. Therefore, OIventures refined actor value propositions to reduce entry barriers - required resource commitments - to successfully engage actors in VCC mechanisms. Whio's development of shapers' value propositions as well as Takahē's revision of physiotherapist value propositions highlighted the challenges of developing engaging offerings that justify actors' resource endowments.

Actors' reluctance to engage in the development of resource ties can be explained by ventures' limited legitimacy (Stinchcombe, 1965; Fisher et al., 2016), asymmetrical dependencies of actors in initially proposed actor value propositions (Gulati \& Sytch, 2007; Katila, Rosenberger, \& Eisenhardt, 2008), and low levels of confidence and the uncertainty resulting from Ol-ventures' substantial development of offerings over time (Günzel-Jensen \& Holm, 2016; Bojovic et al., 2018). The finding aligns with Shafer et al.'s (2005) and Sosna et al.'s (2010) argument that engaging actors requires ventures to balance actors' resource endowments with the value co-creation. Similarly, Burns et al. (2016) outlined that in conditions of uncertainty ventures need to make concessions to engage actors in VCC mechanisms. The findings emphasise the importance of balancing the required resource adaptations and actors' value expectations in the resource tying process.

Moreover, attention is drawn to the importance of flexibility and fungibility of ventures' resource collections to account for experimentation. Takahē's and Whio's failed attempts to establish physical resource ties via pre-sales of customised balance boards and machinery highlighted the importance of developing organisational resource ties - a common economic reasoning for the combination of skills - as a prerequisite for the development of physical resource ties (Burns et al., 2016). Moreover, Ol-ventures' extensive refinement of actor value propositions emphasised the volatile nature of their development approach. As already outlined by Sosna et al. (2010) and further highlighted by the findings, trial-and-error development is a resource intense process and challenges ventures' chances of survival. The findings accentuate the importance of developing a basic consistency of internal and external resources as well as the pitfalls of unilaterally developing resources in a trial-and-error 
approach (Demil \& Lecocq, 2010, 2015).

Overall, the findings imply that FI-, DI-, and Ol- ventures followed different approaches when developing resource ties. However, the process was driven by the aim to leverage external resources while balancing resource collections' fluidity for explorative experimentation and positioning the BM in an ecosystem. Specifically, variations in the temporal sequence of developing organisational and physical resource ties and their distinct functions have hardly been discussed in the literature so far (Burns et al., 2016; Snihur et al., 2017). Thus, the findings provide insights into how the deployment (Dothan \& Lavie, 2016; Teece, 2018), combination (Demil \& Lecocq, 2015; Ritter \& Lettl, 2018), and development (Foss \& Saebi, 2018) of resources can be managed in cooperation with actors to enhance the development of productive resource collections. Moreover, attention is drawn to the importance of balancing dynamic consistency (Demil \& Lecocq, 2010, 2015) in the development of resource collections, the spectrum of ramifications of developing shallow or in-depth resource ties (Dopfer et al., 2017), and the implications of interdependencies for changes of individual resources for BMs' resource collections (Fjeldstad \& Snow, 2018). The findings cast new light on the importance of understanding different approaches of resource tying as coordination mechanisms for the development of productive resource collections.

Central to all resource tying approaches was the aim to manage the exposure of ventures' resource collections to uncertainties in ecosystems (Dyer \& Hatch, 2006; Dyer et al., 2018). Fl-ventures developed few and shallow resource ties with redundant actors in order to reduce the exposure of their resource collections. For instance, Kārearea developed its source-code in docker-containers to maintain a high level of independence of its cloud computing provider. In turn, the venture was capable of changing cloud computing service providers and thus was less prone to any unfavourable developments such as rising prices or the evolution of idiosyncratic features.

In contrast, DI-ventures focused on developing bilateral and in-depth resource ties with wide ranges of actors with the aim to manage and enhance dependencies with others and in turn mitigate the risk of the unilateral development of partners' resource collections. 
For example, Kākāpō's co-development of data-interfaces with government organisations created switching costs for all engaged actors. Moreover, the co-development of resources often yielded information advantages for future developments of ecosystems (Gulati et al., 2000; Dyer \& Hatch, 2006; Bojovic et al., 2018). For example, Kākā was a tester for the software and hardware provided by other actors which gave the venture an opportunity to take advantage of cutting-edge technology and insights into future developments.

Following from this, it can be argued that different resource tying strategies have several implications for the exposure of ventures' resource collections to ecosystem dynamics and uncertainty in the continuous development process. While Mangematin et al. (2003) and Sabatier et al. (2010) emphasised the importance of understanding ecosystem dynamics for developing resource collections, ventures' heterogenous resource tying approaches elicit how the exposure of resource configurations can be managed. Whereas FI-ventures managed exposure of their resource collections by developing shallow, often unilateral resource ties with replaceable actors, DI-ventures focused on the development of bilateral resource ties in order to increase switching costs for other actors and thus mitigate the exposure to ecosystem dynamics. Since ecosystem dynamics can render every venture's resource collection obsolete, understanding the levels of exposure and effectively managing these is vital for the development of a firm-ecosystem fit.

Additionally, the development of resource ties defined the centrality of ventures' resource collections in ecosystems. Centrality can be referred to as the extent to which a venture's resource collections occupy a strategic position in the ecosystem (Lavie, 2006; Frankenberger, Weiblen, Csik, \& Gassmann, 2013). As evident in the findings, ventures followed different approaches when positioning their resource collections via resource ties in the ecosystem. On the one hand, ventures' opportunities to combine resources with others were dependent on the intentions signalled to actors in the ecosystem (Bojovic et al., 2018). On the other hand, the development of resource collections was influenced by the transparency of internal resources (Nenonen \& Storbacka, 2010). For instance, whereas Kārearea (FI) "floated the idea" of developing an interface for ETF/MF providers, Kākāpō (DI) "kept pushing strategic partners" and "exposed its IT-systems' architecture" to enhance the development of resource ties. 
The approaches reflected different aims to position ventures' resource collections in ecosystems (Hannah et al., 2016; Hannah \& Eisenhardt, 2018). Fl-ventures desired to maintain independence and flexibility and favoured low levels of centrality. In contrast, DIventures' ambitions to bundle systems' functionalities for VCC mechanisms resulted in high levels of centrality in respective ecosystems. As such, the findings cast new light on how ventures' resource collections can be positioned (central vs peripheral) in ecosystems and for what reasons (e.g. combining resources for mutual development vs the innovative deployment). In contrast to the firm-centric BM literature (Gulati et al., 2000; Demil \& Lecocq, 2015), the findings suggest that the innovative deployment or combination and mutual development of resources inside and outside is crucial for the value created and captured in ecosystems and thus firms' performance. While the redeployment (Hannah et al., 2016) and combination of resources (Demil \& Lecocq, 2010; Barney et al., 2011) have been discussed in the context of, sometimes multi-business, firms, the findings outline the challenges and opportunities inherent in taking an ecosystem stance on the process of resource bundling and its implications for ventures' performance. While FI- as well as DI-ventures' resource collections were productive, the centrality of the resources combined and deployed was characterised by stark contrasts.

On this note, it's important to highlight the ambidexterity of ventures' resource collections which provide services to the firm but also to other actors (Priem et al., 2012; Massa et al., 2017). Strategically making resources available to other actors can result in the rapid development of several outbound resource ties, a solid foundation for a unique and central position in an ecosystem, and the source of a competitive advantage (Adner \& Kapoor, 2010; Adner, 2017). Despite the absence of an explicit and strategic diffusion of resources in ecosystems amongst the investigated cases, the development of a marketplace, e.g. Kea or Takahē, implies at least some consideration and awareness of how other actors use firms' internal resources.

Additionally, attention is drawn to resource collections that span industries or sectors. For instance, Matuku combined consumers' and lines companies' data with modern machine learning and software solutions to create an offering. The findings highlight the importance of recognising blurred industry boundaries and thus different notions of resource centrality in ecosystems in contrast to industry focused research (Gulati, 1999; Teece, 2018). 
In brief, the centrality of a venture's resource collection is characterised by the strategic position of the services yielded in ecosystems. Whereas low as well as high levels of centrality can characterise productive resource collections, strategically developing resource ties is central for obtaining and maintaining a favourable position. The findings provided insights into how firms can develop resource ties to leverage combinations of internal and external resources (Demil \& Lecocq, 2010; Amit \& Zott, 2015; Ritter \& Lettl, 2018) and secure and strengthen the position of their resource collections in ecosystems (Hannah et al., 2016; Fjeldstad \& Snow, 2018).

Finally, resource collections were characterised by a fluidity describing the flexibility of developed resource ties (Teece, 2007) and ventures' ability to rapidly unbundle, redeploy and recombine resource collections in order to obtain new services from existing and novel resources (Hannah et al., 2016; Teece, 2018). Ventures' contrasting resource tying approaches resulted in different degrees of resource collection fluidity.

The interdependencies of resources and resource ties across BMs' resource collections define fluidity. Although scholars have discussed the challenges of interorganisational resource interdependencies (Casadesus-Masanell \& Ricart, 2007; Aversa, Haefliger, et al., 2015), the intra-organisational linkage of resources enjoyed limited attention in research so far (Klang et al., 2014). Specifically, the findings draw attention to the flexibility as well as rigidity resulting from leveraging external resources.

On the one hand, complementing internal with external resources can offer a high degree of fluidity (Warnier et al., 2013). For example, Kārearea's modular IT-system allowed to substitute resources providing similar services such as cloud computing capacities or as one of the co-founders outlined: "We have designed our code that way; it would be reasonably easy to change a service provider". Next to developing deliberately shallow resource ties, Fl-ventures further enhanced their resource collections' fluidity by maintaining high levels of modularity (Aversa, Haefliger, et al., 2015) in order to reduce interdependencies.

On the other hand, tying internal to external resources can inflict rigidity to ventures' resource collections (Demil \& Lecocq, 2015). For instance, Kākāpō's and other actors' 
mutually developed data interfaces created the interdependent bedrock of the venture's resource collection. The co-founder emphasised that "changes to our or partners' resources have multiple know-on effects for our set-up". The in-depth resource ties DI-ventures crafted by mutually developing resources with multiple actors entrenched the interdependencies and resulted in low levels of resource collection fluidity. In brief, although already CasadesusMasanell and Ricart (2007) and Aversa, Haefliger, et al. (2015) accentuated the decomposability and rearrangement of BMs' elements, the findings cast new light on the implications of employing external resources for BMs' modularity and adaptability to change.

Whereas a spectrum of shallow to in-depth resource ties allow ventures to take advantage of external resources' services, the type of resource ties developed as well as resulting interdependencies govern the fluidity of resource collections. Adequately matching resource collections' fluidity to the pace of ecosystem dynamics is crucial to sustain firms' performance. For instance, ventures maintaining high levels of fluidity in slowly changing ecosystems might forgo the advantages of leveraging external resources (Chesbrough, 2006). In comparison, low levels of fluidity in rapidly changing ecosystems can impede the development of effective resource collections and even render them obsolete (Teece, 2018). Therefore, effectively managing resources' fluidity is vital for developing and maintaining effective resource collections that support a firm-ecosystem fit.

Overall, the findings corroborate DaSilva and Trkman's (2014) argument that selecting the right combinations of resources and associated transactions that generate value are a prerequisite for the development of viable BMs. However, new light is shed on how the process of developing effective resource collections that yield unique services is enabled by crafting organisational and physical resource ties. In contrast to Ritter and Lettl's (2018) argument that resource collections are defined by decisions of 'making, buying, or cooperating' in instances, the findings imply that ventures which follow a consistent yet flexible approach of combining resources (FI, DI) are more likely to develop effective resource collections and viable BMs. Different resource tying approaches allowed ventures to reduce exposure to uncertainties of ecosystems, take advantage of external resources and position their resource collections in ecosystems, and maintain different degrees of fluidity for resource re-deployments, re-combinations and development to cope with ecosystem 
dynamics. Figure 76 elicits the development of the exposure, centrality and fluidity attributes of ventures' resource collections across different strategies over time.

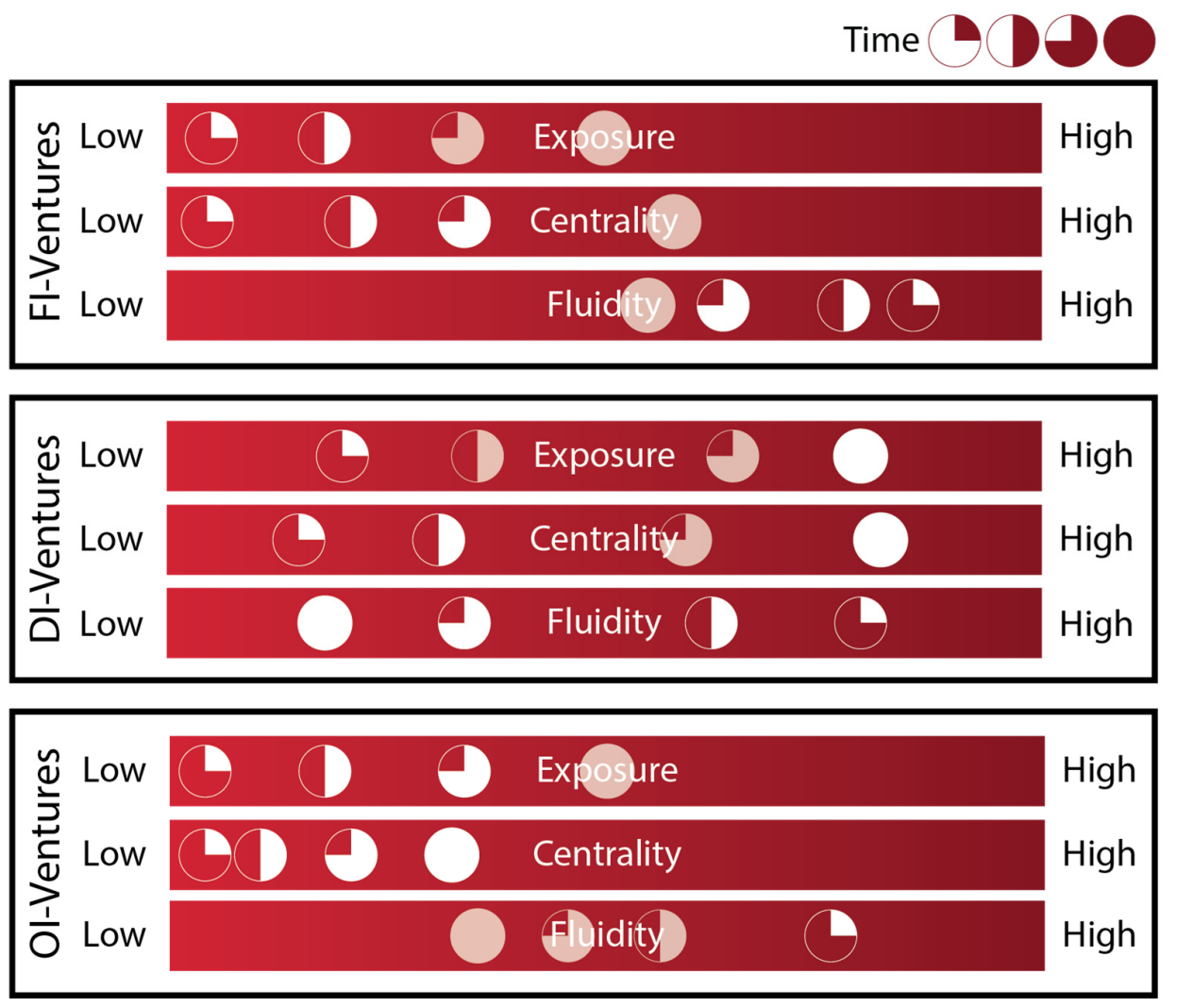

Figure 76 - Resource Ties in BM Configurations

The findings provide evidence for an overlap of the propositions of the ResourceDependency-Theory (RDT) (Pfeffer \& Salancik, 2003) and the Resource-Based-View (RBV) (Penrose, 1959; Wernerfelt, 1984; Barney, 1991) of the firm in the dynamic and ecosystemcentric BM perspective.

On the one hand, ventures' dependence on external resources were managed via contrasting approaches of developing resource ties. Whereas Fl-ventures developed isolated resource ties to maintain low interdependence and high fluidity for BM development, DIventures enhanced the development of interdependencies to shape the ecosystem around them and in turn position the BMs in the centre of it. The heterogenous approaches to craft and control resource dependencies in ecosystems provided interesting insights into ventures' positioning strategies (Shafer et al., 2005; Massa et al., 2017). Moreover, the (de-)centrality 
of BMs' resource collections in ecosystems implies that ventures either seek to obtain a bottleneck-position (Adner, 2017; Hannah \& Eisenhardt, 2018) or maintain fluidity to mitigate effects of potential value migrations (Slywotzky, 1999; Hacklin et al., 2018). Consequently, the findings yield insights into how ecosystem strategies affect resource collection development (Gulati, 1999; Gulati et al., 2000; Aarikka-Stenroos \& Ritala, 2017; Adner, 2017) and therefore the creation of relational rents due to the deployment, combination and mutual development of resources (Dyer \& Singh, 1998; Gulati et al., 2000; Dyer et al., 2018).

On the other hand, the findings draw attention to resource combinations that transcend ventures' boundaries as propagated by Penrose (1959) in the RBV of the firm. Ventures provided evidence that combinations of internal and external resources can yield unique services that enhance VCC mechanisms. Already Schumpeter (1934) outlined that entrepreneurs are not always in control of resources required to introduce innovative organisational forms (Demil et al., 2015; Burns et al., 2016). The ecosystem perspective on BMs' resource collections highlights the importance of (a) the opportunities inherent in the innovative deployment of resources, (b) the combination of resources across ventures' boundaries and (c) respective adaptations and the mutual development of internal to external resources.

Consequently, the deployment, combination and development of resources that are not univocally controlled by the firm can be regarded as the foundation for activities and capabilities that underpin VCC mechanisms. In contrast to the literature (Barney, 2002; Barney et al., 2011), the findings suggest that resource collections spanning ecosystems provide a source of value and competitive advantage as indicated by Massa et al. (2017) and Ritter and Lettl (2018). As a result, the findings provide interesting insights into the process of resource bundling (D. Sirmon et al., 2007; David G. Sirmon et al., 2011; Warnier et al., 2013) and thus potential for creating a competitive advantage based on external resources. Moreover, as evident in the cases presented, balancing integration efforts in the scope of ventures' resource limitations is a critical capability for the development of viable BMs.

In brief, the obtained insights on how, what and why resource ties are developed provide an interesting new perspective for conceptual advancements for the RDT and the RBV (Nason \& Wiklund, 2018). Ventures' capabilities to craft resource ties in order to create effective resource collections that support a firm-ecosystem fit is highlighted by the findings. 
Moreover, the three central attributes of resource collections (exposure, centrality and fluidity) provide a foundation for advancing our understanding of the characteristics of resource collections or bundles and how they influence firms' performance. The findings imply that BMs' resource collections and their respective attributes develop in the outlined patterns (Figure 76). Differences across ventures can be partially explained by varying scope of external resources used and integrated in ventures' emerging BMs and potential costs to maintain the fluidity and/or redundancies of resources in early development stages (Velu, 2017; Pati et al., 2018). However, a wide spectrum of attribute manifestations are considered possible. For example, BMs' resource configurations can be central to an ecosystem and yet fluid. For instance, Doz and Kosonen (2010) provided examples of how incumbents that are central to their respective ecosystem can maintain resource fluidity for future developments. Following from this discussion it can be argued that:

Proposition R1: Crafting coherent sets of resource ties allows ventures to coordinate the deployment, combination and mutual development of internal and external resources in effective resource collections.

Proposition R2: Resource collections are characterised by their exposure to ecosystem dynamics, the centrality of services yielded to ecosystems, and the fluidity of resource interdependencies.

Proposition R3: Crafting coherent sets of resource ties to match resource collections' exposure, centrality and fluidity to ecosystem contextualities is vital to foster a firmecosystem fit.

\subsubsection{Actors and Actor Bonds}

Enrolling actors has been emphasised as a crucial capability in the development of viable BMs (Doganova \& Eyquem-Renault, 2009; Amit \& Zott, 2015). As evident in the findings, developing a wide range of bonds with actors allowed ventures to augment legitimacy, position firms in ecosystems, and facilitate organisational learning.

$\mathrm{Fl}$-ventures developed shallow bonds with small groups of actors to coordinate activities and obtain access to resources. Although shallow actor bonds were intensified over time, Fl-ventures rarely developed in-depth actor bonds to foster knowledge exchange or inter-organisational learning, with Matuku being an exception. In comparison, DI-ventures 
developed an array of in-depth bonds with actors to facilitate knowledge-sharing and interorganisational capability development. For instance, Kākā liaised with several actors to codevelop software and hardware for its flight simulators. Finally, Ol-ventures managed to develop few actor bonds with suppliers and complementors, but had difficulties to enrol critical down-stream partners. However, Ol-ventures leveraged shallow actor bonds to augment legitimacy and position themselves in ecosystems.

The development of actor bonds was often initiated and enhanced due to ventures' participation in accelerator programs. The programs provided a network of established and reliable actors, often sponsors of the program, to engage with. The initial actor bonds crafted allowed ventures to receive much-needed feedback in the process of value proposition development (Bojovic et al., 2018). Developed value propositions were proposed, i.e. signalled (Connelly, Certo, Ireland, \& Reutzel, 2011) to customers and actors, refined based on feedback, and proposed again. This continuous signalling behaviour can be considered as strategic action to develop legitimacy (Zimmerman \& Zeitz, 2002; Zott \& Huy, 2007).

The development of value propositions across all cases illustrates how important actor bonds were for the process (testing vs co-development of offerings). Although the customerinformed development of products and/or service combinations has been amply discussed in literature (Von Hippel, 2005), the findings highlight the importance of refining offerings for other actors to obtain legitimacy and successfully engage them in BMs.

Parallels can be drawn to the persuasion process in order to enrol actors in the exploitation of opportunities (Burns et al., 2016; Snihur et al., 2017). The development of value propositions in order to enrol actors draws attention to the importance of developing legitimacy with heterogenous audiences (Fisher et al., 2017). Legitimacy is considered as a prerequisite to successfully obtain access to external resources and orchestrate activities (Snihur \& Zott, 2013). In contrast to the literature (Bitektine, 2011; Fisher et al., 2017), the findings provide ample evidence that obtaining legitimacy with customers and actors in VCC mechanisms often precedes the need to acquire financial resources from investors.

Developing a proof-of-concept for VCC mechanisms and getting potential actors enrolled can be a critical quality signal for investors (Zott \& Huy, 2007). Although obtaining legitimacy with customers (Zimmerman \& Zeitz, 2002; Shepherd \& Zacharakis, 2003) and other actors, i.e. resource providers (Stinchcombe, 1965; Suddaby, Bitektine, \& Haack, 2017), 
is considered vital for BM development (Bojovic et al., 2018), the research mostly focused on how to gain legitimacy with investors (Doganova \& Eyquem-Renault, 2009; Fisher et al., 2017). The divergence from literature can be explained by the resource- and knowledge-intense industries, e.g. biotechnology, and the extensive research and development efforts preceding value proposition development that legitimacy research is often situated in. However, the findings draw attention to the importance of developing value propositions for customers and actors in order to develop legitimacy with contrasting audiences in different development stages.

Moreover, attention is drawn to the consistency of signals broadcasted to customers and actors in the value propositions development process. FI- and DI-ventures' value propositions were marginally refined, coherently developed, and consistently signalled to customers and actors. In contrast, OI- and failed ventures often extensively refined value propositions and signalled them to customers and actors. In line with Bojovic et al. (2018), the findings imply that sending ambiguous or inconsistent signals has hampered the development of actor bonds and in turn the development of legitimacy. Specifically, Takahē's and Whio's development of value propositions provided a range of signals that can be perceived as ambiguous by other actors. For instance, whereas Takahē encouraged customers to use custom-made balance boards to ensure therapeutic effects in early stages, the venture promoted the use of already available balance boards to increase adoption rates in later development stages. Developing value propositions, refining them based on the feedback from actors, and signalling a coherent evolution can be considered as a continuous quality signal for actors and in turn enhances legitimacy (Zott \& Huy, 2007; Fisher et al., 2017). The findings highlight the development of robust actor bonds that foster continuous interactions in the legitimization process (Stinchcombe, 1965; Kuratko, Fisher, Bloodgood, \& Hornsby, 2017).

In brief, crafting initial actor bonds is vital for the ongoing development of effective value propositions. Moreover, the value proposition development process further enhances actor bonds and provides a quality signal for other actors and thus a solid foundation for legitimacy. Whereas value proposition refinement focused on the development of offerings, the findings also imply that ventures leveraged actors bonds to mutually develop vital element of BMs. Consequently, new light is casted on the antecedents of BM co-development 
(Spieth et al., 2016). The findings imply that the importance of different actor bonds varied in different development stages and thus corroborate Fisher et al.'s (2016) argument that legitimacy demands evolve with ventures' life-cycle. The findings add to our understanding of how ventures can strategically develop actor bonds to drive the development of value propositions and BM elements, and engage other actors successfully in the process to build legitimacy and overcome different legitimacy thresholds across BM development stages.

The actor bonds forged in early stages were often detrimental for ventures' ongoing legitimisation process and positioning in the ecosystem. The findings support Perkmann and Spicer's (2010) argument that developing initial actor bonds results in an identification process performed by audiences that allows ventures to attract vital resources. FI- and DIventures enhanced the identity development process by continuously signalling their actor bonds with reputable actors via SMNs and other channels. For instance, Kea presented " $a$ full profile of newly acquired partners, like the [professional service provider] association, on SMNs channels and the blog". In comparison, OI- and failed ventures hardly broadcasted their engagement with partners.

Signalling actor bonds allows audiences to classify ventures as partner of an established organisation or a type of venture (Aldrich \& Fiol, 1994) and in turn bestow legitimacy upon them by proxy. The benefits of organisational ties for the survival and performance of organisations have been emphasised by Baum and Oliver (1991) and Shan, Walker, and Kogut (1994). However, the findings show the multiple affiliations ventures signalled to heterogenous audiences that transcended engagements with regulators and venture capitalists or investment banks. Developing legitimacy by signalling actor bonds, i.e. organisational ties, highlights the importance of associative legitimacy in the venture creation process (Fisher et al., 2017) and how it can be obtained.

Furthermore, the reciprocity of signalling, i.e. feedback of actors, has been hardly discussed in the literature (Connelly et al., 2011). The findings provide evidence that ventures and actors engaged in VCC mechanisms and mutually signalled affiliations throughout the study. Whereas ventures benefited from being associated with reputable partners, actors enhanced their profile with different audiences as a supporter of start-ups and encouraging innovation. For instance, Kārearea noted that "[ETF provider] talks about Kārearea quite often, we were in their last strategic report". Despite the fact that ventures engage in this 
behaviour independent of different types of developed actor bonds, mostly FI- and DIventures used this practice. Nevertheless, the reciprocity of actors' signals seems to be influenced by differences in actor bonds and thus the external legitimacy enhancing effects. Moreover, actors' reservation of being associated with a venture implies a lack of legitimacy. However, associative legitimacy can be understood as a shared resource developed amongst actors in ecosystems over time. Following from this it can be argued that:

Proposition Aza: Crafting actor bonds is vital for the development of value propositions.

Proposition A2b: Crafting actor bonds is vital for gaining legitimacy with heterogenous audiences.

Proposition A2c: Signalling actor bonds enhances legitimacy with heterogenous audiences.

Developing actor bonds positioned ventures in ecosystems. Actor bonds helped to answer the two crucial questions of who we are and what we do (Navis \& Glynn, 2011). The identity actors attributed to ventures through ecosystems was characterised by the bonds developed and intensified and signalled over time. While actor bonds' effects on firms' positioning in ecosystems has been acknowledged in the literature (George \& Bock, 2011; Aspara et al., 2013), ventures' aim to present themselves as dependent or independent has been largely neglected in research so far. For instance, Fl-ventures aimed to maintain an independent identity and position in ecosystems. The co-founder of Kārearea emphasised that "although we use partners' brands to build trust with customers, we don't want these partnerships to define our brand and us for the rest of days". In contrast, DI-ventures enhanced actor bonds to cement their position in ecosystems. For instance, the co-founder of Kākāpō argued "we became a connected app to [partner] early on; this bond has been defining us and how we related to other partners". Finally, OI- and failed-ventures had difficulties to clearly position themselves in ecosystems via actor bonds. Attention is drawn to Takahē's and Whio's ambitions to serve customers and downstream distribution partners simultaneously. As a result of their aim to serve two markets ( $B 2 C$ and B2B), other actors might had difficulties to attribute an identity to the ventures and position it in the ecosystems (Parmentier \& Gandia, 2017). 
The findings highlight the different positioning approaches ventures pursue in ecosystems (Perkmann \& Spicer, 2010). Ventures' positioning approaches cast new light on being perceived as (in-)dependent actors in ecosystems and related identities. Snihur and Tarzijan (2018) point out the challenges of inter-organisational bonds with diverging identities (ventures and corporates). As evident in the findings and in contrast to the literature (Frankenberger et al., 2014; Velu, 2015), ventures frequently developed bonds with large private and public organisations and focally broadcasted their affiliations. In comparison to Casadesus-Masanell and Ricart's (2007) argument, the findings have not provided any evidence for ventures' reservations to disclose partnerships. In contrast, actor bonds have been leveraged to position ventures in proximity to strategic partners to either enhance legitimacy and/or carve out a position in the ecosystem. However, ventures' positions in ecosystems and their perceived independence of focal actors might affect opportunities to craft new partnerships (Hannah \& Eisenhardt, 2018). As the founder of Kārearea outlined, "we just don't think the time is right for any of those big partnerships because we don't want to become a slave to the man". Following from this it can be argued that:

Proposition A2d: Strategically developing actor bonds and signalling them positions ventures in ecosystems.

Finally, actor bonds enhanced inter-organisational learning and capability development. While FI- and sometimes even Ol-ventures' shallow actor bonds provided insights and industrial intelligence, they rarely facilitated inter-organisational learning and capability development. In contrast, DI-ventures' strong actor bonds fostered the codevelopment of activities and resources and thus inter-organisational learning, capability development, and enhanced the identification of cooperative opportunities. The findings corroborate Amit and Zott's (2015) argument that the evolution of actor bonds leads to an accumulation of trust and mutual knowledge about actors' capabilities and to relational contracting as an efficient interactional mechanism (Gibbons \& Henderson, 2012). Moreover, the findings align with Frankenberger et al. (2014) and Bouncken and Fredrich (2016) who provided evidence that in-depth actor bonds facilitate inter-organisational learning for the development of novel value propositions. However, what and how capabilities are developed 
by creating strong bonds with actors in BMs remained unanswered (Fjeldstad \& Snow, 2018).

The findings show how the development of actor bonds contributes to the evolution of two crucial capabilities. The development of actor bonds enhanced relational capabilities that can be understood as ventures' ability to develop and effectively manage their collaborate efforts (Gulati, 1999; Anand \& Khanna, 2000). On the one hand, relational capabilities enable ventures to (a) identify actors' complementary capabilities and resources, (b) translate opportunities to create relational rents in conceivable actions and potential outcomes (Dyer \& Singh, 1998; Gibbons \& Henderson, 2012; de Figueiredo \& Silverman, 2017; Dyer et al., 2018), and (c) enrol actors under conditions of risk and uncertainty in the exploitation of cooperative opportunities (Burns et al., 2016; Snihur et al., 2017). On the other hand, maintaining relational contracts requires the development and refinement of governance structures, relationship-specific assets, and knowledge exchange routines (Williamson, 1985; Dyer \& Singh, 1998; Dyer et al., 2018; Hannah \& Eisenhardt, 2018).

The development of relational capabilities was prevalent across all cases and thus corroborates Günzel's and Holm's (2013) and Frankenberger et al.'s (2014) argument that relational capabilities are a cornerstone of successfully developing a firm-ecosystem fit. However, differences in the development of actor bonds provide evidence for $\mathrm{Fl}-$, $\mathrm{DI}$ - and $\mathrm{Ol}$ ventures' heterogeneity of relational capabilities.

Whereas FI-ventures' BM development required ventures to establish actor bonds, the minor importance of relationship-specific investments and knowledge exchange mechanisms required limited governance and control (Williamson, 1979; Amit \& Zott, 2001). This suggests that FI-ventures' BM development was primarily supported by relational capabilities that allow ventures to initiate actor bonds. Moreover, FI-ventures' aim to maintain flexibility requires the agile development of new actor bonds rather than the intensification of existing ones. In contrast, DI-ventures' BM development process required ventures to develop relational capabilities to initiate and maintain in-depth actor bonds in order to intensify activity links and resource ties via sharing knowledge (Dyer \& Hatch, 2006; Adner, 2017; Dyer et al., 2018). Consequently, DI-ventures had to develop relational capabilities to initiate and intensify actor bonds to develop and sustain viable BMs. This aligns with DI-ventures' BM development approach to excessively draw upon complementary capabilities and resources in ecosystems. Finally, OI- and failed ventures provide limited 
evidence of developing relational capabilities. Challenges to initiate (e.g. Whio, Moa) or intensify (e.g. Takahē, Pouakai) the development of actor bonds affected ventures' development of value propositions, activity links and resource ties. Following from this it can be argued that:

Proposition Aze: Crafting and maintaining sets of actor bonds is supported by heterogeneous relational capabilities.

Moreover, ventures had to develop knowledge-sharing capabilities to facilitate interorganisational learning (Dyer \& Nobeoka, 2000; Dyer \& Hatch, 2006; Gulati \& Sytch, 2007). The development of absorptive and desorptive capabilities underpins the advancement of inter-organisational learning routines (Cohen \& Levinthal, 1990; Tucci, Chesbrough, Piller, \& West, 2016; Valentim, Lisboa, \& Franco, 2016) and thus was central to harness the benefits of in-depth actor bonds. Unlike FI-ventures, DI-ventures provided evidence for the development of absorptive and desorptive capabilities throughout the study. Joined development projects with actors, such as Kākāpō's development of APIs in cooperation with government agencies, emphasised the importance of knowledge-sharing capabilities for DIventures.

The findings corroborate Dyer and Hatch's (2006) and Chesbrough's (2006) argument that ventures can exploit knowledge resources via sharing it with other actors. Furthermore, they align with Frankenberger et al. $(2014)$ and Velu $(2015,2017)$ who indicated that knowledge-sharing with actors can enhance the firm-ecosystem fit. However, the findings offer novel insights into how ventures can leverage absorptive as well as desorptive capabilities to actively shape ecosystems and enhance a firm-ecosystem fit. While it can be argued that even $\mathrm{FI}$-ventures have to develop absorptive capabilities to internalise knowledge from other ecosystem actors, only very few instances were identified in the Matuku case. OIventures hardly provided evidence for the development of absorptive and/or desorptive capabilities. However, the evidence suggests that DI-ventures actively developed absorptive and desorptive capabilities to shape ecosystems around them. For instance, Kea cooperated with actors to develop offerings based on their services and highlighted that "what's important for us is the development of each party's capabilities in our BM". Following from this, it can be argued that: 
Proposition A2f: Developing absorptive and desorptive capabilities allows ventures to shape ecosystems.

Overall, ventures developed actor bonds to gain and enhance legitimacy, position firms in ecosystems, facilitate inter-organisational learning, and shape ecosystems. Figure 77 illustrates how the development of actor bonds contributed to the emergence of legitimacy, positioned ventures as independent actors in ecosystems, and fostered knowledge-sharing practices across $\mathrm{FI}-, \mathrm{DI}$ - and $\mathrm{Ol}$-ventures. Creating heterogeneous sets of actor bonds requires the development of different relational capabilities. However, Fl-ventures' strategy relied on quickly initiating bonds with new actors whereas DI-ventures had to develop relationship management capabilities to enhance actor bonds. The absence or slow development of relational capabilities was problematic for creating a firm-ecosystem fit as evident in the cases of OI- and failed ventures. Finally, DI-ventures developed knowledge-sharing capabilities to take advantage of strong actor bonds and actively shape ecosystems to create a firmecosystem fit. Ventures' relational capabilities and in turn capabilities to orchestrate sets of actor bonds resulted in different degrees of legitimacy, positions in ecosystems, and intraorganisational knowledge sharing and capability development. 

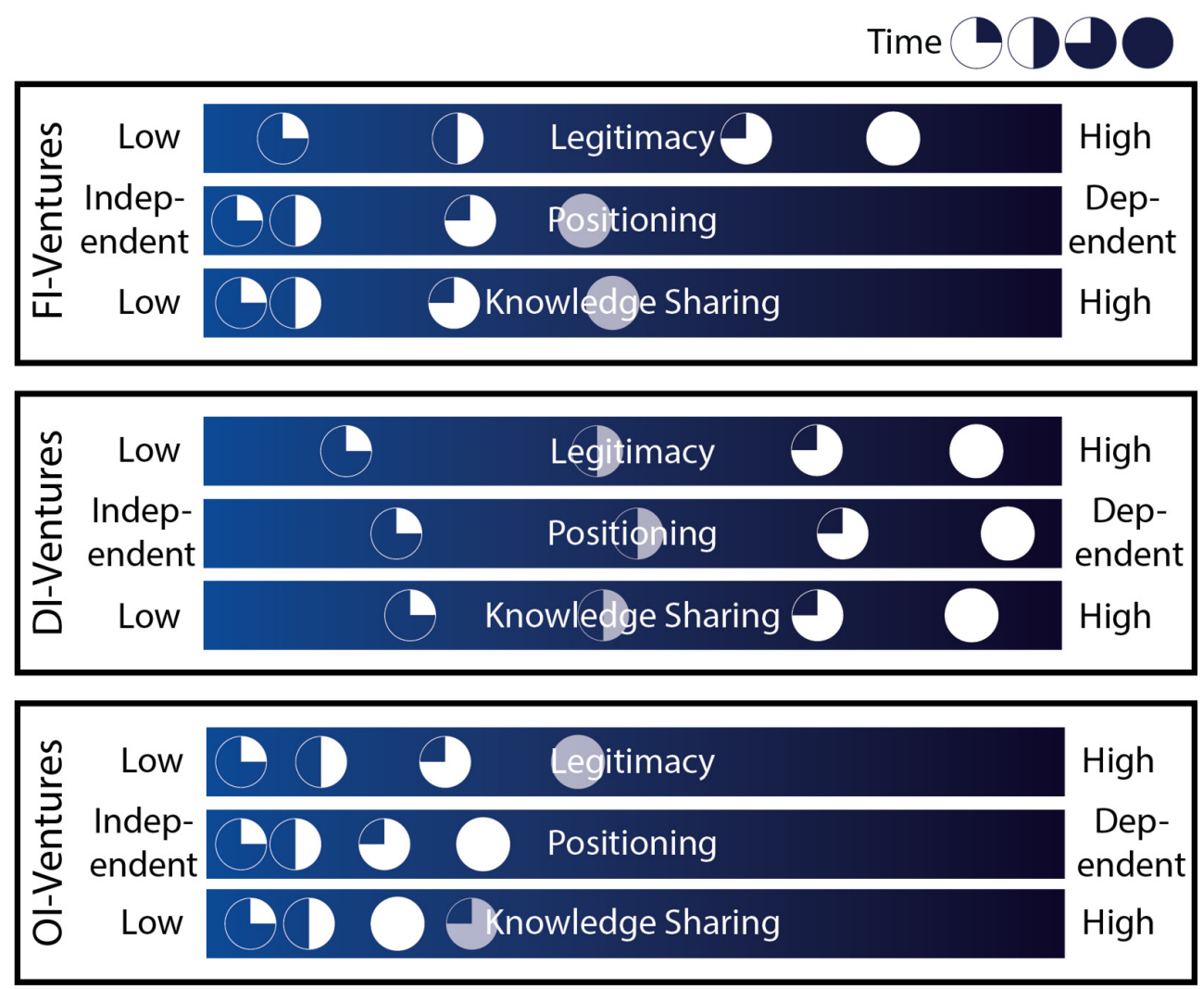

Figure 77 - Actor Bonds in BM Configurations 


\subsection{Summary VARA-Model}

The VARA-model provides a framework to contextualise the development of BMs and their components over time. The proposed value proposition construct allowed the investigation of VCC mechanisms and their interdependencies. The analysis emphasised the bilateral nature of the value co-creation process engaging ventures, customers, and other actors in ecosystems and highlighted the inherent opportunities to capture pecuniary and non-pecuniary value. The surfaced customer value proposition and actor value proposition development patterns drew attention to ventures' heterogenous approaches to conceptualising, refining, and consolidating VCC mechanisms to create and maintain a firmecosystem fit.

Moreover, the VARA-model facilitated an understanding of how VCC mechanisms were underpinned by different activity structures, resource collections, and actor bonds developed over time. The attributes characterising BM component interdependencies provided insights into how viable firm-ecosystem fits emerged over time. The findings draw particular attention to ventures' heterogenous activity linking, resource tying, and actor bonding strategies pursued in the development of BMs. However, across individual BM components (value propositions, activities, resources, actors) and the characterising attributes of their interdependencies (activity links, resource ties, and actor bonds), similarities were identified.

Activity collection reconciliation, resource collection exposure, and the legitimacy actor bonds provide, can be understood as BMs' congruence with ecosystems. The congruence refers to the balance of coherence and tensions of internal and external activities, resources, and actors. Ventures' capabilities to effectively establish and maintain the congruence of internal and external components is crucial for interactions and the evolution of robust firm-ecosystem fits. Already Morris et al. (2005) emphasised the importance of balancing the internal and external fit of BM elements. In a similar vein, Frankenberger et al. (2014) drew attention to the importance of reconciliation of internal and external BM elements. Although widely recognized and as vital for BMs' success (Wirtz et al., 2016), how interactions of internal and external elements have been harmonised has been neglected in 
research so far. The findings highlight how a congruence of BM elements can be developed by crafting a spectrum of activity links, resource ties, and actor bonds to create stable BM configurations (McNamara et al., 2013).

Additionally, activity collection alignment, resource collection centrality, and knowledge sharing via actor bonds can be denoted as the BMs' embeddedness in ecosystems. Embeddedness refers to the degree of $\mathrm{BMs}^{\prime}$ interdependencies with ecosystems. Although embeddedness often paves the way to leveraging external BM components, it can represent a threat to VCC mechanisms as it enhances lock-ins and path-dependency due to opportunity costs of integration development. Consequently, ventures' capabilities to develop and maintain an adequate degree of embeddedness in ecosystems can be regarded as vital for BMs' firm-ecosystem fit.

Finally, activity collection velocity, resource collection fluidity, and the independent position acquired via actor bonds can be summarised as flexibility. Flexibility refers to the ability to resolve existing and create new interdependencies to facilitate BMs' co-evolution of ecosystems. Matching BMs' flexibility with the motion of ecosystems allows ventures to ensure the timeliness of VCC mechanisms while reducing redundancies maintained for developments. Consequently, it can be considered as a paramount capability of ventures to deal with motion in ecosystems and ensuring a firm-ecosystem fit over time.

VCC mechanism development strategies and the congruence, embeddedness, and flexibility of activity links, resource ties, and actor bonds amounts to the viable interactional structure of BMs, i.e. a firm-ecosystem fit. As evident in the findings, FI- and DI-ventures' approaches resulted in the development of viable BMs. The contrast of these two strategies implies that consistency throughout the development process enhances the viability of emerging BMs. Moreover, the volatile development of Ol-ventures and their limited success, evident in proxy indicators (customer growth, funding, etc.), further emphasise the importance of BM development strategies' consistency.

The presence of two distinct but effective strategies highlights the equifinality of BM 
development approaches (Nenonen \& Storbacka, 2010) and the firm-ecosystem fit in similar contexts. Likewise, the heterogenous sets of capabilities required for the successful development of viable BMs emphasises the multivalent nature of the firm-ecosystem fit and the various pathways to secure and sustain it. Figure 78 provides an overview of the VARAmodel characteristics and potential opportunities for the development of an effective firmecosystem fit.

Although this study has surfaced two development strategies that resulted in viable BMs, an array of potential configurations can be envisioned within the VARA-model. In contrast to the design themes proposed by Amit and Zott $(2001,2010)$, the VARA-model allows for a broad band of different configurations spanning organisational boundaries along defined dimensions. Moreover, the VARA-model allows to (a) accommodate the combination of multiple value drivers underpinning different design themes, (b) extend design themes beyond focal firm's boundaries, and consequently (c) emphasise opportunities to combine value drivers at the firm-ecosystem nexus to create innovative and viable BMs. 

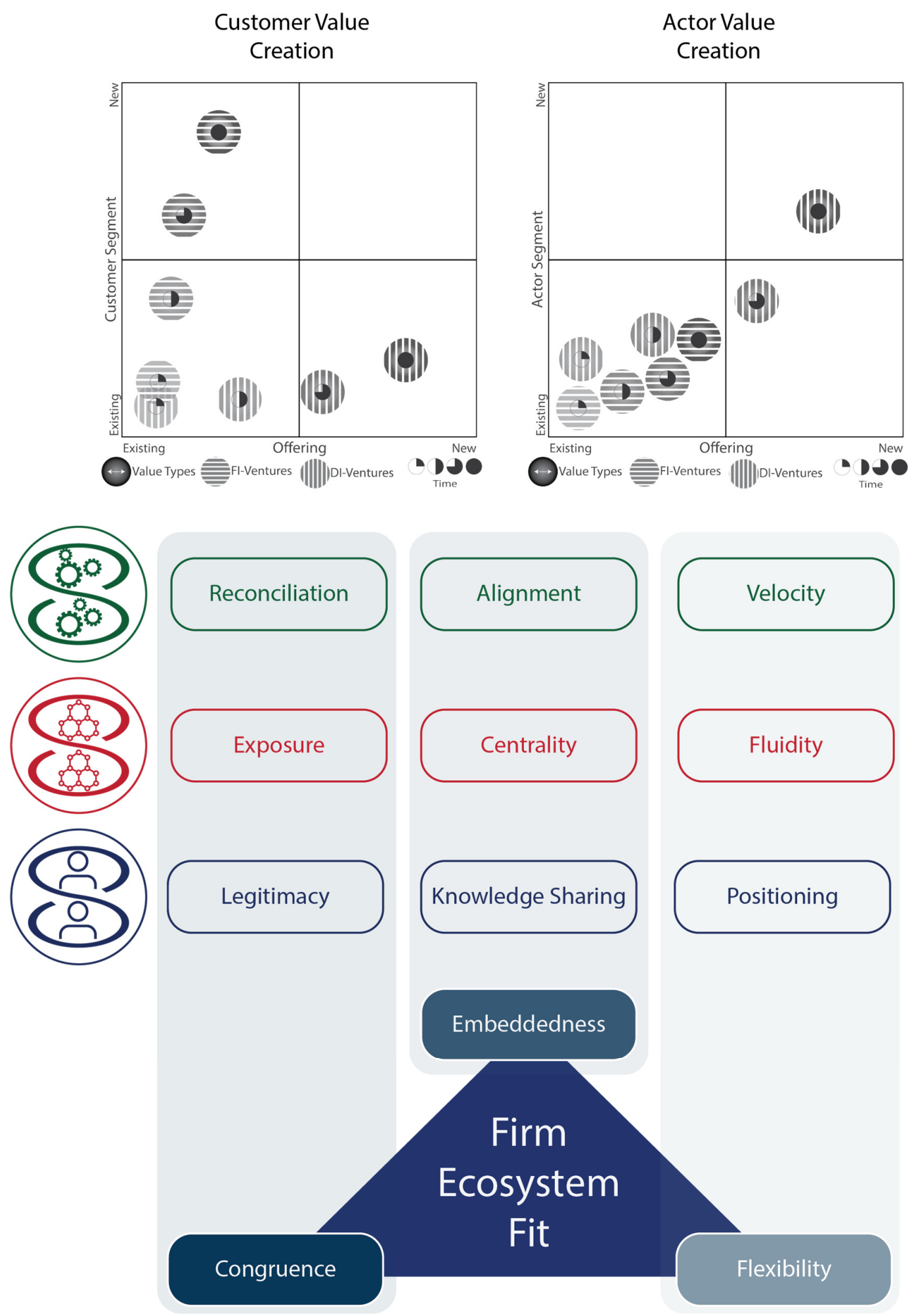

Figure 78 - VARA-Model - Overview 


\subsection{Reflecting on the VARA-Framework}

Analysing and contrasting ventures' approaches to developing viable BMs in ecosystems sheds new light on the BM concept. The VARA-framework emphasises the mutual influence of internal and external activities, resources, and actors and thus transcends existing BM frameworks. It yields novel insights into the development of ventures' VCC mechanisms, activity links, resource ties, and actor bonds as well as how they amount to firmecosystem fits that underpin viable BMs. As such, the VARA-framework can be employed as a tool for entrepreneurs and managers to conceptualise, explore, and refine VCC mechanisms and underpinning interdependencies of activities, resources, and actors beyond their ventures to enhance the viability of their BMs.

Moreover, the VARA-framework highlights interactional dynamics of ventures and their ecosystems when conceptualising, exploring, and refining BMs that are paramount for VCC mechanisms and firms' survival and growth. The VARA-framework draws attention to primarily interactional activities, resources, and actors. However, the emphasised ecosystem perspective points out interdependencies' implications for ventures' and actors' activity structures and resource collections and thus a safeguard against taking a too narrow or only interactional stance in the analysis. 


\section{Conclusions}

\subsection{Chapter Introduction}

The aim of this thesis is to advance our understanding of the BM concept as a firm boundary-spanning construct that is strategically developed in ecosystems in a constant flux. The VARA-model, conceptualised in the literature review, enabled the contextualisation of the BM development process. The investigation and analysis of ten ventures in early development stages revealed foundational processes and capabilities required to develop a firm-ecosystem fit that can be considered as the fulcrum of BMs' viability as it orchestrates the interactions of firms and other ecosystem actors in VCC mechanisms. The findings were discussed and contrasted with the BM literature to reveal commonalities with previous research and yield insights into unexplored fields. Valuable insights were provided into the BM development process, ventures' heterogenous sets of capabilities that supported it, and how they have contributed to the development of viable BMs.

\subsection{Research Questions, Findings, and Contributions}

The research questions' locus on how ventures can develop viable BMs in ecosystems guided the investigation of ten start-ups in the Greater Wellington area. This thesis made several valuable contributions for advancing our understanding of value propositions, VCC mechanisms, and strategic BM development in ecosystems. The connection between the contributions and research questions is illustrated in Figure 79. 


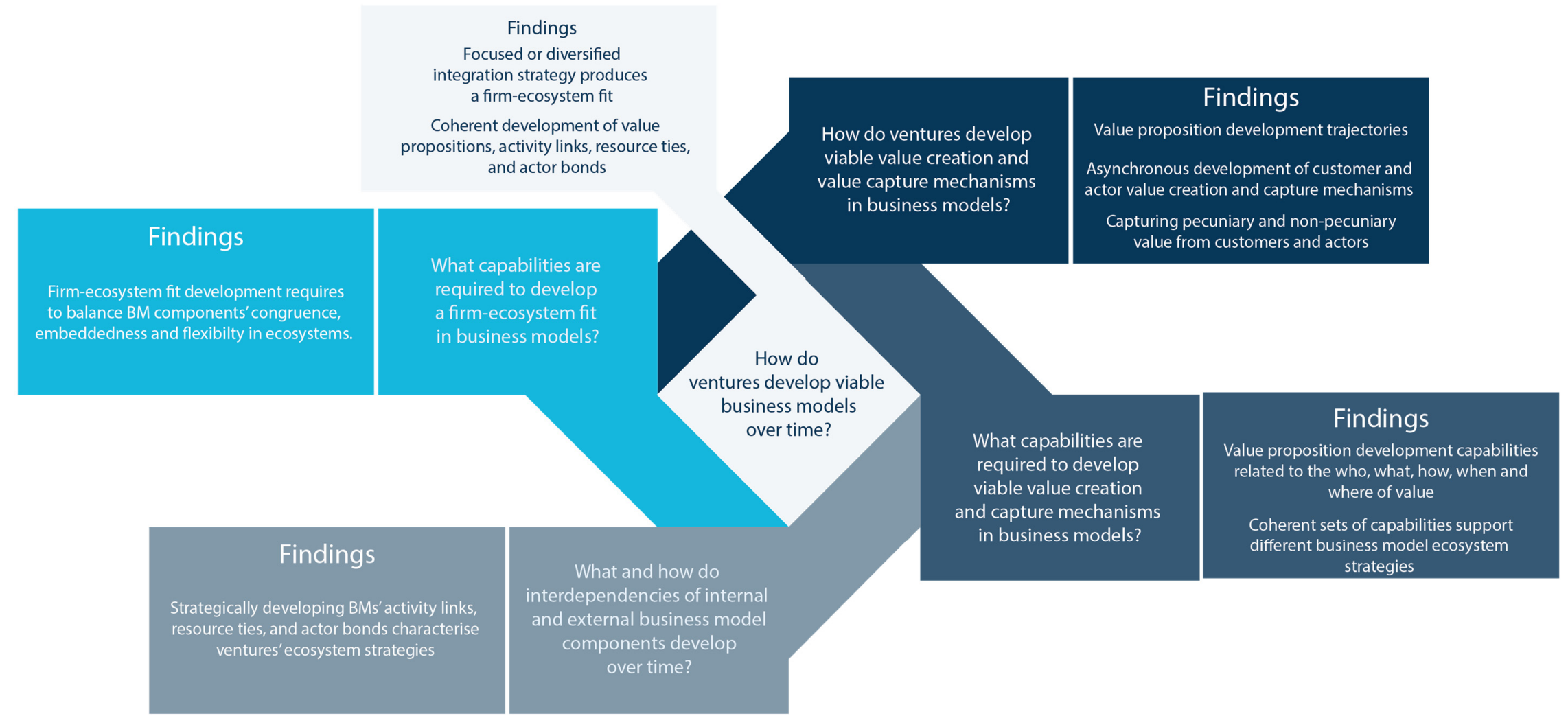

Figure 79 - Research Questions Asked \& Answered 


\subsection{Contributions to the Business Model Concept}

\subsubsection{Value Propositions, Value Co-Creation and Capture in Business Models}

The value proposition framework developed (Chapter 2.4.3.1, p. 44) allowed to contextualise how ventures engage customers and actors in VCC mechanisms. Scholars emphasised the increasing importance of understanding how value is co-created in ecosystems (Prahalad \& Ramaswamy, 2004; Demil et al., 2015; Dyer et al., 2018; Hannah \& Eisenhardt, 2018). Adner (2017) and Priem et al. (2018) drew attention to the value proposition development in BMs as the foundation for VCC and thus firms' performance. However, the value proposition concept remained largely orphaned, under-theorised, and un-explored in the literature (Payne et al., 2017). While practitioners have introduced design thinking tools for value proposition development (e.g. Osterwalder et al., 2015) and related customer journeys (Norton \& Pine Ii, 2013; Enger \& Vollhardt, 2016), academic research provides limited insights to advance our understanding of value propositions and their implications for VCC mechanisms (Massa et al., 2017; Payne et al., 2017; Vargo \& Lusch, 2017).

The here proposed value proposition framework provides a foundation for understanding how the development of individual dimensions (who, what, how, when, and where of value) catalyse VCC mechanisms as a demand- and supply-side phenomenon in ecosystems (Massa et al., 2017; Payne et al., 2017; Priem et al., 2018). The findings revealed two distinct customer value proposition development strategies across ventures. Customer value propositions developed either via the diversification of customer segments (FIventures) or the diversification of offerings for one or two related customer segments (DIventures). Nevertheless, the development of robust customer value creation mechanisms was underpinned by consistently pursued strategies throughout the study (Figure 80). The revealed strategies and how they are reflected in the development of customer value propositions' individual dimensions add to our understanding of how they can be developed to enhance customer value co-creation mechanisms and foster growth (Storbacka et al., 2013; Bojovic et al., 2018; Priem et al., 2018).

Moreover, the findings cast new light on the development of value propositions for actors. Despite the prevalence of VCC engaging external actors (Demil \& Lecocq, 2010; Amit \& Zott, 2015), the development of explicit actor value propositions and/or other means to 
engage actors in BMs has been hardly discussed in the literature. While several valuable contributions were made in the context of multi-sided BMs (e.g. C. Baden-Fuller \& Haefliger, 2013; Rumble \& Mangematin, 2015), the idiosyncratic circumstances provide limited scope for analytical generalisations for the BM development process.

The here proposed value proposition framework allowed the analysis of actor value co-creation mechanisms and what strategies ventures pursue in different contexts and thus provides a first stepping stone to advance our understanding of why, how, and what actor value propositions ventures develop (Saebi et al., 2017; Fjeldstad \& Snow, 2018). The heterogeneous development of actor value propositions across FI-, DI-ventures revealed interesting contrasts. Fl-ventures focused on developing a limited set of offerings for a small group of homogeneous actors. In comparison, DI-ventures developed a wide range of offerings for various actors. Analysing the resulting interactional structures yielded insights into the cooperative dynamics of ventures and actors in distinct ecosystem strategies (Casadesus-Masanell \& Ricart, 2007; Brea-Solís et al., 2015; Hannah \& Eisenhardt, 2018). The dedicated development of actor value propositions indicates that ventures pursue an ecosystem strategy when integrating with actors to co-create relational rents (Dyer et al., 2018) and, as a result, nurture a coherent firm-ecosystem fit underpinning viable BMs. Thus, the findings provide novel insights into how ventures can implement ecosystem strategies, what cooperative dynamics result from those strategies, and how they affect firms' performance (Adner, 2017; Fjeldstad \& Snow, 2018).

Attention is drawn to the prevalent asynchronous development of customer' and actors' value propositions across FI- and DI-ventures. The findings highlight that ventures are not extending the number of offerings and customers or actors engaged in VCC mechanisms at the same time. Pursuing customer and actor as well as offering diversification synchronously might increase complexity beyond ventures' means, i.e. resources and/or capabilities, to address such a development adequately (W. Smith, Binns, \& Tushman, 2010). In brief, the findings highlight different value proposition development trajectories (Figure 80 ) in respect to ventures' ecosystem strategies pursued to create a firm-ecosystem fit.

The contrasting development of value propositions and in turn VCC mechanisms points to the underpinning sets of capabilities (Frow et al., 2014; Payne et al., 2017). The 
findings provide evidence that ventures have to assemble a set of capabilities to develop effective value propositions to engage customers and actors and sustain their engagement in VCC mechanisms. The heterogeneity of capabilities required to develop effective value propositions has been hardly discussed in BM literature (Storbacka et al., 2013; Frankenberger et al., 2014; Fjeldstad \& Snow, 2018; Foss \& Saebi, 2018). The value propositions framework proposed provides a foundation for understanding what capabilities supported the development of value propositions and in turn a firm-ecosystem fit (Zott \& Amit, 2013; Demil et al., 2015; Spieth et al., 2016; Foss \& Saebi, 2018).

Identifying new customer and actor segments, i.e. the who of value, as well as comprehending their use-context, i.e. the when and where of value, was vital for the development of Fl-ventures' value propositions. In contrast translating customer needs and exploring opportunities to co-create value with actors, i.e. the what of value, and experimental offering development, i.e. the how of value, was essential for DI-ventures' value proposition development process. The nexus of value proposition development strategies and ventures' capabilities yielded pivotal insights into how interactions can be fostered, what capabilities underpin the development of a firm-ecosystem fit, and how it affects BMs' robustness (Teece, 2010; Tantalo \& Priem, 2016; Teece, 2018).

In brief, the findings shed new light on different value proposition development trajectories and the heterogenous sets of capabilities supporting their evolution (Figure 80). Of particular interest is the orchestrated asynchronous development of customer value propositions and actor value propositions as well as the heterogenous sets of capabilities that support a dedicated strategy. 
Value Proposition Development Trajectories

Customer Value Proposition Development

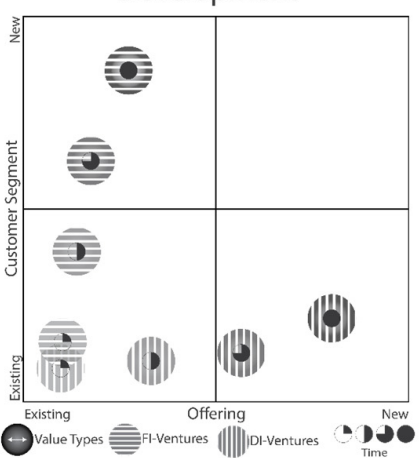

Actor Value Proposition Development

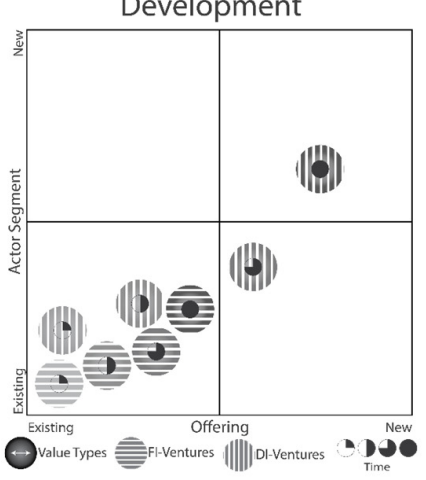

Value Proposition

Development Capabilities

FI-Ventures |||||| DI-Ventures
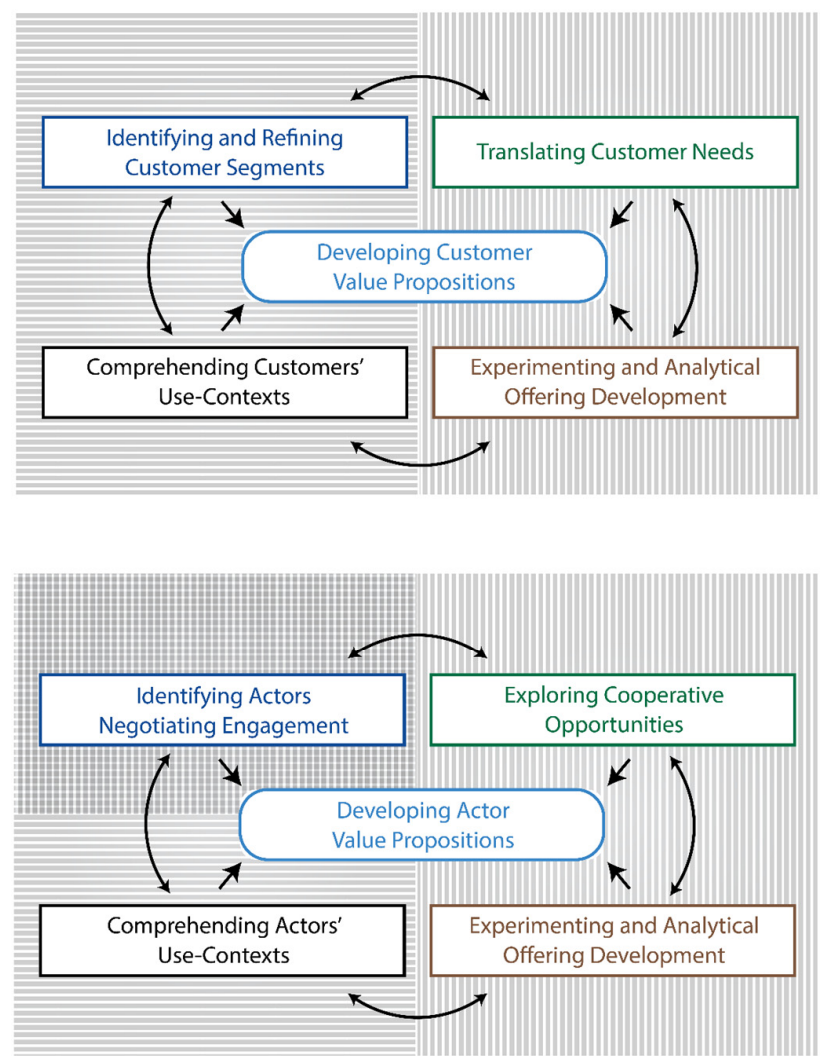

Figure 80 - Customer and Actor Value Proposition Development Capabilities

Finally, the findings advanced our understanding of how value co-creation with customers and actors needs to be reflected by the development of effective value capture mechanisms. The findings amounted to the notion that, next to customers, ecosystems provide a rich array of sources of value (Gordijn, Akkermans, \& Van Vliet, 2001; Sosna et al., 2010). In addition, the findings added to our understanding of value units as common basis to assess the value that is co-created and a fulcrum of interactions and exchanges in ecosystems (Hedman \& Kalling, 2003; McGrath, 2010; C. Baden-Fuller \& Haefliger, 2013). As such, the value unit provides an important bridging construct between value co-created and value captured and in turn elicits how balancing means of capturing pecuniary and nonpecuniary value can enhance value capture in ecosystems (Arend, 2013; Tantalo \& Priem, 2016; Hannah \& Eisenhardt, 2018; Priem et al., 2018). This suggests that means are not 
limited to subscription based pricing models but transcend customer-firm dyads (CasadesusMasanell \& Heilbron, 2015; Foss \& Saebi, 2018).

Moreover, the prevalence of periodical pricing plans highlighted the importance of temporal aspects of value capture mechanisms. Whereas different pricing options are prominently featured in BM literature (Chesbrough, 2010; Velu, 2017), the findings presented provided insights into why and how temporal aspects influenced the development of ventures' value capture mechanisms.

The value proposition framework facilitated an understanding of how and why ventures develop individual dimensions of value capture mechanisms to reflect and address the development of customer value propositions and actor value propositions. Whereas a limited set of development capabilities supported the evolution of customer value propositions and actor value propositions, their asynchronous development mandates a comprehensive set of capabilities to take advantage of a range of interactions with customers and actors and in turn develop effective value capture mechanisms (Figure 81).

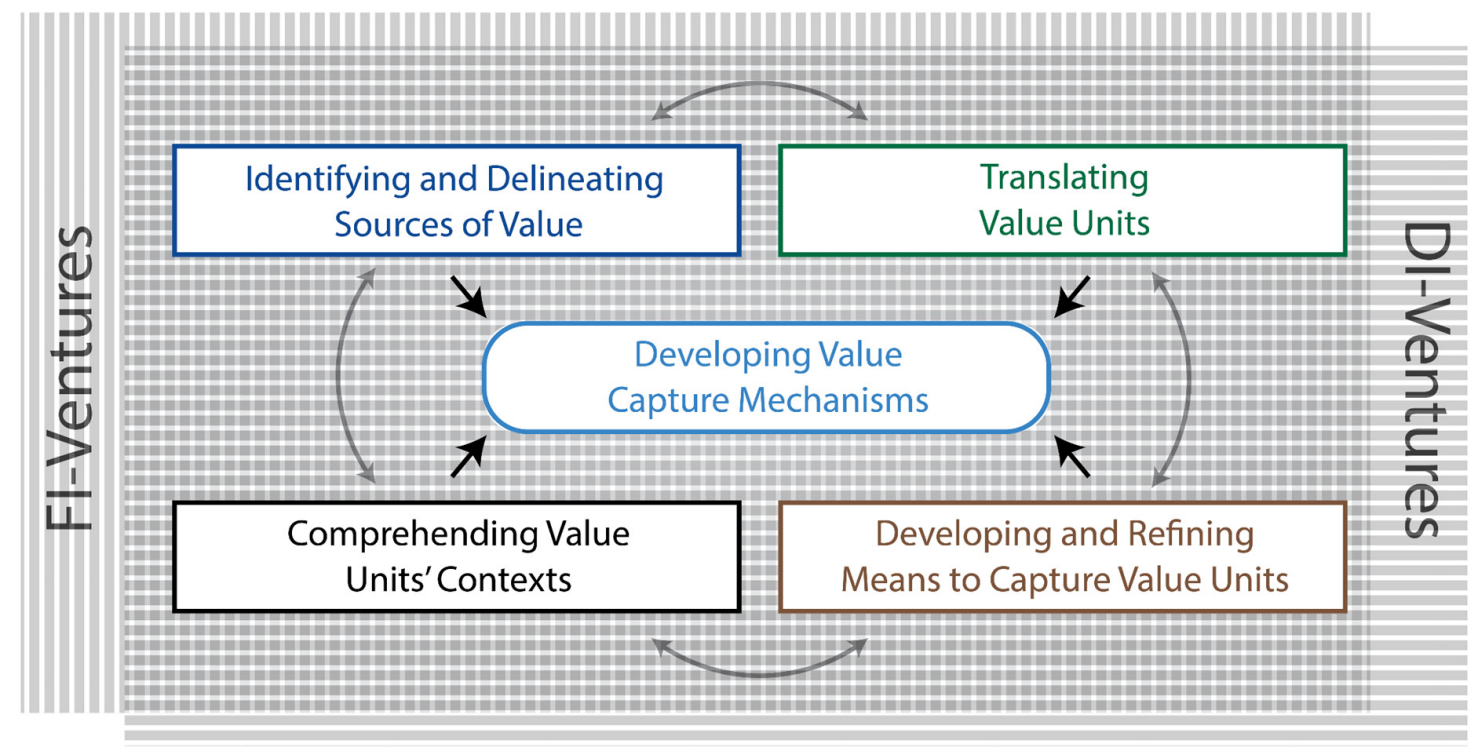

Figure 81 - Value Capture Mechanisms Development Capabilities

To sum up, the introduced value proposition framework allows the contextualisation of VCC mechanisms that span organisational boundaries and thus highlight the interactional 
nature of value co-creation in BMs (Amit \& Zott, 2015; Massa et al., 2017). The findings elicit what strategies ventures purse when developing and refining customer value propositions, actor value propositions, and value capture mechanisms. Additionally, value proposition development capabilities were identified as well as what combinations thereof support ventures' ecosystem strategies. As a result, the findings make valuable contributions to our understanding of value creation and capture in BMs (Fjeldstad \& Snow, 2018), how the underpinning mechanisms develop over time (Pennie \& Adrian, 2011; Frow et al., 2014; Payne \& Frow, 2014; Payne et al., 2017), and what capabilities support the development process (Teece, 2018). As such, the findings provide answers to two research question of how ventures develop viable value creation and capture mechanisms and what capabilities underpin the process.

\subsubsection{Activity Links, Resource Ties, and Actor Bonds}

The advanced understanding of emerging interdependencies of BM components and their attributes is another major contribution of this thesis to the BM literature. The VARAmodel provides a framework that connects VCC mechanisms with the development of activity links, resource ties, and actor bonds and thus elicits how BM components are interconnected and orchestrated to create a firm-ecosystem fit.

Activities and activity links have been a central construct in BM research to explain performance (Zott \& Amit, 2007; Aversa, Furnari, et al., 2015). Although research on activity configurations has widely acknowledged the importance of linking activities beyond focal firms' boundaries (Thompson, 1967; Porter, 1985, 1996; Stabell \& Fjeldstad, 1998), empirical research focused primarily on intra-firm activity links (Siggelkow, 2002; Amit \& Zott, 2015; Täuscher, 2017). The here presented inter-organisational activity linking approaches contribute to our understanding of activity linking that transcends ventures' boundaries. The contributions made provide valuable insights into activity linking across ecosystems and implications for value proposition design (Adner \& Kapoor, 2010; Adner, 2017) as well as potential strategies employed by ventures (Hannah \& Eisenhardt, 2018) to create a firmecosystem fit. 
Furthermore, activity configurations' reconciliation, alignment, and velocity attributes provide insights into what combination of different types of activity links result in operative activity configurations that underpin viable BMs (Zott \& Amit, 2010; Amit \& Zott, 2015). The emerging attributes characterising ventures' activity configuration reflect the perused ecosystem strategies and provide evidence that ventures deliberately craft activity links (Ritter \& Lettl, 2018). Next to Zott and Amit's (2010) static activity configuration design themes, the here introduced attributes provide a means to describe their development over time. The findings cast new light on activity linking in the context of ecosystems and how different strategies can influence the development of ventures' BMs and their success over time (Massa et al., 2017; Fjeldstad \& Snow, 2018).

Moreover, the proposed two-factor theory of activity linking provides a foundation for advancing our understanding of why some ventures have difficulties to develop and maintain working activity configurations (reconciliation) and others are more successful (alignment) in homogeneous ecosystems (Siggelkow, 2002). The argument of an activity configuration consistency threshold enhances our understanding of why and how changes to activity interdependencies in ecosystems can result in the failure of individual firms and the decline of entire sectors (Christensen, 2013; Adner, 2017). Finally, the activity linking capacities proposed can provide a micro-foundation for the development of a set of ecosystem capabilities and how they influence firms' long-term performance.

Resources and resource ties have been considered a critical component in BMs (Demil \& Lecocq, 2010; Hannah et al., 2016). Since idiosyncratic combinations of resources yield unique services and provide a foundation for VCC mechanisms and firms' competitive advantage (Penrose, 1959; Wernerfelt, 1984; Barney, 1991), the importance and potential of opportunities to combine internal with external resources cannot be understated (David G Sirmon \& Hitt, 2003). Although BM research acknowledged the importance of combining internal and external resources to realise complementarities (Amit \& Zott, 2001; Demil \& Lecocq, 2015; Saebi \& Foss, 2015), empirical research lags behind conceptual advancements. The here presented findings provide valuable insights into how ventures can combine and leverage external ecosystem resources to co-create relational rents (Hannah et al., 2016; Dyer et al., 2018). Developing an understanding of combinations of relationship-specific 
organisational and physical resource ties provides valuable insights on resource configurations in BMs. As outlined by Demil et al. (2015) and Ritter and Lettl (2018), an enhanced understanding of resources in the BM context can inform theoretical advancements of the RBV (Nason \& Wiklund, 2018).

The findings draw attention to the ecosystem attributes, namely exposure, centrality, and fluidity, of firms' resource configurations. Since these attributes describe resource configurations, they emphasise that combinations of resources yield unique services and thus reflect Penrose's (1959) argument about what constitutes a source of a competitive advantage (Nason \& Wiklund, 2018).

Special attention is drawn to the exposure attribute of resource configurations. It casts new light on resource configurations' currency of providing valuable services and in turn ecosystem dynamics and what developments can render firms' advantages obsolete (Nason \& Wiklund, 2018). Similarly, the centrality of the services firms' resource configurations provide for an ecosystem draw attention to the importance of understanding what function and role focal firms have and how they can leverage their position in an ecosystem (Eisenhardt et al., 2016; Adner, 2017; Hannah \& Eisenhardt, 2018). Finally, the discussion of resource fluidity in the context of dynamic ecosystems (Teece, 2018) and the related risk of value migration (Slywotzky, 1999; Hacklin et al., 2018) offer another valuable contribution to the discussion of resources in ecosystems and as a potential source of a competitive advantage (Nason \& Wiklund, 2018). The three resource configuration attributes give novel insights into how resources in BMs and ecosystems can be organised to create effective interactional structures (Demil et al., 2015), what resource arrangements might enhance dynamic consistency in BMs (Demil \& Lecocq, 2010), and what internal and external ecosystem resources can be leveraged in BMs (Massa et al., 2017). Finally, the findings advance our understanding of the capabilities ventures have to develop to effectively orchestrate resources in ecosystems over time (Demil \& Lecocq, 2010; Hannah et al., 2016).

Actors and actor bonds have been largely neglected in BM research (Klang et al., 2014; Massa et al., 2017). Although scholars have continuously emphasised the importance of advancing our knowledge of how to interact with actors for VCC mechanisms (Wirtz et al., 2016), research has been limited to firms and customers as the focal actors in BMs (Arend, 
2013). The findings presented made valuable contributions to different domains. First, attention was drawn to the importance of actors and their multiple functions in VCC mechanisms. The findings emphasised what and how actors can be engaged in VCC mechanisms in BMs (Tantalo \& Priem, 2016; Foss \& Saebi, 2018). As such, it allowed the advancement of our understanding of actors as co-creators of value and how different forms of engagement can be facilitated by the development of customer value propositions and actor value propositions over time (Fjeldstad \& Snow, 2018; Priem et al., 2018). Investigations into the value co-creation in BMs are rare and characterised by a firm-customer locus (Storbacka et al., 2012). Thus, the findings made valuable contributions to the notion of value co-creation engaging multiple actors in BMs.

Moreover, with whom, why, and how ventures developed actor bonds explains how engagements with other actors affect the development of viable BMs over time (Arend, 2013; Wirtz et al., 2016). In contrast to contemporary legitimacy development research (Überbacher, 2014; Fisher et al., 2017), the findings point out that ventures develop actor bonds with heterogenous audiences to obtain legitimacy and pivotal access to resources. Additionally, ventures amplify affiliations with actors via SMNs and other channels in order to enhance legitimacy by proxy in ecosystems. Hence, the findings provide interesting insights into how legitimacy can be created with heterogenous sets of actors.

The development of legitimacy coincides with the emergence of ventures' identity and positioning in ecosystems. Broadcasting affiliations with reputable actors in the sector often leads to the association with groups of other ventures (Stinchcombe, 1965; Aldrich \& Fiol, 1994) and results in converging identities of ventures. As such, the findings draw attention to the positioning of BMs in ecosystems (Gulati, 1999), potential scopes of opportunities to cocreate and capture value (Adner, 2017; Hannah \& Eisenhardt, 2018), and related risks of value migration (Slywotzky et al., 1997; Hacklin et al., 2018).

Besides, the development of actor bonds showed how inter-organisational learning and capability development can be facilitated. Whereas inter-organisational learning can be considered important for VCC mechanisms and creating a firm-ecosystem fit (Dyer \& Nobeoka, 2000), developing capabilities that facilitate the process was critical for shaping ecosystems (Amit \& Zott, 2015; Saebi et al., 2017). Thus, understanding the development of absorptive and desorptive capabilities provides insight into how ventures' BMs are influenced 
and even co-developed with other actors (Spieth et al., 2016) not only as a mere reaction to evolving ecosystems but rather an act of active agency (Foss \& Saebi, 2018). The development of different relational and knowledge-sharing capabilities, discussed in this thesis, advanced our understanding of what capabilities support the development of viable BMs in ecosystems.

Finally, the attributes characterising ventures' set of actor bonds explain how and what relationships with which actors can support the development of a firm-ecosystem fit (Amit \& Zott, 2015). Curating actor bonds allowed ventures to manage their legitimacy with different audiences, acquire a desired position in an ecosystem, and facilitate access to vital knowledge. The findings cast new light on the multivalent functions of actor bonds and how they can be leveraged to create a firm-ecosystem fit (Wirtz et al., 2016; Massa et al., 2017).

Combinations of Activity Links, Resource Ties, and Actor Bonds: The attributes of BMs' activity structures, resource collections, and actor bonds elicit the interactional structures that characterise firm-ecosystem fits, how they develop over time, and thus how they enable viable BMs (Fjeldstad \& Snow, 2018). The VARA-Model catalyses BM component combinations' attributes into three distinct ecosystem management capabilities (AarikkaStenroos \& Ritala, 2017; Adner, 2017), namely congruence, embeddedness, and flexibility (Figure 82). Ventures' ability to effectively develop and manage BMs in dynamic ecosystems depends on their capabilities to orchestrate the consistent development of activity links, resource ties, and actor bonds over time.

In short, the VARA-model's ability to describe, explain and explore how and what interdependencies emerge across the most salient BM components and what attributes characterise them (Figure 82), offers a valuable contribution to BM theory (Massa et al., 2017; Fjeldstad \& Snow, 2018; Ritter \& Lettl, 2018). As such, the VARA-model provides answers to two research questions. First what and how interdependencies of internal and external BM components develop over time and second what capabilities support that development. 


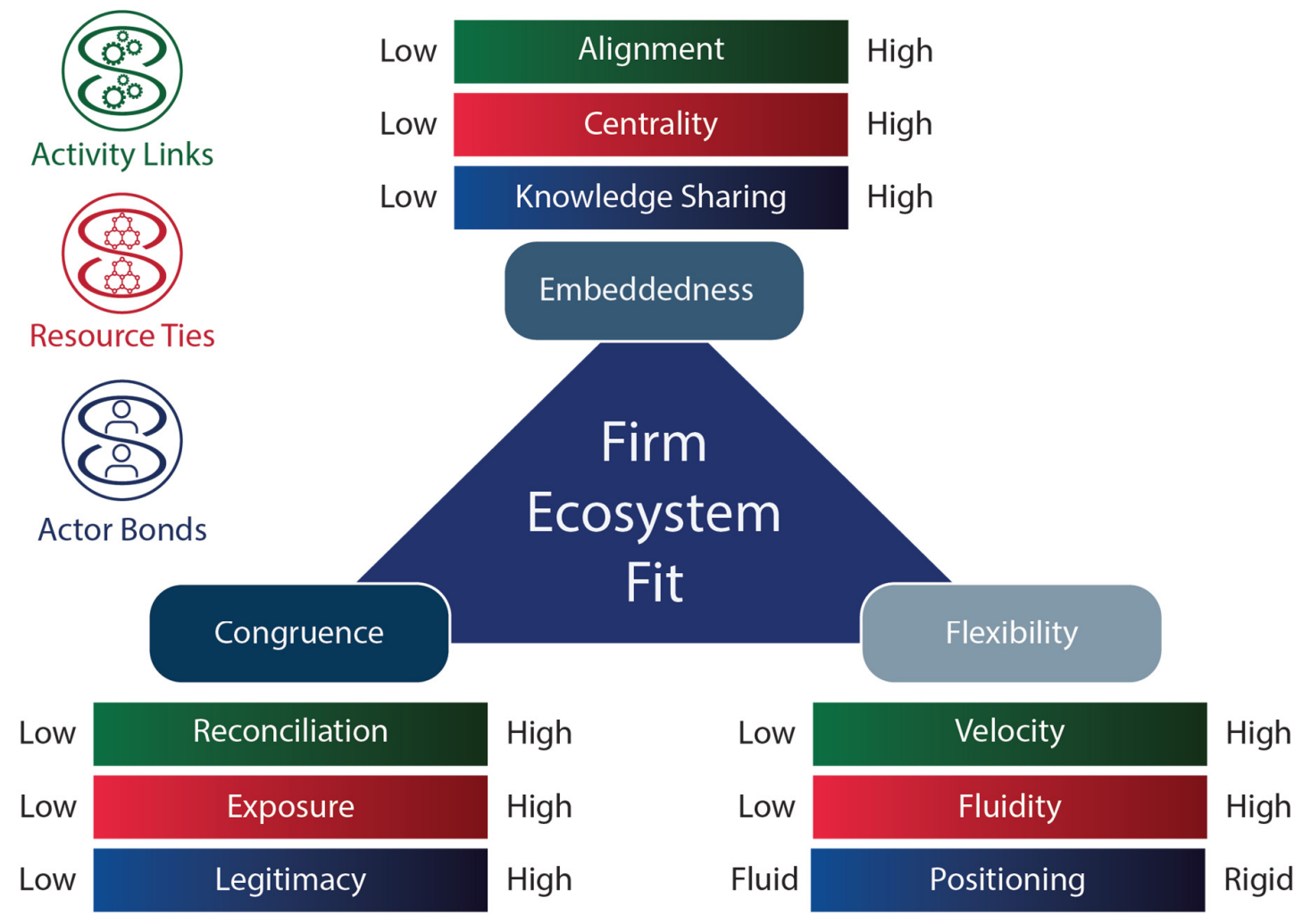

Figure 82 - Interdependency Attributes

\subsubsection{Summary Contributions to the Business Model Concept}

The findings and their discussion provided multiple interesting insights into the development of ventures' BMs and underpinning firm-ecosystem fits over time. Next to identifying strategies that resulted in the development of viable BMs, the VARA-model offers a frame for analysing the development of a firm-ecosystem fit and the underpinning interactional components, their interdependencies, and the attributes characterising them (Demil et al., 2015; Ritter \& Lettl, 2018). The insights provided by this thesis advanced our understanding of the BM development process in ecosystems and how firms can develop and maintain viable VCC mechanisms over time (Wirtz et al., 2016; Saebi et al., 2017; Foss \& Saebi, 2018) 


\subsection{Contributions to the service dominant logic}

The findings contribute on several frontiers to the service dominant logic literature. First, the value proposition framework presented helps to advance our understanding of the concept, its individual dimensions, functions, and how it can be dimensionalised in empirical research (Vargo \& Lusch, 2008). Moreover, the findings illustrate how value propositions for customers as well as actors are developed (Frow et al., 2014; Payne et al., 2017) and orchestrate a wide range of resource-integrating actors in value co-creation mechanisms in ecosystems over time (O'Cass, Svensson, Viet Ngo, \& O'Cass, 2010; O'Cass \& Ngo, 2011). The resulting value architectures further enhance our understanding of interactions undertaken to co-create value and the governing institutional arrangements (Vargo \& Lusch, 2016).

In addition, valuable insights have been provided for how resource-integrating actors can engage with each other to better their chances of survival in dynamic ecosystems (Vargo \& Lusch, 2017). The BM configurations draw attention to how activities are coordinated, operand and operant resources combined by actors, and bonds created to foster the development of institutional arrangements that can structure ecosystems (Vargo \& Lusch, 2010b; Greer et al., 2016; Lusch, Vargo, \& Gustafsson, 2016).

Finally, the contributions made enhance the understanding of how ecosystems assemble and actors within adapt and co-evolve (Vargo \& Lusch, 2017). The findings provided valuable contributions to how actors can position themselves in service-ecosystems, defend their position, and even change governing institutional arrangements (Vargo \& Lusch, 2011; Greer et al., 2016).

\subsection{Contributions to the Industrial Marketing and Purchasing}

The findings make several valuable contributions to the Industrial Marketing and Purchasing research stream and the management of industrial networks (Håkansson, 1982; Håkansson et al., 2009). First, findings on how ventures select and perform activity structures provided insights into the venture creation process in industrial networks. Moreover, how ventures facilitate the reconciliation of focal firms' activity structures and ecosystems' activity patterns via the development of value propositions yielded novel insights into the process of activity linking (Ritter et al., 2004; Bankvall, 2014; Bankvall, Dubois, \& Lind, 2014). Introducing 
the notion of inbound, outbound, and bilateral activity linking provides a solid foundation for further studies on how the standardisation and differentiation of activities and related activity links can contribute to an advantageous economic balance and a favourable position of ventures in ecosystems (Dubois, 1994; Håkansson et al., 2009, p. 101).

In addition, the findings on resource ties and how they influence the development of overall configurations provide insights into how resource collections are developed over time (Håkansson \& Johanson, 1992). Next to solidifying our understanding of physical and organisational resource ties and their diverging functions, the findings show how resource heterogeneity affected the different strategies when combining resources (Holmen \& Pedersen, 2012). Besides, the introduced categories of unilateral and bilateral resource adaptations enhance our understanding of how resource ties facilitate the development of complementarities and relational rents (Dyer et al., 2018) in different contexts (Håkansson et al., 2009, p. 90; Cantù, Corsaro, \& Snehota, 2012).

The findings outline how ventures, without previous history in an industrial network, can develop actor bonds, legitimise their venture, obtain an identity, and position themselves in the network (Håkansson et al., 2009, p. 144). Ventures aimed for different development strategies when initiating, maintaining, and resolving actor bonds with other actors. The heterogeneity of approaches has several implications for ventures' positions in the network and contributes to an advanced understanding of strategies to manage networks (Snehota, 2011; Gadde, 2014; Oukes \& Raesfeld von, 2016).

Finally, the findings contextualise the Industrial Marketing and Purchasing research stream and the ARA-model in the development process of ventures. In contrast to the prevalent research focus of established firms in existing industrial networks (Håkansson \& Snehota, 1995; Ford, Gadde, Håkansson, \& Snehota, 2011), the findings provide insights into how ventures can position themselves in emerging ecosystems and develop a viable firmecosystem fit over time (Cantù, Sepe, \& Tzannis, 2016; Baraldi, Havenvid, Linné, \& Öberg, 2018).

\subsection{Practical Implications}

This thesis describes how ventures can develop value propositions for customers and 
actors in ecosystems and underpinning activity links, resource ties, and actor bonds. The research was contextualised in the VARA-model that resulted from a union of the service dominant logic and Industrial Marketing and Purchasing research streams. Despite the research project's focus on conceptual advancements of the BM concept and its development process in ecosystems, several findings can be valuable for practitioners such as entrepreneurs or entrepreneurial managers developing novel BMs.

One of the most salient findings was that different strategies can result in the successful development of viable VCC mechanisms and BMs. As such, entrepreneurs should consider multiple development strategies when designing new BMs (Sabatier et al., 2010; Zott \& Amit, 2010; Cosenz \& Noto, 2018). Exploring a wide array of development strategies draws attention to the scale and scope of resource requirements and potential development trajectories (McNamara et al., 2013; Schneider, 2017). The exploration of development strategies can enhance the business modelling process (C. M. Baden-Fuller, Vincent, 2015a; Martins et al., 2015) and reveal opportunities and threats to emerging ventures (Saebi et al., 2017).

Since cognitive business modelling draws attention to interactions with potential actors, entrepreneurs can explore ecosystems and inherent development trajectories by proxy (Storbacka \& Nenonen, 2011; Furnari, 2015). Moreover, entrepreneurs can explore different ideas on how to engage customers and other actors in VCC mechanisms before developing prototypical value propositions (Bojovic et al., 2018). The value proposition framework proposed in this thesis can be utilised to describe, explain, and explore how value can be co-created and thus as a tool to design innovative VCC mechanisms. In addition, the value proposition framework can be employed by entrepreneurial managers to mitigate the risk of value migration.

As a tool for analysing VCC mechanisms across ecosystems, the value proposition framework yields insights into how value can be captured across multiple different actors. The advanced understanding of value flows or streams across ecosystems provides several opportunities for entrepreneurs and managers. However, developing innovative value capture mechanisms allows ventures to realise new or additional revenue streams in ecosystems (Tantalo \& Priem, 2016; Massa et al., 2017). The findings draw particular attention to opportunities to capture non-pecuniary value from interactions with multiple actors. 
Although often neglected in BM research (Arend, 2013), entrepreneurs' and managers' capabilities to explore opportunities to identify different sources of pecuniary and nonpecuniary value can be vital for the survival of ventures in early years. The importance of these capabilities is further emphasised in the design and implementation of freemium BMs that often require two-sided VCC mechanisms (Günzel \& Holm, 2013; Holm, Günzel, \& Ulhøi, 2013).

In addition, the findings might provide interesting insights into how ventures can leverage capabilities, resources, and positions of multiple ecosystem actors in the development of BMs (Frankenberger, Weiblen, Csik, et al., 2013; Frankenberger et al., 2014; Spieth et al., 2016). The increasing specialisation of VCC mechanisms across several sectors (Björkdahl, 2009) as well as the growing importance of platforms for the exploitation of (digital) technologies (Bogers, Chesbrough, \& Enkel, 2016) draws attention to the ecosystemcentric perspective of BMs (Dietz, Härle, \& Khanna, 2016; C. Baden-Fuller et al., 2017). These developments can render ventures' resource limitations obsolete and yield interesting opportunities to utilise external input factors in VCC mechanisms. Moreover, the annihilation of transaction costs due to advancements of ICTs, the surge of available APIs, and the newly introduced legislation further emphasise the opportunities for ventures capable of developing various different integrations with multiple actors in ecosystems. The here presented activity links, resource ties, and actor bonds framework allows entrepreneurs to contextualise the development of integrations in new economic realities that challenge the scope of established management tools such as the value chain, value configurations, or even the business model canvas. In contrast to existing tools the VARA framework provides a higher degree of flexibility to depict idiosyncrasies in ventures' BMs.

Finally, the findings draw attention to various capabilities required for the development of viable BMs. Although ventures have to combine several capabilities in the BM development process, different development strategies require heterogenous sets of capabilities. Entrepreneurs can use the proposed frameworks to assess potential room for improvements to implement and execute a particular BM development strategy. 


\subsection{Future Research}

The findings and their discussion open up several avenues for future research in the context of value proposition development, BM development, and ecosystem strategies. First, whereas the here introduced value proposition framework provides a solid foundation for developing an understanding of VCC mechanisms in ecosystems (Payne et al., 2017; Vargo \& Lusch, 2017), further explorative studies on different value dimensions, their interdependencies, and how novel offerings can address isolated or multiple dimensions at once provide intriguing research avenues. Whereas the interdependencies of value proposition dimensions were explored and discussed, advancing our understanding of the implications of individual value proposition dimension changes is critical for conceptual developments (Payne et al., 2017), ecosystem strategies (Hannah et al., 2016; Hannah \& Eisenhardt, 2018), and the co-creation of relational rents (Dyer \& Singh, 1998; Dyer et al., 2018).

The surfaced BM development strategies ( $\mathrm{FI}$ and $\mathrm{DI}$ ) provide a first steppingstone to enhance our understanding of how viable BMs emerge in ecosystems. However, various sequential combinations of value propositions, activity links, resource ties, and actor bonds might result in the development of viable BMs over time. Similarly to other configurations research (Brettel et al., 2012; Amit \& Zott, 2015; Aversa, Furnari, et al., 2015), the identification of additional configurations and strategies that result in the development of viable BMs can yield additional insights for the equifinality of development trajectories. Moreover, the application of a qualitative comparative (Wagemann, 2014; Wagemann, Buche, \& Siewert, 2016) approach seems to be appropriate to elevate the findings to a larger sample of firms, enhance the analytical generalisations made (Täuscher, 2017), and reveal additional strategies.

Since the development of value propositions, activity links, resource ties, and actor bonds were amongst the strongest results in this study, further research on what capabilities enhance the development of individual and combinations of VARA-model dimensions would solidify the theory. Moreover, although case studies were conducted in different sectors to mitigate contextual factors, all ventures were located in the Greater Wellington area and limited their operations largely to the New Zealand market. Additional research on the 
development of viable configurations in the VARA-Model in large as well as small and open economies, different sectors, and novel and incumbent organisations can yield interesting insights for advancing the model.

\subsection{Limitations}

Although providing novel and valuable insights into the development process of viable BMs, the research approach, methodology, and setting suffers from inherent limitations (Creswell, 2013; Yin, 2014; Patton, 2015). The small sample of investigated ventures allows only for the analytical generalisation of results (Miles et al., 2013; Yin, 2014) which are of limited potential for statistical generalisations for a population. The study aimed for the development of a rich understanding of how ventures develop viable BMs over time and thus considered a qualitative case study research method appropriate (Guba \& Lincoln, 1994). Although the thick descriptions developed for the small set of ventures allowed for in-depth insights, the findings might not apply to different contexts.

Since all investigated ventures participated in accelerator programs hosted by the same organisation, effects of the program such as exposed tools and networks might have affected the BM development process and performance trajectory. Comparing the strategic BM development of ventures participating in different accelerator programs as well as ventures that develop independently can offer interesting insights and reveal moderating variables of the BM development process.

Moreover, the idiosyncratic circumstances of different industry sectors set limitations to the application of the findings across different sectors. The heterogeneity of BM configuration across the industrial machinery (Björkdahl, 2009), peer-to-peer lending platforms (Amit \& Zott, 2015), soccer clubs (Demil \& Lecocq, 2010; McNamara et al., 2013), or Formula1 racing teams (Aversa, Furnari, et al., 2015) highlight the limited transferability of findings across multiple sectors. Although this study investigated ventures in the ICT and manufacturing sector to mitigate industry contingencies, the findings might only apply to other sectors with similar structural features.

In a similar vein, the study is limited to the geographic focus on New Zealand based ventures. The country's economic structure and isolated geographical location present an 
additional layer of idiosyncrasy to the investigated ventures' context. For instance, the absence of competitors in the market might create opportunities and mitigate threats ventures in large domestic or small and more open economies would face. In addition, New Zealand is constantly ranked amongst the easiest countries to start new ventures throughout the world and thus a hot-bed for entrepreneurial activity. The ease of starting a venture as well as the abundant opportunities to participate in accelerator programs further enhance the development of ventures. Several scholars have drawn attention to country specific contexts in BM research and emphasised the importance of differences in culture (Yunus et al., 2010), economic structure (Landau et al., 2016), and legislation (Bojovic et al., 2018) for the limited generalisation of findings.

Finally, while interaction and interdependencies were at the heart of the investigation, only entrepreneurs and venture insiders were interviewed. Although the series of sequential interviews and secondary material allowed to mitigate internal biases, the absence of interviews with partners ventures engaged with provides a limited perspective on the case studies. As such, the interdependencies and potential value actors co-created and/or captured were prone to perceptions of individual entrepreneurs. 


\subsection{Concluding Statements}

This thesis was inspired by the puzzling question of how BMs are developed and evolve in dynamic ecosystems over time. At its heart, the project embraced ventures' agency as the driving force of Schumpeter's creative destruction $(1911,1934)$ that continuously reshapes economic realities. As innovative forms of organisation, BMs and how they structure interactions with other ecosystem actors provide a focal construct in entrepreneurship and strategy research to explain the success and failure of firms over time.

Ventures' heterogenous strategies pursued in order to create a firm-ecosystem fit in BMs came as an intriguing surprise. The coordinated development of value propositions and BM component interdependencies highlighted ventures' interaction perspective in the BM development process. Already Schumpeter outlined that "the values of individual goods for everyone form a value system, that separates elements of which are mutually dependent" (1934, p. 40). In contrast to the firm-centric focus of traditional and contemporary strategy and entrepreneurship research (Porter, 1985; Markides, 2015; Ritter \& Lettl, 2018), the findings stressed the importance of understanding value in an ecosystem perspective.

Based on my findings, I want to end with a similar albeit extended notion of the understanding of ecosystems. First, ventures' heterogeneous strategies and approaches to structure interactions and interdependencies for VCC were an unexpected finding. It highlighted the importance of the multivalent nature of the ecosystem-centric perspective on the BM concept. While firm-centric perspectives can provide analytical insights, scholars have to face the realities of modern and interconnected economies, incorporate ecosystem interdependencies, and move the BM concept out of the ivory tower of theoretical assumptions of homogenous and passive environments.

Second, ecosystems and their actors are in a constant flux. Therefore, any firmecosystem fit is only of temporary nature. The often significant developments ventures made in the brief time period of nine to twelve months emphasises the dynamic perspective of the BM concept. In a similar vein, scholars and practitioners have to accept the dynamic realities of ecosystems and integrate them into the BM concept and empirical research. The nexus of ecosystem-centric and dynamic perspectives of the BM concept is a vital conceptual advancement in BM research. 
Finally, the findings stressed the importance of understanding ventures' capabilities required to develop and maintain a firm-ecosystem fit. However, the dynamic ecosystem perspective raises the question of the locus of capability development. What, how, and why are capabilities developed at the organisational and ecosystem levels? 


\section{References}

Aaboen, L., Dubois, A., \& Lind, F. (2012). Capturing processes in longitudinal multiple case studies. Industrial Marketing Management, 41(2), 235-246.

Aarikka-Stenroos, L., \& Ritala, P. (2017). Network management in the era of ecosystems: Systematic review and management framework. Industrial Marketing Management, 67, 23-36.

Achtenhagen, L., Melin, L., \& Naldi, L. (2013). Dynamics of Business Models - Strategizing, Critical Capabilities and Activities for Sustained Value Creation. Long range planning, 46(6), 427-442.

Acs, Z., \& Audretsch, D. (2010). Handbook of Entrepreneurship Research. In International Handbook Series on Entrepreneurship (2nd ed.): Dordrecht : Springer.

Acs, Z., Desai, S., \& Hessels, J. (2008). Entrepreneurship, economic development and institutions. Small Business Economics, 31(3), 219-234.

Adner, R. (2017). Ecosystem as structure: An actionable construct for strategy. Journal of management, 43(1), 39-58.

Adner, R., \& Kapoor, R. (2010). Value creation in innovation ecosystems: How the structure of technological interdependence affects firm performance in new technology generations. Strategic Management Journal, 31(3), 306-333.

Afuah, A., \& Tucci, C. (2001). Internet business models and strategies: Text and cases. Irwin: McGraw-Hill Higher Education.

Aldrich, H., \& Fiol, M. (1994). Fools rush in? The institutional context of industry creation. Academy of management review, 19(4), 645-670.

Alvarez, S., \& Barney, J. (2005). How do entrepreneurs organize firms under conditions of uncertainty? Journal of management, 31(5), 776-793.

Amit, R., \& Schoemaker, P. (1993). Strategic assets and organizational rent. Strategic Management Journal, 14(1), 33-46.

Amit, R., \& Zott, C. (2001). Value creation in e - business. Strategic Management Journal, $22(6-7), 493-520$.

Amit, R., \& Zott, C. (2015). Crafting Business Architecture: the Antecedents of Business Model Design. Strategic Entrepreneurship Journal, 9(4), 331-350.

Anand, B., \& Khanna, T. (2000). Do firms learn to create value? The case of alliances. Strategic Management Journal, 21(3), 295-315.

Ansoff, H. I. (1968). Corporate strategy: An analytic approach to business policy for growth and expansion. Harmondsworth: Penguin.

Anyadike-Danes, M., Hart, M., \& Du, J. (2015). Firm dynamics and job creation in the United Kingdom: 1998-2013. International Small Business Journal, 33(1), 12-27.

Ardichvili, A., Cardozo, R., \& Ray, S. (2003). A theory of entrepreneurial opportunity identification and development. Journal of Business Venturing, 18(1), 105-123.

Arend, R. (2013). The business model: Present and future-beyond a skeumorph. Strategic Organization, 11, 390-402. 
Aspara, J., Lamberg, J.-A., Laukia, A., \& Tikkanen, H. (2013). Corporate Business Model Transformation and Inter-Organizational Cognition: The Case of Nokia. Long range planning, 46(6), 459-474.

Audretsch, D. (2018). Entrepreneurship, economic growth, and geography. Oxford Review of Economic Policy, 34(4), 637-651.

Aversa, P., Furnari, S., \& Haefliger, S. (2015). Business model configurations and performance: A qualitative comparative analysis in Formula One racing, 2005-2013. Industrial \& Corporate Change, 24(3), 655-676.

Aversa, P., Haefliger, S., Rossi, A., \& Baden-Fuller, C. (2015). From Business Model to Business Modelling: Modularity and Manipulation. In C. Baden-Fuller \& V. Mangematin (Eds.), Business Models and Modelling (Vol. 33, pp. 151-185).

Baden-Fuller, C., Giudici, A., Haefliger, S., \& Morgan, M. (2017). Business Models and Value: Analytical comparisons of scalable solutions and digital platforms. Academy of Management Proceedings, 2017(1).

Baden-Fuller, C., \& Haefliger, S. (2013). Business Models and Technological Innovation. Long range planning, 46(6), 419-426.

Baden-Fuller, C., \& Mangematin, V. (2013). Business models: A challenging agenda. Strategic Organization, 11, 418-427.

Baden-Fuller, C., \& Morgan, M. (2010). Business Models as Models. Long range planning, 43(2-3), 156-171.

Baden-Fuller, C. M., Vincent. (2015a). Business Models and Modelling (Vol. 33): Emerald.

Baden-Fuller, C. M., Vincent. (2015b). Introduction: Business Models and Modelling Business Model. In C. Baden-Fuller \& V. Mangematin (Eds.), Business Models and Modelling (Vol. 33, pp. i).

Bankvall, L. (2014). Activity interdependence in industrial networks-Exploring the structural interconnectedness of activities and resources. IMP Journal, 8(1), 22-30.

Bankvall, L., Dubois, A., \& Lind, F. (2014). Towards a Network-based Business Model Concept and The Case of a truck OEM considering its Business Model in India. IMP Journal, 8(2), 44-50.

Baraldi, E., Havenvid, M. I., Linné, Å., \& Öberg, C. (2018). Start-ups and networks: Interactive perspectives and a research agenda. Industrial Marketing Management.

Baraldi, E., Proença, J., Proença, T., \& De Castro, L. M. (2014). The supplier's side of outsourcing: Taking over activities and blurring organizational boundaries. Industrial Marketing Management, 43(4), 553-563.

Barbour, R. (2013). Introducing qualitative research: a student's guide. Thousand Oaks, California: Sage.

Barney, J. (1991). Firm resources and sustained competitive advantage. Journal of management, 17(1), 99-120.

Barney, J. (2002). Gaining and Sustaining Competitive Advantage. Pennsylvania State University: Prentice Hall.

Barney, J., \& Clark, D. (2007). Resource-Based Theory : Creating and Sustaining Competitive Advantage. Oxford: Oxford University Press. 
Barney, J., Ketchen, D., \& Wright, M. (2011). The Future of Resource-Based Theory:Revitalization or Decline? Journal of management, 37(5), 1299-1315.

Baum, J., \& Oliver, C. (1991). Institutional linkages and organizational mortality. Administrative Science Quarterly, 36(3), 187-218.

Bellman, R., Clark, C., Malcolm, D., Craft, C., \& Ricciardi, F. (1957). On the construction of a multi-stage, multi-person business game. Operations Research, 5(4), 469-503.

Bengtson, A., \& Håkansson, H. (2008). An interactive view of innovations: adopting a new timber solution in an old concrete context. IMP Journal, 2(3), 19-35.

Berman, S. (2012). Digital transformation: opportunities to create new business models. Strategy \& leadership, 40(2), 16-24.

Bhaskar, R. (2013). A realist theory of science. New York: Routledge.

Bijker, W. E., Hughes, T. P., Pinch, T., \& Douglas, D. G. (2012). The social construction of technological systems: New directions in the sociology and history of technology: MIT press.

Biloshapka, V., Osiyevskyy, O., \& Meyer, M. (2016). The value matrix: a tool for assessing the future of a business model. Strategy \& leadership, 44(4), 41-48.

Bitektine, A. (2011). Toward a Theory of Social Judgments of Organizations: The case of Legitimacy, Reputation, and Status. Academy of management review, 36(1), 151-179.

Björkdahl, J. (2009). Technology cross-fertilization and the business model: The case of integrating ICTs in mechanical engineering products. Research Policy, 38(9), 14681477.

Bogers, M., Chesbrough, H., \& Enkel, E. (2016). Special issue on open innovation in the digital age. R\&D Management, 46(S2), 706-707.

Bojovic, N., Genet, C., \& Sabatier, V. (2018). Learning, signaling, and convincing: The role of experimentation in the business modeling process. Long range planning, 51(1), 141157.

Bonakdar, A., Frankenberger, K., \& Gassmann, O. (2014). Intra-firm Networks and Noveltycentered Business Models. Academy of Management Annual Meeting Proceedings, $1727-1732$.

Bouncken, R. B., \& Fredrich, V. (2016). Business model innovation in alliances: Successful configurations. Journal of business research, 69(9), 3584-3590.

Bower, J. L., \& Christensen, C. M. (1995). Disruptive technologies: catching the wave. Harvard business review, 73(1), 43-53.

Bowman, C., \& Ambrosini, V. (2000). Value creation versus value capture: towards a coherent definition of value in strategy. British Journal of Management, 11(1), 1-15.

Brandenburger, A., \& Stuart, H. (1996). Value - based business strategy. Journal of Economics \& Management Strategy, 5(1), 5-24.

Brea-Solís, H., Casadesus-Masanell, R., \& Grifell-Tatjé, E. (2015). Business Model Evaluation: Quantifying Walmart's Sources of Advantage. Strategic Entrepreneurship Journal, 9(1), 12-33.

Brettel, M., Strese, S., \& Flatten, T. (2012). Improving the performance of business models with relationship marketing efforts-An entrepreneurial perspective. European Management Journal, 30(2), 85-98. 
Brinckmann, J., Grichnik, D., \& Kapsa, D. (2010). Should entrepreneurs plan or just storm the castle? A meta-analysis on contextual factors impacting the business planningperformance relationship in small firms. Journal of Business Venturing, 25(1), 24-40.

Brock, S., \& Mares, E. (2007). Realism and Anti-Realism (1st Ed.). London Routledge

Brush, C., Greene, P., Hart, M., \& Haller, H. (2001). From Initial Idea to Unique Advantage: The Entrepreneurial Challenge of Constructing a Resource Base [and Executive Commentary]. The Academy of Management Executive, 15(1), 64-80.

Brush, C., Manolova, T., \& Edelman, L. (2008). Properties of emerging organizations: An empirical test. Journal of Business Venturing, 23(5), 547-566.

Bryman, A. (2015). Social Research Methods. Oxford Oxford University Press.

Burkhart, T., Krumeich, J., Werth, D., \& Loos, P. (2011). Analyzing the business model concept - A comprehensive classification of literature. Paper presented at the $32 \mathrm{nd}$ International Conference on Information Systems, Shanghai

Burns, B., Barney, J., Angus, R., \& Herrick, H. (2016). Enrolling Stakeholders under Conditions of Risk and Uncertainty. Strategic Entrepreneurship Journal, 10(1), 97-106.

Calia, R., Guerrini, F., \& Moura, G. (2007). Innovation networks: From technological development to business model reconfiguration. Technovation, 27(8), 426-432.

Callon, M. (1999). Actor - network theory - the market test. The Sociological Review, 47(S1), 181-195.

Cantù, C., Corsaro, D., \& Snehota, I. (2012). Roles of actors in combining resources into complex solutions. Journal of business research, 65(2), 139-150.

Cantù, C., Sepe, G., \& Tzannis, A. (2016). A new relational business model for start-ups. evidences from Italian context. Paper presented at the 32nd-IMP Conference, Poznan.

Carney, T. (1990). Collaborative inquiry methodology. Windsor, Ontario: University of Windsor: Division for Instructional Development.

Casadesus-Masanell, R., \& Heilbron, J. (2015). The Business Model: Nature and Benefits. In C. Baden-Fuller \& V. Mangematin (Eds.), Business Models and Modelling (Vol. 33, pp. 3-30). Bingley Emerald Group Publishing Ltd. .

Casadesus-Masanell, R., \& Ricart, J. (2007). Competing through business models. IESE Business School, WP 713.

Casadesus-Masanell, R., \& Ricart, J. (2010). From Strategy to Business Models and onto Tactics. Long range planning, 43(2-3), 195-215.

Casadesus-Masanell, R., \& Zhu, F. (2013). Business model innovation and competitive imitation: The case of sponsor-based business models. Strategic Management Journal, 34(4), 464-482.

Cavalcante, S., Kesting, P., \& Ulhøi, J. (2011). Business model dynamics and innovation: (re)establishing the missing linkages. Management Decision, 49(8), 1327-1342.

Chandler, A., \& Takashi, H. (2009). Scale and scope: The dynamics of industrial capitalism. Boston: Harvard University Press.

Chandler, J., \& Lusch, R. (2015). Service systems: a broadened framework and research agenda on value propositions, engagement, and service experience. Journal of Service Research, 18(1), 6-22. 
Chesbrough, H. (2006). Open Business Models: How to Thrive in the New Innovation Landscape. Boston Harvard Business Press.

Chesbrough, H. (2007a). Business model innovation: it's not just about technology anymore. Strategy \& leadership, 35(6), 12-17.

Chesbrough, H. (2007b). Why Companies Should Have Open Business Models. MIT Sloan Management Review, 48(2), 22-28.

Chesbrough, H. (2010). Business Model Innovation: Opportunities and Barriers. Long range planning, 43(2-3), 354-363.

Chesbrough, H., \& Rosenbloom, R. (2002). The role of the business model in capturing value from innovation: evidence from Xerox Corporation's technology spin-off companies. Industrial \& Corporate Change, 11(3), 529-555.

Christensen, C. (2013). The innovator's dilemma: when new technologies cause great firms to fail. Boston: Harvard Business Review Press.

Christensen, C., Cook, S., \& Hall, T. (2005). Marketing Malpractice: The Cause and the Cure. Harvard business review, 83(12), 74-83.

Christensen, C., Hall, T., Dillon, K., \& Duncan, D. (2016). Competing against luck. Boston: Harvard Business School

Chwolka, A., \& Raith, M. G. (2012). The value of business planning before start-up-A decision-theoretical perspective. Journal of Business Venturing, 27(3), 385-399.

Clauss, T. (2017). Measuring business model innovation: conceptualization, scale development, and proof of performance. R\&D Management, 47(3), 385-403.

Cohen, W., \& Levinthal, D. (1990). Absorptive Capacity: A New Perspective on Learning and Innovation. Administrative Science Quarterly, 35(1), 128-152.

Connelly, B. L., Certo, S. T., Ireland, R. D., \& Reutzel, C. R. (2011). Signaling theory: A review and assessment. Journal of management, 37(1), 39-67.

Copeland, A. J., \& Agosto, D. E. (2012). Diagrams and relational maps: The use of graphic elicitation techniques with interviewing for data collection, analysis, and display. International Journal of Qualitative Methods, 11(5), 513-533.

Coreynen, W., Matthyssens, P., \& Van Bockhaven, W. (2017). Boosting servitization through digitization: Pathways and dynamic resource configurations for manufacturers. Industrial Marketing Management, 60, 42-53.

Cortimiglia, M. N., Ghezzi, A., \& Frank, A. G. (2016). Business model innovation and strategy making nexus: evidence from a cross-industry mixed-methods study. $R \& D$ Management, 46(3), 414-432.

Cosenz, F., \& Noto, G. (2018). A dynamic business modelling approach to design and experiment new business venture strategies. Long range planning, 51(1), 127-140.

Creswell, J. W. (2013). Research design: Qualitative, quantitative, and mixed methods approaches. Thousand Oaks, California: Sage.

Crilly, N., Blackwell, A. F., \& Clarkson, P. J. (2006). Graphic elicitation: using research diagrams as interview stimuli. Qualitative research, 6(3), 341-366.

DaSilva, C. M., \& Trkman, P. (2014). Business Model: What It Is and What It Is Not. Long range planning, 47(6), 379-389. 
Davidsson, P. (2015). Entrepreneurial opportunities and the entrepreneurship nexus: A reconceptualization. Journal of Business Venturing, 30(5), 674-695.

Davidsson, P., \& Gordon, S. R. (2012). Panel studies of new venture creation: a methodsfocused review and suggestions for future research. Small Business Economics, 39(4), 853-876.

de Figueiredo, J. M., \& Silverman, B. S. (2017). On the genesis of interfirm relational contracts. Strategy Science, 2(4), 234-245.

Decker, R., Haltiwanger, J., Jarmin, R., \& Miranda, J. (2014). The role of entrepreneurship in US job creation and economic dynamism. Journal of Economic Perspectives, 28(3), 324.

Deephouse, D. L., Bundy, J., Tost, L. P., \& Suchman, M. C. (2017). Organizational legitimacy: Six key questions. In The SAGE handbook of organizational institutionalism (pp. 2754). Thousand Oaks, California: Sage.

Delmar, F., \& Shane, S. (2003). Does business planning facilitate the development of new ventures? Strategic Management Journal, 24(12), 1165-1185.

Demil, B., \& Lecocq, X. (2010). Business Model Evolution: In Search of Dynamic Consistency. Long range planning, 43(2-3), 227-246.

Demil, B., \& Lecocq, X. (2015). Crafting an Innovative Business Model in an Established Company: The Role of Artifacts. In C. Baden-Fuller \& V. Mangematin (Eds.), Business Models and Modelling (pp. 31-58).

Demil, B., Lecocq, X., Ricart, J., \& Zott, C. (2015). Introduction to the Sej Special Issue on Business Models: Business Models within the Domain of Strategic Entrepreneurship. Strategic Entrepreneurship Journal, 9(1), 1-11.

Denzin, N., \& Lincoln, Y. (2000). The handbook of qualitative research / edited by Norman K. Denzin and Yvonna S. Lincoln (2nd ed.). Thousand Oaks, California: Sage

Denzin, N., \& Lincoln, Y. (2011). The SAGE handbook of qualitative research. London: Sage.

Dietz, M., Härle, P., \& Khanna, S. (2016). A digital crack in banking's business model. Retrieved from http://www.mckinsey.com/industries/financial-services/our-insights/Adigital-crack-in-bankings-business-model

Doganova, L., \& Eyquem-Renault, M. (2009). What do business models do?: Innovation devices in technology entrepreneurship. Research Policy, 38(10), 1559-1570.

Dopfer, M., Fallahi, S., Kirchberger, M., \& Gassmann, O. (2017). Adapt and strive: How ventures under resource constraints create value through business model adaptations. Creativity and Innovation Management, 26(3), 233-246.

Dothan, A., \& Lavie, D. (2016). Resource Reconfiguration: Learning from Performance Feedback. In Resource Redeployment and Corporate Strategy (pp. 319-369).

Doz, Y. L., \& Kosonen, M. (2010). Embedding Strategic Agility: A Leadership Agenda for Accelerating Business Model Renewal. Long range planning, 43(2-3), 370-382.

Drori, I., \& Honig, B. (2013). A process model of internal and external legitimacy. Organization Studies, 34(3), 345-376.

Drucker, P. (1954). The practice of management. London: Harper Collins.

Dubois, A. (1994). Boundaries within Activity Structures. Paper presented at the Proceedings of the 10th IMP Conference, Groningen. 
Dubois, A., \& Gadde, L.-E. (2002). Systematic combining: an abductive approach to case research. Journal of business research, 55(7), 553-560.

Dubois, A., \& Gadde, L.-E. (2014). "Systematic combining"-A decade later. Journal of business research, 67(6), 1277-1284.

Dyer, J. H., \& Hatch, N. W. (2006). Relation-specific capabilities and barriers to knowledge transfers: creating advantage through network relationships. Strategic Management Journal, 27(8), 701-719.

Dyer, J. H., \& Nobeoka, K. (2000). Creating and managing a high - performance knowledge sharing network: the Toyota case. Strategic Management Journal, 21(3), 345-367.

Dyer, J. H., \& Singh, H. (1998). The relational view: Cooperative strategy and sources of interorganizational competitive advantage. Academy of management review, 23(4), 660-679.

Dyer, J. H., Singh, H., \& Hesterly, W. S. (2018). The relational view revisited: A dynamic perspective on value creation and value capture. Strategic Management Journal, 39(12), 3140-3162.

Easton, G. (1995). Case research as a methodology for industrial networks: a realist apologia. Paper presented at the IMP Conference (11th), Lancaster.

Echeverri, P., \& Skålén, P. (2011). Co-creation and co-destruction: A practice-theory based study of interactive value formation. Marketing Theory, 11(3), 351-373.

Eckhardt, J. T., Ciuchta, M. P., \& Carpenter, M. (2018). Open innovation, information, and entrepreneurship within platform ecosystems. Strategic Entrepreneurship Journal, 12(3), 369-391.

Eisenhardt, K. M. (1989). Building Theories from Case Study Research. The Academy of Management Review, 14(4), 532-550.

Eisenhardt, K. M., \& Graebner, M. (2007). Theory building from cases: Opportunities and challenges. Academy of Management Journal, 50(1), 25-32.

Eisenhardt, K. M., Graebner, M. E., \& Sonenshein, S. (2016). Grand challenges and inductive methods: Rigor without rigor mortis. In: Academy of Management Briarcliff Manor, NY.

Enger, W., \& Vollhardt, K. (2016). Customer experience: Creating value through transforming customer journey. Retrieved from https://www.mckinsey.de/sites/mck files/files/customer-experience-compendium2016.pdf

Ennen, E., \& Richter, A. (2010). The whole is more than the sum of its parts—or is it? A review of the empirical literature on complementarities in organizations. Journal of management, 36(1), 207-233.

Eriksson, P., \& Kovalainen, A. (2015). Qualitative Methods in Business Research: A Practical Guide to Social Research. Thousand Oaks, California: Sage.

Fageda, X., Suau-Sanchez, P., \& Mason, K. J. (2015). The evolving low-cost business model: Network implications of fare bundling and connecting flights in Europe. Journal of Air Transport Management, 42, 289-296.

Fisher, G., Kotha, S., \& Lahiri, A. (2016). Changing with the times: An integrated view of identity, legitimacy, and new venture life cycles. Academy of management review, 41(3), 383-409. 
Fisher, G., Kuratko, D. F., Bloodgood, J. M., \& Hornsby, J. S. (2017). Legitimate to whom? The challenge of audience diversity and new venture legitimacy. Journal of Business Venturing, 32(1), 52-71.

Fiss, P. C. (2007). A set-theoretic approach to organizational configurations. Academy of management review, 32(4), 1180-1198.

Fiss, P. C. (2011). Building Better Casual Theories: A fuzzy set appraoch to typologies in organizational reserach. Academy of Management Journal, 54(2), 393-420.

Fiss, P. C., Cambré, B., \& Marx, A. (2013). Chapter 1 Configurational Theory and Methods in Organizational Research: Introduction. In Configurational Theory and Methods in Organizational Research (pp. 1-22).

Fjeldstad, Ø. D., \& Snow, C. C. (2018). Business models and organization design. Long range planning, 51(1), 32-39.

Fleetwood, S. (1997). Aristotle in the 21st century. Cambridge Journal of Economics, 21(6), 729-744.

Ford, D., Gadde, L.-E., Håkansson, H., \& Snehota, I. (2011). Managing business relationships (Vol. 3rd). Chichester, West Sussex: Wiley.

Foss, N., \& Saebi, T. (2016). Fifteen Years of Research on Business Model Innovation How Far Have We Come, and Where Should We Go? Journal of management, 43(1), 200227.

Foss, N., \& Saebi, T. (2018). Business models and business model innovation: Between wicked and paradigmatic problems. Long range planning, 51(1), 9-21.

Franke, N., \& Hader, C. (2014). Mass or only "niche customization"? Why we should interpret configuration toolkits as learning instruments. Journal of Product Innovation Management, 31(6), 1214-1234.

Franke, N., \& Von Hippel, E. (2003). Satisfying heterogeneous user needs via innovation toolkits: the case of Apache security software. Research Policy, 32(7), 1199-1215.

Frankenberger, K., Weiblen, T., Csik, M., \& Gassmann, O. (2013). The 4I-framework of business model innovation: a structured view on process phases and challenges. International Journal of Product Development, 18(3), 249-273.

Frankenberger, K., Weiblen, T., \& Gassmann, O. (2013). Network configuration, customer centricity, and performance of open business models: A solution provider perspective. Industrial Marketing Management, 42(5), 671-682.

Frankenberger, K., Weiblen, T., \& Gassmann, O. (2014). The antecedents of open business models: an exploratory study of incumbent firms. R\&D Management, 44(2), 173-188.

Frow, P., McColl-Kennedy, J. R., Hilton, T., Davidson, A., Payne, A., \& Brozovic, D. (2014). Value propositions: A service ecosystems perspective. Marketing Theory, 14(3), 327351.

Furnari, S. (2015). A Cognitive Mapping Approach to Business Models: Representing Causal Structures and Mechanisms. In Business Models and Modelling (pp. 207-239).

Gadde, L.-E. (2014). Strategizing at the Boundaries of Firms. IMP Journal, 8(2), 51-63.

Gartner, W. B., Carter, N. M., \& Reynolds, P. D. (2010). Entrepreneurial behavior: Firm organizing processes. In Handbook of entrepreneurship research (pp. 99-127): Springer. 
Gassmann, O., Frankenberger, K., \& Csik, M. (2014). The business model navigator: 55 models that will revolutionise your business: Pearson UK.

Gehman, J., Glaser, V. L., Eisenhardt, K. M., Gioia, D., Langley, A., \& Corley, K. G. (2018). Finding theory-method fit: A comparison of three qualitative approaches to theory building. Journal of Management Inquiry, 27(3), 284-300.

Gentner, D., \& Stevens, A. L. (1983). Mental models. London: Taylor \& Francis Group.

George, G., \& Bock, A. J. (2011). The Business Model in Practice and its Implications for Entrepreneurship Research. Entrepreneurship: Theory \& Practice, 35(1), 83-111.

Gerasymenko, V., De Clercq, D., \& Sapienza, H. J. (2015). Changing the Business Model: Effects of Venture Capital Firms and Outside CEOs on Portfolio Company Performance. Strategic Entrepreneurship Journal, 9(1), 79-98.

Gerring, J. (2006). Case study research: Principles and practices. Cambridge Cambridge University Press.

Ghauri, P. N., \& Grønhaug, K. (2005). Research methods in business studies: A practical guide (3rd ed.). Harlow, England: Financial Times Prentice Hall.

Gibbert, M., Ruigrok, W., \& Wicki, B. (2008). What passes as a rigorous case study? Strategic Management Journal, 29(13), 1465-1474.

Gibbons, R., \& Henderson, R. (2012). Relational contracts and organizational capabilities. Organization Science, 23(5), 1350-1364.

Gioia, D. A., Corley, K. G., \& Hamilton, A. L. (2013). Seeking qualitative rigor in inductive research: Notes on the Gioia methodology. Organizational Research Methods, 16(1), 15-31.

Goertz, G. (2012). Social science concepts: A user's guide. Princeton Princeton University Press.

Gordijn, J., Akkermans, H., \& Van Vliet, J. (2001). Designing and evaluating e-business models. IEEE intelligent Systems, 16(4), 11-17.

Granovetter, M. S. (1973). The strength of weak ties. American journal of sociology, 78(6), $1360-1380$.

Greer, C., Lusch, R., \& Vargo, S. (2016). A service perspective: Key managerial insights from service-dominant (S-D) logic. Organizational Dynamics, 45(1), 28-38.

Grönroos, C. (2011). Value co-creation in service logic: A critical analysis. Marketing Theory, 11(3), 279-301.

Grönroos, C., \& Voima, P. (2013). Critical service logic: making sense of value creation and co-creation. Journal of the Academy of marketing Science, 41(2), 133-150.

Guba, E. G., \& Lincoln, Y. S. (1994). Competing paradigms in qualitative research. Handbook of qualitative research, 2(163-194).

Guest, G., MacQueen, K., \& Namey, E. (2012). Applied Thematic Analysis (1st ed.). Thousand Oaks, California: Sage.

Gulati, R. (1999). Network location and learning: The influence of network resources and firm capabilities on alliance formation. Strategic Management Journal, 20(5), 397-420.

Gulati, R., \& Higgins, M. C. (2003). Which ties matter when? The contingent effects of interorganizational partnerships on IPO success. Strategic Management Journal, 24(2), 127-144. 
Gulati, R., Nohria, N., \& Zaheer, A. (2000). Strategic networks. Strategic Management Journal, 21(3), 203-215.

Gulati, R., \& Sytch, M. (2007). Dependence asymmetry and joint dependence in interorganizational relationships: Effects of embeddedness on a manufacturer's performance in procurement relationships. Administrative Science Quarterly, 52(1), 32-69.

Günzel-Jensen, F., \& Holm, A. (2016). Freemium business models as the foundation for growing an e-business venture: a multiple case study of industry leaders. Journal of Entrepreneurship, Management and Innovation, 11(1), 77-102.

Günzel, F., \& Holm, A. B. (2013). One size does not fit all—understanding the front-end and back-end of business model innovation. International Journal of Innovation Management, 17(1), 1340002.

Hacklin, F., Björkdahl, J., \& Wallin, M. W. (2018). Strategies for business model innovation: How firms reel in migrating value. Long range planning, 51(1), 82-110.

Håkansson, H. (1982). International marketing and purchasing of industrial goods: An interaction approach. Chichester: Wiley.

Håkansson, H. (2015). Industrial Technological Development: A Network Approach. New York: Routledge.

Håkansson, H., Ford, D., Gadde, L.-E., Snehota, I., \& Waluszewski, A. (2009). Business in networks. Chichester: Wiley.

Håkansson, H., \& Johanson, J. (1992). A model of industrial networks. New York: Routledge.

Håkansson, H., \& Snehota, I. (1995). Developing relationships in business networks. New York: Routledge.

Håkansson, H., \& Waluszewski, A. (2002). IKEA, The environment and technlogy. In Managing Technological Development. New York: Routledge.

Hamel, G. (2002). Leading the revolution: How to thrive in turbulent times by making innovation a way of life. Boston: Harvard Business School Press.

Hamermesh, R. G., Marshall, P. W., \& Pirmohamed, T. (2002). Note on Business Model Analysis for the Entrepreneur. Harvard Business School Background Note 802-048.

Hannah, D., Bremner, R., \& Eisenhardt, K. M. (2016). Resource Redeployment in Business Ecosystems. In Resource Redeployment and Corporate Strategy (pp. 19-48).

Hannah, D., \& Eisenhardt, K. M. (2018). How firms navigate cooperation and competition in nascent ecosystems. Strategic Management Journal, 39(12), 3163-3192.

Harré, R. (1975). Causal powers: a theory of natural necessity. In: Basil Blackwell, Oxford.

Hedman, J., \& Kalling, T. (2002). IT and business models. Malmö, Schweden: Liber/Abstrakt.

Hedman, J., \& Kalling, T. (2003). The business model concept: Theoretical underpinnings and empicical illustrations. European Journal of Information Systems, 12(1), 49-59.

Hedvall, K., Dubois, A., \& Lind, F. (2016). Analysing an activity in context: A case study of the conditions for vehicle maintenance. Industrial Marketing Management, 58, 69-82.

Hennink, M., Hutter, I., \& Bailey, A. (2011). Qualitative research methods. Thousand Oaks, California: Sage. 
Hersen, M., \& Barlow, D. h. (1976). Single-case experimental designs: Strategies for studying behavior change. In: Pergamon.

Herzberg, F. (1966). Work and the nature of man. Cleveland: World Pub.

Hock, M., Clauss, T., \& Schulz, E. (2016). The impact of organizational culture on a firm's capability to innovate the business model. R\&D Management, 46(3), 433-450.

Holm, A. B., Günzel, F., \& Ulhøi, J. P. (2013). Openness in innovation and business models: lessons from the newspaper industry. International Journal of Technology Management, 61(3/4), 324-348.

Holmen, E., \& Pedersen, A.-C. (2012). What is resource heterogeneity, and how can a firm handle the resource heterogeneity encountered in its business relationships? IMP Journal, 6(3), 210-239.

Holmen, E., Pedersen, A.-C., \& Torvatn, T. (2005). Building relationships for technological innovation. Journal of business research, 58(9), 1240-1250.

Johansson, I. (2014). Proof of the Existence of Universals-from a Fallibilist. Defending Realism: Ontological and Epistemological Investigations, 7, 51.

Johnson-Laird, P. N. (1983). Mental models: Towards a cognitive science of language, inference, and consciousness. Boston: Harvard University Press.

Johnson-Laird, P. N. (2010). Mental models and human reasoning. Proceedings of the National Academy of Sciences, 107(43), 18243-18250.

Johnson, M., Christensen, C., \& Kagermann, H. (2008). Reinventing your business model. Harvard business review, 86(12), 57-68.

Johnson, M. W. (2010). Seizing the white space: business model innovation for growth and renewal. Boston: Harvard Business Press.

Jones, G. M. (1960). Educators, electrons, and business models: a problem in synthesis. The Accounting Review, 35(4), 619-626.

Katila, R., Rosenberger, J. D., \& Eisenhardt, K. M. (2008). Swimming with sharks: Technology ventures, defense mechanisms and corporate relationships. Administrative Science Quarterly, 53(2), 295-332.

Katz, D., \& Kahn, R. L. (1978). The social psychology of organizations (Vol. 2): Wiley New York.

Kazanjian, R. K. (1988). Relation of dominant problems to stages of growth in technologybased new ventures. Academy of Management Journal, 31(2), 257-279.

Ketchen Jr, D. J., Combs, J. G., Russell, C. J., Shook, C., Dean, M. A., Runge, J., . . Baker, R. (1997). Organizational configurations and performance: A meta-analysis. Academy of Management Journal, 40(1), 223-240.

King, N., \& Horrocks, C. (2010). Interviews in qualitative research. Thousand Oaks, California: Sage.

Klang, D., Wallnöfer, M., \& Hacklin, F. (2014). The Business Model Paradox: A Systematic Review and Exploration of Antecedents. International Journal of Management Reviews, 16(4), 454-478.

Knight, F. H. (1921). Risk, uncertainty and profit: Courier Corporation.

Konczal, E. F. (1975). Models are for managers, not mathematicians. Journal of Systems Management, 26(165), 12-15. 
Kulins, C., Leonardy, H., \& Weber, C. (2016). A configurational approach in business model design. Journal of business research, 69(4), 1437-1441.

Kuratko, D. F., Fisher, G., Bloodgood, J. M., \& Hornsby, J. S. (2017). The paradox of new venture legitimation within an entrepreneurial ecosystem. Small Business Economics, 49(1), 119-140.

Laasch, O. (2018). Beyond the purely commercial business model: Organizational value logics and the heterogeneity of sustainability business models. Long range planning, 51(1), 158-183.

Landau, C., Karna, A., \& Sailer, M. (2016). Business model adaptation for emerging markets: a case study of a German automobile manufacturer in India. R\&D Management, 46(3), 480-503.

Lange, D., Lee, P. M., \& Dai, Y. (2011). Organizational reputation: A review. Journal of management, 37(1), 153-184.

Langley, A. (1999). Strategies for theorizing from process data. Academy of management review, 24(4), 691-710.

Langley, A., Smallman, C., Tsoukas, H., \& Van de Ven, A. (2013a). Process studies of change in organization and management: Unveiling temporality, activity, and flow. Academy of Management Journal, 56(1), 1-13.

Langley, A., Smallman, C., Tsoukas, H., \& Van de Ven, A. H. (2013b). Process studies of change in organization and management: Unveiling temporality, activity, and flow. Academy of Management Journal, 56(1), 1-13.

Lapid, Y. (1989). The third debate: On the prospects of international theory in a post-positivist era. International studies quarterly, 33(3), 235-254.

Latour, B. (1996). On actor-network theory: A few clarifications. Soziale welt, 369-381.

Lavie, D. (2006). The competitive advantage of interconnected firms: An extension of the resource-based view. Academy of management review, 31(3), 638-658.

Law, J. (2009). Actor network theory and material semiotics. Social theory, 141.

Lecocq, X., Demil, B., \& Ventura, J. (2010). Business models as a research program in strategic management: an appraisal based on Lakatos. M@ n@ gement, 13(4), 214225.

Lepak, D., Smith, K., \& Taylor, S. (2007). Introduction to Special Topic Forum: Value Creation and Value Capture: A Multilevel Perspective. The Academy of Management Review, 32(1), 180-194.

Lepak, D. P., Smith, K. G., \& Taylor, M. S. (2007). Value creation and value capture: a multilevel perspective. Academy of management review, 32(1), 180-194.

Levin-Rozalis, M. (2000). Abduction: a logical criterion for programme and project evaluation. Evaluation, 6(4), 415-432.

Lichtenstein, B. M. B., \& Brush, C. G. (2001). How do" resource bundles" develop and change in new ventures? A dynamic model and longitudinal exploration. Entrepreneurship: Theory and Practice, 25(3), 37-37.

Lincoln, Y. S., \& Guba, E. G. (1985). Naturalistic inquiry (Vol. 75). Thousand Oaks, California: Sage. 
Linder, J., \& Cantrell, S. (2000). Changing Busienss Models: Surveying the Landscape. Retrieved http://www.businessmodels.eu/images/banners/Articles/Linder Cantrell.pdf

from

Lippman, S. A., \& Rumelt, R. P. (2003). A bargaining perspective on resource advantage. Strategic Management Journal, 24(11), 1069-1086.

Lusch, R., \& Vargo, S. (2006a). The service-dominant logic of marketing : dialog, debate, and directions / edited by Robert F. Lusch and Stephen L. Vargo. Armonk, N.Y.: Armonk, N.Y. : M.E. Sharpe.

Lusch, R., \& Vargo, S. (2006b). Service-dominant logic: what it is, what it is not, what it might be. The Service-Dominant Logic of Marketing: Dialog, Debate, and Directions, Armonk, NY: ME Sharpe, 43-56.

Lusch, R., Vargo, S., \& Gustafsson, A. (2016). Fostering a trans-disciplinary perspectives of service ecosystems. Journal of business research, 69(8), 2957-2963.

Magretta, J. (2002). Why business models matter. Harvard business review, 80(5), 86-92.

Mahadevan, B. (2000). Business Models for Internet-Based E-Commerce: An Anatomy. California Management Review, 42(4), 55-69.

Mahadevan, B. (2004). A framework for business model innovation. Paper presented at the IMRC Conference, Bangalore.

Makadok, R., \& Barney, J. B. (2001). Strategic factor market intelligence: An application of information economics to strategy formulation and competitor intelligence. Management Science, 47(12), 1621-1638.

Mangematin, V., Lemarié, S., Boissin, J.-P., Catherine, D., Corolleur, F., Coronini, R., \& Trommetter, M. (2003). Development of SMEs and heterogeneity of trajectories: the case of biotechnology in France. Research Policy, 32(4), 621-638.

Manser, K., Hillebrand, B., Woolthuis, R. K., Ziggers, G. W., Driessen, P. H., \& Bloemer, J. (2016). An activities-based approach to network management: An explorative study. Industrial Marketing Management, 55, 187-199.

Manson, J. (2002). Qualitative research (Vol. 2). London: Sage

March, J. G., \& Simon, H. A. (1958). Organizations. Oxford: Wiley.

Margolis, E., \& Pauwels, L. (2011). The Sage handbook of visual research methods. Thousand Oaks, California: Sage.

Markides, C. (2015). Research on Business Models: Challenges and Opportunities. In C. Baden-Fuller \& V. Mangematin (Eds.), Business Models and Modelling (pp. 133-147).

Marshall, C. (2006). Designing qualitative research (4th ed.). Thousand Oaks, California: Sage.

Martins, L. L., Rindova, V. P., \& Greenbaum, B. E. (2015). Unlocking the Hidden Value of Concepts: A Cognitive Approach to Business Model Innovation. Strategic Entrepreneurship Journal, 9(1), 99-117.

Marx, K. (1867). Capital, volume I. In: Harmondsworth: Penguin/New Left Review.

Massa, L., Tucci, C., \& Afuah, A. (2017). A critical assessment of business model research. Academy of Management Annals, 11(1), 73-104.

Maurya, A. (2016). Scaling lean: Mastering the key metrics for startup growth. UK Penguin. 
McAdam, M., Brady, M., Miller, K., \& Spieth, P. (2018). Call for Papers - Special Issue on Business Models and SMEs. Journal of business research.

McGrath, R. G. (2010). Business Models: A Discovery Driven Approach. Long range planning, 43(2/3), 247-261.

McNamara, P., Peck, S. I., \& Sasson, A. (2013). Competing Business Models, Value Creation and Appropriation in English Football. Long range planning, 46(6), 475-487.

Meyer, A. D. (1991). Visual data in organizational research. Organization Science, 2(2), 218236.

Mikhalkina, T., \& Cabantous, L. (2015). Business Model Innovation: How Iconic Business Models Emerge. In C. Baden-Fuller \& V. Mangematin (Eds.), Business Models and Modelling (pp. 59-95).

Miles, M., Huberman, A. M., \& Saldana, J. (2013). Qualitative data analysis. Thousand Oaks, California: Sage.

Mitchell, D., \& Coles, C. (2003). The ultimate competitive advantage of continuing business model innovation. Journal of Business Strategy, 24(5), 15.

Mitchell, R. K., Agle, B. R., \& Wood, D. J. (1997). Toward a theory of stakeholder identification and salience: Defining the principle of who and what really counts. Academy of management review, 22(4), 853-886.

Mizruchi, M. S. (1996). What do interlocks do? An analysis, critique, and assessment of research on interlocking directorates. Annual Review of Sociology, 22(1), 271-298.

Moore, J. F. (1993). Predators and prey: a new ecology of competition. Harvard business review, 71(3), 75-86.

Moore, J. F. (1996). The death of competition: leadership and strategy in the age of business ecosystems. New York: Harper Business

Morris, M., Neumeyer, X., \& Kuratko, D. (2015). A portfolio perspective on entrepreneurship and economic development. Small Business Economics, 45(4), 713-728.

Morris, M., Schindehutte, M., \& Allen, J. (2005). The entrepreneur's business model: toward a unified perspective. Journal of business research, 58(6), 726-735.

Morris, M., Shirokova, G., \& Shatalov, A. (2013). The Business Model and Firm Performance: The Case of Russian Food Service Ventures. Journal of Small Business Management, 51(1), 46-65.

Mulvaney, J., \& Mann, C. (1976). Practial Business Models. London: Heinemann.

Muniesa, F. (2015). Actor-Network Theory A2 - Wright, James D. In International Encyclopedia of the Social \& Behavioral Sciences (Second Edition) (pp. 80-84). Oxford: Elsevier.

Munksgaard, K. B., \& Medlin, C. J. (2014). Self-and collective-interests: Using formal network activities for developing firms' business. Industrial Marketing Management, 43(4), 613621.

Nason, R. S., \& Wiklund, J. (2018). An assessment of resource-based theorizing on firm growth and suggestions for the future. Journal of management, 44(1), 32-60.

Navis, C., \& Glynn, M. A. (2011). Legitimate distinctiveness and the entrepreneurial identity: Influence on investor judgments of new venture plausibility. Academy of management review, 36(3), 479-499. 
Nenonen, S., \& Storbacka, K. (2010). Business model design: conceptualizing networked value co-creation. International Journal of Quality and Service Sciences, 2(1), 43-59.

Niiniluoto, I. (1999). Critical Scientific Realism. Oxford: Oxford University Press.

Normann, R. (1977). Management for growth. London: Wiley.

Normann, R. (2001). Reframing business: When the map changes the landscape. London: Wiley.

Normann, R., \& Ramirez, R. (1993). From value chain to value constellation: Designing interactive strategy. Harvard business review, 71(4), 65-77.

Norton, D. W., \& Pine li, B. J. (2013). Using the customer journey to road test and refine the business model. Strategy \& leadership, 41(2), 12-17.

O'Cass, A., \& Ngo, L. V. (2011). Examining the firm's value creation process: a managerial perspective of the firm's value offering strategy and performance. British Journal of Management, 22(4), 646-671.

O'Cass, A., Svensson, G., Viet Ngo, L., \& O'Cass, A. (2010). Value creation architecture and engineering: A business model encompassing the firm-customer dyad. European Business Review, 22(5), 496-514.

OECD. (2017). Entrepreneurship at a Glance 2017. Retrieved from https://www.oecdilibrary.org/content/publication/entrepreneur aag-2017-en

Ogbor, J. O. (2000). Mythicizing and reification in entrepreneurial discourse: Ideology critique of entrepreneurial studies. Journal of Management Studies, 37(5), 605-635.

Osiyevskyy, O., \& Dewald, J. (2015). Inducements, Impediments, and Immediacy: Exploring the Cognitive Drivers of Small Business Managers' Intentions to Adopt Business Model Change. Journal of Small Business Management, 53(4), 1011-1032.

Osterwalder, A., \& Pigneur, Y. (2002). An e-Business Model Ontology for Modeling eBusiness. Paper presented at the Bled Electronic Commerce Conference, Bled, Slovenia.

Osterwalder, A., \& Pigneur, Y. (2010). Business model generation: a handbook for visionaries, game changers, and challengers. New York: Wiley.

Osterwalder, A., Pigneur, Y., Bernarda, G., \& Smith, A. (2015). Value Proposition Design: How to Create Products and Services Customers Want. New York: Wiley.

Osterwalder, A., Pigneur, Y., \& Tucci, C. L. (2005). Clarifying business models: Origins, present, and future of the concept. Communications of the association for Information Systems, 16(1), 1.

Oukes, T., \& Raesfeld von, A. (2016). A start-up in interaction with its partners. IMP Journal, $10(1), 50-80$.

Ozcan, P., \& Eisenhardt, K. M. (2009). Origin of alliance portfolios: Entrepreneurs, network strategies, and firm performance. Academy of Management Journal, 52(2), 246-279.

Palombo, D. (2015). A tale of two cities: the regulatory battle to incorporate short-term residential rentals into modern law. American University Business Law Review, 4, 287.

Parmentier, G., \& Gandia, R. (2017). Redesigning the business model: from one-sided to multi-sided. Journal of Business Strategy, 38(2), 52-61. 
Pati, R. K., Nandakumar, M. K., Ghobadian, A., Ireland, R. D., \& O'Regan, N. (2018). Article in Press: Business model design-performance relationship under external and internal contingencies: Evidence from SMEs in an emerging economy. Long range planning.

Patton, M. Q. (2002). Qualitative research and evaluation methods. Thousand Oaks, California: Sage.

Patton, M. Q. (2015). Qualitative Evaluation and Research Methods. Thousand Oaks, California: Sage.

Payne, A., \& Frow, P. (2014). Deconstructing the value proposition of an innovation exemplar. European Journal of Marketing, 48(1/2), 237-270.

Payne, A., Frow, P., \& Eggert, A. (2017). The customer value proposition: evolution, development, and application in marketing. Journal of the Academy of marketing Science, 45(4), 467-489.

Peirce, C. (1955). Abduction and Induction. Philosophical writings of Peirce.

Pennie, F., \& Adrian, P. (2011). A stakeholder perspective of the value proposition concept. European Journal of Marketing, 45(1/2), 223-240.

Penrose, E. T. (1959). The Theory of the Growth of the Firm. Oxford Oxford University Press.

Perkmann, M., \& Spicer, A. (2010). What are business models? Developing a theory of performative representations. In Technology and organization: Essays in honour of Joan Woodward (pp. 265-275): Emerald Group Publishing Limited.

Petrovic, O., Kittl, C., \& Teksten, R. D. (2001). Developing business models for ebusiness.

Pfeffer, J., \& Salancik, G. R. (2003). The external control of organizations: A resource dependence perspective. Stanford Stanford University Press.

Phillips, D. C., \& Burbules, N. C. (2000). Postpositivism and educational research: Rowman \& Littlefield.

Piekkari, R., \& Welch, C. (2018). The case study in management research: Beyond the positivist legacy of Eisenhardt and Yin. The Sage handbook of qualitative business and management research methods, 345-359.

Podsakoff, P. M., MacKenzie, S. B., \& Podsakoff, N. P. (2016). Recommendations for creating better concept definitions in the organizational, behavioral, and social sciences. Organizational Research Methods, 19(2), 159-203.

Polanyi, M. (1958). Personal knowledge: Towards a post-critical philosophy: University of Chicago Press.

Porac, J., Ventresca, M., \& Mishina, Y. (2002). Interorganizational cognition and interpretation.

Porter, M. (1985). Competitive advantage: creating and sustaining superior performance, 1985. In: New York: Free Press.

Porter, M. (1996). What Is Strategy? Harvard business review, 74(6), 61-78.

Porter, M. (2001). Strategy and the Internet. Harvard business review, 79(3), 62-78.

Porter, M., \& Kramer, M. (2011). Creating Shared Value. Harvard business review, 89(1/2), 62-77.

Powell, W. W., Koput, K. W., \& Smith-Doerr, L. (1996). Interorganizational collaboration and the locus of innovation: Networks of learning in biotechnology. Administrative Science Quarterly, 41(1), 116-145. 
Prahalad, C., \& Ramaswamy, V. (2004). Co - creation experiences: The next practice in value creation. Journal of interactive marketing, 18(3), 5-14.

Priem, R. L. (2007). A Consumer Perspective on Value Creation. The Academy of Management Review, 32(1), 219-235.

Priem, R. L., Butler, J. E., \& Li, S. (2013). Toward reimagining strategy research: retrospection and prospection on the 2011 AMR decade award article. Academy of management review, 38(4), 471-489.

Priem, R. L., Li, S., \& Carr, J. C. (2012). Insights and new directions from demand-side approaches to technology innovation, entrepreneurship, and strategic management research. Journal of management, 38(1), 346-374.

Priem, R. L., Wenzel, M., \& Koch, J. (2018). Demand-side strategy and business models: Putting value creation for consumers center stage. Long range planning, 51(1), 22-31.

Ragin, C. C. (2009). Redesigning social inquiry: Fuzzy sets and beyond: University of Chicago Press.

Ragin, C. C. (2014). The comparative method: Moving beyond qualitative and quantitative strategies: Univ of California Press.

Rappa, M. A. (2004). The utility business model and the future of computing services. IBM Systems Journal, 43(1), 32-42.

Reichertz, J. (2004). Abduction, deduction and induction in qualitative research. In U. Flick, E. Von Kardorff, \& I. Steineke (Eds.), A Companion to Qualitative Research (pp. 159164). Longon: Sage.

Reymen, I. M., Andries, P., Berends, H., Mauer, R., Stephan, U., \& Van Burg, E. (2015). Understanding dynamics of strategic decision making in venture creation: a process study of effectuation and causation. Strategic Entrepreneurship Journal, 9(4), 351-379.

Richardson, J. (2008). The business model: an integrative framework for strategy execution. Strategic Change, 17(5/6), 133-144.

Ridley, D. (2012). The literature review: A step-by-step guide for students. London: Sage.

Ritter, T. (2014). Alignment ${ }^{2}$ [Alignment Squared]: Driving Competitiveness and Growth through Business Model Excellence: The CBS Competitiveness Platform.

Ritter, T., \& Lettl, C. (2018). The wider implications of business-model research. Long range planning, 51(1), 1-8.

Ritter, T., Wilkinson, I. F., \& Johnston, W. J. (2004). Managing in complex business networks. Industrial Marketing Management, 33(3), 175-183.

Rotger, G. P., Gørtz, M., \& Storey, D. J. (2012). Assessing the effectiveness of guided preparation for new venture creation and performance: Theory and practice. Journal of Business Venturing, 27(4), 506-521.

Rubin, H., \& Rubin, I. (2012). Qualitative interviewing : the art of hearing data (3rd ed.). London: Sage.

Rumble, R., \& Mangematin, V. (2015). Business Model Implementation: The Antecedents of Multi-Sidedness. In C. Baden-Fuller \& V. Mangematin (Eds.), Business Models and Modelling (pp. 97-131).

Russell, B. H., \& Ryan, G. W. (2010). Analyzing qualitative data: Systematic approaches. Analysis, 8, 451. 
Sabatier, V., Mangematin, V., \& Rousselle, T. (2010). From Recipe to Dinner: Business Model Portfolios in the European Biopharmaceutical Industry. Long range planning, 43(2/3), 431-447.

Saebi, T. (2015). Evolution, Adaptation, or Innovation?: A Contingency Framework on Business Model Dynamics. In N. J. Foss \& T. Saebi (Eds.), Business Model Innovation: The Organizational Dimension, Oxford Scholarship Online.

Saebi, T., \& Foss, N. J. (2015). Business models for open innovation: Matching heterogeneous open innovation strategies with business model dimensions. European Management Journal, 33(3), 201-213.

Saebi, T., Lien, L., \& Foss, N. (2017). What Drives Business Model Adaptation? The Impact of Opportunities, Threats and Strategic Orientation. Long range planning, 50(5), 567581.

Saldaña, J. (2016). The coding manual for qualitative researchers. Thousand Oaks, California: Sage.

Saunders, M., Lewis, P., \& Thornhill, A. (2009). Research methods for business students (5th ed.). Harlow, England: Prentice Hall - Finanical Times.

Sayer, A. (1999). Realism and Social Science. London: Sage.

Schmidt, J., \& Keil, T. (2013). What makes a resource valuable? Identifying the drivers of firmidiosyncratic resource value. Academy of management review, 38(2), 206-228.

Schneider, S. (2017). How to approach business model innovation: the role of opportunities in times of (no) exogenous change. R\&D Management.

Schramm, W. (1971). Notes on case studies of instructional media projects. Working paper for the Academy for Educational Development, Washington, DC.

Schumpeter, J. A. (1911). Theorie der wirtschaftlichen Entwicklung: Duncker \& Humblot.

Schumpeter, J. A. (1934). The Theory of Economic Development: An Inquiry into Profits, Capital, Credit, Interest, and the Business Cycle (Social Science Classics) (Vol. 1). Cambridge Cambridge University Press.

Scott, R. (1992). Organizations: Rational, natural, and open systems.

Shafer, S. M., Smith, H. J., \& Linder, J. C. (2005). The power of business models. Business Horizons, 48(3), 199-207.

Shan, W., Walker, G., \& Kogut, B. (1994). Interfirm cooperation and startup innovation in the biotechnology industry. Strategic Management Journal, 15(5), 387-394.

Shane, S. (2003). A general theory of entrepreneurship : the individual-opportunity nexus. Northampton, MA: Edward Elgar Publishing.

Shane, S., \& Delmar, F. (2004). Planning for the market: business planning before marketing and the continuation of organizing efforts. Journal of Business Venturing, 19(6), 767785.

Shane, S., \& Venkataraman, S. (2000). The promise of entrepreneurship as a field of research. Academy of management review, 25(1), 217-226.

Sharma, B. (2010). Postpositivism In A. Mills, G. Durepos, \& E. Wiebe (Eds.), Encyclopedia of Case Study Research. Thousand Oaks, California: Sage.

Sharma, S., \& Gutiérrez, J. A. (2010). An evaluation framework for viable business models for $\mathrm{m}$-commerce in the information technology sector. Electronic Markets, 20(1), 33-52. 
Shepherd, D. A., \& Zacharakis, A. (2003). A new venture's cognitive legitimacy: An assessment by customers. Journal of Small Business Management, 41(2), 148-167.

Siggelkow, N. (2002). Evolution toward fit. Administrative Science Quarterly, 47(1), 125-159.

Simons, R. (2014). Choosing the Right Customer. Harvard business review, 92(3), 48-55.

Singh, J. (1991). Redundancy in constructs: Problem, assessment, and an illustrative example. Journal of business research, 22(3), 255-280.

Singh, J. V., Tucker, D. J., \& House, R. J. (1986). Organizational legitimacy and the liability of newness. Administrative Science Quarterly, 171-193.

Sirmon, D., Hitt, M., \& Ireland, R. D. (2007). Managing Firm Resources in Dynamic Environments to Create Value: Looking inside the Black Box. The Academy of Management Review, 32(1), 273-292.

Sirmon, D. G., \& Hitt, M. A. (2003). Managing resources: Linking unique resources, management, and wealth creation in family firms. Entrepreneurship Theory and Practice, 27(4), 339-358.

Sirmon, D. G., Hitt, M. A., Ireland, R. D., \& Gilbert, B. A. (2011). Resource Orchestration to Create Competitive Advantage:Breadth, Depth, and Life Cycle Effects. Journal of management, 37(5), 1390-1412.

Slywotzky, A. (1999). Creating your next business model. Leader to Leader, 1999(11), 35-40.

Slywotzky, A., Morrison, D., \& Andelman, B. (1997). The profit zone: How strategic business design will lead you to tomorrow's profits: Crown Business.

Smith, A. (1776). The Wealth of Nations.

Smith, B., \& Colgate, M. (2007). Customer value creation: a practical framework. Journal of marketing Theory and Practice, 15(1), 7-23.

Smith, W., Binns, A., \& Tushman, M. (2010). Complex Business Models: Managing Strategic Paradoxes Simultaneously. Long range planning, 43(2/3), 448-461.

Snehota, I. (2011). New business formation in business networks. IMP Journal, 5(1), 1-9.

Snihur, Y., Reiche, B. S., \& Quintane, E. (2017). Sustaining Actor Engagement During the Opportunity Development Process. Strategic Entrepreneurship Journal, 11(1), 1-17.

Snihur, Y., \& Tarzijan, J. (2018). Managing complexity in a multi-business-model organization. Long range planning, 51(1), 50-63.

Snihur, Y., \& Zott, C. (2013). Legitimacy without imitation: How to achieve robust business model innovation. Paper presented at the 35th DRUID Celebration Conference 2013.

Sosna, M., Trevinyo-Rodríguez, R. N., \& Velamuri, S. R. (2010). Business Model Innovation through Trial-and-Error Learning: The Naturhouse Case. Long range planning, 43(23), 383-407.

Spieth, P., Schneckenberg, D., \& Matzler, K. (2016). Exploring the linkage between business model (\&) innovation and the strategy of the firm. R\&D Management, 46(3), 403-413.

Spieth, P., \& Schneider, S. (2016). Business model innovativeness: designing a formative measure for business model innovation. Journal of Business Economics, 86(6), 671696.

Spohrer, J., Maglio, P. P., Bailey, J., \& Gruhl, D. (2007). Steps toward a science of service systems. Computer, 40(1). 
Stabell, C. B., \& Fjeldstad, Ø. D. (1998). Configuring value for competitive advantage: on chains, shops, and networks. Strategic Management Journal, 19(5), 413-437.

Stake, R. E. (2000). Case Studies. In Handbook of qualitative research (Vol. 2nd, pp. 435454). New York: Sage.

Stampfl, G., Prügl, R., \& Osterloh, V. (2013). An explorative model of business model scalability. International Journal of Product Development, 18(3), 226-248.

Stewart, D. W., \& Zhao, Q. (2000). Internet marketing, business models, and public policy. Journal of Public Policy \& Marketing, 19(2), 287-296.

Stinchcombe, A. L. (1965). Social structure and organizations. In Economics Meets Sociology in Strategic Management (pp. 229-259). Bingley, U.K.: Emerald.

Storbacka, K. (2011). A solution business model: Capabilities and management practices for integrated solutions. Industrial Marketing Management, 40(5), 699-711.

Storbacka, K., Brodie, R. J., Böhmann, T., Maglio, P. P., \& Nenonen, S. (2016). Actor engagement as a microfoundation for value co-creation. Journal of business research, 69(8), 3008-3017.

Storbacka, K., Frow, P., Nenonen, S., \& Payne, A. (2012). Designing business models for value co-creation. Review of Marketing Research, 9(2012), 51-78.

Storbacka, K., \& Nenonen, S. (2011). Scripting markets: From value propositions to market propositions. Industrial Marketing Management, 40(2), 255-266.

Storbacka, K., Windahl, C., Nenonen, S., \& Salonen, A. (2013). Solution business models: Transformation along four continua. Industrial Marketing Management, 42(5), 705-716.

Strauss, A., \& Corbin, J. (1994). Grounded theory methodology. Handbook of qualitative research, 17, 273-285.

Strauss, A., \& Corbin, J. (1997). Grounded theory in practice: Sage.

Suddaby, R., Bitektine, A., \& Haack, P. (2017). Legitimacy. Academy of Management Annals, 11(1), 451-478.

Suddaby, R., Hardy, C., \& Huy, Q. N. (2011). Introduction to Special Topic Forum: Where are the new Theories of Organization? The Academy of Management Review, 36(2), 236246.

Svejenova, S., Planellas, M., \& Vives, L. (2010). An Individual Business Model in the Making: a Chef's Quest for Creative Freedom. Long range planning, 43(2/3), 408-430.

Tantalo, C., \& Priem, R. L. (2016). Value creation through stakeholder synergy. Strategic Management Journal, 37, 314-329.

Täuscher, K. (2017). Using qualitative comparative analysis and system dynamics for theorydriven business model research. Strategic Organization, Essays 1-12.

Teddlie, C., \& Tashakkori, A. (2009). Foundations of mixed methods research: Integrating quantitative and qualitative approaches in the social and behavioral sciences. New York: Sage.

Teece, D. J. (2007). Explicating dynamic capabilities: the nature and microfoundations of (sustainable) enterprise performance. Strategic Management Journal, 28(13), 13191350.

Teece, D. J. (2010). Business Models, Business Strategy and Innovation. Long range planning, 43(2-3), 172-194. 
Teece, D. J. (2018). Business models and dynamic capabilities. Long range planning, 51(1), 40-49.

Thompson, J. (1967). Organizsations in Action. New York: McGraw-Hill.

Tikkanen, H., Lamberg, J.-A., Parvinen, P., \& Kallunki, J.-P. (2005). Managerial cognition, action and the business model of the firm. Management Decision, 43(6), 789-809.

Timmers, P. (1998). Business models for electronic markets. Electronic Markets, 8(2), 3-8.

Tucci, C. L., Chesbrough, H., Piller, F., \& West, J. (2016). When do firms undertake open, collaborative activities? Introduction to the special section on open innovation and open business models. Industrial and corporate change, 25(2), 283-288.

Überbacher, F. (2014). Legitimation of new ventures: A review and research programme. Journal of Management Studies, 51(4), 667-698.

Umoquit, M., Tso, P., Varga-Atkins, T., O'Brien, M., \& Wheeldon, J. (2013). Diagrammatic elicitation: Defining the use of diagrams in data collection. The qualitative report, 18(30), 1-12.

Umoquit, M. J., Dobrow, M. J., Lemieux-Charles, L., Ritvo, P. G., Urbach, D. R., \& Wodchis, W. P. (2008). The efficiency and effectiveness of utilizing diagrams in interviews: an assessment of participatory diagramming and graphic elicitation. BMC Medical Research Methodology, 8(1), 53.

Uschold, M., King, M., Moralee, S., \& Zorgios, Y. (1998). The enterprise ontology. The knowledge engineering review, 13(01), 31-89.

Utterback, J. (1994). Mastering the dynamics of innovation: how companies can seize opportunities in the face of technological change: University of Illinois at UrbanaChampaign's Academy for Entrepreneurial Leadership.

Uzzi, B. (1996). The sources and consequences of embeddedness for the economic performance of organizations: The network effect. American sociological review, 674698.

Valentim, L., Lisboa, J. V., \& Franco, M. (2016). Knowledge management practices and absorptive capacity in small and medium - sized enterprises: is there really a linkage? R\&D Management, 46(4), 711-725.

Van de Ven, A. H. (1992). Suggestions for studying strategy process: A research note. Strategic Management Journal, 13(S1), 169-188.

Vargo, S., \& Lusch, R. (2004). Evolving to a New Dominant Logic for Marketing. Journal of Marketing, 68(1), 1-17.

Vargo, S., \& Lusch, R. (2008). Service-dominant logic: continuing the evolution. Journal of the Academy of marketing Science, 36(1), 1-10.

Vargo, S., \& Lusch, R. (2010a). From repeat patronage to value co-creation in service ecosystems: a transcending conceptualization of relationship. Journal of Business Market Management, 4(4), 169-179.

Vargo, S., \& Lusch, R. (2010b). "Relationship" in Transition: An Introduction to the Special Issue on Relationship and Service-Dominant Logic. Journal of Business Market Management, 4(4), 167-168.

Vargo, S., \& Lusch, R. (2011). It's all B2B... and beyond: Toward a systems perspective of the market. Industrial Marketing Management, 40(2), 181-187. 
Vargo, S., \& Lusch, R. (2016). Institutions and axioms: an extension and update of servicedominant logic. Journal of the Academy of marketing Science, 44(1), 5-23.

Vargo, S., \& Lusch, R. (2017). Service-dominant logic 2025. International Journal of Research in Marketing, 34(1), 46-67.

Vargo, S., Maglio, P., \& Akaka, M. (2008). On value and value co-creation: A service systems and service logic perspective. European Management Journal, 26(3), 145-152.

Velamuri, V. K., Bansemir, B., Neyer, A.-K., \& Möslein, K. M. (2013). Product Service Systems as a Driver for Business Model Innovation: Lessons Learned from the Manufacturing Industry. International Journal of Innovation Management, 17(1), 25.

Velu, C. (2015). Business model innovation and third-party alliance on the survival of new firms. Technovation, 35(1), 1-11.

Velu, C. (2017). A Systems Perspective on Business Model Evolution: The Case of an Agricultural Information Service Provider in India. Long range planning, 50, 603-620.

Venkataraman, S. (1997). The distinctive domain of entrepreneurship research. Advances in entrepreneurship, firm emergence and growth, 3(1), 119-138.

Venkatraman, N., \& Henderson, J. (1998). Real strategies for virtual organizing. Sloan Management Review, 40(1), 33-48.

Villani, E., Linder, C., \& Grimaldi, R. (2018). Effectuation and causation in science-based new venture creation: A configurational approach. Journal of business research, 83, 173185.

Voima, P., Heinonen, K., \& Strandvik, T. (2010). Exploring customer value formation: a customer dominant logic perspective. Hanken School of Economics, Working Paper.

von Hippel, E. (1988). Sources of Innovation. New York: Oxford University Press.

Von Hippel, E. (1994). "Sticky information" and the locus of problem solving: implications for innovation. Management Science, 40(4), 429-439.

Von Hippel, E. (2005). Democratizing innovation: The evolving phenomenon of user innovation. Journal für Betriebswirtschaft, 55(1), 63-78.

Von Hippel, E., \& Von Krogh, G. (2013). Identifying Viable 'Need-Solution Pairs': Problem Solving Without Problem Formulation. MIT Sloan Research Paper No. 5071-13.

Wagemann, C. (2014). Qualitative Comparative Analysis (QCA): What It Is, What It Does, and How It Works. Methodological Practices in Social Movement Research, 43-66.

Wagemann, C., Buche, J., \& Siewert, M. B. (2016). QCA and business research: Work in progress or a consolidated agenda? Journal of business research, 69(7), 2531-2540.

Warnier, V., Weppe, X., \& Lecocq, X. (2013). Extending resource-based theory: considering strategic, ordinary and junk resources. Management Decision, 51(7), 1359-1379.

Webb, J. W., Ireland, R. D., Hitt, M. A., Kistruck, G. M., \& Tihanyi, L. (2011). Where is the opportunity without the customer? An integration of marketing activities, the entrepreneurship process, and institutional theory. Journal of the Academy of marketing Science, 39(4), 537-554.

Weill, P., \& Vitale, M. R. (2001). Place to Space, Migrating to ebusiness models. Boston: Harvard Business School Press. 
Wennekers, S., Van Wennekers, A., Thurik, R., \& Reynolds, P. (2005). Nascent entrepreneurship and the level of economic development. Small Business Economics, 24(3), 293-309.

Wernerfelt, B. (1984). A resource - based view of the firm. Strategic Management Journal, 5(2), 171-180.

Williamson, O. (1975). Markets and hierarchies: analysis and antitrust implications: a study in the economics of internal organization: University of Illinois at Urbana-Champaign's Academy for Entrepreneurial Leadership.

Williamson, O. (1979). Transaction-cost economics: the governance of contractual relations. The journal of Law and Economics, 22(2), 233-261.

Williamson, O. (1985). The economic institutions of capitalism. Chicago: The Free Press.

Winter, S. G., \& Szulanski, G. (2001). Replication as strategy. Organization Science, 12(6), 730-743.

Wirtz, B., Pistoia, A., Ullrich, S., \& Göttel, V. (2016). Business Models: Origin, Development and Future Research Perspectives. Long range planning, 49(1), 36-54.

Wright, M., \& Marlow, S. (2012). Entrepreneurial activity in the venture creation and development process. International Small Business Journal, 30(2), 107-114.

Yin, R. (2014). Case study research: Design and methods (5th ed.). New York: Sage.

Yin, R. (2018). Case study research and applications: Design and methods (6th ed.). Thousand Oaks, CA Sage.

Yip, G. S. (2004). Using Strategy to Change Your Business Model. Business Strategy Review, 15(2), 17-24.

Yunus, M., Moingeon, B., \& Lehmann-Ortega, L. (2010). Building Social Business Models: Lessons from the Grameen Experience. Long range planning, 43(2/3), 308-325.

Zachariadis, M., \& Ozcan, P. (2017). The API economy and digital transformation in financial services: The case of open banking. Swift Institute Working Paper No. 2016-001.

Zacharias, M. E., \& Saldaña, J. (2002). Longitudinal Qualitative Research: Analyzing Change through Time. Canadian Journal of Education, 27(2/3), 341.

Zeithaml, V. (1988). Consumer perceptions of price, quality, and value: a means-end model and synthesis of evidence. The Journal of marketing, 52(3), 2-22.

Zhang, J., Lichtenstein, Y., \& Gander, J. (2015). Designing Scalable Digital Business Models. In C. Baden-Fuller \& V. Mangematin (Eds.), Business Models and Modelling (pp. 241277).

Zhang, J., Souitaris, V., Soh, P. h., \& Wong, P. k. (2008). A contingent model of network utilization in early financing of technology ventures. Entrepreneurship Theory and Practice, 32(4), 593-613.

Zhang, Y. (2008). Undergraduate students' mental models of the Web as an information retrieval system. Journal of the Association for Information Science and Technology, 59(13), 2087-2098.

Zimmerman, M. A., \& Zeitz, G. J. (2002). Beyond survival: Achieving new venture growth by building legitimacy. Academy of management review, 27(3), 414-431.

Zobel, A. K. (2017). Benefiting from open innovation: A multidimensional model of absorptive capacity. Journal of Product Innovation Management, 34(3), 269-288. 
Zott, C., \& Amit, R. (2007). Business Model Design and the Performance of Entrepreneurial Firms. Organization Science, 18(2), 181-199.

Zott, C., \& Amit, R. (2008). The fit between product market strategy and business model: implications for firm performance. Strategic Management Journal, 29(1), 1-26.

Zott, C., \& Amit, R. (2010). Business Model Design: An Activity System Perspective. Long range planning, 43(2-3), 216-226.

Zott, C., \& Amit, R. (2013). The business model: A theoretically anchored robust construct for strategic analysis. Strategic Organization, 11(4), 403-411.

Zott, C., Amit, R., \& Massa, L. (2011). The business model: recent developments and future research. Journal of management, 37(4), 1019-1042.

Zott, C., \& Huy, Q. N. (2007). How entrepreneurs use symbolic management to acquire resources. Administrative Science Quarterly, 52(1), 70-105. 


\section{Appendix}

\subsection{Appendix A - Participant Information Sheet}

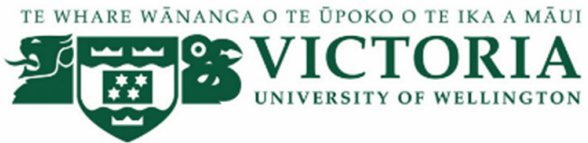

\section{Business Model Emergence in Value Networks \\ FOUNDERS AND MANAGERS: INFORMATION SHEET}

\section{Dear Entrepreneur,}

Thank you very much for your interest in my research project on the emergence process of business models. I would like to invite you to participate in this project and would appreciate the opportunity of talking to you about my research. This handout aims to give you further information about the project and your rights to confidentiality, so that you can decide whether you are willing to participate in the interviews.

The purpose of this study is to develop an understanding of how relationships with customers, suppliers or other stakeholders in a firm's business network contribute to the design and emergence process of business models. The investigation of how and for whom value is created and captured within the firm's business network is at the heart of this project. I would seek to monitor your business models and any changes over a period of nine to twelve months via a series of three to four interviews with at least one internal interviewee (founders, CEO, executive directors) and one external interviewee (business partner). Participation in this research will give you, your venture and your business partners the opportunity to reflect on your business models, value creation and capturing mechanisms, and business relationships.

If you agree to take part, interviews will be conducted at times and locations of your convenience. Each interview will take about 45 to 60 minutes and will be audio recorded with your permission. If you feel uncomfortable about providing answers to any questions, you can decline to answer as well as stop the interview at any time without providing any reason. Furthermore, you can withdraw from the study by contacting the researcher prior to four weeks after your last interview. If you withdraw, the information you provided will be destroyed or returned to you. This research is intended to be used as part of a PhD thesis which will be submitted to Victoria University of Wellington. The findings may also be used for academic publications, conference presentations, and public reports. 


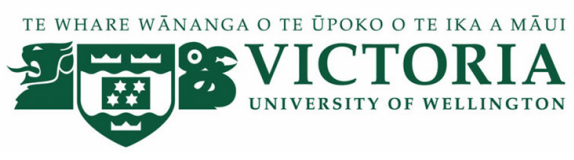

\section{Confidentiality}

All data gathered from interviews and documents you provide will be kept confidential and is only accessible to the researcher and the two supervisors of the project. This means that the researcher named below will be aware of your identity, but the research data will be aggregated and your identity will not be disclosed in any reports, presentations, or public documentation. With your written consent, you may be quoted directly in the final thesis, noting only your job title which should not disclose your identity. However, as you have recommended internal and external stakeholders for interviews and these interviewees know that your venture is participating in the research, they might be able to identify your quotes in the final thesis. The interview transcripts, summaries and any recordings will be kept securely and destroyed five years after the research project has been finalized [December 2023].

\section{What does this mean for you?}

Your voluntary contribution is most welcome and highly valued, but under no circumstances mandatory. If you are willing to participate, you will be asked to fill in a research agreement that, together with this information sheet, outlines your role in this research and how your contributions and rights as a research participant will be respected.

\section{If you do decide to participate, you have the right to}

- choose not to answer any question;

- ask for the recorder to be turned off at any time during the interview

- withdraw from the study until four weeks after your last interview;

- ask any questions about the study at any time;

- read over and comment on a written summary of your interview;

- be able to read any reports of this research by ticking the box in the research agreement and filling in your e-mail address.

Thank you very much for your participation and contributions that make this research possible. Please do not hesitate to contact the researcher or supervisor if you have any questions. Approval for the research has been granted by the Victoria University of Wellington Human Ethics Committee with approval number 23143. If you have any concerns about the ethical conduct of the research you may contact the Victoria University HEC Convener: Associate Professor Susan Corbett. Email susan.corbett@vuw.ac.nz or telephone +64-4-463 5480.

\begin{tabular}{|l|l|}
\hline $\begin{array}{l}\text { Researcher: Dominik Mann, MSc } \\
\text { E-Mail: dominik.mann@vuw.ac.nz }\end{array}$ & $\begin{array}{l}\text { Supervisor: Prof. Sally Davenport } \\
\text { Phone: } 044635144 \\
\end{array}$ \\
\hline \multicolumn{2}{|c}{ E-Mail: sally.davenport@vuw.ac.nz } \\
\hline \multicolumn{2}{|c}{ School of Management, Victoria University of Wellington }
\end{tabular}




\subsection{Appendix B - Research Agreement \\ TE WHARE WĀNANGA O TE ŪPOKO O TE IKA A MĀU

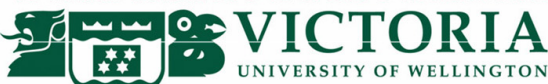

\section{Business Model Emergence in Value Networks \\ FOUNDER AND MANAGERS: RESEARCH AGREEMENT}

I have read the Information Sheet and the nature of the project has been explained to me. I have had the opportunity to ask any questions and have them answered to my satisfaction. Furthermore, I understand that I can ask further questions at any time.

I agree to take part in an audio recorded semi-structured interview.

I understand that:

\ My participation is entirely voluntary and I am free to decline to answer any question during the interview. Moreover, I can request that the audio recording device will be turned off at any time during the interview.

冈 The information I provide will be kept confidential and access is restricted to the researcher and the supervisors only at any time.

\ My name will not be used in any publications, but comments from interviews might be quoted in the final thesis, academic publications, conference presentations, and public reports. Moreover, my job title will be outlined which might enable others in my company and business partners to identify me or my quotes in the final thesis.

\ The data gathered from interviews, documents or any other sources made accessible by me will be securely stored for a period of five years after the completion of this project and then destroyed [December 2023].

\ This research involves at least three interviews over a period of nine to twelve months. I may withdraw from this study at any point until four weeks after the last interview, without giving any reason, and any information that I have provided will be returned to me or destroyed.

\ I understand that the results of the data analysis will be used for an PhD report, and a summary of the results may be used in academic publications, conference presentations, and public reports.

- I would like to receive a summary of my interview via e-mail

- I would like to receive a summary of the final report via e-mail

Yes $\square \quad$ No

- I wish to be identified by the position descriptor:

I agree to take part in at least three audio recorded interviews.

\begin{tabular}{|l|l|}
\hline Name & \\
\hline Organisation/Position & \\
\hline Contact Details/E-Mail & \\
\hline
\end{tabular}

Signature Researcher

Signature Interviewee

Researcher: Dominik Mann, MSc

E-Mail: dominik.mann@vuw.ac.nz

Supervisor: Prof. Sally Davenport, $\mathrm{PhD}$

E-Mail: sally.davenport@vuw.ac.nz

Tel: 044635144

School of Management, Victoria University of Wellington, New Zealand 


\subsection{Appendix C - Interview Schedule}

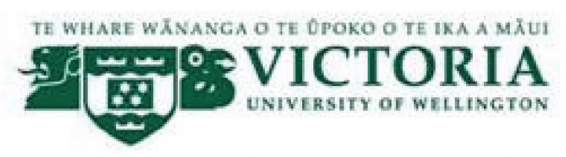

Semi-structured Interview Schedules

These interview schedules outline a list of key questions which the participants will be asked. These schedules will form part of the case study protocol and guide the semi-structured interviews. The exact form of any questions to be asked in any given interview may change, depending on the information obtained during the interview. Core research questions are in bold and possible probing questions listed beneath.

\section{FOUNDERS AND MANAGERS: INTERVIEW SCHEDULE}

Let me thank you very much for participating in my $\mathrm{PhD}$ research regarding the emergence of business models in value networks. Please feel free to interrupt or ask for clarification at any time during the interview. I'm mainly interested in your business model, business relationships and value creation and capturing mechanisms. Do you have any questions before we start?

Introduction:

1.) Can you please describe your venture's business model?

Value creation and capturing:

2.) How does your venture's business model create value?

- What product and/or service combinations does your venture's business model provide and who for?

- What value is provided via the outlined product and/or service combinations and how?

- What are the most important internal and external activities, resources or structure to create the value propositions of your venture's business model?

3.) How does your venture's business model capture value?

- How does your venture's business model charge customers, suppliers and other partners for provided products, services, information or know-how? (e.g. razor-blade model)

- What are the most important internal and external activities, resources and structures to capture value from the provision of the outlined value propositions?

4.) How do external key partners contribute to the value creation and capturing mechanisms of your venture's business model?

- What external key partners (e.g. customers, suppliers, etc.) are engaged in the value creation and capturing mechanisms and why are they important? (e.g. providing resources, information, skills)

- How are value creation and capturing mechanisms of your venture's and your partners' business model interlinked?

Relationships and value networks

5.) How have business relationships with your key partners been established?

- How would you describe the relationships with your venture's key partners? 


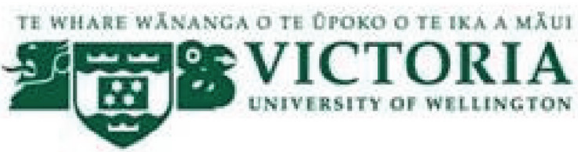

- How frequently and intense does your venture collaborate with key partners?

- What do key partner provide for your business model?

6.) Has your venture's business model been adjusted or adopted to improve collaborations with key partners for value creation and capturing mechanisms? If so, how? If no, why not?

- How have internal and external resources, activities or organizational structure been adjusted or aligned?

7.) Have adjustments of your venture's to your key partners' business model influenced the development your venture's business model? If so, how? If no, why not?

- What business model elements have been affected?

8.) Do you plan to adjust elements of your venture's business model to your key partners' business model in the future? If so, how? If no, why not?

9.) Is there anything you would like to add to this interview?

Thank you very much for the interview. In case of any further questions or notes, please feel free to contact me. 


\subsection{Appendix D - New Zealand Birds / Case Study Names}

\begin{tabular}{|c|c|c|c|}
\hline Name & Description & Link & \\
\hline Kārearea & $\begin{array}{l}\text { The New Zealand falcon is a magpie-sized raptor that feeds predominantly on live prey. Adapted to } \\
\text { hunt within the dense New Zealand forests they are also found in more open habitats such as tussock } \\
\text { lands and roughly grazed hill country. More recently they have been discovered breeding in exotic } \\
\text { pine plantations. Laying their eggs in simple scrapes they can nest in a variety of locations, from } \\
\text { within the epiphytes that grow in large trees, to on the ground under small rocky outcrops. Where } \\
\text { they nest on the ground they are well known for attacking intruders, including humans, with } \\
\text { aggressive dive-bombing strikes to the head. }\end{array}$ & $\begin{array}{l}\text { http://nzbirdsonline.org.nz/species/new-zealand- } \\
\text { falcon } \\
\text { https://www.doc.govt.nz/nature/native- } \\
\text { animals/birds/birds-a-z/nz-falcon-karearea/ }\end{array}$ & \\
\hline Matuku & $\begin{array}{l}\text { Bitterns are extremely cryptic and rarely seen. This is due to their secretive behaviour, inconspicuous } \\
\text { plumage and the inaccessibility of their habitat. Their presence is most commonly discerned through } \\
\text { hearing the distinctive 'booming' call of the males during the breeding season. Bittern occasionally } \\
\text { snow themsemse's in the 'open alon' wetlan'a edge's, ayke's', arains', rloôdea' páddocks or roadsides, } \\
\text { often adopting their infamous 'freeze' stance, with the bill pointing skyward, even when caught out in } \\
\text { the open. }\end{array}$ & $\begin{array}{l}\text { http://nzbirdsonline.org.nz/species/australasian- } \\
\text { bittern } \\
\text { https://www.doc.govt.nz/nature/native- } \\
\text { animals/birds/birds-a-z/australasian-bittern- } \\
\text { matuku/ }\end{array}$ & \\
\hline Ruru & $\begin{array}{l}\text { The morepork is a small, dark, forest-dwelling owl. Found in both native and plantation forests, its } \\
\text { distinctive "more-pork" call is commonly heard at night in many urban parks and well-vegetated } \\
\text { suburbs. Moreporks are relatively common throughout much of New Zealand but are sparse through } \\
\text { the eastern and central South Island. Their diet consists of insects, small mammals and birds, which it } \\
\text { hunts at night. }\end{array}$ & $\begin{array}{l}\text { http://nzbirdsonline.org.nz/species/morepork } \\
\text { https://www.doc.govt.nz/nature/native- } \\
\text { animals/birds/birds-a-z/morepork-ruru/ }\end{array}$ & \\
\hline Kākāpō & $\begin{array}{l}\text { The kakapo is a large, nocturnal, flightless, lek-breeding parrot - a real oddity. It is also critically } \\
\text { endangered, and the focus of considerable conservation attention. Before humans arrived it was } \\
\text { common throughout New Zealand's forests, but predation by introduced mammals brought it to the } \\
\text { brink of extinction - a low point of about } 50 \text { birds only in the mid 1990s. The transfer of the whole } \\
\text { population to predator-free islands and intensive intervention in every stage of its life has led to a } \\
\text { steady increase in numbers. Kakapo have no close relatives. }\end{array}$ & $\begin{array}{l}\text { http://nzbirdsonline.org.nz/species/kakapo } \\
\text { https://www.doc.govt.nz/nature/native- } \\
\text { animals/birds/birds-a-z/kakapo/ }\end{array}$ & \\
\hline Kea & $\begin{array}{l}\text { The kea is an unusual parrot. It is the only truly alpine parrot in the world, and gained early notoriety } \\
\text { among settler farmers for attacks on their sheep. Innately curious, kea are attracted to people } \\
\text { wherever they enter its mountain domain, and are a feature at South Island ski-fields and mountain } \\
\text { huts. Their attraction to people and their paraphernalia is a two-edged sword, providing both new } \\
\text { threats and new opportunities. }\end{array}$ & $\begin{array}{l}\text { http://nzbirdsonline.org.nz/species/kea } \\
\text { https://www.doc.govt.nz/nature/native- } \\
\text { animals/birds/birds-a-z/kea/ }\end{array}$ & \\
\hline
\end{tabular}


Generally heard before they are seen, kaka are large, forest-dwelling parrots that are found on all three main islands of New Zealand and on several offshore islands. Much reduced in range and abundance in the North and South islands due to forest clearance and predation by introduced mammals, kaka are most abundant on offshore islands that have no introduced mammals, or at least no stoats. They remain locally common at some sites on the main islands that are close to offshore island refuges, and have increased in abundance at others where mammalian pests have been controlled. Kaka can be found in a wide variety of native forest types including podocarp and beech forest. They are a common sight in Wellington city, having spread from Zealandia / Karori Sanctuary.

Takahē The South Island takahē is a rare relict of the flightless, vegetarian bird fauna which once ranged New Zealand. Four specimens were collected from Fiordland between 1849 and 1898, after which takahē were considered to be extinct until famously rediscovered in the Murchison Mountains, west of Lake Te Anau, in 1948. Until the 1980s, takahē were confined in the wild to the Murchison Mountains. They have since been translocated to seven islands and several mainland sites, making them more accessible to many New Zealanders. Conservation work by the Department Of Conservation and community groups aims to prevent extinction and restore takahē to sites throughout their original range.

Whio The blue duck or whio is an iconic species of clear fast-flowing rivers, now mostly confined to high altitude segments of rivers in North and South Island mountain regions. Nowhere common, it lives at low densities and its shrill "whio" whistle above the noise of turbulent waters will usher in a longremembered encounter.

Moa The North Island Moa was the second tallest of the nine moa species, standing up to 2 metres at the back and up to 3 metres with neck stretched upwards. Both giant moa species (genus Dinornis) had relatively long, shaggy hair-like feathers up to $18 \mathrm{~cm}$ long, covering the body, and exhibited the greatest size difference between males and females of any bird, with adult females being much larger than adult males. Size also varied by habitat, with lowland populations in mosaic shrubland larger than upland populations in closed forest. DNA study suggests that moa were more closely related to the flighted South American tinamou than to the kiwi.

Pouakai This giant endemic eagle was the largest predator among New Zealand's prehistoric fauna. It is the largest, heaviest eagle species yet described, weighing up to $17.8 \mathrm{~kg}$ and had a wingspan up to 3 metres. Near-complete skeleton finds show that it had the body and wings of a giant eagle, legs and bill larger and stronger than the largest living vulture species, and feet and claws as big as a modern day tiger's. These characteristics made it the top predator in prehistoric South Island terrestrial ecosystems. Like the iconic moa, Haast's eagle evolved through - and survived - multiple glacial periods, when larger body size would have increased survival chances. The species was named after Julius von Haast, first director of Canterbury Museum http://nzbirdsonline.org.nz/species/kakapo

https://www.doc.govt.nz/nature/nativeanimals/birds/birds-a-z/kaka/

\section{http://nzbirdsonline.org.nz/species/south-island-}

takahe

https://www.doc.govt.nz/nature/native-

animals/birds/birds-a-z/takahe/

http://nzbirdsonline.org.nz/species/blue-duck

https://www.doc.govt.nz/nature/nativeanimals/birds/birds-a-z/blue-duck-whio/ http://nzbirdsonline.org.nz/species/north-islandgiant-moa

http://nzbirdsonline.org.nz/species/haasts-eagle

